\title{
Phylogenetic Relationships of the Earliest Anisostrophically Coiled Gastropods
}




\title{
SERIES PUBLICATIONS OF THE SMITHSONIAN INSTITUTION
}

Emphasis upon publication as a means of "diffusing knowledge" was expressed by the first Secretary of the Smithsonian. In his formal plan for the Institution, Joseph Henry outlined a program that included the following statement: "It is proposed to publish a series of reports, giving an account of the new discoveries in science, and of the changes made from year to year in all branches of knowledge." This theme of basic research has been adhered to through the years by thousands of titles issued in series publications under the Smithsonian imprint, commencing with Smithsonian Contributions to Knowledge in 1848 and continuing with the following active series:

\author{
Smithsonian Contributions to Anthropology \\ Smithsonian Contributions to Botany \\ Smithsonian Contributions to the Earth Sciences \\ Smithsonian Contributions to the Marine Sciences \\ Smithsonian Contributions to Paleobiology \\ Smithsonian Contributions to Zoology \\ Smithsonian Folklife Studies \\ Smithsonian Studies in Air and Space \\ Smithsonian Studies in History and Technology
}

In these series, the Institution publishes small papers and full-scale monographs that report the research and collections of its various museums and bureaux or of professional colleagues in the world of science and scholarship. The publications are distributed by mailing lists to libranies, universities, and similar institutions throughout the world.

Papers or monographs submitted for series publication are received by the Smithsonian Institution Press, subject to its own review for format and style, only through departments of the various Smithsonian museums or bureaux, where the manuscripts are given substantive review. Press requirements for manuscript and art preparation are outlined on the inside back cover.

Lawrence M. Small

Secretary

Smithsonian Institution 
SMITHSONIAN CONTRIBUtions TO PALEOBIOLOGY - NUMBER 88

\title{
Phylogenetic Relationships of the Earliest Anisostrophically \\ Coiled Gastropods
}

\author{
Peter J. Wagner
}

ISSUED

JAN 302002

B.MTHSONIAN INSTITUTIO:V

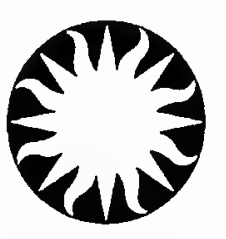

Smithsonian Institution Press

Washington, D.C. 


\section{A B S T R A C T}

Wagner, Peter J. Phylogenetic Relationships of the Earliest Anisostrophically Coiled Gastropods. Smithsonian Contributions to Paleobiology, number 88, 152 pages, 37 figures, 3 tables, 2002.-In order to explore the phylogenetic relationships among early gastropods, cladistic analyses were conducted of nearly 300 "archaeogastropod" species known from the latest Cambrian through the Silurian. The study includes an extended outgroup analysis of Cambrian molluscs. The resulting estimates of gastropod phylogeny differ not only from traditional ideas about early gastropod relationships, but also from most alternative notions. Outgroup analyses suggest that gastropods had ancestors among the Tergomya (= Monoplacophora of many workers) of the Middle or Late Cambrian. Putative gastropods from older strata (e.g., the Pelagiellida and early Onychochilidae) apparently are not closely related to gastropods. The hypothesized ancestor of gastropods possessed dextral-coiling, septation, a deep sinus, and a peripheral band. An anal slit is commonly described as a synapomorphy of gastropods that many clades subsequently lost; however, this study suggests that the slit is a rare, highly derived, and polyphyletic character among early Paleozoic species, and that the ancestors of most "advanced" clades (e.g., the Apogastropoda) never had slits.

This study suggests that two major subclades evolved by the earliest Ordovician. The diagnoses and definitions of these two subclades best correspond to the traditional diagnoses and definitions of the Euomphalina and Murchisoniina. The Pleurotomarioidea is not a paraphyletic ancestral taxon as typically suggested, but instead it is a polyphyletic assemblage derived multiple times from "euomphalinae" and "murchisoniinae" species. The Bellerophontina is at least diphyletic, as the taxon includes both the ancestors of "archaeogastropods" and a clade of planispiral species that is secondarily derived from "archaeogastropods." Macluritoids sensu stricto represent a restricted subclade of the "euomphalinae"; other supposed macluritoids evolved among different euomphalinae subclades or are not gastropods. Early Paleozoic species previously classified as caenogastropods (i.e., the Loxonematoidea and Subulitoidea) represent separate murchisoniinae subclades, with some putative members of the Subulitoidea derived within the Loxonematoidea. Early Paleozoic species assigned to the Trochoidea also represent several subclades, with most of those clades having evolved from the "euomphalinae."

An extensive taxonomic revision is presented, which removes all early Paleozoic taxa from the Pleurotomariina and broadly expands the definitions of the Euomphalina and Murchisoniina.

OfFICIAL PUBLICATION DATE is handstamped in a limited number of initial copies and is recorded in the Institution's annual report, Annals of the Smithsonian Institution. SERIES COVER DESIGN: The trilobite Phacops rana Green.

Library of Congress Cataloging-in-Publication Data

Wagner, Peter J.

Phylogenetic relationships of the earliest anisostrophically coiled gastropods / Peter J. Wagner.

p. $\mathrm{cm} .-$ (Smithsonian contributions to paleobiology ; no. 88)

Includes bibliographic references.

1. Gastropoda, Fossil. I. Title. II. Series.

QE808.W34 $1999560 \mathrm{~s}-\mathrm{dc2}$ I [564\sc1361.3] 98-52464

The paper used in this publication meets the minimum requirements of the American National Standard for Permanence of Paper for Printed Library Materials $\quad$ Z39.48-1984. 


\section{Contents}

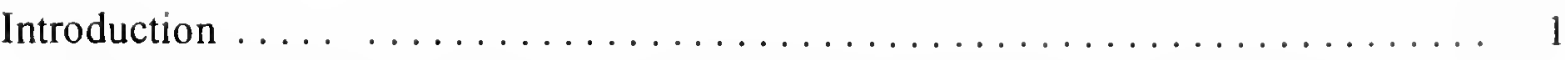

Acknowledgments . ........................... 1

"Archaeogastropods"-A Temporary Definition $\ldots \ldots \ldots \ldots \ldots \ldots \ldots \ldots \ldots$

Review of Previous Phylogenetic Hypotheses . . . . . . . . . . . . . . 2

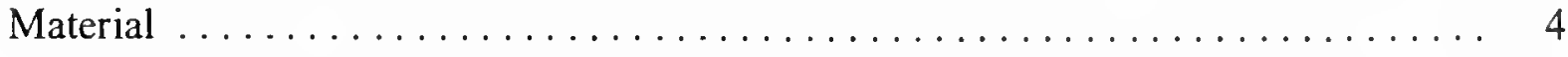

Specimens $\ldots \ldots \ldots \ldots \ldots \ldots \ldots \ldots \ldots \ldots \ldots \ldots \ldots \ldots \ldots$

Biogeography of Analyzed Species . . . . . . . . . . . . . . . . 4

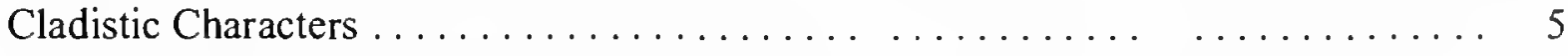

Homology Versus Architecture . . . . . . . . . . . . . . . . . 5

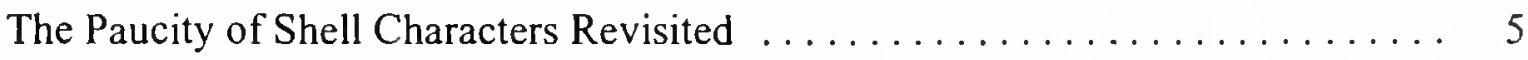

Sinuses, Slits, Selenizones, and Peripheral Bands ............... 9

Shell Mineralogy and Protoconchs $\ldots \ldots \ldots \ldots \ldots \ldots \ldots \ldots$

Phylogenetic Analysis . . . . . . . . . . . . . . . . . . . . . 11

Character Deweighting 1-Balancing Continuous Characters . . . . . . . . . 11

Character Deweighting 2-Asymmetry and Changing Homologies . . . . . . 12

Character Analyses $\ldots \ldots \ldots \ldots \ldots \ldots \ldots \ldots \ldots \ldots \ldots \ldots$

Cambrian Molluscs and the Choice of an Outgroup .............. 15

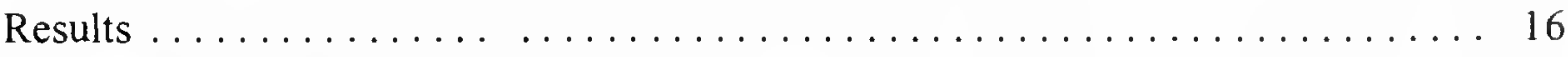

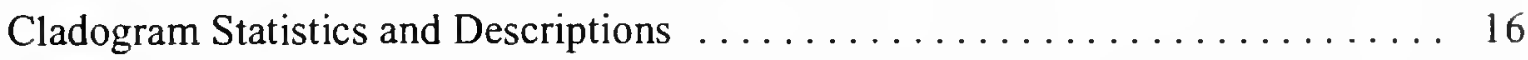

Outgroup Analyses $\ldots \ldots \ldots \ldots \ldots \ldots \ldots \ldots \ldots \ldots \ldots \ldots \ldots \ldots$

Relationships among Early Ordovician Species ................ 21

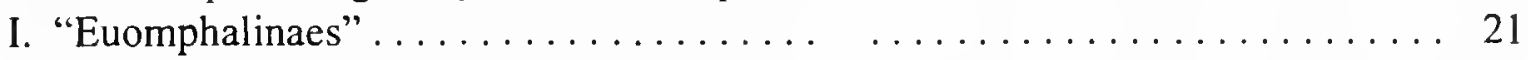

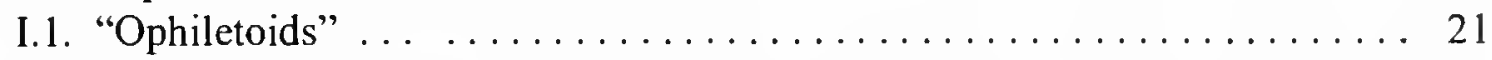

I.2. "Macluritoids" . . . . . . . . . . . . . . . . . . . . 23

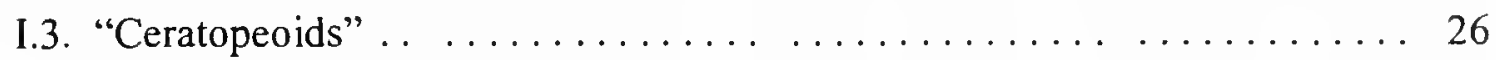

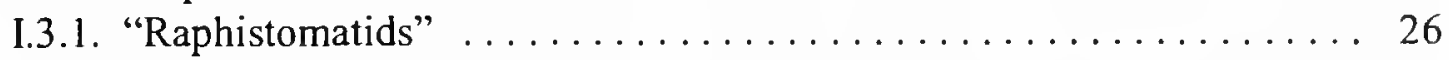

1.3.1.1. "Lesueurillines" ....... . . . . . . . . . . . . . 26

I.3.1.2. "Holopeines" ............................. 29

I.3.2. "Helicotomids" ............................ 29

1.3.2.1. "Ophiletinines" ............... .......... 31

I.3.2.2. "Euomphalopterines" ..................... 31

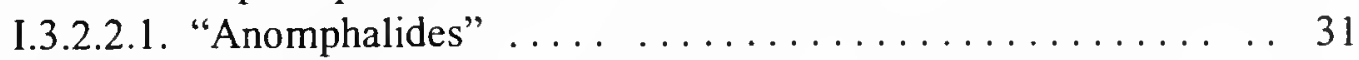

I.3.2.2.2. "Poleumitides" ... . . . . . . . . . . . . . . 31

I.3.2.2.3. "Pseudophorides" ..................... 33

II. "Murchisoniinaes" ............................. 35

II.1. "Plethospiroids" ............................. 39

II.2. "Straparollinoids" . . . . . . . . . . . . . . . . . . . . . 39

II.3. "Hormotomoids" ... . . . . . . . . . . . . . . . . . . . . 39

II.3.1. "Subulitids" ............................. 39

II.3.2. "Cyrtostrophids" ........................... 43

II.3.2.1. "Goniostrophines" .......... ............ 46

II.3.2.2. "Omospirines" ....................... 46

II.4. "Eotomarioids" $\ldots \ldots \ldots \ldots \ldots \ldots \ldots \ldots \ldots \ldots \ldots \ldots \ldots \ldots \ldots$

II.4.1. "Lophospirids" .......................... 50

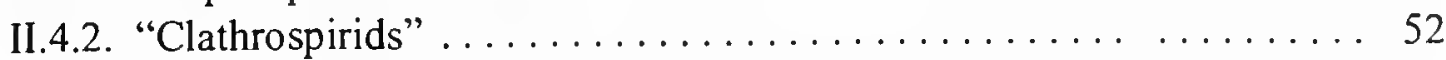

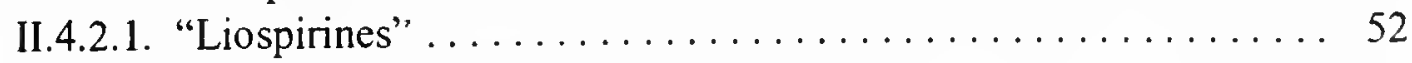

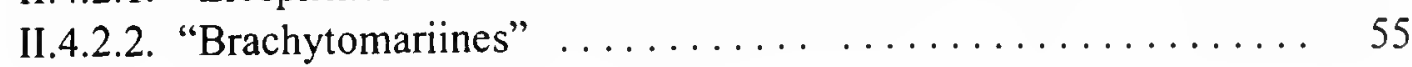




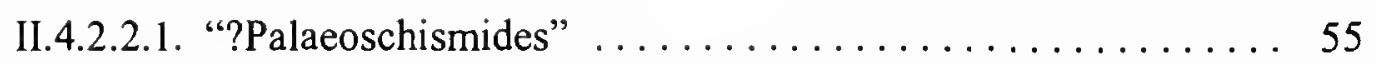

II.4.2.2.2. "Phanerotrematides" $\ldots \ldots \ldots \ldots \ldots \ldots \ldots \ldots \ldots \ldots \ldots$

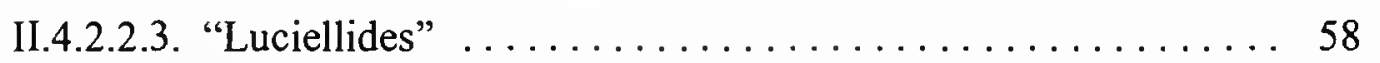

II.4.2.2.4. "Planozonides" . . . . . . . . . . . . . . . . 58

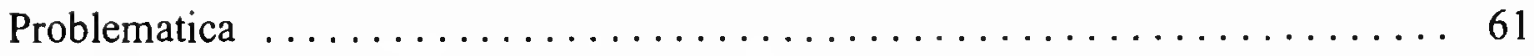

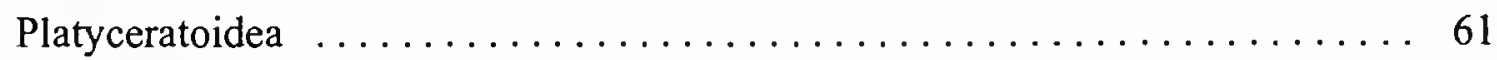

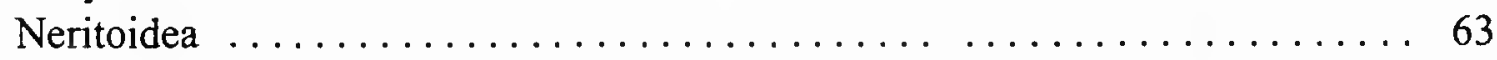

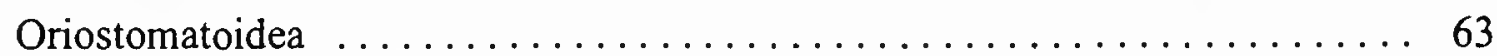

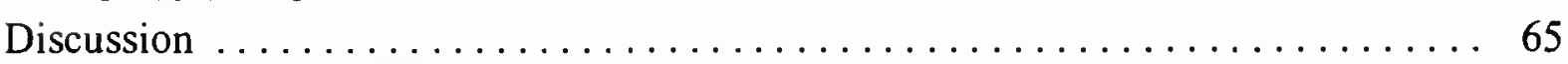

Paleozoic Pleurotomarioids: An Oxymoron? ................. 65

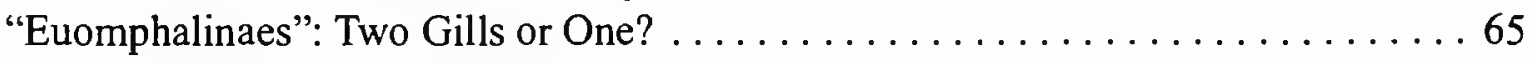

Implications for Relationships among Extant Gastropods $\ldots \ldots \ldots \ldots \ldots 6$

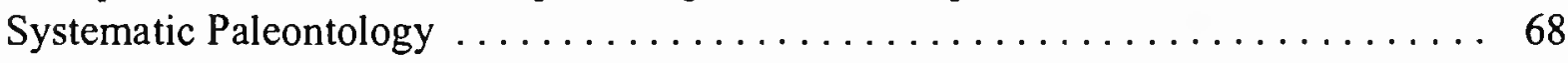

Class GastropodA Cuvier, $1797 \ldots \ldots \ldots \ldots \ldots \ldots \ldots \ldots$

Order "ARCHAEOGASTROPODA" Thiele, $1925 \ldots \ldots \ldots \ldots \ldots \ldots \ldots$

Family $†$ SinUOPEIDAE Wenz, $1938 \ldots \ldots \ldots \ldots \ldots \ldots . \ldots \ldots$

Genus + Sinuopea Ulrich, $1911 \ldots \ldots \ldots \ldots \ldots$

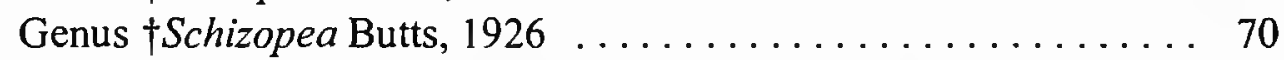

Genus Euconia Ulrich in Ulrich and Scofield, 1897 . . . . . . . 70

Genus Gasconadia Ulrich in Weller and St. Clair, 1928 . . . . . . . 70

?Genus Calaurops Whitfield, $1886 \ldots \ldots \ldots \ldots \ldots$. . . . . . . 70

Suborder EUOMPHALINA de Koninck, $1881 \ldots \ldots \ldots \ldots \ldots \ldots$

Superfamily †OPHILETOIDEA trans. nov. Knight, $1956 \ldots \ldots \ldots \ldots \ldots \ldots 70$

Genus $\dagger$ Ophileta Vanuxem, $1842 \ldots \ldots \ldots \ldots \ldots \ldots$

Genus $\dagger$ Lecanospira Butts, $1926 \ldots \ldots \ldots \ldots \ldots \ldots$

Genus Ecculiomphalus Portlock, $1843 \ldots \ldots \ldots \ldots \ldots \ldots$

Genus $\dagger$ Asgardaspira, new genus ............... 71

Genus Lytospira Koken, $1896 \ldots \ldots \ldots \ldots \ldots$. . . . . . . . . 71

Superfamily MACLURITOIDEA Fischer, $1885 \ldots \ldots \ldots \ldots \ldots \ldots \ldots$

Genus $\nmid$ Macluritella Kirk, $1927 \ldots \ldots \ldots \ldots \ldots$. . . . . . . 72

Genus $\nmid$ Teiichispira Yochelson and Jones, $1968 \ldots \ldots \ldots \ldots 72$

Genus $\nmid$ Maclurites Le Sueur, $1818 \ldots \ldots \ldots \ldots \ldots$. . . . . . . 72

Genus Maclurina Ulrich and Scofield, $1897 \ldots \ldots \ldots . \ldots . \ldots 72$

Genus Palliseria Wilson, 1924 ... . . . . . . . . . . . . 72

?Genus Rousseauspira Rohr and Potter, 1987 . . . . . . . . 73

Superfamily †EUOMPHALOIDEA de Koninck, $1844 \ldots \ldots \ldots \ldots \ldots \ldots 73$

Family $\nmid$ RAPHISTOMATIDAE Koken, $1896 \ldots \ldots \ldots \ldots \ldots$

Genus †Ceratopea Ulrich, $1911 \ldots \ldots \ldots \ldots \ldots \ldots \ldots \ldots$

Genus Bridgeites Flower, 1968a . . . . . . . . . . . . 73

Genus Orospira Butts, 1926 . . . . . . . . . . . . . . . 73

Genus Raphistoma Hall, $1847 \ldots \ldots \ldots \ldots \ldots \ldots$

Genus $\nmid$ Scalites Emmons, $1842 \ldots \ldots \ldots \ldots \ldots \ldots \ldots$

Family HoLOPEIDAE Wenz, $1938 \ldots \ldots \ldots \ldots \ldots \ldots \ldots \ldots$

Genus Raphistomina Ulrich and Scofield, 1897 . . . . . . . . . 74

Genus $\nmid$ Pachystrophia Perner, $1903 \quad \ldots \ldots \ldots \ldots \ldots \ldots 74$

Genus Sinutropis Perner, $1903 \ldots \ldots \ldots \ldots \ldots \ldots$

Genus Umbospira Perner, $1903 \ldots \ldots \ldots \ldots \ldots \ldots \ldots$

Genus Holopea Hall, 1847 . . . . . . . . . . . . . . . . 75

Family LESUEURILLIDAE, new family ................ 75

Genus $\nmid$ Eccyliopterus Remelé $1888 \ldots \ldots \ldots \ldots \ldots 75$

Genus $\nmid$ Lesueurilla Koken, $1898 \ldots \ldots \ldots \ldots \ldots \ldots \ldots$

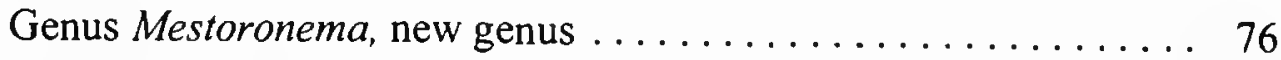

Genus Pararaphistoma Vostokova, $1955 \ldots \ldots \ldots \ldots$

Family + HeLICOTOMIDAE Wenz, $1938 \ldots \ldots \ldots \ldots \ldots$ 
Genus $\nmid$ Lophonema Ulrich in Purdue and Miser, $1916 \ldots \ldots . .76$

Genus Linsleyella Rohr, 1980 ...................... 76

Genus $\dagger$ Helicotoma Salter, 1859 . . . . . . . . . . . . . . . . . . . . 77

Genus Palaeomphalus Koken, 1925 ............... 77

Genus Ophiletina Ulrich and Scofield, $1897 \ldots \ldots \ldots \ldots \ldots .77$

Family †EUOMPHALIDAE de Koninck, $1881 \ldots \ldots \ldots \ldots \ldots \ldots \ldots .77$

Genus $\nmid$ Boucotspira Rohr, $1980 \ldots \ldots \ldots \ldots \ldots \ldots \ldots \ldots \ldots$

Genus $†$ Euomphalopterus Roemer, $1876 \ldots \ldots \ldots \ldots \ldots \ldots 77$

Genus Spinicharybdis Rohr and Packard, $1982 \ldots \ldots \ldots \ldots \ldots 78$

Genus $\nmid$ Poleumita Clarke and Ruedemann, $1903 \ldots \ldots \ldots \ldots .78$

Genus Nodonema Linsley, $1968 \ldots \ldots \ldots \ldots \ldots \ldots \ldots . \ldots 78$

Genus Centrifugus Bronn, $1834 \ldots \ldots \ldots \ldots \ldots \ldots \ldots \ldots$

Genus Euomphalus Sowerby, $1814 \ldots \ldots \ldots \ldots \ldots \ldots \ldots . \ldots 78$

Genus Straparollus de Montfort, $1810 \ldots \ldots \ldots \ldots \ldots \ldots$

Genus Micromphalus Knight, $1945 \ldots \ldots \ldots \ldots \ldots \ldots \ldots \ldots . \ldots 79$

Family ANOMPHALIDAE Wenz, $1938 \ldots \ldots \ldots \ldots \ldots \ldots \ldots \ldots \ldots$

Genus †Trochomphalus Koken, $1925 \ldots \ldots \ldots \ldots \ldots \ldots \ldots$

Genus Pycnomphalus Lindström, $1884 \ldots \ldots \ldots \ldots \ldots \ldots . \ldots 79$

Family PSEUDOPHORIDAE Miller, $1889 \ldots \ldots \ldots \ldots \ldots \ldots \ldots$

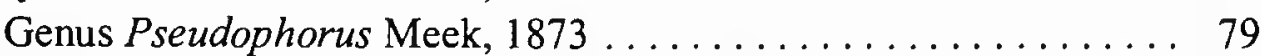

Genus Pseudotectus Pemer, $1903 \ldots \ldots \ldots \ldots \ldots$. . . . . . . 80

Genus $\nmid$ Discordichilus Cossmann, $1918 \ldots \ldots \ldots \ldots \ldots \ldots$

Genus Hystricoceras Jahn, $1894 \ldots \ldots \ldots \ldots \ldots \ldots \ldots \ldots \ldots$. . . . . . . 80

Genus Streptotrochus Perner, $1903 \ldots \ldots \ldots \ldots \ldots \ldots \ldots$. . . . . 80

Genus Elasmonema Fischer, 1885 .................... 80

Suborder MURCHISONIINA Cox and Knight, $1960 \ldots \ldots \ldots \ldots \ldots \ldots 80$

Superfamily †MURCHISONIOIDEA Koken, $1896 \ldots \ldots \ldots \ldots \ldots \ldots .61$

Family †HORMOTOMIDAE Wenz, $1938 \ldots \ldots \ldots \ldots \ldots \ldots \ldots \ldots . \ldots . \ldots . \ldots 1$

Genus $\nmid$ Hormotoma Salter, $1859 \ldots \ldots \ldots \ldots \ldots \ldots \ldots \ldots$. . . . . 81

Genus †Coelocaulus Oehlert, $1888 \ldots \ldots \ldots \ldots \ldots \ldots \ldots \ldots . \ldots 1$

Genus Catazone Perner, $1903 \ldots \ldots \ldots \ldots \ldots \ldots \ldots \ldots$. . . . . . . 81

Genus Mesocoelia Pemer, 1907 ................. 81

Genus Plethospira Ulrich in Ulrich and Scofield, $1897 \ldots \ldots \ldots .81$

Family MURCHISONIIDAE Koken, $1896 \ldots \ldots \ldots \ldots \ldots \ldots \ldots . \ldots \ldots$

Genus †Murchisonia d'Archaic, $1841 \ldots \ldots \ldots \ldots \ldots \ldots \ldots . \ldots 2$

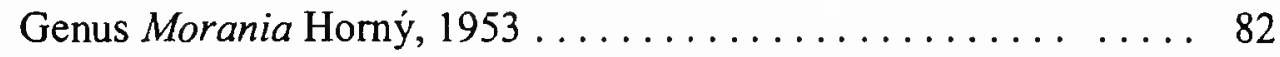

Genus Michelia Roemer, $1854 \ldots \ldots \ldots \ldots \ldots \ldots \ldots \ldots . \ldots 2$

Superfamily LOXONEMATOIDEA Koken, $1889 \ldots \ldots \ldots \ldots \ldots \ldots \ldots . \ldots 2$

Family LoXonEMATIDAE Koken, $1889 \ldots \ldots \ldots \ldots \ldots \ldots \ldots \ldots . \ldots 2$

Genus $\nmid$ Loxonema Phillips, $1841 \ldots \ldots \ldots \ldots \ldots \ldots \ldots \ldots . \ldots 2$

Genus $†$ Omospira Ulrich and Scofield, $1897 \ldots \ldots \ldots \ldots \ldots .83$

Genus Diplozone Perner, 1907 ................... 83

Genus Rhabdostropha Donald, $1905 \ldots \ldots \ldots \ldots \ldots \ldots \ldots$

Genus Spiroecus Longstaff, 1924 . . . . . . . . . . . . . 83

Genus Macrochilus Lindström, $1884 \ldots \ldots \ldots \ldots \ldots \ldots \ldots . \ldots 3$

Genus Stylonema Pemer, $1907 \ldots \ldots \ldots \ldots \ldots \ldots \ldots \ldots .64$

Superfamily EOTOMARIOIDEA Ulrich and Scofield, $1897 \ldots \ldots \ldots \ldots \ldots 84$

Family EOTOMARIIDAE Wenz, $1938 \ldots \ldots \ldots \ldots \ldots \ldots \ldots \ldots . \ldots \ldots$

Genus $\uparrow$ Clathrospira Ulrich and Scofield, $1897 \ldots \ldots \ldots \ldots \ldots .84$

?Genus Spirotomaria Koken, 1925 ................ 84

Genus $\nmid$ Eotomaria Ulrich and Scofield, $1897 \ldots \ldots \ldots \ldots \ldots .8 .64$

Genus Paraliospira Rohr, $1980 \ldots \ldots \ldots \ldots \ldots \ldots \ldots \ldots \ldots . . . \ldots 4$

Genus Liospira Ulrich and Scofield, $1897 \ldots \ldots \ldots \ldots \ldots \ldots . . .65$

Family $\dagger$ GossELETINIDAE Wenz, $1938 \ldots \ldots \ldots \ldots \ldots \ldots \ldots . . \ldots 5$ 
Subfamily $\uparrow$ EURYZONINAE, new subfamily $\ldots \ldots \ldots \ldots \ldots \ldots . \ldots 5$

Genus $\nmid$ Deaechospira, new genus ............... 85

Genus $\nmid$ Cataschisma Branson, $1909 \ldots \ldots \ldots \ldots \ldots \ldots \ldots \ldots . \ldots \ldots$

?Genus Palaeoschisma Donald, $1902 \ldots \ldots \ldots \ldots \ldots \ldots \ldots . . \ldots 6$

Genus $\nmid$ Pleurorima Perner, $1907 \ldots \ldots \ldots \ldots \ldots \ldots \ldots$

Genus Euryzone Koken, $1896 \ldots \ldots \ldots \ldots \ldots \ldots \ldots \ldots \ldots$

Genus Latitaenia Koken, 1925 ................. 86

Subfamily GosSELETININAE Wenz, $1938 \ldots \ldots \ldots \ldots \ldots \ldots . \ldots 6$

Genus †Stenoloron Oehlert, $1888 \ldots \ldots \ldots \ldots \ldots \ldots \ldots \ldots . \ldots 6$

Genus Platyloron Oehlert, $1888 \ldots \ldots \ldots \ldots \ldots \ldots \ldots \ldots$

Genus Umbotropsis Perner, 1907 ................ 87

Family †PHANEROTREMATIDAE Knight, $1956 \ldots \ldots \ldots \ldots \ldots . \ldots 7$

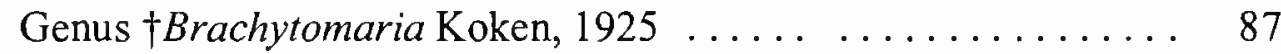

Genus Phanerotrema Fischer, 1885 . . . . . . . . . . . . . . 87

Genus Ulrichospira Donald, $1905 \ldots \ldots \ldots \ldots \ldots \ldots \ldots . \ldots 8$

Family LUCIELLIDAE Knight, $1956 \ldots \ldots \ldots \ldots \ldots \ldots \ldots$

Genus Conotoma Perner, $1907 \ldots \ldots \ldots \ldots \ldots \ldots$. . . . . . 88

Genus Prosolarium Perner, 1907 . . . . . . . . . . . . . 88

Genus Oehlertia Perner, $1907 \ldots \ldots \ldots \ldots \ldots \ldots \ldots . \ldots . \ldots$

Superfamily LOPHOSPIROIDAE Wenz, $1938 \ldots \ldots \ldots \ldots \ldots \ldots \ldots . \ldots$

Family LOPHOSPIRIDAE Wenz, $1938 \ldots \ldots \ldots \ldots \ldots \ldots \ldots$

Genus Ectomaria Koken, 1896 ................. 89

Genus Donaldiella Cossmann, $1903 \ldots \ldots \ldots \ldots \ldots \ldots \ldots . \ldots \ldots$

Genus Lophospira Whitfield, $1886 \ldots \ldots \ldots \ldots \ldots \ldots \ldots \ldots . \ldots 8$

Genus Proturritella Koken, 1889 ................. 89

Genus Eunema Salter, 1859 . . . . . . . . . . . . . . . . . . 89

Genus Gyronema Ulrich in Ulrich and Scofield, $1897 \ldots \ldots \ldots .89$

Genus Ruedemannia Foerste, 1914 ... . . . . . . . . . . . 89

Genus Loxoplocus Fischer, $1885 \ldots \ldots \ldots \ldots \ldots \ldots \ldots \ldots$

Genus Longstaffia Cossman, $1908 \ldots \ldots \ldots \ldots \ldots \ldots \ldots$

Genus Arjamannia Peel, 1975 ...................... 90

Genus Trochonemella Okulitch, 1935 ................... 90

Family TrochonematidaE Zittel, $1895 \ldots \ldots \ldots \ldots \ldots \ldots \ldots \ldots . . \ldots 90$

Genus Trochonema Salter, 1859 ................... . 90

Genus Globonema Wenz, 1938 ...................... 90

Superfamily STRAPAROLLINOIDEA, new superfamily .......... 90

Family STRAPAROLLINIDAE, new family ................. 90

Genus † Straparollina Billings, $1865 \ldots \ldots \ldots \ldots \ldots \ldots \ldots \ldots .90$

Genus Daidia Salter, $1859 \ldots \ldots \ldots \ldots \ldots \ldots \ldots$. . . . . . 90

Genus Haplospira Koken, 1897 . . . . . . . . . . . . . . . . . . 91

Superfamily SUBULITOIDEA Lindström, $1884 \ldots \ldots \ldots \ldots \ldots \ldots \ldots 9 . \ldots \ldots$

Family SUBULITIDAE Lindström, $1884 \ldots \ldots \ldots \ldots \ldots \ldots \ldots \ldots .91$

Genus $\dagger$ Eroicaspira, new genus $\ldots \ldots \ldots \ldots \ldots \ldots \ldots \ldots 9 . \ldots 1$

Genus $\uparrow$ Subulites Emmons, $1842 \quad \ldots \ldots \ldots \ldots \ldots \ldots \ldots \ldots . \ldots 1$

Genus Fusispira Hall, $1872 \ldots \ldots \ldots \ldots \ldots \ldots \ldots \ldots \ldots . .91$

Genus Cyrtospira Ulrich in Ulrich and Scofield, $1897 \ldots \ldots \ldots . .91$

Conclusions .................................. 91

Appendix 1: Characters and Character States $\ldots \ldots \ldots \ldots \ldots \ldots \ldots \ldots . \ldots 9 . \ldots 9$

Appendix 2: Data Matrix .................................... 100

Appendix 3: Stratigraphic Data ............................. 134

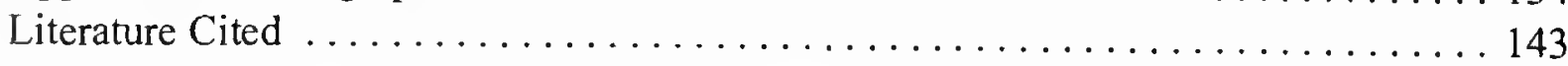




\title{
Phylogenetic Relationships of the Earliest Anisostrophically Coiled Gastropods
}

\author{
Peter J. Wagner ${ }^{1}$
}

\section{Introduction}

The renewed interest in gastropod phylogenetics (see Bieler, 1992, for a review) has generally neglected fossil taxa. This is unfortunate because solely neontological studies exclude many interesting gastropod clades and likely underestimate the complexity of gastropod evolution. The earliest members of diverse, long-lived clades also might possess informative combinations of plesiomorphies and apomorphies (see Gauthier et al., 1988; Donoghue et al., 1989). Many major taxa (extinct and extant) apparently diverged very early in gastropod history (Knight et al., 1960) without obvious intermediates (Erwin, 1990a); therefore, a phylogenetic analysis of the earliest gastropods could contribute much to contemporary ideas about gastropod relationships.

The last phylogenetic study to concentrate on Early Paleozoic gastropods was by Knight (1952). Later workers presented alternative ideas about relationships among particular taxa (e.g., Yochelson, 1967, 1984; Runnegar, 1981; Linsley and Kier, 1984), but none have conducted large-scale phylogenetic analyses. In this paper, I discuss the results of phylogenetic analyses that encompass 295 species of early anisostrophically

\footnotetext{
'Author's Note: The scientific content of this paper originally appeared as a chapter in the author's 1995 dissertation, "The Generation and Maintenance of Morphologic and Phylogenetic Diversity among Early Gastropods" (University of Chicago). This paper was slightly modified from that chapter and was accepted for publication in 1996. Thus, this work is older than studies published by the author since 1997, and readers should consider conclusions in those papers to supercede conclusions in this work. Also, this paper refers to no studies published after 1997 (except in cases where this paper originally referred to works in press or in preparation, or to published abstracts now representing journal articles). As a result, several studies using similar methods and/or data sets are not mentioned. The author regrets any confusion that might arise because of the misleading publication date.
}

Peter J. Wagner, Department of Geology, Field Museum of Natural History, 1400 South Lake Shore Drive, Chicago, Illinois 60605-2496. E-mail address: pwagner@fmnh.org. coiled gastropods. These results are contrasted with the many previous phylogenetic estimates that gastropod systematists have presented. Although the primary goal of the study is to estimate relationships among early gastropods, the study addresses (by necessity) some larger phylogenetic issues. These topics include the relationship of early gastropods to other early Paleozoic molluscs, the relationships of the Paragastropoda (Linsley and Kier, 1984) to each other and to gastropods and other molluscs, and the relationships of the problematic bellerophonts to gastropods, other molluscs, and (to a much lesser extent) each other.

This study differs from its predecessors in two ways. First, it includes only species that appeared from the Cambrian through the Silurian, whereas studies such as those cited above estimated gastropod phylogeny using species that appeared long after major taxa (i.e., orders and suborders) diverged (Yochelson, 1984). Second, this study is essentially a species-level analysis, whereas previous studies typically used one or two exemplar species to represent each higher taxon. Erwin (1990b) rendered both strategies suspect, as a cladistic analysis of higher taxa that used late Paleozoic exemplar species suggested very different relationships than did an analysis of the same higher taxa that used early Paleozoic exemplars. The analysis presented herein avoids both problems by making no assumptions about the definitions or diagnoses of higher taxa.

\section{ACKNOWLEDGMENTS}

A Smithsonian Predoctoral Fellowship during the summer of 1991, sponsored by D.H. Erwin and E.L. Yochelson, funded much of the research presented herein. Additional research funding was provided by an NSF doctoral dissertation improvement grant, the Geological Society of America, Sigma $\mathrm{Xi}$, the Hinds Fund from the Division of the Biological Sciences at the University of Chicago, National Aeronautics and Space Administration (U.S.A.) grant NAGW-1693 to J.J. Sepkoski, Jr., and NSF grant \#EAR-84-177011 to D. Jablonski. I 
thank the following people for allowing me access to the collections housed at their institutions (and also for outstanding hospitality): J. Cooper and N.J. Morris at The Natural History Museum, London; R. Owens at the Welsh Museum of National History in Wales; J. Bergström and V. Jaanuson at the Swedish Natural History Museum in Stockholm; R.J. Horný at the Narodní Museum, Prague; and the staff at the Okresní Museum, Rokycany, Czech Republic. The scanning equipment and grayscale printers that made many of the figures possible were made available by D. Rowley and D. MacAyeal. I thank the following for extended to near-endless discussions about gastropod biology and evolution, and/or phylogenetic theory and methods in general, or for suggesting useful revisions to this manuscript: W. Allmon, J. Alroy, R. Bieler, D.H. Erwin, M. Foote, D. Jablonski, R. Horný, M. LaBarbera, D. Lindberg, R. Linsley, D. Miller, N.J. Morris, P.J. Morris, J.S. Peel, J.A. Schneider, J.J. Sepkoski, Jr., S. Suter, E.L. Yochelson, and the Field Museum systematics discussion group. By no means do I wish to imply that any of the above agree with all (or any) of my results, methods, and/or conclusions.

\section{"Archaeogastropods"-A Temporary Definition}

Workers have classified most early Paleozoic gastropod species within the order Archaeogastropoda; however, the definitions and diagnoses of the taxon has changed drastically in recent years, and there is little consensus on the taxon's meaning or utility. Hickman's (1988) monophyletic definition of extant taxa (Pleurotomarioidea + Fissurelloidea + Haliotoidea + Scissurelloidea + Trochoidea; = the Vetigastropoda of Salvini-Plawen and Haszprunar, 1987) is not obviously applicable to early Paleozoic species. Neither is Haszprunar's (1988) paraphyletic definition, which is based on the nervous system. Gastropod systematics is weighed down with excessive names and an unstable taxonomy (Bieler, 1992), so retaining a definition of the "Archaeogastropoda" that is monophyletic through the Silurian (and hence used in quotes) is useful, if only for purposes of this discussion. For this paper, I define "archaeogastropods" as dextrally coiled molluscs with an anal emargination (i.e., a sinus) and a peripheral band (see diagnosis below), plus all of their descendants through the Silurian. This definition differs from that of other paleontologists (e.g., Knight et al., 1960) and also from the paleontological definition of the Vetigastropoda given by Tracey et al. (1993) in that "archaeogastropods" include not only putative pleurotomarioids and trochoids, but also the earliest species assigned to the Apogastropoda ${ }^{2}$ and other orders. "Archaeogastropods" might be synonymous with a crowngroup definition of gastropods (i.e., the last common ancestor

\footnotetext{
${ }^{2}$ The Apogastropoda include fossil taxa, such as the Loxonematoidea, that Wenz (1938) and Knight et al. (1960) classified in the Caenogastropoda as well as modern caenogastropods, allogastropods, opisthobranchs, and pulmonates (Tracey et al., 1993). Therefore, I use the Apogastropoda as a replacement for the traditional paleontological definition of the Caenogastropoda.
}

of all extant gastropods and all of its descendants), but this analysis cannot demonstrate that possibility.

\section{Review of Previous Phylogenetic Hypotheses}

A standard neontological depiction of gastropod phylogeny suggests that the planispiral Bellerophontina ${ }^{3}$ were the earliest gastropods and that bellerophontinae were ancestral to anisostrophic pleurotomarioids (e.g., Barnes, 1987; see Figure 1A). Pleurotomarioids later produced other archaeogastropods, apogastropods, and the Patellogastropoda (e.g., Fretter and Graham, 1962). The traditional paleontological depiction is similar, essentially differing only by suggesting that a second extinct group of anisostrophic species (i.e., the Macluritoidea and Euomphaloidea) evolved from bellerophontinae (e.g., see Knight, 1952; Knight et al., 1960; Figure 1B).

Proposed alternatives exist to nearly every relationship shown in Figure 1A,B. Some alternatives are only slightly different. For example, Koken (1898, 1925; also N.J. Morris and Cleevely, 1981; P.J. Morris, 1991) thought that macluritoids and pleurotomarioids shared a helically coiled ancestor (Figure 1C). Other proposals are radically different. A key controversy concerns the affinities of the Bellerophontina. Yochelson $(1967,1984)$ suggested that bellerophontinae evolved from (rather than giving rise to) pleurotomarioids (Figure 1D). Ulrich and Scofield (1897) considered bellerophontinae derived, but they thought that bellerophontinae and pleurotomarioids evolved independently from limpet gastropods (Figure 1E). Haszprunar (1988) also considered limpet gastropods to be the ultimate gastropod ancestors of bellerophontinae, without commenting on the relationship between bellerophontinae and heli-

\footnotetext{
${ }^{3}$ In this discussion and elsewhere, the Bellerophontina refers to a diagnosed taxon, which presumably should represent a monophyletic or paraphyletic group. "Bellerophont" denotes a grade of bilaterally symmetrical, planispiral molluscs that might be polyphyletic. I use the former when discussing potential clades and the latter when discussing a morphologic type.
}

FIGURE 1 (opposite).-Summary of previous phylogenetic hypotheses for the Gastropoda. "T" denotes the hypothesized onset of torsion, which is the chief synapomorphy of gastropods. A, Traditional neontological hypothesis. B, Traditional paleontological hypothesis (e.g., Knight, 1952), with bellerophontinae as gastropods that give rise to macluritoids and pleurotomarioids separately, with pleurotomarioids giving rise to murchisonioids. (Murchisonioids later gave rise to apogastropods.) C, Macluritoids and pleurotomarioids sharing a pleurotomarioid-like ancestor (e.g., Koken, 1898, 1925; N.J. Morris and Cleevely, 1981; P.J. Morris, 1991). D, Bellerophontinae as derived pleurotomarioids (Yochelson, 1967, 1984). E, Bellerophontinae and pleurotomarioids derived separately from early limpet gastropods (Ulrich and Scofield, 1897). F, Bellerophontinae as monoplacophorans with no close relationship to gastropods (e.g., Wenz, 1938; Runnegar and Pojeta, 1974; N.J. Morris, 1990). G, Bellerophontinae as monoplacophorans and gastropods and macluritoids (including onychochilids) evolving torsion independently from a pelagiellid ancestor (Runnegar, 1981). H, Bellerophontinae as a collection of monoplacophorans and primitive gastropods (e.g., Homý, 1965; Peel, 1991a). l, Macluritoids as paragastropods and not closely related to gastropods (Linsley and Kier, 1984). 


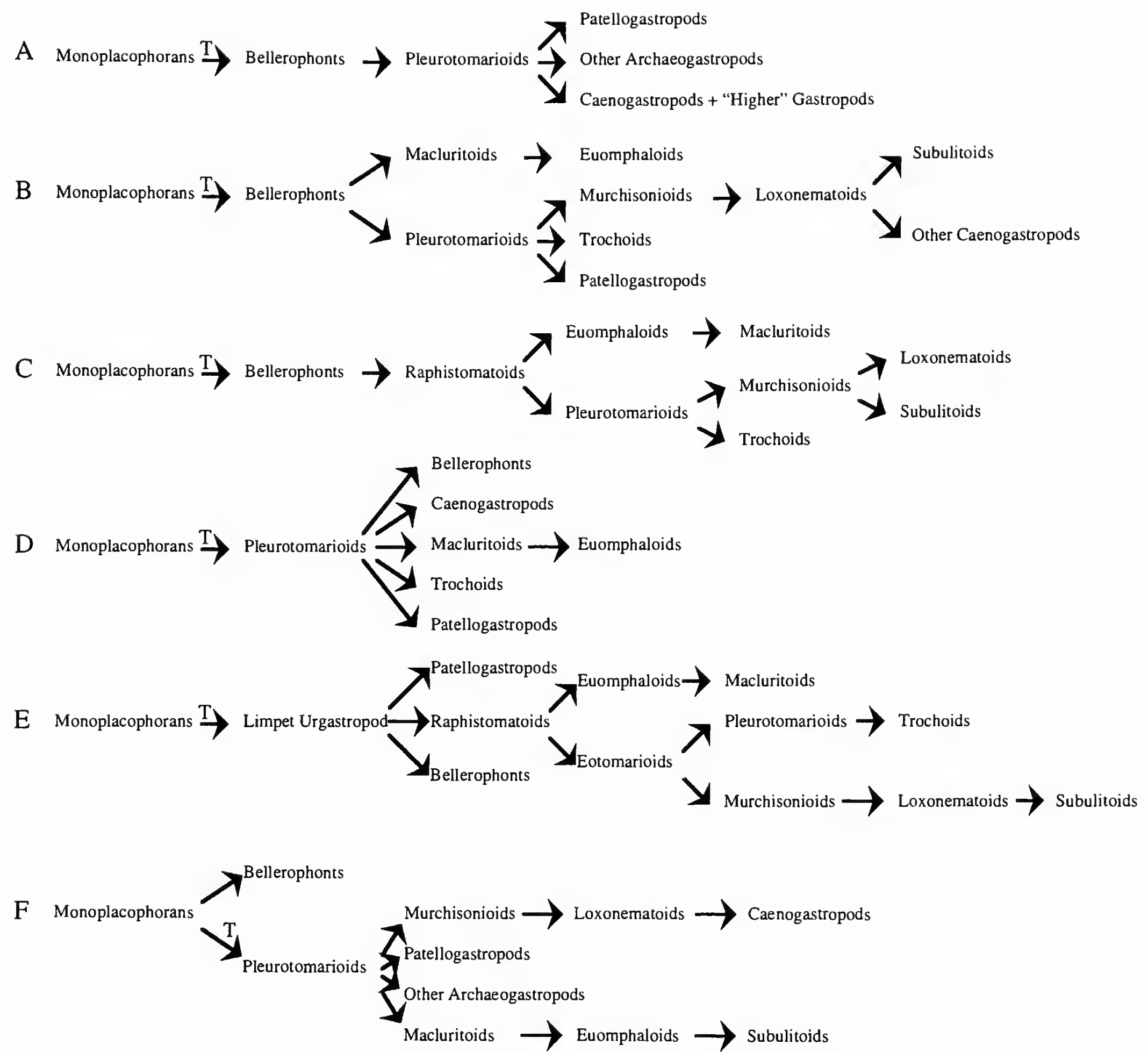

Gonoplacophorans

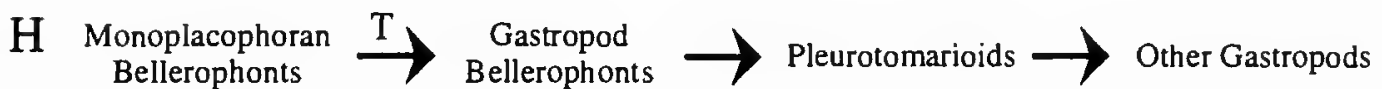

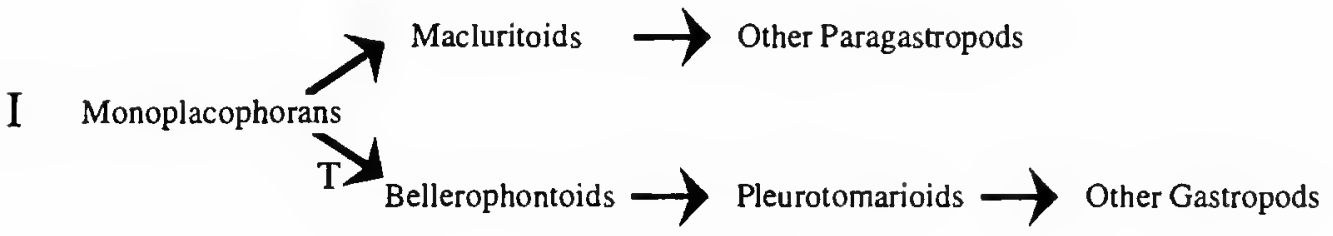


cally coiled gastropods. Conversely, segmented muscle scars in Devonian Cyrtonella Hall, 1879, led Wenz (1938) to conclude that the Bellerophontina were untorted molluscs. Runnegar and Pojeta (1974, 1985; also Runnegar, 1981, 1996; Dzik, 1981; N.J. Morris, 1990) advocated similar views and considered bellerophontinae and gastropods to be distant relatives (Figure $1 F, G)$. Finally, some workers considered traditional definitions of the Bellerophontina to include both untorted and torted molluscs (e.g., Horný, 1965, 1991, 1992b; Harper and Rollins, 1982; Peel, 1991a,c, 1993; Wahlman, 1992). The last author suggested that bellerophont gastropods evolved from anisostrophically coiled gastropods, whereas the first three authors considered some bellerophont gastropods ancestral to all other gastropods (Figure 1H). The second model is not inconsistent with most traditional models (Figure 1A,B), because traditional models often do not specify the gross morphology of the immediate ancestor of gastropods.

The affinities of the Macluritoidea represent another source of contention. Traditionally, workers considered macluritoids to be one of the earliest offshoots within the gastropod clade (e.g., Knight, 1952; N.J. Morris and Cleevely, 1981). Considerations about molluscan functional biology led Linsley and Kier (1984) to suggest that macluritoids belonged to the Paragastropoda, a group of untorted molluscs (Figure 11). The Hyperstrophina (= Mimospirina of Dzik, 1982, plus the Omphalocirridae), a group of molluscs with highly ultra-dextral shells ${ }^{4}$, are pivotal in this controversy. Workers traditionally assumed that macluritoids evolved from the Onychochilidae (e.g., Knight, 1952; Linsley and Kier, 1984; Runnegar, 1981, 1996), an early family of the Hyperstrophina. Runnegar (1981) also considered onychochilids to include the ancestors of true macluritoids. In this scheme, torsion evolved independently in true gastropods and onychochilids, with untorted pelagiellids being the common ancestor of both torted onychochilids and true gastropods. Functional analyses by P.J. Morris (1991), however, suggested that taxa such as Maclurites Le Sueur were torted, whereas hyperstrophinae were untorted. Morris and others (e.g., Peel, 1991a,b) considered hyperstrophinae and gastropods (including Maclurites) as only distant relatives.

\section{Material}

\section{SPECIMENS}

I based the phylogenetic analysis on specimens housed in the type, biologic, and stratigraphic collections at the National Museum of Natural History (Washington, D.C.), the Field Museum of Natural History (Chicago), the Natural History Mu-

\footnotetext{
"'Ultradextral" shells often are described as "hyperstrophic." Hyperstrophy and orthostrophy, however, refer to the orientation of the internal anatomy, whereas "dextral" and "ultra-dextral" refer to whether the shell coils "down" or "up" the coiling axis. Opercula indicate that uitra-dextral species, such as $M a$ clurites, had orthostrophic organizations (Yochelson, 1990), so I use the latter set of terms instead.
}

seum, London, the National Museum of Wales (Cardiff), the Natural History Museum of Sweden (Stockholm), the Národni Museum (Prague), and the Okresní Museum (Rokycany, Czech Republic). These specimens included material from North America (including Alaska), China, Malaysia, the British Isles, Scandinavia, Estonia, and western and central Europe. I also examined material collected in Kentucky (U.S.A.) by the United States Geological Survey (Wagner, 1990). Published photographs were used when available.

The analyses presented herein include 295 species. I excluded most members of the Bellerophontinae, although several were used as outgroups (see below). I also excluded most species assigned to the Subulitidae, except for the earliest and also some later ones suspected of belonging to other clades (Erwin, 1992). Finally, I also omitted species assigned to the Platyceratidae. In this case, I attempted to include some of the earliest species, but I could not identify their relationships satisfactorily (see below). In addition to the deliberately excluded taxa, I also excluded at least 50 "archaeogastropod" species that likely represent valid taxa. Nearly all of those species are known from only one or a few localities, and I was not able to examine enough specimens to code them adequately; however, these species also appear to have been short-lived and apomorphic. As I could include close relatives (which often were potential ancestors of the short-lived species), the exclusion of the short-lived species should not interfere with the stated goal of this paper, i.e., identifying the relationships among major gastropod taxa in the early Paleozoic. Notably, this analysis excluded no species known from five or more localities.

I examined multiple specimens of most species while coding the character states, which allowed me to evaluate ranges of intraspecific variation and also to observe ontogenetic variation within species. I granted no special status to type material beyond determining species assignments. This is important because much of the material that I examined has not been described, especially from the Early Ordovician. Nearly all of the specimens examined fit within the diagnoses of previously described species. A question mark precedes a species name throughout the paper if I was unable to examine the type specimen (or if the type was so poor as to be uninformative).

\section{BIOGEOGRAPHY OF ANALYZED SPECIES}

The biogeographic affinities of the examined species are somewhat complex, largely because of geographic evolution from the latest Cambrian through the Silurian. "Archaeogastropods" from the latest Cambrian through the early Arenig (Early Ordovician) appear to have been restricted to the Laurentian fauna (i.e., eastern North America and Scotland). Even after the Early Ordovician, the tropical Laurentian fauna appears to have maintained the highest "archaeogastropod" diversity of the early Paleozoic realms. By the late Early Ordovician (i.e., middle Arenig), "archaeogastropods" also existed in the Baltic, Toquima-Table Head, Celtic, and Gondwanan faunas (see Neuman and Bruton, 1989; Cocks and Fortey, 1990, for general 
descriptions of those faunas). The Toquima-Table Head fauna represents a tropical to equatorial assemblage, whereas the Baltic fauna represents a temperate fauna, and the Celtic and Gondwanan faunas represent a temperate to near-polar assemblage. The Toquima-Table Head and Celtic faunas (i.e., gastropod species from western North America, the northern east coast of North America, Wales, and parts of Norway) are somewhat problematic. Some workers recognize both faunas as distinct provinces that were unique to the late Early to Middle Ordovician (i.e., Neuman and Bruton, 1989; Neuman and Harper, 1992). Others consider both faunas to be mixtures of Laurentian and Baltic faunas (McKerrow and Cocks, 1986; Cocks and McKerrow, 1993). Gastropods from the Celtic fauna are not well known, but the few described species (e.g., Neuman, 1964) are also known from the Toquima-Table Head faunas (pers. obs.). Although these gastropods do have affinities with both Laurentian and Baltic species, they appear to represent a separate fauna. Ordovician gastropods from the temperate-topolar Gondwanan realm appear to have been rare, and I examined species only from the Middle Ordovician of western and central Europe. Early to Middle Ordovician gastropods also have been reported from the Gondwanan faunas of South America (e.g., Beresi and Rigby, 1993), but I was not able to examine any specimens. Paleogeographic reconstructions suggest that those South American faunas should have been equatorial, and general published descriptions suggest that the gastropods belonged to the tropical Toquima-Table Head fauna.

"Archaeogastropod" biogeography simplified in the Late Ordovician, which witnessed an increasing homogeneity among realms, not only for gastropods, but also for bryozoans (Anstey, 1986), trilobites (Cocks and Fortey, 1990), and brachiopods (Cocks and Ruang, 1988; Cocks and Fortey, 1990). Notably, all of the faunas are thought to have been closer to the equator during the Late Ordovician than they had been in the Early and Middle Ordovician (Scotese, 1989). The Early Silurian (i.e., Llandovery-Wenlock) shows still greater homogeneity, as "archaeogastropods" appear to have represented a single equatorial fauna. Some differentiation is noticeable by the Late Silurian (Ludlow-Prídolí), with the temperate Gondwanan fauna distinct from the tropical Laurentian and Baltic faunas.

\section{Cladistic Characters}

\section{HOMOLOGY VERSUS ARCHITECTURE}

It is important to discuss codings and a priori hypotheses of homology when conducting cladistic or phenetic analyses. Unfortunately, most of the terms used to describe gastropod shells (or portions of those shells) refer to architectural features that might or might not be present depending on the interactions of different character suites (e.g., coiling parameters and aperture shape). For example, terms such as "columella" or "umbilical carina" are not used to label homologous regions of the shell on species with very different gross morphologies. To avoid confusion, I avoid these terms and instead use slightly less com- mon terms. For example, the inner margin forms a columella on a "typical" gastropod shell (e.g., Lophospira perangulata (Hall, 1847)) and thus usually is labeled either the columella or the columellar lip (Cox, 1960; e.g., Figure 2A). On species with sufficiently low shell curvature, such as Clathrospira elliptica (Hisinger, 1829) (Figure 2B) or Spiroraphe bohemica Barrande in Perner, 1907 (Figure 2C), the "columellar lip" fails to form a columella unless it is extremely thick. A columella might still be formed by the parietal inductura (i.e., a funicle) on species with the same basic shell geometry (e.g., Siluriphorus gotlandicus (Lindström, 1884)) (Figure 2D). Finally, the homologous region on nearly planispiral taxa, such as Barnesella ?lecanospiroides Bridge and Cloud, 1947 (Figure 2E) or Palliseria robusta Wilson, 1924 (Figure 2F), forms the base of the shell rather than a columella (see, e.g., Figure $2 F$ ). Given the inconsistent relationship between this feature and the columella (and the fact that the columella is an architectural feature rather than a true homology), I refer to that portion of the aperture as the inner margin.

A columella at the base of the inner margin typically encircles the umbilicus and hence is labeled a basal carina. On nearly planispiral forms, however, the carina is at the periphery of the shell base. Accordingly, I refer to the feature as a basal carina. In addition, the "upper" and "lower" ramps of normally coiled species (e.g., Figure 2A-D) are the "right" and "left" ramps of nearly planispiral species (Figure 2E,F). As the latter terminology also refers to the post-torsional orientation of internal organs, I use right ramp throughout this paper. Batten (1989) labeled the left ramp the alveozone, a term that I use herein.

\section{The Paucity of Shell Characters Revisited}

Appendix 1 gives the characters and character states used in this study. Appendix 2 gives the data matrix. I discuss additional data relevant to both appendices below. I used 143 characters encompassing 352 character-states for this study (Appendix 1; note that I count continuous characters as only one state). There are four reasons why I used so many characters. First, the species analyzed herein encompass sufficient morphological disparity to be classified in multiple orders. One usually can describe any specimen with fewer than 50 characters, but one needs many more characters to describe the entire spectrum of gastropod shell morphologies.

The second reason for the high number of characters is that this is a species-level analysis. Supraspecific phylogenetic analyses of gastropods average less than one shell character per operational taxonomic unit (OTU), whereas species-level analyses average more than one shell character per OTU (Table 1). This likely is because many shell characters vary within clades as well as among clades, so if a study uses only a few exemplar species to represent higher taxa, then many shell characters become uninformative. Thus, many shell characters that are useful in phylogenetic analyses of closely related species are not useful in phylogenetic analyses of distantly related ones. 

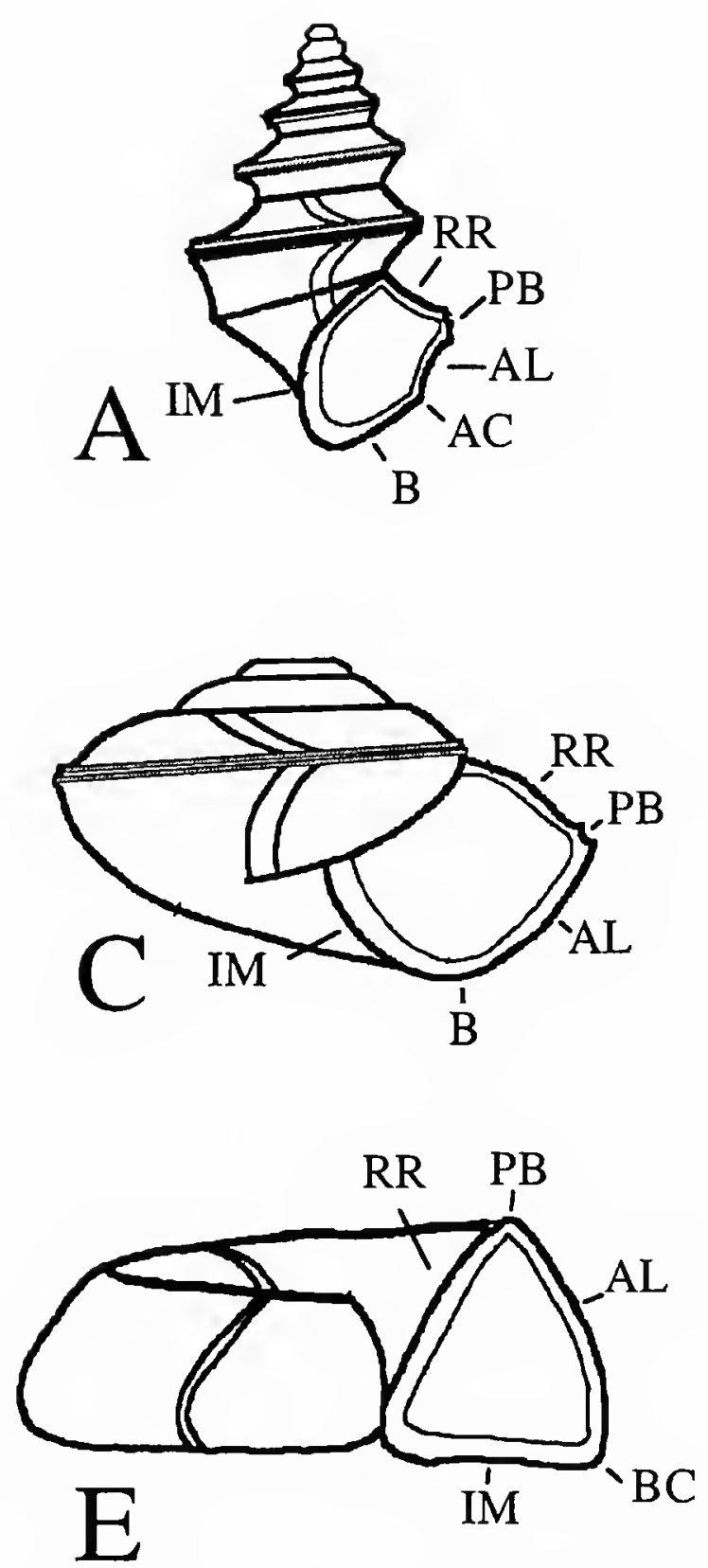
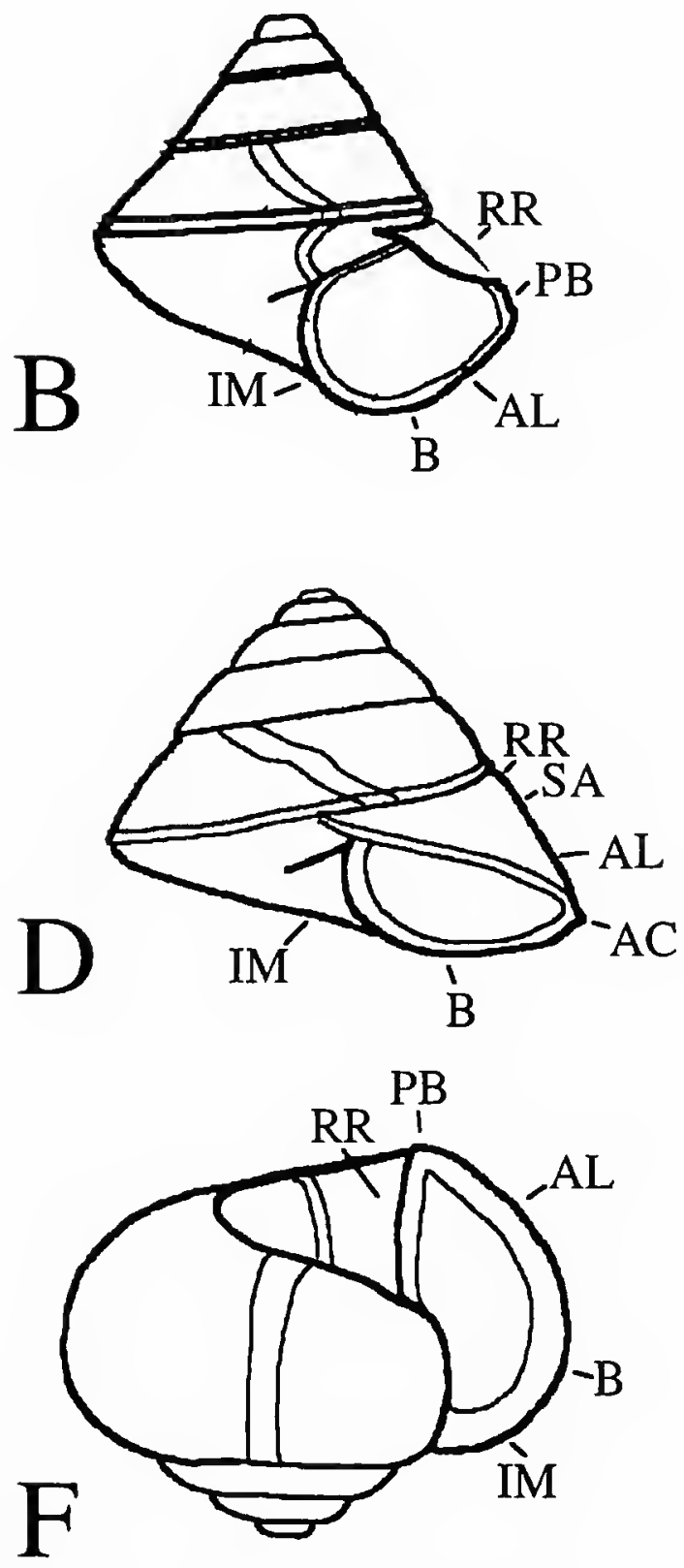

FIGURE 2.- Some basic terms and characters used in the analyses. $\mathrm{AC}=$ Carina at base of Alveozone; $\mathrm{AL}=$ Alveozone (= Post-Torsional Left Ramp; Batten, 1989); B = Base of Inner Margin; BC = Basal Carina (typically an umbilical carina); $I M=$ Inner Margin; $\mathrm{PB}=$ Peripheral Band (almost always located at the sinus apex); $\mathrm{RR}=$ Right Ramp; SA = Sinus Apex (for specimens without a peripheral band). A, Lophospira perangulata (Hall): IM thick, nearly straight, trends nearly parallel to coiling, reflects around coiling axis and forms columella; BC absent; AC present, sharp; left and right ramps symmetrical in shape (concave) and length; PB trilineate (i.e., bearing both peripheral lira and a medial lirum), bisects left and right ramps and oriented approximately $30^{\circ}$ adapically from perpendicular to IM. B, Clathrospira elliptica (Hisinger) IM little thicker than rest of shell, curved and nearly parallel to coiling axis; $\mathrm{BC}$ and $\mathrm{AC}$ absent; $\mathrm{AL}$ and RR convex, but AL shorter than RR; $\mathrm{PB}$ bilineate (i.e., peripheral lira present), bisecting $A L$ and RR and oriented nearly perpendicular to IM. C, Spiroraphe bohemica Barrande in Perner: IM curved, oriented nearly $30^{\circ}$ off parallel to coiling axis; $\mathrm{BC}$ and $\mathrm{AC}$ absent; $\mathrm{AL}$ and RR convex, but RR more convex and longer than AL; PB bilineate, falling partially on RR and oriented approxmiately $10^{\circ}$ abapically from perpendicular to IM. D, Siluriphorus gotlandicus (Lindström): IM strongly curved, thicked above base, approximately $15^{\circ}$ off perpendicular to coiling axis; $\mathrm{BC}$ present, thin and weak; $A C$ present, "squared" and strong; $A L$ and RR convex, with RR very short relative to AL; PB absent, with SA near suture. E, Barnesella ?lecanospiroides Bridge and Cloud: IM runs nearly perpendicular to coiling axis (forming flat base of shell); $\mathrm{BC}$ thick but weak; $\mathrm{AC}$ absent; $\mathrm{AL}$ and RR flat and long, symmetric in shape and length; PB monolineate, sharp, weak. F, Palliseria robusta Wilson: IM thick, curved and oriented at very high angle $\left(-120^{\circ}\right)$ relative to coiling axis (forming curved base of the aperture); $\mathrm{BC}$ dull thickening; $\mathrm{AC}$ absent; $\mathrm{AL}$ and $\mathrm{RR}$ equal in length, but with convex $\mathrm{AL}$ and flat or concave $\mathrm{RR}$.

The third reason for the large number of characters is that this analysis used many traits that are inapplicable to extant species. Characters describing sinuses, peripheral bands, slits, and differential shell asymmetry are not relevant to studies of most extant taxa, but they are very important to the study of early Paleozoic species (Table 2). For example, only a few types of peripheral bands exist on a handful of extant species; however, most early Paleozoic species possessed peripheral 
TABLE 1.-Operational taxonomic units (OTUs) versus shell characters for some previous phylogenetic analyses of gastropods. Included are the number and taxonomic level of taxa and the number of shell characters that they utilized. Only characters that could be utilized in this study were counted, so some characters, such as shell mineralogy, were excluded. "No. of OTUs" is the number of taxa that were analyzed, including outgroup taxa.

\begin{tabular}{l|cccc}
\hline \multicolumn{1}{c|}{ Study } & Taxon & $\begin{array}{c}\text { Taxic level } \\
\text { of OTUs }\end{array}$ & $\begin{array}{c}\text { No. of } \\
\text { OTUs }\end{array}$ & $\begin{array}{c}\text { No. of shell } \\
\text { characters }\end{array}$ \\
\hline Ponder and Lindberg (1996) & Gastropoda & "superfamily" & 22 & 3 \\
Haszprunar (1988) & Gastropoda & "superfamily" & 15 & 3 \\
Houbrick (1988) & Cerithioidea & superfamily & 15 & 15 \\
Ponder and Lindberg (1997) & Gastropoda & "family" & 25 & 5 \\
Davis et al. (1985) & Rissoidea & subfamily & 8 & 1 \\
Hickman and McLean (1990) & Trochoidea & subfamily/tribe & 29 & 26 \\
Hickman (1996) & Trochoidea & subfamily/tribe & 20 & 20 \\
Hickman (1996) & Turbinidae & subfamily/tribe & 9 & 13 \\
Davis and Pons da Silva (1984) & Hydrobiidae & genus & 8 & 4 \\
Ponder (1984) & Iravadiidae & genus & 14 & 9 \\
Bieler (1988) & Architectonicidae & genus & 12 & 12 \\
Reid (1989) & Littorinidae & genus & 36 & 2 \\
Jung (1992) & Planorbidae & genus & 9 & 27 \\
Kool (1993b) & Ocenebrinae & genus & 5 & 3 \\
Kool (1993a) & Rapaninae & genus & 24 & 4 \\
Houbrick (1984)/ & Cerithidea & subgenus & 4 & 9 \\
Erwin (1988) & Glyptospira & species & 8 & 21 \\
Michaux (1989) & Ancillinae & species & 32 & 32 \\
Wagner (1995a) & Lophospiridae & species & 42 & 79 \\
This study & "Archaeogastropods" & species & 295 & 352 \\
\hline
\end{tabular}

TABLE 2.-Importance of "archaeogastropod" shell characters in this analysis versus their importance in other analyses. Columns give the number of character states used in each study for the particular trait. Asterisks denote examples discussed in the text. PB denotes characters describing perhipheral bands, and InAn denotes characters describing apertural inclination. Coiling denotes coiling and/or growth parameters.

\begin{tabular}{l|ccccccc}
\hline \multirow{2}{*}{ Study } & \multicolumn{7}{c}{ Characters } \\
\cline { 2 - 8 } & Slit & Sinus & PB & Asymmetry & lnAn & Coiling & Ornament \\
\hline Ponder and Lindberg (1996) & 0 & 0 & 0 & $0^{*}$ & 0 & 0 & 0 \\
Haszprunar (1988) & $1^{*}$ & 0 & 0 & 0 & 0 & 2 & 0 \\
Houbrick (1988) & 0 & 0 & 0 & 0 & 0 & 1 & 1 \\
Ponder and Lindberg (1997) & 0 & 0 & 0 & 1 & 0 & 0 & 0 \\
Davis et al., 1985 & 0 & 0 & 0 & 0 & 0 & 1 & 0 \\
Hickman and McLean (1990) & 1 & 0 & 0 & $0^{*}$ & 1 & 2 & 4 \\
Hickman (1996) & 1 & 0 & $0 *$ & 0 & 1 & 1 & 1 \\
Davis and Pons da Silva (1984) & 0 & 0 & 0 & 0 & 0 & 1 & 1 \\
Ponder (1984) & 0 & 0 & 0 & 0 & 3 & 0 & 4 \\
Bieler (1988) & 0 & 0 & 0 & 0 & 0 & 1 & 8 \\
Reid (1989) & 0 & 0 & 0 & 0 & 0 & 1 & 1 \\
Kool (1993a) & 0 & 0 & 0 & 0 & 0 & 1 & 0 \\
Kool (1993b) & 0 & 0 & 0 & 0 & 0 & 0 & 2 \\
Houbrick (1984) & 0 & 0 & 0 & 0 & 0 & 0 & 2 \\
Erwin (1988) & 0 & 0 & 3 & 0 & 0 & 1 & 11 \\
Jung (1992) & 0 & 0 & 0 & 0 & 0 & 5 & 4 \\
Michaux (1989) & 0 & 0 & 0 & 0 & 0 & 6 & 1 \\
Wagner (1995a) & 1 & 3 & 5 & 0 & 4 & 5 & 4 \\
This study & 9 & 21 & 58 & 15 & 5 & 11 & 16 \\
\hline
\end{tabular}

bands, and several different types existed. The transition from symmetric morphologies to asymmetric ones introduces additional character states, as both the left and right sides of several features must be coded independently. Some additional implications of this pattern are discussed in detail below.

Finally, this study used finer divisions of shell characters than employed by previous workers. Gastropods can produce very similar shell shapes using different combinations of growth parameters, aperture shapes and orientations, and shell thicknesses. Character complexes often have been treated as single characters, but I divided these into several characters and multiple states. Hickman and McLean's (1990; see also Hickman, 1996) cladistic analysis of the Trochoidea used tangential and radial apertures (i.e., inclined versus noninclined) as two states of one character. Early Paleozoic gastropods produced inclined apertures in many ways (Table 2; Appendix 1, charac- 
ters 109-119). Figure 3 illustrates some examples. The apertures of some species, such as Siluriphorus gotlandicus, form a plane that is inclined relative to the coiling axis (Figure 3A). For other species, different parts of the aperture are inclined to different degrees. On species such as the Middle Ordovician Clathrospira conica Ulrich and Scofield, 1897, the left ${ }^{5}$ side of the aperture is much more inclined than the right side (Figure 3B). The opposite condition exists on Pleurorima migrans (Barrande in Perner, 1907), where the right side provides most of the inclination (Figure 3C).

The base of the aperture also can deviate from radial by projecting either anteriorly or posteriorly. An example of the former is the Middle Ordovician species Helicotoma tennesseensis Ulrich and Scofield, 1897 (Figure 3D). The Early Ordovician species Pararaphistoma qualteriata (Schlotheim, 1820 ) is an example of the latter (Figure 3E). Note that the posterior projection is not the same as a basal excavation (where the base has a sigmoidal or $U$-shape), which is coded as a separate character. Posterior projection of the base is especially common in species with very low spire heights (especially planispiral species) and might serve to alter the center of grav-

\footnotetext{
"Left" and "right" here and elsewhere refer to the post-torsional left and right. For species with selenizones, the right corresponds to the area between the selenizone and the coiling axis (i.e., usually above the "upper whorl").
}

ity within a nearly planispiral shell in a manner that is analogous to the standard inclination of the aperture on a normally coiled shell (e.g., Linsley, 1977). Anterior projection of the base occurs in both low-spired and high-spired species and also might serve to enhance apertural inclination.

Aperture shape is another trait that previous workers have used as a single character (e.g., Houbrick, 1984; Hickman and McLean, 1990). Different parts of "archaeogastropod" apertures (or, more appropriately, different portions of the outer and inner whorl faces) can have different shapes (e.g., convex, flat, concave) on the left and right side of the aperture owing to the decoupling of left-right homologies with increasing asymmetry. Accordingly, I coded the shape of the left and right sides of the aperture separately rather than trying to code a whole shape for the aperture.

An additional important point to this breakdown of character complexes concerns the functional biology of gastropod shells. Features such as spire height, apertural inclination, aperture shape, and columellar type strongly affect how easily snails can balance and move their shells (e.g., Linsley, 1977, 1978; McNair et al., 1981; Signor, 1982). Thus, convergent evolution of similar functional complexes among different clades is a major concern. The characters comprising functional complexes are used herein, however, rather than the complexes themselves. Because different combinations of characters will yield very
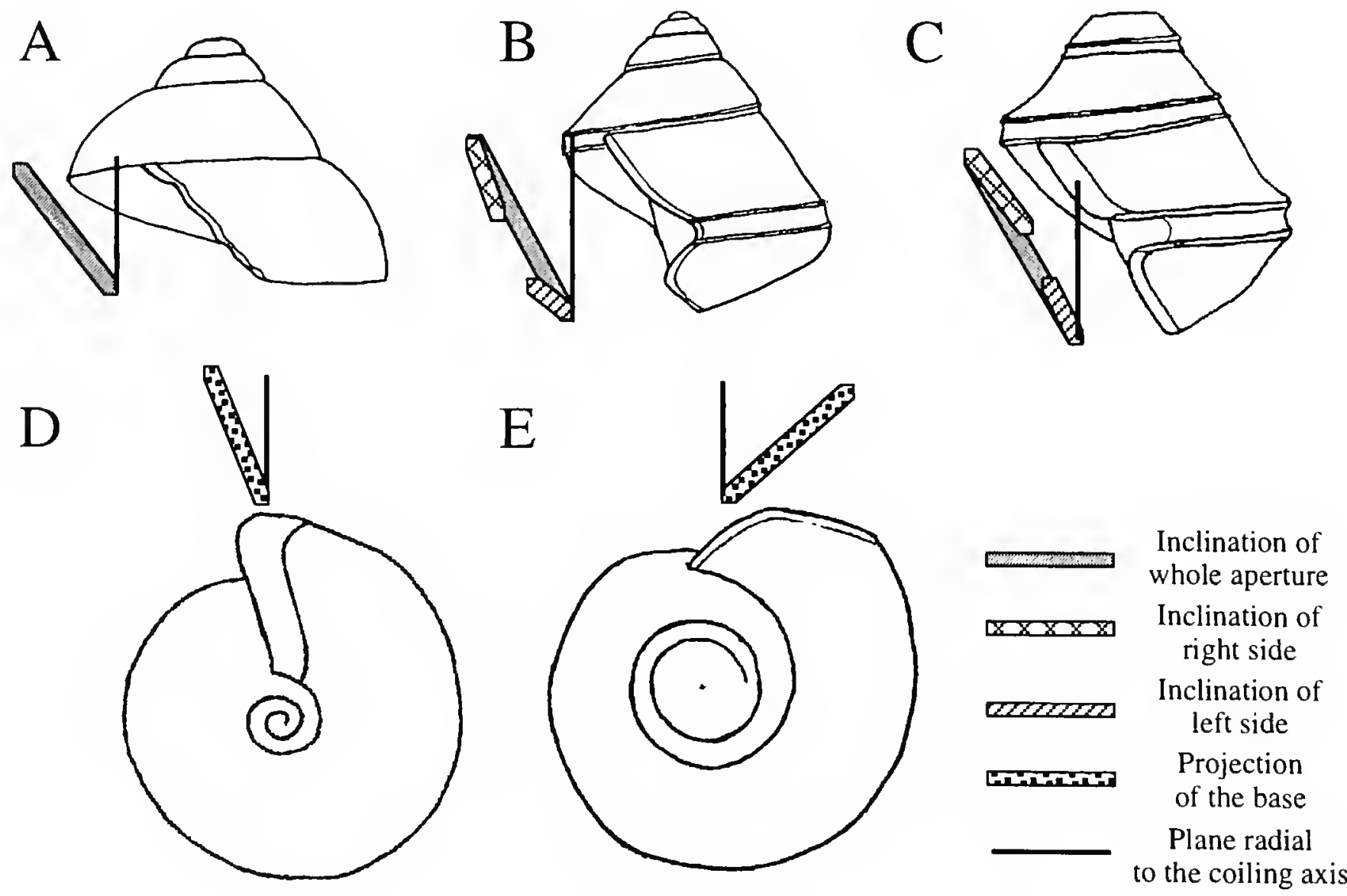

FIGURE 3.-Different ways in which early Paleozoic gastropods produced tangential apertures. A, Inclination of the whole aperture. B, Inclination provided primarily by the left side of the aperture only. Note that the lower part of the aperture has a stronger inclination than the upper part. $\mathrm{C}$, Inclination provided primarily by the right side of the aperture. D, Anterior projection of the aperture base. E, Posterior projection of the aperture base. 
similar character complexes (e.g., gross aperture shapes, spire heights, overall apertural inclinations, and columellas), two distantly related but grossly similar morphologies that functional biologists might consider to be the "same" probably will have very different character codings. Similarly, two closely related but grossly different morphologies might have very similar character codings. This does not mean that the coding scheme used herein will identify all functional convergences. Functional convergence between closely related clades or involving simplification of the shell (and necessarily reducing applicable characters) will confound any coding scheme. The breakdown of the characters (coupled with the use of stratigraphic data as tests of parsimony estimates), however, should increase the accuracy of the phylogenetic analyses.

\section{Sinuses, SLits, SElEnizones, AND Peripheral Bands}

Among modern gastropods, the sinus (a broad, acute emargination culminating at the presumed site of the exhalent current; Figure 4A) exists only on some vetigastropods (i.e., pleurotomarioids and some scissurelloids) and on some basal caenogastropods (e.g., turritellids), whereas the slit (a thin linear cleft, also culminating at the presumed exhalent current; Figure 4B) occurs on other vetigastropods and on species in some other clades, such as the Architectonicidae. Neontologists generally have ignored the sinus and have considered the slit to be a synapomorphy of the earliest gastropods (e.g., Haszprunar, 1988). Paleontologists noted that the sinus evolved prior to the slit, but most considered the two features to be homologous (e.g., Knight, 1952). Horný (1962), however, suggested that the two features represented independent homologues, at least in the case of bellerophonts. This study supports Horny's idea. Although much attention has been paid to the slit, the sinus is far more informative phylogenetically, as sinuses provide multiple characters that are distinguishable among nearly all "archaeogastropod" species (Table 2; see also Appendix 1, characters 1-11). Slits provide far fewer traits (Table 2; see also Appendix 1, characters 34-36), but as slits are much rarer than sinuses, they tend to be highly informative where they exist (see below).

An associated issue herein is the relationship between the slit and the peripheral band (i.e., the "slit-band" of 19th and early 20th century literature). Knight (1934) relabeled the feature the "selenizone" and defined it as a structure generated by a slit. This assumed that the band was simply a distortion produced by a linear cleft in the shell. Several previous workers (e.g., Lindström, 1884; Ulrich and Scofield, 1897; Donald, 1902, 1906) had noted that slit-bands predate slits in the fossil record. Although slits were not common before the Devonian and were very rare during the Ordovician, the ubiquitous peripheral band appeared by the Late Cambrian. Knight $(1941,1952)$ later recognized this and considered the band to be homologous on both slit-bearing and slitless species. Instead of abandoning the previous morphogenetic hypothesis, Knight (1952) abridged it by inferring an unseen notch in the aperture that generated the peripheral band for slitless species. Knight (and subsequent workers) used the term "pseudoselenizone" to describe such peripheral bands. Despite frequent allusions to a notch, this feature has never been observed and its existence has been inferred solely on the assumption that a peripheral band is an artifact of a cleft in the aperture.

Knight and others apparently did not consider the possibility that peripheral bands had no morphogenetic relation to slits or notches. One line of evidence suggesting that this is the case is that the pseudoselenizone of species with no such slit (e.g., "Longstaffia" "laquetta" (Lindström, 1884) (Figure 4A) typically differs little from selenizones of closely related species with slits (e.g., "Seelya" lloydi (Sowerby in Murchison, 1839) (Figure 4B). A related point is that when the slit is a variable feature on individual specimens, the selenizone is unaffected. The growth lines of some species (e.g., Clathrospira subconica (Hall, 1847) (Figure 4C) suggest that the specimens had inconsistent slits, i.e., the presence or absence of the slit varied. The growth lines within the peripheral band (i.e., lunulae) correspond with the growth lines outside the band, which indicates that the animal did not have a slit (or a "notch") when that part of the shell was secreted. There are fewer lunulae than growth lines, however, and the initial growth did not include shell deposition within the selenizone. This suggests that deposition within the peripheral band was halted for a period, resulting in the production (and subsequent lengthening of) a slit. The short slit later is filled, leaving the shell temporarily slitless. Despite the inconsistent nature of the slit, the peripheral band of $C$. subconica remains the same, which indicates that the slit is not responsible for the structure.

Species such as Pararaphistoma qualteriata provide an example similar to that of Clathrospira Ulrich and Scofield (Figure 4F). Pararaphistoma Vostokova species and their relatives lack slits on their juvenile whorls, and the presence of a slit sometimes is erratic on the adult whorls. The nature of the selenizone, however, does not vary over ontogeny or change with the production of a slit.

The apex of a sharp (e.g., V-shaped) sinus, such as seen on Clathrospira, Pararaphistoma, and most other early Paleozoic taxa, might act as Knight's notch. Several species with very sharp sinuses (e.g., the Silurian Sinuspira tenera Barrande in Perner, 1907), however, lose the peripheral band over ontogeny without any corresponding ontogenetic changes in sinus morphology. If the band were purely an artifact of sinus morphology, this would not be possible.

If a slit generated the peripheral band, then we would expect the position of the two features to coincide on the shell. This usually is true, as the peripheral band usually borders the slit (e.g., Figure 4B-D), especially on species with bilineate bands (i.e., two carinae). Species such as Pararaphistoma qualteriata, however, have slits that are wider than the peripheral band and are positioned somewhat differently on the aperture (Figure 4F). Another extreme is shown by Oehlertia scutulata 


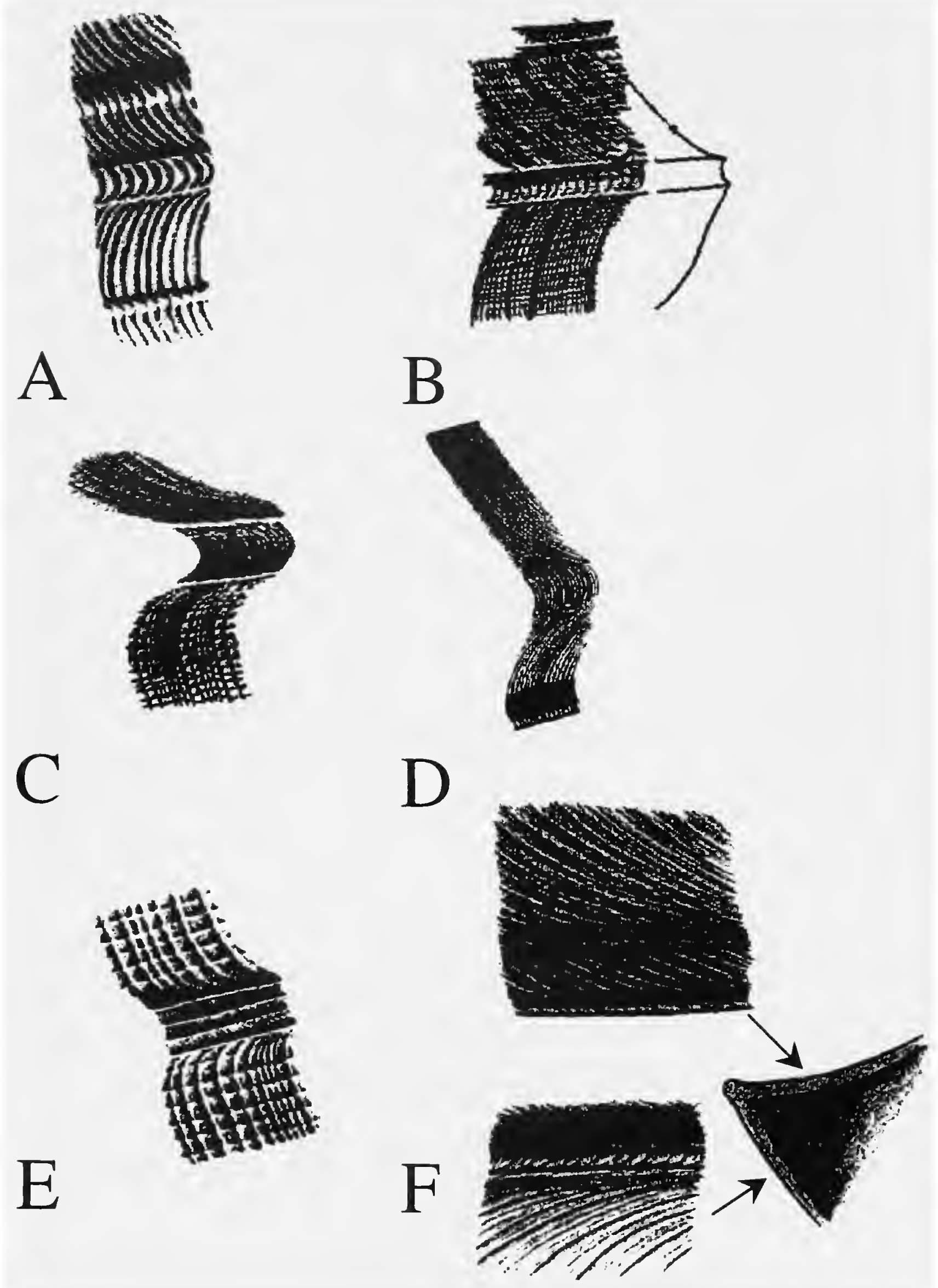

FIGURE 4.--Sinuses, slits, and peripheral bands. A, Gastropod with a sinus (the curved emargination), a peripheral band (the paired threads at the apex of the sinus), but no slit. B, Gastropod with a sinus, peripheral band, and periodic production of a slit in the middle of the peripheral band. C, D, Gastropods with sinus, peripheral bands, and slits. E, Gastropod with a narrow, shallow sinus, and a broad peripheral band lunulae angling straight into a very narrow slit that is bordered by two sharp threads. F, Gastropod with a sharp, single carina for a peripheral band, and a slit that begins above the base of the peripheral band and terminates above the top of the peripheral band. In this case, separate views of the right (upper) and left (lower) ramps are shown, as well as a profile with arrows denoting the positions of the ramps. Note that the slit is not always produced, as some growth lines give way immediately to sigmoidal-shaped lunulae. $A$ and $\mathrm{C}-\mathrm{F}$ taken from Lindström (1884); B taken from Ulrich and Scofield (1897).

(Lindström, 1884), which has a very thin slit (shown by the inner pair of sharp lira in Figure $4 E$ ) that is much narrower than the peripheral band (shown by the outer pair of sharp lira in Figure 4E). Note that the outer pair appear to be homologous with the peripheral band of other gastropods, whereas the inner pair represent a feature unique to Oehlertia and related taxa.

In summary, (1) peripheral bands evolved long before slits did, (2) peripheral bands on early Paleozoic gastropods cannot have been created by slits or notches, and (3) there is no evidence that "notches" of any sort ever existed. The definition of a "pseudoselenizone" is rendered logically complex and certainly must be discontinued. Knight's definition of the selenizone also is logically complex (as the peripheral bands do not coincide with slits in either ontogeny or phylogeny). Knight (1952) and previous workers did, however, recognize the homology of selenizones and pseudoselenizones. Although a cor- 
rected definition of "selenizone" could be used, the term has become too strongly identified as a by-product of a slit rather than an independent anatomical feature. Accordingly, the use of selenizone also should be abandoned, at least in reference to the peripheral band of most Paleozoic gastropods. The term "fasciole" suffers from the same problems. In the absence of a more appropriate term, I will use the cumbersome "peripheral band" to label the band at the apex of the sinus (and presumably denoting the location of the anus).

In addition to clarifying terminology, the importance of this lengthy discussion is that it indicates the need for a slightly broader coding scheme than is implied by the earlier literature. The morphogenetic scheme of Knight (1952) implies that the peripheral band is an architectural artifact similar to a columella, which therefore would require coding only the presence/absence of a notch/slit (e.g., Hickman, 1996). Instead, the presence or absence of a slit represents one character and the presence/absence of a peripheral band represents another character. As noted above, the presence/absence of a sinus is a completely independent third character.

\section{Shell Mineralogy and ProtoconChS}

Many workers consider shell mineralogy and protoconch morphology to be phylogenetically informative (e.g., Batten, 1972, 1984; Bandel, 1988, 1991; Ponder, 1990a, 1990b); however, I did not use these characters in this analysis. Shell mineralogy probably varied widely among "archaeogastropods," but it rarely is possible to identify the exact types of shell mineralogy. Taphonomic characteristics reveal which species had at least partially calcitic shells, but recrystalization usually obscures the relative amount of calcite or its exact nature. Most of the specimens that I examined were silicified. Silicification can reveal the number of mineral layers and their relative thicknesses, but it leaves no other evidence about those layers (see Carson, 1991). When possible, I do discuss some basic aspects of mineralogy (i.e., aragonitic versus calcitic shells), especially if they support or contradict the results presented herein.

I omitted protoconchs for a different reason. A distinct protoconch morphology typifies modern species, but not early Paleozoic ones. I examined many extremely well-preserved specimens representing a number of different taxa, but the boundaries between protoconch and teleoconch usually were vague at best (some exceptions are discussed below). I also examined microfossils from beds rich in gastropods. Sinus and peripheral band morphologies usually were not observable on microfossils, but the basic profiles of the shells matched those of macrofossils known from the same beds. Dzik (1978) figured protoconchs of two early Paleozoic "archaeogastropod" species, which also possessed adult profiles but lacked clearly defined sinuses and peripheral bands.

Many species show distinct ontogenetic changes. These differ from the abrupt transitions between protoconchs and teleoconchs because the changes are gradual. For example, species

classified as Macluritella Kirk, Teiichispira Yochelson and Jones, and Malayaspira Kobayashi have juvenile shells that are similar in overall morphology to Prohelicotoma Flower (Figure 5A). Similarly, species of Pararaphistoma Vostokova and Climacoraphistoma Vostokova have juvenile shells similar to that of Lesueurilla Koken (Figure 5B). Therefore, I did not code juvenile shell types as separate characters. Instead, I coded the types of ontogenetic changes (e.g., counter-clockwise rotation of the aperture and differential expansion of the left side in macluritids, or clockwise rotation of the aperture and increased translation in raphistomatids) as present or absent. I then coded the traits that changed during ontogeny as polymorphic, with all the states produced by an ontogenetic trajectory coded as present.

\section{Phylogenetic Analysis}

\section{Character Deweighting 1-Balancing Continuous Characters}

There are two standard justifications for character weighting: accounting for differential homoplasy among characters (e.g., Farris, 1969; Goloboff, 1993) and mitigating the effects of ordered characters (Thiele and Ladiges, 1988; Chappill, 1989; Hauser and Presch, 1991; Skelton and McHenry, 1992). I did not weight or reweight characters because of homoplasy. I did deweight ordered characters, however, to accommodate continuous characters. In all cases these represented continuous morphologic features, such as shell growth parameters or apertural inclination. An ordered trait with 10 characters will result in a nine-step difference between species coded as "1" and those coded as " 10 "; however, the maximum difference

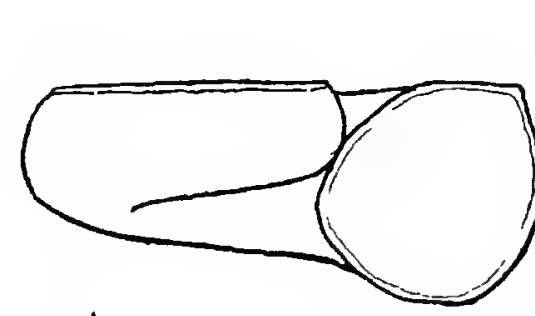

A

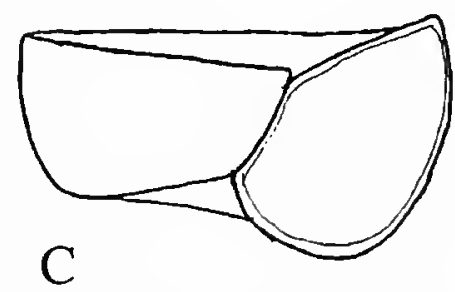

FIGURE 5.- Ontogenetic changes in shell morphology. A, Morphology of adult Prohelicotoma and juvenile Macluritella or Teiichispira. B, Morphology of adult Teiichispira, with negative translation, the left side of the aperture expanded, and the entire aperture rotated counter-clockwise. C, Morphology typical of adult Lesueurilla and juvenile Climacoraphistoma or Pararaphistoma. D, Morphology of adult Climacoraphistoma, with higher translation and the aperture rotated clockwise. 
between a presence/absence character is only one step (i.e., " 0 " to " 1 "). The concern herein is that ordered characters with many states will have an excessively strong effect on a cladistic analysis. The "over-weighting" effects of ordered characters noted by Hauser and Presch (1991) is of particular concern herein, as malacologists have documented the potential plasticity of shell characters within species (e.g., Kemp and Bertness, 1984; Palmer, 1985; Boulding and Hay, 1993). Unweighted continuous characters then might separate close relatives by several steps due to evolutionarily minor differences. Therefore, I deweighted continuous characters as follows:

$$
\text { continuous character weight }=\frac{1}{\text { no. of character states }-1}
$$

(see Thiele and Ladiges, 1988). One presence/absence synapomorphy always contributes at least as much (and usually more) to the parsimony analysis as does a continuous synapomorphy. Deweighted continuous characters are denoted with a "C" in Appendix 1.

Farris' (1990) contentions against the deweighting of continuous characters assume that discrete characters are recognizable. This assumption is unsound for the continuous characters used herein. Techniques used to categorize quantitative characters (e.g., Thorpe, 1984; Archie, 1985; Goldman, 1988) all assume that intraspecific variation is roughly equal for all species, but intraspecific variation can vary among different morphotypes (Schindel, 1990) and at different times in a clade's history (Hughes, 1991). The latter problem appears to have been the case among early gastropods (Wagner, 1995b, 1996). These factors also discouraged the use of simple maximum likelihood methods for quantitative characters (e.g., Felsenstein, 1981, 1988); therefore, I used segment coding (Chappill, 1989), which simply divides continuous characters into equal distributions (e.g., "narrow" < 0.1 , "medium" $\geq 0.1$ and $<0.2$, etc.). This defines no discrete states, so the characters are meaningful only if ordered. Segment coding links adjacent characters so that "narrowness" is a synapomorphy of a "narrow" and "very narrow" species relative to a "wide" outgroup. This is an inexact method of describing character states, but it makes the fullest use of the available data and thus should be used in analyses such as this one.

Several authors have criticized segment coding (e.g., Pimentel and Riggins, 1987; Cranston and Humphries, 1988) on the grounds that because one cannot define homologies in a repeatable manner for continuous characters, such features lack phylogenetic information. These arguments assume that meaningful evolution always proceeds like a cladistic character state optimization, with states clicking on and off without intermediate forms (see Janvier, 1984; Gayon, 1990). This is a contentious view of morphologic evolution that is better examined within the contexts of phylogenetic estimates than assumed when conducting phylogenetic analyses.

\section{CharaCter DEWEIGHTING 2-ASYMMETRY AND CHANGING HOMOLOGIES}

I employed character deweighting for another situation that previous workers have not discussed. Evolutionary events can couple or decouple homologies (e.g., Schaeffer and Lauder, 1986; Wake and Roth, 1989; Atchley and Hall, 1991), resulting in multiple characters becoming one or one character becoming several. In such cases, some species possess multiple characters for a morphologic structure whereas other species have only one. Among gastropods, the loss of bilateral symmetry represents an example of the decoupling of homologies. This has had appreciable effects on the internal anatomy. Among gastropods, left and right homologues often serve different functions (or the right organ is absent); these organs are paired in other molluscs. Indeed, trends toward asymmetrical conditions have been so pervasive that parsimony optimization finds bilaterally symmetrical conditions to be derived within gastropods (e.g., Ponder and Lindberg, 1996). This pattern also is reflected in shell morphology. For example, the left and right sides of the sinus and aperture are symmetrical on most early appearing species, but asymmetrical morphologies appeared by the Early Ordovician. This leads to a coding paradox. The left and right can change independently on asymmetrical species and, thus, can represent separate character states. If one codes the left and right sides as separate traits, however, then symmetric species have many of the same characters coded twice.

Ideally, one would code features that vary in symmetry in the following manner. First, one would distinguish "symmetric" versus "asymmetric" as a presence/absence character. There are two mutually exclusive types of asymmetries: greater development of the right side and greater development of the left. Without a priori evidence that one type cannot evolve from the other, one should code these as unordered character states.

Among species with the same type of asymmetry, any difference on the left or right side should be coded as one step (or $1 \mathrm{n}^{\text {th }}$ of a step for continuous characters with $\mathrm{n}+1$ states). When describing the difference between asymmetric and symmetric species, the coding must avoid assuming how asymmetry evolved. An aperture with a more pronounced left side can be produce by enlarging the left side or contracting the right side. Thus, one should code such asymmetric species so that they are equally close to symmetric species with identical left or right sides. For example, consider a species on which the right side of the sinus retreated at $30^{\circ}$ whereas the left side retreated at $50^{\circ}$. That species should be considered equally similar to species with symmetric sinuses retreating at either $30^{\circ}$ or $50^{\circ}$. The $30^{\circ}: 50^{\circ}$ species should be coded as one step away from either the $30^{\circ}: 30^{\circ}$ or $50^{\circ}: 50^{\circ}$ species (i.e., the absence versus the presence of symmetry), with the $20^{\circ}$ difference on the left or right side considered to be produced by the onset of asymmetry. 
If a symmetrical species differs from both the left and right sides of an asymmetrical species, then one should code species so that there is a difference of one step (symmetry versus asymmetry) plus the minimum number of steps needed to make either the left or right side of the symmetrical species identical to the left or right side of the asymmetrical one. Continuing the example started above, the $30^{\circ}: 50^{\circ}$ species would differ from a $40^{\circ}: 40^{\circ}$ species by one step (symmetry to asymmetry) plus $1 / \mathrm{n}^{\text {th }}$ steps (either $30^{\circ}$ to $40^{\circ}$ on the left side or $50^{\circ}$ to $40^{\circ}$ on the right side, with $1 / \mathrm{n}^{\text {th }}$ being one over the number of character states +1 ; see the discussion of continuous characters, above). The $30^{\circ}: 50^{\circ}$ species would differ from a $20^{\circ}: 20^{\circ}$ species by one step (symmetry to asymmetrically deep left side) plus two more steps (i.e., $20^{\circ}$ to $40^{\circ}$ on the left side). The major difference between species for the other side is attributed to the change in symmetry. This scheme is the most parsimonious possible because it assumes the minimum differences between species.

Step matrices (Swofford and Olsen, 1990; Maddison, 1993) permit the character coding scheme described above. Unfortunately, using step matrices slows down computer analyses so much that I could not analyze even small data sets; therefore, I could not use step matrices in this analysis. Instead, I coded the symmetry as "present," "absent (left side greater)" or "absent (right side greater)." I then weighted the left and right sides of potentially asymmetric characters as separate characters. The deweighting means that $30^{\circ}: 30^{\circ}$ species and $50^{\circ}: 50^{\circ}$ species differ by $2 \mathrm{n}$ steps $\left(30^{\circ}\right.$ to $\left.50^{\circ}\right)$ instead of $4 \mathrm{n}\left(30^{\circ}\right.$ to $50^{\circ}$ on the right side and $30^{\circ}$ to $50^{\circ}$ on the left side). The $30^{\circ}: 50^{\circ}$ species, however, differs from either species by 1 step (symmetry to asymmetry) plus $2 \mathrm{n}$ (the difference on the right or left side). There are two disadvantages to this scheme. First, the number of differences between symmetrical and asymmetrical species is slightly greater than it should be (i.e., $1+2 \mathrm{n}$ steps instead of 1), as differences in both the left and right sides are tallied. More importantly, this scheme means that the cladistic analysis can imply chimeras. Figure 6A gives an example where parsimony will predict an ancestor with symmetrical sinus but different left and right sides. In these cases, I had to reoptimize the character states so that no chimeras existed (e.g., Figure 6B). I then kept the shortest trees without chimeras. Until cladistic programs can implement step matrices efficiently, the imperfect approach used herein represents the best solution for this type of problem.

\section{ChARACTER ANALYSES}

I analyzed the data using PAUP 3.1 (Swofford, 1993). I used heuristic searches, with multiple replications and random sequence addition of species employed to account for islands of similar trees (see D.R. Maddison, 1991). This does not guarantee finding the shortest trees, especially for a matrix of this size; therefore, I reanalyzed smaller portions of the data, with the initial results providing estimates of subclade membership and appropriate outgroups. Ultimately, these analyses were reduced to four clades, which are referred to below as the "helicotomatids," "euomphalinae" (minus "helicotomatids"), "eotomarioids," and "murchisoniinae" (minus "eotomarioids"). A disadvantage of this strategy is that the basic clade assignments might represent local minima rather than global solutions (D.R. Maddison, 1991). This also permitted the analysis of a far greater number of trees within those local minima.

The phylogenetic estimate presented is not derived from the most-parsimonious cladograms, but instead from the mostparsimonious trees that stratigraphic data could not reject. Many systematists have asserted that stratigraphic data cannot
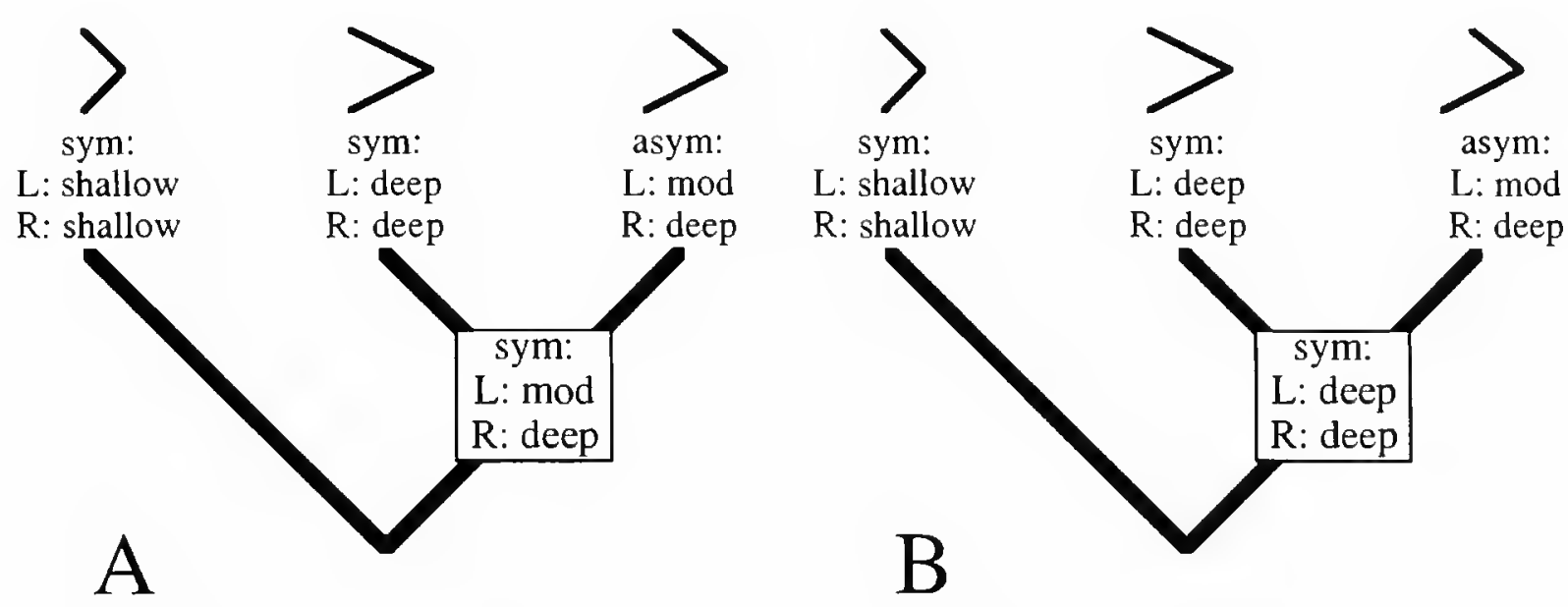

FIGURE 6.-Effects of asymmetrical characters. Hypothetical cladogram for species on which the sinus becomes asymmetrical. A, The most parsimonious optimization of characters states, given that symmetry/asymmetry is coded as a presence/absence feature, and the left and right sides are coded independently. Note that the node predicts an impossible collection of character states, as the hypothesized ancestor is symmetrical yet features different left and right sides. B, The shortest acceptable interpretation, in which the hypothetical ancestral morphology is assumed to be identical to the middle morphology. Coding with step matrices (Swofford and Olsen, 1990) would permit parsimony analyses to produce these results; however, these were not computationally feasible in this study. 
offer tests of parsimony estimates, on the assumption that the effects of incomplete sampling distorts stratigraphic data more than it does parsimony estimates (e.g., Smith, 1994). Simulations studies indicate the opposite, however, at least when sampling levels are comparable to those observed among most shelly invertebrates (Huelsenbeck, $1991 \mathrm{la}$; Wagner, 2000). Several methods that integrate stratigraphic data into phylogenetic analyses have been proposed to date (e.g., Fisher, 1991; Huelsenbeck, 1994), but like parsimony itself, these methods are fundamentally ad hoc because they use stratigraphy as an arbitrary parsimony or reweighting criterion. A non-ad hoc method uses confidence intervals on stratigraphic ranges to test parsimony assessments of phylogeny (Wagner, 1995a). I saved all trees as short as or shorter than the shortest tree known to be fully consistent with stratigraphic data and then used a computer program that searched for trees that implied no statistically significant stratigraphic gaps. I evaluated the significance of stratigraphic gaps using confidence intervals on stratigraphic ranges (Strauss and Sadler, 1989; Marshall, 1990). As a first step, I used Appearance Event Ordination (AEO; Alroy, 1994a) to array the fossiliferous horizons that preserve "archaeogastropods," bellerophontinae, tergomyans, bivalves, and rostroconchs with aragonitic shells ${ }^{6}$. I then used the AEO ordination as a substitute for stratigraphic ranges and calculated confidence intervals using the formula given by Strauss and Sadler (1989) and Marshall (1990) (Appendix 3).

The calculation of confidence intervals assumes that horizons are distributed randomly throughout stratigraphic ranges (Strauss and Sadler, 1989; Marshall, 1990; but see Marshall, 1994). Differences in ecology, taphonomy, and/or biogeography will violate this assumption (Wagner, 1995a). Closely related species might be assumed to have similar ecologies and taphonomies owing to phylogenetic autocorrelation; however, different clades and morphotypes likely will have different ecologic distributions and taphonomies, and hence have different fossil records. The absence of species from horizons in which no close relatives or morphologically similar snails occur are not meaningful (e.g., Bottjer and Jablonski, 1988) and to include such horizons inflates confidence intervals unrealistically. To control for such differences in expected preservation patterns, I described the stratigraphic ranges of species based on only horizons including members of their more inclusive clades (see Appendix 3). To control for differences in biogeography, I determined stratigraphic ranges and confi-

\footnotetext{
${ }^{6}$ Species with calcitic shells occur in horizons in which aragonitic shells are absent or rendered unrecognizable. Including these horizons biases the statistical analyses of stratigraphic ranges for calcitic species by giving such species more finds (and thus shorter confidence intervals) than is possible for aragonitic species with identical stratigraphic ranges. Using only horizons that included noncalcitic "archaeogastropods" offers a taphonomic control and, thus, each species is evaluated based on fossiliferous horizons that could have preserved any gastropod shell.
}

dence intervals within the individual provinces discussed above (see "Biogeography of Analyzed Species," above). As a result, some very widespread species have stratigraphic ranges in multiple provinces. When sister species existed in different provinces, the stratigraphic ranges could not be contrasted directly. In such cases, stratigraphic correlations based on Harland et al. (1990) were used to determine whether any stratigraphic gap was significant. This was done loosely, so if parsimony considered a Caradocian species from Baltica to be the sister species of a Llanvirn species from Laurentia, then the relationship was rejected only if the confidence interval's lower bound for the Baltic species was restricted to the Llandeilo or Caradoc. If that lower bound for the Baltic species extended into the Late Llanvirn, then the estimated relationship was accepted even if the Laurentian species was known from the Early Llanvirn. This accommodates the imprecision of cross-provincial stratigraphic correlations.

Appendix 3 gives the stratigraphic ranges of analyzed species plus the 95 percent confidence intervals on those stratigraphic ranges. Appendix 3 also includes species that could not be included in the cladistic analyses due to inadequate numbers of well-preserved specimens, but that might bridge stratigraphic gaps.

I used ACCTRAN character optimization, which favors parallelisms to reversals (Swofford and Maddison, 1987). The choice of character optimization does not affect the initial results of parsimony analyses. Ancestor-descendant hypotheses eliminate many significant stratigraphic gaps, however, and ACCTRAN makes it less likely that putative ancestors will have apomorphies. Any putative autapomorphies of ancestral species must be considered reversals in descendants, which lengthens a cladogram. Therefore, ACCTRAN ultimately can imply shorter lengths for identical cladistic topologies (Wagner, 1995a).

Culling trees that implied statistically significant stratigraphic gaps (i.e., gaps greater than the $95 \%$ confidence interval extensions on the stratigraphic ranges of relevant species) resulted in the analysis finding very few equally parsimonious alternatives. Typically only a few trees out of several thousand would contain no significant stratigraphic inconsistencies. Some subclades did produce multiple trees of equal length and no significant inconsistencies. In these cases, I used the following criteria. First, I selected the tree that required the fewest unknown ancestors. This represents a secondary parsimony criterion that other workers have advocated (Alroy, 1995; see also Fisher, 1994; Smith, 1994). Second, I chose trees that had the smallest stratigraphic parsimony debt (Fisher, 1994; Suter, 1994). Any stratigraphic gaps at this point were not statistically significant; however, given the choice of two otherwise equal assessments of a phylogeny, it is logical to select the one that comes closest to predicting the observed pattern in the fossil record (Fisher, 1991; Smith, 1994). Finally, I chose some trees simply because a particular set of synapomorphies led me to prefer that topology over its 
rivals. This last criterion is obviously ad hoc; therefore, when discussing these trees below, I describe the rival topologies and detail why I accepted one over the other.

Other phylogenetic methods do yield results that have some notable differences from those presented herein. This is particularly true of strict parsimony, as characters or (especially) suites of characters identified by some methods as parallelisms between sister clades are identified as synapomorphies of more inclusive clades by parsimony. The general results described herein (i.e., the membership of basic clades and the relationships among those basic clades) are replicated by other phylogenetic methods, including strict parsimony. Thus, a major change in phylogenetic methods would be required to obtain radically different results using this character data. Sampling is another concern, as the ability of parsimony to reconstruct phylogeny decreases with decreasing sample size (Lanyon, 1985; Lecointre et al., 1993). Sampling also decreases the accuracy of methods incorporating stratigraphic data, albeit to a lesser extent (Wagner, 2000). The sampling density of early gastropods, however, appears to be quite good. Based on the metrics of Foote and Raup (1996), between $50 \%$ and $60 \%$ of the broadly distributed species apparently are included in this analysis (estimates vary according to binning criteria and subclade). These levels are even higher during the crucial early phases of gastropod evolution (i.e., the latest Cambrian and Early Ordovician of Laurentia, where estimates improve to $70 \%$ ). This means that we should have sampled many direct and indirect ancestors (see Foote, 1996), especially from the critical intervals during which the major groups were diverging. Such sampling greatly increases the efficacy of phylogenetic methods (Huelsenbeck, 1991a) and greatly reduces the concern that new finds will radically alter the estimates presented herein.

I place least confidence in the estimated relationships among groups appearing in the earliest Silurian, as this represents the interval of poorest sampling. Unfortunately, this poor sampling seems to coincide with rapid diversification during the rebound from the end-Ordovician mass extinction. As a result, relationships among clades appearing in the Early Silurian form many polytomies, and there are several species and very small clades with very uncertain affinities. The discovery of heretofore unknown Llandovery species undoubtedly will change some of the relationships proposed herein. Many of the cases where this is especially true are emphasized in the text, with the accepted and alternative estimates presented. It should be stressed that these difficulties concern relatively fine-scale relationships, however, and do not effect the estimated relationships among the major groups that were established in the Ordovician. Thus, Silurian sampling is unlikely to affect the basic results of this analysis. As noted above, obtaining radically different results probably will require radically different reinterpretations of shell characters.

\section{CAMBRIAN MOLlusCS AND THE CHOICE OF AN OUTGROUP}

Smith (1994) suggested that, of the available methods for rooting a cladogram, the outgroup method of polarizing characters makes the fewest a priori assumptions. Choosing an outgroup however, makes a major assumption about a group's phylogeny, namely, that the close relatives of the group of interest (i.e., the ingroup) are known (Adrain and Chatterton, 1990). This often makes the choice problematic (e.g., Ballard et al., 1992). The different phylogenetic models summarized above and in Figure 1 suggest very different outgroups for the "archaeogastropods"; essentially, nearly every possible relationship among bellerophontinae, macluritinae, and "archaeogastropods" has been proposed at one point. Ballard et al. (1992) addressed a similar problem for arthropods by using a wider phylogenetic analysis to establish an appropriate outgroup. I adopted a similar strategy by including over 20 different Cambrian molluscs as potential outgroups. These included species assigned to the Bellerophontina, Onychochilida, Pelagiellida, Helcionelloida, and Tergomya. I also included two Late Cambrian members of the Hypseloconidae, which might represent the ancestors of cephalopods (Yochelson et al., 1973; Webers and Yochelson, 1989; but see Teichert, 1988). These species are important because cephalopods are likely gastropods' closest relatives among the major extant molluscan classes (Naef, 1911; Wingstrand, 1985). I included an Early Ordovician cyrtonelloid, as the only known Late Cambrian representative of the group is represented by only a few poorly preserved specimens (McGhee, 1989). Finally, I also included some early Ordovician bellerophonts, owing to the relatively poor preservation of known Cambrian bellerophonts.

I coded all outgroup species as if they were gastropods. For example, I treated the circumbasal carinae of onychochilids as a gastropod peripheral band. Thus, the analysis would not separate onychochilids and pelagiellids from "archaeogastropods" based on a priori interpretations of homology or assumptions about higher taxonomic associations.

Density of species sampling strongly affects the precision of phylogenetic analyses (Lecointre et al., 1993). The outgroup analysis represents a very incomplete sample of the known Cambrian molluscs, which in turn represents only a portion of the species that actually existed. One might worry about the potential affect of species that I did not include. To address this, I reran the analyses multiple times after jackknifing the outgroup (i.e., deleting one of the species; see Lanyon, 1985). I also employed rudimentary rarefaction (see Raup, 1975; Lecointre et al., 1993), running 50 analyses with random subsets of $50 \%$ and $75 \%$ of the outgroup species each. The rarefied analyses test whether the cladistic relationships among the ingroup species are dependent on a few outgroup species. If the relationships within the ingroup vary widely depending upon the outgroup species included (especially at the $75 \%$ level), then estimated relationships among ingroup species likely depend upon the inclusion of particular outgroup species. This 
suggests that adding more species could easily change estimates of relationships among "archaeogastropods" and that more outgroup species are needed before the results should be trusted. Conversely, if the relationships are stable (especially at the $50 \%$ level), then the ingroup results obviously are not strongly dependent on particular outgroup species. In this case, adding new Cambrian molluscs is not likely to affect phylogenetic inferences among "archaeogastropod" species.

\section{Results}

\section{Cladogram Statistics AND DESCRIPTIONS}

I subjected the character-state matrix to two tests for phylogenetic signal, the $g_{1}$ skewness test (Huelsenbeck, 1991b; Hillis and Huelsenbeck, 1992) and the Permutation Compatibility (PC) test (Alroy, 1994b). PAUP estimated the $g_{1}$ statistic based on 10,000 random trees. For the entire matrix, $g_{1} \cong-0.234(\mathrm{p}$ $<0.0001$, Sokal and Rohlf, 1981:174). The significant result indicates that the character-state matrix is significantly more structured than a random collection of characters. Phylogenetic autocorrelation (and thus signal) is a primary candidate for that structure, although nonphylogenetic signals also will produce similar structure. Simulation studies suggest that the most parsimonious trees derived from structured matrices are likely to be good approximations of the true phylogeny (albeit, not necessarily exactly correct; Huelsenbeck, 1991a).

The PC test examines whether a matrix contains greater character compatibility and hierarchical signal than randomly scrambled matrices. Unlike other permutation tests (e.g., the Permutation Tail Test of Faith, 1991; Faith and Cranston, 1991), the PC test does not assume a particular model of treebuilding. Also, although phylogenetic autocorrelation (see Raup and Gould, 1974; Felsenstein, 1985) will produce character correlations, other nonrandom but nonphylogenetic signals (e.g., allometry or functional complexes) also will produce character correlations (Källersjö et al., 1992). The PC test, however, should be less susceptible to nonphylogenetic signals (Alroy, 1994b). Finally, the PC test is computationally feasible and could be applied to the whole matrix. Ten thousand permutations found that none of the random permutations of the original data matrix possessed either the character compatibility or the hierarchical signal of the original data matrix. This indicates that the character state matrix possesses the type of character correlation that is expected if a phylogenetic signal is present.

Each figure includes the consistency index (C.I.) and retention index (R.I.) for the species shown, plus the immediate outgroup (given at the base of the figure). The C.I. is simply the reciprocal of the average number of steps per derived state (Kluge and Farris, 1969); the R.I. is the difference between hypothesized tree length and theoretical minimum tree length divided by the difference between the theoretical maximum tree length and the theoretical minimum tree length (Farris, 1989; Archie, 1989). Note that the uninformative characters were excluded when calculating C.I. and R.I. These homoplasy indices (especially C.I.) are meaningful only when compared to other analyses (Archie, 1989; Sanderson and Donoghue, 1989), and I include them for that reason only. Observed C.I.'s did typically fall within the range expected given the number of OTUs (see Sanderson and Donoghue, 1989).

Workers discussing individual genera and species often have made suggestions about the phylogenetic relationships of those taxa. Whenever possible, I discuss whether this analysis corroborates those ideas. Also, I treat the taxonomic schemes presented in major works (e.g., Knight et al., 1960, in the Treatise on Invertebrate Paleontology) as general phylogenetic schemes. In an evolving system, such as early Paleozoic gastropods, higher taxonomic definitions should be either monophyletic or cohesively paraphyletic (sensu Estabrook, 1986). Some of the higher taxa defined by Knight et al. (1960) were explicitly polyphyletic (see Tracey et al., 1993). I will treat all other taxonomic schemes, however, as general phylogenetic estimates (i.e., proposed monophyly or cohesive paraphyly) when contrasting my results with the ideas of previous authors.

Figures 7 through 35 present the accepted cladograms. The nodes are numbered uniformly throughout these figures: for example, node 1 is the same in Figures 7 and 8 and node 11 is the same in Figures 9 and 11. Nodes from the outgroup analysis are lettered rather than numbered. Species with open boxes are identical to the nodes to which they are attached; these species are considered to be ancestors in this study. Black boxes denote species with sufficient autapomorphies to be considered not ancestral to any other taxa included in this analysis. Gray boxes denote equivocal cases (i.e., the taxa lack autapomorphies but there are missing data). The cladogram includes line sketches of each species. Note that these are drawn to a roughly uniform size, not to actual or relative scale.

The figure captions give the morphologic changes for each node, as hypothesized by ACCTRAN parsimony (Swofford and Maddison, 1987). I have edited these so that the captions do not simply list the character-state changes, but instead describe the types of morphologic change. Because one type of change can affect two otherwise independent characters (e.g., see the above discussions about the right and left sides of asymmetric morphologies), this presents a more realistic metric of the amount of morphologic change than does a simple count of synapomorphies.

Several points about my use of taxonomy in the following sections need to be stressed here. When I use the Linnaean taxonomy formally (e.g., the Murchisoniina, Murchisonioidea, Murchisoniidae, etc.), I am referring to taxa previously defined by other workers. The one exception is the boxed generic names shown on the cladograms in Figures 7-35, which outline the taxonomic revision discussed below. When I use suprageneric names in quotes, I am labeling noteworthy clades defined by this analysis. Clade names are entirely informal and are designed to describe the phylogeny, obviating the need to follow conventional taxonomic rules. To avoid confusion, all subclades have different names than their more inclusive clades. 
For example, the "murchisoniinae" clade does not include a "murchisonioid" or "murchisoniid" subclade simply because the names look too similar in print. Also, not every species is assigned to a subclade at every level. This means that the paraphyletic collection of "raphistomatids" that do not belong to the "lesueurillines" or "holopeines" (see below) are not assigned to any "-ine" subclade.

I usually name clades after their least derived members instead of following the conventions of priority. I use previously named higher taxa whenever possible, but in many cases, no previously named higher taxa are appropriate. Naming clades after their plesiomorphic members is the only way that morphologic grade affects clade names. As a result, the "murchisoniinae" included many species with morphologies that are very different from that of traditional diagnoses of murchisonioids.

Finally, note that "subclade" describes a monophyletic group within the clade that is being discussed immediately. Thus, the "lesueurillines" are a "raphistomatid" subclade if I am discussing relationships among the "raphistomatids," but it is a clade if I am discussing relationships among the "lesueurillines." Table 3 summarizes the "archaeogastropod" clades and subclades discussed herein. As noted above, this classification is for use in this discussion only and must not be interpreted as a formal taxonomic revision.

I also include a numerical ranking of the clades and subclades in Table 3 and in the discussions below. This follows the scheme proposed by Hennig (1969) as a replacement for the Linnaean hierarchy. Again, this is not meant as a formal reclassification but simply as an aid for the reader.

A formal taxonomic revision for the early gastropods based on this analysis and adhering to traditional Linnaean taxonomy is presented at the end of the paper. As noted above, the revised generic taxonomy also is presented in Figures 7-35.

\section{OUTGROUP ANALYSES}

Figure 7 shows the results of the outgroup analysis, with "archaeogastropods" condensed into the Schizopea typica Ulrich and Bridge in Ulrich et al., 1930, plus Dirhachopea normalis Ulrich and Bridge in Ulrich et al., 1930, clade. Jackknifing the outgroups and rarefying them to $75 \%$ of the initial total had no effect on the relationships within the ingroup (Figure 8). Rarefying the outgroup species to $50 \%$ of the initial total produced the same ingroup relationships in 46 of 50 analyses and in 205 of the 216 total trees produced by those analyses. The runs that did not result in S. typica being the stem-"archaeogastropod" did not include tropidodiscines, such as Strepsodiscus major Knight, 1948. In all other runs, those species are considered the immediate outgroups of the "archaeogastropods." Thus, the results shown in Figure 8 depend only on our knowing about bellerophonts, such as $S$. major, and do not depend on the inclusion of any one species of Cambrian mollusc. This reduces the concern that adding more Cambrian molluscs will affect assessments of gastropod relationships.
TABLE 3.- "Archaeogastropod" clades and subclades discussed herein. Note that I have addcd "-itcs" to described subclades within "-ides."

"Archaeogastropods" (Figures 7-35, nodes I-215)

1. "Euomphalinae" (Figures 8-19, nodes 2, 11-108)

1.1. "Ophiletoids" (Figure 9, nodes 12-24)

1.1.1. "Ecculiomphalids" (Figure 9, nodes 15-18)

1.1.2. "Lytospirids" (Figure 9, nodes 19-24)

1.2. "Macluritoids" (Figure 10, nodes 25-36)

1.3. "Ceratopeatoids" (Figure 11-19, nodes 37-108)

1.3.1. "Raphistomatids" (Figures 11-14, nodes 42-69)

1.3.1.1. "Lesueurillines" (Figure 12, nodes 44-54)

1.3.1.2. "Scalitines" (Figures 13, 14, nodes 55-69)

1.3.1.3. "Holopeids" (Figure 14, nodes 62-69)

1.3.2. "Helicotomids" (Figures 11, 15-19, nodes 41, 70-108)

1.3.2.1. "Ophiletinines" (Figure 15, nodes 74-80)

1.3.2.2. "Euomphalopterines" (Figures 16-19, nodes 81-108)

1.3.2.2.1. "Anomphalides" (Figure 16, nodes 83-87)

1.3.2.2.2. "Poleumitides" (Figures 15, 17, 18, nodes 81, 88-96)

I.3.2.2.3. "Pseudophorides" (Figure 19, nodes 97-108)

11. "Murchisoniinae" (Figures 8, 20-35, nodes 7, 109-215)

II.1. "Plethospiroids" (Figure 20, nodes 110, 111)

II.2. "Straparollinoids" (Figure 21, nodes 112-118)

Il.3. "Hormotomoids" (Figures 22-26, nodes 119-154)

11.3.1. "Subulitids" (Figure 22, nodes 120-123)

I1.3.2. "Cyrtostrophids" (Figure 23-26, nodes 124-154)

II.3.2.1. "Goniostrophines" (Figure 24, nodes 131-138)

I1.3.2.2. "Omospirines" (Figures 25, 26, nodes 139-154)

II.3.2.2.1. "Loxonematides" (Figure 25, nodes 141-145)

11.3.2.2.2. "Rhabdostrophides" (Figure 26, nodes 146-154)

11.4. "Eotomarioids" (Figures 27-35, nodes 155-215)

I1.4.1. "Lophospirids" (Figure 27, nodes 158-165)

11.4.2. "Clathrospirids" (Figures 27-35, nodes 157, 168-215)

II.4.2.1. "Liospirines" (Figures 28, 29, nodes 170-181)

II.4.2.2. "Brachytomariines" (Figures 28, 30-35, nodes 167, 168, $182-215)$

I1.4.2.2.1. "?Palaeoschismides" (Figures 30, 31, nodes 183, 188)

II.4.2.2.2. "Phanerotrematides" (Figures 30, 32, nodes 185, 186, $190,191)$

Il.4.2.2.3. "Luciellides" (Figures 30, 33, nodes 184, 197-201)

II.4.2.2.4. "Planozonides" (Figures 34, 35, nodes 202-215)

Il.4.2.2.4.1. "Coelozonites" (Figure 34, nodes 202-208)

II.4.2.2.4.2. "Gosseletinites" (Figure 35, nodes 209-215)

Figure 7 places onychochilids and pelagiellids as distant outgroups of tergomyans (nodes E-J), and considers "archaeogastropods" to be a tergomyan subclade (i.e., node L and above). This matches the predictions of Peel (1991a). In addition, these results support the hypothesis that gastropods originated in the late Middle to Late Cambrian (e.g., Linsley and Kier, 1984; Peel, 1991a; Tracey et al., 1993) rather than in the Early Cambrian (e.g., Knight, 1952; Runnegar and Pojeta, 1974, 1985; Pojeta, 1980). The exact relationships among tergomyans are vague as there are no obvious synapomorphies linking hypseloconoids, cyrtonelloids, or the clade of bellerophontinae + "archaeogastropods". The sole synapomorphy linking Cyrtolites Conrad, 1838, to early gastropods at node $\mathrm{N}$ is the presence of a peripheral band, and most workers would not interpret the carina of Cyrtolites as homologous with the peripheral band of gastropods. If the features are convergent, then it would be 


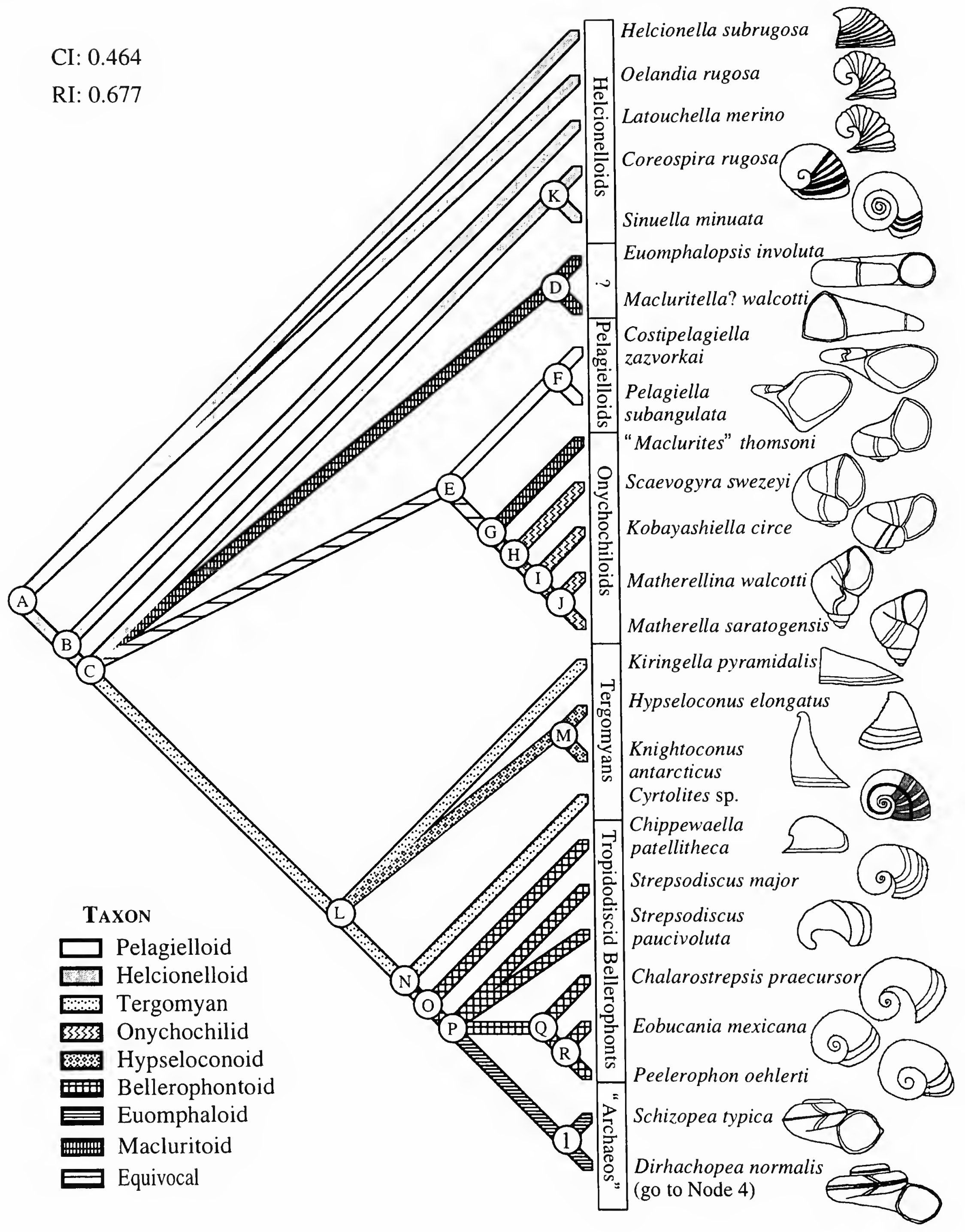


FigURE 7 (opposite).-O Outgroup analysis. Nodes with letters denote the outgroups, whereas nodes with numbers denote "archaeogastropods." Planispiral species are shown from a side view, anisostrophic species are shown from an apertural view. In this and subsequent figures the following conditions apply: (1) line drawings are not to scale; (2) numbers (or letters in small capitals) denote nodes, whereas numbers in parentheses denote characters (see Appendix 1); (3) abbreviations for synapomorphy linking include the following: $\mathrm{ACh}$ $=$ anal channel beneath peripheral band; $\beta=$ angle between inner margin and peripheral band $\left(90^{\circ}=\right.$ peripheral band perpendicular to inner margin; $0^{\circ}=$ parallel); $\mathrm{BC}=$ basal carina; $\mathrm{BL}=$ paired peripheral lira of peripheral band; $\mathrm{CA}=$ coiling axis; $\mathrm{E}=$ shell expansion; $\mathrm{GL}=$ growth lines; $1 \mathrm{M}=$ inner margin (= columellar lip of "normally" coiled species); $K$ = shell curvature; $L R=$ alveozone; $\mathrm{LRC}=$ alveozone carina; $\mathrm{ML}=$ single peripheral lira of peripheral band; $\mathrm{PB}=$ peripheral band; $\mathrm{PI}=$ parietal inductura; $\mathrm{RR}=$ right ramp; $\mathrm{RRC}=$ right ramp carina; $T=$ shell torque; $\|=$ parallel to the coiling axis; $\perp=$ perpendicular to the coiling axis; and (4) branch patterns denote previous higher taxonomic assignments (see text). Node A ("Helcionelloids"), tiny univalve shell with no sinus or $\mathrm{PB}$, very strong growth lines, symmetric aperture with moderately broad, short ramps, posterior projection of the aperture, and channeled, curved IM. Node B (Latouchella merino clade), straight IM (95). Node C, very long ramps $(55,56)$; moderately broad aperture $(58,59)$; IM channel lost $(102)$. Node $D$, $\mathrm{ACh}$ at top of aperture (48); lM base angle $\approx 60^{\circ}(94) ; 1 \mathrm{M} \perp$ to $\mathrm{CA}(98)$; base projected posteriorly $\sim 10^{\circ}(116,117)$; extremely low $E(121)$; open coiling (123); anisostrophic shell (?) (125). Node E ("Paragastropods"), asymmetric aperture (contracted right side) with very long, narrowly projected ramps (55-59); $1 \mathrm{M}$ at $\sim 45^{\circ}$ to CA (98); PI $\|$ to aperture (104); moderate K (123); anisostrophic shell (125); loss of septation (128). Node F (Pelagielloids), sigmoidal aperture (13); ACh rotated towards top of aperture (48); IM at high angle relative to CA (98); inclined aperture (109); moderate K (123); anisostrophic shell (125). Node $G$ (Onychochiloids), sharp ML (28); $\beta \approx-10^{\circ}$ (48); flat RR $(51,52)$; asymmetric aperture with longer right side (54-56); IM $\sim 15^{\circ}$ past $\perp$ to CA (98); aperture inclined backwards (115); anterior projection of aperture (116, 118); high K (123); moderate ultradextral coiling (126). Node H, long LR (56); asymmetric aperture (right side broader) (57-59); lM base angle $\approx 105^{\circ}$ (94); curved IM (95). Node 1, extremely strong GL (15); concave RR (52); very low $\mathrm{E}$ (121); high ultradextral T (126). Node J, $\beta \approx-30^{\circ}$ (48); very narrow broad right side of aperture (58). Node K (Sinuella minuata + Coreospira rugosa), moderately long ramps $(55,56)$; very broad aperture $(58,59)$; RR swelling present (60); moderate E (121); small size (141). Node L (Tergomyans), very narrow aperture $(58,59)$; curved IM $(95)$; base projected posteriorly $\sim 50^{\circ}$ (117). Node M (Hypseloconoids), low K (123); large size (141). Node N, PB present (19). Node o (?Gastropods), presence of a sinus (1); dull, lump-like ML (28); extremely long ramps $(55,56)$; RR swelling present $(60)$. Node $P$, swollen base of RR and LR (60,73); low E (121); low K (123); curvature decreases over ontogeny (124). Node $Q$, narrow sinus $(6,7)$; BL present (21); slit present (34); weak swelling atop RR $(60,61)$; straight IM (95). Node R, moderate K (123); isometric curvature (124). Node 1 ("Archaeogastropods"), round $\mathrm{ML}(28) ; \beta \approx 100^{\circ}$ (48); RR swelling dulls over ontogeny (62); moderate swelling at LR base $(73,74)$; $\mathrm{BC}$ present $(89) ; 1 \mathrm{M} 15^{\circ}$ off parallel to CA (98); base projected posteriorly $-30^{\circ}$ (117); anisostrophic shell (125); low T (126).

more parsimonious to consider cyrtonelloids and gastropods to have evolved separately from a limpet-like tergomyan similar to Kiringella Rosov, 1975. Horný (1965, 1991) objected to the suggested link between cyrtonelloids and gastropods in part because of the absence of Late Cambrian cyrtonelloids. Since then, Berg-Madsen and Peel (1994) described Telamocornu, a cyrtonelloid from the Late Cambrian. Telamocornu existed in the Avalonian province, whereas early gastropods and their other tergomyan relatives dwelt in the Laurentian province, so there is still a biogeographic gap. Extended species-level analy- ses of Cambrian tergomyans obviously are needed to make any firm estimates of exact tergomyan relationships. Although this should be a priority for future research, the resampling results described above suggest that such research will not greatly affect estimates of relationships within the Gastropoda.

The limpet-like bellerophont Chippewaella patellitheca Gunderson, 1993, is the least derived member of the tergomyan subclade that includes "archaeogastropods." Synapomorphies uniting this clade include a strongly curved sinus and a dull (i.e., broad but weakly expressed) peripheral band. This is a noteworthy result because $C$. patellitheca has an external morphology appropriate for Haszprunar's (1988:407) "urgastropod." Chippewaella patellitheca is only known from one Late Cambrian specimen (Gunderson, 1993), so I consider this result tentative. Excluding $C$. patellitheca produced the same ingroup topologies, so even if $C$. patellitheca is important for understanding the immediate relationships and origins of gastropods, it does not affect assessments of "archaeogastropod" relationships.

Perhaps the most intriguing result of the outgroup analysis is that the Bellerophontina appear to be diphyletic, including a cohesive paraphylum of species assigned to the Tropidodiscinae (i.e., Chalarostrepsis Knight, 1948, Eobucania Yochelson, 1968, and Peelerophon Yochelson, 1982) and a secondarily derived clade (Figure 8, node 10, which includes Sinuites Koken, 1896, and Owenella Ulrich and Scofield, 1897). Essentially, this results from the hypothesis that lenticular-shaped apertures with deep, hyperbolically curving sinuses, monolineate peripheral bands, and posterior projection of the aperture (e.g., Strepsodiscus or Schizopea Butts, 1926) are plesiomorphic, whereas apertures with swollen left and right ramps and compressed midsections, U-shaped, shallow sinuses, and bilineate or absent peripheral bands (e.g., Taeniospira Ulrich and Bridge in Ulrich et al., 1930, Sinuopea, or Sinuites) are derived. This means that the definition of "archaeogastropods" used herein includes many species assigned to the Sinuitidae. Four of the outgroup analyses run at 50\% rarefaction considered Sinuites and relatives to be the immediate outgroup of coiled gastropods and Sinuopea sweeti Whitfield, 1882, to be the most primitive coiled gastropod; however, as noted above, these runs did not include species such as Strepsodiscus. Characters shared among Strepsodiscus and species such as Schizopea typica result in a phylogeny that considers species with round apertures, $U$-shaped sinuses, and no peripheral bands to be highly derived rather than primitive.

This study does not resolve whether taxa such as Strepsodiscus or Tropidodiscus Meek and Worthen, 1866, were gastropods. Interpretations of Sinuites as untorted center partially on a hypothesized association between of the origin of torsion and anisostrophic coiling (e.g., Ghiselin, 1966; Runnegar, 1981). Regardless of the merits of that hypothesis, its implications are irrelevant for any bellerophonts that evolved from anisostrophically coiled species. The muscle scars of some sinuitids are segmented, which has been cited as evidence that sinuitids 


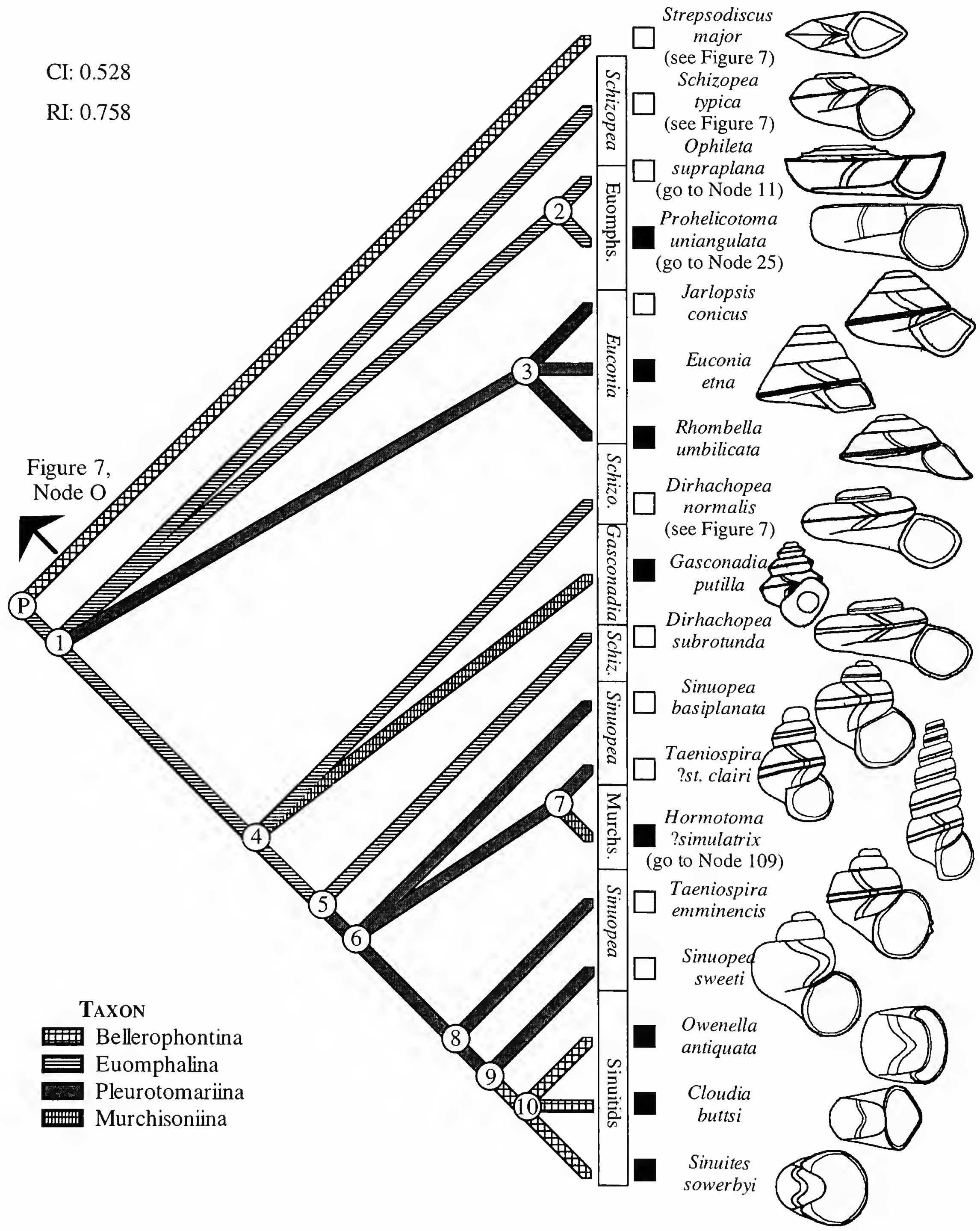


FIGURE 8 (opposite).-Relationships among the earliest "archaeogastropods." Genus names in boxes denote proposed generic revisions (see "Systematic Paleontology," below). For abbreviations, see legend to Figure 7. Node P, swollen base of RR and LR $(60,73)$; low E (121); low K (123); curvature decreases over ontogeny (124). Node l "Archaeogastropods," round ML (28); $\beta \approx 100^{\circ}(48)$; RR swelling dulls over ontogeny (62); moderate swelling at LR base $(73,74)$; BC present $(89) ; 1 \mathrm{M} 15^{\circ}$ off parallel to CA (98); base projected posteriorly $-30^{\circ}$ (117); anisostrophic shell (125); low T (126). Node 2 ("Euomphalinae"), moderately strong, flange-like $\operatorname{ML}(28,29)$; PB curves adapically (42); ACh present (45); $\beta \approx 70^{\circ}$ (48); very long ramps (55, 56 ); weak LR swelling (71, 74); IM at $-45^{\circ}$ to CA (98); curved base (120). Node 3 (Rhombella clade), asymmetric sinus (shallower left side, wider right side) $(2-7) ; \beta=110^{\circ}(48)$; asymmetric aperture (left side shorter and narrower) (54-59); IMlbase angle $\approx 120^{\circ}(94) ; 1 \mathrm{M} 30^{\circ}$ off parallel to CA (98); thin PI (103); inclined aperture (109); moderate K (123); moderate T (126). Node 4 (Dirhachopea normalis clade), BL present (21); 1M lbase angle $\approx 75^{\circ}$ (94). Node 5 , sinus angle $\approx 50^{\circ}(3,4)$; PB bilineate throughout ontogeny $(27$, 41 ); $\beta \approx 90^{\circ}$ (48); RR swelling with isometric shape (62). Node 6 , sinus angle $\approx 40^{\circ}(3,4)$; sinus curvature continuous $(9,10)$; PB width $\approx 20^{\circ}(20)$; strong LR swelling $(71,74) ; 1 \mathrm{M} \|$ to CA $(98)$; radial base $(116,118)$; septation absent (128). Node 7, PB width $\approx 25^{\circ}$ (20); elongated RR (54-56); broad symmetric aperture $(58,59)$; weak swelling atop RR $(60,61)$ and base of $L R$ (74); $1 \mathrm{M}$ thicker than shell (87); IM base angle $\approx 90^{\circ}$ (94); thin PI (103); IM reflected around umbilicus (106); high $\mathrm{K}(123)$; very high $\mathrm{T}$ increasing over ontogeny $(126,127)$. Node 8 , strong RR swelling (61). Node 9, narrow, Ushaped sinus $(6,7,9,10)$; PB lost (19); weak lunulae (39); high K (123); small size (141). Node 10 (Sinuitids), sinus angle $\approx 30^{\circ}(3,4)$; isostrophic, planispiral shell $(125,126)$

were untorted (e.g., Runnegar, 1981) and as evidence that sinuitids were highly derived gastropods (e.g., Haszprunar, 1988; Peel, 1991c; Horný, 1992b, 1995a). This analysis obviously supports the latter scenario. Given the sparse number of sinuitid species included in this analysis, however, broader analyses of sinuitids and other bellerophonts obviously are necessary.

\section{RELATIONSHIPS AMONG EARLY ORDOVICIAN SPECIES}

Two major subclades of "archaeogastropods" diverged by the Tremadoc (Figure 8). These correspond to nodes 2 and 7 on the cladogram. One clade contains species classified in Plethospira Ulrich in Ulrich and Scofield, 1897, Hormotoma Salter, 1859, and Turritoma Ulrich in Ulrich and Scofield, 1897 (Figures 8 and 20, nodes 7 and 109). Workers have classified the above genera in the Murchisoniina, so I refer to their clade as the "murchisoniinae" hereafter. Synapomorphies include a bilineate peripheral band with two moderately strong, rounded threads, a thickened and reflected inner margin, a relatively shallow, continuously curving sinus, and high translation that increases over ontogeny. The other clade includes species classified in genera, such as Ophileta Vanuxem, 1842, Ceratopea Ulrich, 1911, and Lecanospira Butts, 1926 (Figures 8-11, nodes $2,11,37$ ). Previous workers provided no consensus about the superfamilial classifications of these genera: Knight et al. (1960) considered Ophileta to be a pleurotomarioid, Ceratopea to be an euomphaloid, and Lecanospira to be a macluritoid; Yochelson $(1973,1984)$ considered all three to be pleurotomarioids, and N.J. Morris and Cleevely (1981; also Ulrich and Scofield, 1897; Koken, 1925; Wenz, 1938) considered all three to be euomphaloids. The phylogeny suggested in Figures 8-19 best matches the phylogenetic model of N.J. Morris and Cleevely, so it seems most appropriate to designate the second clade the "euomphalinae." There also is no evidence suggesting that the Mesozoic Pleurotomaria Defrance, 1824, evolved within this clade rather than from the "murchisoniinae"; in fact, as discussed below, the opposite seems more likely. "Euomphalinae" synapomorphies include strong, flange-like monolineate peripheral bands that curve abapically, an inner margin that projects away from the coiling axis, curved bases, and circumumbilical thickenings.

\section{I. "EUOMPHALINAES"}

There are several "euomphalinae" subclades, including three that approximate traditional definitions of the Raphistomatidae, Macluritoidea, and Euomphaloidea. The "euomphalinae" also include most of the putative trochoids of the early Paleozoic.

As noted above, the "euomphalinae" clade defined herein is very similar to the Euomphaloidea sensu N.J. Morris and Cleevely (1981). Those authors suggested that the Euomphaloidea included two basic clades, the Ophiletidae and the Helicotomidae (with two other families, the Euomphalidae and the Omphalotrochidae, considered to have evolved from helicotomids). This analysis suggests that most of the taxa assigned by N.J. Morris and Cleevely (1981) to the Schizopea group of the Ophiletidae (e.g., Schizopea, Ophileta, Ceratopea, Dirhachopea) represent a paraphylum relative to all later gastropods: Ophileta species (e.g., O. supraplana Ulrich and Bridge in Ulrich et al., 1930, and $O$. complanata (Miller, 1889)) are plesiomorphic relative to later-appearing "euomphalinae," Dirhachopea species are plesiomorphic relative to the "murchisoniinae," and Schizopea is plesiomorphic relative to all other "archaeogastropods."

\section{I.1. "Ophiletoids"}

Most of the genera assigned by N.J. Morris and Cleevely (1981) to two other ophiletid groups (e.g., the Lecanospira and Lytospira groups) represent a single clade of early "euomphalinae" (Figure 9, nodes 11-24). The earliest member of this clade is the type species of the genus Ophileta, so I refer to the clade as the "ophiletoids." "Ophiletoid" synapomorphies include a very lenticular aperture, the loss of the swelling at the base of the alveozone (i.e., left ramp), and a very strong peripheral band. More-derived species (e.g., the Lecanospira compacta clade) share a very narrow, sharp monolineate peripheral band that is near the top of the whorl, a concave right ramp and slightly ultra-dextral coiling that give specimens a "bowl" shape, and a flat "base" that is perpendicular to the coiling axis. Septation is plesiomorphic to "archaeogastropods," but it is especially prominent in many "ophiletoids." Some derived species assigned to the genus Lytospira display a long channel 


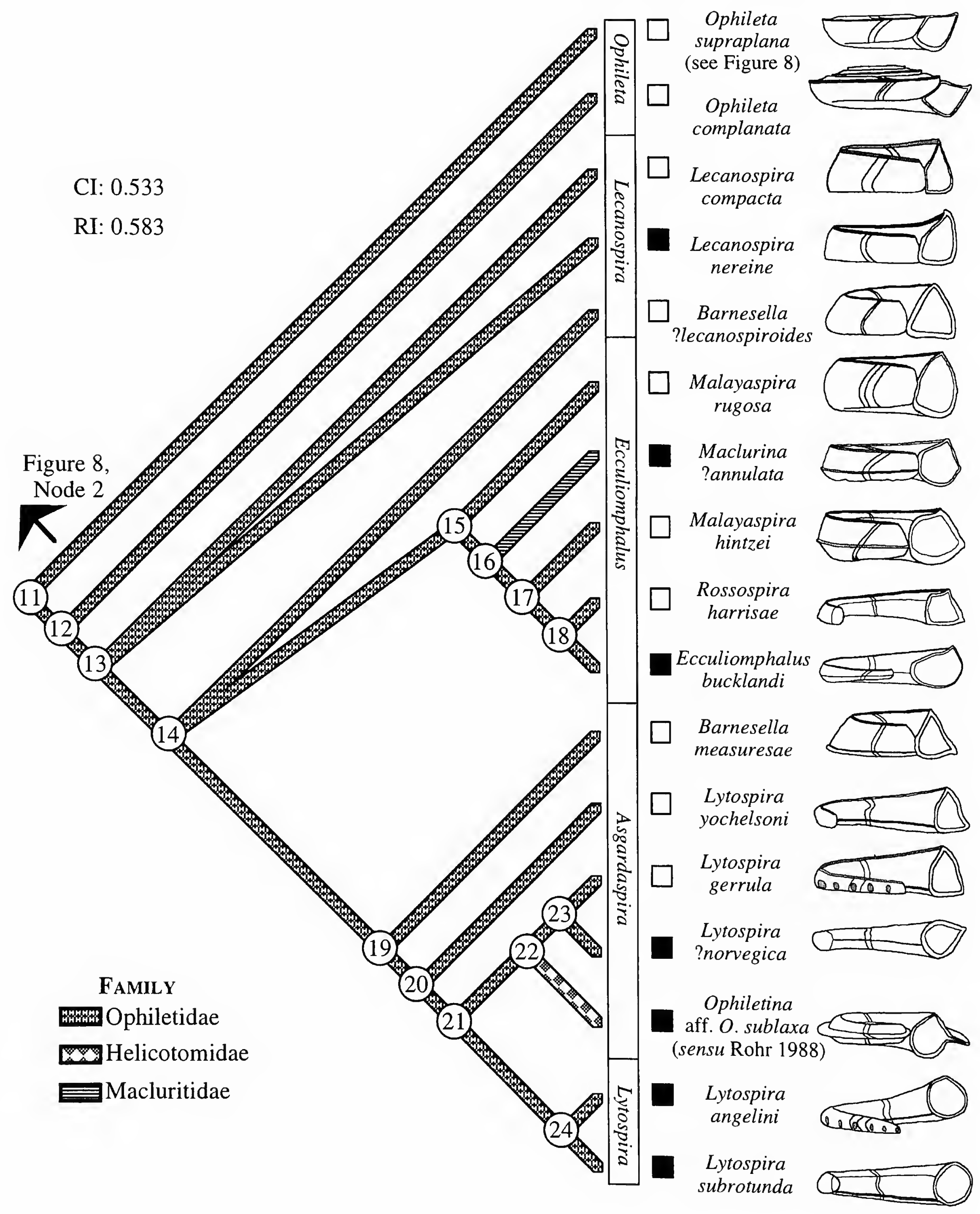


FIGURE 9 (opposite).-Relationships among the "ophiletoids." For abbreviations, see legend to Figure 7. Node 11 ("Euomphalinae"), strong BC (91); thin PI (103); very low E (121). Node 12 ("Ophiletoids"), strong ML (29); LR flatter than RR $(51,52,72)$; long ramps $(55,56)$; loss of LR swelling (73). Node 13 (Lecanospira compacta clade), PB width $\approx 10^{\circ}(20)$; sharp ML (28); weak lunulae (39); $\mathrm{PB}$ on top of aperture $\approx 0^{\circ}(48)$; extremely narrow aperture (58, 59); weak RR swelling (61); IM $\perp$ to CA (98); low ultradextral T (126). Node 14 (Barnesella ?lecanospiroides clade), sinus angle $\approx 45^{\circ}(3,4)$; juvenile GL stronger (16); V-shaped lunulae (38); ACh lost (45); asymmetric aperture (LR contracted) (54-56); RR swelling dulls over ontogeny (62). Node 15 ("Ecculiomphalids"), strong lunulae (39); $\beta \approx 10^{\circ}$ (48); asymmetric ramp shapes (RR more convex $)(52,53,72)$; narrow aperture $(58,59)$; RR becoming shorter and rounder over ontogeny (63); BC lost (89); curved $1 \mathrm{M}$ (95); 1M becoming thicker and rounder over ontogeny (97); IM nearly $\perp$ to CA (98). Node 16 , left side of sinus sharper than right (2-4); weakly imbricated GL (17); LR wider than RR (57-59); RRC and LRC present $(64,75)$. Node 17 , moderately broad left side of aperture (59); small size (141). Node 18, basal GL strength same as rest of shell (18); RR swelling acute through ontogeny (62); $1 \mathrm{M} \perp$ to $\mathrm{CA}$ (98); open coiling (123). Node 19 ("Lytospirids"), sinus curvature continuous ( 9 , $10)$; flat RR (52); projecting, peg-like $B C$ beneath outer margin $(90,91,93)$. Node 20 , very narrow aperture $(58,59)$; RR swelling becoming acute over ontogeny (62); open coiling (123); carrier-shell scars (140). Node 21, PB width $\approx 05^{\circ}(20)$; PB $\perp$ to aperture (42). Node 22, (Ophiletina cf. $O$. sublaxa clade), sinus angle $-30^{\circ}$ on right side (3) with little curve on right side of sinus (9). Node 23 , left side of sinus sharper than right $(2-4)$; sinus angle $-50^{\circ}$ on left side (4); left angle of sinus sharper $(6-8)$; extremely narrow aperture $(58,59)$; extremely low E (121); open coiling (123). Node 24 (Lytospira angelini clade), no ontogenetic change in GL strength (16); concentric lunulae (38); convex RR (52); symmetric ramp widths (54-56).

along the base (see Rohr, 1993). This likely is a site of muscle attachment, which suggests that the base of "ophiletoid" species is homologous with the inner margin of more typical gastropods. Although Rohr (1993) described this channel as unique to Lytospira, similar channels exist on the columellas of species classified in Ceratopea, Pararaphistoma, and Pachystrophia. Thus, the columellar channel seems to have been a recurring, polyphyletic character among the "euomphalinae."

A noteworthy feature in "ophiletoid" evolution is the parallel development of open-coiling in the "ecculiomphalids" (Figure 9, nodes 15-18) and "lytospirids" (Figure 9, nodes 19-24). This shell form evolved only infrequently after the Early Ordovician, but it appeared many times among Early Ordovician "euomphalinae." The open-coiled forms illustrated in Figure 9 almost certainly were sessile filter-feeders, as the animals would not have been able to effectively balance their shells (Yochelson, 1971; Linsley, 1977; N.J. Morris and Cleevely, 1981). This also has been considered the likely mode of life for nearly planispiral but close-coiled (i.e., coiled with whorls in contact) gastropods, such as those that occupy the base of the "ophiletoid" cladogram (Linsley, 1978). By deriving these more specialized sessile morphologies from the close-coiled forms more than once, these results support the idea that sessile filter feeding first appeared early in "ophiletoid" evolution.

"Lytospirid" species bear external shell scars suggesting that they were carrier shells, i.e., small shells, shell fragments, or pebbles were cemented onto the side of the shell as the animal grew (Rohr, 1993; see Linsley and Yochelson, 1973). The one exception is the slightly problematic species Ophiletina $\mathrm{cf}$. $O$. sublaxa (sensu Rohr, 1988, not Ulrich and Scofield, 1897), which possesses a broad frill in the same position as the shell scars on Lytospira species. Linsley and Yochelson (1973) suggested that attached shells and large shell frills might serve a similar functional role, i.e., serving as a support or a "snowshoe" on soft substrates (see also Linsley et al., 1978). In addition, early Lytospira species possess a moderately strong, peglike (i.e., with a parallel surface) carina in nearly the same location (at the alveozone-base intersection), which is just below the scars. Therefore, it seems plausible that the frill is functionally homologous with shell carrying and phylogenetically homologous with the carina of Lytospira.

There has been little discussion of the phylogenetic relationships among these snails. In general, the analysis supports the suggestion that Lecanospira and its relatives are not closely related to macluritoids (Linsley and Kier, 1984; Yochelson, 1984; contra Knight et al., 1960). It also supports the idea that Lecanospira and Barnesella Bridge and Cloud, 1947, are closely related (node 14; Bridge and Cloud, 1947; Knight et al., 1960). Rohr (1994) suggested a close relationship between Rossospira Rohr and Malayaspira, which this analysis also supports; however, this analyses" suggestion that Ecculiomphalus Portlock evolved from that clade (see node 18) appears to be novel. Finally, there are Silurian and Devonian species assigned to Lytospira (e.g., Horný, 1992a), but this study suggests that those species belong to the "raphistomatid" clade (see below). Thus, it appears that the "ophiletoids" were entirely extinct by the Early Silurian.

\section{I.2. "Macluritoids"}

This analysis indicates that Prohelicotoma, Macluritella, Teiichispira, Monitorella Rohr, 1994, Maclurites, and Palliseria Wilson, 1924, represent a subclade of "euomphalinae" (Figure 10 , node 25). "Macluritoid" synapomorphies include a straight, shallow sinus with a weak monolineate peripheral band, exaggerated basal growth lines, a nearly round aperture, and nearly planispiral coiling that opens in the adult whorls. Many of these characters are apparent in the juvenile whorls of species classified as Macluritella or Teiichispira, which produced characters typical of more-derived macluritids later in ontogeny. More-derived species (e.g., nodes 27-36) share distinctive ontogenetic changes involving differential expansion of the base and left side, counter-clockwise rotation of the aperture, and ultra-dextral coiling. Still more-derived species (e.g., nodes 31-36) have narrow sinuses and complete filling of juvenile whorls instead of septa.

Additional synapomorphies not used in this analysis are associated with the calcareous opercula of "macluritoid" species (Yochelson, 1975). Opercula associated with Teiichispira species are fibrous, horn-shaped structures, which include knoblike muscle attachments on later species. The opercula of morederived species (i.e., Maclurites, Monitorella, and possibly 


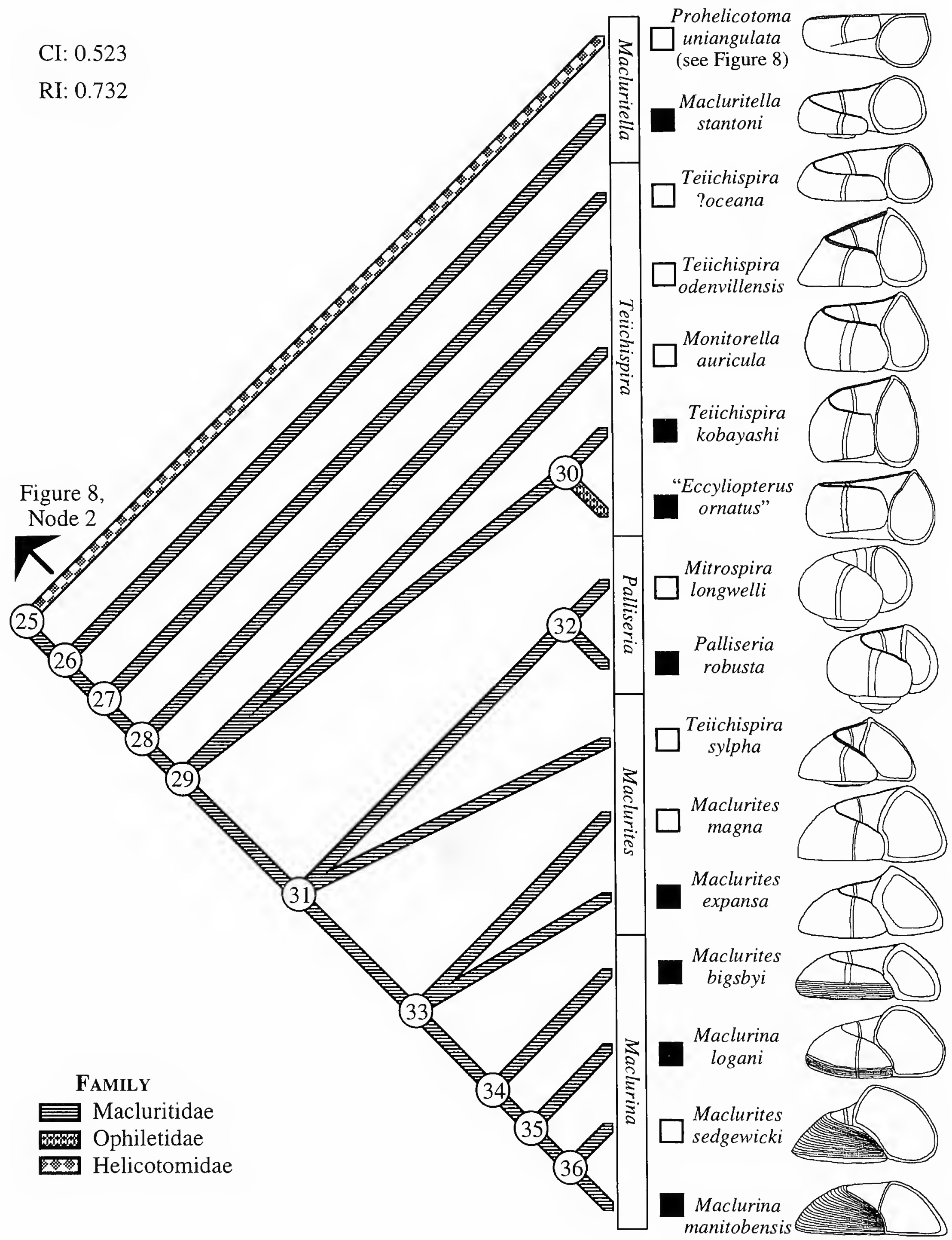


FIGURE 10 (opposite).-Relationships among the "macluritoids." For abbreviations, see legend to Figure 7. Node 25 ("Macluritoids"), sinus angle $\approx 30^{\circ}(3$, 4); sinus curve nearly straight $(9,10)$; PB width $\approx 10^{\circ}(20)$; $\mathrm{ML}$ becoming weaker over ontogeny (30); weak lunulae (39); $\beta \approx 40^{\circ}$ (48); globular ramps $(52,72)$; moderately long ramps $(55,56)$; $1 \mathrm{M}$ nearly $\perp$ to $\mathrm{CA}(98)$; moderately high $\mathrm{E}(121)$. Node 26 , sinus angle $\approx 20^{\circ}(3,4)$; weak GL $(15)$; PB width $\approx 05^{\circ}$ (20); PB on top of aperture $\approx 0^{\circ}(48)$; counter-clockwise rotation of aperture over ontogeny (49); RR becoming more concave over ontogeny (53); IM $\perp$ to CA (98); low ultradextral T (126). Node 27, extremely narrow aperture (58, 59); differential ontogenetic expansion of $\operatorname{LR}(86,122)$. Node 28 , loss of RR and LR swellings $(60,73)$; convex LR $(72)$; base projected posteriorly $\sim 10^{\circ}$ (117); straight base (120). Node 29 (Monitorella auricula clade), $\mathrm{PB}$ width $\approx$ $10^{\circ}(20)$; round $\mathrm{ML}(28) ; \beta \approx-10^{\circ}(48)$; IM $\backslash$ base angle $\approx 75^{\circ}(94)$; weakly curved IM (95). Node 30 (Teiichispira kobayashi clade), PB $\perp$ to aperture (42); moderately long RR and $\operatorname{LR}(55,56) ; 1 \mathrm{M}$ nearly $\perp$ to $\mathrm{CA}(98)$; high $\mathrm{E}(121)$. Node 31 (Teiichispira sylpha clade), narrow sinus $(6,7)$; isometric ML strength (30); lunulae same strength as GL (39); ACh lost (45); symmetric ramp shapes $(52,53,72)$; asymmetric ramp lengths (LR longer than RR) (54-56); asymmetric aperture (RR wider than LR) (57-59); thickened IM (87); complete infilling of juvenile whorls (128). Node 32 (Palliseria clade), weak ML (29); flat RR (52); BC lost (89); strongly curved IM with very thick middle $(87,95,96)$; $1 \mathrm{M}$ $-30^{\circ}$ past $\perp$ to CA (98); isometric E (121, 122); moderate ultradextral T (126). Node 33 (Maclurites clade), very narrow sinus $(6,7)$; fine, sharp GL (15); PB width $\approx 05^{\circ}(20) ; \mathrm{PB} \perp$ to aperture (42); no ontogenetic rotation of aperture (49); asymmetric ramp shapes ( $R R$ more convex) $(52,53,72)$; base projected posteriorly $-20^{\circ}$ (117); high E (121). Node 34 (Maclurites bigsbyi clade), weak ML (29); flat RR (52); moderately long RR (55); narrow right side of aperture (58); no differential expansion of left side $(86,121,122)$; straight IM (95); $1 \mathrm{M}$ $\perp$ to CA (98); base projected posteriorly $-10^{\circ}$ (117); omate base (129). Node 35 , very weak ML (29); stronger ornament (131). Node 36, ornate LR (129).

Palliseria; but see Rohr, 1994) are shield-like rather than hornlike, but retain the knob. The cladogram suggests that the shield-like operculum is derived from the horn-like one. Unfortunately, there are too few exact shell-operculum associations to use opercular characters, but more detailed analyses of macluritoid opercula and associated shells could be used to test these results in the future.

Although Knight (1952) and Erwin (1990b) previously suggested a close relationship between euomphaloids and macluritoids, this study proposes a very different model of "macluritoid" evolution than those authors suggested. Knight (1952) and others (e.g., Wängberg-Eriksson, 1979; Runnegar, 1981, 1996; Linsley and Kier, 1984) assumed that Maclurites and related species evolved from onychochilids and, therefore, diverged from the main gastropod clade during the Early to Middle Cambrian. This analysis, however, suggests that onychochilids and pre-Ordovician species assigned to the Macluritidae (e.g., Macluritella? walcotti Yochelson and Stinchcomb, 1987, and Euomphalopsis involuta Ulrich and Bridge in Ulrich et al., 1930) are related only distantly to the "macluritoids" and other gastropods (see Figure 7, nodes E, G-J).

The results of this study corroborate the predictions of P.J. Morris (1991) and, in part, McLean (1981), Linsley and Kier (1984), and Yochelson (1984), but the traditional models merit further investigation. This is best done by examining whether a more traditional estimate of phylogeny produces a significantly longer tree than the one accepted herein. The shortest tree linking the two clades assumes that the Middle Ordovician Palliseria and Maclurites are the least derived members of the clade and that the earliest species (e.g., Macluritella and early Teiichispira) are the most derived. Sampling of "macluritoid" species (especially of Palliseria and Maclurites) is dense, so stratigraphic data reject at high levels any tree that considers the morphologic intermediates to be phylogenetic intermediates (see Appendix 3). Accordingly, I used the shortest non-rejectable tree that linked the "macluritoids" with members of the Onychochilidae (which placed "macluritoids" outside the Gastropoda) and compared this tree to the accepted tree (including the outgroups and "macluritoid" species that appeared through the Early Arenig (Early Ordovician)). To test whether a less-parsimonious tree is significantly longer than a more-parsimonious tree, Alroy (pers. comm., 1994) proposed bootstrapping character-states matrices to determine whether random sections of the matrix suggested that one estimate of phylogeny is as short as another. Bootstrapping is appropriate only when resampling independent units. This assumption is violated by the additive coding schemes used herein (see O'Grady et al., 1989); for example, it is impossible to know that some species have a particular type of peripheral band without simultaneously knowing that those species have a peripheral band. Thus, if we sampled character 21 (the presence or absence of peripheral lira on the peripheral band), then we know that we have sampled character 19 (the presence or absence of the peripheral band itself). Similarly, if one randomly samples a character describing the left side of some feature, one should know that the species has a right side of that same feature. As an alternative, I bootstrapped the branch lengths on the two different cladograms. For two trees with the same taxa and characters, greater branch lengths indicate some combination of greater homoplasy and poorer sampling of evolutionary transitions (i.e., with poorer sampling, more morphologic change happens between sampled species). This means that bootstrapping branch-lengths tests whether one tree requires significantly more homoplasy and/or worse sampling than another.

None of the 1000 bootstrap analyses of the accepted tree are as long as the alternative tree, nor are any of the 1000 bootstrap analyses of the alternative tree as short as the accepted tree. This apparently is because the putative homologies between the "macluritoids" and onychochilids exist largely in late appearing "macluritoids," not in the early appearing species. Overall, these data suggest that the traditional hypothesis is significantly less parsimonious than the tree presented herein and also strongly implies that "macluritoids" represent a very restricted clade of Ordovician gastropods that are not closely related to other ultra-dextral molluscs of the early Paleozoic. Thus, contrary to Runnegar $(1981,1996)$, there is neither a morphologic nor a stratigraphic progression linking onychochilids and "macluritoids." 


\section{I.3. "Ceratopeoids"}

The other major "euomphalinae" subclade (Figures 11-14, nodes 37-69) contains a number of species classified in the genus Ceratopea. This genus has not been used previously to label any higher taxon, but the plesiomorphic nature of Ceratopea species makes it the most appropriate label for this clade. The earliest "ceratopeoids" (Figure 11) possess deep, strongly curved sinuses, strong abapically hooked peripheral bands (see Figure 11), a sharp, thick basal carina, a crenulated base, and a Lytospira-like channel within the columella. Synapomorphies linking later members of the clade include similar ontogenetic changes in aperture orientation, asymmetrical sinuses, and peripheral bands placed asymmetrically onto the right ramp.

"Ceratopeoids" feature two major subclades, the "raphistomatids" and "helicotomids," and one smaller subclade. This small subclade includes species that have been classified under a variety of generic names, including Bridgeites Flower, 1968a, and Bridgeina Flower, 1968a (Figure 11, nodes 38, 39). The "bridgeitids" are diagnosed by a sharply hooked peripheral band, strongly exaggerated basal and juvenile growth lines, and an extremely lenticular aperture. More-derived species feature nearly planispiral shells with open-coiling in adult stages. This short-lived subclade was relatively diverse during the early Arenig (Early Ordovician) but apparently became extinct shortly thereafter.

\section{I.3.1. "RAPHISTOMATIDS"}

One of the major "ceratopeoid" clades includes a number of taxa that workers from the turn of the century (e.g., Koken, $1898,1925)$ associated with the Raphistomatidae. Accordingly, this clade is labeled the "raphistomatids" (Figures 11-14, nodes 42-68). The "raphistomatid" clade is much broader than the most recent definitions of the family (i.e., Wenz, 1938; Knight et al., 1960), but it is similar to the definitions presented herein. Synapomorphies include a very high sinus angle, pronounced growth lines on juvenile whorls, and a crenulated base.

I.3.1.1. "LESUEURILLINES".--Species classified in the genus Lesueurilla dominate one of the major "raphistomatid" subclades (Figure 12, nodes 44-54). That genus name has never been used to label a suprageneric taxon, but it is the most appropriate name for this particular clade. "Lesueurilline" synapomorphies include very strong, hooked peripheral bands and a distinctive sigma-shaped lunulae (see Figure 4F). An interesting feature of "lesueurilline" evolution is that nearly planispiral coiling is the primitive condition both ontogenetically and phylogenetically. Juvenile and early forms possess Lesueurilla-like morphologies, whereas adult forms (among derived species) possess more lenticular morphologies (e.g., see Figure 3). The "lesueurillines" also include the earliest clade diagnosed by a slit (the L. prima clade, Figure 12, node 48). The slit of these species is not a distinct feature, but instead it is an extension of the sinus where the left and right halves run parallel to each other near the apex. The morphogenetic development of the slit from the sinus is most obvious on species such as Pararaphistoma qualteriata (Schlotheim) and P. schmidti (Koken, 1925) on which the slit appears later in ontogeny.

This analysis supports Yochelson's $(1982,1984)$ proposition that Lesueurilla and Climacoraphistoma are close relatives. All of the characters that Yochelson cited as linking the two taxa are synapomorphies of relevant nodes, and there are additional synapomorphies that Yochelson did not list, such as the narrower, somewhat asymmetrically shaped sinus and the loss of the columellar channel. Another pertinent implication is that Eccyliopterus Remelé, 1888 , is closely related to Ecculiomphalus Portlock, 1843 (Knight et al., 1960). Ecculiomphalus (or at least the type species of that genus, E. bucklandi Portlock, 1843) apparently is an "ophiletoid" (see discussion above), whereas Eccyliopterus represents a sister group to derived Lesueurilla plus the clade of Climacoraphistoma + Pararaphistoma. A more tentative suggestion by Yochelson and Copeland (1974) is that Ceratopea and Pararaphistoma are synonymous. This analysis implies that the similarities between Pararaphistoma and Ceratopea are due to reversals during the evolution of Climacoraphistoma and Pararaphistoma.

The second "lesueurilline" subclade includes species classified as Raphistoma Hall, 1847, and Scalites Emmons, 1842. Synapomorphies of the clade include increased curvature and differential expansion of the lower portion of the shell, which increased both the whorl expansion and translation rates (sensu Raup, 1966) and provided a more oval aperture shape. Some later species (e.g., $R$. striata Emmons, 1842, $R$. peracuta Ulrich and Scofield, 1897, and $S$. katoi Kobayashi, 1934) possess sinuses with a distorted right half and a sigmoidal left half (Figure 13 , nodes $55-59$ ).

"Lesueurillines" were relatively diverse during the late Arenig through the Llandeilo (Middle Ordovician). Although a few species survived into the Caradoc (Middle to Late Ordovician), there are no known Silurian "lesueurillines." It also

FIGURE 11 (opposite).-Relationships among the "ceratopeoids." For abbreviations, see legend to Figure 7. Node 11 ("Euomphalinae"), strong BC (91); thin PI (103); very low E (121). Node 37 ("Ceratopeoids"), long ramps (55, 56); weak RR swelling becoming acute over ontogeny $(61,62)$; flat LR with no swelling $(72,73)$; thickened IM (87); moderate K (123). Node 38 (Bridgeites clade), $\beta \approx 50^{\circ}(48) ; 1 \mathrm{M}$ nearly $\perp$ to $\mathrm{CA}(98)$; base projected posteriorly $-30^{\circ}$ (117); low K (123); curvature decreases over ontogeny (124); nearly planispiral coiling (126). Node 39, ACh lost (45); asymmetric ramp shapes (RR rounder (51-53)), ramp lengths (LR contracted (54-56)), and aperture breadth (RR wider than LR (57-59)); strong RR swelling that dulls over ontogeny (61, 62); IM $\perp$ to CA (98); IM channel lost (102). Node 40 (Ceratopea ?laurentia clade), strong basal GL (18); strong, flange-like $\operatorname{ML}(28,29)$; asymmetric ramp shapes (RR rounder) (51-53); pronounced, channeled BC (90); IM Ibase angle $\approx 105^{\circ}(94)$; base projected posteriorly $\sim 30^{\circ}(117)$; moderate E (121). Node 41 ("Helicotomids"), fine, sharp GL (15); clockwise rotation of aperture over ontogeny (49); ontogenetic increase in T (127). Node 42 ("Raphistomatids"), juvenile GL stronger (16); counter-clockwise rotation of aperture over ontogeny (49); elongated RR (54-56); RR swelling dulls over ontogeny (62). 


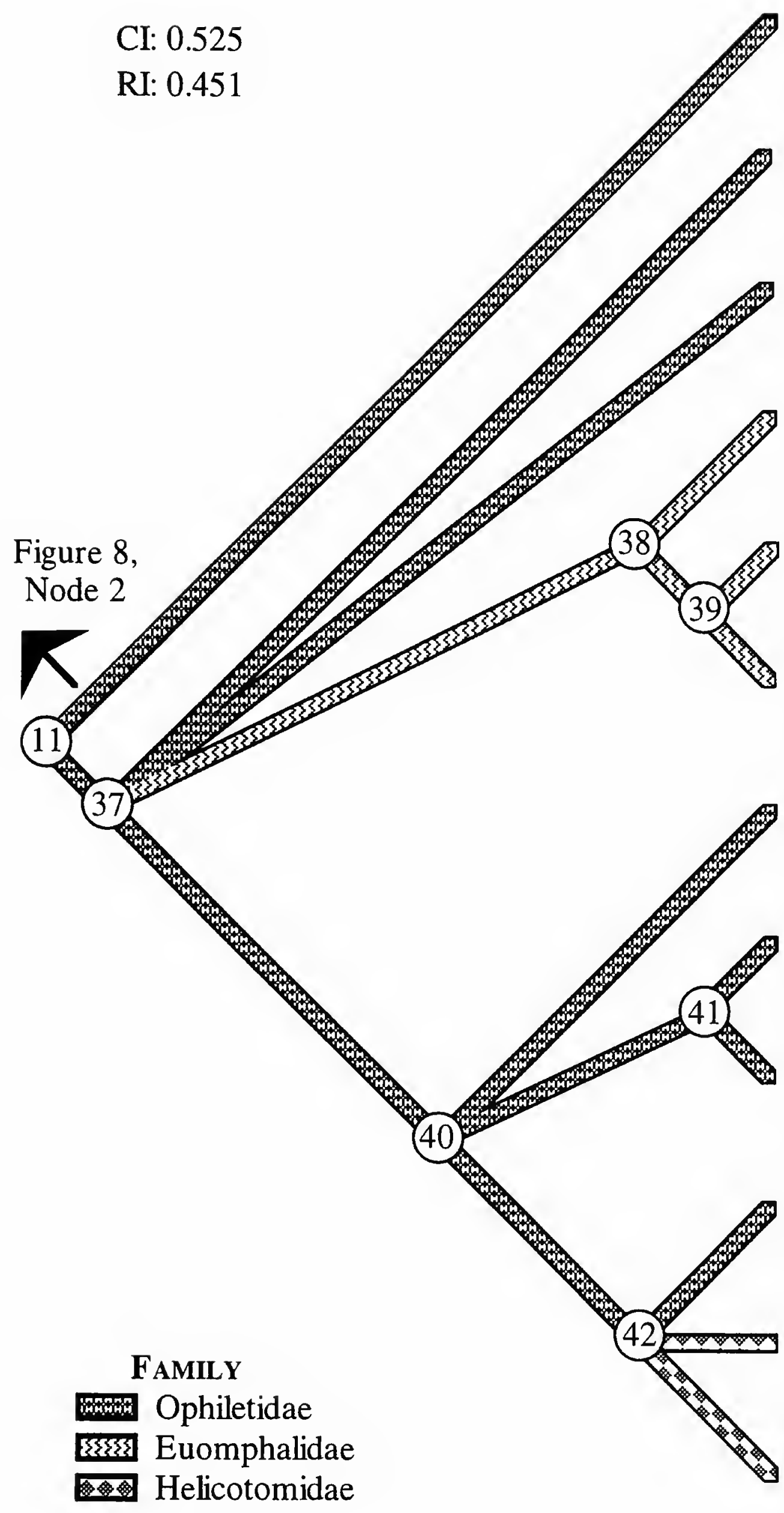

Ophileta supraplana (see Figure 8)

Figure 8 Node 2

FAMILY

Ophiletidae

Helicotomidae
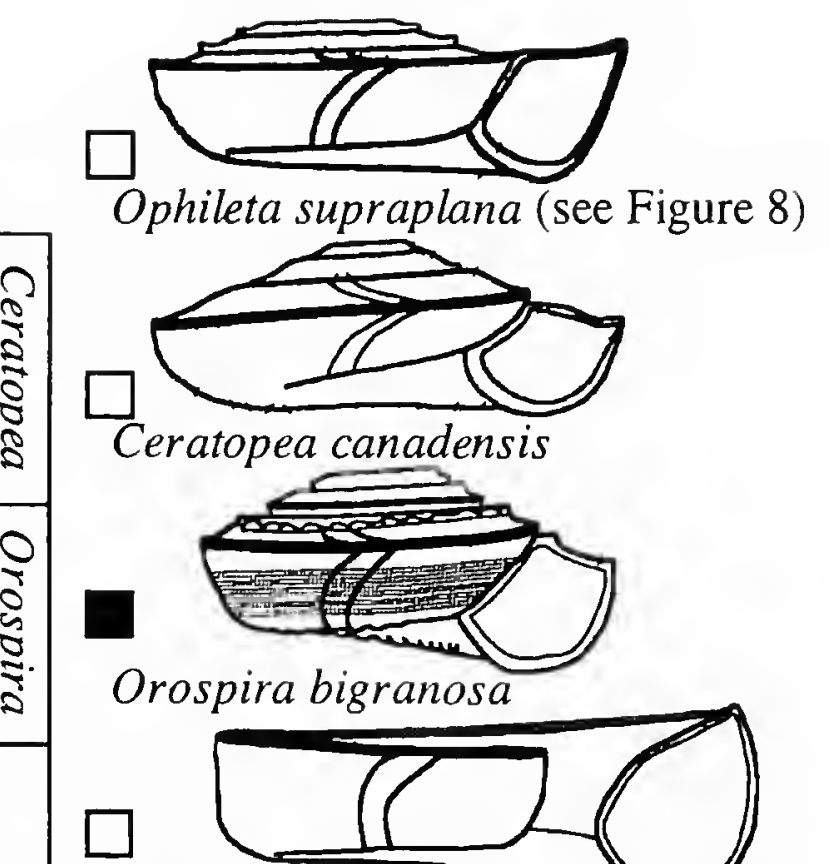

Ceratopea canadensis

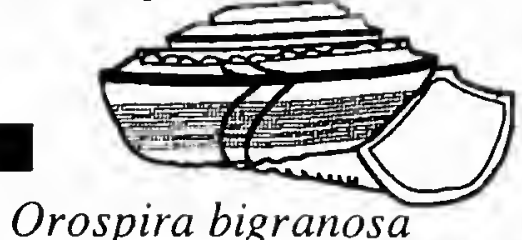

Orospira bigranosa

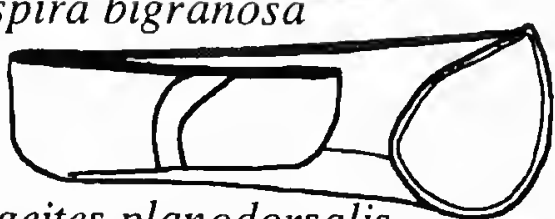

Bridgeites planodorsalis

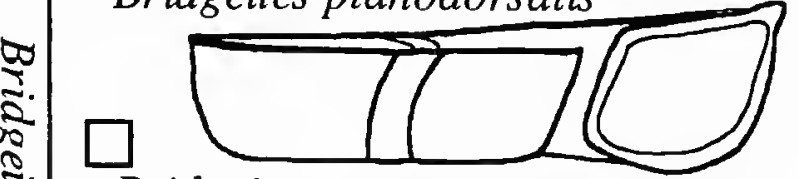

Bridgeites supraconvexa

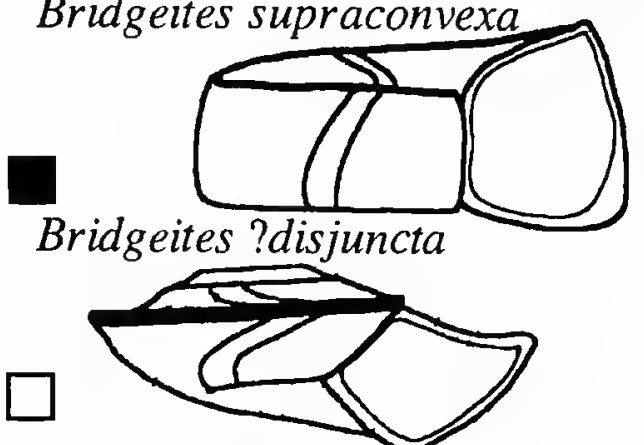

Ceratopea ?laurentia

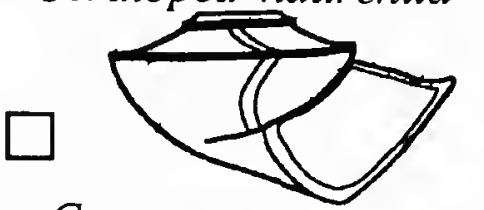

Ceratopea pygmaea

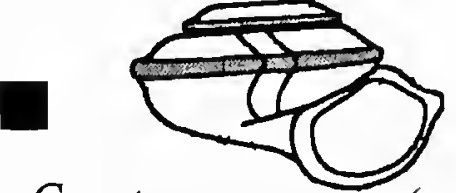

Ceratopea unguls (go to Node 70)

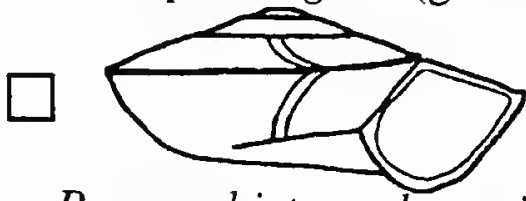

Pararaphistoma lemoni
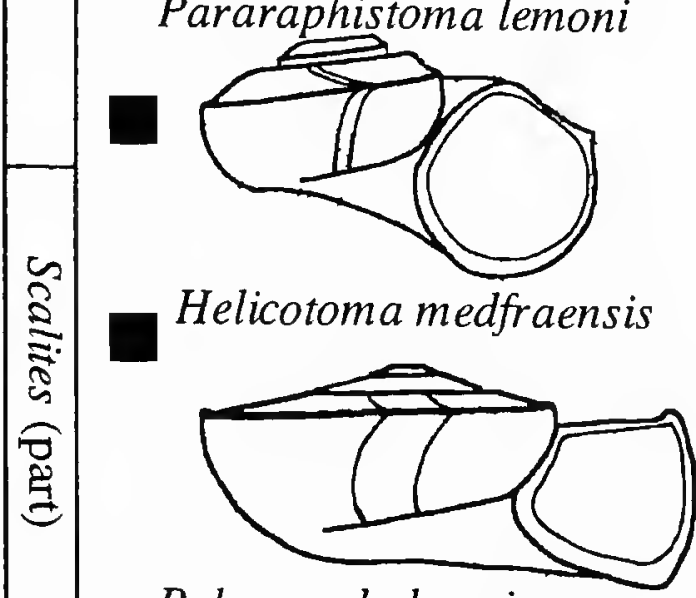

Palaeomphalus giganteus

(go to Node 43) 


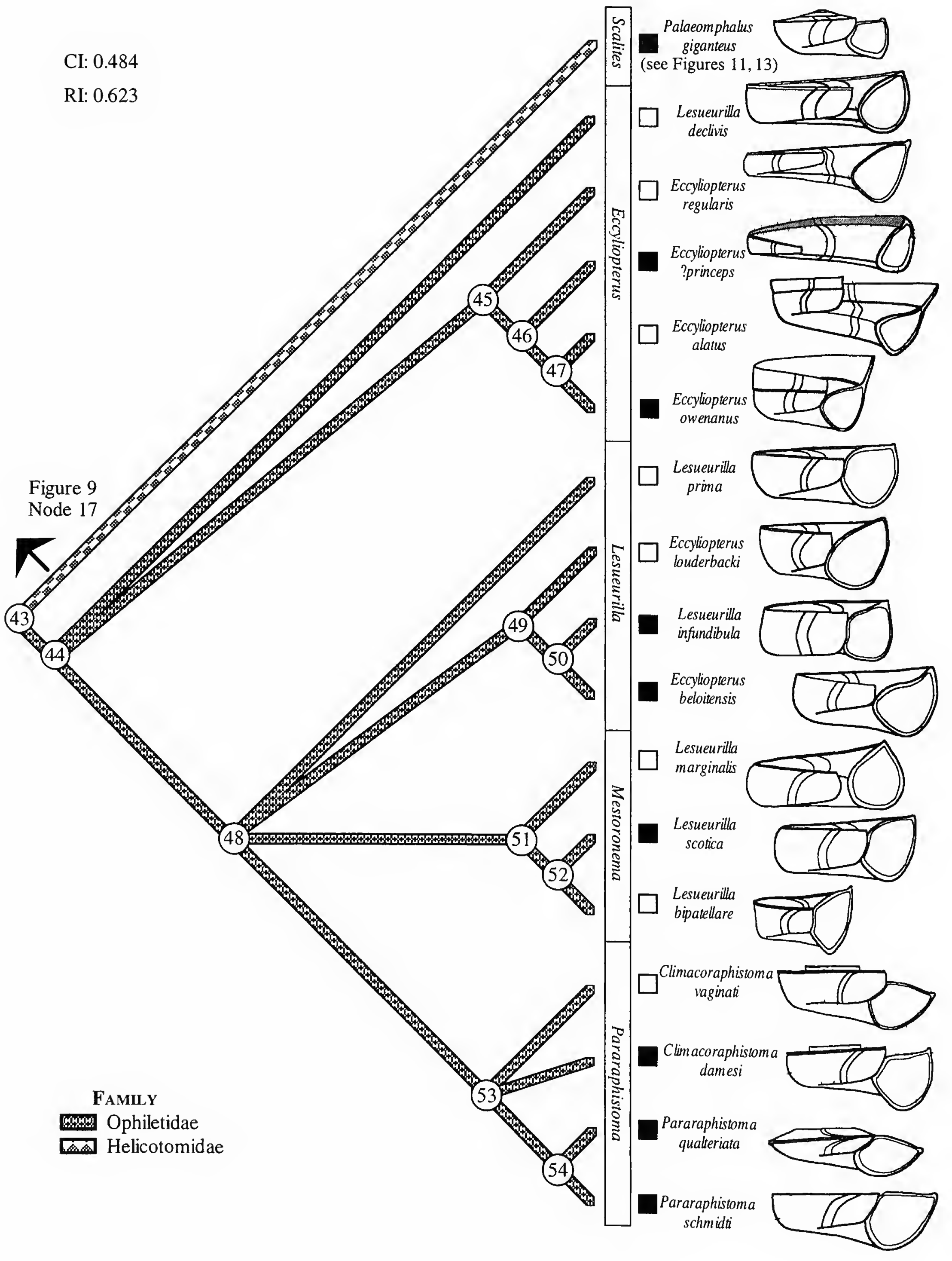


FIGURE 12 (opposite).--Relationships among the "lesueurillines." For abbreviations, see legend to Figure 7. Node 43 (Palaeomphalus giganteus clade), sinus angle $\approx 50^{\circ}(3,4)$; stronger juvenile GL (16); sigma-shaped lunulae (38); loss of RR swelling (60); curved IM (95). Node 44 ("Lesueurillines"), PB width = $10^{\circ}(20) ; \beta=30^{\circ}-40^{\circ}(48)$; asymmetric ramp shapes (LR rounder than RR) $(51,52,72)$; IM thickness same as rest of shell (87); IM base angle $=90^{\circ}(94)$; IM $60^{\circ}$ off parallel to CA (98); nearly planispiral coiling (126). Node 45 (Eccyliopterus regularis clade), sinus angle $\approx 40^{\circ}(3,4)$; very strong ML (29); no ontogenetic rotation of aperture (49); Pl thickness same as rest of shell (103); extremely low K (123). Node 46 , asymmetric aperture (LR contracted) (54-56). Node $47, \mathrm{~PB}$ width $\approx 05^{\circ}(20)$; extremely strong ML (29); asymmetric aperture (RR wider than LR) (57-59); thickened IM (87); $1 \mathrm{M}$ at $-45^{\circ}$ to CA (98). Node 48 (Lesueurilla prima clade), left side of sinus more obtuse (2-4); left side of sinus narrower (5-7); slit present, leaving weak lunulae $(34,39)$; PB partially on RR (43); IM channel lost (102). Node 49 (Eccyliopterus louderbacki clade), PB slightly raised relative to whorl (33); RR becoming more concave over ontogeny (53); BC lost (89); curved base (120); high E (121); large size (141). Node 50, wide left side of sinus (7); no ontogenetic rotation of aperture (49); very high E (121); isometric T (127). Node 51 (Lesueurilla marginalis clade), IM at $-45^{\circ}$ to $\mathrm{CA}(98)$; isometric T (127). Node 52, fine, sharp GL (15); no ontogenetic change in GL strength (16); ACh lost (45); flat LR (72). Node 53 (Climacoraphistoma clade), high rotation of aperture (50); asymmetric ramp shapes ( $R R$ more convex) $(52,53,72)$; IM at $\sim 45^{\circ}$ to $\mathrm{CA}(98)$. Node 54 , basal GL strength same as rest of shell (18); symmetric ramp shapes (51); IM $30^{\circ}$ off parallel to CA (98); straight base (120); low T (126).

bears noting that the two basic "lesueurilline" subclades generally were restricted to different biogeographic realms from their origins in the middle Arenig (Early Ordovician) through the Llandeilo (Middle Ordovician). The Lesueurilla clade (Figure 12) occurs predominantly in the Baltoscandian faunas of Europe, whereas early members of the Scalites clade (Figure 13) exist predominantly in the early Laurentian fauna of North America. Some geographic overlap between the two clades does occur in Malaysia and western North America during that time, and members of both clades occur in both faunas from the Caradoc through the Ashgill (Middle to Late Ordovician).

I.3.1.2. "HoLOPEINES".-The second "raphistomatid" subclade comprises species classified in Raphistomina Salter, 1859, Pachystrophia Perner, 1903, Sinutropis Perner, 1903, and Holopea Hall, 1847 (Figures 13, 14, nodes 60-69). This clade is diagnosed primitively by a completely $U$-shaped sinus (nodes 60-69), although some derived species have no sinus. Pachystrophia includes the least derived members of a clade diagnosed by the loss of a peripheral band (Figure 14, nodes 62-69). Later species (i.e., Pachystrophia gotlandica (Lindström, 1884) and Lytospira subuloides Barrande in Perner, 1903) (Figure 14, nodes 68,69) include the only open-coiled, nearly planispiral species known from the Silurian. In addition, Silurian species placed by Knight et al. (1960) in the family Sinuopeidae (e.g., Horiostomella Perner, 1903, and Sellinema Perner, 1903) likely also belong to this clade. The status of the post-Silurian members of that family are not known, but it is much more likely that they are "holopeines" than it is that they are related to the Late Cambrian-earliest Ordovician Sinuopea species.
Species assigned to the genus Holopea are a particularly conspicuous development within the "holopeines" (Figure 14, nodes 64,65). The earliest Holopea species are nearly identical to contemporaneous Pachystrophia species, save for the absence of the sinus (with the absence of a peripheral band being a synapomorphy that links Pachystrophia and Holopea). The trochiform shell typically associated with the genus is shared among derived Holopea species (node 65). Holopea is an important genus when discussing gastropod phylogeny because its family (the Holopeidae) represents the earliest putative members of the Trochoidea in some classification schemes (e.g., Knight et al., 1960). None of the other genera typically assigned to the Holopeidae, however, seem to have been close relatives of Holopea. Although the genus is reported through the Devonian (Knight et al., 1960), this analysis did not find any post-Ordovician members of the $H$. insignis clade. This makes it seem unlikely that Holopea represents an early trochoid. Other phylogenetic scenarios concerning the Trochoidea are discussed below.

Some general phylogenetic proposals concerning the genus Pachystrophia are not supported here. Wenz (1938) considered Pachystrophia to be a close relative of "ophiletoid" genera such as Ecculiomphalus and Lytospira. Also, some "holopeides" from the Silurian (at least one of which extends into the early Devonian; see Horny 1992a) have been classified in the genus Lytospira. A very different suggestion was made by Knight et al. (1960), who considered Pachystrophia to be a junior synonym of Lesueurilla. This analysis contradicts all of these ideas, suggesting instead that Pachystrophia is distantly related to the "ophiletoids" and that Lesueurilla and Pachystrophia have closer relatives than one another.

\section{I.3.2. "HELICOTOMIDS"}

The other major "ceratopeoid" subclade includes many of the traditional euomphaloid genera (sensu Knight et al., 1960), plus most of the early Paleozoic taxa classified in the Trochoidea (also sensu Knight et al., 1960; Tracey et al., 1993). The earliest species of the clade agree well with the definition of the Helicotomidae (sensu Knight et al., 1960, not Wenz, 1938), so I refer to the clade as the "helicotomids." The clade presented herein (Figures 15-19, nodes 70-108) is very similar to N.J. Morris and Cleevely's (1981) genus-level definition of the Euomphalidae + Helicotomidae clade. "Helicotomid" synapomorphies include a sigmoidal aperture shape with the base of the aperture projected in front of the inner margin, a broadly expanded (i.e., nearly round or square instead of lenticular) aperture, a shallow, weakly curved sinus, a weak monolineate peripheral band, a weak thread-like basal carina, and strong channels beneath the right and left carina.

This analysis also corroborates N.J. Morris and Cleevely's (1981) opinion that derived "euomphalinae," such as $\mathrm{Po}$ leumita Clarke and Ruedemann, evolved from early members of the Helicotomidae. Those authors divided the Euompha- 


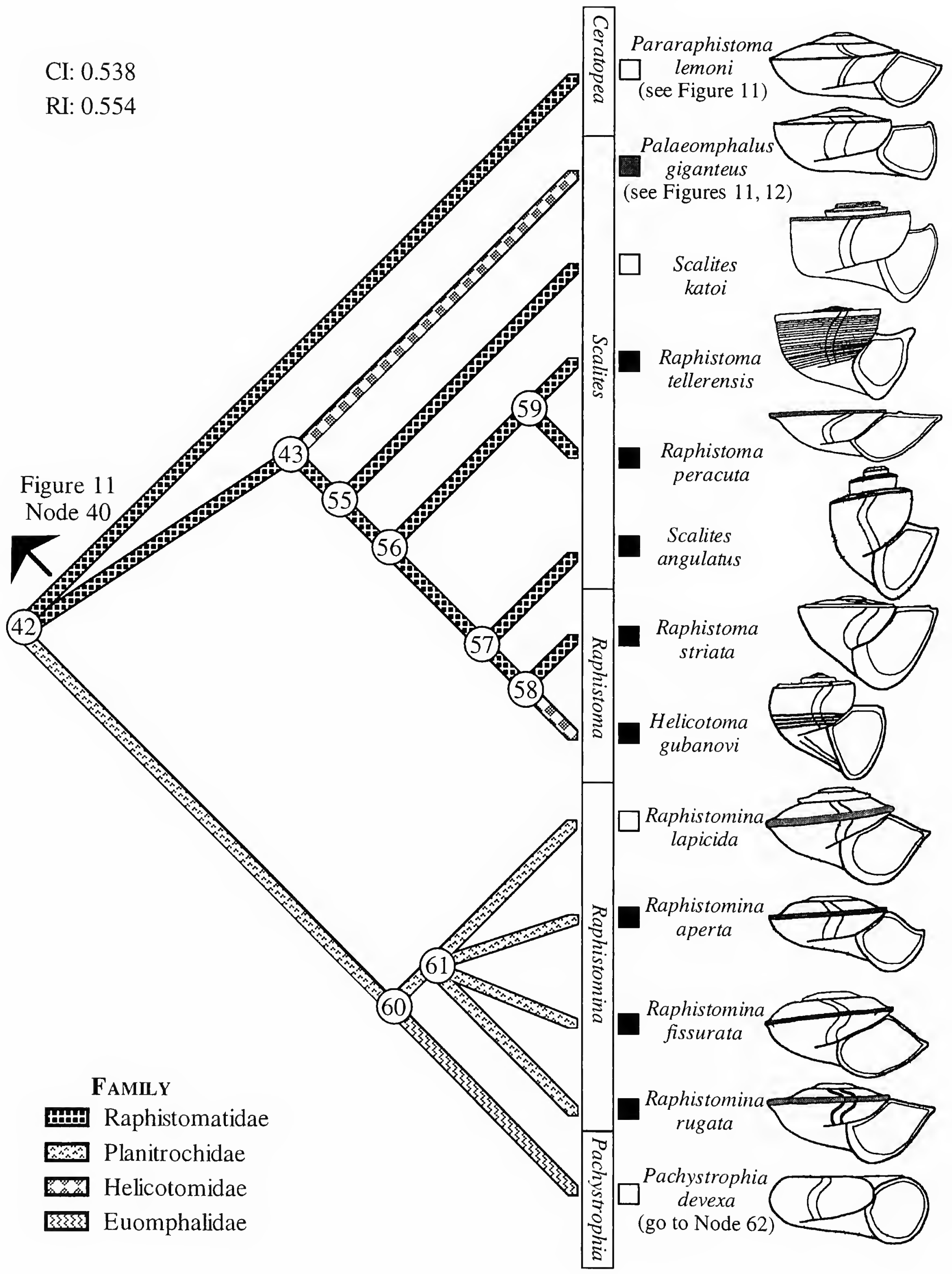


FIGURE 13 (opposite).-Relationships among the "scalitines" and "holoepeids." For abbreviations, see legend to Figure 7. Node 42 ("Raphistomatids"), juvenile GL stronger (16); counter-clockwise rotation of aperture over ontogeny (49); elongated RR (54-56); RR swelling dulls over ontogeny (62). Node 43 (Palaeomphalus giganteus clade), sinus angle $\approx 50^{\circ}(3,4)$; stronger juvenile GL (16); sigma-shaped lunulae (38); loss of RR swelling (60); curved IM (95). Node 55 ("Scalitines"), basal GL strength same as rest of shell (18); PB width $=10^{\circ}(20)$; very strong ML (29); symmetric ramp shapes (51); asymmetric ramp lengths (right contracted) (54-56); very thick $1 \mathrm{M}(87)$; IM base angle $=75^{\circ}(94) ; 1 \mathrm{M}-15^{\circ}$ off parallel to CA (98); IM channel lost (102). Node 56, wrinkled right side of sinus (?) (11); ACh lost (45). Node 57, squared ML (28); very short RR (55); asymmetric ramp projection (RR higher) (57-59); whole aperture inclined $-20^{\circ}(109,110)$; noncrenulated base $(120)$; high E (121). Node 58, U-shaped left side of sinus (10); BL present (21); PB slightly raised relative to whorl (33); slit present (34); convex RR (52); strong, nonprojecting BC (91). Node 59 (Raphistoma tellerensis clade), U-shaped left side of sinus (10). Node 60 ("Holopeids"), sinus angle $=25^{\circ}(3,4)$; U-shaped sinus $(9,10)$; no ontogenetic change in GL strength $(16)$; basal GL strength same as rest of shell (18); $\beta \approx 70^{\circ}$ (48); asymmctric ramp shapes (RR rounder) (51-53); symmetric ramp lengths (54-56); RRC present (64); strong, nonprojecting BC (91); IM $30^{\circ}$ off parallel to CA (98); low E and low K (121, $123)$; isometric $\mathrm{T}$ (127). Node $61, \mathrm{~PB} \perp$ to aperture (42); moderately long ramps $(55,56)$; extremely narrow aperture $(57,58) ; 1 M$ thickness same as rest of shell (87); nonchanneled, weak BC $(90,91) ; 1 \mathrm{M}$ base angle $\approx 105^{\circ}(94) ; 1 \mathrm{M}$ $15^{\circ}$ off parallel to CA (98); curved base (120).

loidea into two early families, the Ophiletidae and the Helicotomidae, which they considered to be sister clades. This analysis suggests that N.J. Morris and Cleevely's definition of the Ophiletidae (which is very close to the "euomphalinae" as defined herein, but without species from the Middle Ordovician and later) is paraphyletic relative to their Helicotomidae.

I.3.2.1. "OPHILETININES".- Two "helicotomid" subclades evolved by the Middle Ordovician. The first of these includes species assigned to Helicotoma Salter, 1859, Palaeomphalus Koken, 1925, and Ophiletina Ulrich and Scofield, 1897 (Figure 15 , nodes $74-80$ ). As I previously labeled the more inclusive clade the "helicotomids," I designate this clade the "ophiletinines." "Ophiletinine" synapomorphies include a moderately wide, flange-like peripheral band that curves abapically and overlies a weak channel, a wide, obtuse left carina that overlies a shallow channel, and very low translation. No known species matches the hypothetical common ancestor of the "ophiletinines," although it likely was most similar to Oriostoma bromidensis Rohr and Johns, 1992, of the Early Caradoc. Synapomorphies uniting the $O$. bromidensis clade (Figure 15, nodes $75,76)$ include a very shallow, very narrow sinus and a strong, sharp basal carina. Ophiletina species (node 76) share a peglike left carina and a bilineate peripheral band. These species also appear to have had partially calcitic shells, although this was not used in the cladistic analysis.

Synapomorphies uniting the Helicotoma tennesseensis clade (Figure 15, nodes 77-80) include a rounded right carina that weakens over ontogeny, an expanded, rounded base, very faint growth lines, an unusually strong, hooked peripheral band, and extreme swelling of the left carina. A disc-like paucispiral operculum is associated with one Helicotoma species (Yochel- son, 1966a). This operculum is very different from the hornshaped opercula associated with early "helicotomids" and other early "ceratopeoids" (e.g., Ceratopea unguis Yochelson and Bridge, 1957; see Yochelson and Wise, 1972). If the phylogeny presented herein is reasonably accurate, then a paucispiral, disc-like operculum is derived, but it unfortunately is not known how common that operculum was among the "helicotomatid" clade.

"Ophiletinines" were moderately diverse from the Middle Ordovician through the Late Ordovician, but this study found no Silurian members of the clade.

I.3.2.2. "EUOMPHALOPTERINES".-The second "helicotomid" subclade includes a diverse array of Silurian species that typically have been assigned to the Anomphalidae, Elasmonematidae, Euomphalopteridae, and Pseudophoridae (Figures 16-19, nodes 81-108). The Ordovician precursors of this clade have been classified in the genus Euomphalopterus Roemer, 1876 (e.g., Euomphalopterus cariniferus Koken, 1925). I categorize the clade as the "euomphalopterines," even though this clade is very different from previous definitions of the Euomphalopteridae (e.g., see Wenz, 1938, or Knight et al., 1960). "Euomphalopterine" synapomorphies include a very strong left carina, a shallow $V$-shaped sinus with a very narrow sharp peripheral band, and very broadly projecting ramps.

1.3.2.2.1. "Anomphalides".-Three major "euomphalopterine" subclades arose during the latest Ordovician and Early Silurian from an Euomphalopterus cariniferus-like ancestor (Figures 16-19, nodes 81-108). One of these subclades (Figure 16, nodes 83-87) consists predominately of species assigned to the Anomphalidae (e.g., Pycnomphalus Lindström, 1884, and Grantlandispira Peel, 1984a). Characters diagnosing the "anomphalide" clade include a strong but dull carina on a swollen alveozone, a strong lirum on the inner margin that partially fills the umbilicus, and a $\mathrm{U}$-shaped sinus with an apex near the suture. Among more-derived species (e.g., nodes 86,87 ), the umbilicus is entirely filled and the peripheral band is highly reduced or lost. Kase (1989) noted that some of the earliest species assigned to the Omphalotrochidae (e.g., Middle Devonian species assigned to Labrocuspis Kase) have synapomorphies with "anomphalide" species; however, the majority of omphalotrochids, including Devonian species assigned to Pseudomphalotrochus Blodgett, 1992, appear to share synapomorphies with Straparollus de Montfort, 1810, and Euomphalus Sowerby, 1814 (Erwin, in prep.; Wagner, in prep.).

I.3.2.2.2. "Poleumitides",-The second major "euomphalopterine" subclade contains species assigned to Poleumita, Euomphalopterus, Centrifugus Bronn, 1834, and (possibly) Spinicharybdis Rohr and Packard, 1982 (Figures 17, 18, nodes 88-96). This clade bears little resemblance to the Poleumitidae of Wenz (1938), which links Poleumita with the problematic Oriostoma Munier-Chalmas, 1876 (see also Boucot and Yochelson, 1966). Because the Poleumitidae is an established name, I designate this clade as the "poleumitides." "Poleumitides" evidently shared a common ancestor in the Early Silurian that 


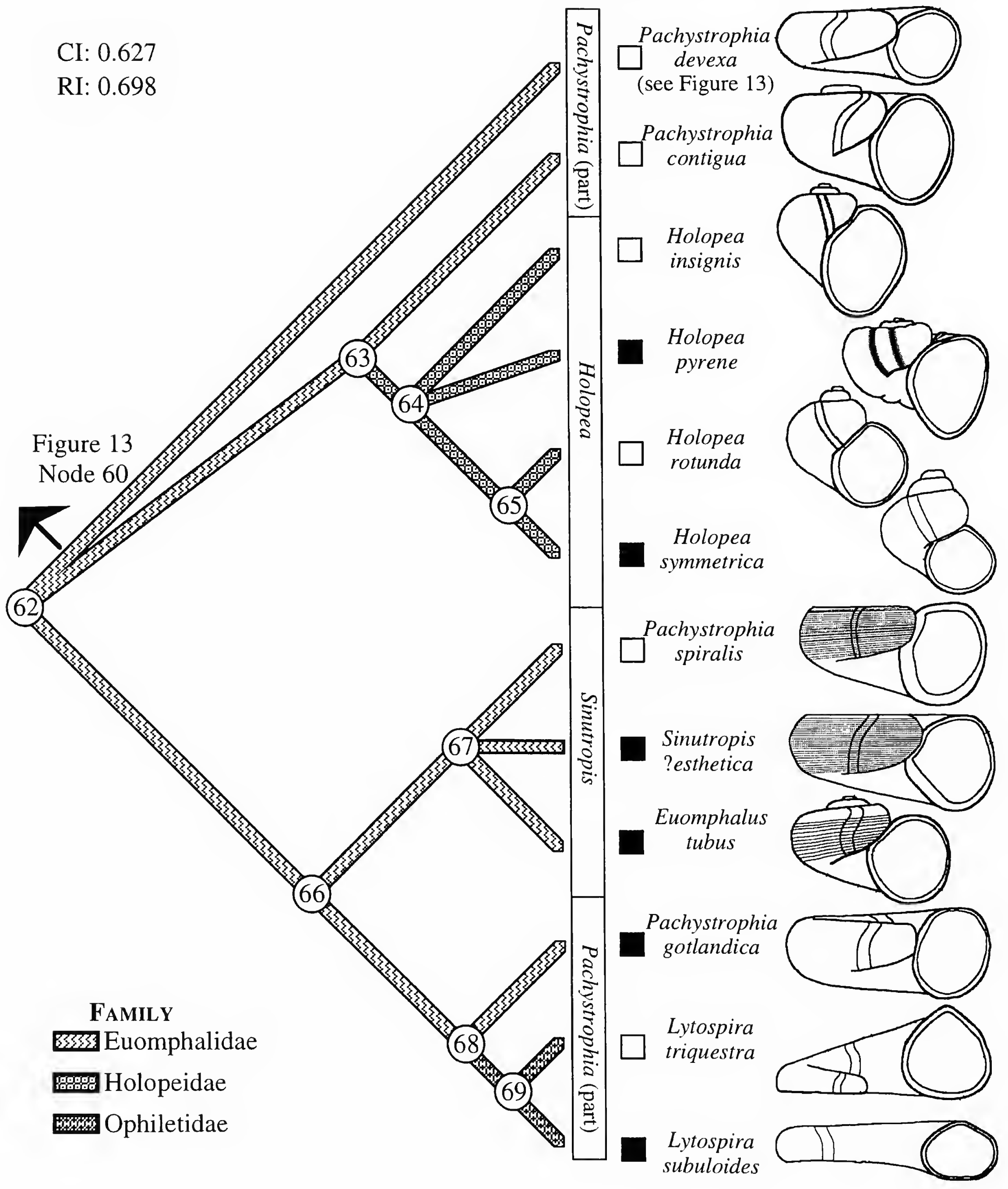


FIGURE 14 (opposite).-Relationships among the derived "holopeids." For abbreviations, see legend to Figure 7. Node 62 ("Pachystrophides"), fine, sharp GL (15); PB lost (19); ACh lost (45); $\beta \approx 60^{\circ}$ (48); no ontogenetic rotation of aperture (49); very narrow aperture $(58,59)$; RRC lost (64); convex LR (72); BC lost (89); thickened Pl (103). Node 63 (Pachystrophia contigua clade), asymmetric aperture (left side broader) (57-59); IM $15^{\circ}$ off parallel to CA (98); whole aperture inclined $-20^{\circ}(109,110)$; moderate $K(123)$. Node 64 (Holopea insignis clade), sinus lost (1); asymmetric ramp lengths (RR contracted) (54-56); broad left side of aperture (59); lM $\backslash$ base angle $\approx 60^{\circ}(94)$; moderate $T$ (126). Node $65, \beta \approx 40^{\circ}$ (48); symmctric ramp shapes (51-53); very short $R R$ (55); moderately wide right side of aperturc (58); very convex LR (72); thin Pl (103); wholc aperture inclined $-30^{\circ}(109,110)$; base projected posteriorly $-10^{\circ}$ (117); straight base (120); moderate E (121); high T (126); ontogenetic increase in T (127); septation absent (128). Node 66 (Sinutropis ?esthetica clade), asymmetric sinus shape (left curve stronger) $(8-10) ; \beta \approx 30^{\circ}$ (48); asymmetric ramp shapes ( $L R$ rounder than $R R)(51,52,72)$; long ramps $(55,56)$; asymmetric aperture (RR wider than LR) (57-59); base projected posteriorly $-20^{\circ}$ (117). Node 67 , asymmetric ramp lengths (LR longer than RR) (54-56); very convex LR (72). Node 68 (Pachystrophia gotlandica clade), IM channel present (102). Node 69 , sinus angle $\approx 20^{\circ}(3,4)$; narrow sinus $(6,7)$; weak GL (15); $\beta \approx 20^{\circ}$ (48); moderately long ramps $(55,56)$; moderately widc aperture $(58,59)$; $1 \mathrm{M} \perp$ to $\mathrm{CA}(98)$; base projected posteriorly $\sim 10^{\circ}(116,117)$; open coiling (123); low ultradextral T (126).

was much like E. cariniferus but with a frill-like left carina, slightly imbricated growth lines, ontogenetic weakening of the right carina and peripheral band, and strong increases in whorl convexity over ontogeny. A calcitic shell also diagnoses this clade, although again I did not use this as a character state. In the Euomphalopterus subcarinatus clade (Figure 17, nodes 88-92), the frill becomes strongly developed (see also Linsley et al., 1978). This frill is highly crenulated on species such as E. praetextus (Lindström, 1884) or replaced with a series of tubes on others such as $E$. togatus (Lindström, 1884). The latter feature is best developed in Spinicharybdis, although it is possible that this represents a parallelism. Rohr and Packard (1982) commented on similarities between Spinicharybdis and Euomphalopterus, but they did not explicitly suggest that the two genera were related. The elongate, widely spaced tubes of S. wilsoni Rohr and Packard, 1982, are more similar to those seen on species of Hystricoceras Jahn than they are to the short, tightly-spaced tubes of E. togatus. Yochelson (1966b) cited this as evidence that the species since classified as Spinicharybdis are related to Hystricoceras. Spinicharybdis wilsoni shares other synapomorphies with E. togatus, however, including the shape of the ramps, the development of the sinus, and the complete absence of a peripheral band. There are other species of Spinicharybdis that I could not include in this analysis because the only known specimens are too incomplete. These species do show a series of tubes that are very similar to the tube-bearing frill of E. togatus, save that they are much longer; however, there is no evidence of frill-bounding lira on any of these species, which exist on E. togatus and its relatives. Only the bases and lower whorls are visible on any of the pertinent specimens, so it is not known if the sinuses and peripheral bands of these specimens are like those of Euomphalopterus or like those of Hystricoceras. Therefore, it is con- ceivable that Spinicharybdis actually is a "pseudophoride" (see below).

Finally, Spinicharybdis also shares features with contemporary Straparollus (e.g., S. paveyi Foerste, 1924), and the spacing of the tubes on $S$. wilsoni is similar to the spacing of carrier shell scars of $S$. paveyi (see further discussion, below). The long tubes of Spinicharybdis might have served the same functional purpose as the agglutinated shells on Straparollus species (e.g., Linsley and Yochelson, 1973). Therefore, another possibility is that the spines of Spinicharybdis represent a morphologic novelty that maintained a functional "homology" with carrier-shell ancestors such as $S$. paveyi. In this case, the more frill-like tubes of other species represent convergence toward a Euomphalopterus-like morphology. As a similar functional interpretation applies to the extended frill of some $E u-$ omphalopterus species (but not to the short tubular frill of species such as E. togatus; e.g., Linsley et al., 1978), however, it seems as or more likely that the spines and frills represent different adaptations on the same homologies that were functional parallelism.

Euomphalopterus apparently is the sister taxon of a Silurian clade that includes Poleumita and Centrifugus (Figure 18, nodes 93-96). The earliest known species from this clade, $P$. alata (Lindström, 1884), retains a strong lower ramp carina, but later species possess a wide, dull swelling in this region. Other synapomorphies include a flat, very shallow sinus, a thickened and rounded inner margin, well-developed ormament, and near planispiral coiling with very low curvature. The diagnosis of Poleumita differs from that of Euomphalus primarily in that Poleumita possesses ornamentation. Excluding ornament (which is plesiomorphic above node 94), "poleumitide" species, such as $E$. walmstedti Lindström, 1884, lack any obvious autapomorphies relative to Euomphalus. Thus, the "poleumitides" likely represent the "euomphalinae" in the truest sense.

As noted above, Late Silurian species classified as Straparollus possess carrier shell scars. This feature is retained on many Devonian species (e.g., Linsley and Yochelson, 1973) and might be a synapomorphy between these species and early omphalotrochids (pers. obs.).

I.3.2.2.3. "Pseudophorides".-The final "euomphalopterine" subclade (Figure 19, nodes 97-108) includes species assigned to Pseudophorus Meek, 1873, Discordichilus Cossmann, 1918, Hystricoceras, Siluriphorus Cossmann, 1918, and Streptotrochus Perner, 1903. Previous workers classified many of these species in the Pseudophoroidea (e.g., Knight et al., 1960), so I refer to this clade as the "pseudophorides." The clade also includes the Late Ordovician Euomphalopterus ?ordovicius Longstaff, 1924. "Pseudophoride" synapomorphies include a tangential aperture (i.e., the inclination of the entire aperture rather than just portions of the aperture), a thickened inner margin with little projection relative to the coiling axis that fills the umbilicus, and moderately high translation. The clade initially retains the sharp peripheral band and the sharp 


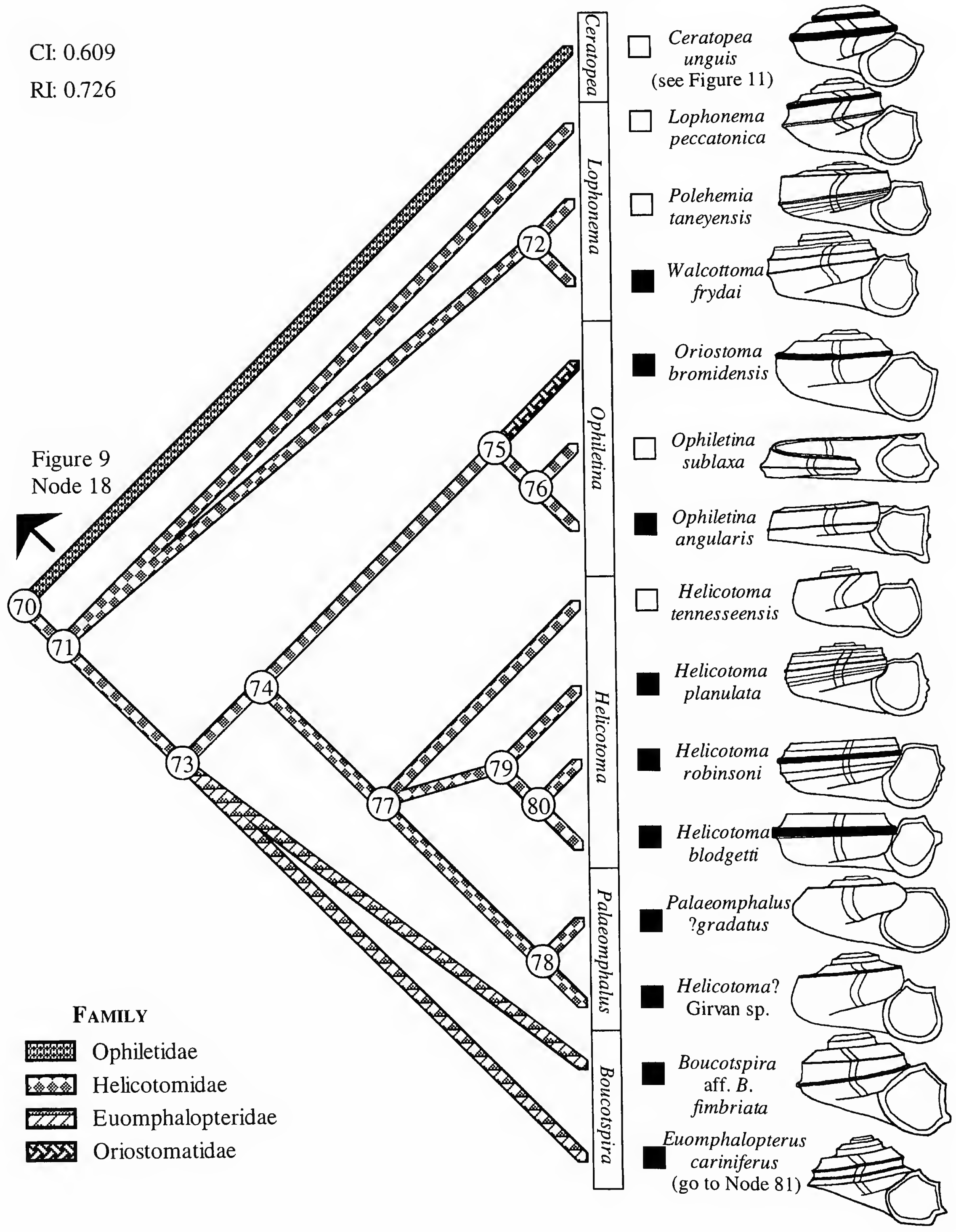


FIGURE 15 (opposite).-Relationships among the "helicotomids." For abbreviations, see legend to Figure 7. Node 70 ("Helicotomids"), sinus angle $=50^{\circ}(3$, $4)$; moderately strong, round $\mathrm{ML}(28,29)$; asymmetric ramp lengths (RR narrower than left) (54-56); asymmetric aperture (right side wider) (57-59); IMlbase angle $\approx 90^{\circ}(94)$; curved IM $(95)$; base projected posteriorly $-20^{\circ}$ (117); curved base (120). Node 71, sigmoidal aperture (13); basal GL strength same as rest of shell (18); PB width $=10^{\circ}(20)$; $\mathrm{PB} \perp$ to aperture (42); strong ACh (46); $\beta=60^{\circ}(48)$; symmetric ramp shapes $(51,52,72)$; moderately broad (slightly asymmetric) aperture $(58,59)$; loss of RR swelling $(60)$; sharp carina on RR and LR $(64,75)$; IM thickness same as rest of shell (87); 1M base angle $\sim 75^{\circ}$ (94); IM channel lost (102); base projected anteriorly $-10^{\circ}(116,118$, 119); low E (121); moderate T (126). Node 72 (Polehemia taneyensis clade), ornament throughout left side of aperture (129). Node 73 (Boucotspira aff. $B$. fimbriata clade), sinus angle $\approx 30^{\circ}(3,4)$; weak GL $(15)$; $V$-shaped lunulae (38); $\beta \approx 50^{\circ}$ (48); no ontogenetic rotation of aperture (49); left and right widths of aperture symmetrical (57-59); base projected anteriorly $-20^{\circ}(119)$; isometric T (127). Node 74 ("Ophiletinines"), weak ACh (46); low K (123); low T (126); septation lost (128). Node 75 (Oriostoma bromidensis clade), narrow sinus $(6,7)$; strong GL (15); projecting BC (91); base projected anteriorly $-10^{\circ}$ (119); small size (141). Node 76, BL present (21); concentric lunulae (38); very strong lunulae (39); $\beta=50^{\circ}$ (48); highly asymmetric ramps (LR nearly twice as long as RR) $(55,56)$; slightly asymmetric aperture (left side contracted slightly) (57-59); squared ridge-like LRC (76); thickened IM (87); $B C$ beneath outer margin ( 93$)$; $1 \mathrm{M} \backslash$ base angle $\approx 105^{\circ}(94)$; inclined aperture (109). Node 77 (Helicotoma tennesseensis clade), weak RRC (65); LR swelling present with weak LRC $(73,77)$; dull, thickened BC $(90)$. Node 78 (Palaeomphalus ?gradatus clade), $\mathrm{PB}$ width $\approx 05^{\circ}(20)$; BC lost (89); strongly curved IM (95). Node 79 (Helicotoma planulata clade), asymmetric aperture (LR moderately contracted) (57-59); thickened IM (87); ontogenetic increase in T (127); omate LR (129). Node 80, ACh lost (45); asymmetric ramp lengths (LR strongly contracted) (54-56); moderately strong RRC (65); strong, squared ridge-like $\operatorname{LRC}(76,77)$.

right and left carinae that are common to plesiomorphic "euomphalopterines." The left carina, however, becomes prominent with a square periphery, whereas the right carina and the peripheral band are strongly reduced or lost in the Siluriphorus gotlandicus clade (Figure 19, node 104). Also, the sinus is reduced to a shallow kink near the suture, and the sigmoidal shape of the aperture becomes extreme. Among very derived members of the Discordichilus clade (Figure 19, node 106), the peg-like left carina is very weak and obtuse, whereas the ramps become strongly rounded. Among other members of the Pseudophorus clade, the peg-like carina becomes a hood-like frill (Figure 19, node 105).

A second "pseudophoride" subclade (Figure 19, node 101) includes species assigned to Streptotrochus and Hystricoceras. This clade's synapomorphies include an inner margin that reflects around the coiling axis and that is thickened at the top and bottom, a thin parietal inductura, and notable increases in both shell expansion and shell torque over ontogeny. The most derived species of this clade possess a projected, strongly channeled left carina (e.g., S. lundgreni (Lindström, 1884)), which forms a series of closely connected tubes on Hystricoceras.

Knight et al. (1960) considered Raphistomina to be the earliest member of the Pseudophoroidea, based on the assumption that the peripheral band on Raphistomina species is homologous with the strong lower ramp carina or frill on species of Sil- uriphorus and Pseudophorus. Previous workers had interpreted this band as a peripheral band because it lies in the middle of a prominent sinus (e.g., Ulrich and Scofield, 1897; Wenz, 1938). I follow the latter interpretation, which leaves Raphistomina species without any important "pseudophoride" synapomorphies; therefore, this analysis contradicts the relationships implied by the taxonomy of Knight et al. (1960). Knight et al. also considered Trochomphalus Koken to be a pseudophoroid. These results agree better with that idea, but they suggest that Trochomphalus is a member of the "anomphalide" clade.

Knight et al. (1960) assigned both Streptotrochus and Discordichilus to the Microdomatoidea. This analysis supports a close relationship between these two genera, but it also implies that they have closer relatives than each other among the Pseudophoroidea. The analysis includes only one other putative microdomatoid, Daidia Wilson, 1951, but species belonging to that genus are considered to be "murchisoniinae" and not at all closely related to the "pseudophorides" (see the "straparollinoids" below)

N.J. Morris and Cleevely (1981) previously linked the Pseudophoroidea to the Euomphaloidea. Morris and Cleevely, however, thought that the Pseudophoroidea diverged from those species very early, i.e., prior to the divergence of taxa such as Ophiletina and Helicotoma. This analysis suggests that "pseudophorides" actually are highly derived "euomphalinae," evolved within the "helicotomids." N.J. Morris and Cleevely (1981) also suggested that another taxon, the Trochonematoidea, are even more closely related to the Euomphaloidea than are the Pseudophoroidea. My analyses, however, suggest that the Trochonematoidea evolved from "lophospiroids" (Wagner, 1995a; see also Ulrich and Scofield, 1897; Knight et al., 1960). As discussed below, lophospirids apparently evolved from the "murchisoniinae," so this study does not support that part of Morris and Cleevely's phylogenetic scheme.

\section{II. "MURCHISONIINAES"}

The "Murchisoniinae" contain several important taxa, including the earliest putative apogastropods and most of the early Paleozoic taxa assigned to the Pleurotomarioidea (Figures 20-35, nodes 109-215). The relationships among the major "murchisoniinae" subclades (Figure 20, node 109) approaches a star phylogeny (sensu Felsenstein, 1985), with several taxa derived from the same ancestor. Although systematists usually interpret such polytomies as unresolved relationships, the analysis suggests that the polytomy represents the real relationship among these taxa. The polytomy includes Hormotoma ?simulatrix (Billings, 1865), which is plesiomorphic relative to all "murchisoniinae" subclades. This suggests that the long-lived and geographically wide ranging $H$. ?simulatrix is ancestral to these clades through separate cladogenetic events (see Hoelzer and Melnick, 1994; Wagner and Erwin, 1995). The earliest members of the major subclades all co-occur with $H$. ?simulatrix, and it often was difficult for me to de- 


\section{FAMILY}

Euomphalopteridae

Ez3zয3 Euomphalidae

Enomphalidae

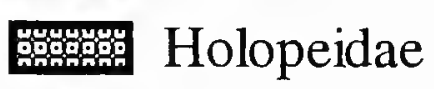

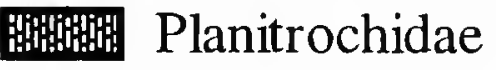

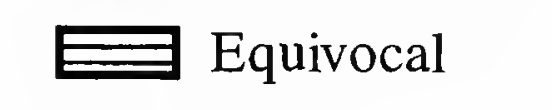


CI: 0.695

RI: 0.646

FAMLY

Euomphalopteridae

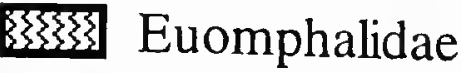

$\Longrightarrow$ Uncertain

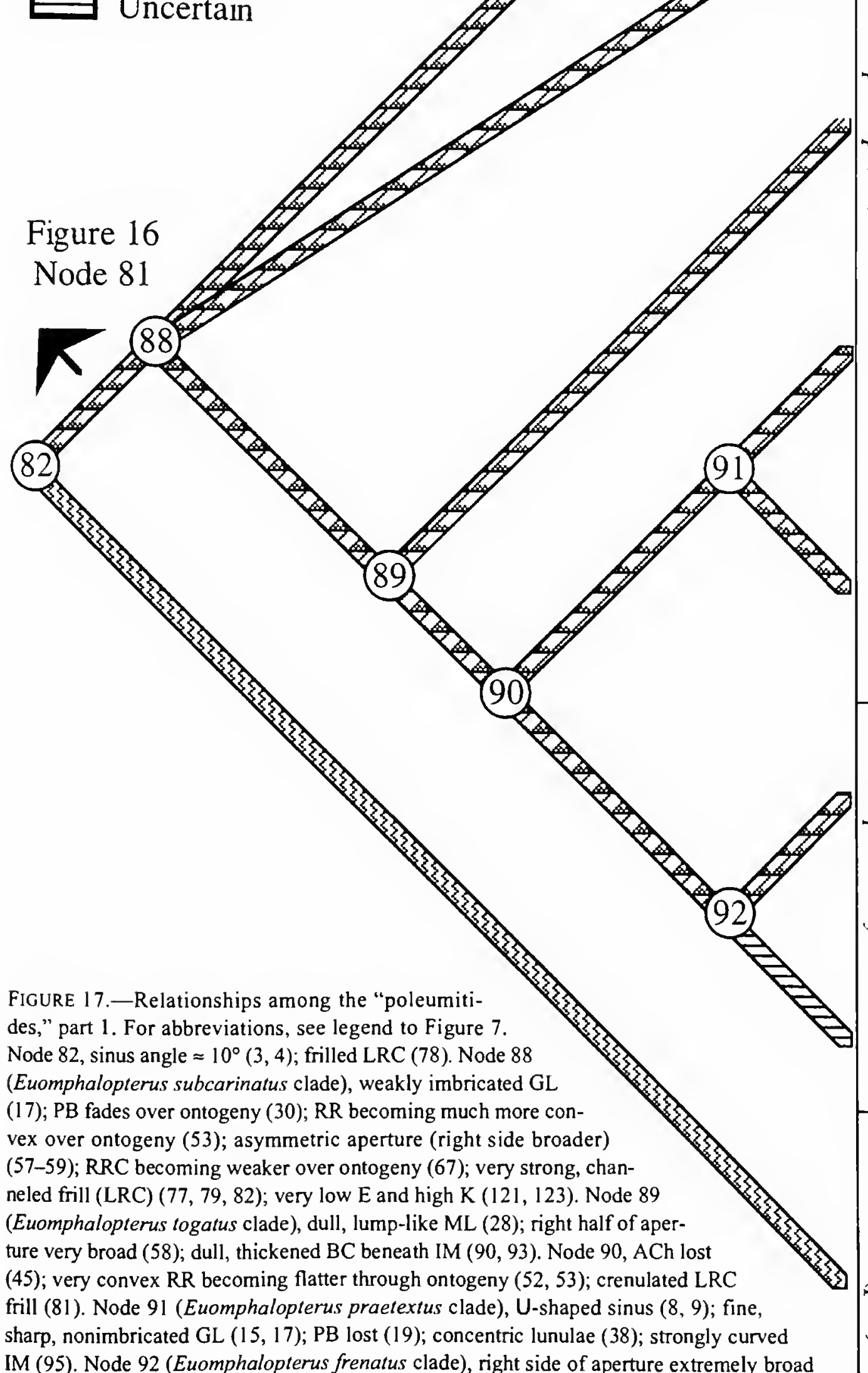

IM (95). Node 92 (Euomphalopterus frenatus clade), right side of aperture extremely broad

(58); LRC frill forming tubes (85); high T (126).
Euomphalopterus

subcarinatus

(see Figure 16)

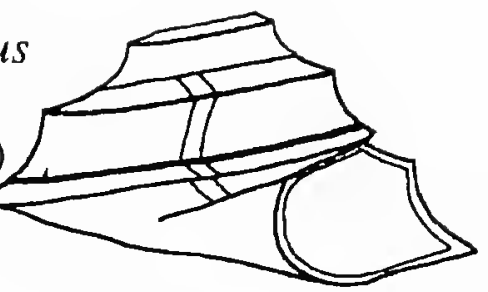

Euomphalopterus alatus

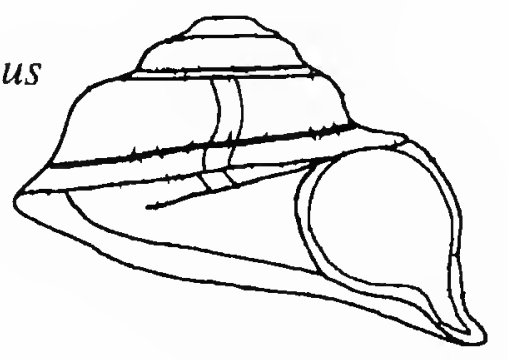

Euomphalopterus

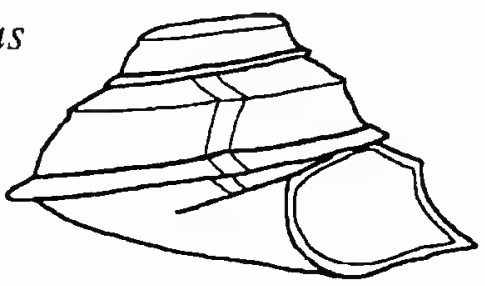

Euomphalopterus praetextus

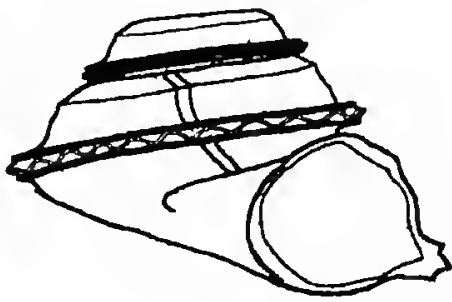

Euomphalopterus undulans

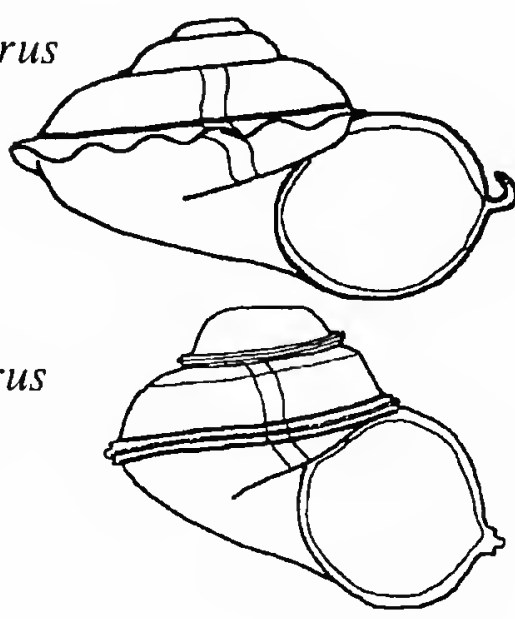

Euomphalopterus frenatus
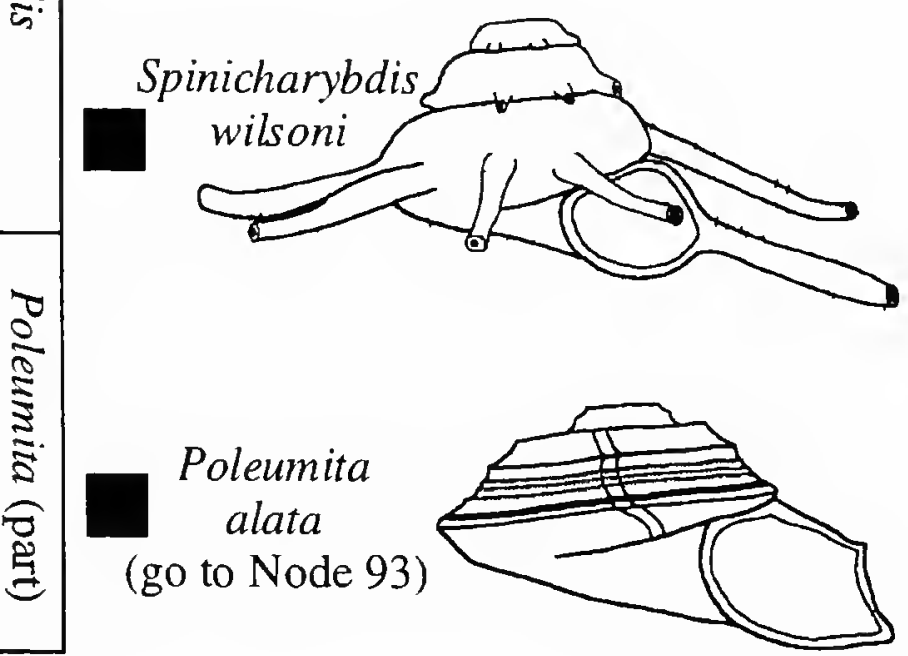


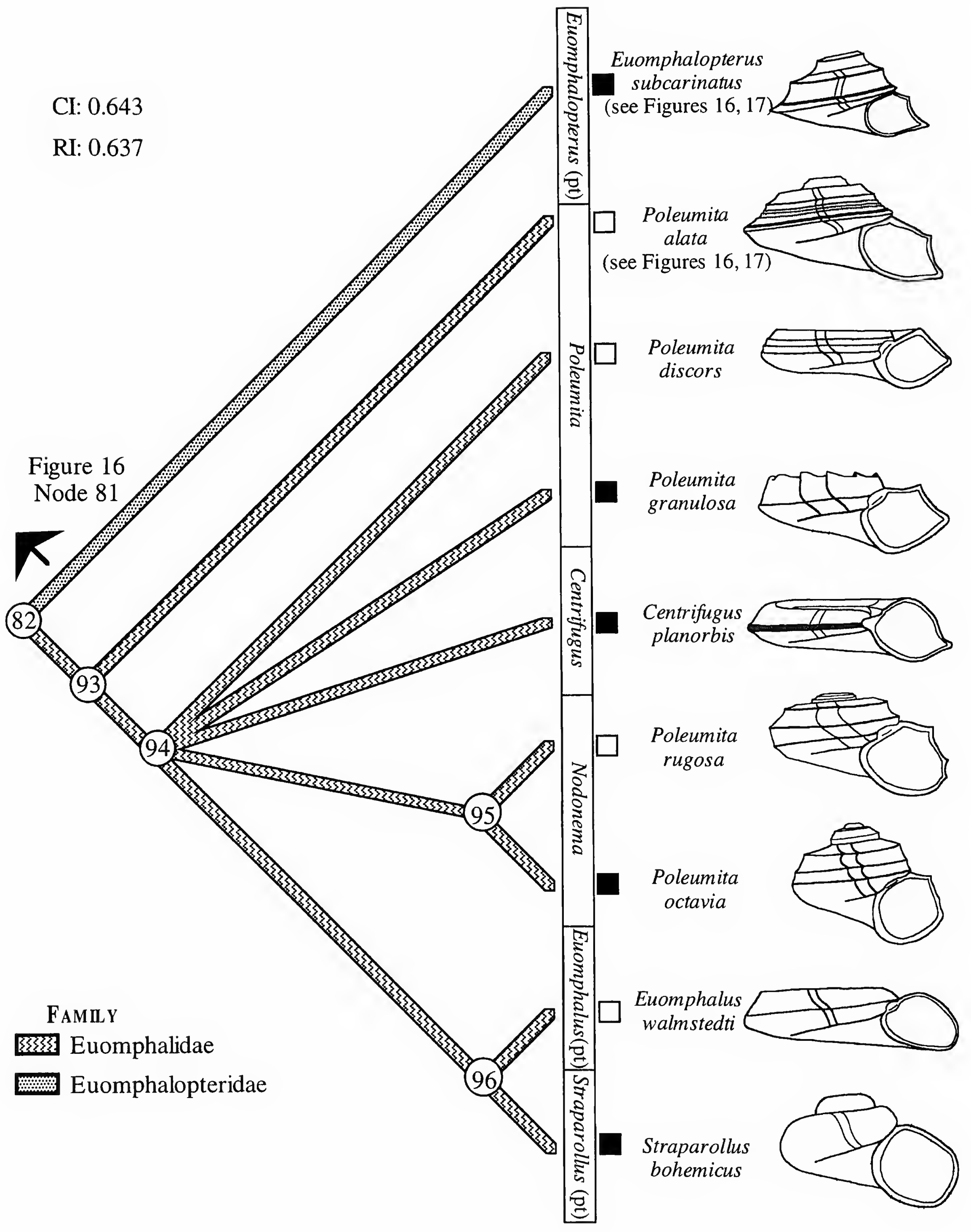


FIGURE 18 (opposite).-Relationships among the "poleumitides," part 2. For abbreviations, see legend to Figure 7 . Node 82 , sinus angle $\approx 10^{\circ}(3,4)$; frilled LRC (78). Node 93 (Poleumita alata clade), sinus nearly absent $(3,4)$; crenulated aperture (12); highly sigmoidal aperture (14); IMlbase angle $\approx 90^{\circ}(94)$; straight IM (95); thickened middle of IM (96); IM $30^{\circ}$ off parallel to CA (98); very thick $\mathrm{PI}$ in concentrated strip, projecting in front of aperture $(103,104)$; strongly curved base with slight posterior projection $(116,118,120)$; moderately dense ornament on LR and RR (129, 130, 133, 134). Node 94 (Poleumita discors clade), periodically flared ML (32); weak ACh (46); $\beta \approx 10^{\circ}$ (48); long LR (56); weak RRC (65); thick contusion LRC (76); thickened IM (87); BC lost (89); IM $\backslash$ base angle $\approx 75^{\circ}(94)$; low T (126); large size (141). Node 95 (Poleumita rugosa clade), extremely strong GL (15); strongly imbricated GL (17); convex RR (52); dull, lump-like LRC (66); convex LR (72); moderate E (121); denser omament on LR (130). Node 96 (Euomphalus marix clade), nonimbricated GL (17); convex LR (72); LRC lost (75); uniform thickness of IM (96); IM at $\sim 45^{\circ}$ to CA $(98)$; base projected posteriorly $\sim 10^{\circ}(116,117)$; straight base (120); loss of omament $(129,133)$.

termine whether a specimen should be classified as $H$. ?simulatrix or as another Hormotoma species (e.g., H. confusa Cullison, 1944, or H. dubia Cullison, 1944). Hormotoma confusa and H. dubia, however, share synapomorphies with different "murchisoniinae" subclades, so I treated them as separate species based on the "phylogenetic species" concept (de Queiroz and Donoghue, 1988; Nixon and Wheeler, 1990).

\section{II.1. "Plethospiroids"}

One early "murchisoniinae" subclade includes species classified in the Plethospiridae (Figure 20, nodes 110, 111). "Plethospiroid" synapomorphies include a shallow sinus and a thickened, siphonate inner margin. This morphologically novel clade appears to include no members younger than the Early Ordovician, even though Knight et al. (1960) assigned several other genera to the Plethospiridae. Seelya ventricosa Ulrich in Ulrich and Scofield, 1897, belongs to the "plethospiroids," but none of the other Ordovician or Silurian species assigned to Seelya Ulrich in Ulrich and Scofield belong to the clade. Another putative plethospirid, Diplozone Perner, 1907, appears to be related to Loxonema Phillips (see below). Erwin (1992) suggested that the Plethospiridae include the sister taxa of the apogastropod-like subulitoids. This analysis suggests that the two clades are closely related, but that other "murchisoniinae" likely are more closely related to subulitids. This is discussed further, below.

\section{II.2. "Straparollinoids"}

Hormotoma dubia represents the stem-member of a moderately diverse "murchisoniinae" subclade that includes species classified as Daidia Salter, Haplospira Koken, 1897, and Straparollina Billings, 1865 (Figure 21, nodes 112-118). Previous workers assigned these taxa to the Holopeidae and the Microdomatidae, which in turn were classified in the Trochoidea (Knight et al., 1960; Tracey et al., 1993). As noted above, the present definitions of those families (and the Paleo- zoic trochoids) is highly polyphyletic, and it is not clear which of these species, if any, represent the precursors of true microdomatids or trochoids. Accordingly, I label the clade the "straparollinoids," which is appropriate given that species assigned to Straparollina represent some of the least derived members of the clade.

"Straparollinoid" synapomorphies include a dull monolineate peripheral band (which is bilineate on the juvenile whorls of early species and becomes monolineate with age) and a narrow sinus. Slightly more-derived "straparollinoids," such as Lophospira grandis Butts, 1926 (nodes 114-118), share a very narrow, sharp peripheral band, a nonreflected inner margin, a well-developed left carina, and higher shell torque. Even morederived species (e.g., Straparollina pelagica Billings, 1865, and more-derived species, nodes 115 and above) possess very narrow sinuses and reduced right sides of the aperture. The most derived "straparollinoids" (e.g., Daidia and Haplospira species, nodes 116,117 ) have a weak monolineate peripheral band near attenuated sutures, no sinus, and an inner margin that is entirely contiguous with the previous whorl.

Previous workers (e.g., Knight et al., 1960; Erwin, 1988; Tracey et al., 1993) classified Daidia in the Microdomatidae, but the next oldest microdomatids first appear in the Devonian (Blodgett and Johnson, 1992; Blodgett, 1993). The statistical significance of this gap is difficult to assess without data for those Devonian species. It seems unlikely that Daidia is closely related to those species. The "pseudophoride" clade includes Silurian species assigned to the Microdomatoidea (albeit, to the Elasmonematidae). Overall, it appears more likely that true microdomatoids arose in that clade rather than from "straparollinoids."

\section{II.3. "Hormotomoids"}

Hormotoma confusa Cullison, 1944, is the least derived member of a clade that includes most of the species classified in the Murchisonioidea, Subulitoidea, and Loxonematoidea (Figure 8, node 7; Figures 22-26, nodes 119-154). The earliest species in this clade have been classified in the genus Hormotoma by numerous authors, so I refer to the clade as the "hormotomoids." Note that the definition of this clade is much broader than that of the Hormotominae sensu Wenz (1938). The chief synapomorphy uniting the clade is an asymmetrical sinus that is much broader and much sharper on the left side than on the right. The "hormotomoids" represent the earliest species in which the left side of the aperture is more pronounced than the right side, which is a feature associated with reduction of the right organs.

\section{II.3.1. "SUBULITIDS"}

The Subulitoidea represent one of the most poorly understood but intriguing products of early gastropod evolution. The earliest subulitoids appeared in the Arenig (Early Ordovician), 


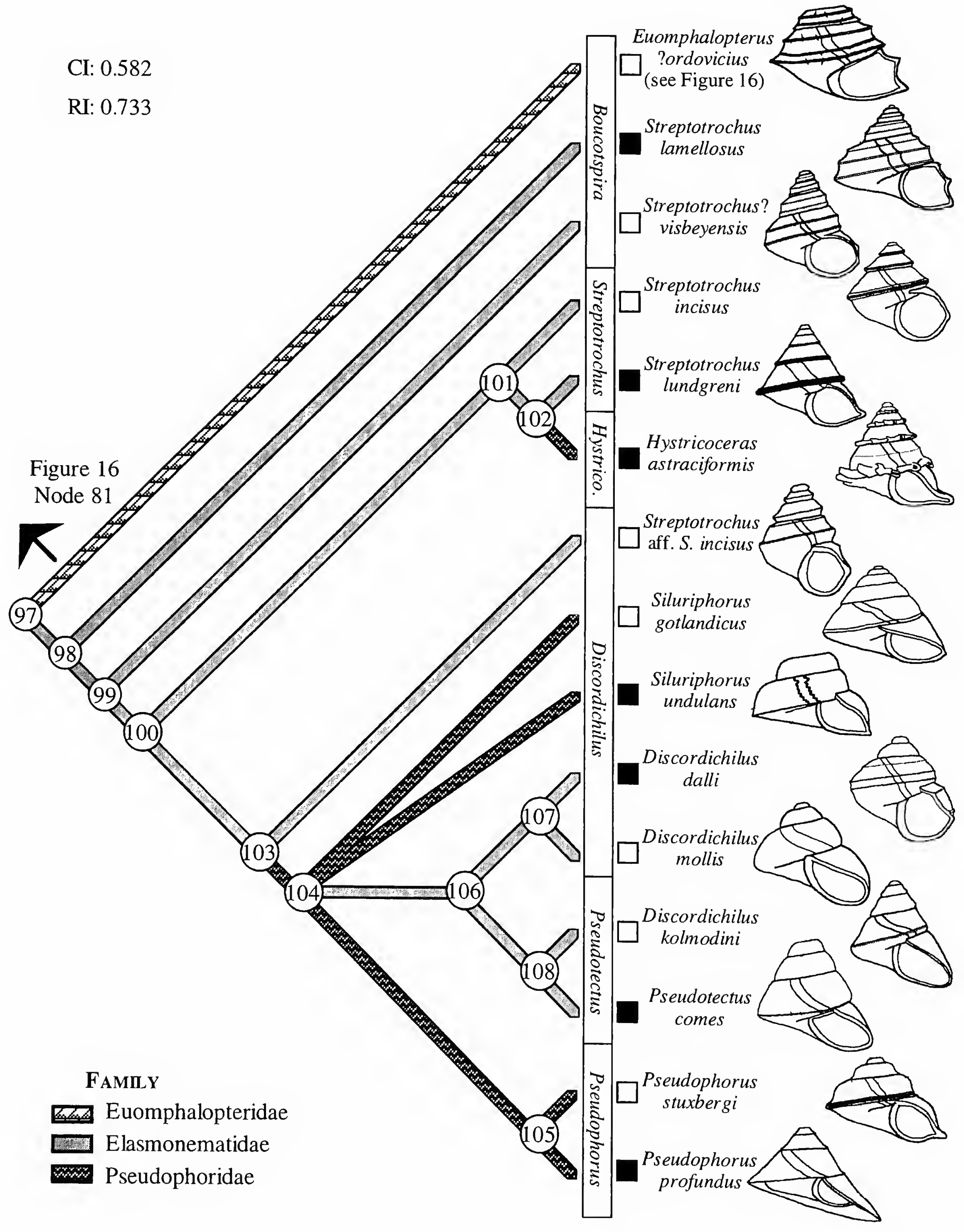


FIGURE 19 (opposite).-Relationships among the "pseudophorides." For abbreviations, see legend to Figure 7. Node 97 ("Pseudophorides"), funicle present (107); base projected anteriorly $\sim 30^{\circ}$ (119); high K (123). Node 98 , asymmetric ramp shapes ( $R R$ more convex) $(52,53,72)$; strong, sharp LRC (76); BC lost (89); IM $-15^{\circ}$ off parallel to CA (98); aperture inclined $20^{\circ}$ (110); high T (126). Node 99 (Streptotrochus? visbeyensis clade), moderately strong LRC (77); variable RRC (weak to absent) $(63,64)$. Node 100 , straight lunulae (38); $\beta \approx 30^{\circ}-40^{\circ}$ (48); asymmetric aperture (RR wider than LR) (57-59); RRC lost (64). Node 101 (Streptotrochus incisus clade), IM thicker at top and bottom and reflected around umbilicus $(96,106)$; thin, complete PI (103); ontogenetically increasing E and T $(122,127)$. Node 102 , convex $\operatorname{RR}$ and $\operatorname{LR}(52,72)$; moderately asymmetric aperture (right side extremely broad, left side broad) $(58,59)$; very strong LRC (77). Node 103 (Streptotrochus aff. S. incisus clade), PB lost (19); little ontogenetic change in RR convexity (53); right side of aperture inclined (113). Node 104 , highly sigmoidal aperture (14); kinked lunulae (38); acute suture (69, $70)$; strong, squared LRC $(76,77)$; PI projecting in front of aperture $(104)$; funicle present (107); base projected anteriorly $\sim 50^{\circ}$ (119); moderate $\mathrm{K}$ (123). Node 105 (Pseudophorus clade), broad symmetric aperture (57-59); very strong, hood-like LRC frill $(76,77,79,84)$; both IM and base thickened (88); BC present (89); IM $30^{\circ}$ off parallel to CA (98); moderate T (126). Node 106 (Discordichilus clade), convex $\operatorname{RR}$ and $\operatorname{LR}(52,72)$; very asymmetric ramp lengths ( $R R$ extremely short, $L R$ long) $(55,56)$; weak, squared LRC (77); whole aperture inclined $-50^{\circ}(109,110,113)$. Node 107 (Discordichilus dalli clade), fine, sharp GL (15); thin, complete PI (103); small size (141). Node 108 (Discordichilus kolmodini clade), moderately asymmetric aperture (right side extremely broad, left side broad) $(58,59)$; thick, contuse LRC (76).

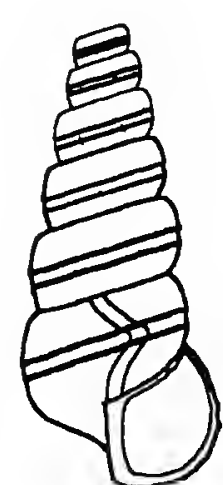

Hormotoma ?simulatrix

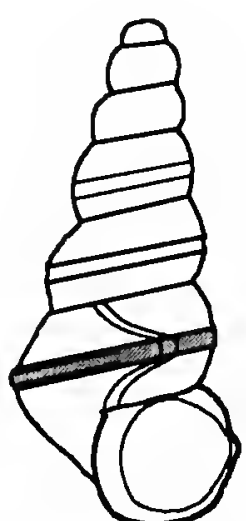

Turritoma aff. T. acrea

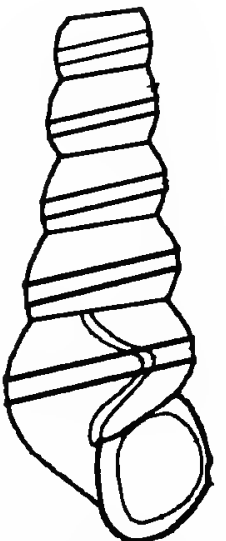

Hormotoma confusa

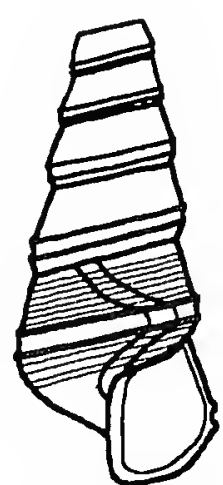

Turritoma

Cotter Fm sp. cannonensis

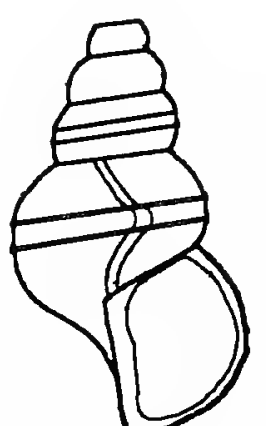

Plethospira (see Figure 8) (go to Node 112)(go to Node 119)(go to Node 155)
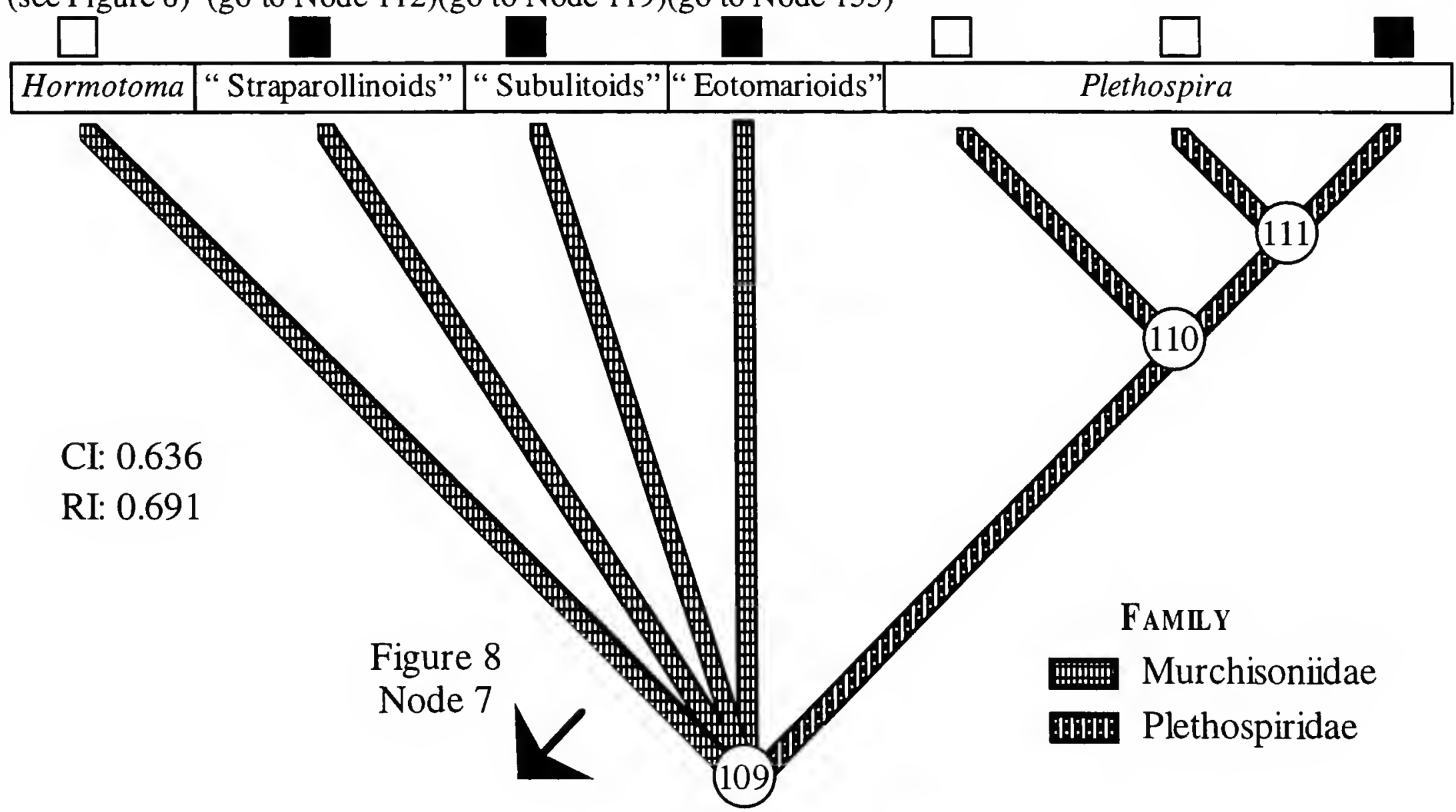

FIGURE 20.-Relationships among basal "murchisoniinae." For abbreviations, see legend to Figure 7. Node 109, weak GL (15); extremely low E and very high $\mathrm{T}(121,126)$. Node 110 ("Plethospiroids"), sinus angle $\approx 30^{\circ}(3$, 4 ); narrow sinus $(6,7)$; PB width $\approx 20^{\circ}(20) ; \beta \approx 70^{\circ}(48)$; slightly asymmetric aperture $(58,59)$; IM 1 base angle $\approx$ $60^{\circ}(94)$; slightly twisted siphon (99); nonreflected IM filling umbilicus $(106,108)$; low E (121). Node 111, loss of RR and LR swellings $(60,73)$; aperture inclined $\sim 20^{\circ}(109,110)$; large size $(141)$. 


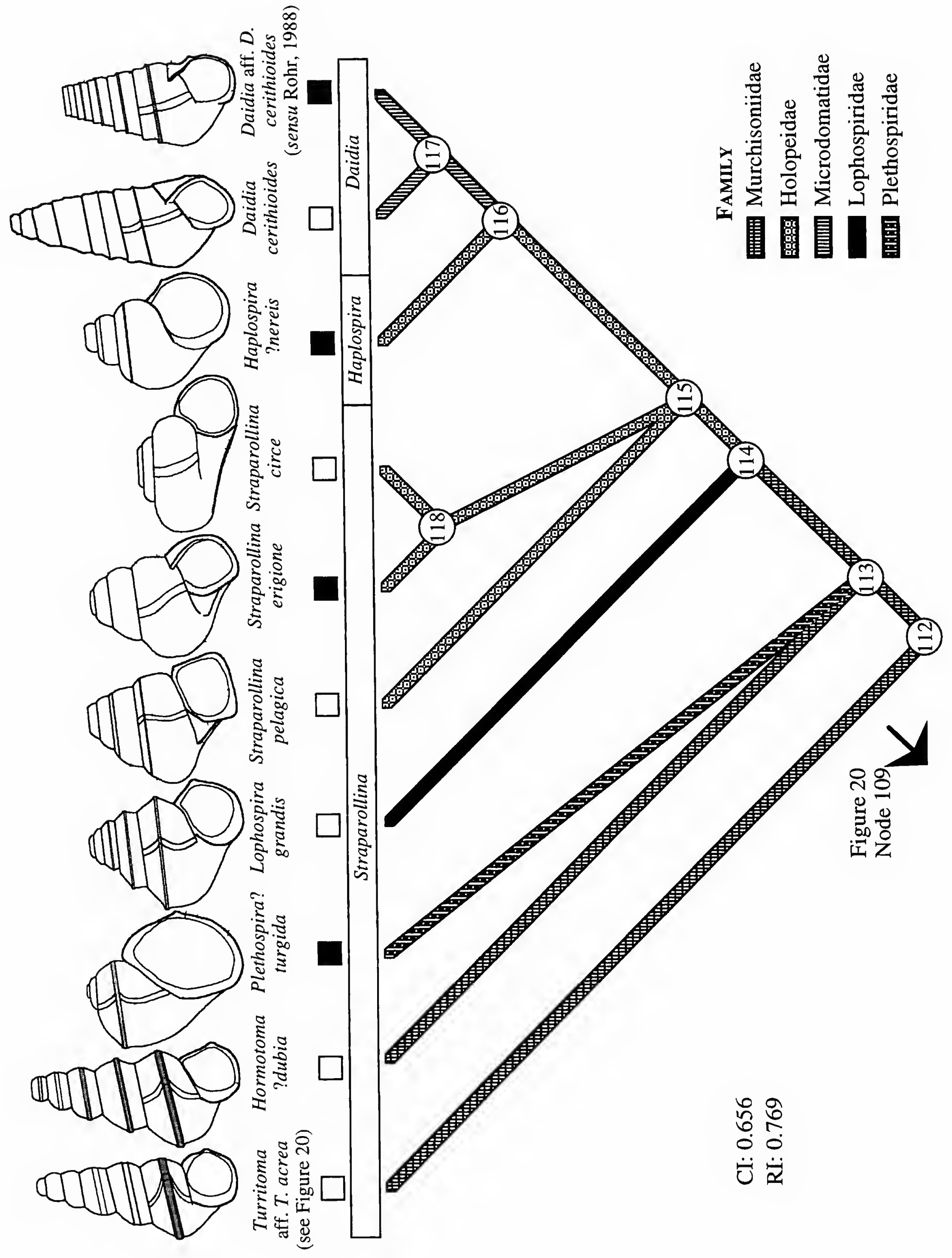


FIGURE 21 (opposite).-Relationships among the "straparollinoids." For abbreviations, see legend to Figure 7. Node 112 ("Straparollinoids"), increasing prominence of PB over ontogeny with ML developing $(27,40,47)$; asymmetric ramp shapes ( $R R$ flatter) (51-53); symmetric, moderately long ramps (54-56). Node 113 (Hormotoma dubia clade), narrow sinus (6, 7); PB width $=15^{\circ}(20)$; asymmetric aperture (left side broader) $(57,58)$. Node 114 , sinus angle $\approx 30^{\circ}$ $(3,4) ; \beta \approx 60^{\circ}(48)$; asymmetric ramp shapes (LR rounder than RR) $(51,52$, 72); very asymmetric aperture breadth (expanded right side, contracted left side) (57-59); loss of RR and LR swellings $(60,73)$; nonreflected IM (106); high K (123); high T (126). Node 115 (Straparollina pelagica clade), sinus angle $=10^{\circ}(3,4) ; \mathrm{PB}$ width $\approx 10^{\circ}(20)$; BL lost (21); highly asymmetric ramp lengths (RR extremely narrow, LR moderately long) (54-56); BC present (89); inclined aperture (109). Node 116 (Haplospira ?nereis clade), sinus lost (1); $\mathrm{PB}$ width $=05^{\circ}(20)$; nonprominent $\mathrm{PB}(33)$; IMlbase angle $=75^{\circ}(94)$; aperture contiguous with previous whorl (108); very low $\mathrm{E}$ (121); very high $\mathrm{K}$ (123). Node 117 (Daidia clade), concave RR (52); very asymmetric aperture breadth (left side much broader) $(58,59)$; RRC present (64); attenuated suture $(69,70)$; very high T (126). Node 118 (Straparollina erigione clade), PB lost (19); ACh lost (45); convex RR (52); moderate T (126).

with seemingly very "modern" synapomorphies (e.g., a siphon, no sinus or peripheral band, and an elongated aperture). These simplified morphologies leave subulitids with few obvious homologies with other gastropods. The distinctive twisted inner margin of the earliest subulitoids, however, which contributes to a weak siphon, also exists on Early Ordovician species typically classified as Hormotoma (Figure 22, nodes 120-123). The earliest known subulitoid (identified as Hormotoma sp. in Bridge and Cloud, 1947) co-existed with one of these species (H. zelleri Flower, 1968a), differing "only" in the absences of the peripheral band and the right side of the aperture. These early, sinus-bearing "subulitids" possess the asymmetric sinus and wide, weak, and swollen bilineate peripheral band diagnostic of the $H$. confusa clade. As noted above, the highly asymmetric aperture and sinus implies that the organs on the right side of the anus were reduced relative to those on the left side. Apogastropod-like species, such as Subulites Emmons, 1842, show this to an extreme, as the right side of the aperture is absent. For features involving the sinus, I did not code asymmetry as homologous among subulitids and other "hormotomoids" because the subulitids lack a sinus. The aperture of early subulitids, however, does curve backward (i.e., ophisthocyrt) to the suture, which could represent a remnant of the left side of the sinus.

Sinus-bearing, siphonate "subulitid" species (nodes 122 , 123) were not simply ephemeral intermediates, as some species (e.g., Hormotoma augustina (Billings, 1865), and H. bellicincta (Hall, 1847) existed into the late Caradoc (Late Ordovician). This subclade was never diverse, but its species were the dominant gastropod components of many Ordovician fossil assemblages.

"Subulitids" represent one of the few cases where the results of this analysis do not agree with any previous interpretation of gastropod phylogeny. Wenz (1938) linked subulitids to the raphistomatids, apparently deeming the asymmetric apertures and lack of a slit to be synapomorphies between the two taxa, and the apertural asymmetry of some raphistomatids to be a precursor to an apogastropod-like morphology. This analysis obviously suggests that "scalitines" and "subulitids" are only distant relatives. Others (e.g., Ulrich and Scofield, 1897; Knight et al., 1960) proposed that subulitids evolved from the Loxonematoidea, which many consider to be the earliest apogastropods (e.g., Haszprunar, 1988). This analysis suggests that loxonematoids and "subulitids" shared a Hormotoma-like ancestor (see discussion below), but that "subulitids" evolved long before the Loxonematoidea. Notably, this pattern also is consistent with the fossil record.

As noted above, Erwin (1992) considered the plethospirids to be the sister taxon of subulitids. The main synapomorphy between plethospirids and subulitids is the presence of a siphon. Although I scored the siphon as homologous among "plethospiroids" and "subulitids," more synapomorphies exist between "subulitids" and other "hormotomoids" than between "subulitids" and "plethospiroids." Therefore, this analysis suggests that "plethospiroid" and "subulitid" siphons are convergent.

Finally, this analysis suggests that the traditional definition of the Subulitoidea is polyphyletic, because some Silurian species (i.e., Auriptygma Perner, 1903, and Macrochilus Lindström, 1884) appear to have evolved from "hormotomoid" subclades other than "subulitids." These species are discussed further below.

\section{II.3.2. "CYRTOSTROPHIDS"}

The sister taxon of "subulitids" (Figures 23-26, nodes 124-154) is diagnosed by an extremely asymmetric sinus, with the left side being much deeper and much more strongly curved than the right side. Most of these species also have been classified in Hormotoma. I use that name to designate the more inclusive clade, so I refer to the subclade as "cyrtostrophids." Cyrtostropha Donald, 1912, is a Silurian genus that has not previously been used to label a higher taxon; Knight et al. (1960) even considered the genus to be a junior synonym of Murchisonia d'Archaic and de Verneuil in d'Archaic. Cyrtostropha retains many of the features that are plesiomorphic to node 131, so it is the most appropriate label available. Additional "cyrtostrophids" synapomorphies include a wide peripheral band with thin sharp lira, a round, relatively symmetric aperture, and a strongly reflected, L-shaped inner margin. Note that the inner margin is distinctly nonsiphonate.

Two major "cyrtostrophid" subclades evolved by the Middle Ordovician. These are discussed below. Smaller subclades appeared in the Late Ordovician and Early Silurian. One of these (Figure 23, node 126) includes Cyrtostropha coralli (Sowerby in Murchison, 1839) and is diagnosed by a sharp lirum in the middle of the right ramp. The second (Figure 23, nodes 127-130) includes species classified as Hormotoma and Catazone Perner. This clade is diagnosed by strongly asymmetrical ramp shapes and lengths (with the right ramp being flatter and much longer), somewhat reduced shell torque, and the periph- 


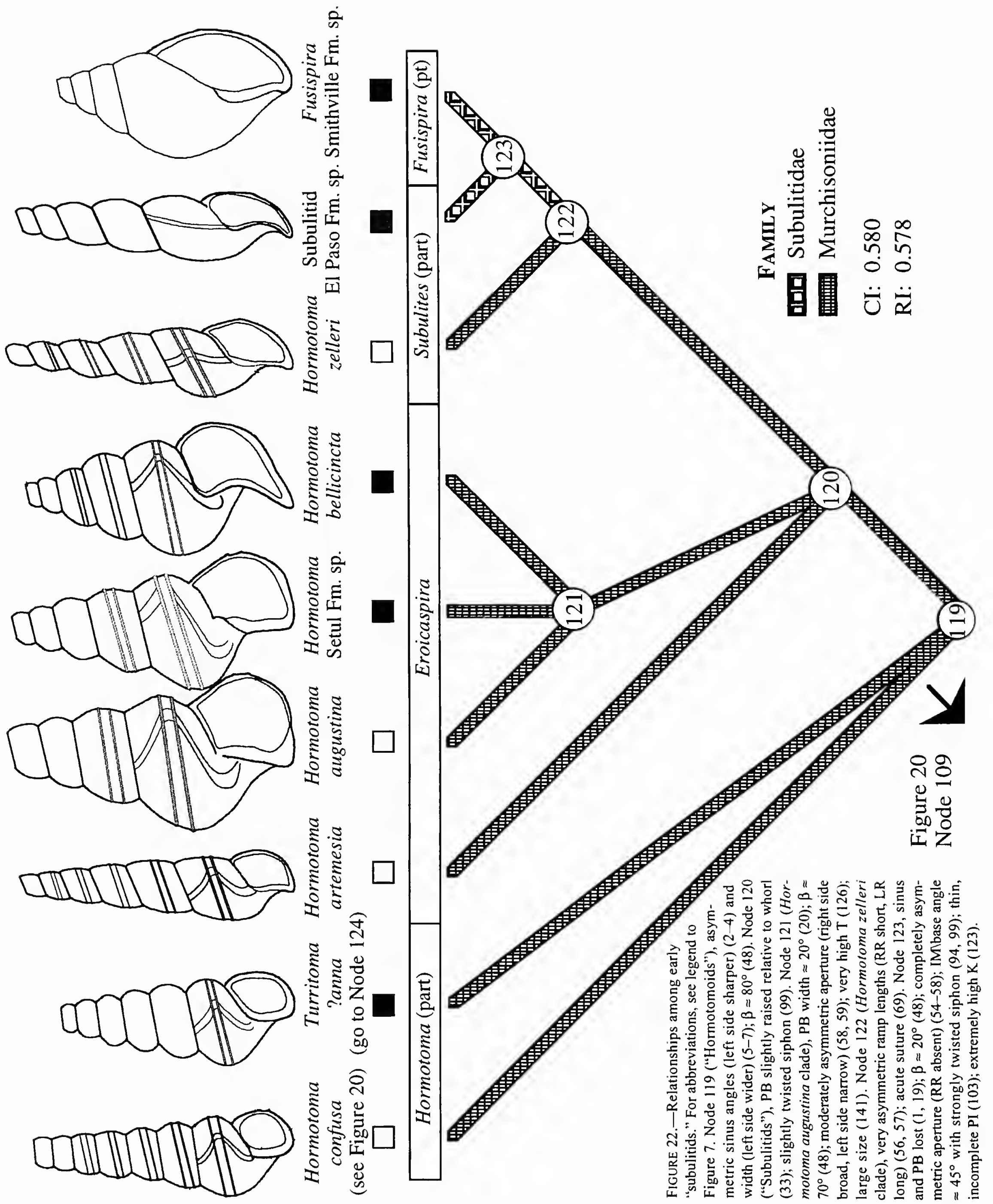




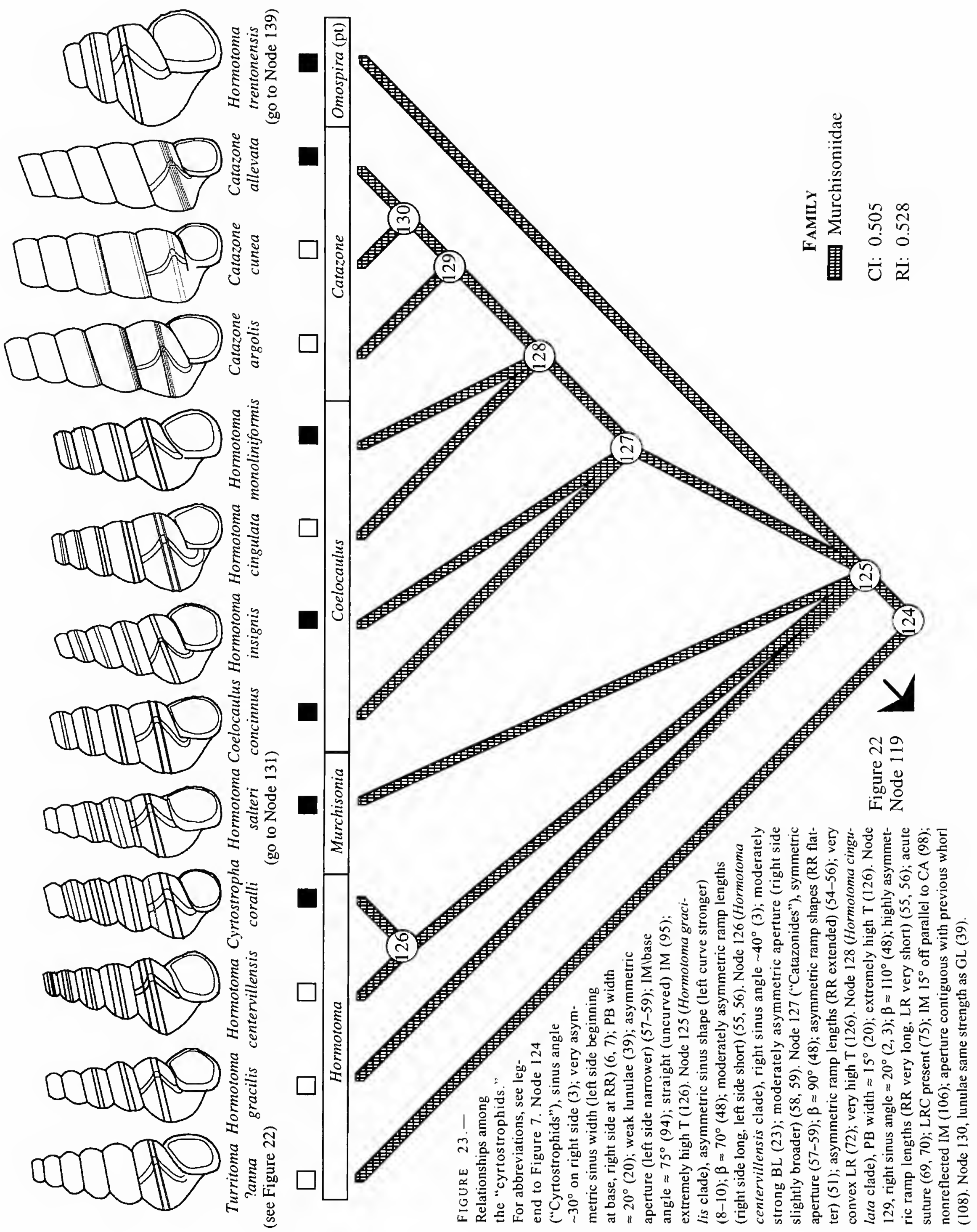


eral band being very low on the whorl. A more-derived subclade (Catazone; nodes 129, 130) share a reduced peripheral band, a slit, and an inner margin that is contiguous with the previous whorl rather than reflected.

II.3.2.1. "GONIOSTROPHINES".-One of the major "cyrtostrophid" subclades includes species classified in Murchisonia, Hormotoma, Goniostropha Oehlert, and Sinuspira Perner (Figure 24, nodes 131-138). The last genus is highly derived and not typical of the clade, so I label this clade the "goniostrophines." Synapomorphies of the clade include an asymmetric whorl shape, with a rounded left side and a flat or concave right side that culminates in an acute, attenuated suture. The clade is composed primarily of Silurian species. One Silurian subclade, the $H$. attenuata clade (node 138), is diagnosed by the loss of the peripheral lira that are primitive to "murchisoniinae." Species in another Silurian clade (the $H$. subplicata clade, nodes 132-137) possess very strong, sharp peripheral band lira, flat ramps, a more symmetrical shallower sinus, an acute suture, and an acute basal portion of the inner margin. The last feature becomes somewhat siphonate in the Donaldiella declivis clade (node 136), and a slit is present just under the suture on those species.

The definition of Murchisonia given by both Knight et al. (1960) and Wenz (1938) includes Goniostropha. The type species of Murchisonia, M. bilineata (Dechen in De la Beche, 1832 ) is known from the Middle Devonian, so it could not be included here. Murchisonia bilineata possesses Goniostropha synapomorphies, such as a wide peripheral band with strong lira and a reduced sinus, so extended analyses probably will support the shared opinion of Wenz and Knight et al. The latter authors also included Cyrtostropha within Murchisonia, but these results suggest that Cyrtostropha evolved independently from Hormotoma.

"Goniostrophines" (= Hormotoma salteri clade) include the only early Paleozoic species known to have had distinct protoconch morphologies. Unfortunately, the high-spired "cyrtostrophids" rarely preserve the apex. At least two species in the Hormotoma salteri clade (Sinuspira tenera Barrande in Perner, 1907, and Donaldiella declivis (Barrande in Perner, 1907)) possess large, planispiral protoconchs; however, an interesting implication of this analysis is that this distinctive protoconch morphology arose among some "cyrtostrophids" by the Middle Ordovician

II.3.2.2. "OMOSPIRINES".-The earliest members of the other major "cyrtostrophid" subclade (Figures 25, 26, nodes 139-154) include species classified in Omospira Ulrich in Ulrich and Scofield, so I refer to the clade as the "omospirines." "Omospirine" synapomorphies include increased shell expansion, reduced reflection and thickness of the inner margin, and a more symmetrical sinus. Omospira itself (node 139) is linked by a weaker peripheral band that is closer to the suture, a U-shaped sinus, and increased left to right asymmetry of the aperture.
Most previous authors considered Omospira as an aberrant raphistomatid (e.g., Knight et al., 1960), but this analysis corroborates Wenz's (1938) classification of Omospira as a murchisonioid. It also should be noted that the "omospirines" bear little resemblance to the definition of the Omospirinae given by Knight et al. (1960), which included putative Silurian Omospira and post-Silurian genera. This analysis suggests that none of the post-Caradoc (Middle-Late Ordovician) members of this clade retained Omospira-like morphologies. Instead, the other "omospirine" species closely match traditional definitions of the Loxonematoidea. Most workers (e.g., Ulrich and Scofield, 1897; Koken, 1898; Wenz, 1938; Knight et al., 1960; Erwin, 1990b) considered loxonematoids to be derived murchisonioids. This analysis corroborates that view, with the caveat that Omospira-like "murchisoniinae" species are intermediate between Loxonema and traditional murchisonioid species, such as Hormotoma gracilis (Hall, 1847).

Two "omospirine" subclades evolved during the Ordovician. One of these includes Loxonema, so I designate it the "loxonematides." This clade is discussed below. The sister clade (Figure 26, nodes 146-154) of the "loxonematides" is diagnosed by a very weak peripheral band and weak ornament. Previous workers placed these species in the Loxonematidae (e.g., Donald, 1905; Wenz, 1938; Knight et al., 1960), and this analysis suggests that they form a sister clade to the one including Loxonema. The genus Rhabdostropha Donald, 1905, appears to be typical of the group, so I refer to this clade as the "rhabdostrophides" for lack of a more appropriate name.

Synapomorphies of the "loxonematides" (Figure 25, nodes 142-145) include the loss of the peripheral band, a thick inductura, and a slightly flaring aperture. In the Loxonema beraultensis clade (Figure 25, node 145), the sinus becomes deeper and culminates close to the suture. This culminates in Diplozone crispa (Lindström, 1884), which has a siphonate base and a nearly slit-like sinus just under the suture.

The "rhabdostrophides" are diagnosed by an inner margin that is contiguous with previous whorls, anterior production of

FIGURE 24 (opposite).-Relationships among the "goniostrophines." For abbreviations, see legend to Figure 7. Node 125 (Hormotoma gracilis clade), asymmetric sinus shape (left curve stronger) (8-10); $\beta \approx 70^{\circ}$ (48); moderately asymmetric ramp lengths (right side long, left side short) $(55,56)$. Node 131 ("Goniostrophines"), duIl, wide ML present between BL (27); attenuated suture $(69,70)$. Node 132 (Hormotoma subplicata clade), sharp BL (22); slightly asymmetric aperture (right side broad, left side moderately broad) (58, 59). Node I33, fine, sharp GL (15); ML lost (27). Node 134 (Goniostropha cava clade), thin, incomplete PI (I03). Node 135 , left sinus angle $\approx 40^{\circ}(4) ; \beta \approx$ $90^{\circ}$ (48); long, asymmetric ramps (RR moderately long, LR long) $(55,56)$; flat LR (72). Node 136 (Murchisonia paradoxa clade), $\mathrm{PB}$ width $\approx 10^{\circ}(20)$; slit present (34); nonattenuated acute suture $(69,70)$; strong, sharp LRC present (75-77). Node 137 , very asymmetric ramp lengths (RR short, LR very long) $(56,57)$; very asymmetric aperture (right side extremely broad, left side narrow) $(58,59)$; IM $\backslash$ base angle $\approx 60^{\circ}$ (94). Node 138 (Hormotoma attenuata clade), fine, sharp GL (15); PB width $\approx 10^{\circ}(20)$; BL lost (21); IM $\backslash$ base angle $\approx$ $60^{\circ}(94)$; moderate size (141). 


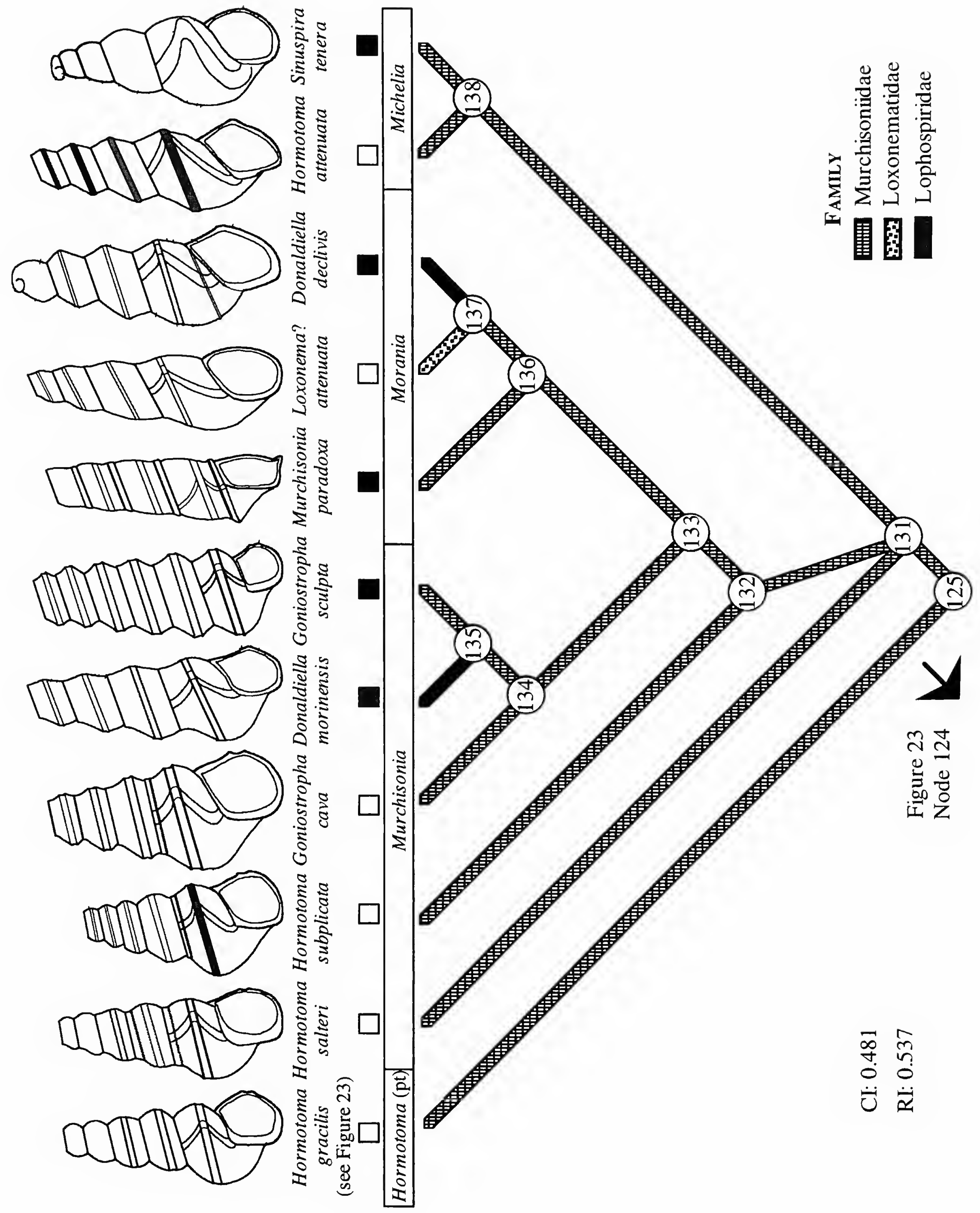




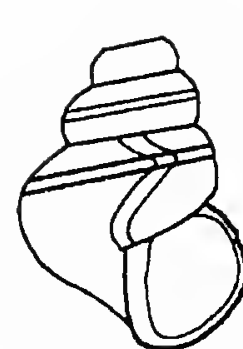

Hormotoma trentonensis (see Figure 23)
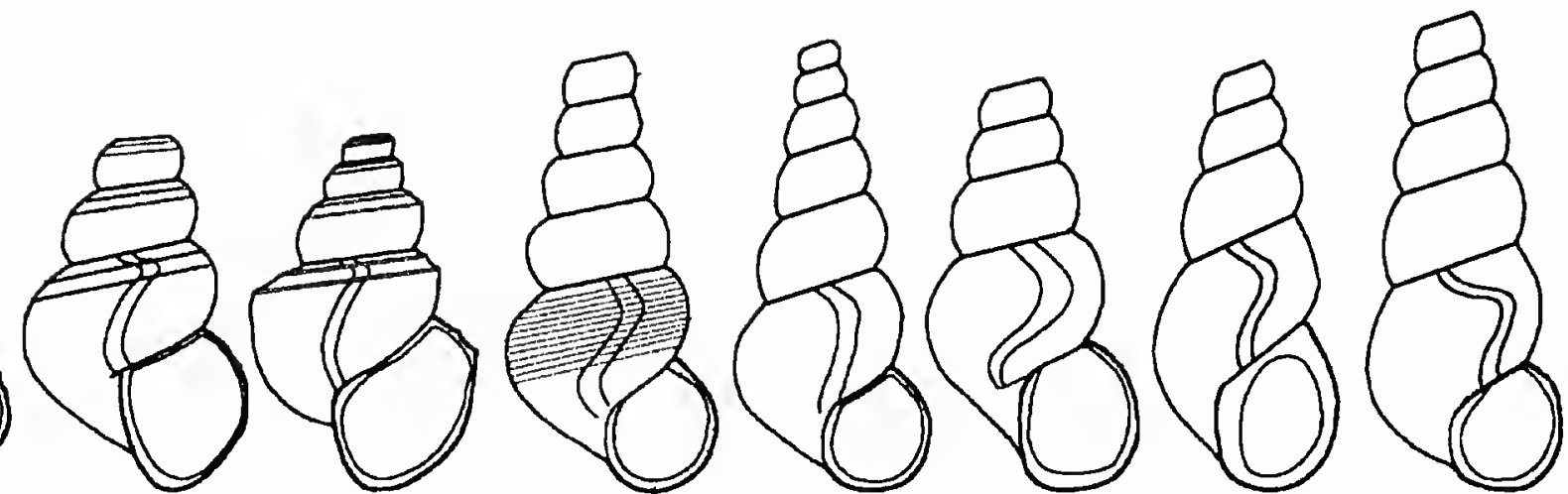

Loxonema beraultensis

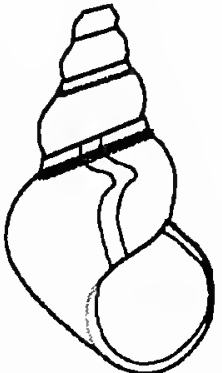

Diplozone crispa

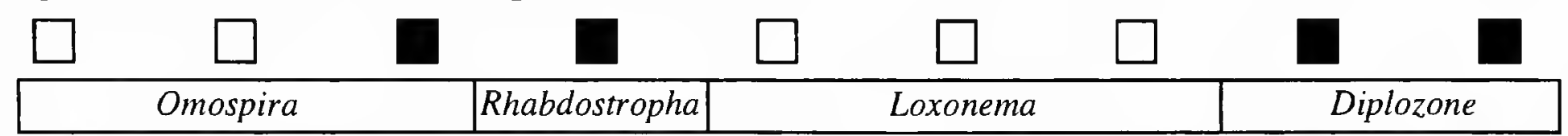

$\mathrm{CI}=0.773$

$\mathrm{RI}=0.781$

Figure 23

Node 125
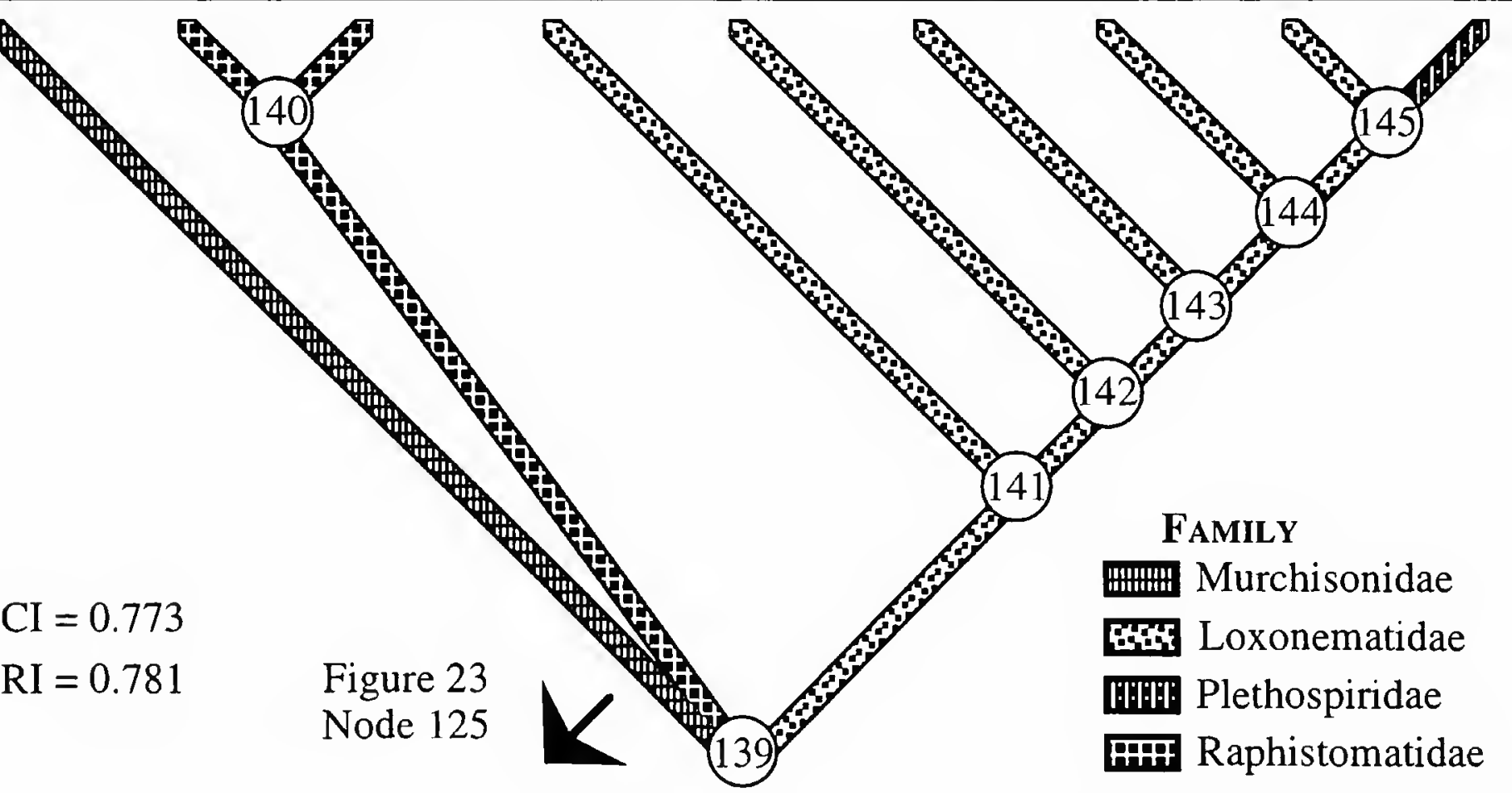

FiGURE 25.-Relationships among the "omospirines" and "loxonematides." For abbreviations, see legend to Figure 7. Node 139 ("Omospirines"), left sinus angle $-40^{\circ}$ (4); nonreflected $\mathrm{IM}(106)$; very high $\mathrm{T}$ increasing over ontogeny $(126,127)$. Node 140 (Omospira clade), $\beta \approx 50^{\circ}(48)$; very asymmetric ramp lengths (RR very short, LR long) $(55,56)$; large size (141). Node 141 (Rhabdostropha primitiva clade), left sinus begins at base of LR (7); nonthickened IM (87). Node 142 ("Loxonematides"), PB lost (19); very asymmetric ramp lengths (RR very short, LR very long) $(55,56)$; broad (asymmetric) aperture $(58,59)$; acute suture $(69)$; nonthickened $1 \mathrm{M}(87)$; arched $1 \mathrm{M}$ (95); Pl thickness same as rest of shell (103); weakly flaring aperture (105); very low E (121). Node 143, left side of sinus beginning near base of LR (7); fine, sharp GL (15); IM $15^{\circ}$ off parallel to CA (98). Node 144 (Loxonema sinuosa clade), sinus angle $\approx 30^{\circ}(3,4)$; $1 \mathrm{M}$ fills umbilicus (108). Node 145 (Loxonema beraultensis clade), sinus angle $\approx 40^{\circ}(3,4)$; symmetric sinus width $(5-7)$; attenuated suture $(69,70)$; strongly curved $1 \mathrm{M}(95)$; $1 \mathrm{M}$ contiguous with previous whorl (108); inclined aperture (109).

FIGURE 26 (opposite).-Relationships among the "rhabdostrophides." For abbreviations, see legend to Figure 7. Node 146 ("Rhabdostrophides"), nearly symmetric sinus angles $\approx 20^{\circ}(3,4)$; very weak $\mathrm{BL}(23)$; aperture contiguous with previous whorl (108); isometric T (127); sparse, fine ornament present (129-133). Node 147 (Girvania excavata clade), symmetric U-shaped sinus $(5-7,9,10)$; $\mathrm{PB}$ width $\approx 05^{\circ}(20)$; dense ornament $(130,134)$. Node 148 , very shallow sinus angles $\approx 20^{\circ}(3,4)$; fine, sharp GLs $(15)$; loss of RR omament (133). Node 149 (Holopella regularis clade), sinus angle $\approx 10^{\circ}(3,4)$; U-shaped sinus $(9,10)$. Node 150 (Kjerulfonema clade), sinus nearly absent $(3,4)$; thickened IM (87); extremely low E (121); strong ornamentation (129-137). Node
151 (Macrochilus buliminus clade), sinus nearly absent $(3,4) ; \beta \approx 30^{\circ}(48)$; highly asymmetric ramp lengths (RR highly contracted) $(55,56)$; thickened middle of IM (96); Pl absent (103). Node 152, extremely asymmetric ramp lengths (RR extremely contracted) $(55,56) ; 1 M \|$ to CA (98). Node 153, sinus lost (1); IM $\backslash$ base angle $\approx 45^{\circ}(94)$; straight $1 \mathrm{M}(95)$; IM reflected around umbilicus (106); open umbilicus (108). Node 154 (Stylonema clade), symmetric sinus width (5-7); $\beta \approx 70^{\circ}(48)$; slightly asymmetric, very broad aperture (very broad right side, broad left side) $(58,59)$; RR swelling present $(60)$; swollen base of LR (73); thin, incomplete P1 (103); IM contiguous with previous whorl (108); curved base (120); ormament throughout left side of aperture (129). 


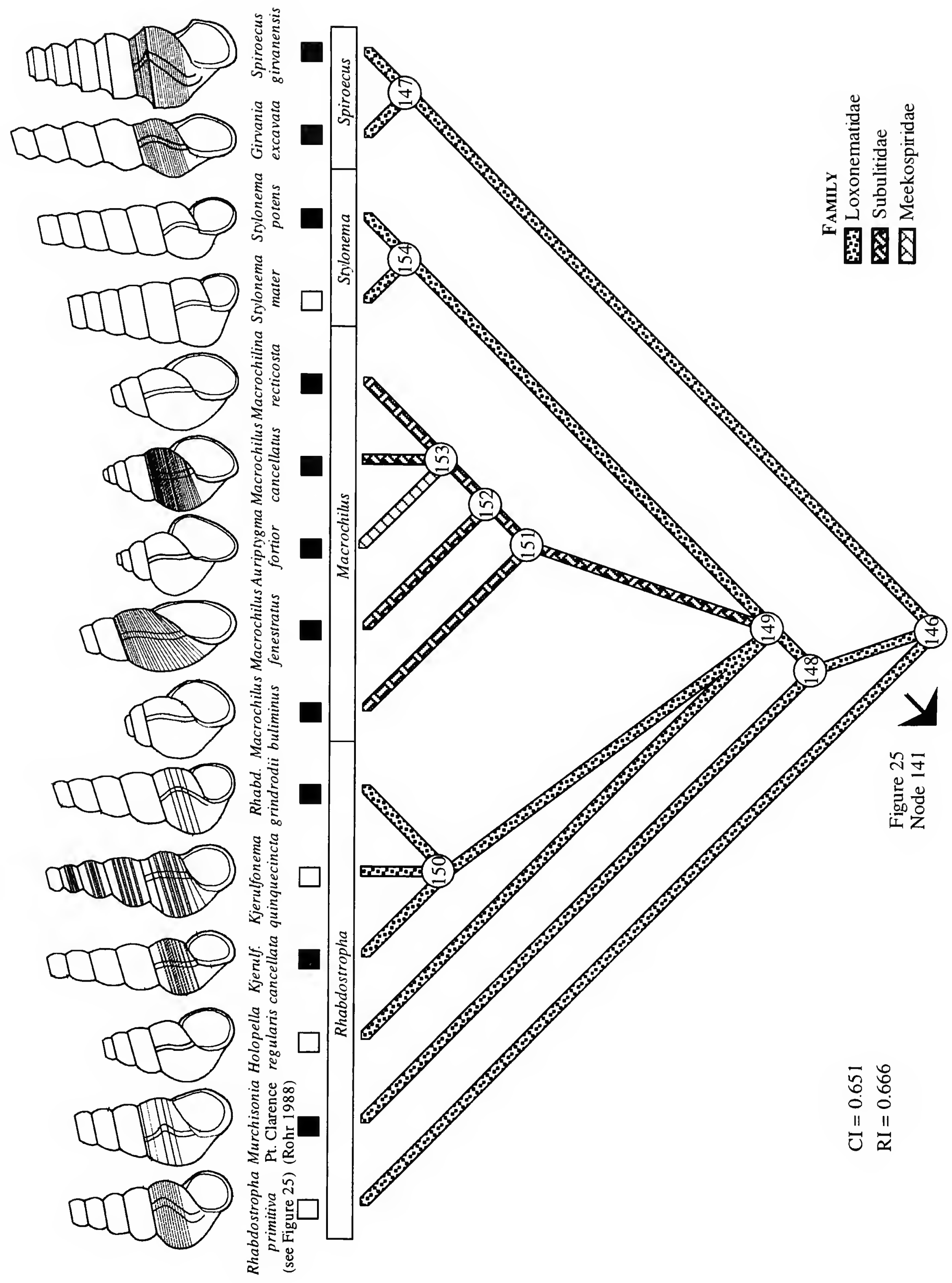


the aperture (e.g., Figure 3D), and well-developed ornamentation. Early species in this clade might retain a very weak bilineate peripheral band, but it is not clear whether the feature is a peripheral band or general ornament. Among more-derived species, such as the Holopella regularis clade (Figure 26, nodes 149-154), the sinus is extremely reduced and broadly $U$ shaped. Stylonema Perner, 1907 (Figure 26, node 154) is somewhat more divergent, possessing a curved base, a much rounder and slightly more asymmetric aperture, and marked swelling near the suture. Horny (1955) discussed the phylogenetic position of Stylonema, but only in general terms relative to Loxonema, so this exact estimate cannot be compared to that assessment. The most noteworthy subdivision within the $H$. regularis clade is the Macrochilus buliminus subclade (Figure 26 , nodes $151-153)$. This last subclade possesses a gross morphology that converges strongly on that of derived "subulitids" (see Figure 22, node 122). Synapomorphies include the near loss of the sinus (which is completely lost in the most derived species), a inner margin that is differentially thickened in the middle, the loss of the parietal inductura, and an extremely asymmetric aperture with the right side strongly reduced.

This analysis supports the commonly held view that the Loxonematoidea evolved from the Murchisonioidea (e.g., Wenz, 1938; Knight et al., 1960). I noted above that these results contradicted the proposal by Knight et al. (1960) that the Subulitoidea evolved from the Loxonematoidea. This study does suggest, however, that a clade of species classified in the Subulitoidea (i.e., the Macrochilus buliminus clade) did evolve from the "loxonematides." This corroborates Erwin's (1992) claim that traditional definitions of the Subulitoidea are polyphyletic.

In addition to the general suggestions about loxonematoid relationships, authors also have discussed more specific relationships of these species. As noted above, the idea of Knight et al. (1960) that Diplozone evolved among the Plethospiridae is rejected by this study. Their suggestion that both Holopella M'Coy, 1851, and Rhabdostropha are closely related to Loxonema is upheld, although this analysis indicates that the former genera belong to a different subclade than does Loxonema. The suggestion by Peel and Yochelson (1976) that the Silurian genus Kjerulfonema Peel and Yochelson is related to Girvania is supported herein.

\section{II.4. "Eotomarioids"}

Most of the taxa classified in the Pleurotomarioidea by Knight et al. (1960) form a major clade that includes species classified in the Eotomariidae, Gosseletinidae, Lophospiridae, Luciellidae, and Phanerotrematidae (Figures 27-35, nodes 155-215). This clade is similar to Ulrich and Scofield's definition of the Eotomarioidea, although their definition does include many "raphistomatids" (see above). "Eotomarioid" synapomorphies include a peripheral band with stronger, sharper lira and weak channels beneath those lira, a straight inner mar- gin, flatter ramps, and the loss of swellings on top of the ramps. The earliest species belonging to this clade fit the general description of Turritoma, which corroborates Ulrich and Scofield's (1897:1013) suggestion that eotomarioids evolved from Turritoma.

\section{II.4.1. "LOPHOSPIRIDS"}

"Eotomarioids" include two major subclades. One of these contains the Lophospiridae plus species assigned to the genera Solenospira Ulrich and Scofield, 1897, and Ectomaria Koken, 1896 (Figure 27, nodes 156-165). "Lophospirid" synapomorphies include flat to slightly concave right and left ramps, a strong lower ramp carina, a deep $V$-shaped sinus, and sharp threads on a bilineate peripheral band. An early appearing "lophospirid" subclade that includes several species classified as Solenospira and Ectomaria (node 160 and above) represents the sister taxon of traditional lophospirids. The primary synapomorphy of this subclade is an extremely wide peripheral band with very strong peripheral lira. Most workers considered Solenospira to be redundant with Ectomaria (e.g., Wenz, 1938; Knight et al., 1960), a view that this analysis supports. Those authors also considered Ectomaria to be a close relative of Hormotoma and other traditional murchisoniids, which this analysis contradicts.

Node 160 and its descendants represents the most diverse "archaeogastropod" clade of the Ordovician, including species classified as Arjamannia Peel, 1975a, Donaldiella Cossmann, 1903, Eunema Salter, 1859, Globonema Wenz, 1938, Gyronema Ulrich in Ulrich and Scofield, 1897, Longstaffia Cossmann, 1908, Lophospira Whitfield, 1886, Loxoplocus Fischer, 1885, Pagodospira Grabau, 1922, Proturritella Koken, 1889, Ptychozone Perner, 1907, Ruedemannia Foerste, 1914, Schizolopha Ulrich in Ulrich and Scofield, 1897, Trochonema Salter, 1859, and Trochonemella Okulitch, 1935. The primary synapomorphies of lophospirids are a trilineate peripheral band with a

FIGURE 27 (opposite).--Relationships among the "eotomarioids." For abbreviations, see legend to Figure 7. Node 155 ("Eotomarioids"), sharp, moderately strong BL $(22,23)$; LR swelling lost (73). Node 156 , flat ramps $(52,72)$. Node 157 ("Clathrospirids"), left side of sinus sharper and narrower than right (2-7); very asymmetric ramp lengths ( $R R$ very long, $L R$ short) $(55,56)$; left and right widths of aperture symmetrical (57-59). Node 158 ("Lophospirids"), weak GL (15); $\beta \approx 70^{\circ}$ (48); asymmetric ramp lengths (RR shorter) (54-57); RRC and LRC present $(64,75)$; both IM and base thickened (88); isometric T (127). Node 159 (Pagodospira cicelia clade), PB width $=15^{\circ}$ (20); ML present (27); $A C h$ present (45); asymmetric ramp shapes (RR more convex) $(52,53,72)$. Node 160 (Ectomaria adelina clade), $\mathrm{PB}$ width $\approx 30^{\circ}(20)$; extremely strong BL (23). Node 161, sharp, thread-like RRC and LRC $(66,76)$. Node 162 (Murchisonia callahanensis clade), sinus angle $=30^{\circ}(3,4)$; concave ramps $(52,72)$; RR becoming more concave over ontogeny $(53)$; very low $E(121)$; ontogenetically increasing expansion (122); high $\mathrm{K}$ (123); isometric $\mathrm{T}$ (127). Node 163 (Ectomaria pagada clade), moderately strong LRC (77). Node 164 (Ectomaria nieszkowskii clade), symmetric ramp lengths (54-56). Node 165 (Ectomaria prisca clade), RRC lost (64). 


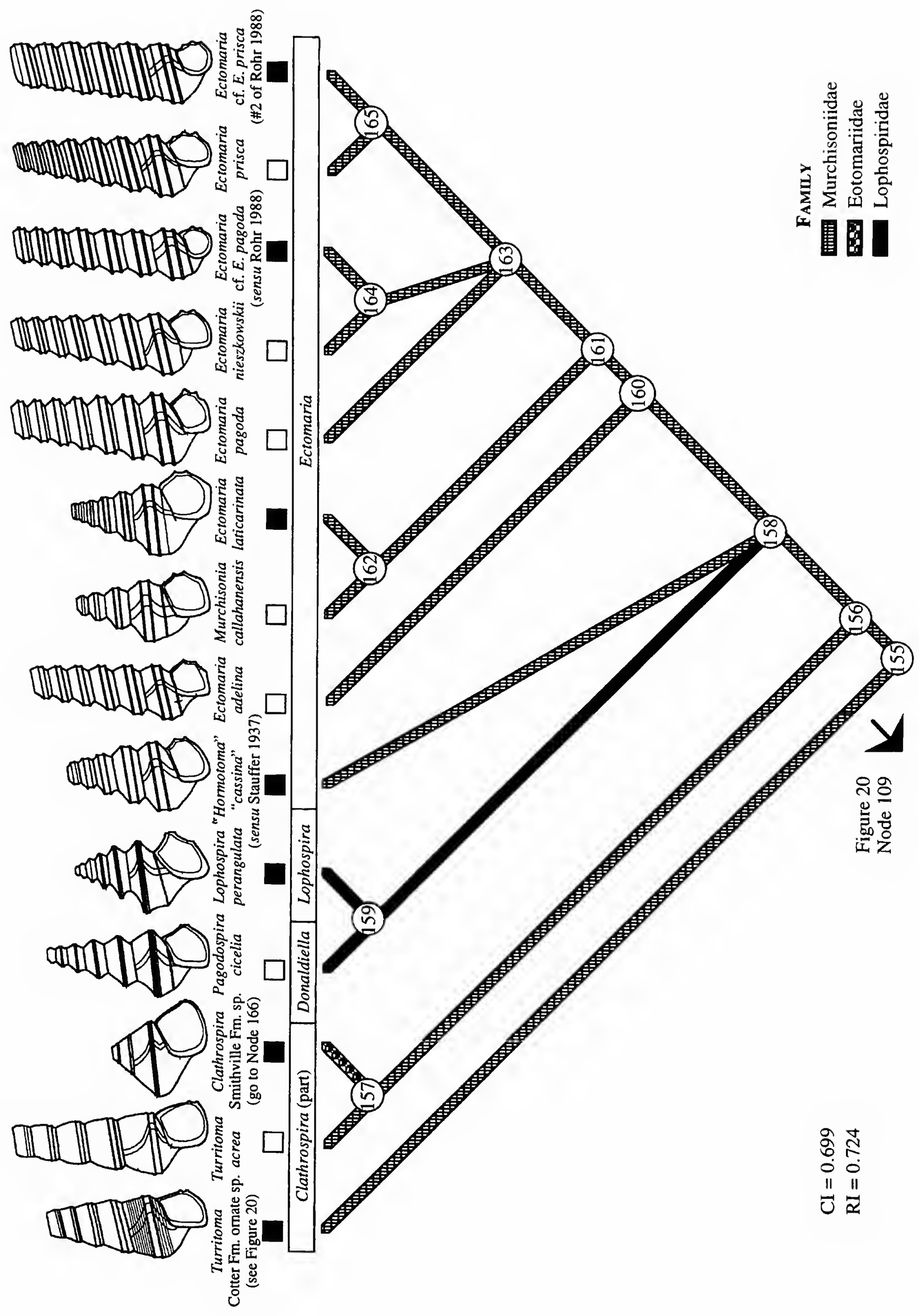


pronounced channel. The phylogenetics of this clade are discussed elsewhere (Wagner, 1990, 1995a, 1999).

\section{II.4.2. "CLATHROSPIRIDS"}

The second major "eotomarioid" subclade includes the remainder of the taxa previously classified in the Pleurotomarioidea (Figures 28-35, nodes 166-215). I designate the clade as "clathrospirids" because most of the earliest species have been classified in the genus Clathrospira. "Clathrospirid" synapomorphies include an extended right ramp, placement of the peripheral band partially on the right ramp, and an asymmetrical sinus with a wider, shallower right half.

Like the "raphistomatids," two early "clathrospirid" subclades existed in different biogeographic realms, with one primarily North American (Laurentian) and the second primarily Baltic; however, there is substantial biogeographic overlap between the two clades by the end of the Ordovician.

II.4.2.1. "LIOSPIRINES".- The Laurentian "clathrospirid" subclade includes species classified as Eotomaria, Liospira Ulrich and Scofield, and Paraliospira Rohr, with the first genus representing a paraphylum relative to the latter two (Figure 29 , nodes 172-181). I label this clade as the "liospirines," although the clade differs greatly from the definition of the Liospirinae sensu Knight et al. (1960). "Liospirine" synapomorphies include the projection of the inner margin at a high angle relative to the coiling axis (e.g., Figure $3 \mathrm{C}$ ), the presence of a channel under the peripheral band, and a dull carina on top of the right ramp, which fills the suture. Two "liospirine" subclades were moderately diverse during the Caradoc and Ashgill (Middle-Late Ordovician). One includes true Liospira (Figure 29, nodes 174-177). Liospira synapomorphies include a thickened inner margin, very weak threads on the peripheral band, a shallower, more symmetric sinus, isometric translation (in contrast to the increasing translation shown over the ontogeny by more plesiomorphic members of the clade), and the filling of the umbilicus by the inner margin and an extended inductura. The last features suggest that in life Liospira wore their shells like caps on top of the body rather than carrying them by the aperture. A slit does not diagnose the clade, but it is present on the most derived species.

The second "liospirine" clade includes species assigned by Rohr (1980) to Paraliospira (Figure 29, nodes 178-181). Paraliospira synapomorphies include very strong squareshaped peripheral band lira, a very shallow right side of the sinus, and a nearly planispiral, widely umbilicate form produced by very low curvature and translation. In addition, the base is projected much further in front of the inner margin. More-derived species (i.e., the $P$. mundula clade) have much stronger channels beneath the peripheral band, a channeled carina on top of the right ramp, a dull, channeled left carina, and a more symmetrical sinus. It is noteworthy that this clade includes $L i$ ospira larvata (Salter, 1859) and Eotomaria supracingulata Ulrich and Scofield, 1897, as this substantiates Ulrich and
Scofield's (1897) suggestion that those species are closely related to $P$. mundula (Ulrich and Scofield, 1897), P. angulata (Ulrich and Scofield, 1897), and their allies (which Ulrich and Scofield tentatively placed in Liospira).

Ambiguity about character-state polarity affects the exact clade structure within the L. larvata clade. Paraliospira mun$d u l a$ and $P$. rugata (Ulrich and Scofield, 1897) share a very thick inner margin that is folded back into the umbilicus to form a funicle. This feature obscures the inner margin and makes it impossible to determine if an inner margin lirum is present or absent. To be more exact, if the feature was present, then it would be obliterated by the umbilicus. If the feature is assumed to be absent, the best reconstruction is to link $P$. angulata to the Eotomaria rupestris clade. This reconstruction is supported by the fact that some specimens of $P$. mundula lacking funicles (owing either to intraspecific variation or differences in taphonomy) lack the lirum, suggesting that the feature is actually absent.

This analysis supports the idea that Liospira and allies are closely related to Eotomaria, which was the opinion of Ulrich and Scofield (1897) and Wenz (1938). The analysis strongly differs from the views of Knight et al. (1960) in two ways. First, those authors considered the Liospirinae to be a subdivision of the Raphistomatidae. There are strong similarities between some "raphistomatids" (e.g., Pararaphistoma) and Liospira. In fact, the widely distributed and somewhat variable species $P$. qualteriata appears to have been classified as Liospira by some authors (e.g., Longstaff, 1924). Only the most derived Liospira species, such as L. micula (Hall in Hall and Whitney, 1862), display "lesueurilline" synapomorphies. Linking these species directly (i.e., so that $L$. micula is considered a plesiomorphic member of Liospira or so that L. micula is removed from the "liospirines" to the "lesueurillines") also invokes statistically significant stratigraphic gaps (see Appendix 3).

The second difference between these results and the taxonomy of Knight et al. (1960) is that those authors included postOrdovician species in the Liospirinae. Although Liospira commonly is reported from Silurian strata (e.g., Peel, 1977), this analysis found no Silurian "liospirines." This might be due to the poor preservation of the relevant specimens, as several of the important synapomorphies (e.g., peripheral band type and

FIGURE 28 (opposite).-Relationships among basal "clathrospirids." For abbreviations, see legend to Figure 7 . Node $166, \mathrm{~PB}$ width $\approx 15^{\circ}(20)$; slightly prominent PB (33); left side of aperture inclined $-20^{\circ}(111,112)$; base projected anteriorly $\sim 20^{\circ}(118,119)$; moderate $\mathrm{E}(121)$; moderate $\mathrm{K}$ (123); high T (126). Node 167 (Clathrospira ?trochiformis clade), $\beta \approx 80^{\circ}$ (48); both IM and base thickened (88). Node 168 (Clathrospira euconica clade), symmetric sinus depth (2), ACh lost (45); asymmetric aperture (RR wider than LR) (57-59); $\mathrm{RRC}$ present (64). Node 169 (Clathrospira inflata clade), sinus angle $-60^{\circ}$ on left side (4); asymmetric aperture (RR much wider than LR) (57-59); moderately convex whorls $(52,72)$. Node 170 (Mourlonia mjoela + Eotomaria convexa), narrow PB with moderately strong PL $(20,23)$; very convex whorls (52, 72); IM $15^{\circ}$ off parallel to CA (98); moderate size (141). 


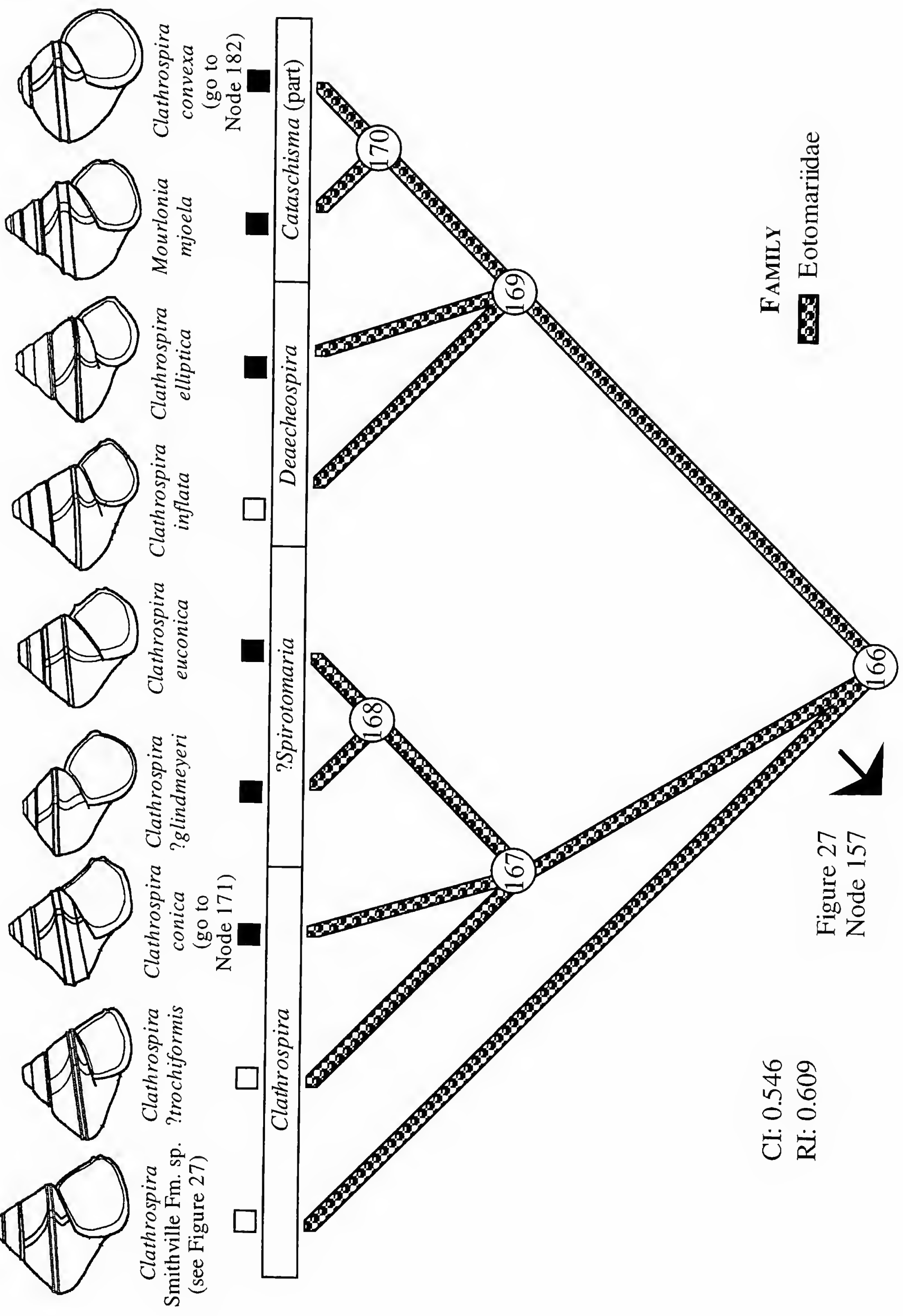




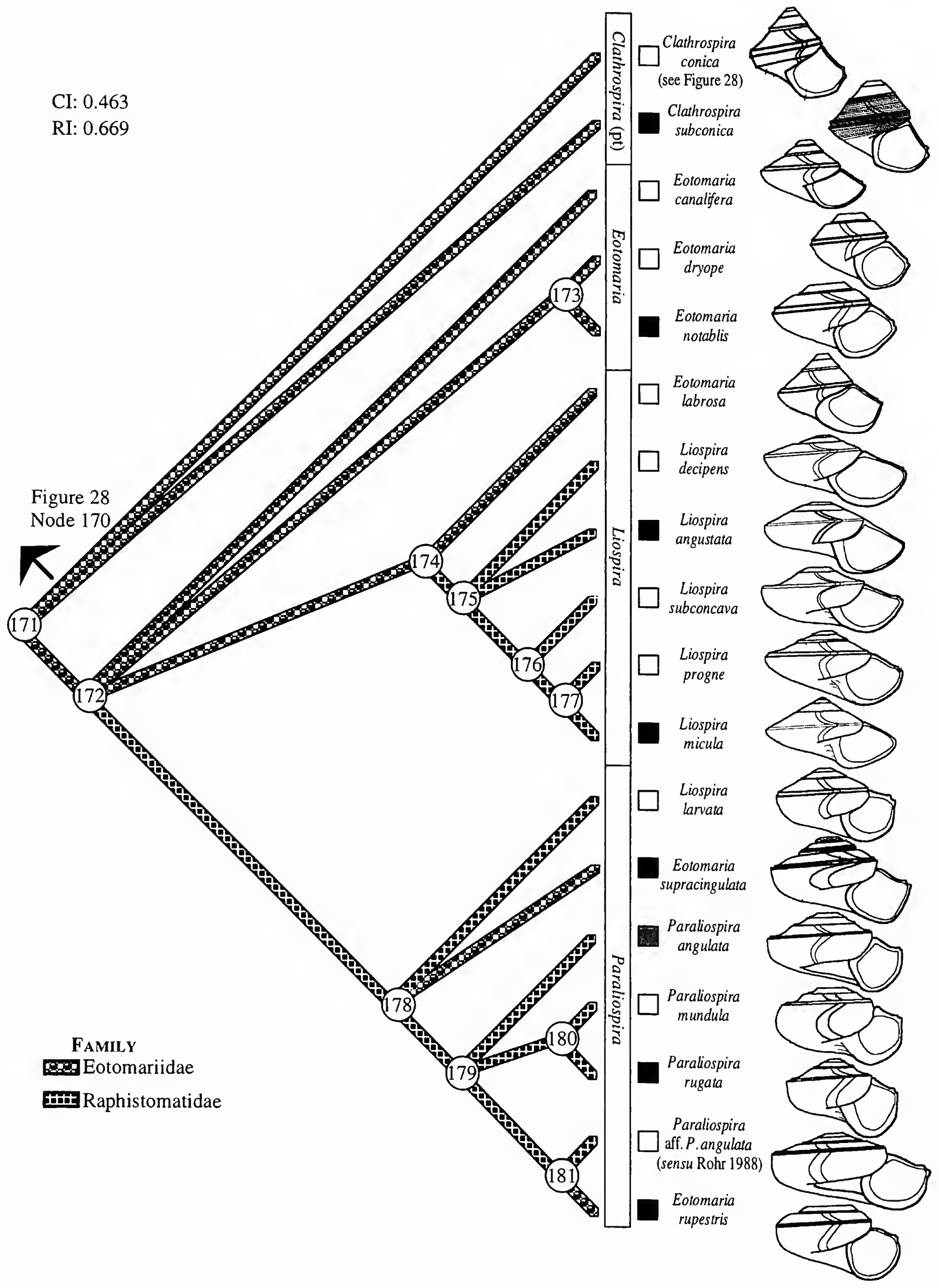


FIGURE 29 (opposite).-Relationships among the "liospirines." For abbreviations, see legend to Figure 7. Node 171 ("Liospirines"), thick, squared BL (22); thin, complete Pl (I03). Node 172 (Eotomaria canalifera clade), left angle of sinus sharper (6-8); asymmetric aperture (RR wider than LR) (57-59); RRC present (64); IM at $-45^{\circ}$ to CA (98); moderate T (126). Node 173 (Eotomaria dryope clade), very asymmetric aperture (contracted left side); weak, round RRC filling suture (65); dull, thick LRC present (75); 1M $-15^{\circ}$ off parallel to CA (98); left side of aperture inclined $\sim 10^{\circ}(112)$. Node 174 (Eotomaria labrosa clade), $\mathrm{PB}$ width $=10^{\circ}(20)$; moderately strong, sharp BL (23); asymmetric ramp shapes (LR rounder) (51); middle of IM very thick $(87,96) ; 1 M$ extended and folded back into umbilicus (108); base projected anteriorly $-30^{\circ}$ (119); moderate $\mathrm{E}$ (I21); decrease in T over ontogeny (127). Node 175 (Liospira), symmetric sinus width (5-7); weak GL (15); PB largely on RR (43); ACh lost (45); nearly symmetric, narrow aperture $(58,59)$; weak $R R C$ (65); no ontogenetic change in RRC strength (67); $1 \mathrm{M} \backslash$ base angle $=105^{\circ}$ (94); left side of aperture inclined $-10^{\circ}(112)$. Node 176 , symmetric sinus curvature (8-10); extremely weak BL (23); PI projecting in front of aperture (104); funicle present (107); base projected anteriorly $-50^{\circ}$ (119). Node 177 , slit present (34); left and right widths of aperture symmetrical (57-59); uniformly thick $1 \mathrm{M}(87,96)$. Node 178 (Liospira larvata clade), asymmetric sinus shape (left side much sharper) (8-10); strong GL (15); strong ACh (46); $\beta=60^{\circ}$ (48); asymmetric aperture (right side contracted) (57-59); IM $\backslash$ base angle $\approx 105^{\circ}(94)$; top and bottom of $1 \mathrm{M}$ thicker (96); left side of aperture inclined $-30^{\circ}$ (I12); base projected anteriorly $-40^{\circ}$ (119); low T (126); isometric T (127); small size (14I). Node 179 (Paraliospira angulata clade), very asymmetric sinus widths (right side narrowed) (5-7); RR becoming more concave over ontogeny (53); very asymmetric ramp lengths (RR long, LR short) $(55,56)$; RRC rounded and channeled with no ontogenetic change in RRC strength (66-68); LRC present (75); BC present (89); IM projected $30^{\circ}$ relative to CA (98). Node I 80 (Paraliospira mundula clade), $\mathrm{PB}$ width $\approx 20^{\circ}$ (20); strong RRC (65); very thick IM (87); IM extended and folded back into umbilicus (108). Node 181 (Eotomaria rupestris clade), clockwise rotation of aperture over ontogeny $(49)$; convex ramps $(52,72)$; left side of aperture inclined $\sim 10^{\circ}(112)$.

orientation, and sinus shape) are visible only on well-preserved Liospira. The filling of the umbilicus by the shell produces a dense, easily preserved core, which is unknown from Silurian strata. The Late Silurian species, L. marklandensis McLearn, 1924, however, possesses a right ramp, peripheral band, and slit similar to that of $L$. micula, with a funicle (i.e., shell material plugging the umbilicus) being a variable feature. Therefore, it is possible that the clade survived the end-Ordovician extinction.

Baltic "liospirines" are not well known, although two species (Eotomaria notablis Eichenwald, 1859, and Eotomaria rupestris Koken, 1925) are included herein. These species do not appear to have been closely related, suggesting that they represent separate incursions into Baltica by a primarily Laurentian clade. This finding corroborates Koken's assessment of gastropod phylogeny, which separated the "notablis" group from the "rupestris" group (Koken, 1925:190-194). Koken, however, derived Stenoloron from the latter group. Although there are possible synapomorphies linking Stenoloron to some Paraliospira species (especially involving the thin but strong bilineate peripheral band), Early Silurian Stenoloron species appear to share more characters with another "clathrospirid" clade (see discussion below). Thus, it appears that a
"Stenoloron" morphology is grossly convergent between two distantly related "clathrospirid" clades.

II.4.2.2. "BRACHYTOMARIINES".--The Baltic "clathrospirids" include most of the Ordovician and Silurian taxa classified in the Gosseletinidae, Luciellidae, and Phanerotrematidae, as well as most of the non-Laurentian taxa classified in the Eotomariidae (Figures 28, 30-35, nodes 169, 170, 182-215). The earliest clear members best fit descriptions of the genus Brachytomaria Koken, so I refer to the clade as the "brachytomariines." The clade appears to have been derived from Baltic species classified as Clathrospira, being united by characters including convex whorls (especially in comparison with Clathrospira from the Early Ordovician of Laurentia) and a peripheral band with only moderately strong lira that bisects the right and left ramps (rather than sloping onto the right ramp as on Clathrospira from the Early Ordovician of Laurentia). The biogeographic affinities of the clade are nearly opposite those of the "liospirines," with most species known from Baltica and a few incursions into Laurentia. It appears that all Silurian "eotomarioids" are "brachytomariines."

Relationships among the major "brachytomariine" subclades are among the most difficult to assess. The phylogenetic interpretation accepted herein suggests that the "brachytomariines" began diversifying during the Late Ordovician (i.e., late Caradoc and Ashgill), even though many of the subclades do not appear in the fossil record until the Silurian. Unfortunately, sampling is very poor for the latest Ordovician and Early Silurian, which is an interval of importance here. Thus, a greater number than usual of intermediate species probably are excluded from the analyses of these species. Consequently, better sampling of the Llandovery (Early Silurian) might easily result in different estimates about basic relationships among "brachytomariines." The probable outcome of such changes will be to decrease the apparent intensity of pre-Silurian diversification and to increase the apparent intensity of Early Silurian evolution.

II.4.2.2.1. "?Palaeoschismides".-One "brachytomariine" clade is confined almost exclusively to the Ordovician (Figures 30,31 , nodes 188,189 ). This clade includes species classified in a potpourri of eotomariid genera. One of the important plesiomorphic species in the clade, "Bembexia" globosa Longstaff, 1924, certainly does not belong to the Devonian genus, and it might have some affinities with Palaeoschisma Longstaff, 1924. Unfortunately, Palaeoschisma is known from only a single specimen of the species $P$. girvanensis Longstaff, 1924, and that specimen was too incomplete to include in this analysis. Thus, this suggestion is highly tentative at best. Some of these species have been linked with Bembexia Oehlert, 1888; however, that genus sensu stricto first appears in the Early Devonian and those species appear to have affinities with other "eotomarioids." All the other genus names have been used to label other clades, so I refer to this clade as the "?palaeoschismides." Synapomorphies of this clade include a strongly developed carina on the upper ramp and a very asymmetrical 


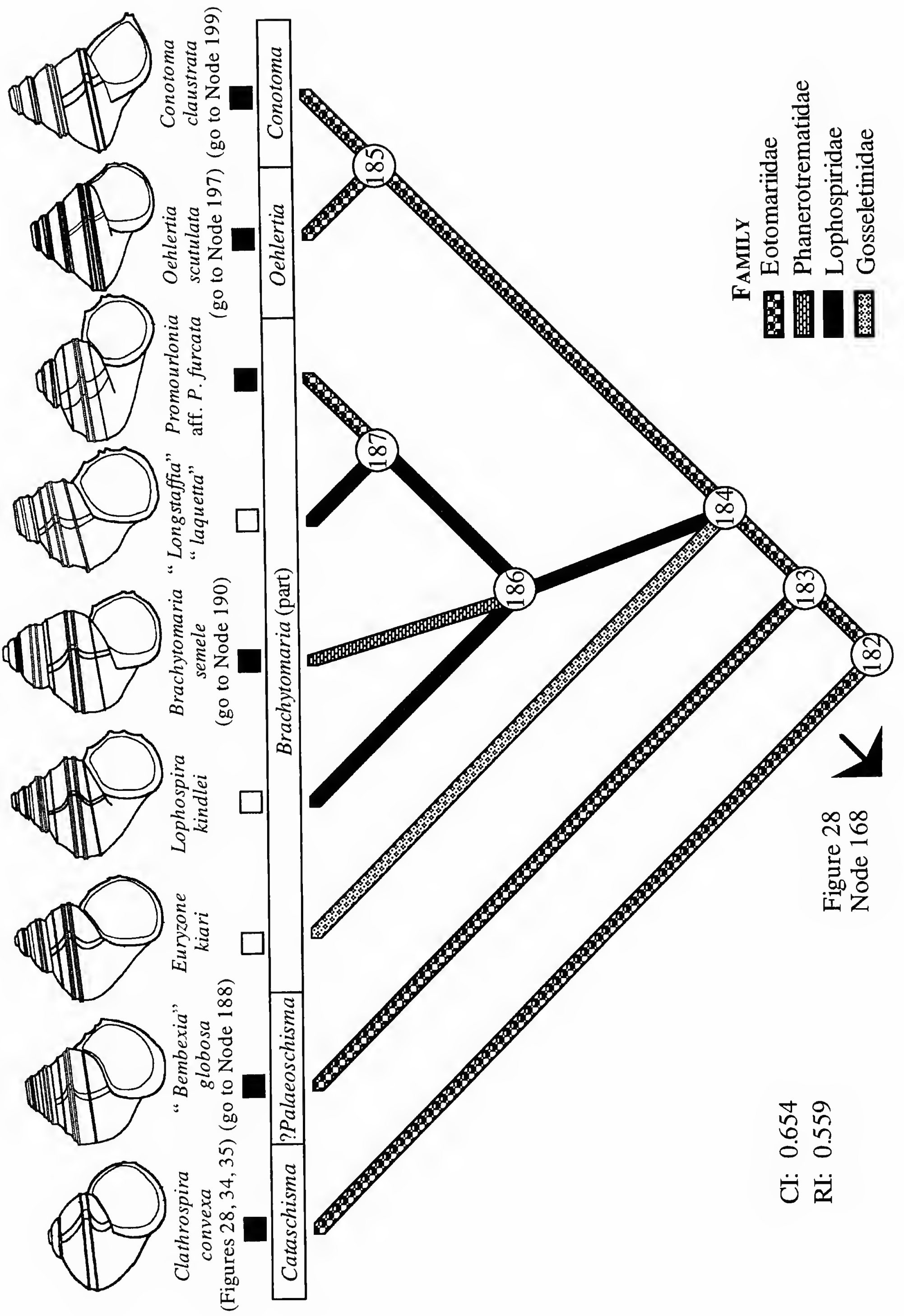


FigURE 30 (opposite).-Relationships among basal "brachytomariines." For abbreviations, see legend to Figure 7. Node 182 ("Brachytomariines"), sinus angle $-30^{\circ}$ on right side (3); PB bisects aperture (43); ACh lost (45); arched IM (95); right side of aperture inclined (113); base projected anteriorly $-10^{\circ}$ (119). Node 183 , right sinus angle $-20^{\circ}(3) ; \beta=70^{\circ}(48)$; asymmetric aperture (RR wider than LR) (57-59); RRC present (64); IM \| to CA (98). Node 184 (Euryzone kiari clade), convex RR and LR $(52,72)$. Node 185 ("Luciellides"), very narrow $\mathrm{PB}(6,7)$; extremely asymmetric ramp lengths (RR extremely long, LR very short) $(55,56)$; ormament throughout left side of aperture (129); omament on RR (133). Node 186 ("Phanerotrematides"), symmetric sinus width (5-7); strong GL (15); symmetric ramp widths (54-56); LRC present (75). Node 187 ("Longstaffia" "laquetta" clade), narrow sinus $(6,7) ; \mathrm{PB}$ width $\approx 10^{\circ}(20)$; $\beta \approx 60^{\circ}$ (48); asymmetric ramp shapes (RR flatter) (51); RR shortcr than LR (54-56); strong RRC (65); strong LRC (77); moderate E (121); large size (141).

aperture with a reduced left side. Some of the more-derived species (node 187) are highly asymmetrical, with the peripheral band much closer to the suture and the inner margin extended and siphon-like. This line of morphologic evolution is particularly interesting because it converges on the asymmetric morphologies seen in "plethospiroids," some "scalitines," and various "hormotomoids."

II.4.2.2.2. "Phanerotrematides".-Another major "brachytomariine" subclade (Figures 30, 32, nodes 186, 187, 190-196) closely matches the Phanerotrematidae as defined by Knight et al. (1960) and later authors (e.g., Peel, 1984b). Synapomorphies of "phanerotrematides" include a narrow, symmetrically shaped sinus and apertures, very strong growth lines, and a prominent carina on the lower ramp.

The stem species, all classified as Brachytomaria, are known from the Late Ordovician, but the primary subclades appear in the Silurian. One "phanerotrematide" subclade includes Silurian species with prominent right ramp and alveozone carinae (Figure 30, node 187), reminiscent of Ordovician Brachy-

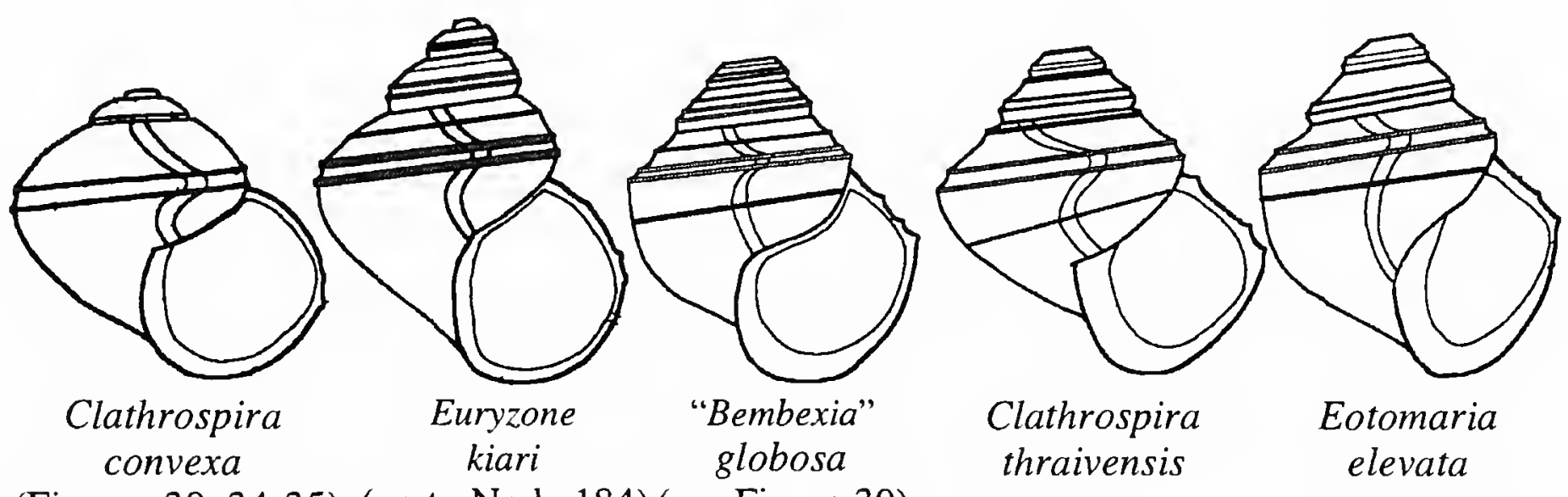

(Figures 30, 34-35) (go to Node 184) (see Figure 30)

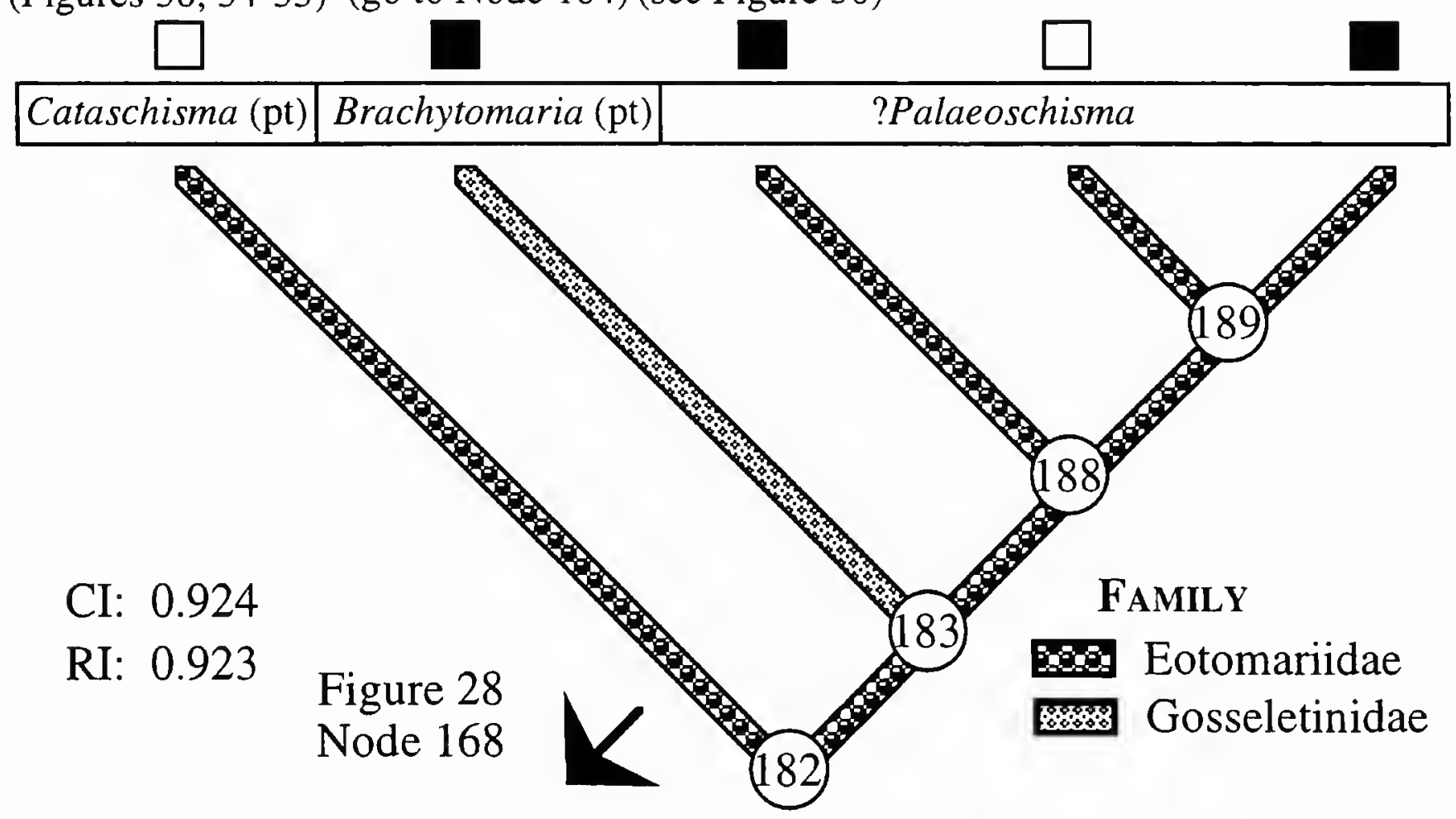

FIGURE 31.-Relationships among the "?palaeoschismides." For abbreviations, see legend to Figure 7. Node 182 ("Brachytomariines"), sinus angle $-30^{\circ}$ on right side (3); PB bisects aperture (43); ACh lost (45); arched IM (95); right side of aperture inclined (113); base projected anteriorly $\sim 10^{\circ}$ (119). Node 183 , right sinus angle $-20^{\circ}(3) ; \beta=70^{\circ}$ (48); asymmetric aperture (RR wider than LR) (57-59); RRC present (64); IM \| to CA (98). Node 188 ("?Palaeoschismides"), asymmetric sinus (left side wider) (5); moderately strong BL (23); PB entirely on RR (43); $\beta \approx 60^{\circ}$ (48); asymmetric ramp shapes (RR flatter) (51); asymmetric ramp lengths (RR contracted) (54-57). Node 189 (Eotomaria elevata + Clathrospira thraivensis), right sinus angle $-35^{\circ}(3)$; nonprominent PB (33); concave RR (52); moderately asymmetric aperture (broad right side, narrow left side) $(58,59)$; sharp, thread-like RRC $(66)$; acute suture $(69,70)$; LRC present (75); 1M lbase angle $\approx 75^{\circ}(94)$; P1 lost (103); IM fills umbilicus (108); small size (141). 
tomaria species. Additional synapomorphies include flatter and wider right ramps, and inclination of the entire aperture. The clade includes species assigned to Promourlonia Longstaff, 1924, which Knight et al. (1960) considered to be a junior synonym of Mourlonia de Konick, 1883. This analysis implies that the two taxa are not closely related.

Another "phanerotrematide" subclade includes species classified in Phanerotrema Fischer, 1885, and Ulrichospira Donald, 1905 (Figure 32, nodes 193-196). The primary character linking this clade is the presence of a slit within the peripheral band. The aperture of these species also is more asymmetric than on Brachytomaria species, which is a feature that becomes very pronounced on some derived Phanerotrema (e.g., node 195). That, coupled with the extended, nearly siphonate inner margin, represents another parallel development of the asymmetric morphology discussed above.

II.4.2.2.3. "Luciellides".-Perhaps the most problematic "brachytomariine" subclade includes all of the Silurian species classified in the Luciellidae (Figures 30, 33, nodes 185, 197-201). "Luciellide" species share extremely narrow, very asymmetrical sinuses and well-developed ornament. The results indicate that two "luciellide" subclades evolved by the late Llandovery (Early Silurian). One of these includes species of Oehlertia Perner, 1907 (Figure 33, nodes 197, 198). These species possess strong swellings on either side of the peripheral band, straight lunulae, and a slit bordered by very strong lira that is within a much broader peripheral band. The final set of features are illustrated in Figure 4E. The sister group of Oehlertia is the Conotoma claustrata clade (Figure 33, nodes 199-201), whose synapomorphies are a greatly extended right ramp, a peripheral band very low on the whorl, and frill-like peripheral band lira with the upper lirum noticeably stronger than the lower one. More-derived species of the Crenilunula hallei clade (nodes 200,201 ) have the peripheral band lira developed into a small frill. In addition, species within this clade possess a slit that produced unusual zipper-shaped lunulae.

Linking Crenilunula Knight, 1945, to Prosolarium Perner, 1907, is consistent with the opinion of Linsley et al. (1978) that Crenilunula is related to the Luciellidae rather than to Euomphalopterus (Knight et al., 1960). This analysis also supports Flower's (1968a) and Linsley et al.'s suggestions that the Early Ordovician Rhombella (Figure 8, node 3 ) is not closely related to the Luciellidae.

Neither the estimates of the relationships between the two "luciellide" subclades nor the hypothesized relationship of "luciellides" to other "brachytomariines" are well-resolved. This analysis implies that the clade diverged from other "brachytomariines" by the late Caradoc (Late Ordovician), even though the earliest known species do not appear until the late Llandovery (Early Silurian). This gap is somewhat disconcerting, but it is not quite statistically significant. "Luciellides," however, are a highly derived clade relative to Ordovician "brachytomariines," and this long-branch problem (Felsenstein, 1978) creates two difficulties. First, many "lu- ciellide" synapomorphies are homoplastic on even the most parsimonious tree. Second, the highly derived nature of "luciellides" means that some of their seemingly singular features might be homologous with traits on other species. For example, Oehlertia species possess strong swellings on either side of the peripheral band, which I coded as unique characters (Appendix 1, character 47). They also lack the strong carina on the right and left ramps that diagnose the derived "brachytomariines" of the Ordovician (i.e., nodes 190-192); however, the strong right ramp and left ramp carinae of "phanerotrematide" species, such as "Longstaffia" "laquetta" and Promourlonia aff. P. furcata Longstaff, 1924, are similar to those swellings. If one codes the swellings of Oehlertia as homologous with the carinae of other "brachytomariines," then it becomes most parsimonious to place Oehlertia within the "L." "laquetta" clade. Similarly, some members of the rather variable species Crenilunula hallei (Whiteaves, 1895) appear to bear slightly weaker versions of the carina displayed by $P$. aff. $P$. furcata. These are lost amidst strong ornament in other members of the species, however, and on species such as Crenilunula limata (Lindström, 1884). Again, if one assumes that these carina are present, then it becomes more parsimonious to assume that $C$. hallei is the stem-member of a clade derived from a species similar to $P$. aff. $P$. furcata. In this case, Conotoma claustrata (Lindström, 1884) is considered to be a somewhat derived member of the same clade (albeit plesiomorphic relative to Oehlertia gradata), whereas Oehlertia is considered to be a separate derivative within the "L." "laquetta" clade.

II.4.2.2.4. "Planozonides".-The final "brachytomariine" subclade (Figures 34, 35, nodes 202-215) includes species classified in the Gosseletinidae by Knight et al. (1960). Because the least derived members of this clade (i.e., species classified as Cataschisma Branson, 1909, and Globispira Koken, 1925) have been classified as the Planozonides (a tribe within the Gosseltinidae), I label the clade the "planozonides." I reserve "gosseletinite" for one of the two major "planozonide"

FIGURE 32 (opposite).-Relationships among the "phanerotrematides." For abbreviations, see legend to Figure 7. Node 190 (Brachytomaria semele clade), symmetric sinus angle $-20^{\circ}(2-4)$; symmetric sinus width (5); very strong lunulae (39); LRC present (75); both IM and base thickened (88); nonarched IM (95); right side of aperture not inclined (113); no anterior projection of base (118). Node 191, narrow sinus $(6,7) ; \beta=50^{\circ}$ (48); flat $L R$ (72); very thick $1 M$ (87). Node 192 (Brachytomaria striata clade), thin, thread-like RRC (66); weak LRC (77); left side of aperture not inclined (111). Node 193, PB width $\approx$ $15^{\circ}$ (20); slit present (34). Node 194 (Ulrichospira similis clade), moderately strong BL (23); lunulae same strength as GL (39); very asymmetric aperture (narrow left side) $(58,59)$; thick IM (87); only IM (not base) thickened (88); very low E (121); isometric T (127). Node 195 (Phanerotrema clade), very narrow sinus $(6,7)$; crenulated aperture (12); $\mathrm{PB}$ width $\approx 10^{\circ}(20)$; $\mathrm{PB}$ partially on RR (43); asymmetric ramp shapes (RR rounder) (51-53); acute suture $(69,70)$; LRC lost (75); thickened middle of IM (96); IM $15^{\circ}$ off $\|$ to CA (98); P1 thickness same as rest of shell (103); left side of aperture inclined $-20^{\circ}(111,112)$; moderate E (121); ornament throughout left side of aperture (129). Node 196, oblique suture (69); IM || to CA (98); no anterior production of aperture (118). 


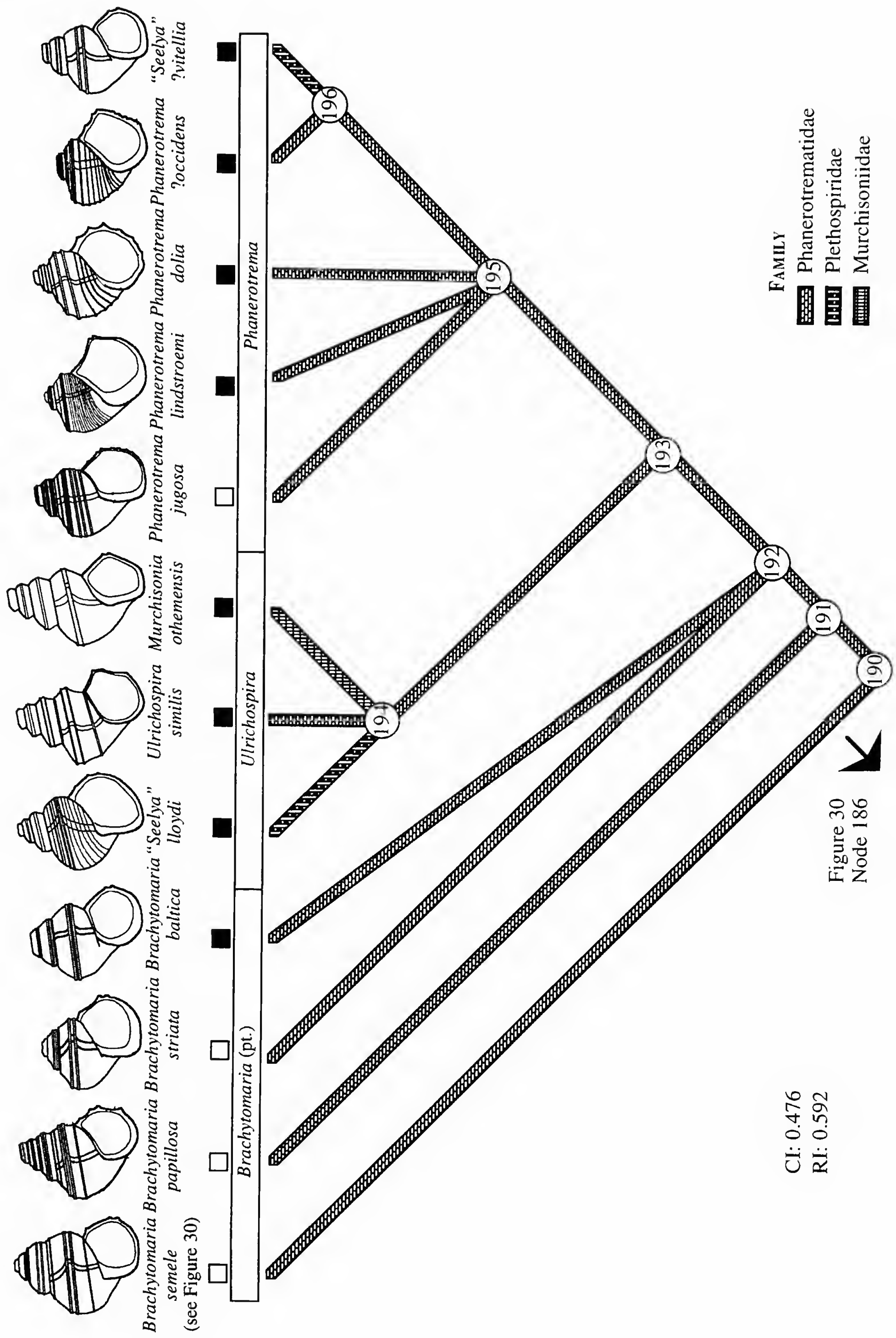




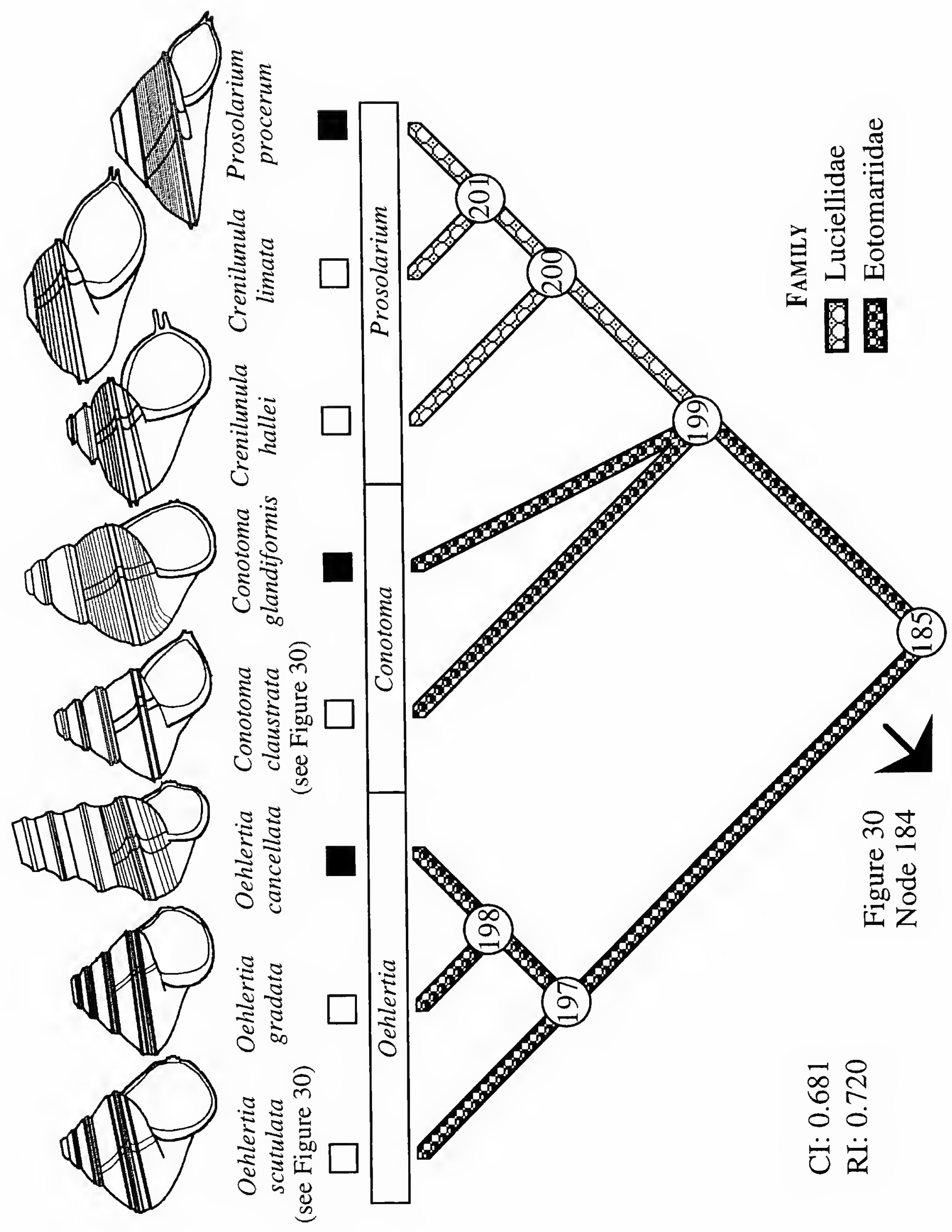


FIGURE 33 (opposite).-Relationships among the "luciellides." For abbreviations, see legend to Figure 7. Node 185 ("Luciellides"), very narrow PB $(6,7)$; very asymmetric ramps ( $R R$ extremely wide, $L R$ very short) $(55,56)$; omament throughout left side of aperture (129); omament on RR (133). Node 197 (Oehlertia clade), very narrow slit bordered by two sharp lira within the $\mathrm{PB}(34,37$, 38); dull swellings on both sides of PB (47); asymmetric aperture (left side much wider than right) (57-59). Node 198, both IM and base thickened (88); thickened middle of IM (96); Pl lost (103). Node 199 (Conotoma claustrata clade), $\mathrm{PB}$ width $\approx 15^{\circ}(20)$; $\mathrm{BL}$ frilled with upper lira stronger $(24,26)$; $\mathrm{PB}$ asymmetrically on $\operatorname{LR}(43) ; \beta \approx 100^{\circ}(48)$; LR flatter than RR $(51,52,72)$; RRC lost (64). Node 200 (Crenilunula hallei clade), strong GL (15); strongly frilled BL (25); slit creating zipper-like lunulae present $(34,38)$; asymmetric aperture (right side broader) (57-59); IM $30^{\circ}$ off parallel to CA (98); right side of aperture inclined $-30^{\circ}$ (114); moderate K (123); LR and RR ornament of strong lira (131, 135); large size (141). Node 201, PB width $\approx 10^{\circ}(20)$; IM at $-45^{\circ}$ to CA (98).

subclades, which is comprised of species classified in the subfamily Gosseletininae sensu Knight et al. (1960) (Figure 35, nodes 209-215). The second "planozonide" subclade is dominated by species classified in the other gosseletinid subfamily, the Coelozoninae, and is labeled the "coelozonites" (Figure 34, nodes 203-208). "Planozonide" synapomorphies include isometric translation (see Figure 5) and a peripheral band with very weak lira that bisects the aperture. These species also possess a slit that produces extremely weak lunulae. The earliest members of the clade that I include in this analysis are from the Silurian. I have observed incomplete specimens from the late Caradoc and Ashgill (Late Ordovician) that bear the important "planozonide" synapomorphies (e.g., C. exquisita (Lindström) in Rohr, 1988), so this aspect of the cladistic results does not conflict with the fossil record.

"Coelozonite" synapomorphies include weak ornament, an extremely wide peripheral band, a swollen right ramp, and increased expansion. Late Silurian species in the Pleurorima migrans clade (Figure 34, node 206) feature stronger peripheral lira, ornament in the peripheral band, and a thickened inner margin and inductura. The derived Euryzone Koken, 1896, + Coelozone Perner, 1907, subclade (Figure 34, node 208) possesses an extremely wide peripheral band with very sharp lira, an expanded base, a strong swelling on top of the right ramp, and low translation and curvature.

"Gosseletinites" include species classified as Stenoloron Oehlert, 1888, Spiroraphe Perner, 1907, Eocryptaulina Foerste, 1936, and Umbotropis Perner, 1903 (Figure 35, nodes 209-215). The synapomorphies linking these species include a narrow, slightly swollen peripheral band and low curvature and translation. The analysis presently indicates that Eocryptaulina and Umbotropis form a sister clade to Stenoloron. If the analysis includes an incompletely known species, E. filitexta (Foerste, 1893), however, then it becomes just as parsimonious to link that subclade directly to node 211 (i.e., the $S$. shelvensis clade). Fully corroborating or refuting this possibility requires better specimens of $E$. filitexta than are presently available.
The Stenoloron shelvensis clade (Figure 35, nodes 211-215) is diagnosed by a very narrow peripheral band with sharp lira, posterior projection of the base, and a thin carina on the right ramp that fills the suture. Species within this clade also appear to share a relatively deep slit. Slit depth usually is difficult to ascertain, so I did not use it as a character. Slits of "coelozonite" species appear to have been much shallower, however, so the deeper slit represents a synapomorphy somewhere within the "gosseletinites." The $S$. shelvensis clade includes a subclade (node 212) diagnosed by a nearly symmetrical aperture and ontogenetic change towards planispiral coiling. These features are shared with the Devonian genus Porcellia Léveillé, 1835 (see Bandel, 1993), which is of particular interest because it converges on bellerophont morphology. I have run analyses with the Early Devonian species P. sinistra Perner, and those analyses place that species within node 212 . Broader analyses that include more Devonian species are needed to support this possibility.

Another Stenoloron subclade (nodes 212, 213) is diagnosed by a curved base that extends behind the aperture rather than in front, and an asymmetrical sinus with the right side deeper rather than the left. This clade includes Spiroraphe bohemica Barrande in Perner, 1907, which Knight et al. (1960) thought to be related to Eotomaria. This analysis suggests that this is not the case.

\section{Problematica}

This analysis could not place some major early Paleozoic taxa among "archaeogastropods," namely the Platyceratoidea, Neritoidea, and Oriostomatidae. Possible relationships of these taxa are outlined below.

PLATYCERATOIDEA.-The earliest platyceratoid (Cyclonema praecipitum Ulrich and Scofield, 1897) appeared in the early Caradoc (Middle Ordovician). It possesses the major synapomorphies of the Platyceratoidea but lacks any diagnostic synapomorphies of the other "archaeogastropods" discussed herein. In platyceratoids, a septum separates the protoconch from the teleoconch. Septation is plesiomorphic for "archaeogastropods," but this feature is unknown in Ordovician "murchisoniinae." The retention of a symplesiomorphy usually is not evidence of phylogentic relationships (but see Sober, 1988), and one might think it possible that platyceratoids are a sister taxon of "murchisoniinae" that retain plesiomorphic septation. This would predict, however, that platyceratoids diverged from other gastropods by the Tremadoc (Early Ordovician), however, which is thoroughly rejected by stratigraphic data (minimum $\alpha=2.06, \mathrm{H}=12, \mathrm{p}=8.9 \times 10^{-6}$, where $\alpha$ is the stratigraphic gap between the first known appearance of $C$. praecipitum and the first known appearance of "murchisoniinae," and $\mathrm{H}$ is the number of horizons preserving that species; note that $\alpha$ is the fraction of $C$. praecipitum's known stratigraphic range; see Strauss and Sadler, 1989; Marshall, 1990). Additional lines of evidence suggest that platyceratoids are de- 


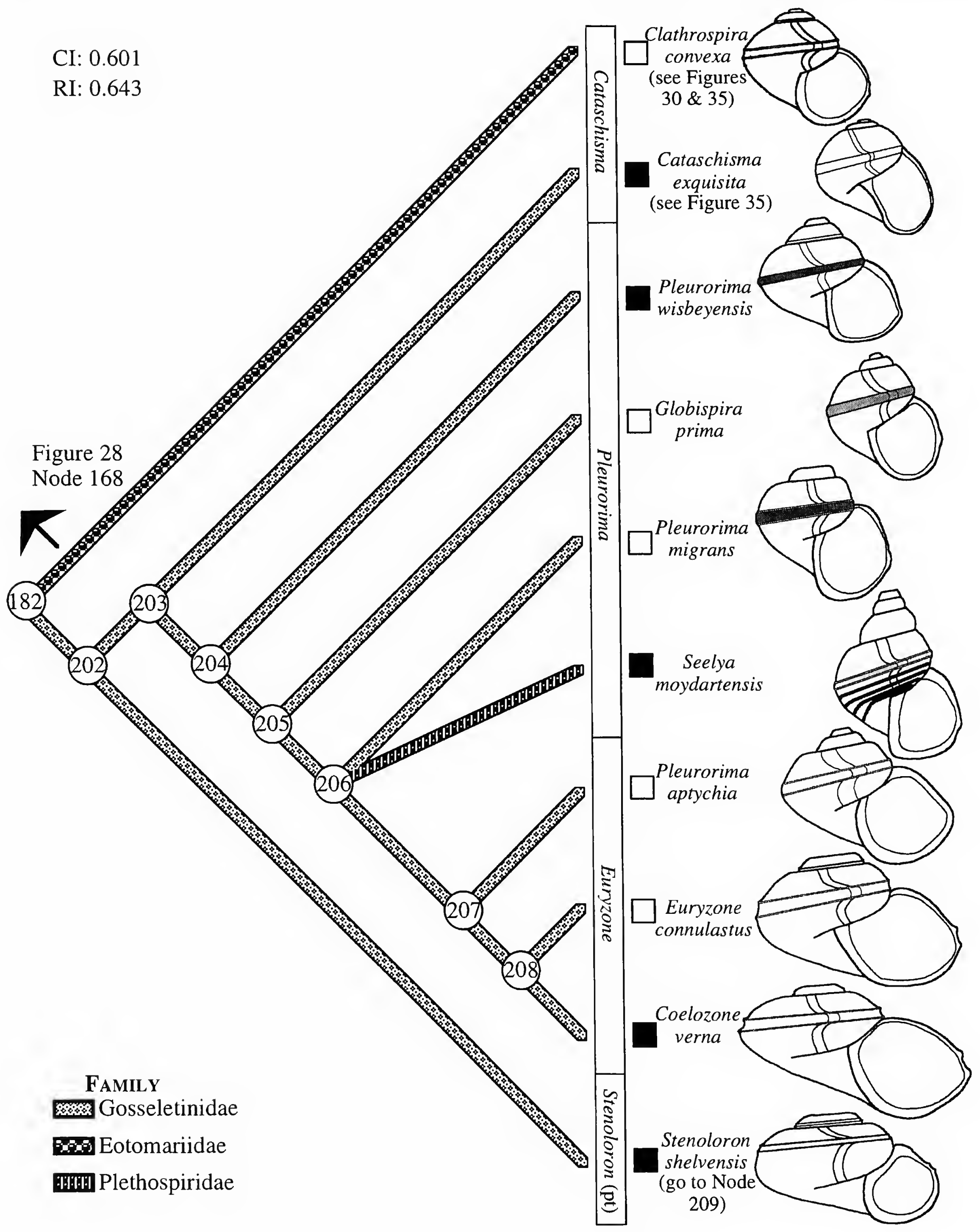


FIGURE 34 (opposite).-Relationships among the "coelozonites." For abbreviations, see legend to Figure 7. Node 182 ("Brachytomariines"), sinus angle $\sim 30^{\circ}$ on right side (3); PB bisects aperture (43); ACh lost (45); arched IM (95); right side of aperture inclined (113); base projected anteriorly $-10^{\circ}(119)$. Node 202 ("Planozonides"), left sinus angle $=30^{\circ}(4)$; narrow sinus $(6,7)$; slit present (34); weak lunulae (39); IM no thicker than shell (87); isometric T (127). Node 203 ("Coelozonites"), $\beta \approx 110^{\circ}$ (48); very asymmetric ramps (RR extremely wide, LR extremely short) $(55,56)$; left side of aperture inclined $\sim 30^{\circ}(112)$; omate $\mathrm{LR}, \mathrm{RR}$, and PB $(129,133,139)$. Node 204 , right sinus angle $-20^{\circ}(3)$; ML present (27); asymmetric ramp shapes (RR rounder) (51-53); RR swelling present (60); convex LR (72); high E (121). Node 205, weakly imbricated GL (17). Node 206 (Pleurorima migrans clade), right side of sinus very narrow (6); PB width $\approx 25^{\circ}(20)$; thickened IM (87); right side of aperture inclined $-10^{\circ}$ (114); large size (141). Node 207 (Pleurorima aptychia clade), moderately strong $\mathrm{BL}(23) ; \mathrm{ML}$ lost (27); $\beta \approx 100^{\circ}$ (48); strong RR swelling (61); right side of aperture not inclined (113); moderate K (123). Node 208, strong GL (15); PB partially on RR (43); very convex RR (52); moderately asymmetric, moderately broad aperture (narrow right side, broad left side) $(58,59)$; only top of IM thickened (88); IMlbase angle $\approx 105^{\circ}(94)$; low K (123); moderate T (126); loss of omament on LR, RR, and PB $(129,133,139)$.

rived "euomphalines." Yochelson and Linsley (1972) noted that a Devonian platyceratoid assigned to Cyclonema possess a paucispiral, discoidal operculum very similar to opercula associated with Helicotoma (Yochelson, 1966a). (Those authors, however, attributed the similarities to convergence.) Moreover, a "helicotomid" species with a calcitic shell, Oriostoma bromidensis, appeared at about the same time and in the same region as Cyclonema praecipitum (Rohr and Johns, 1990). Unfortunately, it is not known if the two species shared a similar type of calcitic shell. Finally, the "fish-hook" shaped protoconch of numerous Devonian platyceratoids (Frýda and Bandel) is very similar to the conical protoconch diagnosing numerous "euomphaline" species (e.g. Dzik, 1994); therefore, I consider the best inference at this time to be that platyceratoids are a "euomphaline" subclade. Obviously, more detailed investigations about the shell mineralogies and opercula of "euomphalinae" species are necessary before the estimate can be considered robust.

NERITOIDEA.-The relationships of the Neritoidea have long vexed malacologists. Traditionally, workers considered neritoids to be highly derived, aberrant archaeogastropods, but more recent estimates of the relationship of neritoids to other gastropods are completely conflicting. Molecular (Rosenberg et al., 1994) and some morphologic studies (Haszprunar, 1988) suggest that neritoids are an outgroup to the vetigastropodapogastropod clade. Other morphologic studies (Naef, 1911; Ponder and Lindberg, 1996) and embryological data (van den Beggelaar, 1993) suggest that neritoids and apogastropods are more closely related to one another than either taxon is to vetigastropods. The only consensus that workers have reached is that neritoids diverged early in gastropod evolution. Bandel (1992) suggested that neritoids are related (and actually ancestral) to platyceratoids based on protoconch morphology. This conjecture, however, was based on Triassic specimens, which evolved over 200 million years after neritoids likely diverged from other gastropods, and Bandel (1998) has subsequently dismissed this hypothesis. The earliest putative neritoids are the Naticopsidae, the oldest representative of which appeared in the Middle Silurian. This species, Naticopsis transversus (Lindström, 1884), lacks the distinctive early platyceratoid synapomorphies, such as a flattened inner margin. Lindström (1884) classified the species as Holopea, and $N$. transversus does fit the generic diagnosis of Holopea. The synapomorphies of derived Holopea are all losses of features, however, rather than distinct homologies (see above); therefore, it is not clear that $N$. transversus is a member of the "holopeides" (e.g., Figure 14, nodes 62-64).

A key synapomorphy of neritoids that would be recognizable on fossil specimens is coiling in which the aperture is essentially contiguous with the previous whorls, leaving no architectural columella (character 108 , state 3 ) and reducing the homology. This feature is observed in the "straparollinoid" and "loxonematide" clades. Deriving neritoids from "loxonematides" is consistent with hypotheses that neritoids and the Apogastropoda are sister taxa relative to the Vetigastropoda. Deriving neritoids from "straparollinoids" is consistent with hypotheses that neritoids, Apogastropods, and Vetigastropods represent a virtual trichotomy. Notably, the latter is essentially the consensus of the available estimates. The inclusion of species with more definite neritoid affinities obviously is necessary to contrast these two (and possibly other) estimates. The inability of neontological studies to resolve neritoid affinities consistently, however, suggests that extended paleontological data will represent important evidence for resolving their relationships.

ORIOSTOMATOIDEA.--Some early species classified as Oriostoma appear to represent "euomphalinae" species. The Early Ordovician O.? canningensis Yü appears to be an ornate relative of Malayaspira. The Middle Ordovician O. bromidensis is the immediate outgroup to the Ophiletina clade (Figure 15, node 75). Yü (1993) assigned the former species to Oriostoma because it possessed ornament, but that is a highly homoplastic character among gastropods. Rohr and Johns (1990) assigned the latter species to Oriostoma because of its similarities to Poleumita, and those authors followed Boucot and Yochelson's (1966) proposition that Poleumita is a junior synonym of Oriostoma. These two species and all other "euomphalinae" lack any unequivocal synapomorphies with obvious Oriostoma species (e.g., O. angulata) from the latest Ordovician or Silurian. Wängberg-Eriksson (1964) and Yochelson (in Webers et al., 1992) suggested that true Oriostoma species are related closely to species of Isospira Koken, and preliminary analyses suggested that the sister taxon of Isospira are cyclomyans, such as Cyrtolites and Sinuitopsis Perner (see Wagner, 1995d), rather than a gastropod clade. Synapomorphies include strong, channeled lira on either side of the umbilicus, a shallow $U$-shaped sinus, and a widely umbilicate, slowly expanding shell. Notably, Wenz (1938) linked Isospira with Cyrtolites, and both Linsley and Kier (1984) and P.J. 


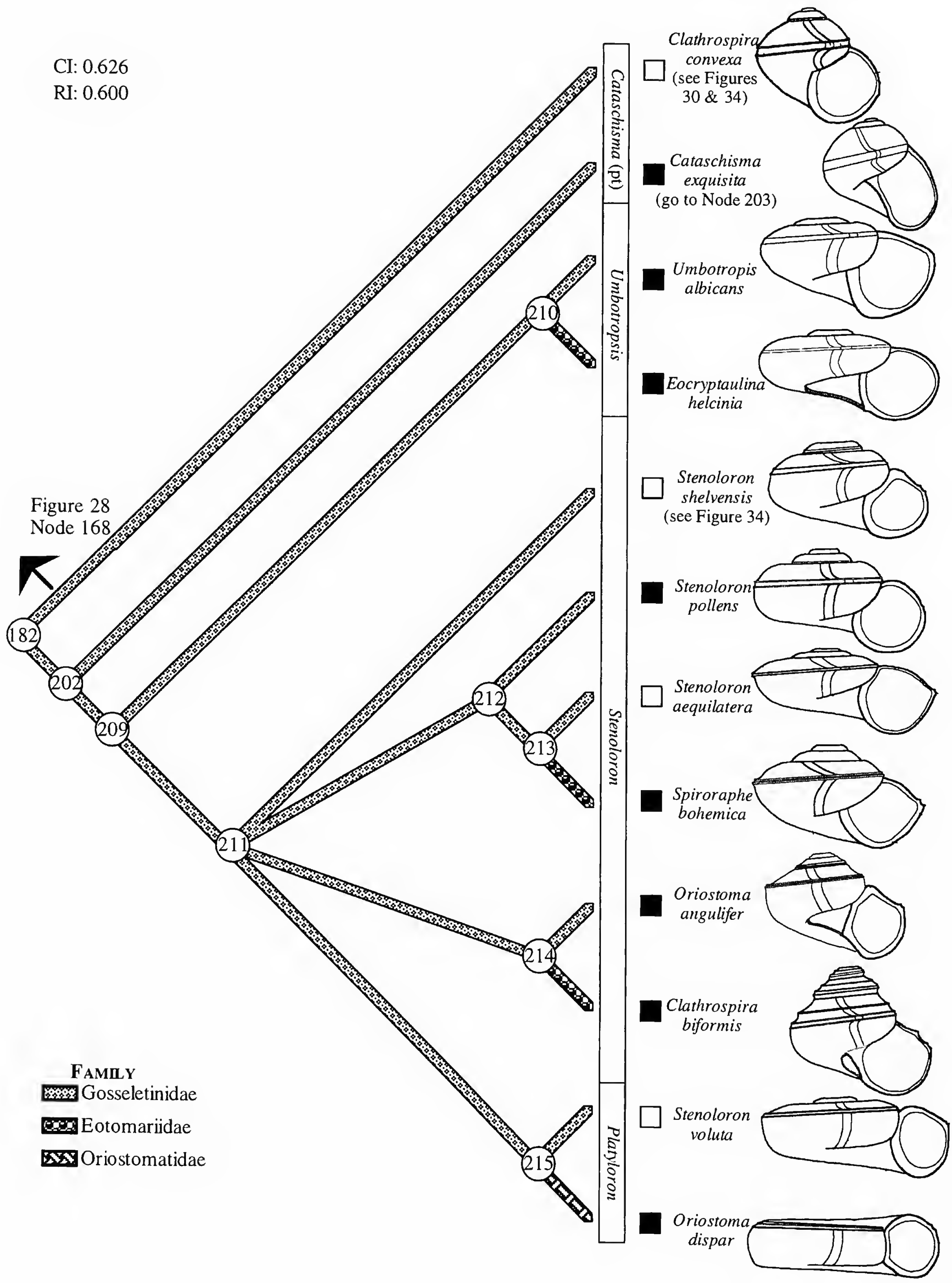


FIGURE 35 (opposite).-Relationships among the "gosseletinites." For abbreviations, see legend to Figure 7. Node 182 ("Brachytomariines"), sinus angle $-30^{\circ}$ on right side (3); PB bisects aperture (43); ACh lost (45); arched IM (95); right side of aperture inclined (113); base projected anteriorly $-10^{\circ}$ (119). Node 202 ("Planozonides"), left sinus angle $\approx 30^{\circ}(4)$; narrow sinus $(6,7)$; slit present (34); weak lunulae (39); $1 \mathrm{M}$ no thicker than shell (87); isometric T (127). Node 209 ("Gosseletinites"), PB width $\approx 10^{\circ}$ (20); sharp BL (22); PB entirely on $R R(43) ; \beta \approx 70^{\circ}(48)$; symmetric, convex ramps (51, 52, 72); IM $\perp$ to CA (94); left side of aperture inclined $-10^{\circ}(112)$; right side of aperture not inclined (113); low E (121); moderate K (123); moderate T (126). Node 210 (Eocryptaulina helcinia + Umbotropis albicans), right sinus angle $-20^{\circ}(3) ; \beta$ $\approx 60^{\circ}$ (48); convex LR (72). Node 211 (Stenoloron shelvensis clade), PB width $\approx 05^{\circ}(20)$; ACh present (45); asymmetric ramp shapes (LR rounder) $(51,72)$; broad, symmetric aperture (54-56); RRC present (64); IM $30^{\circ}$ off parallel to CA (98); base projected posteriorly $-10^{\circ}(116,117)$. Node 212 (Stenoloron pollens clade), right sinus angle $\sim 40^{\circ}(3)$; strong GL (15); PB slightly raised relative to whorl (33); very convex RR (52); asymmetric ramp lengths (RR narrower) $(57-59) ; 1 \mathrm{M} \backslash$ base angle $=105^{\circ}(94)$; very little left side inclination (112); no anterior projection of base (118); curved base (120). Node 213, deep asymmetric sinus angles (right angle $\approx 50^{\circ}$; left angle $\approx 30^{\circ}$ ) (2-4); strong, sharp BL (23); lunulae same strength as GL (39); asymmetric, convex ramp shapes (RR rounder) $(51,52,72)$; very asymmetric ramp lengths (very long $R R$, moderately long $L R)(55,56)$; very asymmetric aperture (broad right side, very nartow left side) $(58,59)$; RRC lost $(64)$; large size (141). Node 214 , very narrow sinus $(6,7)$; sharp RRC (64); IM lira present (100). Node 215 (Stenoloron voluta clade), asymmetric sinus (left side wider) (5); asymmetric sinus shape (left side half- $U$ ) (8-10); ML developing during ontogeny (41); $\beta=$ $50^{\circ}$ (48); left side of aperture not inclined (111).

Morris (1991) suggested that oriostomatids are untorted molluscs. Although Isospira might be a cyclomyan, Oriostoma likely is neither a cyclomyan nor derived from Isospira. Horný (1995b) documented paired muscle scars (similar to those of Bellerophon species) on several species of Late Silurian Oriostoma. Also, Rohr (1996) described an obvious Oriostoma species from the early Middle Ordovician, which significantly predates the earliest known Isospira (Wagner, unpublished data). Peel (pers. comm., 1996) noted that the Oriostomatidae might represent a polyphyletic assemblage, which necessitates detailed species-level analyses, such as those undertaken herein, before any firm estimates of the taxon's phylogenetic status or relationships can be made.

\section{Discussion}

\section{PALEOZOIC PLEUROTOMARIOIDS: AN OXYMORON?}

The genotype of Pleurotomaria is... a species that is only remotely related to any Paleozoic forms. In anything but the broadest most unscientific sense, the genus Pleurotomaria does not occur in the Paleozoic, and to employ the name for Paleozoic forms today is only a confession of ignorance. (J. Brookes Knight, 1941:21)

Knight (1952) and Knight et al. (1954) followed the accepted neontological theory of the time and depicted the Pleurotomarioidea as a paraphyletic assemblage that included the ancestors of several "advanced" clades of gastropods. The phylogenetic scheme proposed herein suggests a nearly opposite model of evolution, with the major pleurotomarioid families of the Paleozoic having evolved independently within two different clades.
Perhaps the most important implication of this study for understanding gastropod phylogeny is that a pleurotomarioid-grade shell is no less derived than an apogastropod-grade shell (from an Ordovician perspective), and that it is not a suitable archetype for deriving the early "murchisoniinae" or "euomphalinae." The results presented herein suggest a pattern of shell evolution that is somewhat different from traditional models. Sinuate and slitless morphologies with peripheral bands (Figure $36 \mathrm{~A}-\mathrm{C}$ ) gave rise to several types of sinuate, slit-bearing morphologies (Figure 36D-F) during the early Paleozoic. The former condition (not represented by any known extant species) likely represents the ancestral "archaeogastropod" (and possibly gastropod) condition. Morphologies traditionally thought of as "advanced" (Figure 36G-1) arose only from slitless species in the early Paleozoic. These results appear to be robust. For example, experimental searches through trees that are consistent with traditional phylogenetic hypotheses indicate that the shortest "traditional" trees are nearly twice as long as the most parsimonious (or the accepted) results (Wagner, unpublished data).

Neontological data also question the appropriateness of pleurotomarioids as an archetype for more-derived gastropods. For example, Haszprunar (1989) suggested that scissurelloid anatomy represents a more appropriate archetype. One might wish to use the Pleurotomarioidea to label the early Paleozoic ancestors of extant pleurotomarioids (see de Queiroz and Gauthier, 1990; de Queiroz, 1992). It is not obvious which early Paleozoic lineage gave rise to the different extant vetigastropods (but see discussion below), nor is it yet clear when those clades diverged. Hence, I take Knight's (1941) indictment of the taxon a step further: classifying any group of early Paleozoic gastropods in the Pleurotomarioidea (or the Scissurelloidea) has no descriptive utility and should be discontinued.

Similar statements apply to the Trochoidea. McLean (1981) and Hickman (1988; also Hickman and McLean, 1990) suggested that trochoids might have evolved in the early Paleozoic, and Tracey et al. (1993) gave a Middle Ordovician origin for the clade. Morphologic (Hickman and McLean, 1990; see also Haszprunar, 1987, 1988, 1989) and molecular phylogenies (Tillier et al., 1992) suggest that trochoids had a slit-bearing ancestor among the vetigastropods. Phylogenetic estimates presented herein find none of the trochoid-like species from the early Paleozoic to be derived from species with slits. This suggests that the Trochoidea evolved in the middle Paleozoic or later. Thus, "Paleozoic trochoids" also is an oxymoron, at least for the early Paleozoic. This makes the repeated evolution of trochoid-like forms all the more interesting to evolutionary biologists.

\section{"EuOMPHALINAES": TWO GILLS OR ONE?}

An interesting pattern revealed by this analysis is the iterative evolution of trochoid-like species within the "euomphalinae" clade in general, and within "euomphalopterines" in particular. Several workers have suggested that species classified 
A

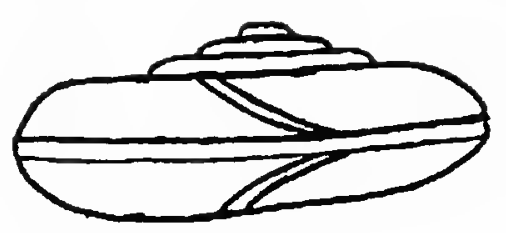

B

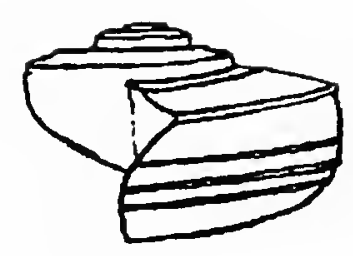

$\mathrm{D}$

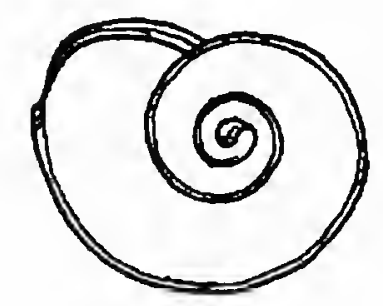

$\mathrm{E}$

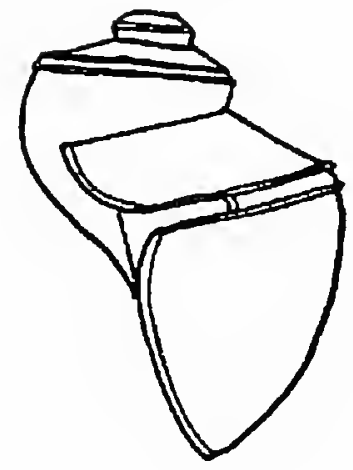

$\mathrm{H}$

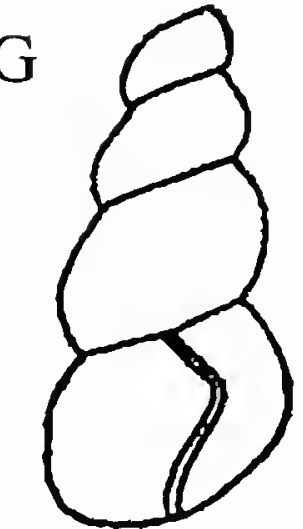

C

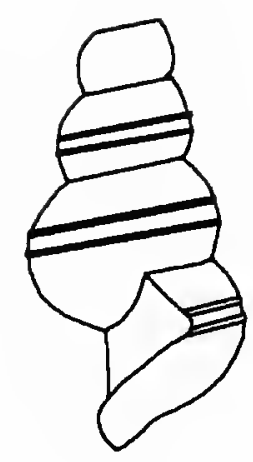

$\mathrm{F}$

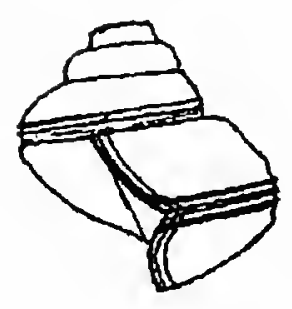

FIGURE 36.--Slitless sinuses (e.g., A-C) produce both slit-bearing sinuses (e.g., D-F) and "modern" morphologies during the Ordovician. In no cases did species with $\mathrm{D}, \mathrm{E}$, or $\mathrm{F}$ morphologies give rise to $\mathrm{G}, \mathrm{H}$, or I morphologies. Sinus shape is given by the growth lines in most examples. A, symmetrical, curved sinus with no slit (e.g., most early "archaeogastropods"). B, symmetrical $V$-shaped sinus with no slit (e.g., Polehemia). C, asymmetrical sinus with no slit (e.g., early "hormotomoids"). $D$, sinus curvature increasing to produce a slit at the apex (e.g., apical view of Lesueurilla). E, slit at the end of the sinus (e.g., most slit-bearing species). F, slit much thinner than peripheral band (e.g., Oehlertia). The slit is within the inner pair of lira; the outer pair are homologous with the peripheral lira of other "murchisoniinae" (e.g., A). G, shallow, U-shaped sinus (e.g., Loxonema). $\mathrm{H}$, sigmoidal, trochoid-like aperture (e.g., Discordichilus). I, shallow anal notch next to suture (e.g., Subulites).

in the Euomphaloidea might have possessed only one gill or at least possessed a very reduced right gill (e.g., McLean, 1981, 1990; Yochelson, 1984; P.J. Morris, 1991). Nearly all "anomphalides" and "pseudophorides" possess morphologies associated with reduced right organs. "Poleumitides" are predominately low-spired, but they also include some highspired, trochoid-like species (e.g., Poleumita octavia (M'Coy, 1851)) with reduced right sides of the aperture. Among other "euomphalinae," the functional experiments of P.J. Morris (1991) suggest that derived "macluritoids" would have functioned best with only one gill. The common ancestors to most of these clades featured deep sinuses, channeled right carinae, and equal proportions of the left and right ramps. All of these characters imply that the early "euomphalinae" possessed both gills. An implication of the phylogeny presented herein, however, is that the loss of the right gill was not uncommon among "euomphalinae," especially during the first half of the Ordovician.

\section{IMPLICATIONS FOR RELATIONSHIPS AMONG EXTANT GASTROPODS}

It is difficult to compare these results with the different estimated relationships among extant gastropods (e.g., Haszprunar, 1988; Tillier et al., 1992; Ponder and Lindberg, 1996) simply because it is not clear which early Paleozoic taxa are the precursors of the different modern clades. There has been abundant speculation about how these early taxa fit into gastropod phylogeny, and it is useful to compare how well those ideas compare with this analysis.

Vetigastropods, apogastropods, and patellogastropods are the three most important taxa to consider because the relationships among these three taxa are fairly well resolved, something that cannot be stated for other higher gastropod taxa. Identifying the early Paleozoic precursors of these clades should place some basic parameters on ideas about gastropod evolution (Figure 37). The "eotomarioids" represent the best candidate for including the ancestor of modern vetigastropods, simply because 


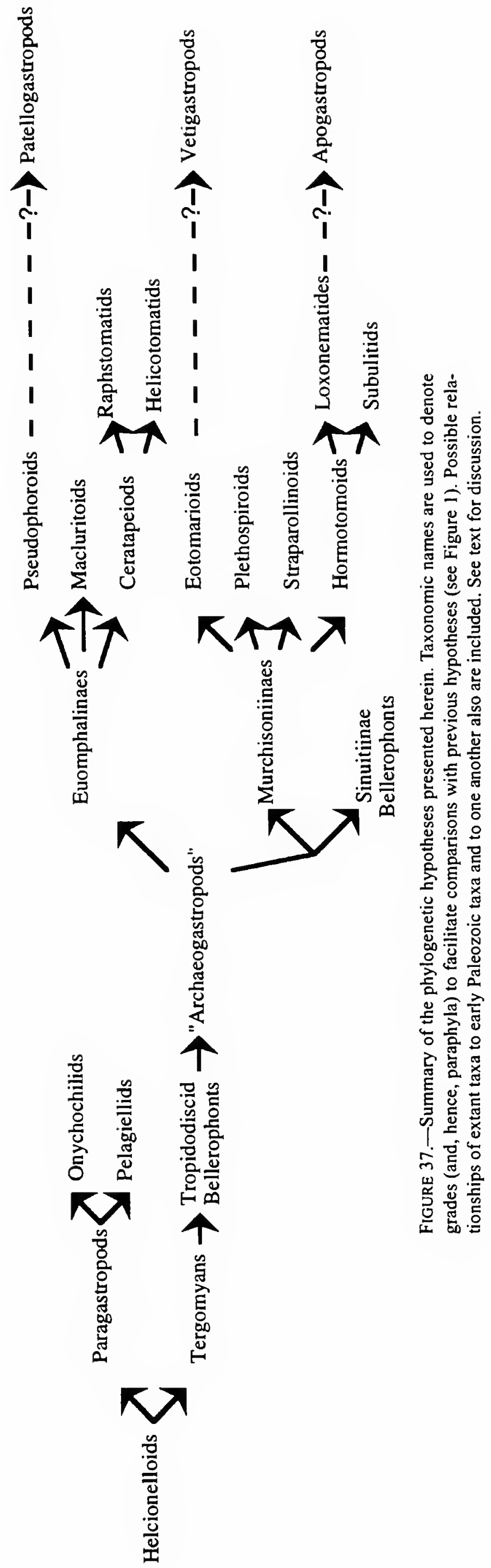

all the vetigastropod-like species of the Silurian belong to that clade. I suggest (tentatively) that "clathrospirids," especially within the "planozonide" subclade, represent the most likely candidates because these derived "clathrospirids" share similar slits, sinuses, peripheral bands, and apertural orientations with modern pleurotomarioids and coiled scissurelloids. Many workers have suggested that the Loxonematoidea are the earliest apogastropods (e.g., Wenz, 1938; Knight et al., 1960; Fretter and Graham, 1962; Houbrick, 1979, but see Houbrick, 1988), and many workers (e.g., Haszprunar, 1988; Tracey et al., 1993) consider loxonematoids to be plesiomorphic apogastropods. Other "hormotomoids" make poor candidates for the ancestors of the Apogastropoda. If vetigastropods are derived "clathrospirids" and apogastropods are "loxonematides," then the vetigastropod-apogastropod divergence (roughly Figure 20 , node 109) occurred no later than the Tremadoc (Early Ordovician), i.e., around 490 million years ago (Harland et al., 1990).

The origins of patellogastropods are less obvious. D.R. Lindberg (pers. comm., 1993) has suggested that the clade evolved from coiled, sinus-bearing, septate gastropods. If so, then the "euomphalinae" represent the most likely ancestor. This extension of Lindberg's basic scenario fits the neontological data well, as nearly all recent phylogenetic analyses indicate that patellogastropods are the outgroup to all other gastropods (Lindberg, 1988; Haszprunar, 1988; Tillier et al., 1992). Other aspects of this phylogenetic model also fit paleontological data, as some trochoid-like "euomphalinae" (e.g., Pseudophorus) possessed morphologies suggesting single-gilled anatomies, adaptations for clamping onto hard substrates, and septa restricted to the youngest whorls. These assessments of patellogastropod-"euomphalinae" relationships clearly must be considered highly tentative, and other data (e.g., protoconch morphology and shell mineralogy) are necessary to corroborate it. If accurate, however, then patelloids and the vetigastropod + apogastropod clade diverged by the Late Cambrian, i.e., around 510 million years ago (Harland et al., 1990).

Linking patellogastropods and the "euomphalinae" contradicts Haszprunar's (1988) suggestion that the Euomphaloidea are closer to vetigastropods than to patellogastropods. This analysis suggests that the "euomphalinae" are not closely related to the most appropriate precursors to the vetigastropods. McLean $(1981,1989,1990)$ linked the Euomphaloidea with the Neomphalina. As with the Neritoidea, neontological studies have reached little consensus about the relationships of the Neomphalina, so paleontological data likely will be important. Unfortunately, almost nothing is known about the fossil antecedents of that taxon, so it is difficult for paleontological data to address McLean's phylogenetic hypothesis at this time.

The speculations about the early Paleozoic precursors of patellogastropods, vetigastropods, and apogastropods can only be described as consistent with both paleontological and neontological data. It still has important implications for phylogenetic analyses of the higher taxa, however, because it is evi- 
dent that the most likely antecedents of those taxa should have diverged by the Early Ordovician, i.e., shortly after gastropods evolved. As noted above, the phylogenetic affinities of the Neomphalina, Neritoidea, and the various hydrothermal-vent taxa are poorly understood. The one consistent implication of the conflicting results from different molecular and morphologic analyses is that these gastropod problematica diverged before or around the time that vetigastropods and apogastropods diverged, which this study suggests was some 490 million years ago (Harland et al., 1990). Long divergence times lead to "long branches," which confound phylogenetic analyses (Felsenstein, 1978; Huelsenbeck and Hillis, 1993). Echinoderms provide an important analogy, as the five extant major classes within that phylum also diverged during the early Paleozoic. Cladistic analyses using 18s rRNA have not been able to resolve the relationships among those classes, and different morphologic data sets produce conflicting results (Smith, 1989). Given that extant orders and suborders of gastropods diverged at about the same time, we should expect different neontological data sets to produce very different hypotheses about relationships among the Gastropoda.

Figure 37 presents a summary of the general phylogenetic relationships proposed herein, for comparison with the hypotheses outlined in Figure 1. It also includes the possible implications for neontological relationships that this analysis suggests.

\section{Systematic Paleontology}

In the discussion of the estimated relationships among early gastropods, I repeatedly emphasized the many similarities between the results of this analysis and the previously held views of numerous workers. Despite the general congruence, however, it is clear that gastropod taxonomy requires major revision in order to reflect many aspects of gastropod phylogeny, and also to reflect more accurately the evolutionary dynamics within the clade.

It must be emphasized that the taxonomy proposed herein is phylogenetic rather than typologic. Type species are granted no special importance except as convenient labels for genera; i.e., if a clade or paraclade (see definition below) includes a previously designated type species, then that genus labels the clade or paraclade. If a clade or paraclade comprises multiple type species, then I adhered to standard taxonomic priority. Because the taxonomy is phylogenetic and given that the text of this paper discusses the characters uniting each clade in some detail, little discussion of diagnostic characters is given here. Also, gastropods typically are described by characters such as spire height, general aperture shape and inclination, columella type, and ornament. As noted in the text, these features are compound characters that rarely denote particular homologies and convey only indirect phylogenetic information. Accordingly, I eschew "traditional" descriptions, referring the reader to the character matrices and synapomorphy lists provided in the ap- pendices and figures. I did attempt, however, to adhere to more traditional grade-based criteria to separate derived suprageneric taxa from their "ancestral" taxa.

Another important point is that I have attempted to eliminate monotypic genera. Some monotypic genera, however, are known from poorly sampled intervals (especially the Llanvirn-Llandeilo and the Early Llandovery). Further sampling of those intervals could easily reveal that those species belong to separate clades or paraclades; if and when such species are sampled and included in phylogenetic analyses, then those genera should be reinstated.

In addition to reflecting general phylogenetic relationships, taxonomy also should reflect evolutionary dynamics (e.g., patterns of standing diversity and relative extinction and origination intensities). Contrary to the claims that only monophyletic taxonomy reflects evolution (de Queiroz and Gauthier, 1990, 1992, 1994), monophyletic taxa actually reflect history. When using a historical system to define taxa, later evolution will distort the apparent evolutionary patterns of earlier time intervals by "retroactively" affecting which clusters of species are recognized as taxa (Van Valen, 1978; Sepkoski, 1987; Janis, 1992). Wagner (1995c) demonstrated the lack of congruence between the evolutionary patterns implied by phylogeny and monophyletic taxonomy among the gastropods described in this paper. Thus, regardless of whether strictly monophyletic taxa might be desirable for other reasons, paraphyletic taxa usually are necessary to reflect evolutionary dynamics accurately (Sepkoski and Kendrick, 1993; Patterson, 1994; Smith, 1994; Wagner, 1995c; Maley et al., 1997). There is a close correspondence between diversity patterns implied by the phylogeny presented herein and the patterns implied by traditional taxa (Wagner, 1995c). This has important implications for historical biodiversity studies that use higher taxa. Higher taxa are not considered entities in themselves in such studies, but rather they are sampling proxies for species (Sepkoski, 1987). Using higher taxa as proxies for species assumes that those higher taxa are not polyphyletic. The fact that highly polyphyletic gastropod taxa still accurately reflect species-level patterns suggests that taxonomic diversity studies are robust to violations of at least one important assumption.

Although many of the taxa are paraphyletic, all supraspecific taxa defined herein include at least one monophyletic clade at all times. Such taxa are labeled "paraclades" below (e.g., Raup and Gould, 1974). Paraclades are denoted with a " $†$ " symbol. Patterson and Rosen (1977) proposed this notation for denoting plesions (i.e., extinct sister clades of extant taxa). Although paraclades and plesions are not synonymous, plesions also have been described as plesiomorphic sister groups (e.g., Wiley, 1979; Eldredge and Cracraft, 1980). Paraclades as defined herein include a plesiomorphic sister taxon of a morphologically derived clade, with the plesion retaining the name associated with the ancestral morphotype. This emendation of the plesion concept allows both the recognition of ancestral types 
(if only in a broad sense) and the accurate depiction of diversity dynamics within the clade.

Traditional "evolutionary" taxonomy (e.g., Simpson, 1961) has relied as much on perceived morphologic grade and disparity as perceived phylogenetic relationships. Cladistic taxonomy grants no importance to disparity, on the basis that only sister taxa represent real units in biology. Curiously, it has never been demonstrated that clade membership is a better predictor of extinction and speciation dynamics or any other "real" aspects of evolution than is morphologic or ecologic grade. In the absence of appropriate analyses for distinguishing such groups (see, e.g., Purvis et al., 1995), I used traditional criteria for separating derived families and superfamilies from their paraphyletic relatives. This is done in part to maintain as many traditionally recognized taxa as possible, for an overly radical revision of any taxon probably is useless if the taxonomy is unrecognizable to workers specializing on that taxon. Also, it seems unlikely that malacologists would adhere to a taxonomic scheme that would reduce derived taxa, such as opisthobranchs, to a subfamily or genus within the Loxonematoidea. Many differences usually accorded generic or even familial-level disparities (e.g., ornamentation, closed-or opencoiling, spire height) are recognized, however, only when they coincide with major clades. In the future, methods of optimizing evolutionary parameters onto estimated phylogenies (see, e.g., Sanderson and Bharathan, 1993; Purvis et al., 1995) but designed to recognize major changes in those parameters might be used to construct quantitative, repeatable evolutionary taxonomies.

The primary taxonomic revision proposed herein is the removal of all early Paleozoic gastropods from the Pleurotomariina and transferring nearly all of them into either the Murchisoniina or Euomphalina. Pleurotomarioids are a subclade of the Vetigastropoda (Haszprunar, 1987), which in turn likely is a subclade of (or possibly equivalent to) one of the major subclades documented in this study. Determining the origin of the Pleurotomarioidea and other vetigastropods will be a topic of future research.

\section{Class Gastropoda Cuvier, 1797}

\section{Order "ARChAEOGASTROPODA" Thiele, 1925}

REMARKS.-As noted in the text, the "Archaeogastropoda" is not a particularly useful label owing to uncertainties and inconsistencies in the grade or paraphylum it defines. Better understanding of the relationships of modern gastropods to their early Paleozoic ancestors should obviate the need for the taxon. Ultimately, ordinal status probably should be granted to the clades corresponding to the Euomphalina and Murchisoniina as defined below; however, too much speculation is required presently to equate those taxa diagnosed herein with clades comprising modern taxa.

\section{Family $\nmid$ SINUOPEIDAE Wenz, 1938}

REMARKS.-Several Late Cambrian and earliest Ordovician gastropods do not belong to either the murchisoniinae or euomphalinae clades. It is simplest to place these taxa within the family Sinuopeidae, although the new definition of that taxon is very different from that of either Wenz (1938) or Knight et al. (1960). Wenz's original subfamilial definition of the taxon was limited to Sinuopea and Taeniospira, which are considered synonymous herein. The definition of Knight et al. included many post-Ordovician species that possessed $U$-shaped sinuses and no peripheral bands (like Sinuopea and Chepultapecia), but this analysis suggests that those species are members of the Raphistomatidae (see definition below). Although this family is paraphyletic relative to the Euomphalina and Murchisoniina (and possibly the Sinuitidae), sinuopeids represent a cohesive group whose termination in the Early Arenig is marked by the extinction of at least two true clades that retain very primitive morphologies.

\section{Genus $\dagger$ Sinuopea Ulrich, 1911}

FIGURE 8

?Chepultapecia Ulrich in Weller and St. Clair, 1928.

Taeniospira Ulrich and Bridge in Ulrich et al., 1930.

TYPE SPECIES.-Sinuopea sweeti (Whitfield, 1882).

FIRST KNOWN APPEARANCE (FKA).-S. sweeti: Oneota Sandstone (Late Trempealeauan).

LAST KNOWN APPEARANCE (LKA).--Taeniospira ?st. clairi Ulrich and Bridge in Ulrich et al., 1930: Smith Basin Limestone (Late Tremadoc (Demingian)).

ADDITIONAL ASSIGNED SPECIES.-Sinuopea basiplanata Ulrich and Bridge in Ulrich et al., 1930; Taeniospira emminencis Ulrich and Bridge in Ulrich et al., 1930.

REMARKS.-Sinuopea typically is diagnosed as lacking a peripheral band, although at least one previously recognized species ( $S$. basiplanata) retains the feature. Peripheral bands typically are highly diagnostic features, but the feature evidently was plastic among the earliest gastropods. As there is no phylogenetic boundary between Sinuopea and Taeniospira, they are synonymized herein. Taeniospira frequently is described as possessing a slit; however, the feature occurs only on the type specimen of one species and, moreover, appears to represent breakage rather than a true slit. Chepultapecia is somewhat more problematic, as it appears to be monotypic and known only from small, poorly preserved specimens. These specimens seem to possess $U$-shaped sinuses and lack peripheral bands, which are possible synapomorphies with very derived Sinuopea. Interestingly, the most parsimonious tree places them intermediate between $S$. sweet $i$ and the bellerophont Owenella. Better specimens for both Chepultapecia and Owenella are needed to explore this possibility more fully. 


\section{Genus $\nmid$ Schizopea Butts, 1926}

FIGURES 7,8

Dirhachopea Ulrich and Bridge in Ulrich et al., 1930.

Rhachopea Ulrich and Bridge in Ulrich et al., 1930.-Knight et al., 1960.

TYPE SPECIES.-Schizopea washburnis Butts, 1926.

FKA.-Dirhachopea normalis Ulrich and Bridge in Ulrich et al., 1930; D. subrotunda Ulrich and Bridge in Ulrich et al., 1930; Schizopea typica (Ulrich and Bridge in Ulrich et al., 1930): Eminence Dolomite (Late Trempealeauan).

LKA.-Schizopea washburnis: Roubidoux Formation (Late Tremadoc (Demingian)).

REMARKS. - The species classified in the genera listed above vary in peripheral band and coiling features. These features are more static in later gastropods, but they evidently varied among closely related species during the early phases of gastropod evolution.

\section{Genus Euconia Ulrich in Ulrich and Scofield, 1897}

\section{FIGURE 8}

Roubidouxia Butts, 1926.

Rhombella Bridge and Cloud, 1947.

Jarlopsis Heller, 1954.—Knight et al., 1960.

TYPE SPECIES.-Euconia etna (Billings, 1865).

FKA.-Jarlopsis conicus Heller, 1954: Gasconade Dolomite

(Early Tremadoc (Gasconadian)).

LKA.-Euconia etna: Smithville Formation (Early Arenig (Cassinian)).

AdDITIONAL AsSIGNED SPECIES.-Rhombella umbilicata (Ulrich and Bridge in Dake and Bridge, 1932).

REMARKS.-Several monotypic genera belonging to one clade are lumped herein. The species are united principally by greatly expanded right ramps and contracted left ramps, leaving the monolineate peripheral band very low on the whorl. The orientation and shape of the right ramp coupled with the relatively high translation produces a trochiform gross morphology.

\section{Genus Gasconadia Ulrich in Weller and St. Clair, 1928}

\section{FIGURE 8}

TYPE SPECIES.—Gasconadia putilla (Sarderson, 1896).

FKA.-Gasconadia putilla: Chepultepec Dolomite (Early Tremadoc (Gasconadian)).

LKA._Gasconadia putilla: Gasconade Dolomite (Early

Tremadoc (Gasconadian)).

REMARKS.-The highly derived nature of this monotypic genus makes determining its relationships difficult. Although it is simplest to link it to Dirhachopea, it is not much less parsimonious to derive it from Sinuopea. Therefore, I retain the genus at the present.

\section{?Genus Calaurops Whitfield, 1886}

REMARKS.-This genus is represented by numerous poorly preserved specimens. It might be derived from Late Tremadoc Dirhachopea, if so, then the two should be synonymized. It is also equally likely that Calaurops is derived from Bridgeites or even Macluritella. If so, then it should become the senior synonym for either of those two genera. Although the genus name has priority over all possible relatives, it should be considered invalid until better material can place its relationships

\section{Suborder EuOMPHALINA de Koninck, 1881}

REMARKS.-The Euomphalina herein equals the "euomphalinae" clade defined and diagnosed above. Four superfamilies are recognized, the Ophiletoidea, Macluritoidea, Euomphaloidea, and Platyceratoidea. The first three all evolved in the Tremadoc from species that would be classified in the genus Ophileta, which renders the Ophiletoidea nominally paraphyletic relative to the others. The final superfamily, the Platyceratoidea, likely evolved within the Euomphaloidea, but the great morphologic (apparently accompanied with ecologic) disparity renders its exact relationships problematic. This study does not thoroughly examine platyceratoids and detailed systematic work certainly is necessary. In the interim, it is prudent to separate the clade at a fairly high taxonomic level.

Because Knight et al. (1960) placed the Euomphaloidea within the Macluritina, one might argue for labeling the taxon the Macluritina in order to preserve priority. Macluritoids are associated with a particular highly derived morphology, however, and workers insisting on grade-based classifications likely would find "macluritoids" an unacceptable classification for many species within this clade. A similar argument would apply to labeling the clade the Patellogastropoda, if in fact patelloids did evolve from members of this clade. If the latter is true, then the Euomphalina (as defined herein) likely is equal to the Eogastropoda of Ponder and Lindberg $(1996,1997)$. Because "Euomphalina" also is associated with a morphologic grade, "Eogastropoda" would be a preferable label for this clade.

\section{Superfamily †OPHILETOIDEA trans. nov. Knight, 1956}

REMARKS.-The Ophiletoidea corresponds to the "ophiletoid" clade plus the species Ophileta supraplana. It is much more similar to the Ophiletidae as defined by Morris and Cleevely (1981) than to the Ophiletinae as defined by Knight et al. (1960). Members of this clade typically are diagnosed by a combination of characters yielding a lenticular aperture, a strong monolineate peripheral band, and an inner margin that typically forms the base of the shell. As with other higher taxa, all of these features are modified in the most derived members of the clade. 


\section{Genus $†$ Ophileta Vanuxem, 1842}

FIGURES 8,9

Ozarkispira Walcott, 1924.

TYPE SPECIES.-Ophileta complanata Miller, 1889.

FKA.-Ophileta supraplana Ulrich and Bridge in Ulrich et al., 1930: Chepultepec Dolomite (Early Tremadoc (Gasconadian)).

LKA.-Ophileta complanata: Nittany Dolomite (Late Tremadoc (Demingian)).

AdDitional ASSIGNED SPECIES.-Ozarkispira leo Walcott, 1924.

REMARKS. - The inclusion of species classified in Ozarkispira (one or more small species that typically are poorly preserved) maintains Ophileta as a paraclade.

\section{Genus $†$ Lecanospira Butts, 1926}

\section{FIGURE 9}

Barnesella Bridge and Cloud, 1947.

TYPE SPECIES.-Lecanospira compacta (Salter, 1859).

FKA.-Lecanospira compacta: Nittany Dolomite (Late Tremadoc (Demingian)).

LKA.-Barnesella aff. B. lecanospiroides Bridge and Cloud, 1947 (sensu Rohr et al., 1995): Skoki Formation (Early Llanvirn).

Additional ASSIGNED SPECIES.-Barnesella ?lecanospiroides Bridge and Cloud, 1947; Lecanospira nereine (Billings, 1865).

REMARKS.-Lecanospira now includes most species classified in Barnesella, which previously was separated at the subgenus or genus level based on stratigraphic position. Ultimately, it might be more appropriate to consider Lecanospira a junior synonym of Ophileta.

\section{Genus Ecculiomphalus Portlock, 1843}

\section{FIGURE 9}

Malayaspira Kobayashi, 1959.

Rossospira Rohr, 1994.

TYPE SPECIES.-Ecculiomphalus bucklandi Portlock, 1843.

FKA.-Malayaspira rugosa Kobayashi, 1959: Setul Formation (Late Arenig).

LKA.-Ecculiomphalus bucklandi: Balclatchie Group (Middle Caradoc (Harnagian)).

ADDITIONAL ASSIGNED SPECIES.-Ecculiomphalus fredricus Raymond, 1908; Maclurina ?annulata (Walcott, 1884); Malayaspira hintzei Rohr, 1984; Rossospira harrisae Rohr, 1994.

REMARKS.-Ecculiomphalus includes species with broad rectangular or pentagonal aperture shapes and a strong peripheral carina. Open coiling now diagnoses only derived members of the genus, and the frill-like peripheral band does not diagnose any members of Eccyliopterus.

\section{Genus $\dagger$ Asgardaspira, new genus}

FIGURE 9

TYPE SPECIES.—Lytospira yochelsoni Rohr, 1994.

FKA.-Barnesella measuresae Rohr, 1994: Antelope Valley (Late Arenig).

LKA.-Ophiletina aff. O. sublaxa of Rohr (1988) and Ecculiomphalus ?potteri (Rohr, 1988): Port Clarence Limestone (Ashgill).

ADDITIONAL ASSIGNED SPECIES.-Lytospira gerrula Rohr, 1993; L. ?norvegica (Koken, 1925).

ETYMOLOGY.-After the mythological Norse serpent, reflecting the open-coiled nature of most species.

REMARKS.-This paraclade includes species retaining lenticular apertures, sharp peripheral bands, and moderately deep Vshaped sinuses. Primitive members are diagnosed by a strong basal carina, which forms a stubby frill at the base of the outer margin. Carrier-shell scars and a columellar lirum typify both Asgardaspira and Lytospira, but the retention of the sharp peripheral band and sharp sinus separates Asgardaspira from Lytospira. Many of the species previously assigned to Lytospira are reassigned here. In addition, some poorly known Baltic species likely belong here.

\section{Genus Lytospira Koken, 1896}

FIGURE 9

TYPE SPECIES.-Lytospira angelini (Lindström, 1884).

FKA.—Lytospira angelini: Lower Gray Orthoceras Limestone (Late Arenig (Kundan)).

LKA.—Lytospira aff. L. subrotunda (sensu Rohr, 1994): Port Clarence Limestone (Ashgill (Richmondian)). ?Lytospira valida Koken, 1925: Lyckholm Formation (Late Ashgill (Porkuni)).

ADDITIONAL ASSIGNED SPECIES.-Lytospira subrotunda (Ulrich and Scofield, 1897).

REMARKS.-Lytospira is substantially reduced from previous definitions and now includes only open-coiled species with shallow $V$-shaped to $U$-shaped sinuses and weak peripheral bands. Also, the aperture profile is round (owing to the rounder ramps and the greater projections of the right and left ramps), whereas that of Asgardaspira is lenticular (see above). Lytospira almost certainly includes several other Baltic species described by Koken (1925) and others; however, the available material was too poor for me to include those species here. See remarks on Pachystrophia below.

\section{Superfamily MACLURITOIDEA Fischer, 1885}

REMARKS. - The Macluritoidea corresponds to the "macluritoid" clade. As noted herein and elsewhere (e.g., Linsley and Kier, 1984), many of the species previously placed in this taxon likely were not gastropods. Species within this superfamily typically are diagnosed by a base formed from a posteriorly projecting inner margin, nearly planispiral to visually dextral coiling, a shallow $\mathrm{V}$-shaped sinus, and a sharp thin peripheral 
band located on top of the aperture. Another diagnostic character is the change in shape of the aperture over ontogeny, with the left side expanding differentially to produce a rhombohedral adult aperture from a lenticular juvenile one. Finally, a horn-shaped calcified operculum with a handle-like knob diagnoses Teiichispira and more-derived species.

\section{Genus $†$ Macluritella Kirk, 1927}

FIGURES 8,10

?Bridgeina Flower, 1968a.

Prohelicotoma Flower, 1968b.

TYPE SPECIES.—Macluritella stantoni Kirk, 1927.

FKA.-Prohelicotoma uniangulata (Hall, 1847): Chepultepec Dolomite (Early Tremadoc (Gasconadian)).

LKA.-Macluritella stantoni: Rochdale Run Formation (Early Arenig (Jeffersonian)).

REMARKS.-Macluritella represents a primitive grade and paraclade of macluritoids. Although it is paraphyletic relative to later macluritoids, it appears to include a monophyletic clade of open-coiled, strongly septate species (e.g., M. stantoni and "Lytospira" gyrocera (Roemer)). Unfortunately, species other than $M$. stantoni are not well enough known to include in this analysis. If it should prove that those species do not belong to a Macluritella paraclade, then Macluritella should be expanded to include species presently assigned to Teiichispira.

\section{Genus †Teiichispira Yochelson and Jones, 1968}

FIGURE 10

Monitorella Rohr, 1994.

TYPE SPECIES.-Teiichispira kobayashi Yochelson and Jones, 1968.

FKA.-Maclurites ?oceana (Billings, 1865): Watts Bight Formation (Late Tremadoc (Demingian)).

LKA.-Undescribed species (initially described as " $E c$ cyliopterus ornata" by E.O. Ulrich in an unpublished manuscript): Murfreesboro Limestone (Early Caradoc (Ashbian)).

AdDitional ASSIGNED SPECIES.-Monitorella auricula Rohr, 1994; Teiichispira odenvillensis Yochelson and Jones, 1968.

REMARKS. - Teiichispira is a paraclade composed of species with juvenile whorls similar to that of adult Macluritella, but with apertures becoming more lenticular over ontogeny (with the long axis becoming parallel to the coiling axis). The diagnosis for Teiichispira originally was based on opercula (Yochelson and Jones, 1968), but the definition provided herein is based entirely on shell features. Monitorella Rohr, 1994, a monotypic genus from the Antelope Valley Formation, represents a species with somewhat rounder whorls than other species and does not appear to represent a separate clade. Owing to the inherent difficulty of linking opercula to shells, it might be advisable to replace Teiichispira with Monitorella in the future. Early Caradocian specimens labeled but not published by E.O. Ulrich appear to belong to this genus, which extends the range of Teiichispira somewhat. This highly derived species from the Murfreesboro Formation is noteworthy for strongly crenulated growth lines.

\section{Genus $\uparrow$ Maclurites Le Sueur, 1818}

FIGURE 10

TYPE SPECIES.-Maclurites magna Le Sueur, 1818.

FKA.-Teiichispira sylpha (Billings, 1865): Aguantha Formation (Early Arenigian (Cassinian)).

LKA.--Maclurites expansa Koken, 1925: Bøsnes Formation (Ashgill (Pirgu)).

AdDITIONAL AsSigned SPECIES.-Maclurites crassus Ulrich and Scofield, 1897; M. klamathensis Rohr, 1980.

REMARKS.-Maclurites is distinguished from Teiichispira by (1) greater expansion of the lower left portion of the aperture throughout ontogeny (producing a rhombohedral aperture rather than a lenticular one), (2) the peripheral band being above the "umbilicus" rather than above the center of the aperture, (3) a flatter inner margin (yielding a flat base), and (4) complete visually dextral coiling, with (at most) only the base of the aperture coiling in a planispiral plane. The inclusion of $T$. sylpha renders Maclurites paraphyletic relative to both Maclurina and Palliseria (see remarks below).

\section{Genus Maclurina Ulrich and Scofield, 1897}

\section{FIGURE 10}

TYPE SPECIES.-Maclurina manitobensis (Whiteaves, 1890).

FKA.-Maclurites bigsbyi (Hall, 1861): Platteville Formation (Early Caradoc (Black Riverian)).

LKA.-Maclurina manitobensis: Bighorn Dolomite (Ashgill (Richmondian)).

AdDITIONAL ASSIGNED SPECIES.-Maclurina logani Salter, 1859; Maclurites sedgewicki (Longstaff, 1924).

REMARKS.-Rohr, Blodgett, and Furnish (1992) separated Maclurites and Maclurina based on the latter taxon possessing a strong revolving ornament. The analyses herein suggest that the ornate species do form a clade, so Maclurina is recognized herein. Species not analyzed herein, such as Maclurites klamenthensis, leave Maclurites a paraclade.

\section{Genus Palliseria Wilson, 1924}

FIGURE 10

Mitrospira Kirk, 1929.—Knight et al., 1960.

Zhuozishanospira Yü, 1961

TYPE SPECIES.-Palliseria robusta Wilson, 1924.

FKA.-Palliseria robusta: Antelope Valley Limestone (Late Arenig (Whiterockian Zone M)).

LKA.-Palliseria robusta: Oil Creek Formation (Llanvirn). ADDITIONAL ASSIGNED SPECIES.-Mitrospira longwelli Kirk, 1929; Zhuozishanospira sinensis Yü, 1961.

REMARKS.-Palliseria is a highly derived clade of visually sinistral shells. The clade is diagnosed by a rounded inner mar- 
gin that forms the lower portion of the outer margin and ontogenetic "increase" in translation accompanied by some decrease in expansion yielding a somewhat cerithioid-form. These features, combined with expansion of the lower left portion of the aperture (present in ancestral Maclurites sylpha), produce counter-clockwise rotation of the aperture over ontogeny. The monotypic Zhuozishanospira differs only in the presence of ornament and is included within Palliseria in order to maintain monophyly.

\section{?Genus Rousseauspira Rohr and Potter, 1987}

TYPE SPECIES.-Rousseauspira teicherti Rohr and Potter, 1987.

FKA.-Rousseauspira aff. R. teicherti Rohr and Potter, 1987: Klamath Mountains Limestone (Llandeilo).

LKA.-Rousseauspira teicherti: Port Clarence Limestone (Ashgill (Richmondian)).

REMARKS.-Rohr and Potter, 1987, recognized this genus based solely on opercula. When these opercula are associated with shells, it is likely that they will diagnose a distinct clade within either Maclurites or Maclurina (or possibly even Teiichispira). Until that time, the genus should be considered questionable.

\section{Superfamily †EUOMPHALOIDEA de Koninck, 1844}

REMARKS.-With the likely exception of the Platyceratoidea, the Euomphaloidea corresponds to the "ceratopeatoid" clade described above. Early members of the family are diagnosed by a sigma-shaped inner margin, a strong channeled basal carina, an adapically curved monolineate peripheral band, and increasing translation accompanying abapical rotation of the aperture over ontogeny. Some or all of these features are modified on more-derived members of the clade.

\section{Family $†$ RAPHISTOMATIDAE Koken, 1896}

REMARKS. - This family corresponds to the "scalitine" clade diagnosed and defined above, plus the basal members of the Euomphalidae. Post-Silurian genera typically assigned to the Raphistomatidae (e.g., Arizonella Stoyanow, 1948, Buechelia Schlüter, 1894, Denayella Blodgett and Johnson, 1992, Scalitina Spriesterbach, 1919, and Wisconsinella Blodgett, 1987) appear to be related to eotomarioid taxa, such as Phanerotrema, rather than to raphistomatids (Wagner, in prep.). Thus, they are removed from the Raphistomatidae.

\section{Genus $\dagger$ Ceratopea Ulrich, 1911}

FIGURES 11-13

Proliospira Flower, 1968a.

TYPE SPECIES.-Ceratopea keithi Ulrich, 1911.

FKA.-Ceratopea canadensis (Billings, 1865): Fort Ann Limestone (Late Tremadoc (Demingian)).
LKA.-Helicotoma medfraensis Rohr and Blodgett, 1988: Telsitina Formation (Early(?) Llanvim).

AdDitional ASSigned SPECIES (excluding operculum species).-Ceratopea buttsi (Yochelson and Bridge, 1957); C. hammsi (Stauffer, 1937); C. ?laurentia (Billings, 1865); C. pygmaea (Stauffer, 1937); Pararaphistoma lemoni Flower, 1968a.

REMARKS.-Previous diagnoses of the genus have been based purely on operculum morphology, and the type species, Ceratopea keithi, is diagnosed by an operculum. This confounds typologic categorizations of the genus. Also, some $\mathrm{Cer}$ atopea opercula that are associated with shells are now transferred to other genera. Ceratopea is paraphyletic relative to the rest of the Euomphaloidea. The species retained within the genus, however, typically are diagnosed by lenticular apertures, strong adapically hooked peripheral bands, strong basal carinae, and deep strongly curved sinuses.

\section{Genus Bridgeites Flower, 1968a}

FIGURE 11

TYPE SPECIES.—Bridgeites discoideus Flower, 1968a.

FKA.-Bridgeites ?disjuncta (Billings, 1865): Oxford Formation (Late Tremadoc (Demingian)).

LKA.-Bridgeites planodorsalis (Cullison, 1944): Smithville Formation (Early Arenig (Cassinian)).

AdDITIONAL ASSIGNED SPECIES.-Bridgeites supraconvexa (Cullison, 1944).

REMARKS.-Early Ordovician species from North America previously classified as Lesueurilla by Cullison (1944) and others belong to this clade. The clade is diagnosed by nearly planispiral coiling, very strong basal carinae, and decreasing curvature over ontogeny that yields open-coiling (sensu Yochelson, 1971) in later stages.

\section{Genus Orospira Butts, 1926}

FIGURE [1

TYPE SPECIES.-OOrospira bigranosa Butts, 1926.

FKA.-Orospira gainesvillensis Cullison, 1944: Rich Fountain beds, Jefferson Formation (Early Arenig (Jeffersonian)).

LKA.-Orospira bigranosa: Cotter Formation (Early Arenig (Cassinian)).

REMARKS.-This is essentially an omate version of Ceratopea, including at most only two species. Most of the other "species" (see, e.g., Cullison, 1944) are simply variants of $O$. bigranosa.

\section{Genus Raphistoma Hall, 1847}

FIGURE 13

TYPE SPECIES.-Raphistoma striata (Emmons, 1842).

FKA.-Helicotoma gubanovi (Rohr, 1994): Antelope Valley Formation (Late Arenig (Whiterockian Zone M)). 
LKA.-Raphistoma striata: Valcour Formation (Late Llandeilo).

AdDITIONAL AsSIGNED SPECIES.-Scalites alaskensis (Rohr in Rohr, Blodgett, and Furnish, 1992).

REMARKS.-Although most of the species within the "raphistomatids" were once classified as Raphistoma, the current definition includes only a very restricted set of highly derived species. The clade is diagnosed in part by a slit and a dull broad peripheral band. Finally, although the stratigraphic record of first appearances within this group appears to run opposite to the cladogram, it should be noted that there is no Late Arenigian record for the eastern United States (which contains the most primitive members of the clade). Thus, there is no reason to think that $R$. striata evolved prior to the Llanvirn.

\section{Genus $\nmid$ Scalites Emmons, 1842}

FIGURE 13

TYPE SPECIES.-Scalites angulatus Emmons, 1842.

FKA._Palaeomphalus giganteus Kobayashi, 1959: Unkaku Beds (Late Arenig).

LKA.-Raphistoma tellerensis (Rohr, 1988): Port Clarence Limestone (Ashgill (Richmondian)).

ADDITIONAL ASSIGNED SPECIES.-Raphistoma peracuta (Ulrich and Scofield, 1897); Scalites katoi (Kobayashi, 1934).

REMARKS.-Scalites is expanded to include most of the species previously classified in Raphistoma. The type species, $S$. angulatus, is not typical of the paraclade and shares several synapomorphies with Raphistoma. It would be more consistent with the phylogeny to use Scalites for the Raphistoma genus as defined above, but this would require then creating a new genus for the paraclade. Keeping $S$. angulatus in the same genus as other Scalites species does not distort diversity dynamics (i.e., obscuring any originations or extinctions), so I chose to keep the traditional genera. Members assigned to the genus are diagnosed by flattened right ramps that (owing to the overall orientation of the aperture) are nearly perpendicular to the coiling axis, strong adapically hooked peripheral bands, and strong channeled basal carina.

\section{Family HolOPEIDAE Wenz, 1938}

REMARKS.- The new definition of the Holopeidae differs drastically from those presented by Wenz (1938) or Knight et al. (1960). Those definitions appear to be highly polyphyletic, and Holopea represents the only trochoid-like genus within the present definition of the family. This is unfortunate, as it means that the genus is very atypical of the eponymous family. Although taxonomic priority rules do not apply strictly to suprageneric taxa, it seems preferable to maintain as much of the old taxonomic structure as possible. The family is diagnosed by $U$-shaped sinuses, thus including many genera previously as- signed to the Sinuopeidae, and the loss of the peripheral band in all but the least derived members (e.g., Raphistomina species).

\section{Genus Raphistomina Ulrich and Scofield, 1897}

FIGURE I3

TYPE SPECIES.-Raphistomina lapicida (Salter, 1859).

FKA.-Raphistomina lapicida: Lower Antelope Valley Limestone (Late Arenig (Whiterockian, Zone M)).

LKA.-Raphistomina rugata Ulrich and Scofield, 1897: Port Clarence Limestone (Ashgill (Richmondian)).

AdDITIONAL Assigned SPECIES.-Liospira americana (Billings, 1865); Raphistomina aperta Wilson, 1921; R. fissurata Steele and Sinclair, 1971.

REMARKS.- The initial analyses (e.g., Wagner, 1995d) suggested that a ghost lineage linked Early Caradocian (and possible Llandeilian) Raphistomina with Llanvirnian Pachystrophia. (Pre-Llanvirnian reports of Raphistomina had invariably proved to be Ceratopea.) Since then, Rohr (1996) described Raphistomina from the Late Arenig and Early Llanvirn of the western United States. This represents one of the first confirmations of a ghost taxon estimate known to the author. The somewhat problematic specimens of Liospira americana are assigned here provisionally; it appears to represent a primitive grade of Raphistomina that retains a V-shaped sinus rather than a U-shaped one. The species also lacks any of the important synapomorphies of Liospira.

\section{Genus $\nmid$ Pachystrophia Perner, 1903}

FIGURES 13, 14

TYPE SPECIES.-Pachystrophia devexa (Eichwald, 1859).

FKA.-Pachystrophia devexa: Asirian Limestone (Late Llanvirn (Asirian)).

LKA.-Devonian species classified as "Lytospira" are known through the Late Eifelian.

ADDITIONAL ASSIGNED SPECIES.-Lytospira subuloides Barrande in Perner, 1903; L. triquestra (Lindström, 1884); Pachystrophia contigua (Ulrich and Scofield, 1897); P. gotlandica (Lindström, 1884).

REMARKS.-Pachystrophia is used herein to label an inornate paraclade of species with broad $U$-shaped sinuses and no peripheral bands. Post-Ordovician species previously classified as Lytospira are removed to Pachystrophia. Late Silurian and younger species are diagnosed by carrier-shell scars. Open-coiled Pachystrophia can be distinguished from Lytospira by the very broad whorls (produced by the very high angles of right and left ramp projections) with the long axis perpendicular to the coiling axis owing to the orientation of the whorl. Lytospira features a nearly circular aperture. In addition, Pachystrophia has a much broader $U$-shaped sinus than does Lytospira, and Pachystrophia has no trace of a peripheral band. 


\section{Genus Sinutropis Perner, 1903}

FIGURE I4

TYPE SPECIES.-Sinutropsis esthetica Barrande in Perner, 1907.

FKA.-Pachystrophia spiralis Rohr, 1980: Kangaroo Creek Formation (Caradoc (?Harnagian)).

LKA.-Sinutropis esthetica: Kopanina Formation (Late Ludlow (Ludfordian)).

ADDITIONAL ASSIGNED SPECIES.-Euomphalus tubus (Lindström, 1884); Sinutropsis ?esthetica (sensu Rohr, 1988).

REMARKS.-Sinutropis labels a clade of ornate species derived from Pachystrophia. The correlations for beds containing the earliest known species are uncertain; however, quantitative analysis of molluscan assemblages using Appearance Event Ordination (Alroy, 1994a) suggests that those Kangaroo Creek Formation beds correspond to the Harnagian (Wagner, in prep.).

\section{Genus Umbospira Perner, 1903}

Horiostomella Perner, 1903.

Sellinema Pemer, 1903.

Turbomaria Perner, 1903.

TYPE SPECIES.-Umbospira nigricans Barrande in Perner, 1907.

FKA._Umbospira yochelsoni Peel, 1977: Ross Brook Formation (Late Llandovery (Telychian)).

LKA.-Several species known from the Kopanina Formation (Late Ludlow (Ludfordian)).

AdDitionAl ASSIGNED SPECIES.-Horiostomella otiosa Barrande in Perner, 1907; Sellinema dive Barrande in Perner, 1907; Turbomaria sepulta Barrande in Perner, 1907.

REMARKS.-Umbospira represents an apparent clade of largely Gondwanan species derived from Pachystrophia. The genus is diagnosed by a very shallow and fairly narrow sinus. If Leptozone belongs to this clade, then the range of the genus extends through the Early Devonian (Pragian). The numerous junior synonyms of the genus reflects the taxonomy of Barrande and Perner in Perner $(1903,1907)$, which severely oversplits gastropods at both the species and genus level. My examinations suggest that many of Perner's genera comprise one recognizable species, with the additional species names within those genera usually reflecting intraspecific variants. This is partially rectified here.

\section{Genus Holopea Hall, 1847}

FIGURE 14

Litiopsis Salter, I866.

TYPE SPECIES.-Holopea symmetrica Hall, 1847.

FKA.-Holopea insignis Ulrich and Scofield, 1897: Lowville Formation (Early Caradoc (Black Riverian)).

LKA.- - Holopea has been recorded as late as the Early Serpukhovian. Given the featureless nature of the genus, however, its present definition likely is very polyphyletic. Holopea paludiniformis Hall, 1847, and $H$. parvula Ulrich and Scofield, 1897 , represent the latest species that certainly belong to the genus, being known from the Cobourg Formation (Late Caradoc, latest Shermanian/early Edenian). Holopea vermiculosa Barrande in Perner, 1907, from the Bohladec Formation (Late Caradoc) represents a roughly contemporaneous species. None of the species identified as "Holopea" by Lindström belong to this genus.

Additional AsSigned SPECIES.-Holopea ampla Billings, $1865 ; H$. pyrene Billings, $1865 ; H$. rotunda Ulrich and Scofield, 1897.

REMARKS.-Holopea is a highly derived clade of "raphistomatids." Unfortunately, the derivations involve the reduction of shell features, which limits the number of diagnostic characters (as opposed to diagnostic absences). Many shells that are featureless owing to poor preservation have been inappropriately assigned to Holopea. There do not appear to be valid members of this genus from the Ashgill or later.

\section{Family LESUEURILLIDAE, new family}

REMARKS.-This family corresponds to the "lesueurilline" clade diagnosed above. The most noteworthy features include a sharp peripheral band, often strongly developed, a deep Vshaped sinus culminating in a short notch (producing distinctive lunulae), and distinct ontogenetic changes from a "Raphistoma"-like early morphology to a "Maclurites"-like (e.g., Lesueurilla) morphology. One derived clade shows the opposite pattern, however, by producing "Liospira"-like late morphologies (i.e., Pararaphistoma).

\section{Genus $\dagger$ Eccyliopterus Remelé, 1888}

FIGURE 12

TYPE SPECIES.-Eccyliopterus alatus (Roemer, 1876).

FKA.-Lesueurilla declivis Koken, 1925: Asaphuskalk (Early Arenig (Volkov)).

LKA.-Eccyliopterus owenanus (Meek and Worthen, 1866): Fusispira bed, Prosser Formation (Middle Caradoc (Kirkfieldian)).

ADDITIONAL ASSIGNED SPECIES.-Eccyliopterus ?princeps Koken, 1925; E. regularis Koken, 1925.

REMARKS. - This paraclade comprises open-coiled "lesueurillines," with a derived clade featuring a very strong frill-like and adapically curved peripheral band. The confounding of this genus with Ecculiomphalus is puzzling, as the two share very few features. These differences include a number of characters involving the orientation and shape of different parts of the aperture (resulting in lenticular apertures for Eccyliopterus species and rhombohedral apertures with the inner margin forming a base for Ecculiomphalus species), the peripheral band (which is very strong with a pronounced adapical hook on Eccyliopterus species but weak and nearly 
straight on Ecculiomphalus species), and the sinus (which curves back strongly and culminates in a short notch on $E c$ cyliopterus species but is fairly shallow and V-shaped on $E c$ culiomphalus species).

\section{Genus $\nmid$ Lesueurilla Koken, 1898}

FIGURE I2

TYPE SPECIES.-Lesueurilla infundibula (Koken, 1896).

FKA.-Lesueurilla prima Barrande in Perner, 1907: Niveau G (Early Arenig (Klabava)).

LKA.-Eccyliopterus beloitensis Ulrich and Scofield, 1897: Platteville Formation (Early Caradoc (Black Riverian)).

AdDitional Assigned SPECIES.-Eccyliopterus louderbacki Endo, 1932.

REMARKS.-Usage of Lesueurilla is now restricted to a paraclade of nearly planispiral species with lenticular apertures oriented nearly parallel to the coiling axis and curved inner margins forming rounded bases. Lesueurilla and derivatives represent the earliest clade diagnosed by a slit, which is formed by an extension of the sinus and appears later in ontogeny on primitive members. Some derived Lesueurilla appear to have slits throughout ontogeny.

\section{Genus Mestoronema, new genus}

FIGURE 12

TYPE SPECIES.-Lesueurilla bipatellare Koken, 1925.

FKA.-Lesueurilla marginalis Koken, 1925: Revel Formation (Late Llanvirn (Asirian)).

LKA._Lesueurilla acutangulata Koken, 1925: Wesenberger Shale (Late Caradoc (Vormsi)).

ADDITIONAL ASSIGNED SPECIES.-Lesueurilla scotica Longstaff, 1924; L. spiralis Koken, 1925; L. aff. L. marginalis (in Rohr, 1980).

ETYMOLOGY.-After the ruler of the intelligent evil gastropods from the world's longest running science fiction serial, Doctor Who.

REMARKS.-This new genus recognizes a monophyletic group of close-coiled, generally small lesueurillids with strong, blunt and angled peripheral bands, and short slits that are apparently present throughout ontogeny and are produced as extensions of the sinus. Species can be distinguished from Lesueurilla by the strong angular umbilical carina, which sometimes creates as much of a profile as the periphal band.

\section{Genus Pararaphistoma Vostokova, 1955}

FIGURE I2

Climacoraphistoma Vostokova, 1955.-Knight et al., I960.

TYPE SPECIES.-Pararaphistoma qualteriata (Schlotheim, 1820).
FKA.—Climacoraphistoma vaginati (Koken, 1925): Niveau $G$ (Early Arenig (Klabava)).

LKA.-Climacoraphistoma spiralis (Koken, 1925): Keila Formation (Middle Caradoc (Keila)).

AdDITIONAL ASSIGNED SPECIES.-Climacoraphistoma damesi (Koken, 1925); Pararaphistoma schmidti (Koken, 1925).

REMARKS.-This derived genus is diagnosed by the development of a slit on more adult whorls and an ontogenetic rotation of the aperture and an increase in translation that produces a Ceratopea-like adult morphology from a Lesueurilla-like juvenile morphology.

\section{Family †HeLICOTOMIDAE Wenz, 1938}

REMARKS.-The Helicotomidae paraclade corresponds to the Ordovician members of the "helicotomid" clade; however, its extinction at the end of the Ordovician coincides with the true extinction of at least two and possibly three relatively primitive subclades. Nearly all members of this family and its derivatives are diagnosed by an anteriorly produced aperture with a distinct sigmoidal shape when viewed from the side (owing to the anterior angling of the base of the alveozone).

\section{Genus $\nmid$ Lophonema Ulrich in Purdue and Miser, 1916}

FIGURES II, 15

Polehemia Cullison, I944.

Walcottoma Rohr, 1994.

TYPE SPECIES.-Lophonema peccatonica Ulrich in Purdue and Miser, 1916.

FKA.-Ceratopea unguis Yochelson and Bridge, 1957: Watts Bight Formation (Late Tremadoc (Demingian)).

LKA.-Walcottoma frydai Rohr, 1994: Antelope Valley Formation (Llanvirn (Whiterockian Zone N)).

AdDitional Assigned SPECIES.-Polehemia taneyensis Cullison, 1944.

REMARKS.-Lophonema represents the basal paraclade of the helicotomids. Typical features include sharp carina on either side of the peripheral band and an anteriorly projected aperture. The monophyletic portion of the paraclade includes some of the earliest ornate species.

\section{Genus $\nmid$ Linsleyella Rohr, 1980}

Ellisella Rohr, 1980. [Not Gray, I858.]

Yochelsoniella Rohr and Huddleston, I982 [replacement name for Ellisella].

TYPE SPECIES.—Linsleyella johnstoni Rohr, 1980.

FKA.—Linsleyella greggi (Rohr, 1980): Kangaroo Creek

Formation (Llandeilo? Caradoc (Harnagian)).

LKA.-Linsleyella johnstoni: Kangaroo Creek Formation (Llandeilo? Caradoc (Harnagian)).

ADDITIONAL ASSIGNED SPECIES.-Helicotoma spinosa (Salter, 1859). 
REMARKS.-This genus is represented only by poor specimens; however, it is diagnosed by strong, spinose ornament and strong nodular lira on either side of the peripheral band. The stratigraphic position of the Kangaroo Creek beds in which two of the species are found is uncertain; however, quantitative analyses suggest an Early Caradocian age. This concurs well with the better constrained Black Riverian age for the basal member of the clade, L. spinosa.

\section{Genus $\nmid$ Helicotoma Salter, 1859}

\section{FIGURE 15}

TYPE SPECIES.-Helicotoma planulata Salter, 1859.

FKA.-Helicotoma tennesseensis Ulrich and Scofield, 1897 : Murfreesboro Limestone (Early Caradoc (Ashbian)).

LKA.- - Helicotoma robinsoni Rohr, 1988, and H. blodgetti Rohr, 1988: Port Clarence Limestone (Ashgill (Richmondian)).

AdDITIONAL ASSIGNED SPECIES.-Helicotoma planulatoides Ulrich and Scofield, 1897.

REMARKS. - The definition of Helicotoma presented herein is restricted to a paraclade of species with a strong adapically curved peripheral band and a round, anteriorly projected aperture with a broad dull carina on the border of the alveozone and base.

\section{Genus Palaeomphalus Koken, 1925}

\section{FIGURE IS}

TYPE SPECIES.-Palaeomphalus gradatus Koken, 1925.

FKA.-Helicotoma olsoni Rohr, 1980 (? = Helicotoma griffinora Rohr, 1980): Kangaroo Creek Formation (Caradoc (?Harnagian)).

LKA.-Palaeomphalus ?gradatus: Borkholm Formation (Late Ashgill (Porkuni)).

ADDITIONAL ASSIGNED SPECIES.-Euomphalus obtusangulus Koken, 1925.

REMARKS.-Palaeomphalus is restored here to label a clade of helicotomids with obtuse weak peripheral bands and highly reduced swellings on the alveozone, but with sharper circumbasal carina than found on Helicotoma species. An apparently undescribed species from the Thraive Limestone (Ashgillian) belongs here.

\section{Genus Ophiletina Ulrich and Scofield, 1897}

FIGURE 15

TYPE SPECIES.-Ophiletina sublaxa Ulrich and Scofield, 1897.

FKA.—Ophiletina sublaxa: Murfreesboro Limestone (Early Caradoc (Ashbian)) or Oriostoma bromidensis Rohr and Johns, 1990: Bromide Formation (Early Caradoc (Ashbian)).

LKA.—Ophiletina sublaxa: Fusispira Beds, Prosser Formation (Middle Caradoc (Kirkfieldian)).
AdDITIONAL ASSIGNED SPECIES.-Ophiletina angularis Ulrich and Scofield, 1897; Oriostoma bromidensis Rohr and Johns, 1990.

REMARKS.-Ophiletina represents a monophyletic genus diagnosed by the characters discussed in the text.

\section{Family †EUOMPHALIDAE de Koninck, 1881}

REMARKS.-The Euomphalidae represents a paraclade that includes the Silurian species corresponding to traditional diagnoses of the family (e.g., Knight et al., 1960). Ordovician species previously assigned to Euomphalopterus (reassigned herein to Boucotspira) represent the only Ordovician members of the family, and render the family paraphyletic relative to the Pseudophoridae and Anomphalidae. Although the Silurian assemblage within the family is monophyletic, preliminary analyses suggest that the Euomphalidae as defined herein include the ancestors of Devonian and later taxa presently assigned to both the Omphalotrochidae and the Omphalocirridae.

\section{Genus $\nmid$ Boucotspira Rohr, 1980}

Figures I5, 16, 19

TYPE SPECIES.-Boucotspira fimbriata Rohr, 1980.

FKA.-Boucotspira aff. B. fimbriata: Lower Antelope Valley Limestone (Late Arenig (Whiterockian Zone M)).

LKA.-Streptotrochus incisus (Lindström, 1884) Slite Bed (Unit G) (Wenlock (Sheinwoodian)).

ADDITIONAL AsSIGNED SPECIES.-Euomphalopterus ?cariniferus Koken, 1925; E. ?ordovicius Longstaff, 1924; $E$. aff. $E$. ordovicius Longstaff, 1924; Streptotrochus lamellosus (Lindström, 1884); Streptotrochus? visbeyensis (Lindström, 1884); Trochonemella antelopensis Rohr, 1996.

REMARKS.-This paraclade is strongly convergent on the lophospirid genera Trochonema and Trochonemella. Trochonemella antelopensis is either a variant of $B$. fimbriata or a closely related slit-bearing species. Boucotspira includes the Late Ordovician species that were previously classified as $E \mathbf{~}$ omphalopterus. Silurian species retaining strong right and left ramp carina are retained within Boucotspira. The paraclade is diagnosed by these prominent right and left carina, with the left (alveozone) carina usually stronger than the right.

\section{Genus $†$ Euomphalopterus Roemer, 1876}

Figures 16-18

Pleuromphalus Perner, 1903.-Knight et al., I960.

Bathmopterus Kirk, I928.-Knight et al., I960.

?Siskyouspira Rohr, 1980.

TYPE SPECIES.-Euomphalopterus alatus (Wahlenberg, 1821).

FKA.-Euomphalopterus subcarinatus (Lindström, 1884): Solvik Formation (Middle Llandovery (Aeronian)). 
LKA.-Euomphalopterus has been recorded as late as the Emsian.

AdDitional ASSigned SPECIES.-Euomphalopterus aliger Barrande in Perner, 1903; E. praetextus (Lindström, 1884); E. togatus (Lindström, 1884); E. undulans (Lindström, 1884).

REMARKS.-Euomphalopterus represents the basal paraclade of the Euomphalidae. It is diagnosed by a very strong alveozone carina that often produces a frill, which is lost or highly modified in other euomphalid genera. The exceptionally strong development of this feature in the type species appears to be unique.

\section{Genus Spinicharybdis Rohr and Packard, 1982}

FIGURE 17

TYPE SPECIES.-Spinicharybdis wilsoni Rohr and Packard, 1982.

FKA.-?Euomphalopterus frenatus (Lindström, 1884): Lower Visby Formation (Late Llandovery (Telychian)).

LKA.-Spinicharybdis wilsoni: Barrow Inlet Formation (Late Ludlow (Ludfordian)).

ADDITIONAL ASSIGNED SPECIES.-Spinicharybdis billingsi Rohr and Packard, 1982; S. ehlora (Billings, 1865).

REMARKS. - Spinicharybdis is diagnosed by strong tubes at the base of the lower ramp. These apparently were derived from the frill of Euomphalopterus, although some alternative phylogenetic scenarios are discussed above in "Results."

\section{Genus †Poleumita Clarke and Ruedemann, 1903}

FIGURES $16-18$

?Kiaeromphalus Peel and Yochelson, 1976.

?Offleyotrochus Peel, 1979.

TYPE SPECIES.-Poleumita discors (Sowerby, 1814).

FKA.-Poleumita discors: Lower Visby Formation (Late Llandovery (Telychian)).

LKA.-Poleumita discors: Upper Ludlow Formation (Late Ludlow (Ludfordian)). (Poleumita are reported as late as the Emsian, but the veracity of these assignments cannot be evaluated herein).

Additional ASSIGNed SPECIES.-Poleumita alata (Lindström, 1884); P. granulosa (Lindström, 1884).

REMARKS.-Poleumita represents a paraclade containing the ancestors of important euomphalids of the late Paleozoic, such as Euomphalus and Straparollus. A thick, strip-like parietal inductura projecting well in front of the aperture diagnoses the genus as well as some descendants (e.g., Nodonema and Centrifugus). Poleumita differs from Euomphalus by the retention of strong ornament and from Straparollus by the retention of both ornament and a peripheral band.

Kiaeromphalus and Offleyotrochus are tentatively placed within Poleumita. Both genera are known from a single spe- cies, and little of the overall characteristics are known, especially for Offleyotrochus. More and better material are required before separate generic assignments can be justified.

\section{Genus Nodonema Linsley, 1968}

FIGURE 18

TYPE SPECIES.—Nodonema granulata Linsley, 1968.

FKA.-Poleumita rugosa (Lindström, 1884): Lower Visby Formation (Late Llandovery (Telychian)).

LKA.-Nodonema granulata: Anderdon Limestone (Eifelian).

Additional Assigned Species.-Poleumita octavia (M'Coy, 1851).

REMARKS.-Nodonema represents a high-spired variant of Poleumita, with strong nodular ornament. It is very similar to the contemporaneous lophospirid genus Globonema, but it differs in its slightly sigmoidal aperture, thick parietal inductura strip, and nodular ornament. Many post-Silurian species previously assigned to Gyronema might belong here.

\section{Genus Centrifugus Bronn, 1834}

FIGURE 18

TYPE SPECIES.-Centrifugus planorbis Bronn, 1834.

FKA.-Centrifugus planorbis: Upper Hemse Beds (Early Ludlow (Gorstian)).

LKA.-Centrifugus planorbis: Lower Ludlow Formation (Early Ludlow (Gorstian)).

REMARKS.-This is one of the few monotypic genera maintained herein. It might be better to lump this genus with Poleumita (in which case, Centrifugus would represent the senior synonym). Given the morphologic disparity between this species and its closest relatives, however, I keep them separate for now.

\section{Genus Euomphalus Sowerby, 1814}

FIGURE 18

TYPE SPECIES.-Euomphalus pentangulatus Sowerby, 1814. FKA.-Euomphalus walmstedti Lindström, 1884: Wenlock Limestone (Late Wenlock (Gleedonian)).

LKA.-Euomphalus is recorded as late as the Norian (e.g., Yin and Yochelson, 1983).

REMARKS.-The definition presented herein is highly abbreviated, as Euomphalus is one of the most commonly described genera of the Paleozoic. Whether it represents a cohesive phylogenetic unit requires further investigation. Euomphalus almost certainly represents a phylogenetic unit distinct from Straparollus (pers. obs.), so there is no reason to consider the former a subgenus of the latter. 
Genus Straparollus de Montfort, 1810

FIGURE 18

TYPE SPECIES.-Straparollus dionysii de Montfort, 1810. FKA.-Straparollus paveyi Foerste, 1924 (?= S. bohemicus Barrande in Perner, 1907): Racine Dolomite (Early Ludlow (Gorstian)).

LKA.-Straparollus is recorded as late as the Guadalupian.

REMARKS.-Like Euomphalus, Straparollus is a commonly described genus; however, it seems highly unlikely that it presently constitutes a cohesive phylogenetic unit (pers. obs.).

\section{Genus Micromphalus Knight, 1945}

REMARKS.-Tassell (1979) assigned a Late Silurian species to this genus but did not specify the species or formation. This genus might belong to the Pseudophoridae.

\section{Family ANOMPHALIDAE Wenz, 1938}

REMARKS.-This monophyletic family corresponds to the "anomphalides" described above in "Results." In addition to the genera included herein and elsewhere (e.g., Knight et al., 1960), some genera assigned to the Omphalotrochidae (e.g., Labrocuspis Kase, 1989) might belong here. It appears, however, that true omphalotrochids likely evolved elsewhere within the Euomphalidae (Erwin, in prep.). The family is diagnosed by a $U$-shaped sinus located high on the aperture and a very strong lirum on the inner margin, which frequently produces a callus that fills the umbilicus.

\section{Genus $\dagger$ Trochomphalus Koken, 1925}

FIGURE 16

Grantlandispira Peel, 1984a.

TYPE SPECIES.-Trochomphalus ?dimidiatus (Koken, 1896).

FKA.-Trochomphalus ?dimidiatus: Borkholm Formation (Ashgill (Pirgu)).

LKA.-Grantlandispira christei Peel, 1984a: Offley Island Formation (Late Llandovery (Telychian)).

ADDITIONAL ASSIGNED SPECIES.-Straparollina aff. $S$. circe of Rohr (1988).

REMARKS.-It is not clear that this genus represents a paraclade, so it might prove better to consider this a junior synonym of Pycnomphalus. Conversely, given that it certainly spans through the poorly sampled earliest Silurian, it is possible that additional sister species of $T$. christei exist, which would justify reinstatement of Grantlandispira.

\section{Genus Pycnomphalus Lindström, 1884}

FIGURE 16

?Nematotrochus Perner, 1903.

?Pycnotrochus Perner, 1903.
Turbocheilus Perner, 1903.

?Isfarispira Gubanov et al., 1995.

TYPE SPECIES.-Pycnomphalus obesus Lindström, 1884.

FKA.-Pycnomphalus acutus Lindström, 1884: Lower Visby Formation (Late Llandovery (Telychian)).

LKA.-Pycnomphalus inflatus Barrande in Perner, 1903 $(?=$ P. obesus $)$ Prídoli Formation (Prídolí).

ADDITIONAL AsSigned SPECIES.-?Nematrochus concurens Barrand in Perner, 1907; Turbocheilus immaturum (Barrande in Perner, 1903).

REMARKS.-Pycnomphalus clearly is paraphyletic relative to later anomphalids; as such, its last appearance must be considered tentative pending additional systematic work on the anomphalids. The genus is diagnosed by a callus filling (or nearly filling) the umbilicus and by the loss of the peripheral band. All species but the most primitive lack the prominent alveozone. Pycnotrochus (Kopanina Formation, Late Ludlow) might represent basal members of Anomphalus rather than derived Pycnomphalus, but too little material is available to verify this. Isfarispira appears to retain the basic synapomorphies of Pycnomphalus, although it clearly has a derived ontogenetic change in the basic coiling parameters. Gubanov et al. (1995) suggested that other species might be assignable to $I s$ farispira; if so, then the genus should be maintained as a separate entity.

\section{Family PSEUdOPHORIDAE Miller, 1889}

REMARKS.-The family corresponds to the "pseudophoride" clade diagnosed above in "Results." Most of the middle Paleozoic gastropods previously classified in the Trochina belong to this family. As extant trochoids are vetigastropods, it is highly unlikely that pseudophorids and trochoids are closely related. The family is diagnosed by strongly tangential apertures produced by a greatly reduced sinus and anterior production of the base, a strongly sigmoidal aperture, and a strong inclination of the aperture.

\section{Genus Pseudophorus Meek, 1873}

FIGURE 19

TYPE SPECIES.-Pseudophorus antiquus (Meek, 1872).

FKA.—Discordichilus kolmodini (Lindström, 1884): Conchidium Bed, Slite Formation (Early Wenlock (Sheinwoodian)).

LKA.-Yochelson and Saunders (1967) record this species from Tournaisian strata.

ADDITIONAL ASSIGNED SPECIES.-Pseudophorus profundus Lindström, 1884.

REMARKS.-Pseudophorus likely represents a paraclade relative to several post-Silurian taxa. More detailed systematic work is necessary to ascertain whether the paraclade actually extends into the Carboniferous. 


\section{Genus Pseudotectus Perner, 1903}

FIGURE 19

Planitrochus Perner, 1903.

Palaeonustus Perner, 1903.

TyPE SPECIES.-Pseudotectus comes Barrande in Perner, 1907.

FKA.-Discordichilus kolmodini (Lindström, 1884): Conchidium Bed, Slite Formation (Early Wenlock (Sheinwoodian)).

LKA.-Pseudotectus comes: Konéprussy Formation (Pragian). Blodgett, Rohr, and Boucot (1988) reported Planitrochus from "Lockhovian-Emsian" aged material from the MacKenzie Mountains. Linsley (1979) recorded Eifelian Planitrochus but did not make reference to particular specimens or formations.

AdDitionAl Assigned SPECIES.-Pseudotectus amicus Barrande in Perner, 1907.

REMARKS.-Pseudotectus comprises (in part) two monotypic genera diagnosed by Perner (1907), Planitrochus and Palaeonustus. It is diagnosed by the loss of the sinus, the loss of the peripheral band and right ramp, and a strong thick alveozone carina that produces a weak frill.

\section{Genus $\nmid$ Discordichilus Cossmann, 1918}

FIGURE 19

?Umbotrochus Perner, 1907.

Siluriphorus Cossmann, 1918.

TYPE SPECIES.-Discordichilus mollis (Lindström, 1884).

FKA.-Siluriphorus gotlandicus (Lindström, 1884): Lower Visby Formation (Early Wenlock (Sheinwoodian)).

LKA.-Dischordichilus mollis: Hemse Marl (Early Ludlow (Gorstian)); ?Umbotrochus asperus (Barrande in Perner, 1903): Kopanina Formation (Late Ludlow (Ludfordian)).

ADDITIONAL ASSIGNED SPECIES.-Dischordichilus dalli (Lindström, 1884); Siluriphorus undulans (Lindström, 1884).

REMARKS.- This paraclade includes the ancestors of Streptotrochus. In order to make Discordichilus a paraclade, species previously assigned to Siluriphorus now belong to Discordichilus. The paraclade appears to become truly extinct in the Ludlow, but Eifelian species have been assigned to Siluriphorus. Umbotrochus is represented by one poorly preserved species, but it is very similar to $D$. mollis. If it is related, then the range of the genus is extended slightly.

\section{Genus Hystricoceras Jahn, 1894}

FIGURE 19

TYPE SPECIES.-Hystricoceras spinosum Jahn, 1894.

FKA.-Hystricoceras astraciformis (Lindström, 1884): Lower Visby Formation (Early Wenlock (Sheinwoodian)).

LKA.-Hystricoceras spinosum: Kopanina Formation (Late Ludlow (Ludfordian)).
REMARKS. - This genus is diagnosed by distinctive spines on the alveozone-base periphery. Devonian taxa, such as $A s$ tralites, might have evolved from within Hystricoceras; if so, then it is possible that the extinction of the genus is later than reported herein.

\section{Genus Streptotrochus Perner, 1903}

FIGURE 19

Perneritrochus Cossmann, 1908.

TYPE SPECIES.-Streptotrochus venalis (Barrande in Perner, 1903).

FKA.-Streptotrochus incisus (Lindström, 1884): Lower Visby Formation (Early Wenlock (Sheinwoodian)).

LKA.-Streptotrochus carinatus (Barrande in Perner, 1907): Konéprussy Formation (Pragian). Blodgett, Rohr, and Boucot (1988) reported Perneritrochus from "Lockhovian-Emsian" aged material from the MacKenzie Mountains.

ADDITIONAL ASSIGNED SPECIES.-Streptotrochus lundgreni (Lindström, 1884).

REMARKS.-Streptotrochus is used herein to label a paraphyletic group diagnosed by the characters discussed above in "I.3.2.2.3 Pseudophorides." Perneritrochus differs by the nearly complete elimination of the sinus. It is included within Streptotrochus to maintain monophyly.

\section{Genus Elasmonema Fischer, 1885}

TYPE SPECIES.-Elasmonema bellatula (Hall, 1861).

FKA.-Elasmonema imitator (Hall and Whitfield, 1872): Racine Dolomite (Late Wenlock (Gleedonian)).

LKA.-Linsley (1979) reported a Frasnian occurrence for this genus.

REMARKS.-Preliminary analyses of Devonian members of this genus place it as a sister taxon to Discordichilus mollis. The Silurian specimens that I have examined corroborate this hypothesis.

\section{Suborder MurChisoniINA Cox and Knight, 1960}

REMARKS.-The Murchisoniina now include most of the genera traditionally placed in the Pleurotomariina. The Murchisoniina also include the earliest caenogastropods sensu lato and the ancestors of more-derived gastropods, such as opisthobranchs. It seems unlikely that most malacologists will accept ranking those taxa below the suborder (the preceding examples have been accorded ordinal or class level). Thus, future work likely will render the murchisoniinae paraphyletic.

Although the suborder defined herein is similar to the Pleurotomariina as defined by Yochelson (1984; see also Gordon and Yochelson, 1983), retaining the Pleurotomariina would be at odds with recent neontological work (e.g., Haszprunar, 1988; Ponder and Lindberg, 1996, 1997). The definition also differs from Yochelson's Pleurotomariina by excluding bellerophonts. 
Should future work corroborate suggestions that Sinuites and/ or other bellerophont gastropods belong to this clade, then they too should be included in the Murchisoniina. Finally, future work might equate this clade with the Orthogastropoda of Ponder and Lindberg (1996); again, this would be a preferable label than "murchisoniinae" simply because "Orthogastropoda" is not associated with a morphologic grade.

\section{Superfamily $\nmid$ MURCHISONIOIDEA Koken, 1896}

REMARKS.-As the earliest members of the Murchisoniina have been classified as Hormotoma, the Murchisonioidea is used to label the paraclade within the Murchisoniina. In fact, the paraphyletic portions of the Murchisonioidea all are assigned to Hormotoma, so it is monophyletic excepting for that genus. The clade is diagnosed by several features yielding an asymmetrical aperture, with the post-torsional left side greatly expanded at the expense of the right side. A weak bilineate peripheral band also typifies members of the superfamily, although the feature is lost or highly modified on some species.

\section{Family †HORMOTOMIDAE Wenz, 1938}

REMARKS.-The family Hormotomidae is resurrected to label the paraclade within the Murchisonioidea. The Murchisoniidae, Eotomarioidea, Subulitoidea, and Loxonematoidea all are derived from members of this family. The paraclade includes at least one monophyletic group at all times, however, and the post-Ordovician definition (see below) is strictly monophyletic.

\section{Genus $\nmid$ Hormotoma Salter, 1859}

FIGURES $8,20,22-24$

Cyrtostropha Donald, 1902

TYPE SPECIES.-Hormotoma gracilis (Hall, 1847).

FKA.-Hormotoma ?simulatrix (Billings, 1865): Watt's Bight Formation (Late Tremadoc (Demingian)).

LKA.-Cyrtostropha coralli (Sowerby in Murchison, 1839): lower Ludlow Formation (Early Ludlow (Gorstian)).

ADDITIONAL ASSIGNED SPECIES.-Hormotoma centervillensis (Foerste, 1923); H. confusa Cullison, 1944; Turritoma ?anna (Billings, 1865).

REMARKS. - Hormotoma as used herein is a large paraclade including high-spired species with round whorls and strong bilineate peripheral bands. The genus terminates with a true extinction with the demise of the $H$. centervillensis clade in the Late Silurian. Pre-Silurian species classified as Coelocaulus belong to this clade.

\section{Genus $\nmid$ Coelocaulus Oehlert, 1888}

\section{FIGURE 23}

TYPE SPECIES.—Coelocaulus davidsoni (Oehlert, 1877).

FKA.-Hormotoma insignis Koken, 1925: Wesenberger Shale (Late Caradoc (Vormsi)).
LKA.-Blodgett et al. (1990) reported Coelocaulus species from unspecified Emsian localities.

ADDITIONAL ASSIGNED SPECIES.-Coelocaulus concinnus Horný, 1952; Hormotoma cingulata (Lindström, 1884); $H$. monoliniformis (Lindström, 1884).

REMARKS.-Silurian Coelocaulus represent a purely paraphyletic group relative to both Catazone and Mesocoelia. A Devonian monophylum that includes the type of the genus ( $C$. davidsoni) certainly is derived from this paraclade, so the name is used for the larger paraclade. The genus differs from Hormotoma in the presence of a slit. It differs from slit-bearing murchisoniids (see below) in retaining very round whorls, a bilineate peripheral band with weak lira, and a highly asymmetrical sinus.

\section{Genus Catazone Perner, 1903}

FIGURE 23

TYPE SPECIES.-Catazone cunea Barrande in Perner, 1907.

FKA.-? Catazone argolis Barrande in Perner, 1907, and other species: Prídolí Formation (Prídolí).

LKA.- "Murchisonia" nevadana Blodgett and Johnson, 1992: Robert Mountains kockelianus-zone Limestone (Eifelian).

AdDitional ASSIGNED SPECIES.-Catazone allevata Barrande in Perner, 1907.

REMARKS.-The definition of Catazone used herein is much broader than that based on the traditional diagnosis of the genus. The weak peripheral band low on the whorl now diagnoses only the most-derived species. The major feature now diagnosing the clade is an inflated upper ramp that gives the aperture a nearly square shape.

\section{Genus Mesocoelia Perner, 1907}

TYPE SPECIES.-Mesocoelia janus Barrande in Perner, 1907. FKA.-Kopanina Formation (Late Ludlow (Ludfordian)).

LKA.-Eifelian (Linsley, 1978).

REMARKS.-Unfortunately, the available specimens for this genus all are incomplete; however, it does appear to represent a sister taxon to the Catazone argolis clade. If it does represent a separate monophyletic group, then the basal species in Catazone should be transferred here, as Mesocoelia retains a more primitive morphology.

\section{Genus Plethospira Ulrich in Ulrich and Scofield, 1897}

FIGURE 20

Seelya Ulrich in Ulrich and Scofield, 1897.

TYPE SPECIES.-Plethospira cassina (Whitfield, 1886).

FKA.-Plethospira cannonensis (Stauffer, 1937): Gorman Falls Formation (Late Tremadoc (Jeffersonian)).

LKA.-Plethospira cassina and Seelya ventricosa Ulrich in Ulrich and Scofield, 1897: Fort Cassin Formation (Early Arenig (Cassinian)). 
REMARKS. - It actually is inappropriate to put Plethospira in the Hormotomidae, as the other clades branching at this time are accorded superfamilial status. Plethospira was a more rapidly terminated dead end (producing as few as three species), so according it higher rank than a genus seems absurd. Also, it maintains the paraclade status of the Hormotomidae at a higher level, ensuring that there is always at least one monophyletic clade within the family at all times. Seelya is synonymized herein; it previously was separated only by the presence of ornamentation.

As none of the other genera previously classified in the Plethospiridae are closely related to Plethospira, usage of that family should be discontinued.

\section{Family MURCHISONIIDAE Koken, 1896}

REMARKS. - The Murchisoniidae herein are restricted to a monophyletic group of "hormotomoids" with concave upper whorls and fairly acute sutures. The clade also appears to be diagnosed by a large, planispirally coiled protoconch.

\section{Genus $\nmid$ Murchisonia d'Archaic, 1841}

FigURES 23,24

Goniostropha Oehlert, 1888

TYPE SPECIES.-Murchisonia bilineata Dechen in De la Beche, 1831.

FKA.-Hormotoma salteri (Ulrich and Scofield, 1897):

Black River Formation (Early Caradoc (Black Riverian)).

LKA.-Late Guadalupian.

AdDitional AsSigned SPECIES.-D. morinenis Horný, 1953; Goniostropha cava (Lindström, 1884); G. sculpta (Barrande in Perner, 1907); Hormotoma subplicata (Lindström, 1884); Murchisonia laphami Whiteaves, 1895.

REMARKS.-Murchisonia as defined herein represents a much narrower range of species than it has in traditional definitions. It is still a paraclade, however, as Morania is considered a derivative herein. The chief difference between Murchisonia and Hormotoma is the acute, somewhat channeled suture of Murchisonia, which contrasts with the rounded upper whorl of Hormotoma. A slit diagnoses more-derived members of Murchisonia.

\section{Genus Morania Horný, 1953}

FIGURE 24

?Leptorima Perner, 1907.

TYPE SPECIES.-Morania v-sinuata Horný, 1953.

FKA.-Loxonema? attenuata (Lindström, 1884): Bed G, Slite Formation (Early Wenlock (Sheinwoodian)).

LKA.—Donaldiella declivis (Barrande in Perner, 1907): Kopanina Formation (Late Ludlow (Ludfordian)).

ADDITIONAL ASSIGNED SPECIES.-Murchisonia paradox Lindström, 1884.
REMARKS. - The problematic Leptorima likely is synonymous with Morania. Because Leptorima is known from very poor material and has not been used aside from the original description, it cannot be used reliably and should be disregarded.

\section{Genus Michelia Roemer, 1854}

FIGURE 24

Sinuspira Perner, 1907.

TYPE SPECIES.-Michelia cylindrica Roemer, 1854.

FKA.- - Hormotoma attenuata (Lindström, 1884): Bed B, Slite Formation (Early Wenlock (Sheinwoodian)).

LKA.-The type and other species are known from the Emsian.

AdDitional Assigned SPECIES.-Sinuspira tenera Barrande in Perner, 1907.

REMARKS.-Michelia and Sinuspira are united herein based on their shared loss of the peripheral band late in ontogeny. The deep, highly asymmetrical sinus clearly links them to murchisoniids rather than to loxonematids.

\section{Superfamily LOXONEMATOIDEA Koken, 1889}

$$
? \text { = Basal Apogastropoda + Euthyneura }
$$

REMARKS.-This represents one of the few clades separated at a higher rank because of morphologic disparity. The superfamily probably is synonymous with traditional paleontological definitions of the Caenogastropoda, which is a suborder. Among more modern taxonomies, it likely is synonymous with the Apogastropoda + Euthyneura of Haszprunar, 1988. Whether this disparity contributes to any real difference relative to the Murchisonioidea (i.e., changes in rates of speciation, extinction, or morphologic change) awaits later testing.

\section{Family LoXONEMATIDAE Koken, 1889}

REMARKS.-The addition of Devonian species will render this a paraclade, as it is unlikely that the earliest heterostrophs (e.g., Pseudozygopleura) will be retained with other loxonematoids. Again, whether heterostrophic coiling sufficiently alters evolutionary patterns to merit such recognition will require quantitative demonstration.

\section{Genus $\nmid$ Loxonema Phillips, 1841}

Figure 25

TYPE SPECIES.-Loxonema sinuosa Phillips, 1841.

FKA.-Loxonema murrayana Salter, 1859: Paquette Rapids Black River Formation (Early Caradoc (Black Riverian)).

LKA.-Wenz (1938) recorded a Norian occurrence of the genus.

AdDitional ASSIGNED SPECIES.-Loxonema brogeri Koken, 1925; L. costulata Barrande in Perner, 1907; L. cross- 
manni Phillips, 1841; L. fasciata Lindström, 1884; L. strangulata Lindström, 1884.

REMARKS.-As used herein, Loxonema represents a paraclade of "omospirines" with deep U-shaped sinuses but no peripheral bands. The paraclade status is maintained in the Silurian through several species that are not illustrated. Future work probably will break the present definition (which extends through the Triassic) into several genera.

\section{Genus $†$ Omospira UIrich and Scofield, 1897}

FIGURES 23, 25

TYPE SPECIES.-Omospira laticincta Ulrich and Scofield, 1897.

FKA.-Omospira laticincta and $O$. alexandra Ulrich and Scofield, 1897: Platteville Formation (Early Caradoc (Black Riverian)).

LKA.-Turritoma pinguis (Donald, 1902) (? = Turritoma polita (Barrande in Perner, 1907)): Starfish Bed, Thraive Glen Formation (Ashgill (Rawtheyan)).

ADDITIONAL ASSIGNED SPECIES.- - Hormotoma trentonensis (Ulrich and Scofield, 1897).

REMARKS.-This paraclade is diagnosed by the retention of a weak bilineate peripheral band, a shallow nearly symmetrical sinus, globose whorls, and reduced translation.

\section{Genus Diplozone Perner, 1907}

FIGURE 25

TYPE SPECIES.-Diplozone innocens Barrande in Perner, 1907.

FKA.-Diplozone crispa (Lindström, 1884): Upper Hemse Marl (Early Ludlow (Gorstian)).

LKA.-Diplozone innocens: Konéprussy Formation (Pragian).

AdDitional ASSIGNed SPECIES.-Loxonema beraultensis Barrande in Perner, 1907.

REMARKS.-This Plethospira-like genus apparently represents a short-lived siphonate experiment within "loxonematides." It is diagnosed by an extended, tightly coiled columella lip that yields a weak siphon and by a short, narrow but very sharp (almost slit-like) sinus.

\section{Genus Rhabdostropha Donald, 1905}

FIGURES 25, 26

?Holopella $\mathrm{M}^{\prime} \mathrm{Coy}, 1851$.

Kjerulfonema Peel and YocheIson, 1976.

TYPE SPECIES.-Rhabdostropha grindrodii (Donald, 1905).

FKA.-Rhabdostropha primitiva Longstaff, 1924: Shalloch Mill Formation (Late Caradoc (Onnian)).

LKA.-Holopella regularis Lindström, 1884: Hemse Marls (Early Ludlow (Gorstian)).
ADDITIONAL ASSIGNED SPECIES.-Kjerulfonema cancellata (Sowerby in Murchison, 1839); K. quinquecincta Peel and Yochelson, 1976; Murchisonia sp. (Point Clarence Limestone; Rohr, 1988); Rhabdostropha latisinuata Longstaff, 1924.

REMARKS.-Rhabdostropha is used for a clade of "omospirines" with shallow sinuses and ornament. Holopella has taxonomic priority over Rhabdostropha and certainly has been used more frequently. Unfortunately, the diagnosis of Holopella was based on a steinkern, thus making it impossible to determine its affinities and probably contributing to the very inconsistent applications of the genus name. Usage of Holopella should, therefore, be discontinued.

\section{Genus Spiroecus Longstaff, 1924}

FIGURE 26

Girvania Longstaff, 1924.

TYPE SPECIES.—Spiroecus girvanensis Longstaff, 1924.

FKA.-Girvania excavata (Longstaff, 1924): Whitehouse Group (Late Caradoc (Onnian)).

LKA.-Spiroecus girvanensis: Girvan Limestone (Early Ashgill (Pusgillian)).

REMARKS.-This labels an early but highly derived clade of ornate loxonematoids. A key diagnostic feature, a strong lirum on the left side of the sinus apex, might be a remnant peripheral band.

\section{Genus Macrochilus Lindström, 1884}

FIGURE 26

Auriptygma Pemer, 1903.

TYPE SPECIES.-Macrochilus fenestratus Lindström, 1884.

FKA.-Macrochilus fenestratus: Slite Bed, Unit G (Early Wenlock (Sheinwoodian)).

LKA.- “Auriptygma" species: Zlíchov Limestone (Emsian).

ADDITIONAL ASSIGNED SPECIES.-Auriptygma fortior Barrande in Perner, 1903; Macrochilina recticosta (Barrande in Perner, 1907); Macrochilus buliminus Lindström, 1884; M. cancellatus Lindström, 1884.

REMARKS. - Knight et al. (1960) considered Macrochilus to be a junior synonym of Soleniscus, which appears to be a true subulitoid. Some post-Emsian "Soleniscus" species, however, might belong to Macrochilus. Although these species converge strongly on the subulitioid form, they retain a broad but shallow sinus, and they display a much weaker siphon than do subulitioids. The siphon of Macrochilus also differs from that of Soleniscus. In Macrochilus the siphon is formed by elongating and slightly bending the inner margin. In Soleniscus the siphon is produced by widening the base of the inner margin as it is extended beneath and around the base of the penultimate whorl (which yields the distinctive plicate columella of subulitioids). 


\section{Genus Stylonema Perner, 1907}

FIGURE 26

TYPE SPECIES.-Stylonema potens Barrande in Perner, 1907. FKA.-Stylonema potens: Kopanina Formation (Late Ludlow (Ludfordian)).

LKA.-? Stylonema opposita Barrande in Perner, 1907: Zlíchov Limestone (Emsian).

AdDITIONAL ASSIGNED SPECIES.-Stylonema domestica Barrande in Perner, 1907; S. mater Barrande in Perner, 1907.

REMARKS.-The sinistral S. opposita might not belong to this genus. Another Emsian species, S. dilatata (Spitz, 1907) is too poorly known to accurately place. Thus, the last appearance of this genus might be in the Pragian (S. domestica).

\section{Superfamily EOTOMARIOIDEA Ulrich and Scofield, 1897}

$$
(? \text { = Vetigastropoda) }
$$

REMARKS.-This taxon corresponds to the "eotomarioid" clade. Of the superfamilies defined herein, the Eotomarioidea corresponds most closely to traditional definitions of the Pleurotomarioidea. It is very possible that the Eotomarioidea are synonymous (or nearly so) with the Vetigastropoda. The clade is diagnosed primitively by a peripheral band with strong peripheral lira, a slight increase in translation over ontogeny, and an asymmetrical sinus with the right side broader and shallower than the left side.

\section{Family EOTOMARIIDAE Wenz, 1938}

REMARKS.-The Eotomarioidea encompasses the basal paraclade of the "eotomarioids," plus the monophyletic "liospirines." Again, it includes at least one monophyletic group of clades throughout its history. The family is diagnosed by the features primitively diagnosing the superfamily.

\section{Genus $†$ Clathrospira Ulrich and Scofield, 1897}

FIGURES 20, 27-29

Turritoma Ulrich and Scofield, 1897.

TYPE SPECIES.-Clathrospira subconica (Hall, 1847).

FKA.-Turritoma acrea (Billings, 1865): Boat Harbor Formation (Early Arenig (Jeffersonian)).

LKA.-Clathrospira conica Ulrich and Scofield, 1897: Meaford Formation (Ashgill (Richmondian)).

ADDITIONAL ASSIGNED SPECIES.-Clathrospira ?trochiformis Butts, 1926; Clathrospira species, Smithville Formation; Turritoma ornate species, Cotter Formation.

REMARKS.-The most radical change in the present definition of Clathrospira is the inclusion of Turritoma species. That name, however, does not define any type of phylogenetically cohesive group, and the type species is plesiomorphic relative to typical Clathrospira. It is best considered a primitive highspired version of Clathrospira. Clathrospira is diagnosed by a very strong bilineate peripheral band that is located very low on the whorl owing to a very short left ramp relative to the right ramp.

\section{?Genus Spirotomaria Koken, 1925}

FIGURE 28

TYPE SPECIES.-Spirotomaria rudissima Koken, 1925.

FKA.- Spirotomaria rudissima: Vaginatum Limestone (Late Arenig (Kundan)).

LKA.-?Clathrospira euconica Butts, 1926: ?Tulip Creek Formation (Late Llandeilo (Chazyan)).

ADDITIONAL ASSIGNED SPECIES.-Clathrospira ?glindmeyeri Rohr, 1996; Clathrospira ?ulrichi (Endo, 1932).

REMARKS.-These assignments are made based on the similarities between $S$. ?glindmeyeri, $S$. ?ulrichi, and figures of the poorly known type species, $S$. rudissima. As I have not been able to examine any $S$. rudissima specimens, so the assignments must be considered tentative. The high asymmetry in the left and right ramp lengths, coupled with a high angle between the base of the columella and the alveozone, leave the peripheral band very low on Spirotomaria species.

\section{Genus $†$ Eotomaria Ulrich and Scofield, 1897}

FIGURE 29

?Pseudocryptaenia Koken, 1925.

TYPE SPECIES.-Eotomaria canalifera Ulrich and Scofield, 1897.

FKA.-Eotomaria canalifera: Murfreesboro Limestone (Early Caradoc (Ashbian)).

LKA.-Eotomaria notablis (Eichenwald, 1859): Lyckholm Formation (Ashgill (Late Pirgu)).

ADDITIONAL ASSIGNED SPECIES.-Eotomaria dryope Ulrich and Scofield, 1897; ?E. tumida Koken, 1925.

REMARKS.-The definition of Eotomaria presented herein is somewhat reduced relative to most definitions, as it focuses on Baltic species. Most Laurentian species previously placed in Eotomaria now are placed in Paraliospira or Liospira. Eotomaria is a paraclade relative to both genera, but it suffers true extinction with the termination of the Baltic clade. Pre-Caradocian specimens assigned to Eotomaria usually belong to Ceratopea. There possibly are multiple Baltic species within this clade, as $E$. notablis has not been well defined as a species; however, I was unable to examine enough specimens to ascertain this. Also, the poorly known Pseudocryptaenia might belong to this clade; if so, then it should be considered a junior synonym unless it forms a distinct monophyletic group with Eotomaria.

\section{Genus Paraliospira Rohr, 1980}

\section{FIGURE 29}

TYPE SPECIES.-Paraliospira angulata (Ulrich and Scofield, 1897). 
FKA.-Liospira larvata (Salter, 1859): Murfreesboro Limestone (Early Caradoc (Ashbian)).

LKA.-Paraliospira aff. P. angulata: Port Clarence Limestone (Ashgill (Richmondian)).

ADDITIONAL ASSIGNED SPECIES.-Eotomaria rupestris Koken, 1925; E. supracingulata (Billings, 1865); Paraliospira mundula (Ulrich and Scofield, 1897); P. rugata (Ulrich and Scofield, 1897).

REMARKS.--Rohr's (1980) initial definition of Paraliospira remains largely unchanged, save that it now includes some species previously assigned to Eotomaria. Relative to Eotomaria, Paraliospira is diagnosed by a stronger peripheral band that is higher on the aperture owing to rotation of the aperture (e.g., the projection of the inner margin) and much stronger anterior projection of the outer margin of the aperture. The poorly known Eocryptaenia might belong here. If so, it technically would be a senior synonym, but as the type material was poorly illustrated and subsequently lost (Knight, 1941), the name probably should be abandoned.

Specimens from the Nanook Limestone of Alaska (Ashgill (Richmondian)) identified as "Siskyouspira" by Blodgett, Rohr, Harris, and Rong (1988) either are Paraliospira rupestris or are close relatives of that species. Another species placed in Siskyouspira by those authors, $S$. majewski (intially classified as Pseudocryptaenia majewski by Rohr and Blodgett (1985)) also appears to belong to the Paraliospira clade. The type species of Siskyouspira Rohr is known only from deformed specimens. These specimens, however, appear to show synapomorphies with "helicotomoids" rather than with "eotomarioids."

\section{Genus Liospira Ulrich and Scofield, 1897}

FIGURE 29

TYPE SPECIES.-Liospira micula (Hall and Whitney, 1862).

FKA.-Eotomaria labrosa Ulrich and Scofield, 1897: Murfreesboro Limestone (Early Caradoc (Ashbian)).

LKA._Liospira micula: Port Clarence Limestone (Ashgill (Richmondian)); ?L. marklandensis McLearn, 1924: Stonehouse Formation (Prídolí).

AdDITIONAL ASSIGNED SPECIES.-?Liospira affinis Pitcher, 1939; L. angustata Ulrich and Scofield, 1897; L. decipens Ulrich and Scofield, 1897; L. progne Ulrich and Scofield, 1897; L. subconcava Ulrich and Scofield, 1897.

REMARKS.-The question marks above denote Silurian species that might not belong to Liospira; however, better material is needed to evaluate this possibility. The genus is best diagnosed by a very strong columella partly produced by a thickened inner margin that is folded backwards, but mainly by a funicle produced by an extension of the parietal inductura. Putative Liospira species lacking these features likely belong to Raphistomina or Pararaphistoma. Notably, the type species of the genus is strongly convergent on Pararaphistoma species, although it can be distinguished by (1) anterior rather than posterior projection of the aperture, (2) a slit that is consistent throughout phylogeny and that does not appear to be an exten- sion of the sinus, and (3) a thick columella plus a strong funicle filling the umbilicus. The genus also is diagnosed by a strongly reduced peripheral band. On the most-derived species (e.g., $L$. micula), the band is almost entirely absent, although a true selenizone (i.e., distortion in growth lines produced by a slit) exists on the left side of the remnant peripheral band.

\section{Family $\nmid$ GosSELETINIDAE Wenz, 1938}

REMARKS.-The definition of this family is nearly identical to the one provided by Knight et al. (1960), which highlights the tendency for traditional taxonomy to be far more congruent with the phylogeny of post-Ordovician taxa than with the phylogeny of Ordovician genera. As it includes a genus that is paraphyletic relative to the Phanerotrematidae (see below), it is a paraclade. Notably, this clade is comprised predominantly of Baltic species during the Ordovician and provides much of the post-Ordovician diversity.

\section{Subfamily †EURYZONINAE, new subfamily}

REMARKS.-The definition of this subfamily is nearly identical to that of the Coelozoninae provided by Knight et al. (1960). Coelozone appears to be a junior synonym of $\mathrm{Eu}$ ryzone, so I am simply updating the subfamily name.

\section{Genus $\nmid$ Deaechospira, new genus}

FIGURE 28

TYPE SPECIES._Clathrospira elliptica (Hisinger, 1829).

FKA.-Deaechospira elliptica: Huk Formation (Early Llanvirn (Kundan)).

LKA.-Clathrospira maritima Koken, 1925: Wesenberger Shale (Late Caradoc (Vormsian)).

ADDITIONAL ASSIGNED SPECIES.-Clathrospira inflata Koken, 1925.

ETYMOLOGY.-Named for the favorite baseball rule of Douglas H. Erwin, the Designated Hitter (DH) rule. Among the features separating Deaechospira from the ancestral Clathrospira is a rounder profile, a feature that typically separates designated hitters from other baseball players. The naming of a typically European clade after a rule in a typically American game is odd and inappropriate, but so is the rule.

REMARKS.-Baltic species previously classified in Clathrospira form their own clade. The clade differs from Clathrospira by the narrower peripheral band that features weaker but sharper lira. Deaechospira might include more species than I have recognized, as $D$. elliptica and $D$. inflata have been used imprecisely. Compared to Clathrospira, Deaechospira has a peripheral band with only moderately strong threads of little prominence. Also, this band bisects the left and right ramps evenly on Deaechospira, whereas the peripheral band of Clathospira is located on the base of the right ramp. Deaechospira also displays greater symmetry between the left and right 
ramps than does Clathrospira, placing the peripheral band nearer the center of the whorl. Finally, Deaechospira displays rounder right and left ramps than does Clathrospira.

\section{Genus $†$ Cataschisma Branson, 1909}

FiguRES $28,30,31,34,35$

Globispira Koken, 1925.-Knight et al., 1960.

TYPE SPECIES.-Cataschisma exquisita (Lindström, 1884).

FKA.-Mourlonia mjoela Yochelson, 1963: Cephalopod Shale, Huk Formation (Early Llanvirn (Kundan)).

LKA._Cataschisma exquisita: Mulde Beds (Late Wenlock (Whitwellian)).

ADDITIONAL ASSIGNED SPECIES.-Clathrospira convexa Ulrich and Scofield, 1897; Globispira pillula (Koken, 1925).

REMARKS. - This is another paraclade that includes the basal members of the Gosseletinidae plus a small clade diagnosed by strong transverse ornament. The genus is distinguished from both Clathrospira and Deaechospira by much rounder ramps and greatly reduced asymmetry between the left and right ramps, leaving the weaker peripheral band in the middle of the aperture. The peripheral band of Cataschisma also is wider than on Deaechospira. On derived members, the peripheral band is very low owing to the right ramp being much broader than the left ramp.

\section{?Genus Palaeoschisma Donald, 1902}

FIGURES 30,31

TYPE SPECIES.-Palaeoschisma girvanensis Donald, 1902.

FKA.-?Eotomaria elevata Ulrich in Ulrich and Scofield, 1897: Lexington Limestone (Middle Caradoc (Rocklandian)).

LKA.-?Clathrospira thraivensis Longstaff, 1924: Starfish Bed, Thraive Glen Formation (Ashgill (Rawtheyan)).

AdDitional AsSigned SPECIES.—"Bembexia" globosa Longstaff, 1924.

REMARKS.-Much about this genus is tentative. Three species, ?P. globosa, ?P. thraivensis, and ?P. elevata, clearly form a monophyletic group; however, it is not clear that these species actually are related to $P$. girvanensis (the type species).

\section{Genus $\nmid$ Pleurorima Perner, 1907}

\section{FIGURE 34}

TYPE SPECIES.-Pleurorima migrans Barrande in Perner, 1907.

FKA.-Pleurorima wisbeyensis (Lindström, 1884): Unit G, Slite Formation (Early Wenlock (Sheinwoodian)).

LKA.-See remarks.

ADdITIONAL ASSIGNEd SPECIES.-Globispira prima Barrande in Perner, 1907; Seelya moydartensis Peel, 1977.

REMARKS.- The last record of Pleurorima is from the Late Ludlow (Ludfordian) of Central Europe and Canada. Preliminary analyses of Devonian species, however, indicate that spe- cies assigned to Mourlonia and Ptychomphalina clearly belong to the Pleurorima clade. Thus, it is not clear when a monophyletic assemblage best assigned to Pleurorima became extinct. The genus is diagnosed by a broad and swollen peripheral band with wide but weak lira bordering a seemingly short slit.

\section{Genus Euryzone Koken, 1896}

FIGURE 34

?Coelozone Perner, 1907.

TYPE SPECIES.-Euryzone delphinuloides (Schlotheim, 1820).

FKA.-Euryzone calva Barrande in Perner, 1907, and Coelozone verna Barrande in Perner, 1907: Kopanina Formation (Late Ludlow (Ludfordian)).

LKA.-Euryzone has been reported as late as the Frasnian.

ADDITIONAL ASSIGNED SPECIES.-Euryzone connulastus Barrande in Perner, 1907; Pleurorima aptychia Barrande in Perner, 1907.

REMARKS.-Euryzone and Coelozone are provisionally united herein, pending work on Devonian species. Coelozone has been recorded in Devonian rocks, so it is possible that it includes a separate clade. The species identified by Koken (1925) as "Euryzone" belong to Brachytomaria.

\section{Genus Latitaenia Koken, 1925}

TYPE SPECIES.—Latitaenia rotelloidea (Koken, 1896).

FKA.-Latitaenia rotelloidea: Lower Chasmops Shale (Early Caradoc (4a- $\alpha=$ Idavere)).

LKA.-Latitaenia aequicrescens Koken, 1925, and Latitaenia kirnaensis Koken, 1925: Lyckholm Formation (Ashgill (Pirgu)).

REMARKS.-Members of this genus are not featured in this analysis because I have not been able to examine any specimens personally. Analyses of figured specimens, however, indicate that Latitaenia represents a small clade derived from the Cataschisma paraclade.

\section{Subfamily GosseletininaE Wenz, 1938}

REMARKS.-A monophyletic definition of this subfamily is very similar to the one provided by Knight et al. (1960). Analyses of Devonian species, however, indicate that the (nearly) bilaterally symmetrical Porcellidae belong to this clade.

\section{Genus $†$ Stenoloron Oehlert, 1888}

FIGURES 34, 35

Spiroraphe Perner, 1907.

TYPE SPECIES.-Stenoloron aequilatera Oehlert, 1888.

FKA.-Stenoloron shelvensis Pitcher, 1939: Pentamerous Beds (Late Llandovery (Telychian)). 
LKA.-Stenoloron minor Blodgett and Johnson, 1992: Lone Mountain Limestone, ensensis-zone (Late Eifelian).

AdDitional AsSigned SPECIES.-Clathrospira biformis (Lindström, 1884); Oriostoma angulifer Lindström, 1884; Spiroraphe bohemica Barrande in Perner, 1907; Stenoloron pollens Barrande in Perner, 1907; S. viennayi Oehlert, 1888.

REMARKS.-This paraclade includes the ancestors of Platyloron (see below) and the Porcellidae. If future work corroborates the estimate linking?S. angulifer and ?S. biformis, then those species should be removed into a separate genus. Stenoloron is diagnosed by a curved base with a slight posterior projection and by a very narrow peripheral band that appears to encompass a moderately long slit. Some derived members of Paraliospira (e.g., P. rupestris) have very similar gross morphologies to Stenoloron; however, Stenoloron can be distinguished from those species by the narrow sinus and the curved base of the inner margin.

\section{Genus Platyloron Oehlert, 1888}

FIGURE 35

TYPE SPECIES.-Platyloron bischoffi (Goldfuss, 1844).

FKA.-Oriostoma dispar Lindström, 1884: Unit G, Slite Beds (Early Wenlock (Sheinwoodian)).

LKA.-Platyloron is known through the Famennian.

ADDITIONAL ASSIGNED SPECIES.-Stenoloron voluta (Lindström, 1884).

REMARKS.-This distinctive genus is diagnosed by a peripheral band near the top of the whorl, owing to both rotation of the aperture and expansion of the left ramp relative to the right ramp. Silurian species, however, retain Stenoloron-like profiles. Like Stenoloron, the peripheral band encompasses a slit.

\section{Genus Umbotropsis Perner, 1907}

FIGURE 35

Eocryptaulina Foerste, 1936.

TYPE SPECIES.-Umbotropsis albicans Barrande in Perner, 1907.

FKA.-Eocryptaulina helcinia (Lindström, 1884): Unit A, Lower Visby Formation (Late Llandovery (Telychian)).

LKA.-Umbotropsis albicans: Kopanina Formation (Late Ludlow (Ludfordian)).

ADDITIONAL ASSIGNED SPECIES.-Eocryptaulina filitexta (Foerste, 1893).

REMARKS. - This genus currently is poorly known but seems to represent a monophyletic group. Umbotropsis is diagnosed by a thin, weak peripheral band encompassing a slit and thickened bases of the inner margin, sometimes forming a sharp lira.

\section{Family $\nmid$ PHANEROTREMATIDAE Knight, 1956}

REMARKS.- This family also is very similar to the definition presented by Knight et al. (1960). There is one major difference, however, as preliminary analyses of Devonian species place post-Ordovician "raphistomatids" Buechelia, Scalitina, Denayella, and Wisconsinella in the Phanerotrematidae. These analyses also place Pleuromphalus in the family, which converges strongly on a euomphalinae, such as Lesueurilla. Ordovician and Silurian species are diagnosed by narrow and shallow sinuses with unusually rugose growth lines, including very strong lunulae.

\section{Genus $\nmid$ Brachytomaria Koken, 1925}

FIGURES $30-32$

?Promourlonia Longstaff, 1924.

TYPE SPECIES.-Brachytomaria baltica Koken, 1925.

FKA.-Euryzone kiari Koken, 1925: Keila Formation (Middle Caradoc (Keila)).

LKA.-Bembexia cognata Barrande in Perner, 1903: Kopanina Formation (Late Ludlow (Ludfordian)).

ADDITIONAL ASSIGNED SPECIES.-Brachytomaria papillosa (Billings, 1852); B. semele (Ulrich and Scofield, 1897); B. striata (Ulrich and Scofield, 1897); $B$., new species, Gotland (some specimens assigned to Pleurotomaria laquetta by Lindström (1884); the type of that species, however, is a lophospiroid); Lophospira kindlei Foerste, 1924; Promourlonia furcata Longstaff, 1924.

REMARKS. - This paraclade includes the basal members of all Silurian genera of phanterotrematids. In the Silurian it appears to represent a monophyletic group that includes species with lower translations that previously were classified as Promourlonia. If the phylogenetic assessment presented herein is correct, then Promourlonia has priority over Brachytomaria. The lone possible Promourlonia species included herein differs from carinate Brachtyomaria species (e.g., B. semele) largely in having slightly lower curvature, resulting in an umbilicus. Even if morphologic separation is sometimes grounds for separating supraspecific taxa, small differences in coiling parameters certainly are not sufficient for diagnosing genera. Promourlonia has not been used since the original diagnosis, and the name incorrectly implies a close relationship with Mourlonia, whereas Brachytomaria has been used by many workers and is a phylogenetically neutral name. Thus, retaining Brachytomaria clearly is ultimately preferable.

Members of the genus typically are diagnosed by a very shallow sinus, a strong peripheral band with prominent peripheral lira, and strong carina on the upper and lower ramps. The very strong growth lines and lunulae of most Brachytomaria species are contiguous through the peripheral band, indicating the absence of a slit (contra Knight, 1945). Some of the more-derived species, however, display evidence of short slits.

\section{Genus Phanerotrema Fischer, 1885}

FIGURE 32

Pseudoscalites Boucot et al., [967. [Not Diener, 1926.]

TYPE SPECIES.-Phanerotrema labrosa (Hall, 1859). 
FKA.-Phanerotrema jugosa Pitcher, 1939: Beechhill Cove Formation (Early Llandovery (Rhuddanian)).

LKA.-Phanerotrema is recorded through the Bashkirian.

ADDITIONAL ASSIGNED SPECIES.-Phanerotrema australis (Etheridge, 1891); P. dolia (Lindström, 1884); P. lindstroemi (Boucot et al., 1967); P. ?occidens (Hall, 1860); "Seelya" ?vitellia (Billings, 1865).

REMARKS.-Silurian species recently assigned to the genus/ subgenus Pseudoscalites are now returned to Phanerotrema, as the former name is preoccupied by a Triassic caenogastropod genus. Pseudoscalites illustrates an important misconception about Phanerotrema, i.e., that it is related to Scalites and Raphistoma. These analyses, plus preliminary ones that include Devonian species, indicate that the similarities (which are striking in some post-Silurian taxa) are convergences. Phanerotrema appears to represent the paraclade from which post-Silurian taxa previously assigned to the Raphistomatidae arose. The genus is diagnosed by rotation and alteration of the aperture, leaving the peripheral band higher on the whorl (and producing a more step-like profile) than observed on Brachytomaria.

\section{Genus Ulrichospira Donald, 1905}

\section{FIGURE 32}

TYPE SPECIES.-Ulrichospira similis Donald, 1905.

FKA.-Ulrichospira similis: Pentamerous Beds (Middle Llandovery (Telychian)). Note that the phylogenetic analyses indicate that it must have originated by the Early Llandovery.

LKA.- "Seelya" lloydi Sowerby in Murchison, 1839: Kopanina Formation (Late Ludlow (Ludfordian)).

ADDITIONAL ASSIGNED SPECIES.-Murchisonia othemenis (Lindström, 1884).

REMARKS.-This restricted clade of phanerotrematids is diagnosed by high translations and a weak peripheral band that encompasses a slit. The peripheral band appears to be on the upper periphery owing to the orientation of the left and right ramps plus some displacement of the peripheral band toward the suture.

\section{Family LUCIELLIDAE Knight, 1956}

REMARKS.-Preliminary analyses suggest that Devonian genera assigned to the Portlockidae belong to the Luciellidae. The clade is diagnosed by a narrow peripheral band that is low on the whorl owing to high asymmetry between the right and left ramps.

\section{Genus Conotoma Perner, 1907}

\section{FIGURES 30, 33}

TYPE SPECIES.-Conotoma eximia (Goldfuss, 1844).

FKA.-Conotoma claustrata (Lindström, 1884): Lower Visby Formation (Early Wenlock (Sheinwoodian)).
LKA.-Conotoma eximia: Kopanina Formation (Late Ludlow (Ludfordian)).

ADDITIONAL ASSIGNED SPECIES.-Conotoma glandiformis (Lindström, 1884).

REMARKS.-This genus represents a paraclade relative to the rest of the Luciellidae. Species within the genus previously have been classified in Clathrospira and Euconospira. The genus is diagnosed by pronounced increase in translation over ontogeny and a peripheral band on which the right (upper) lirum is slightly stronger than the left (lower) lirum. The peripheral band is very low on the whorl owing to the right ramp being much longer than the left ramp.

\section{Genus Prosolarium Perner, 1907}

FIGURE 33

Platyconus Perner, 1907.

Crenilunula Knight, 1945.

TYPE SPECIES.—Prosolarium procerum Barrande in Perner, 1907.

FKA.-Crenilunula hallei (Whiteaves, 1895): Lower Visby Formation (Early Wenlock (Sheinwoodian)).

LKA.-Platyconus incumbens Barrande in Perner, 1907: Pridoli Beds (Pridoli). Some Devonian members of the Luciellidae likely belong to this genus.

AdDITIONAL ASSIGNED SPECIES.-Crenilunula limata (Lindström, 1884).

REMARKS.-Prosolarium labels a clade that evidently includes the Devonian Luciella de Koninck, 1883. It is possible that work in progress will unite Prosolarium and Luciella. Prosolarium includes species previously placed in Crenilunula in order to maintain a cohesive phylogenetic unit. Platyconus is represented by a scrappy specimen, which appears to be either $P$. hallei or a closely related species. The genus has not been used since Perner first proposed it and should be eliminated.

Prosolarium is diagnosed by extreme asymmetry between the right and left ramps (leaving the peripheral band very low on the whorl), very strong peripheral lira that create a short frill (which Knight et al. (1960) confounded with the frill-like alveozone carina of Euomphalopterus; see Linsley et al., 1978), and an unusual "zipper-like" lunulae pattern within the peripheral band.

\section{Genus Oehlertia Perner, 1907}

Figures 30,33

?Quadricarina Blodgett and Johnson, 1992.

TYPE SPECIES.-Oehlertia senilis (Barrande in Perner, 1903).

FKA.-Oehlertia scutulata (Lindström, 1884): Lower Visby Formation (Early Wenlock (Sheinwoodian)).

LKA.-Oehlertia lenticularis (Goldfuss, 1844): Stringocephalen Limestone (Givetian). 
AdDitional AsSigned SPECIES.-Oehlertia cancellata (Lindström, 1884); O. gradata (Lindström, 1884); Quadricarina glabrobasis Blodgett and Johnson, 1992.

REMARKS.-Preliminary analyses of Devonian species place Quadricarina within the Oehlertia clade. The genus is diagnosed by a thin slit bordered by strong lira that lies well within the peripheral band. The assignment of Oehlertia to the Luciellidae is considered tentative, as the genus' phylogenetic position is uncertain.

\section{Superfamily LOPHOSPIROIDEA Wenz, 1938}

REMARKS.-Wagner (1999) elevated the taxon to superfamily status. It includes taxa formerly assigned to the Superfamily Trochonematoidea, including the genus Trochonema; however, due to the highly polyphyletic nature to the Trochonematoidea and also to the very dissimilar taxon definitions, it is recommended that the Trochonematoidea be abandoned.

\section{Family LOPHOSPIRIDAE Wenz, 1938}

REMARKS.-The phylogeny and systematics of this clade are described elsewhere (Wagner, 1990, 1995a, 1999; Wagner and Erwin, 1995); however, a summary of the clade's taxonomy is presented herein for comparison with other taxa.

\section{Genus Ectomaria Koken, 1896}

FIGURE 27

Solenospira Ulrich and Scofield, 1897.--Knight et aI., 1960.

TYPE SPECIES.-Ectomaria nieszkowskii Koken, 1925.

FKA.-Ectomaria adelina (Billings, 1865): Boat Harbor Formation (Early Arenigian (Jeffersonian)).

LKA._Ectomaria nieszkowskii: Borkholm Formation (Late Ashgill (Porkunian)).

ADDITIONAL ASSIGNED SPECIES.-Ectomaria adventa (Butts, 1926); E. laticarinata Koken, 1925 (=E. cf. E. prisca sp. 1 of Rohr (1988)); E. pagoda (Ulrich and Scofield, 1897); $E$. cf. E. pagoda of Rohr (1988); E. prisca (Ulrich and Scofield, 1897); E. cf. E. prisca (=E. cf. E. prisca sp. 2 of Rohr (1988)); Ectomaria Shakopee Dolomite species ("Hormotoma cassina" of Stauffer, 1937); Murchisonia callahanensis Rohr, 1980.

REMARKS.-Ectomaria is a basal paraclade by merit of one species and is monophyletic thereafter. Ultimately, one subclade of relatively low-spired species (E. callahanensis, E. laticarinata, and the unfigured $E$. adventa) might be separated into a new genus. If so, then this new genus would range from the Late Llanvirn (Lenoir Limestone) through the Ashgill (Port Clarence Limestone).

\section{Genus Donaldiella Cossmann, 1903}

FIGURE 27

Pagodospira Grabau, 1922.-Knight et al., 1960.
TYPE SPECIES.-Donaldiella filosa (Donald, 1902).

FKA.-Pagodospira cicelia (Billings, 1865): Durness Limestone (Early Arenig (Cassinian)).

LKA._"Hormotoma" trilineata Foerste, 1923: Belfast Formation (Middle Llandovery (Rhuddanian)).

\section{Genus Lophospira Whitfield, 1886}

FIGURE 27

TYPE SPECIES.-Lophospira milleri (Hall in Miller, 1877).

FKA.-Lophospira perangulata (Hall, 1847): Smithville Formation (Early Arenig (Cassinian)).

LKA.-Lophospira milleri: High Mains Formation (Late Ashgill (Hirnantian)).

\section{Genus Proturritella Koken, 1889}

TYPE SPECIES.-Proturritella gracilis Koken, 1889.

FKA.-Proturritella bicarinata Koken, 1925: Elnes Formation (Late Arenig (Kundan)).

LKA.-Proturritella gracilis: Folkeslundekalk (Late Llanvirn (Lasnamagian)).

\section{Genus Eunema Salter, 1859}

TYPE SPECIES.-Eunema strigillata Salter, 1859.

FKA.-Lophospira centralis (Ulrich and Scofield, 1897): Murfreesboro Limestone (Early Caradoc (Ashbian)). See Wagner (1999).

LKA.-Lophospira quadrisulcata (Ulrich and Scofield, 1897): Maquoketa Formation (Early Ashgill (Maysvillian)). See Wagner (1999).

\section{Genus Gyronema Ulrich in Ulrich and Scofield, 1897}

TYPE SPECIES.-Gyronema pulchellum Ulrich and Schofield, 1897.

FKA.—Gyronema pulchellum: Platteville Limestone (Early Caradoc (Black Riverian)).

LKA.-Gyronema quadrisulcata (Ulrich and Scofield, 1897): Rockland Formation (Middle Caradoc (Rocklandian)).

\section{Genus Ruedemannia Foerste, 1914}

Coronilla Perner, 1907. [Not Beneden, 1871.]

Ptychozone Perner, 1907.

?Schizolopha Ulrich and Scofield, 1897.

TYPE SPECIES.-Ruedemannia lirata (Ulrich in Ulrich and Schofield, 1897).

FKA.-Ruedemannia humilis (Ulrich and Scofield, 1897): Lexington Limestone (Middle Caradoc (Shermanian)).

LKA.--Ruedemannia is reported as late as the Toumaisian.

REMARKS.-This definition includes the types of two genera (Schizolopha and Ptychozone) that should have taxonomic pri- 
ority; however, both genera are (1) monotypic, (2) known from very few specimens, and (3) very derived relative to other species in the genus. Also, neither genus has been used, whereas Ruedemannia has been used extensively. Thus, usage of the two genera (which has been nearly nonexistent) should be discontinued.

\section{Genus Loxoplocus Fischer, 1885}

Kiviasukkaan Peel, 1975b.

TYPE SPECIES.—Loxoplocus solutus (Whiteaves, 1884).

FKA.-Lophospira sedgewicki Donald, 1905: Girvan Limestone (Early Ashgill (Pusgillian)).

LKA._Lophospira gotlandica Ulrich and Scofield, 1897: Kopanina Formation (Late Ludlow (Ludfordian));

REMARKS.-Worthenia likely is derived from this genus, which extends its range past the Silurian. Analyses place the monotypic Kiviasukkaan as the sister taxon of the type species, Loxoplocus solutus, with the ubiquitous L. gotlandicus seemingly ancestral to that clade (Wagner, in prep.).

\section{Genus Longstaffia Cossman, 1908}

TYPE SPECIES.-Longstaffia laquetta (Lindström, 1884).

FKA._Longstaffia centervillensis (Foerste, 1923): Beechhill Cove Formation (Middle Llandovery (Rhuddanian)).

LKA.--Longstaffia is reported as late as the Eifelian.

\section{Genus Arjamannia Peel, 1975}

TYPE SPECIES.-Arjamannia cancellata (M'Coy in Sedgwick and M'Coy, 1852).

FKA.-Lophospira bellicarinata (Longstaff, 1924): Shalloch Mill Formation (Late Caradoc (Onnian)).

LKA.—Arjamannia aulongensis Peel, 1975a: Doctors Brook Formation (Middle Wenlock (Whitwellian)).

\section{Genus Trochonemella Okulitch, 1935}

TYPE SPECIES. - Trochonemella notablis (Ulrich in Ulrich and Schofield, 1897).

FKA.-Trochonemella knoxvillensis (Ulrich and Scofield, 1897): Lenoir Limestone (Late Llanvirn).

LKA.-Trochonemella churkini Rohr, 1988, and T. reusingi Rohr and Blodgett, 1985: Port Clarence Limestone (Ashgill (Richmondian)).

\section{Family TrochonematidaE Zittel, 1895}

REMARKS. - A greatly revised definition and diagnosis of this taxon was presented in Wagner (1999).

\section{Genus Trochonema Salter, 1859}

TYPE SPECIES.-Trochonema umbilicata (Hall, 1847).

FKA.-Trochonemella trochonemoides (Ulrich and Scofield, 1897): Valcour Formation (Late Llandeilo).

LKA.-Trochonema panderi Koken, 1925: Borkholm Formation (Late Ashgill (Porkuni)).

\section{Genus Globonema Wenz, 1938}

TYPE SPECIES.-Globonema bicarinata (Koken, 1925).

FKA.-Trochonema salteri Ulrich and Scofield, 1897: Fusispira Beds, Prosser Formation (Middle Caradoc (Rocklandian)).

LKA(?).-Eunema murricata Lindström, 1884: Unit A, Hamra Formation (Late Ludlow (Ludfordian)).

\section{Superfamily STRAPAROLLINOIDEA, new superfamily \\ Family STRAPAROLLINIDAE, new family}

REMARKS.-This new superfamily and family represents an early experiment with trochoid-like shell designs. Its members have been assigned to the Microdomatidae and Holopeidae. It is diagnosed by a very small and a strong but dull monolineate peripheral band. Post-Early Ordovician species are diagnosed by a nearly absent sinus and a contiguous coiling of the whorls that yields no columella.

\section{Genus $\uparrow$ Straparollina Billings, 1865}

FIGURES 20, 21

TYPE SPECIES.-Straparollina pelagica Billings, 1865.

FKA.-Turritoma aff. T. acrea: Fort Ann Limestone (Late Tremadoc (Demingian)).

LKA.-Straparollina erigione Billings, 1865, and S. circe Billings, 1865: Rockland Formation (Middle Caradoc (Rocklandian)).

AdDITIONAL Assigned SPECIES.-Holopea hennigsmoeni Yochelson, 1963; Hormotoma dubia Cullison, 1944; Lophospira grandis Butts, 1926; Plethospira? turgida (Hall, 1847); Raphispira martinensis Rohr, 1996.

REMARKS.-Straparollina is used herein to label the basal paraclade, which terminates in the extinction of a Middle Ordovician clade. Post-Caradocian species assigned to Straparollina appear to belong to the Anomphalidae.

\section{Genus Daidia Salter, 1859}

FIGURE 21

TYPE SPECIES.—Daidia cerithioides Salter, 1859.

FKA.-Daidia cerithioides: Paquette Rapids Black River Formation (Early Caradoc (Black Riverian)). 
LKA._Daidia aff. D. cerithioides in Rohr, 1988: Port Clarence Limestone (Ashgill (Richmondian)).

REMARKS.-This represents a very small, highly derived clade of straparollinoids.

\section{Genus Haplospira Koken, 1897}

FIGURE 21

TYPE SPECIES.-Haplospira variablis Koken, 1897.

FKA.-Haplospira ?nereis (Billings, 1865): Paquette Rapids Black River Formation (Early Caradoc (Black Riverian)).

LKA.-Haplospira sibeliuxeni Peel, 1977: Stonehouse Formation (Prídolí).

\section{Superfamily SUBULITOIDEA Lindström, 1884}

\section{Family SubulitidaE Lindström, 1884}

REMARKS.-The systematics of this clade will be treated separately (Erwin, in prep.), so I present only a summary of the Ordovician-Silurian genera here. The basal genus of the clade is described here in some detail as it provides a link between "murchisonioid"-grade gastropods and this highly derived clade.

\section{Genus $\dagger$ Eroicaspira, new genus}

FIGURE 22

TYPE SPECIES.-Hormotoma bellicincta Hall, 1847, sensu Ulrich and Scofield, 1897.

FKA.-Hormotoma artemesia (Billings, 1865): Roubidoux Formation (Late Tremadoc (Demingian)).

LKA.-Hormotoma bellicincta: Hudson River Formation (Ashgill (Richmondian)).

ADDITIONAL ASSIGNED SPECIES.-Hormotoma augustina (Billings, 1865); H. zelleri Flower, 1968b; Hormotoma Setul Formation species (see Kobayashi, 1959).

ETYMOLOGY.-Named for Beethoven's Third Symphony, which possesses some of the innovations diagnosing Romantic music while retaining elements of the ancestral Classical form.

REMARKS. - This paraclade is monophyletic if the earliest species is omitted. It is diagnosed by the strongly asymmetrical sinus of derived Hormotoma as well as a siphon formed from a twisting of the base of the columella. The subclade of post-Early Arenig species also is diagnosed by unusually large sizes.

\section{Genus $\uparrow$ Subulites Emmons, 1842}

FIGURE 22

TYPE SPECIES.-Subulites elongata Emmons, 1842.
FKA.-Subulites sp.: El Paso Limestone (Early Arenig (Cassinian)).

LKA.-Subulites is recorded as late as the Gedinnian.

\section{Genus Fusispira Hall, 1872}

FIGURE 22

TYPE SPECIES.-Fusispira ventricosa Hall, 1872.

FKA._Fusispira sp.: Smithville Formation (Early Arenig (Cassinian)).

LKA.-Blodgett and Johnson (1992) recorded Fusispira from Tortodus kockelianus-zones of the Roberts Mountain and Lone Mountain Limestones (Late Eifelian).

\section{Genus Cyrtospira Ulrich in Ulrich and Scofield, 1897}

TYPE SPECIES.-Cyrtospira tortilis Ulrich in Ulrich and Scofield, 1897.

FKA.-Cyrtospira raymondi Ulrich and Scofield, 1897: Chazy Limestone (Early Llandeilo).

LKA.—Cyrtospira ventricosus Lindström, 1884: Kopanina Formation (Late Ludlow (Ludfordian)).

\section{Conclusions}

Phylogenetic analyses of early Paleozoic "archaeogastropods" suggest that (1) "archaeogastropods" evolved in the Late Cambrian from bellerophonts with monolineate peripheral bands and deep sinuses but no slits; (2) "archaeogastropods" quickly diverged into two clades, corresponding best with previous definitions of the Euomphalina and Murchisoniina; (3) sinuitid gastropods might represent secondarily derived bellerophonts, which would be the sister taxon of the "murchisoniinae"; (4) the Pleurotomarioidea do not represent a paraphylum containing the ancestors of more-derived gastropods but instead represent a polyphyletic assemblage of "euomphalinae" and "murchisoniinae" subclades; (5) trochoidlike and apogastropod-like morphologies evolved nearly as frequently as pleurotomarioid-like morphologies; and (6) the paleontological hypothesis presented is easily reconciled with neontological hypotheses.

In many ways, the results presented herein better match the estimates of 19 th century workers, which were based on early Paleozoic material, than more recent estimates, which apparently were based largely on middle to late Paleozoic or Recent species. This analysis cannot directly assess the relationships among extant gastropods, but it does put parameters on viable hypotheses and sets the stage for more inclusive analyses that could further the value of a rich fossil record for determining relationships among extant gastropods. 
Appendices 1-3 


\title{
Appendix 1. Characters and Character States
}

\begin{abstract}
A superscript letter "S" denotes characters weighted by one-half to account for symmetry/ asymmetry. A superscript letter " $C$ " denotes continuous characters, which are weighted $1 /$ $(\mathrm{n}-1)$, where $\mathrm{n}$ is the number of states. Other multistate characters are considered unordered.
\end{abstract}

1. Sinus
1. Absent
2. Present

2. Symmetry of sinus depth

1. Angle of right side greater (as on "clathrospirids")

2. Symmetrical

3. Angle of left side greater (as on "hormotomoids")

$\mathrm{S}, \mathrm{C}_{3}$. Sinus depth on right side (= angle of sinus retreat)
$0 .>0^{\circ}$
1. $-10^{\circ}$
2. $-20^{\circ}$
3. $-30^{\circ}$
4. $-40^{\circ}$
5. $-50^{\circ}$
6. $-60^{\circ}$
7. $-70^{\circ}$

$\mathrm{S}, \mathrm{C}_{4}$. Sinus depth on left side (= angle of sinus retreat)

$0 .>0^{\circ}$

1. $-10^{\circ}$

2. $-20^{\circ}$

3. $-30^{\circ}$

4. $-40^{\circ}$

5. $-50^{\circ}$

6. $-60^{\circ}$

7. $-70^{\circ}$

5. Sinus width symmetry

1. Right side wider (as on Clathrospira species and descendants)

2. Symmetric

3. Left side wider (as on Hormotoma confusa and relatives)

$\mathrm{s}, \mathrm{C}_{6}$. Width of right side of sinus (NOTE: variation in the ramp length affects sinus width without changing the character state.)

1. Just above peripheral band

2. Between peripheral band and top of right ramp

3. At top of right ramp

4. Above top of right ramp

$\mathrm{S}, \mathrm{C} 7$. Width of left side of sinus

1. Just below peripheral band

2. Between peripheral band and alveozone (= left ramp)

3. At base of alveozone

4. Between alveozone and inner margin
8. Symmetry of sinus shape

1. More acute curve on the left (as on Hormotoma species)

2. Symmetric

3. More obtuse curve on the left (as on Clathrospira or Pleurorima)

s9. Shape of right side of sinus

1. Plateaus before apex (half a "U" as on Raphistoma and Raphistomina)

2. Straight into apex (as on Ectomaria)

3. Continuous curve towards apex (as on Hormotoma)

4. Hyperbolic curve towards apex (as on Climacoraphistoma)

$\mathrm{s}_{10}$. Shape of left side of sinus

1. Plateaus before apex (half a " $U$ " as on as on Raphistomina)

2. Straight into apex

3. Continuous curve towards apex (as on Clathrospira)

4. Hyperbolic curve towards apex (as on Hormotoma)

11. Wrinkled right sinus (= a strong kink in the sinus, as on Raphistoma)

1. Absent

2. Present

12. Crenulated aperture (usually represented by undulating growth lines)

1. Absent

2. Present

13. Aperture with reverse sigma shape (when viewed from the side)

1. Absent

2. Present (as on "helicotomids")

14. Extent of sigmoidal aperture

1. Absent

2. Sigmoidal

3. Hypersigmoidal

15. Growth-line prominence

1. Not visible

2. Weak

3. Fine sharp

4. Strong

5. Extremely strong

16. Ontogenetic change in growth-line strength

1. No change over ontogeny 
2. Stronger on juveniles (as on Lesueurilla)

17. Imbricated growth lines
1. Absent
2. Weak
3. Moderate
4. Strong

18. Growth lines on base

1. Same

2. Stronger than on the rest of shell (as on Malayaspira)

19. Peripheral band
1. Absent
2. Present

c20. Peripheral-band width
1. $\Sigma \approx 05^{\circ}$
2. $\Sigma \approx 10^{\circ}$
3. $\Sigma \approx 15^{\circ}$
4. $\Sigma \approx 20^{\circ}$
5. $\Sigma \approx 25^{\circ}$
6. $\Sigma \approx 30^{\circ}$

21. Peripheral lira (i.e., lira bordering the peripheral band; present with "single" lirum (27) only if there is ontogenetic change (41) or if the peripheral band is trilineate)
1. Absent
2. Present

22. Peripheral-lira shape

1. Round (as on Hormotoma)

2. Sharp (as on Ectomaria and Lophospira)

3. Square (i.e., with edges as on Eotomaria and Paraliospira)

23. Peripheral-lira strength

1. Extremely weak

2. Weak

3. Moderate

4. Strong

5. Extremely strong

24. Peripheral lira forming a frill

1. Absent

2. Present (as on Conotoma and Crenilunula)

25. Frill strength

1. Weak

2. Strong

26. Relative strength of right and left peripheral-band lira

1. Same

2. Right lirum stronger than left lirum (as on Conotoma and Crenilunula)

27. Medial lirum (= single keel at apex of sinus; present with peripheral lira (21) only if there is ontogenetic change (41) or if the peripheral band is trilineate)

1. Absent

2. Present

28. Medial lirum type

1. Rounded (as on Schizopea)

2. Sharp (as on Barnesella and Malayaspira)
3. Flange (as on Lesueurilla)

4. Squared ridge (as on Ophiletina)

5. Dull lump (as on Euomphalopterus)

29. Single peripheral-lira strength

1. Very weak

2. Weak

3. Moderate

4. Strong

5. Very strong

6. Extremely strong

30. Ontogenetic change in single peripheral-lira strength

1. No change over ontogeny

2. Becomes weaker

3. Becomes stronger

31. Single peripheral-lira tubes

1. Absent

2. Present

32. Imbricated single peripheral lira

1. Consistent

2. Flares periodically (as on Poleumita discors and relatives)

33. Peripheral-band prominence

1. None

2. Slight

3. Strong

34. Slit

1. Absent

2. Present

35. Continuity of slit

1. Periodic slit (i.e., absent periodically as on some Clathrospira)

2. Continuous slit (as on Pleurorima and relatives)

36. Width of slit relative to peripheral band

1. Subsuming peripheral band (as on Pararaphistoma)

2. Within peripheral band (as on Pleurorima and relatives)

3. Thinner than peripheral band (as on Oehlertia)

37. Lira within peripheral band (usually bordering thin slits (36))

1. Absent

2. Two lira bordering slit (as on Oehlertia)

38. Lunulae shape

1. Concentric

2. Zipper-like (as on Crenilunula)

3. Sigma-shaped (as on Pararaphistoma)

4. V-shaped (as on Eccyliopterus)

5. Kinked (as on onychochilids)

6. Straight (as on Oehlertia)

39. Lunulae strength relative to the growth lines

1. Weaker than growth lines (as on Liospira or Pleurorima)

2. Same as growth lines

3. Stronger than growth lines (as on Brachytomaria baltica and relatives) 
40. Ontogenetic change in peripheral-band prominence

1. None

2. Increasing prominence (as on Straparollina)

3. Decreasing prominence (as on Catazone)

41. Ontogenetic change from a bilineate to a monolineate peripheral band

1. Bilineate throughout ontogeny

2. Becoming monolineate over ontogeny (as on early Straparollina)

42. Peripheral-band attitude

1. Projecting normally to the aperture

2. Peripheral band curves adapically (as on "lesueurillids" or Helicotoma)

43. Symmetry of peripheral band relative to the aperture

1. Asymmetrical on alveozone (as on "gosseletides")

2. Bisects whorl

3. Asymmetrical on right ramp (as on Lesueurilla and Eccyliopterus)

4. Entirely on right ramp (as on Eotomaria and Paraliospira)

44. Ontogenetic change in peripheral-band symmetry

1. No change

2. Moving from the right ramp to bisecting aperture (as on Paraliospira)

45. Channel beneath peripheral band

1. Absent

2. Present (as on Lophospira perangulata)

46. Channel strength

1. Weak

2. Strong

47. Thickenings on either side of peripheral band (NOTE: these might be homologous with the right and left ramp carina)

1. Absent

2. Present (as on Oehlertia)

$\mathrm{C}_{48}$. Position of anal notch (based on plane passing through centroid and sinus apex; if perpendicular to inner margin, $\beta=0^{\circ}$; if parallel to inner margin and oriented adapically, $\beta=0^{\circ}$; if parallel to inner margin and oriented abapically, $\beta=180^{\circ}$ ).

1. $\beta \approx 150^{\circ}$ (e.g., Prosolarium)

2. $\beta \approx 140^{\circ}$

3. $\beta \approx 130^{\circ}$

4. $\beta \approx 120^{\circ}$

5. $\beta \approx 110^{\circ}$

6. $\beta \approx 100^{\circ}$

7. $\beta \approx 90^{\circ}$

8. $\beta \approx 80^{\circ}$

9. $\beta \approx 70^{\circ}$

A. $\beta \approx 60^{\circ}$

B. $\beta \approx 50^{\circ}$

C. $\beta \approx 40^{\circ}$

D. $\beta \approx 30^{\circ}$

E. $\beta \approx 20^{\circ}$

F. $\beta \approx 10^{\circ}$ (e.g., Centrifugus)
49. Ontogenetic change in $\beta$ (due to rotation of the aperture clockwise or counter-clockwise)

1. Absent

2. Decreasing $\beta$ (as on basal "raphistomatoids")

3. Increasing $\beta$ (as on Paraliospira)

50. Magnitude of ontogenetic rotation

1. Small $\left(<30^{\circ}\right)$

2. Great $\left(>30^{\circ}\right)$

51. Symmetry of ramp shapes

1. Right ramp rounder (as on "holopeides")

2. Symmetric

3. Alveozone rounder (as on "lesueurillids")

s52. Right-ramp shape (see also 72)

1. Extremely globular (forming an acute angle)

2. Globular

3. Convex

4. Flat

5. Concave

53. Ontogenetic change in right-ramp shape

1. Ramp becoming more concave

2. Ramp becoming slightly more convex (as on Pachystrophia)

3. Ramp becoming much more convex (as on Pararaphistoma)

54. Symmetry of ramp lengths

1. Right ramp longer (as on "luciellides")

2. Symmetric

3. Alveozone longer (as on Raphistoma striata and relatives)

S,C55. Right-ramp length (= degrees between peripheral band and the top of ramp)

$0 .<20^{\circ}$

1. $-30^{\circ}$

2. $\sim 40^{\circ}$

3. $-50^{\circ}$

4. $-60^{\circ}$

5. $-70^{\circ}$

6. $-80^{\circ}$

7. $-90^{\circ}$

8. $-100^{\circ}$

$\mathrm{s}, \mathrm{C}_{56}$. Alveozone length $(=$ degrees between peripheral band and the base of ramp)

$0 .<20^{\circ}$

1. $-30^{\circ}$

2. $-40^{\circ}$

3. $-50^{\circ}$

4. $-60^{\circ}$

5. $-70^{\circ}$

6. $-80^{\circ}$

7. $-90^{\circ}$

8. $-100^{\circ}$

9. $-110^{\circ}$

57. Symmetry of ramp projections (see 58,59 )

1. Right higher (as on "helicotomids")

2. Symmetric 
3. Left higher (as on "holopeides")

$\mathrm{S}, \mathrm{C} 58$. Right-ramp projection (= angle between peripheral band and top of ramp)
1. $\sim 20^{\circ}$
2. $-30^{\circ}$
3. $\sim 40^{\circ}$
4. $\sim 50^{\circ}$
5. $\sim 60^{\circ}$
6. $-70^{\circ}$
7. $-80^{\circ}$
8. $-90^{\circ}$
9. $-100^{\circ}$

$\mathrm{S}, \mathrm{C} 59$. Alveozone projection (= angle between peripheral band and base of ramp)
0. $\sim 20^{\circ}$
1. $\sim 30^{\circ}$
2. $\sim 40^{\circ}$
3. $-50^{\circ}$
4. $-60^{\circ}$
5. $-70^{\circ}$
6. $-80^{\circ}$
7. $-90^{\circ}$

60. Thickening of shell at the top of right ramp

1. Absent

2. Present (as on early "archaeogastropods" and bellerophonts)

61. Degree of thickening
1. Weak
2. Moderate
3. Strong
4. Very strong

${ }^{\mathrm{C}} 62$. Ontogenetic change in right-ramp swelling

1. Always acute (as on Ecculiomphalus)

2. Going from acute to obtuse over ontogeny (as on $\mathrm{Ma}$ layaspira)

3. Always obtuse

63. Ontogenetic change in right ramp

1. None

2. Ramp becoming shorter and rounder (as on Malayaspira)

64. Right-ramp carina ( $R R C$ in figure captions)

1. Absent

2. Present

65. Right-ramp carina strength (in terms of prominence)

1. Weak

2. Moderate (roughly equal to a weak-to-moderate peripheral band)

3. Strong (roughly equal to a strong peripheral band)

66. Right-ramp carina type

1. Dull thick thread

2. Dull thin thread

3. Round thin-to-moderately wide lira

4. Sharp thin-to-moderately wide thread

67. Ontogenetic change in right-ramp carina strength

1. None
2. Becomes weaker (as on Raphistomina species)

3. Becomes sharper (as on Raphistoma species)

68. Channel beneath right-ramp carina

1. Absent

2. Present (as on "poleumitids")

69. Suture type

1. Right ramp oblique at suture

2. Right ramp acute at suture

70. Degree of acuteness

1. Acute (as on subulitids)

2. Attenuated (as on Hormotoma salteri)

71. Aperture curving back at suture

1. Absent

2. Present (as on Liospira)

72. Alveozone shape (see also 52)

1. Extremely globular (forming an acute angle)

2. Globular

3. Convex

4. Flat

5. Concave

73. Thickening of shell at the base of alveozone

1. Absent

2. Present

74. Degree of thickening

1. Weak

2. Moderate

3. Strong

4. Very strong

75. Alveozone carina

1. Absent

2. Present

76. Alveozone-carina type

0 . Dull thick thread

1. Thick swelling of shell

2. Sharp thin-to-moderately wide thread

3. Frill (as on Euomphalopterus species-go to character 79)

4. Square thread (as on Ophiletina sublaxa)

77. Alveozone-carina strength

1. Weak

2. Moderate ( $\approx$ peripheral band)

3. Strong

4. Very strong

78. Channeled alveozone carina

1. Absent

2. Present

79. Frilled alveozone carina

1. Peg (as on Euomphalopterus cariniferus)

2. Weak frill (as on Poleumita alatum)

3. Extended frill (as on Euomphalopterus alatus)

80. Frill bordered by lira

1. Absent

2. Present (as on Euomphalopterus togatus)

81. Crenulated frill

1. Absent 
2. Present (as on Euomphalopterus undulans)

82. Channeled frill

1. Absent

2. Present (as on Euomphalopterus alatus)

83. Projection of frill relative to coiling axis

1. Behind aperture

2. Parallel to aperture

3. In front of aperture

84. Hood-like frill

1. Absent

2. Present (as on Pseudophorus praetextus)

85. Alveozone-carina tubes

1. Absent

2. Present (as on Euomphalopterus togatus)

86. Increasing expansion at base of alveozone over ontogeny (inducing a more "bowl"-like apical umbilicus)

1. Absent

2. Present (as on Teiichispira)

87. Inner-margin (= columellar lip of most species) thickness, relative to rest of shell

1. No different

2. Thicker

3. Much thicker

88. Thickened region(s) of inner margin

1. Only top of inner margin thicker

2. Entire inner margin thicker

3. Inner margin and base thicker

4. Only base of inner margin thicker

89. Basal carina ( $\mathrm{BC}$ in figure captions)
1. Absent
2. Present

90. Basal-carina type

1. Narrow thickening on the base

2. Dull extension with channel

3. Sharp thread

4. Rounded thread

5. Peg

91. Prominence of basal carina

1. Weak

2. Strong

3. Projecting

92. Ontogenetic change in basal carina

1. None

2. Becomes weaker with age

3. Becomes stronger with age

93. Position of basal carina

1. Beneath inner margin of aperture

2. Middle of whorl

3. Beneath outer margin of aperture

C94. Angle between inner margin and base

$0 .<45^{\circ}$

1. $>45^{\circ}$

2. $>60^{\circ}$

3. $>75^{\circ}$

4. $>90^{\circ}$
5. $>105^{\circ}$

95. Shape of inner margin on the inner margin of aperture

1. Round

2. Curved

3. Straight

4. Arched inwards

96. Shape of inner margin on the outer margin of aperture

1. More obtuse than the inner margin

2. Same

3. More acute than the inner margin

97. Ontogenetic change in inner-margin shape

1. None

2. Becomes rounder with age

C98. Inner-margin attitude relative to coiling axis

1. $\sim 0^{\circ}$

2. $\sim 15^{\circ}$

3. $-30^{\circ}$

4. $\sim 45^{\circ}$

5. $-60^{\circ}$

6. $\sim 75^{\circ}$

7. $-90^{\circ}$

8. $\sim 105^{\circ}$

9. $\sim 120^{\circ}$

99. Siphon

1. Absent

2. Slight twist of inner margin

3. Strong extension of inner margin

100. Inner-margin lira

1. Absent

2. Present

101. Type of inner-margin lira

1. Lira (as on Paraliospira)

2. Callous (as on Pycnomphalus)

102. Inner-margin channel

1. Absent

2. Present

103. Parietal-inductura strength

1. Absent

2. Thin and incomplete

3. Thin

4. Same as shell

5. Thicker than shell

104. Inductura projection

1. Parallels rest of aperture

2. Extended in front of aperture (as on Liospira)

3. A thick, concentrate strip extended in front of aperture (as on Poleumita)

4. Fills umbilicus (as on Eotomaria)

105. Flaring aperture

1. Absent

2. Weak (as on Loxonema)

3. Strong (as on Gasconadia)

106. Reflected inner-margin lip

1. Absent 
2. Present (as on basal "hormotomoids")

107. Funicle

1. Absent

2. Present (as on Liospira)

108. Inner margin fills umbilicus

1. Umbilicus open or filled by inductura

2. Inner margin fills umbilicus

3. Inner margin contiguous with previous whorl

4. Inner margin folds back into umbilicus

109. Whole aperture inclined (species with left and right halves both inclined (111 and 113), but to different degrees, were scored as unknown (?))

1. Radial/backwards inclination (see 115)

2. Left and right side inclined to same degree (as on Straparollina)

$\mathrm{C}_{110}$. Angle of inclination of whole aperture

1. $\operatorname{In} A n \approx 10^{\circ}$

2. $\operatorname{In} A n \approx 20^{\circ}$

3. $\operatorname{In} A n \approx 30^{\circ}$

4. $\operatorname{In} A n \approx 40^{\circ}$

5. $\operatorname{In} A n \approx 50^{\circ}$

6. $\operatorname{In} A n \approx 60^{\circ}$

111. Inclination of left half of aperture

1. Radial

2. Inclined (right side different or radial; e.g., Clathrospira)

$\mathrm{C}_{112 .}$ Inclination of left side of aperture

0 . $\operatorname{In} A n \approx 5^{\circ}$

1. $\operatorname{In} A n \approx 10^{\circ}$

2. $\operatorname{In} A n \approx 20^{\circ}$

3. $\operatorname{In} A n \approx 30^{\circ}$

4. $\operatorname{In} A n \approx 40^{\circ}$

113. Inclination of right half of aperture

1. Radial

2. Right side inclined (left side different or radial; e.g., Pleurorima)

$\mathrm{C}_{114}$. Inclination of right side of aperture

1. $\operatorname{In} A n \approx 10^{\circ}$

2. $\operatorname{In} A n \approx 20^{\circ}$

3. $\operatorname{InAn} \approx 30^{\circ}$

4. $\operatorname{In} A n \approx 40^{\circ}$

115. Aperture inclined "backwards"

1. Absent/forward inclination

2. Present (as on onychochilids)

116. Posterior projection of aperture base

1. Absent (as on all species with anterior projections; see also 120)

2. Present (as on Schizopea)

${ }^{\mathrm{C}} 117$. Magnitude of posterior projection

1. $\sim-10^{\circ}$

2. $\sim-20^{\circ}$

3. $\sim-30^{\circ}$

4. $\sim-40^{\circ}$

5. $\sim-50^{\circ}$
118. Anterior projection of aperture base

1. Absent

2. Present (as on "helicotomids" and "eotomarioids")

$\mathrm{C}_{119}$. Magnitude of anterior projection
1. $\sim 10^{\circ}$
2. $\sim 20^{\circ}$
3. $-30^{\circ}$
4. $\sim 40^{\circ}$
5. $\sim 50^{\circ}$

120. Shape of inner-margin base

1. Straight

2. Excavated (curved) (as on Spiroraphe)

3. Excavated (crenulated) (as on Lesueurilla)

${ }^{\mathrm{C}} 121$. Shell expansion (in radians)

1. $\mathrm{E}<0.05$ (extremely low)

2. $0.05<\mathrm{E}<0.10$ (very low)

3. $0.10<\mathrm{E}<0.15$ (low)

4. $0.15<\mathrm{E}<0.20$ (moderate)

5. $0.20<\mathrm{E}<0.25$ (high)

6. $\mathrm{E}>0.25$ (very high)

7. E $>1.0$ (extremely high)

122. Ontogenetic change in expansion

1. Decreasing expansion over ontogeny

2. None

3. Increasing expansion over ontogeny

${ }^{\mathrm{C}} 123$. Shell curvature around coiling axis (in radians)

0 . $\mathrm{K}<0.40$ (open coiling)

1. $\mathrm{K}<0.5$ (extremely low)

2. $0.5<\mathrm{K}<0.55$ (very low)

3. $0.55<\mathrm{K}<0.65$ (low)

4. $0.65<\mathrm{K}<0.75$ (moderate)

5. $0.75<\mathrm{K}<0.85$ (high)

6. $0.85<\mathrm{K}<0.95$ (very high)

7. $\mathrm{K}>0.95$ (extremely high)

124. Ontogenetic change in curvature

1. No change over ontogeny

2. Decreasing curvature over ontogeny

125. Anisostrophy (applies only to coiling, not left-right asymmetry)

1. Isostrophic

2. Anisostrophic

${ }^{\mathrm{C}} 126$. Shell torque

0 . High ultradextral

1. Moderate ultradextral

2. Low ultradextral

3. Nearly planispiral

4. Low dextral

5. Moderate dextral

6. High dextral

7. Very high dextral

8. Extremely high dextral

127. Ontogenetic change in shell torque

1. Increasing torque over ontogeny

2. Isometric 
3. Decreasing torque over ontogeny

128. Septation
1. Absent

2. Septation present (as on most "euomphalinae")

3. Complete filling of juvenile whorls (as on Palliseria)

129. Ornament on left side of aperture

1. Absent

2. Present throughout the alveozone and base

3. Present on the alveozone only

130. Density of ornament

1. One thread per $20^{\circ}$

2. One thread per $10^{\circ}$

3. One thread per $5^{\circ}$

4. One thread per $1^{\circ}$

131. Strength of alveozone ornament

1. Fine threads

2. Weak lira

3. Strong lira

132. Consistency of alveozone omament

1. Uniform

2. Threads stronger higher on the alveozone

3. Threads stronger lower on the lower ramp

4. Highest threads strong, the rest uniform

133. Ornamentation of right ramp

1. Absent

2. Present throughout

3. Omament present on upper half of right ramp only

134. Density of ornament on right side

1. One thread per $20^{\circ}$

2. One thread per $10^{\circ}$

3. One thread per $5^{\circ}$

4. One thread per $1^{\circ}$
135. Strength of ornament on right side

1. Fine threads

2. Weak lira

3. Strong lira

136. Pattern of ornament on right side

1. Uniform

2. $2: 1: 2$ (every other thread twice as strong as intermediate thread)

137. Type of right-ramp omament

1. Local thickenings on shell

2. Local changes in aperture shape

138. Transverse ornament

1. Absent

2. Present (as on Cataschisma)

139. Peripheral-band ornament

1. Absent

2. Present (as on Crenilunula)

140. Carrier-shell scars

1. No scars

2. Scars (as on Lytospira)

141. Size (= shell volume)

0 . Very small (micro-mollusc: $<10 \mathrm{~mm}^{3}$ )

1. Small $\left(>10 \mathrm{~mm}^{3}<10^{2} \mathrm{~mm}^{3}\right)$

2. Moderate $\left(>10^{2} \mathrm{~mm}^{3}<10^{3} \mathrm{~mm}^{3}\right)$

3. Large $\left(>10^{3} \mathrm{~mm}^{3}<10^{4} \mathrm{~mm}^{3}\right)$

4. Huge $\left(>10^{4} \mathrm{~mm}^{3}<10^{5} \mathrm{~mm}^{3}\right)$

142. Protoconch coiling

1. Like teleoconch

2. Planispiral (as on Sinuspira)

143. Protoconch size

1. Small $\left(<10^{-1} \mathrm{~mm}\right)$

2. Large ( $>10^{-1} \mathrm{~mm}$, as on Murchisonia and Loxonema) 


\section{Appendix 2. Data Matrix}

Data matrix for the analyzed species. Character numbers correspond to those in Appendix 1, and species numbers correspond to those in Appendix 3. Outgroup species have letters rather than numbers. 
APPENDIX 2.-Continued.

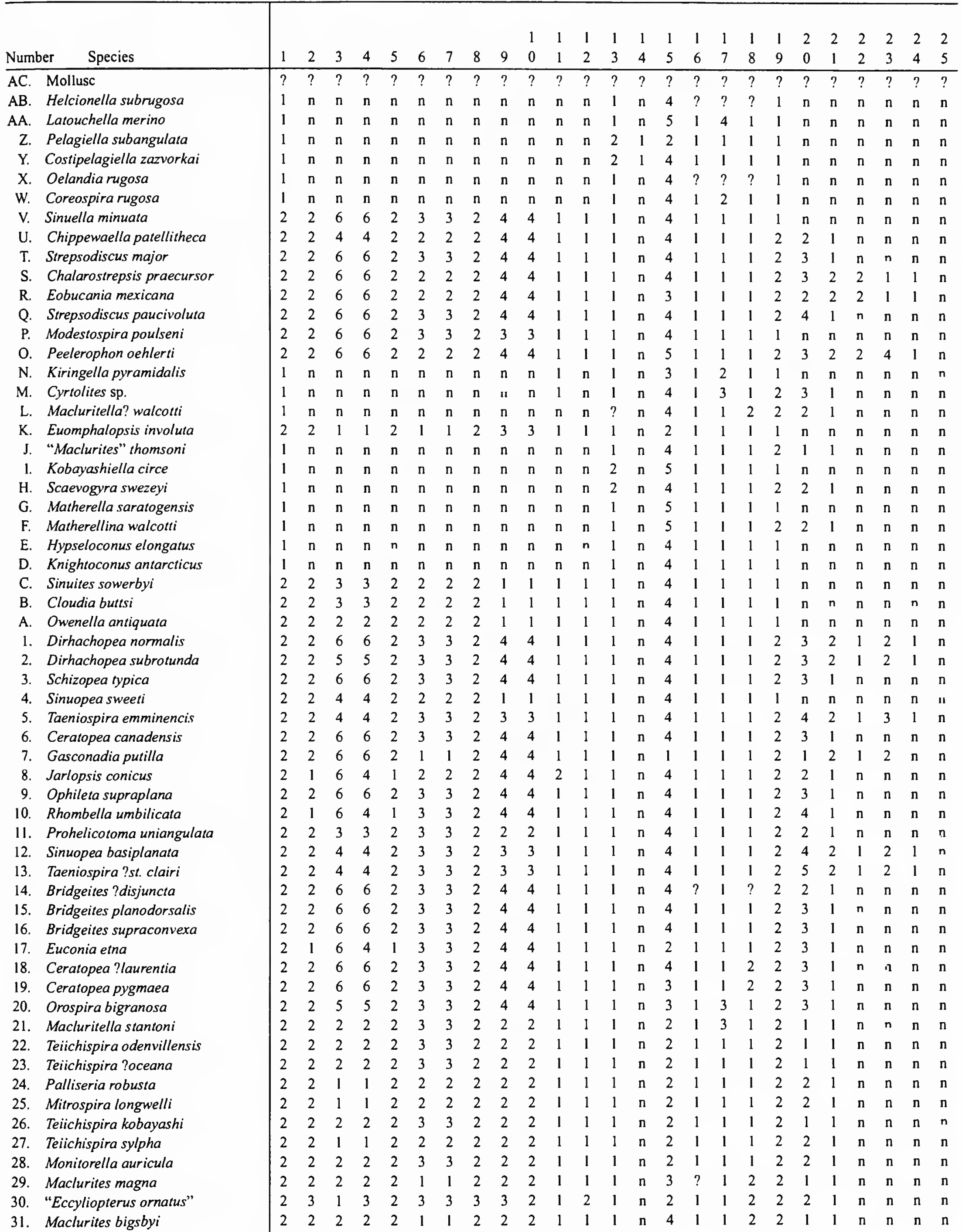


APPENDIX 2.-Continued.

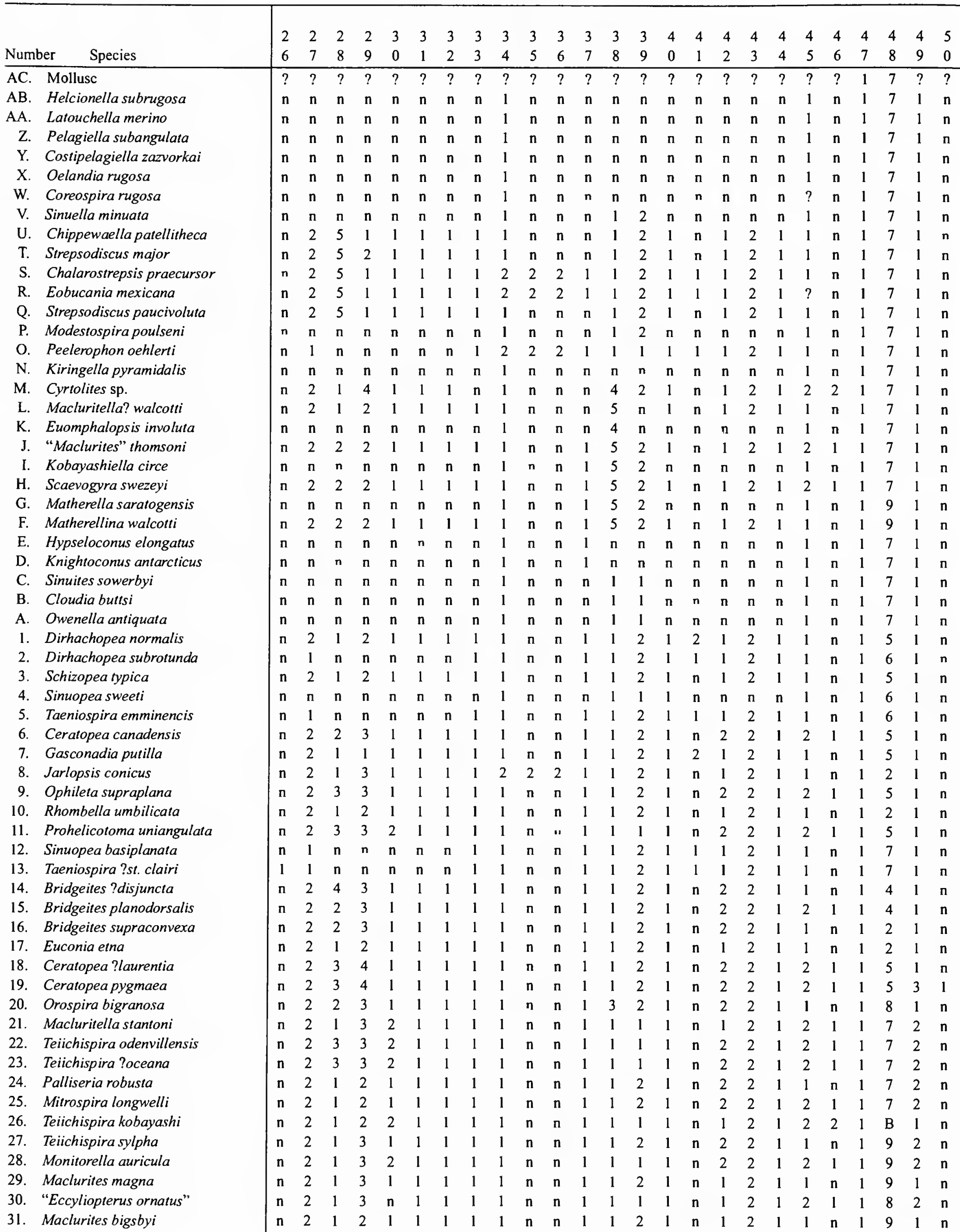


APPENDIX 2.-Continued.

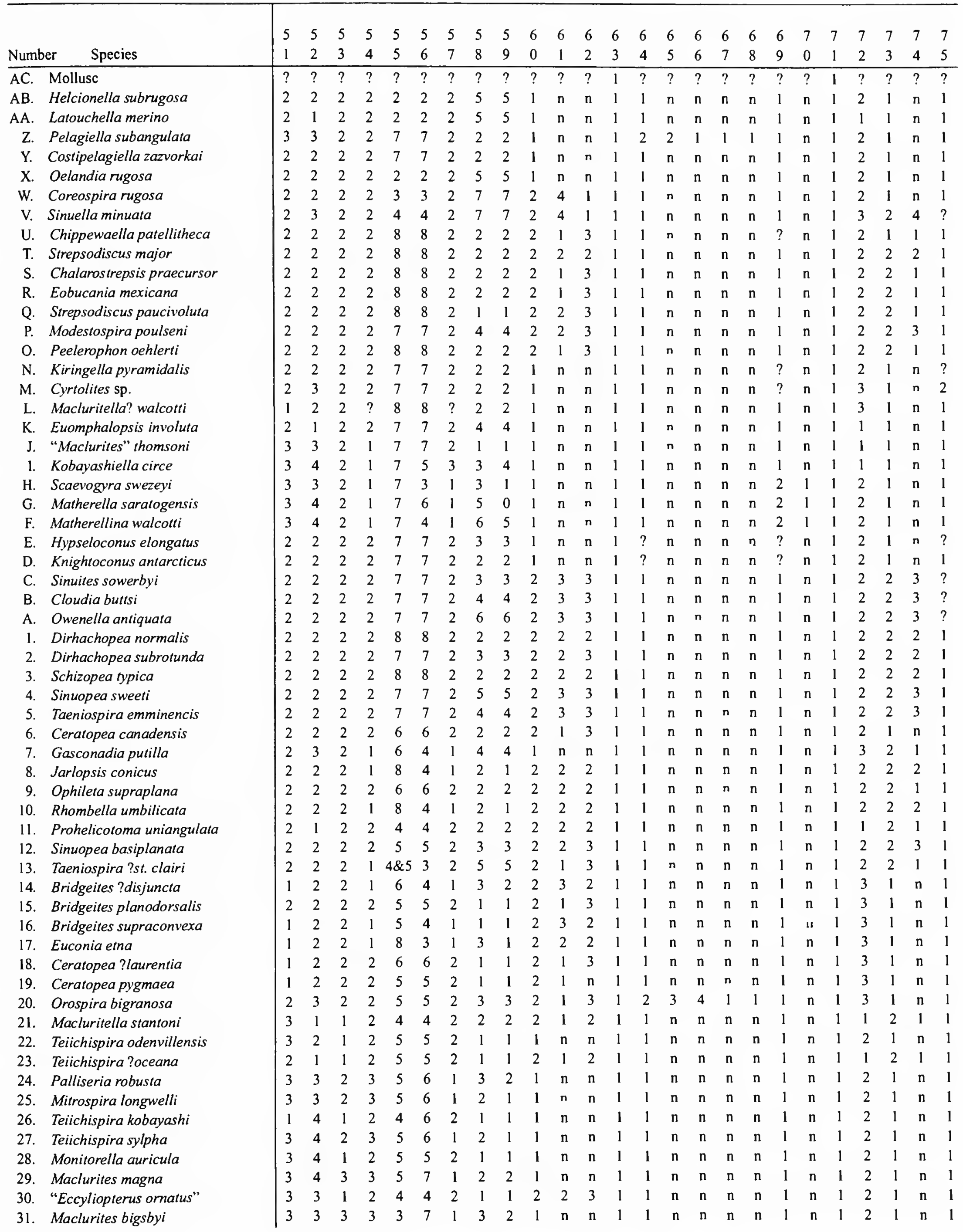


APPENDIX 2.-Continued.

\begin{tabular}{|c|c|c|c|c|c|c|c|c|c|c|c|c|c|c|c|c|c|c|c|c|c|c|c|c|c|c|}
\hline \multirow{2}{*}{ Number } & \multirow[b]{2}{*}{ Species } & \multirow{2}{*}{$\begin{array}{l}7 \\
6\end{array}$} & \multirow{2}{*}{$\begin{array}{l}7 \\
7\end{array}$} & \multirow{2}{*}{$\begin{array}{l}7 \\
8\end{array}$} & 7 & 8 & 8 & 8 & 8 & 8 & $\begin{array}{l}8 \\
5\end{array}$ & 8 & $\begin{array}{l}8 \\
7\end{array}$ & 8 & 8 & 9 & 9 & 9 & 9 & 9 & 9 & 9 & $\begin{array}{l}9 \\
7\end{array}$ & 9 & $\begin{array}{l}9 \\
0\end{array}$ & $\begin{array}{l}0 \\
0\end{array}$ \\
\hline & & & & & 9 & 0 & 1 & 2 & 3 & 4 & & 6 & & 8 & & & 1 & 2 & 3 & & 5 & 6 & & & $y$ & \\
\hline AC. $\mathrm{M}$ & Mollusc & $?$ & $?$ & $?$ & $?$ & $?$ & $?$ & $?$ & $?$ & $?$ & $?$ & $?$ & $?$ & $?$ & $?$ & $?$ & $?$ & $?$ & $?$ & $?$ & $?$ & $?$ & 1 & 1 & $?$ & $?$ \\
\hline AB. $\quad H$ & Helcionella subrugosa & $\mathrm{n}$ & $\mathrm{n}$ & $\mathrm{n}$ & $\mathrm{n}$ & $\mathrm{n}$ & $\mathrm{n}$ & $\mathrm{n}$ & $\mathrm{n}$ & $\mathrm{n}$ & $\mathrm{n}$ & 1 & 1 & $\mathrm{n}$ & 1 & $\mathrm{n}$ & $\mathrm{n}$ & $\mathrm{n}$ & $\mathrm{n}$ & 3 & 1 & 2 & 1 & 1 & 1 & 1 \\
\hline AA. Lo & Latouchella merino & $\mathrm{n}$ & $\mathrm{n}$ & $\mathrm{n}$ & $\mathrm{n}$ & $\mathrm{n}$ & $\mathrm{n}$ & $\mathrm{n}$ & $\mathrm{n}$ & $\mathrm{n}$ & $\mathrm{n}$ & 1 & 1 & $\mathrm{n}$ & 1 & $\mathrm{n}$ & $\mathrm{n}$ & $\mathrm{n}$ & $\mathrm{n}$ & 3 & 3 & 2 & 1 & 1 & 1 & 1 \\
\hline Z. $P C$ & Pelagiella subangulata & $\mathrm{n}$ & $\mathrm{n}$ & $\mathrm{n}$ & $\mathrm{n}$ & $\mathrm{n}$ & $\mathrm{n}$ & $\mathrm{n}$ & $\mathrm{n}$ & $\mathrm{n}$ & $\mathrm{n}$ & 1 & 2 & $\mathrm{n}$ & 1 & $\mathrm{n}$ & $\mathrm{n}$ & $\mathrm{n}$ & $\mathrm{n}$ & 3 & 3 & 2 & 1 & 4 & 1 & 1 \\
\hline Y. $\mathrm{Co}$ & Costipelagiella zazvorkai & $\mathrm{n}$ & $n$ & $\mathrm{n}$ & $n$ & $\mathrm{n}$ & $\mathrm{n}$ & $n$ & $\mathrm{n}$ & $n$ & $\mathrm{n}$ & 1 & 1 & $\mathrm{n}$ & 1 & $\mathrm{n}$ & $\mathrm{n}$ & $\mathrm{n}$ & $\mathrm{n}$ & 5 & 2 & 2 & 1 & 4 & 1 & 1 \\
\hline X. $O$ & Oelandia rugosa & $\mathrm{n}$ & $\mathbf{n}$ & $\mathbf{n}$ & $n$ & $\mathbf{n}$ & $\mathrm{n}$ & $\mathbf{n}$ & $\mathrm{n}$ & $\mathrm{n}$ & $\mathbf{n}$ & 1 & 1 & $\mathrm{n}$ & $?$ & $?$ & $?$ & $?$ & $?$ & 3 & 1 & 2 & 1 & 1 & 1 & $?$ \\
\hline W. $\mathrm{Co}$ & Coreospira rugosa & $\mathrm{n}$ & $\mathbf{n}$ & $\mathbf{n}$ & $n$ & $\mathrm{n}$ & $\mathrm{n}$ & $\mathrm{n}$ & $\mathrm{n}$ & $n$ & $\mathrm{n}$ & 1 & 1 & $\mathrm{n}$ & 1 & $\mathrm{n}$ & $\mathrm{n}$ & $\mathrm{n}$ & $\mathrm{n}$ & 5 & 3 & 2 & 1 & 1 & 1 & 2 \\
\hline V. Sir & Sinuella minuata & $?$ & $?$ & $?$ & $\mathrm{n}$ & $\mathrm{n}$ & $\mathrm{n}$ & $\mathrm{n}$ & $\mathrm{n}$ & $\mathrm{n}$ & $\mathrm{n}$ & 1 & $?$ & $?$ & 1 & $\mathrm{n}$ & $\mathrm{n}$ & $\mathrm{n}$ & $\mathrm{n}$ & 3 & 3 & 2 & 1 & 1 & 1 & 1 \\
\hline U. $C$ & Chippewaella patellitheca & $n$ & $n$ & $n$ & $n$ & $\mathrm{n}$ & $\mathrm{n}$ & $\mathrm{n}$ & $n$ & $\mathrm{n}$ & $\mathrm{n}$ & 1 & $?$ & $?$ & 1 & $\mathrm{n}$ & $\mathrm{n}$ & $\mathrm{n}$ & $\mathrm{n}$ & 5 & 2 & 2 & 1 & 1 & 1 & 1 \\
\hline T. $S t$ & Strepsodiscus major & $n$ & $\mathrm{n}$ & n & $n$ & $\mathbf{n}$ & $n$ & $n$ & $n$ & $n$ & $\mathrm{n}$ & 1 & 1 & $n$ & 1 & $\mathrm{n}$ & $\mathrm{n}$ & $\mathbf{n}$ & $n$ & 4 & 2 & 2 & 1 & 1 & 1 & 1 \\
\hline S. $C$ & Chalarostrepsis praecursor & $n$ & $\mathrm{n}$ & $\mathrm{n}$ & $\mathrm{n}$ & $\mathrm{n}$ & $n$ & $n$ & $\mathrm{n}$ & $n$ & $\mathrm{n}$ & 1 & 1 & $\mathrm{n}$ & 1 & $\mathrm{n}$ & $\mathrm{n}$ & $\mathrm{n}$ & $\mathrm{n}$ & 4 & 3 & 2 & 1 & 1 & 1 & 1 \\
\hline R. $E c$ & Eobucania mexicana & $\mathrm{n}$ & $\mathrm{n}$ & $\mathrm{n}$ & $\mathrm{n}$ & $\mathrm{n}$ & $\mathrm{n}$ & $\mathrm{n}$ & $\mathrm{n}$ & $\mathrm{n}$ & $\mathrm{n}$ & 1 & 1 & $\mathrm{n}$ & 1 & $\mathrm{n}$ & $\mathrm{n}$ & $\mathrm{n}$ & $\mathrm{n}$ & 4 & 3 & 2 & 1 & 1 & 1 & 1 \\
\hline Q. $S t$ & Strepsodiscus paucivoluta & $\mathrm{n}$ & $\mathrm{n}$ & $\mathrm{n}$ & $\mathrm{n}$ & $\mathbf{n}$ & $\mathrm{n}$ & $\mathrm{n}$ & $n$ & $\mathrm{n}$ & $\mathrm{n}$ & 1 & 1 & $\mathrm{n}$ & 1 & $\mathrm{n}$ & $\mathrm{n}$ & $\mathrm{n}$ & $\mathrm{n}$ & 4 & 2 & 2 & 1 & 1 & 1 & l \\
\hline P. $M$ & Modestospira poulseni & $n$ & $n$ & $\mathrm{n}$ & $\mathrm{n}$ & $n$ & $\mathrm{n}$ & $\mathrm{n}$ & $n$ & $\mathrm{n}$ & $\mathrm{n}$ & 1 & 1 & $n$ & 1 & $n$ & $n$ & $n$ & $n$ & 4 & $?$ & 2 & 1 & 1 & 1 & 1 \\
\hline O. $P \epsilon$ & Peelerophon oehlerti & $\mathrm{n}$ & $n$ & n & $n$ & $\mathrm{n}$ & $\mathrm{n}$ & $\mathbf{n}$ & $n$ & $n$ & $\mathrm{n}$ & 1 & 1 & $n$ & 1 & $\mathrm{n}$ & $\mathrm{n}$ & $\mathrm{n}$ & $\mathrm{n}$ & 4 & 3 & 2 & 1 & 1 & 1 & 1 \\
\hline N. $K i$ & Kiringella pyramidalis & $?$ & $?$ & $?$ & $\mathrm{n}$ & $\mathrm{n}$ & $\mathrm{n}$ & $\mathrm{n}$ & $\mathrm{n}$ & $\mathrm{n}$ & $\mathrm{n}$ & 1 & 1 & $\mathrm{n}$ & 1 & $\mathrm{n}$ & $\mathrm{n}$ & $n$ & $\mathrm{n}$ & 5 & $?$ & 2 & 1 & 1 & 1 & 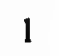 \\
\hline M. $\quad C_{y}$ & Cyrtolites sp. & 1 & 1 & $\mathrm{n}$ & $\mathrm{n}$ & $\mathrm{n}$ & $\mathrm{n}$ & $\mathrm{n}$ & $\mathrm{n}$ & $\mathrm{n}$ & $\mathrm{n}$ & 1 & 1 & $\mathrm{n}$ & 1 & $\mathrm{n}$ & $n$ & $\mathbf{n}$ & $\mathrm{n}$ & 3 & $?$ & 2 & 1 & 1 & 1 & 2 \\
\hline L. $M$ & Macluritella? walcotti & $\mathrm{n}$ & $\mathrm{n}$ & $\mathrm{n}$ & $\mathrm{n}$ & $\mathrm{n}$ & $\mathrm{n}$ & $\mathrm{n}$ & n & $\mathrm{n}$ & $\mathrm{n}$ & 1 & 1 & $\mathrm{n}$ & 1 & $\mathrm{n}$ & 11 & $\mathbf{n}$ & $\mathrm{n}$ & 1 & 3 & 2 & 1 & 7 & 1 & 1 \\
\hline K. $\quad E_{2}$ & Euomphalopsis involuta & $\mathrm{n}$ & $\mathrm{n}$ & $\mathrm{n}$ & $n$ & $\mathbf{n}$ & $n$ & $n$ & $\mathrm{n}$ & 11 & $\mathrm{n}$ & 1 & 1 & $n$ & 1 & $\mathrm{n}$ & $n$ & $n$ & $n$ & 2 & 1 & 2 & 1 & 7 & 1 & 1 \\
\hline J. “ $\wedge$ & "Maclurites" thomsoni & $\mathrm{n}$ & $\mathrm{n}$ & $\mathrm{n}$ & $n$ & $\mathrm{n}$ & $\mathrm{n}$ & $\mathrm{n}$ & $\mathrm{n}$ & $\mathrm{n}$ & $\mathrm{n}$ & 1 & 1 & $\mathrm{n}$ & $?$ & $?$ & $?$ & $?$ & $?$ & 4 & 3 & 2 & 1 & 8 & 1 & 1 \\
\hline I. $K c$ & Kobayashiella circe & $\mathrm{n}$ & $\mathrm{n}$ & $n$ & $n$ & $\mathbf{n}$ & $\mathrm{n}$ & $\mathrm{n}$ & $\mathrm{n}$ & $\mathbf{n}$ & $\mathrm{n}$ & 1 & $?$ & $?$ & $?$ & $?$ & $?$ & $?$ & $?$ & 5 & 2 & 2 & 1 & 7 & 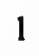 & 1 \\
\hline H. $S c$ & Scaevogyra swezeyi & $\mathrm{n}$ & $\mathrm{n}$ & $n$ & $\mathrm{n}$ & $\mathrm{n}$ & $n$ & $\mathrm{n}$ & $\mathrm{n}$ & $\mathrm{n}$ & $\mathrm{n}$ & 1 & 1 & $\mathrm{n}$ & $?$ & $?$ & $?$ & $?$ & $?$ & 5 & 2 & 2 & 1 & 8 & 1 & 1 \\
\hline G. $M$ & Matherella saratogensis & $\mathbf{n}$ & $\mathbf{n}$ & $\mathrm{n}$ & $\mathrm{n}$ & $\mathbf{n}$ & $\mathrm{n}$ & $\mathrm{n}$ & $n$ & $\mathrm{n}$ & $\mathrm{n}$ & 1 & 1 & $\mathrm{n}$ & $?$ & $?$ & $?$ & $?$ & $?$ & 5 & 3 & 2 & 1 & 8 & 1 & 1 \\
\hline F. $M$ & Matherellina walcotti & $\mathrm{n}$ & $\mathbf{n}$ & $\mathrm{n}$ & $\mathbf{n}$ & $\mathrm{n}$ & $\mathrm{n}$ & $\mathrm{n}$ & $n$ & $\mathrm{n}$ & $\mathrm{n}$ & 1 & 1 & $\mathrm{n}$ & $?$ & $?$ & $?$ & $?$ & $?$ & 5 & 2 & 2 & 1 & 8 & 1 & 1 \\
\hline E. $H_{3}$ & Hypseloconus elongatus & $\mathrm{n}$ & $n$ & $\mathrm{n}$ & $\mathrm{n}$ & $\mathrm{n}$ & $\mathrm{n}$ & $n$ & $\mathrm{n}$ & $\mathrm{n}$ & $\mathrm{n}$ & 1 & 1 & $n$ & 1 & $n$ & $\mathrm{n}$ & $\mathrm{n}$ & $\mathrm{n}$ & 5 & 2 & 2 & 1 & 1 & 1 & 1 \\
\hline D. $K r$ & Knightoconus antarcticus & $n$ & $\mathrm{n}$ & $\mathrm{n}$ & $\mathrm{n}$ & $\mathrm{n}$ & $\mathrm{n}$ & $\mathrm{n}$ & $\mathrm{n}$ & $\mathrm{n}$ & $\mathrm{n}$ & 1 & 1 & $\mathrm{n}$ & 1 & $\mathrm{n}$ & $\mathbf{n}$ & 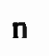 & $\mathrm{n}$ & 5 & 2 & 2 & 1 & 1 & 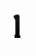 & 1 \\
\hline C. Si & Sinuites sowerbyi & $\mathrm{n}$ & $n$ & $\mathrm{n}$ & $\mathbf{n}$ & $n$ & $n$ & $\mathrm{n}$ & n & $n$ & $n$ & 1 & 1 & $\mathrm{n}$ & 1 & $n$ & $n$ & $n$ & $\mathrm{n}$ & 3 & $?$ & 2 & 1 & 1 & 1 & 1 \\
\hline B. $\mathrm{Cl}$ & Cloudia buttsi & $\mathbf{n}$ & $n$ & $n$ & $\mathrm{n}$ & $\mathrm{n}$ & $n$ & $\mathrm{n}$ & $\mathrm{n}$ & $n$ & $n$ & 1 & 1 & n & 1 & $\mathrm{n}$ & $n$ & $\mathrm{n}$ & $\mathrm{n}$ & 3 & 2 & 2 & 1 & 1 & 1 & 1 \\
\hline A. $O$ & Owenella antiquata & $\mathbf{n}$ & $\mathbf{n}$ & $\mathrm{n}$ & $\mathbf{n}$ & $\mathrm{n}$ & $\mathrm{n}$ & $\mathbf{n}$ & $\mathrm{n}$ & $\mathrm{n}$ & $\mathrm{n}$ & 1 & 1 & $\mathbf{n}$ & 1 & $n$ & $\mathbf{n}$ & $\mathbf{n}$ & $\mathbf{n}$ & 3 & 2 & 2 & 1 & 1 & 1 & 1 \\
\hline 1. $D i$ & Dirhachopea normalis & $n$ & $\mathrm{n}$ & $\mathrm{n}$ & $\mathrm{n}$ & $\mathrm{n}$ & $\mathrm{n}$ & $\mathrm{n}$ & $\mathrm{n}$ & $\mathrm{n}$ & $\mathrm{n}$ & 1 & 1 & $\mathrm{n}$ & 2 & 1 & 1 & 1 & 2 & 3 & 2 & 2 & 1 & 2 & 1 & 1 \\
\hline 2. $D i$ & Dirhachopea subrotunda & $\mathrm{n}$ & $\mathrm{n}$ & $\mathrm{n}$ & $\mathrm{n}$ & $\mathrm{n}$ & $n$ & $\mathrm{n}$ & $n$ & $\mathrm{n}$ & $n$ & 1 & 1 & $\mathbf{n}$ & 2 & 1 & 1 & 1 & 2 & 3 & 2 & 2 & 1 & 2 & 1 & l \\
\hline 3. $S c$ & Schizopea typica & $\mathrm{n}$ & $\mathrm{n}$ & $\mathrm{n}$ & $\mathrm{n}$ & $\mathrm{n}$ & $\mathrm{n}$ & $\mathrm{n}$ & $\mathrm{n}$ & $\mathbf{n}$ & $\mathrm{n}$ & 1 & 1 & $\mathrm{n}$ & 2 & 1 & 1 & 1 & 2 & 4 & 2 & 2 & 1 & 2 & 1 & 1 \\
\hline 4. Si & Sinuopea sweeti & $n$ & $\mathrm{n}$ & $\mathrm{n}$ & $n$ & $n$ & $n$ & $n$ & $\mathbf{n}$ & $n$ & $n$ & 1 & 1 & $\mathrm{n}$ & 1 & $n$ & $n$ & $\mathrm{n}$ & $n$ & 3 & 2 & 2 & 1 & 1 & 1 & 1 \\
\hline 5. $T a$ & Taeniospira emminencis & $\mathbf{n}$ & $\mathbf{n}$ & $n$ & $\mathbf{n}$ & $\mathrm{n}$ & $\mathbf{n}$ & $\mathrm{n}$ & $\mathrm{n}$ & $\mathrm{n}$ & $\mathrm{n}$ & 1 & 1 & $\mathbf{n}$ & 1 & $\mathbf{n}$ & $\mathbf{n}$ & $\mathrm{n}$ & $\mathrm{n}$ & 3 & 2 & 2 & 1 & 1 & 1 & 1 \\
\hline 6. $C e$ & Ceratopea canadensis & $\mathbf{n}$ & $\mathrm{n}$ & $\mathrm{n}$ & $\mathrm{n}$ & $\mathrm{n}$ & $\mathrm{n}$ & $\mathrm{n}$ & $\mathrm{n}$ & $\mathrm{n}$ & $\mathbf{n}$ & 1 & 2 & 2 & 2 & 1 & 1 & 1 & 2 & 4 & 3 & 2 & 1 & 4 & 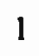 & 1 \\
\hline 7. $G c$ & Gasconadia putilla & $\mathrm{n}$ & $\mathrm{n}$ & $\mathrm{n}$ & $\mathrm{n}$ & $\mathrm{n}$ & $n$ & $\mathrm{n}$ & $\mathrm{n}$ & $n$ & $n$ & 1 & 1 & $\mathbf{n}$ & 1 & $n$ & $\mathbf{n}$ & $\mathrm{n}$ & $\mathrm{n}$ & 3 & 2 & 3 & 1 & 2 & 1 & 1 \\
\hline 8. Ja & Jarlopsis conicus & $\mathrm{n}$ & n & $\mathrm{n}$ & $\mathrm{n}$ & $\mathrm{n}$ & $\mathrm{n}$ & $\mathrm{n}$ & $\mathrm{n}$ & $\mathrm{n}$ & $\mathrm{n}$ & 1 & 1 & $\mathrm{n}$ & 2 & 1 & 1 & 1 & 2 & 6 & 2 & 2 & 1 & 3 & 1 & 1 \\
\hline 9. $O_{f}$ & Ophileta supraplana & $\mathrm{n}$ & $\mathrm{n}$ & $\mathrm{n}$ & $\mathrm{n}$ & $\mathrm{n}$ & $\mathrm{n}$ & $\mathrm{n}$ & $\mathrm{n}$ & $n$ & $\mathrm{n}$ & 1 & 1 & $\mathrm{n}$ & 2 & 1 & 2 & 1 & 2 & 4 & 3 & 2 & 1 & 4 & 1 & 1 \\
\hline 10. $R h$ & Rhombella umbilicata & 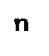 & $\mathrm{n}$ & $\mathrm{n}$ & $\mathrm{n}$ & $n$ & $n$ & $\mathrm{n}$ & " & $\mathrm{n}$ & n & 1 & 1 & $\mathrm{n}$ & 2 & 1 & 1 & 1 & 2 & 6 & 2 & 2 & 1 & 3 & | & 1 \\
\hline 11. $P r$ & Prohelicotoma uniangulata & $\mathrm{n}$ & $\mathrm{n}$ & $\mathbf{n}$ & $\mathrm{n}$ & $\mathrm{n}$ & $\mathrm{n}$ & $\mathrm{n}$ & $\mathrm{n}$ & $\mathrm{n}$ & $\mathbf{n}$ & 1 & 1 & $\mathrm{n}$ & 2 & 1 & 1 & 1 & 2 & 4 & 1 & 2 & 1 & 6 & 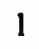 & \\
\hline 12. Sir & Sinuopea basiplanata & $\mathbf{n}$ & $\mathrm{n}$ & $\mathrm{n}$ & n & $\mathrm{n}$ & $\mathrm{n}$ & $\mathrm{n}$ & $\mathbf{n}$ & $\mathrm{n}$ & $\mathbf{n}$ & 1 & 1 & $\mathbf{n}$ & 1 & n & $\mathrm{n}$ & $r$ & $\mathrm{n}$ & 3 & 2 & 2 & 1 & 1 & 1 & 1 \\
\hline 13. $\mathrm{Ta}$ & Taeniospira ?st. clairi & $n$ & $\mathrm{n}$ & $\mathrm{n}$ & $\mathrm{n}$ & $n$ & $n$ & $\mathrm{n}$ & $\mathbf{n}$ & $\mathrm{n}$ & $\mathrm{n}$ & 1 & 2 & 2 & 1 & $n$ & $\mathbf{n}$ & $n$ & $\mathrm{n}$ & 4 & 2 & 2 & 1 & 1 & 1 & 1 \\
\hline 14. $B r$ & Bridgeites ?disjuncta & $\mathrm{n}$ & $\mathrm{n}$ & $\mathrm{n}$ & $\mathrm{n}$ & $\mathrm{n}$ & $\mathbf{n}$ & $n$ & $\mathrm{n}$ & $\mathrm{n}$ & $\mathrm{n}$ & 1 & 2 & 2 & 2 & 1 & 3 & 1 & 2 & 3 & 2 & 2 & 1 & 7 & 1 & I \\
\hline 15. $\mathrm{Br}$ & Bridgeites planodorsalis & $\mathrm{n}$ & $\mathrm{n}$ & $\mathrm{n}$ & $\mathrm{n}$ & $\mathrm{n}$ & $\mathbf{n}$ & $\mathrm{n}$ & $\mathbf{n}$ & $\mathbf{n}$ & $\mathrm{n}$ & 1 & 2 & 2 & 2 & 1 & 1 & 1 & 2 & 5 & 3 & 2 & 1 & 6 & 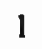 & I \\
\hline 16. $\mathrm{Br}$ & Bridgeites supraconvexa & $\mathrm{n}$ & $\mathrm{n}$ & $\mathrm{n}$ & $\mathrm{n}$ & $\mathrm{n}$ & $\mathrm{n}$ & $\mathrm{n}$ & $\mathrm{n}$ & $\mathrm{n}$ & $n$ & 1 & 2 & 2 & 2 & 1 & 3 & 1 & 2 & 5 & 3 & 2 & 1 & 7 & l & 1 \\
\hline 17. $E_{u}$ & Euconia etna & $\mathrm{n}$ & $\mathrm{n}$ & $\mathrm{n}$ & $\mathrm{n}$ & $\mathrm{n}$ & $\mathbf{n}$ & $\mathrm{n}$ & $\mathrm{n}$ & $\mathrm{n}$ & $\mathrm{n}$ & 1 & 1 & $\mathrm{n}$ & 1 & $\mathrm{n}$ & $\mathrm{n}$ & $\mathrm{n}$ & $\mathrm{n}$ & 6 & 2 & 2 & 1 & 3 & 1 & 1 \\
\hline 18. $C e$ & Ceratopea ?laurentia & $n$ & $n$ & $\mathrm{n}$ & $\mathrm{n}$ & $\mathrm{n}$ & $\mathrm{n}$ & $\mathrm{n}$ & $\mathbf{n}$ & $\mathrm{n}$ & $\mathbf{n}$ & 1 & 2 & 2 & 2 & 2 & 3 & 1 & 2 & 5 & 3 & 2 & 1 & 4 & 1 & 1 \\
\hline 19. $\mathrm{Ce}$ & Ceratopea pygmaea & $\mathrm{n}$ & $\mathrm{n}$ & $\mathbf{n}$ & $\mathrm{n}$ & $\mathrm{n}$ & $\mathbf{n}$ & $\mathrm{n}$ & n & $\mathrm{n}$ & n & 1 & 2 & 2 & 2 & 2 & 3 & 1 & 2 & 5 & 3 & 2 & 1 & 4 & 1 & 1 \\
\hline 20. Or & Orospira bigranosa & $n$ & $\mathrm{n}$ & $\mathrm{n}$ & $\mathrm{n}$ & $n$ & $\mathbf{n}$ & $\mathrm{n}$ & $\mathrm{n}$ & $\mathbf{n}$ & $\mathbf{n}$ & 1 & 2 & 2 & 2 & 3 & 2 & 1 & 1 & 4 & 3 & 2 & 1 & 2 & 1 & 2 \\
\hline 21. $M c$ & Macluritella stantoni & $\mathrm{n}$ & $\mathrm{n}$ & $\mathrm{n}$ & $\mathrm{n}$ & $\mathrm{n}$ & $\mathrm{n}$ & $\mathrm{n}$ & $\mathrm{n}$ & $\mathrm{n}$ & $\mathrm{n}$ & 1 & 1 & $\mathbf{n}$ & 2 & 1 & 1 & $?$ & $?$ & 4 & 1 & 2 & 1 & 7 & 1 & \\
\hline 22. $\mathrm{Te}$ & Teiichispira odenvillensis & $\mathrm{n}$ & $\mathrm{n}$ & $\mathrm{n}$ & $\mathrm{n}$ & $\mathrm{n}$ & $\mathrm{n}$ & $\mathrm{n}$ & $\mathrm{n}$ & $\mathrm{n}$ & $\mathrm{n}$ & 2 & 1 & $\mathrm{n}$ & 2 & 1 & 1 & 1 & 2 & 4 & 1 & 2 & 1 & 7 & 1 & 1 \\
\hline 23. $\mathrm{Te}$ & Teiichispira ?oceana & $\mathrm{n}$ & $\mathrm{n}$ & $\mathrm{n}$ & $\mathrm{n}$ & $\mathrm{n}$ & $\mathrm{n}$ & $\mathrm{n}$ & $\mathrm{n}$ & $\mathrm{n}$ & $\mathrm{n}$ & 2 & 1 & $\mathrm{n}$ & 2 & 1 & 1 & 1 & 2 & 4 & 1 & 2 & 1 & 7 & 1 & 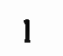 \\
\hline 24. $\mathrm{Pa}$ & Palliseria robusta & $\mathrm{n}$ & $\mathrm{n}$ & $\mathrm{n}$ & $\mathrm{n}$ & $\mathrm{n}$ & $\mathbf{n}$ & $\mathrm{n}$ & $\mathrm{n}$ & $\mathrm{n}$ & $\mathrm{n}$ & 2 & 3 & 2 & 1 & $n$ & $\mathrm{n}$ & $\mathrm{n}$ & 2 & 3 & 1 & 1 & 1 & 9 & 1 & 1 \\
\hline 25. $M i$ & Mitrospira longwelli & $\mathrm{n}$ & $\mathrm{n}$ & $n$ & $\mathrm{n}$ & $\mathrm{n}$ & $\mathrm{n}$ & $\mathrm{n}$ & n & $\mathrm{n}$ & $\mathrm{n}$ & 2 & 3 & 3 & 1 & $\mathrm{n}$ & $\mathrm{n}$ & $\mathbf{n}$ & 2 & 3 & 1 & 1 & 1 & 9 & 1 & \\
\hline 26. $T e$ & Teiichispira kobayashi & $\mathbf{n}$ & $\mathrm{n}$ & $\mathrm{n}$ & $\mathrm{n}$ & $\mathrm{n}$ & $\mathrm{n}$ & $\mathrm{n}$ & $\mathrm{n}$ & $\mathrm{n}$ & $\mathrm{n}$ & 2 & 1 & $\mathrm{n}$ & 2 & 1 & 1 & 1 & 2 & 3 & 2 & 2 & 1 & 5 & 1 & 1 \\
\hline 27. $\mathrm{Te}$ & Teiichispira sylpha & $n$ & $\mathrm{n}$ & $n$ & $n$ & $\mathrm{n}$ & $\mathrm{n}$ & $\mathrm{n}$ & $\mathrm{n}$ & $\mathrm{n}$ & $\mathrm{n}$ & 2 & 2 & $\mathrm{n}$ & 2 & 1 & 1 & 1 & 2 & 3 & 2 & 2 & 1 & 8 & 1 & 1 \\
\hline 28. $M c$ & Monitorella auricula & n & $\mathbf{n}$ & $\mathrm{n}$ & $n$ & $\mathrm{n}$ & $\mathrm{n}$ & $\mathrm{n}$ & $\mathrm{n}$ & $\mathrm{n}$ & $n$ & 2 & 1 & $\mathrm{n}$ & 2 & 1 & 1 & 1 & 2 & 3 & 2 & 2 & 1 & 7 & 1 & \\
\hline 29. $M c$ & Maclurites magna & $\mathrm{n}$ & $\mathrm{n}$ & $\mathrm{n}$ & $\mathrm{n}$ & $\mathrm{n}$ & $\mathrm{n}$ & $\mathrm{n}$ & $n$ & $\mathrm{n}$ & $\mathrm{n}$ & 1 & 1 & $\mathrm{n}$ & 2 & 1 & 1 & 1 & 2 & 3 & 3 & 2 & 1 & 7 & 1 & \\
\hline 30. " $E$ & "Eccyliopterus ornatus" & $\mathbf{n}$ & $\mathrm{n}$ & $\mathrm{n}$ & $\mathrm{n}$ & $\mathrm{n}$ & $\mathrm{n}$ & $\mathrm{n}$ & $\mathrm{n}$ & $\mathrm{n}$ & $\mathrm{n}$ & 1 & 1 & $\mathrm{n}$ & 1 & $\mathrm{n}$ & $\mathrm{n}$ & $\mathrm{n}$ & $\mathbf{n}$ & 3 & 2 & 2 & 1 & 6 & 1 & \\
\hline 31. $M c$ & Maclurites bigsbyi & $\mathrm{n}$ & $\mathbf{n}$ & $\mathrm{n}$ & $\mathrm{n}$ & $\mathrm{n}$ & $\mathrm{n}$ & $\mathrm{n}$ & $\mathrm{n}$ & $\mathrm{n}$ & $\mathrm{n}$ & 1 & 1 & $\mathrm{n}$ & 2 & 1 & 1 & 1 & 2 & 4 & 3 & 2 & 1 & 7 & 1 & \\
\hline
\end{tabular}


APPENDIX 2.-Continued.

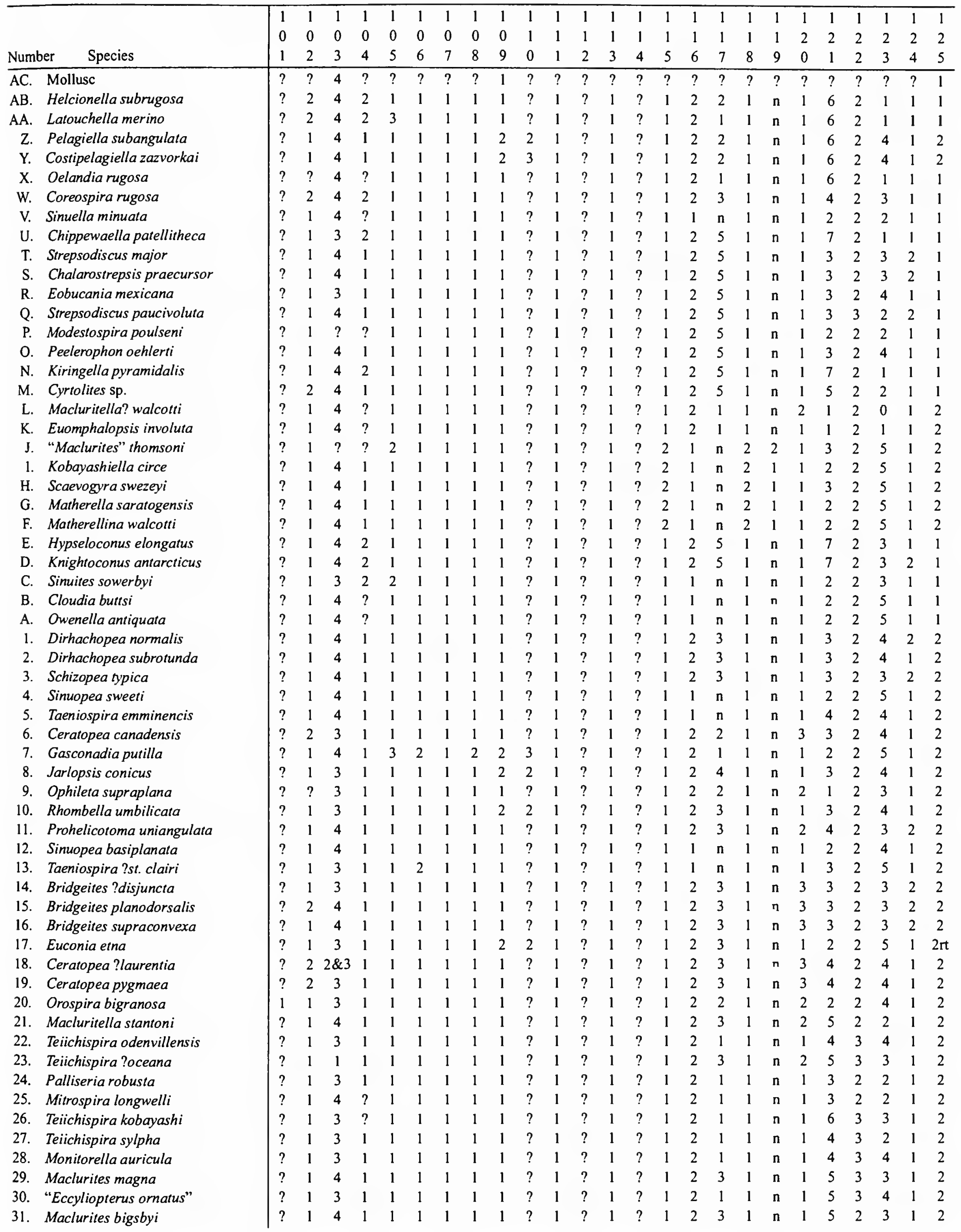


APPENDIX 2.-Continued.

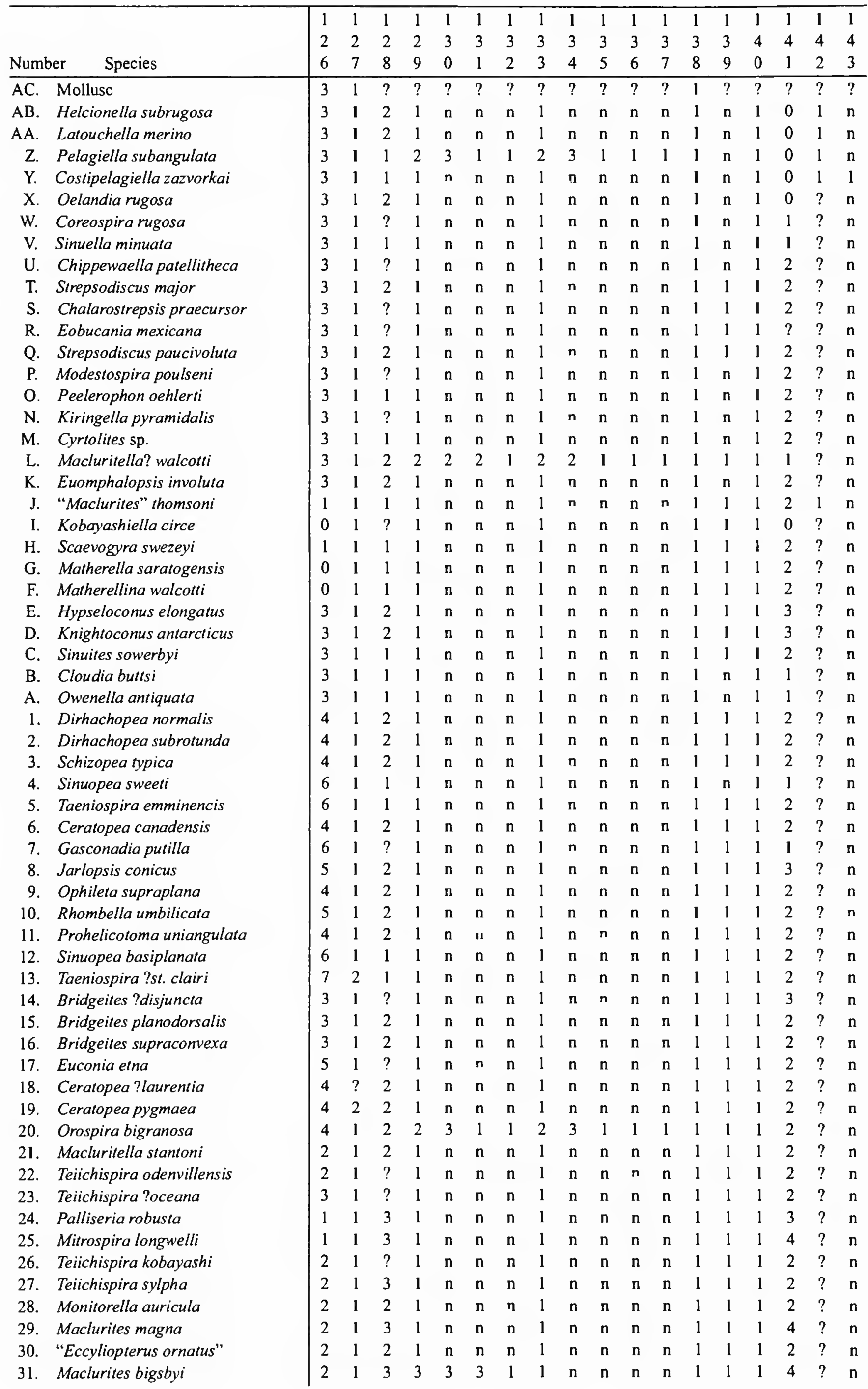


APPENDIX 2.-Continued.

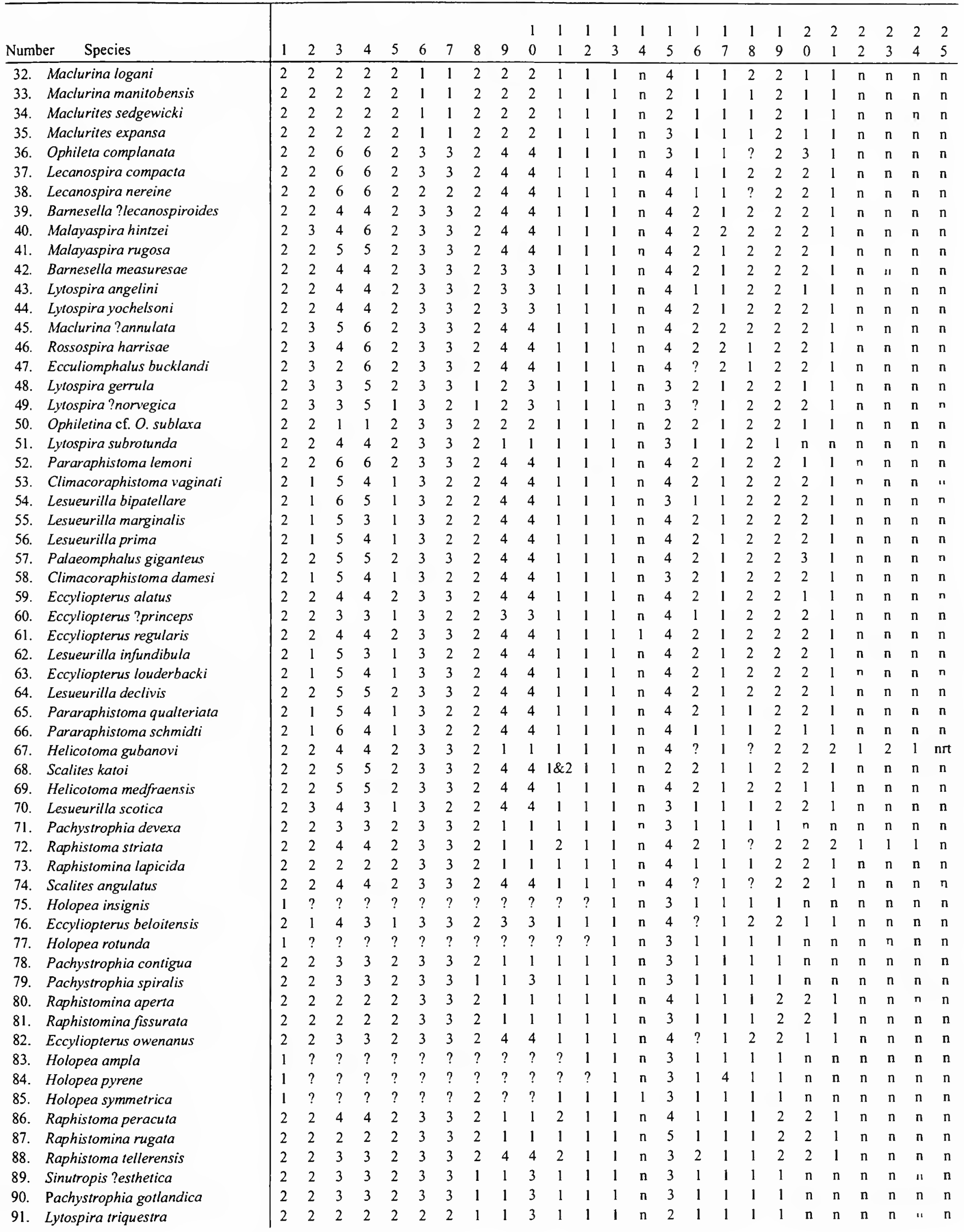


APPENDIX 2.-Continued.

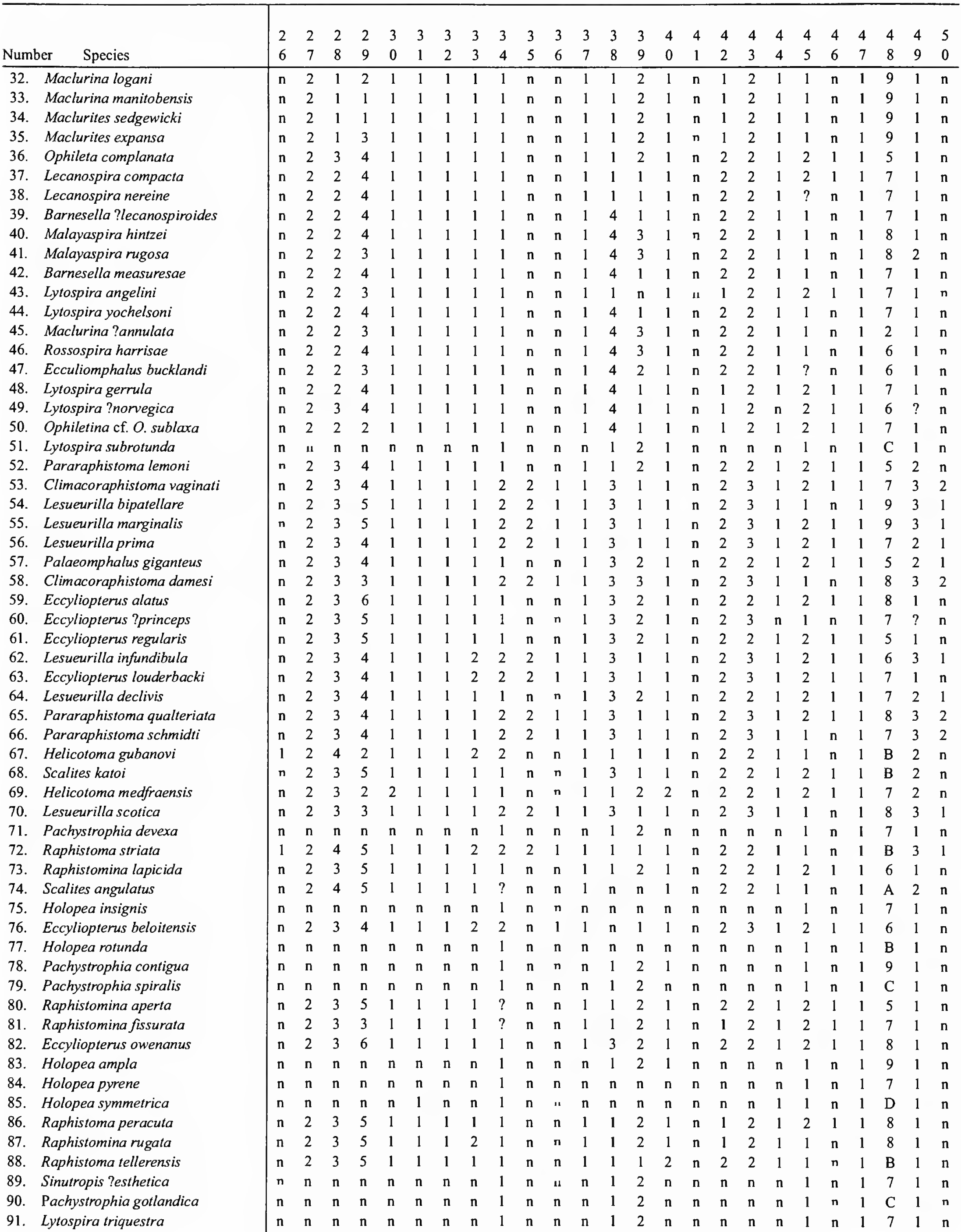


APPENDIX 2.-Continued.

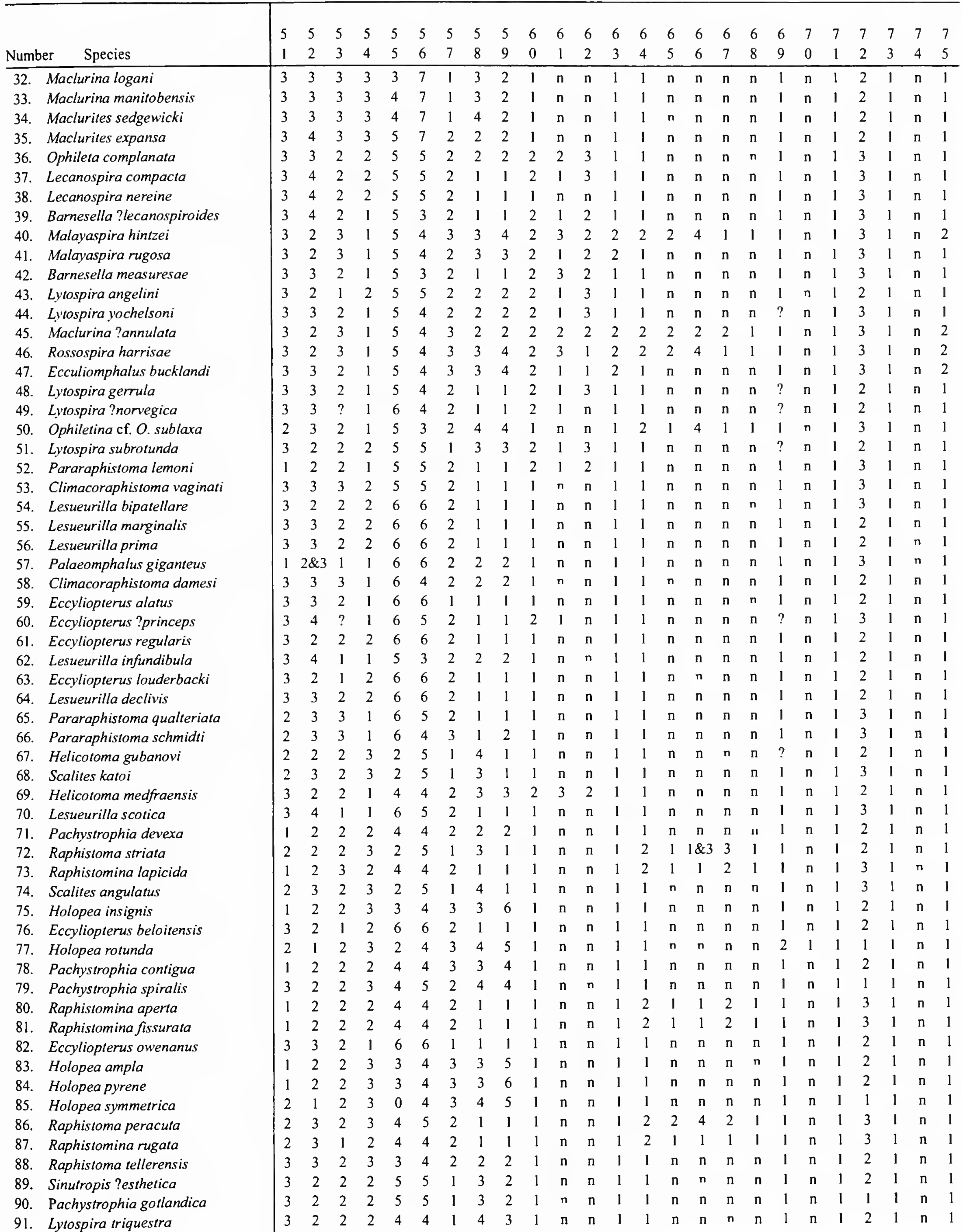


APPENDIX 2.-Continued.

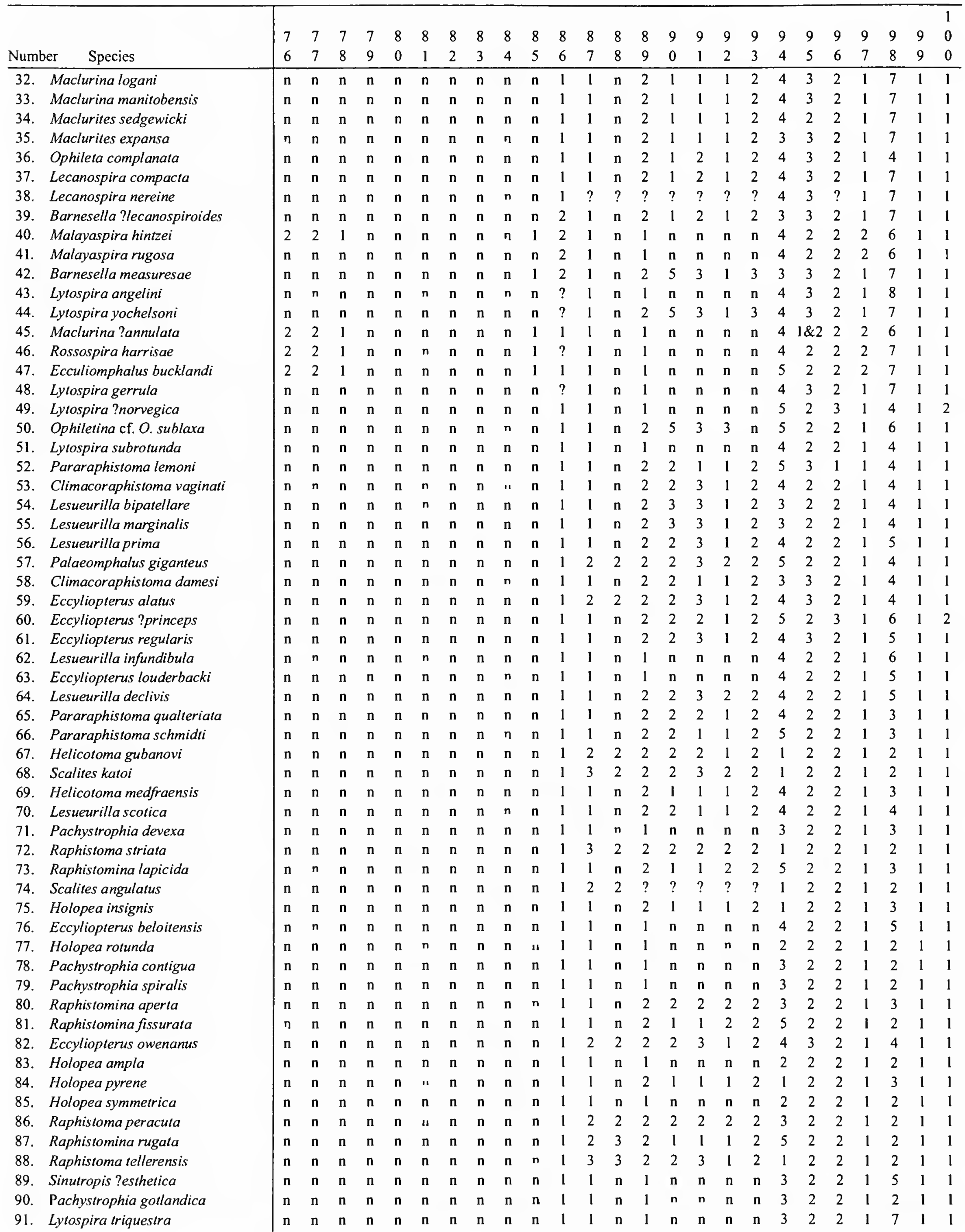


APPENDIX 2.-Continued.

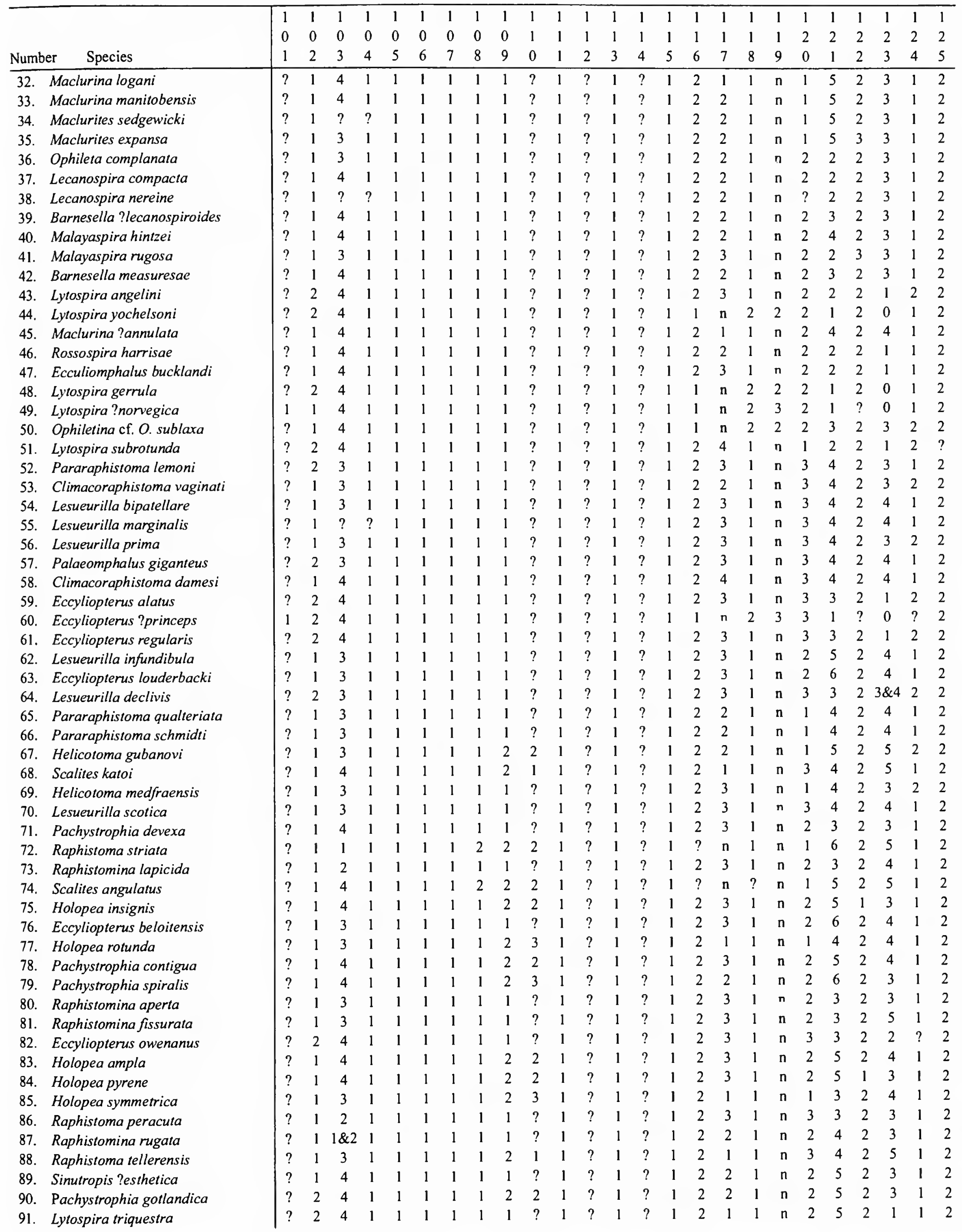


APPENDIX 2.-Continued.

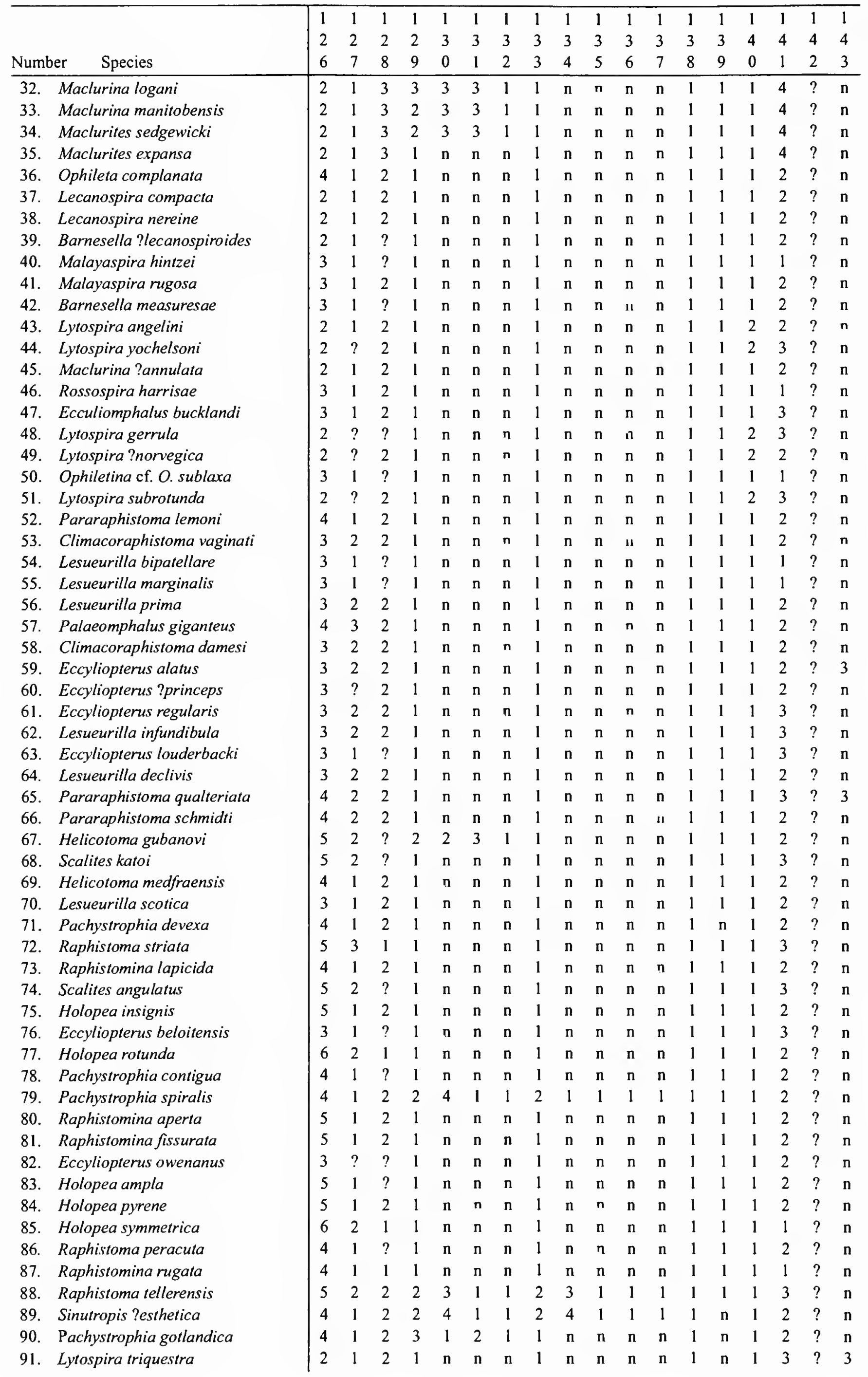


APPENDIX 2.-Continued.

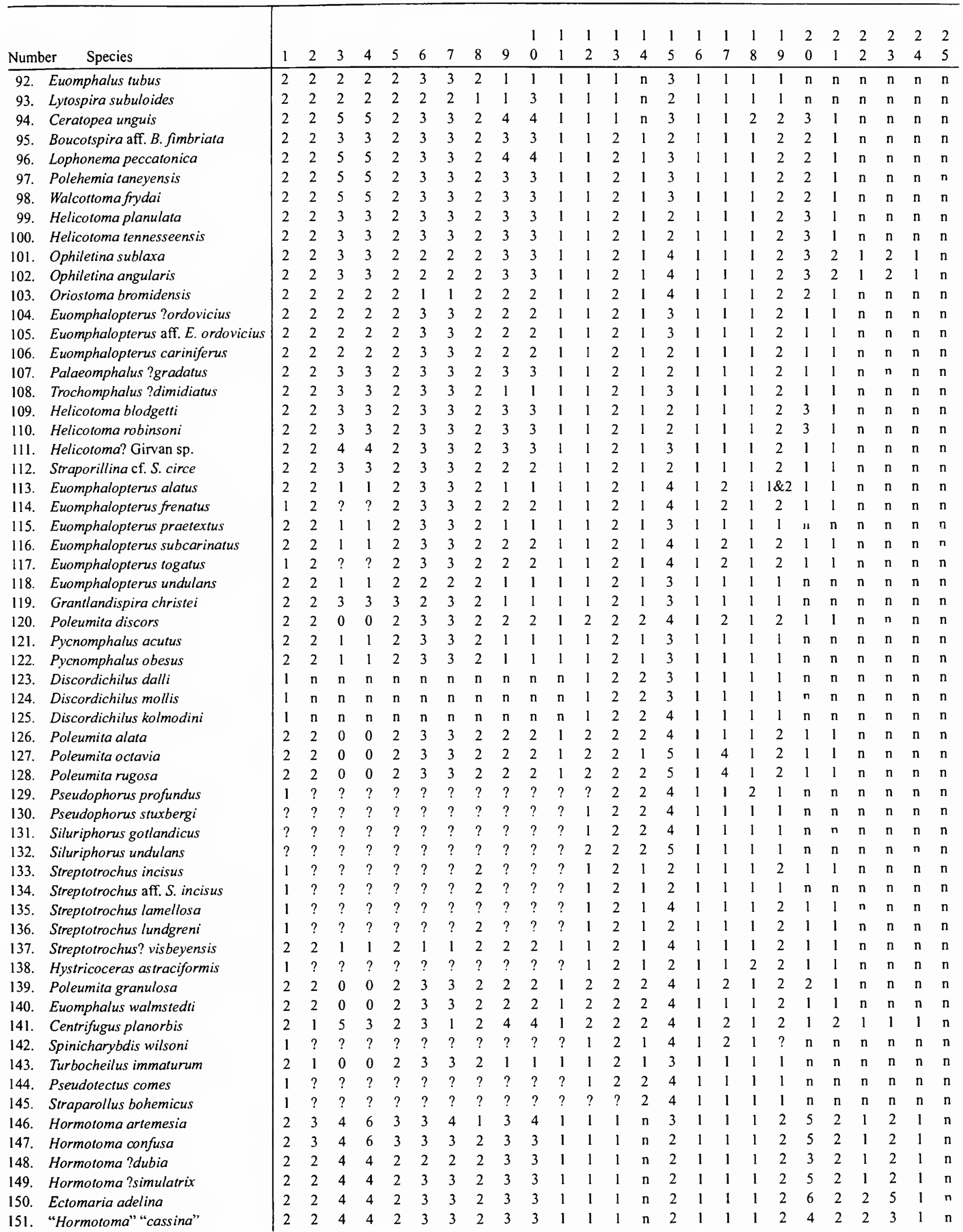


APPENDIX 2.-Continued.

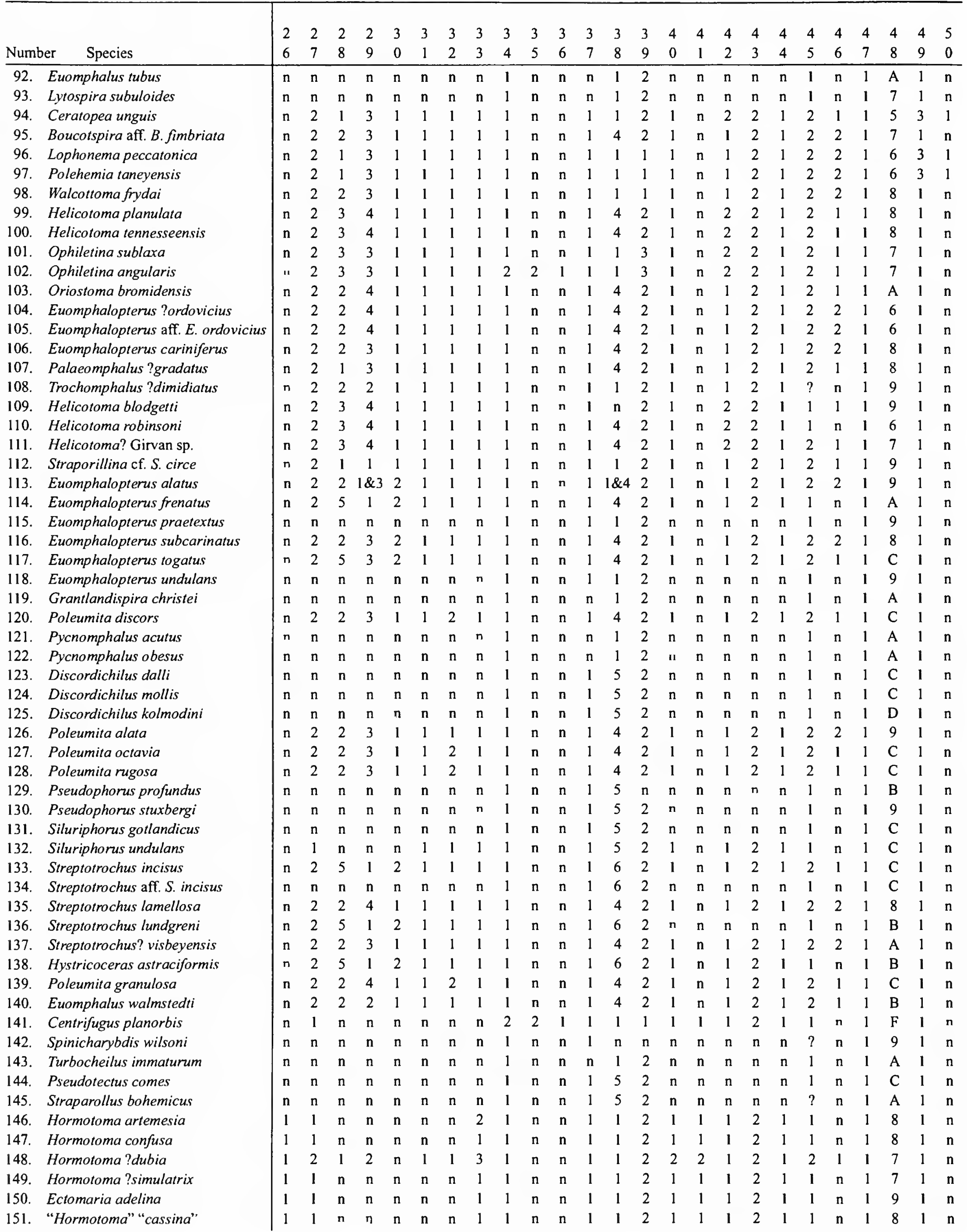


APPENDIX 2.-Continued.

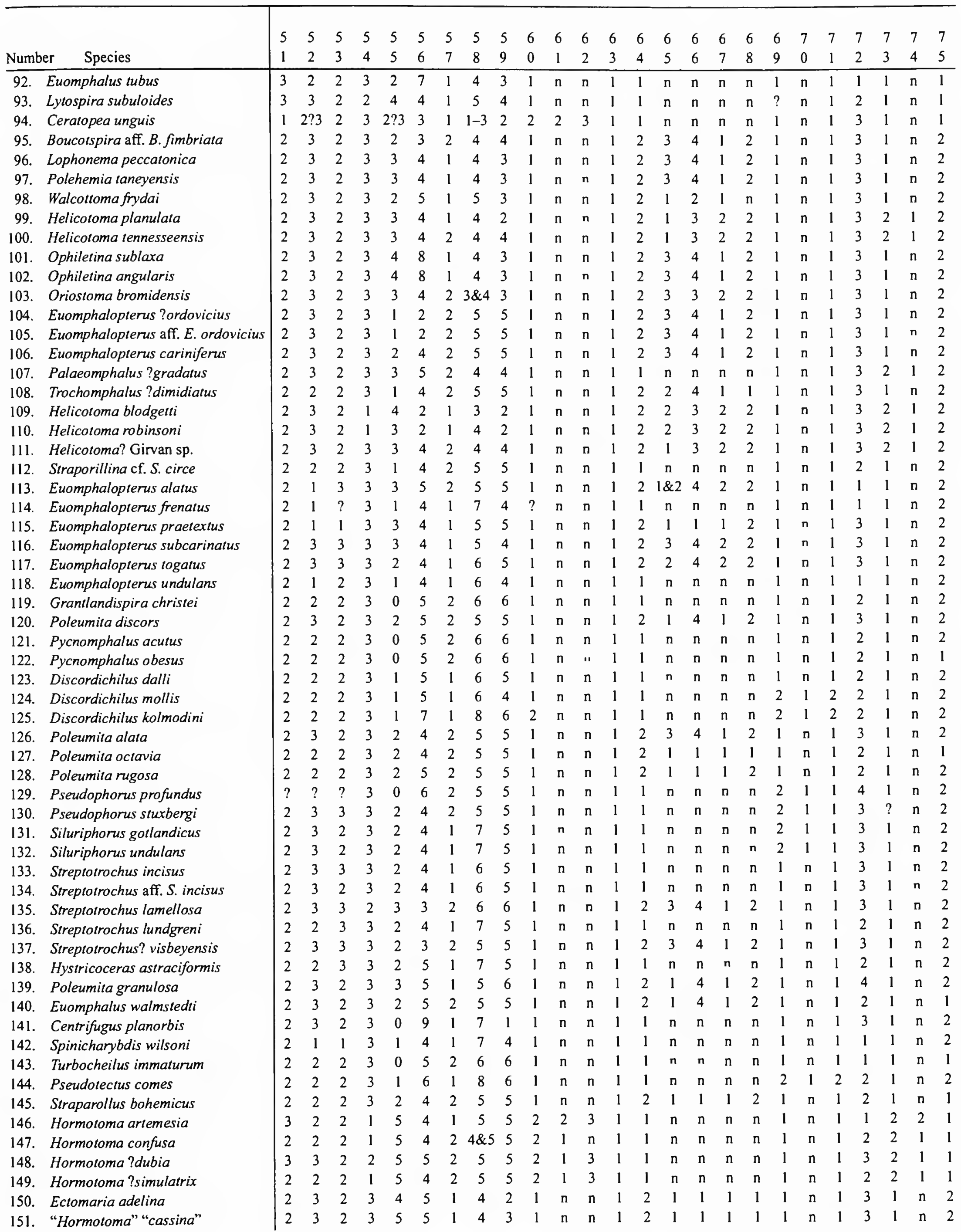


APPENDIX 2.-Continued.

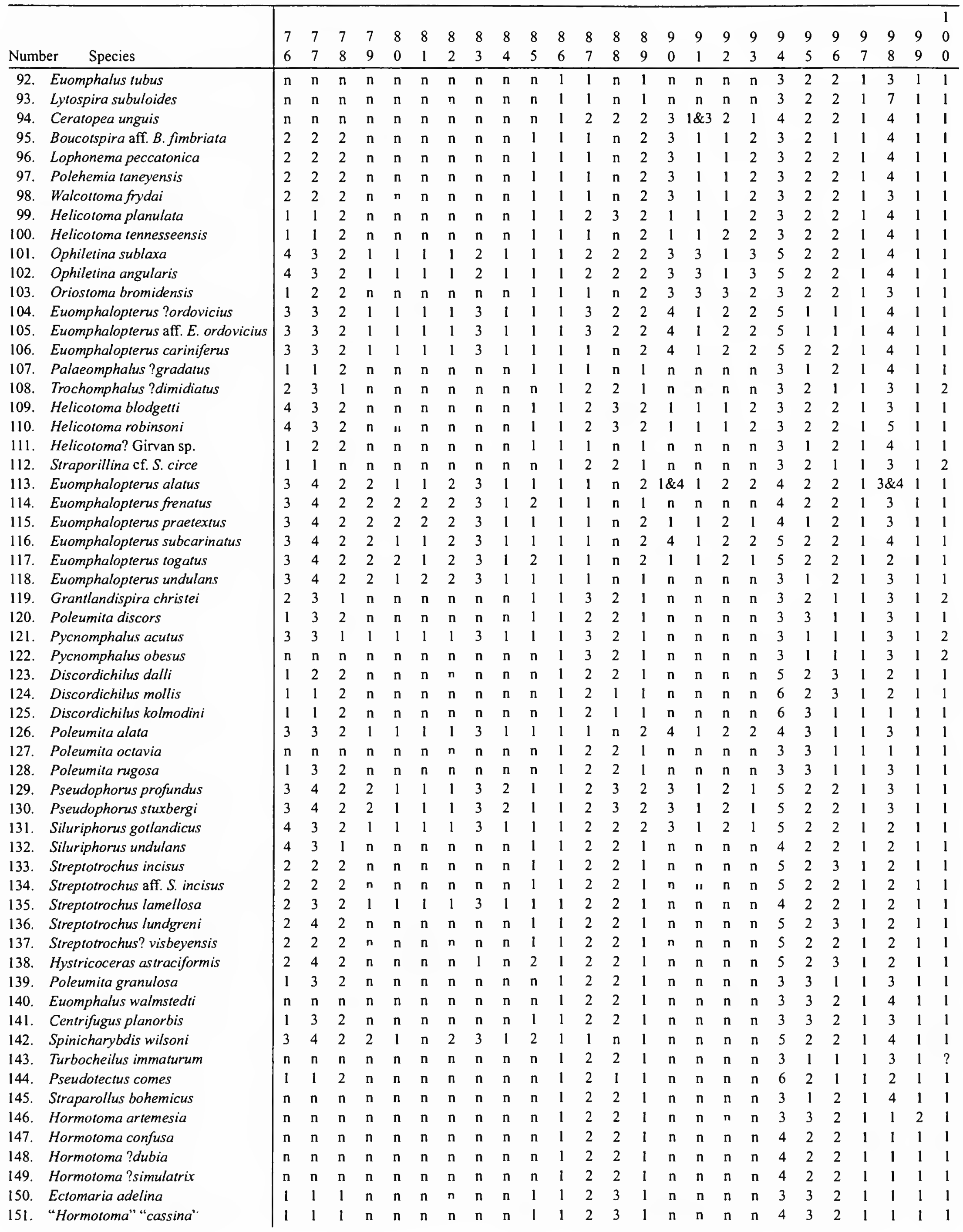


APPENDIX 2.-Continued.

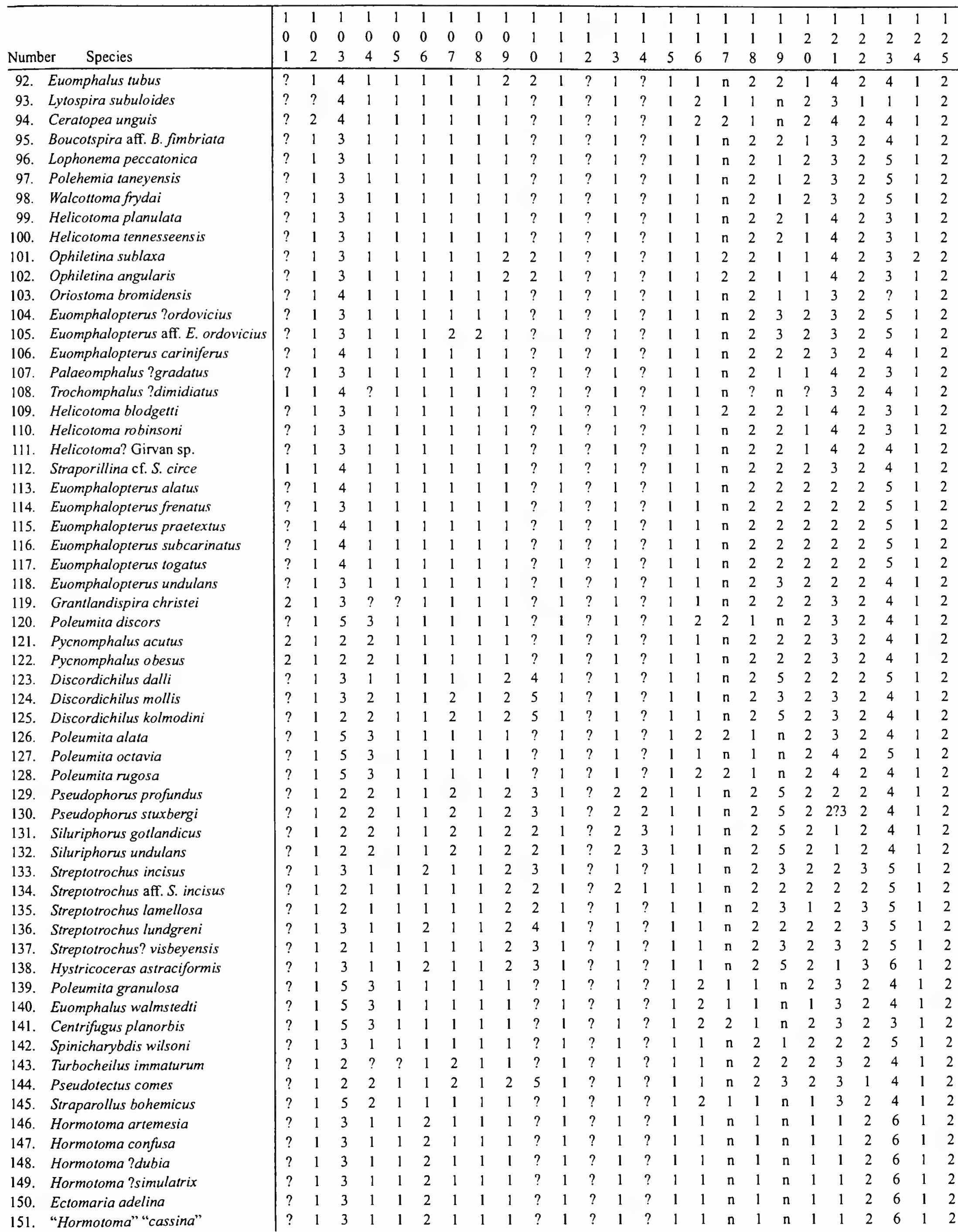


APPENDIX 2.-Continued.

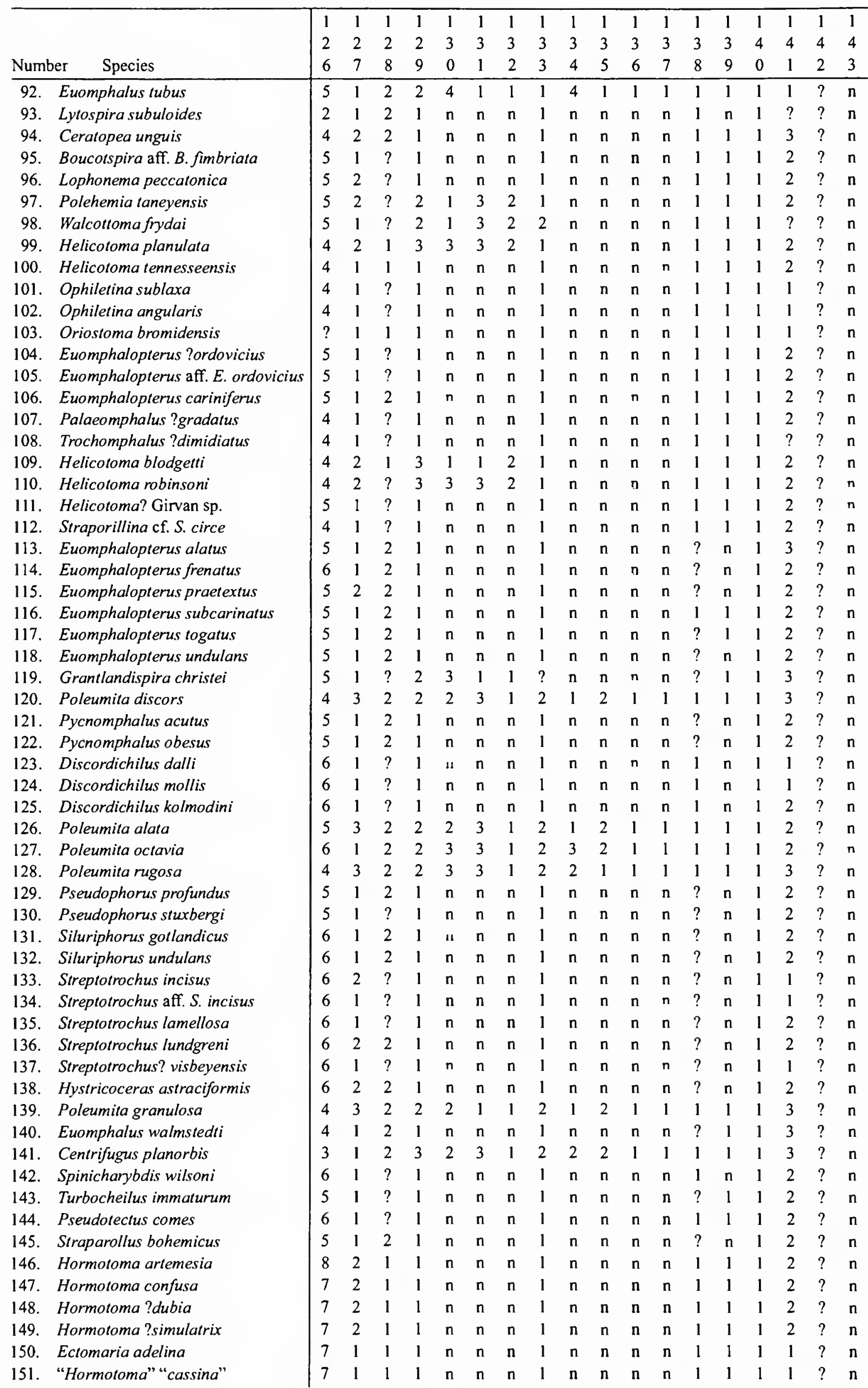


APPENDIX 2.-Continued.

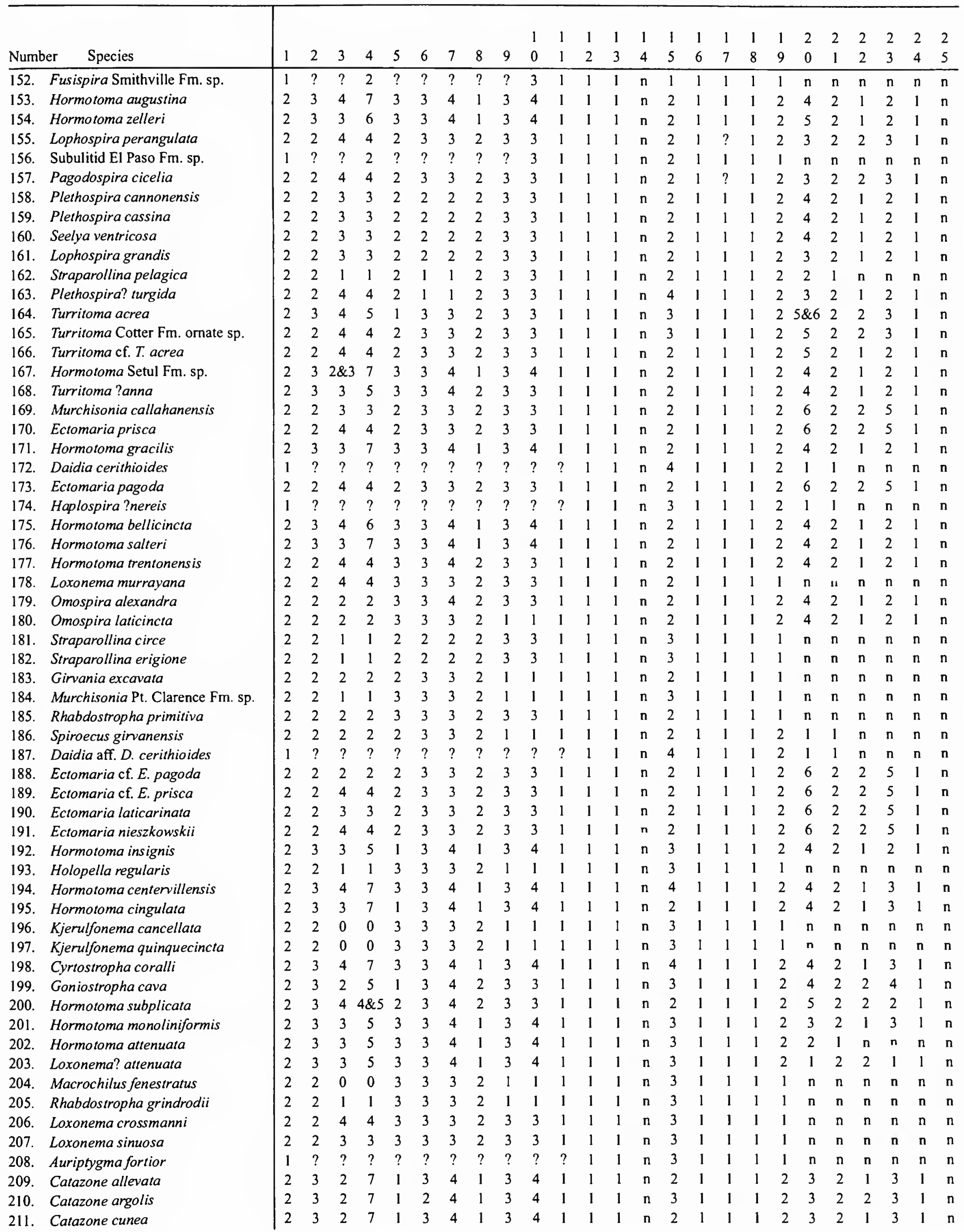


APPENDIX 2.-Continued.

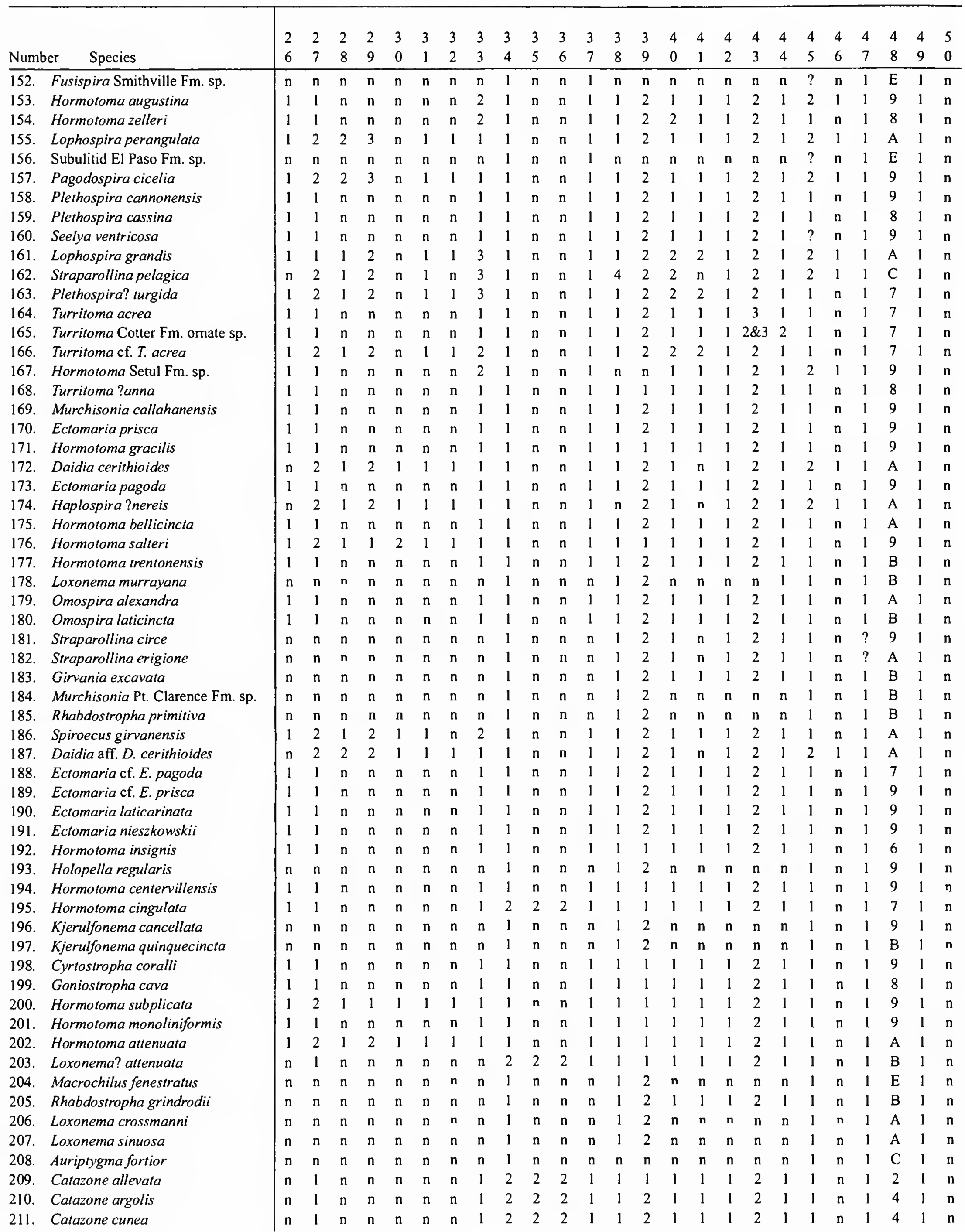


APPENDIX 2.-Continued.

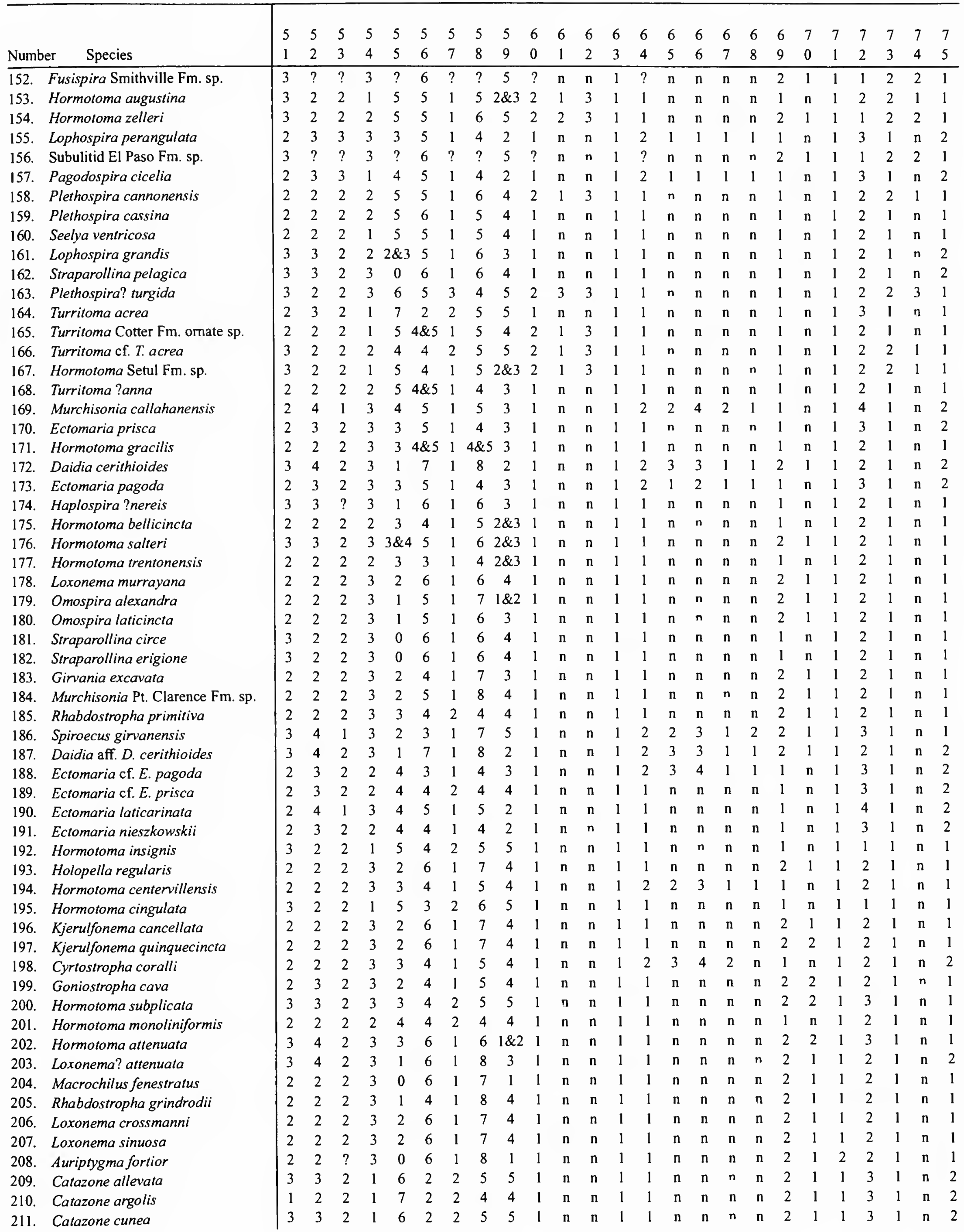


APPENDIX 2.-Continued.

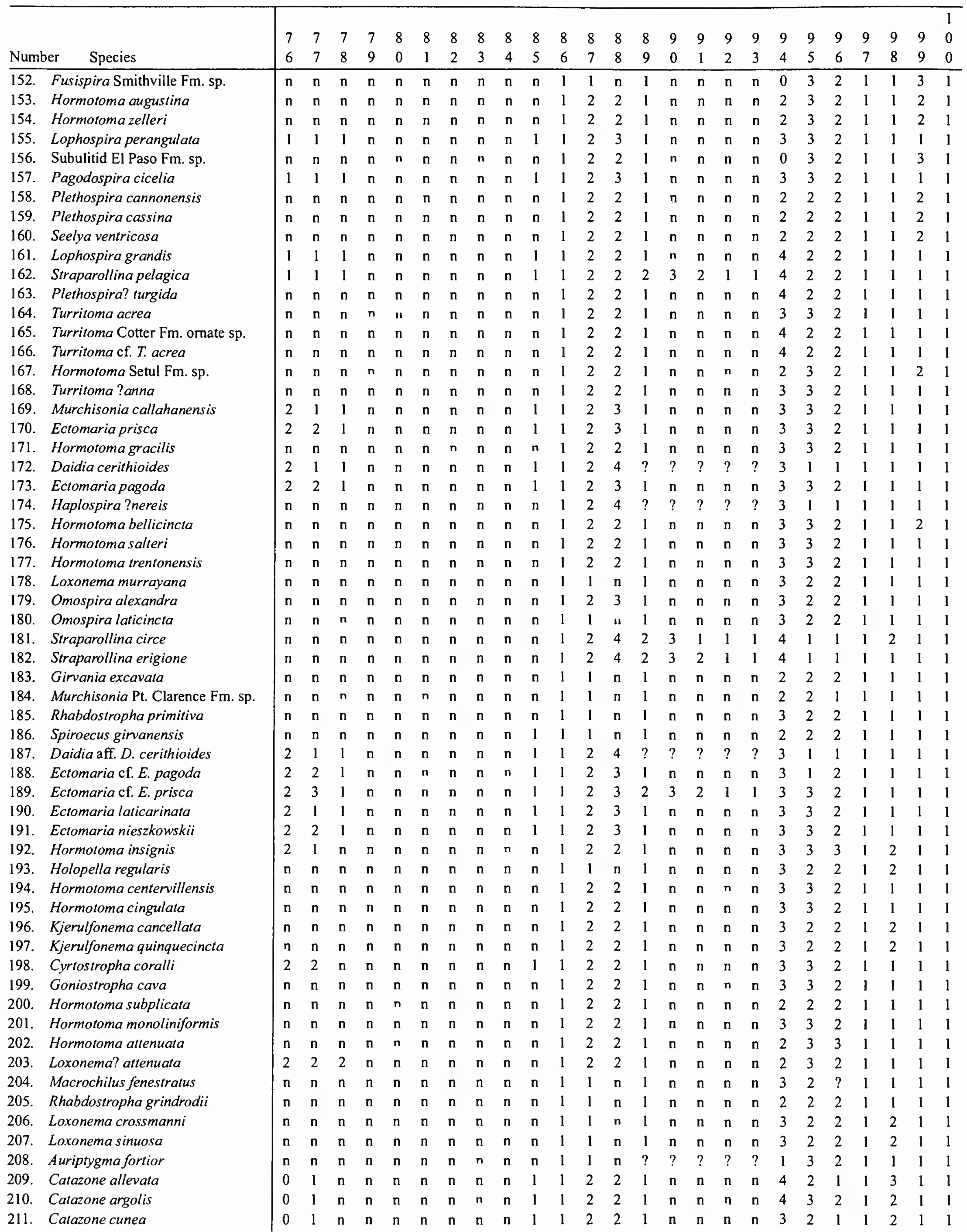


APPENDIX 2.-Continued.

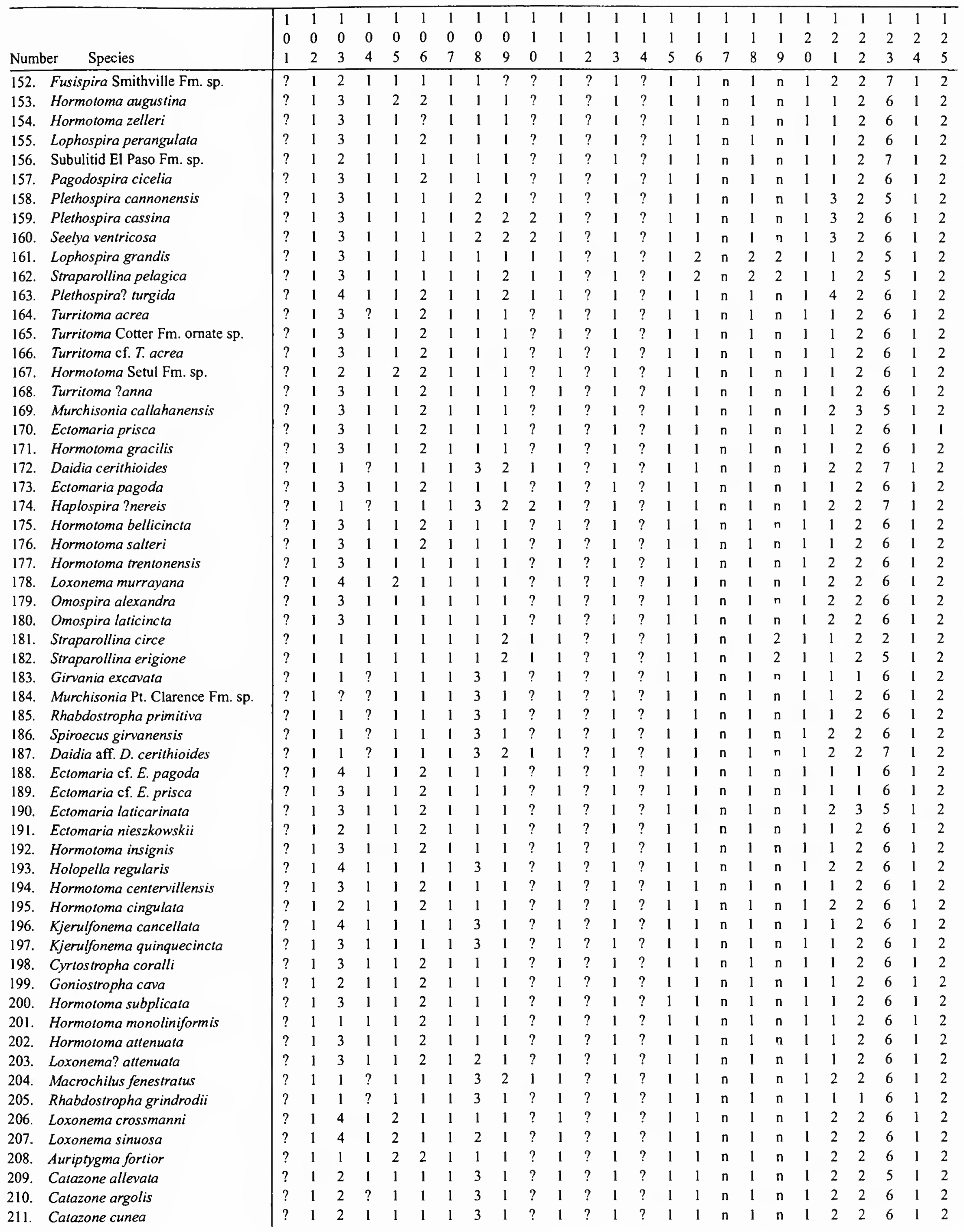


APPENDIX 2.-Continued.

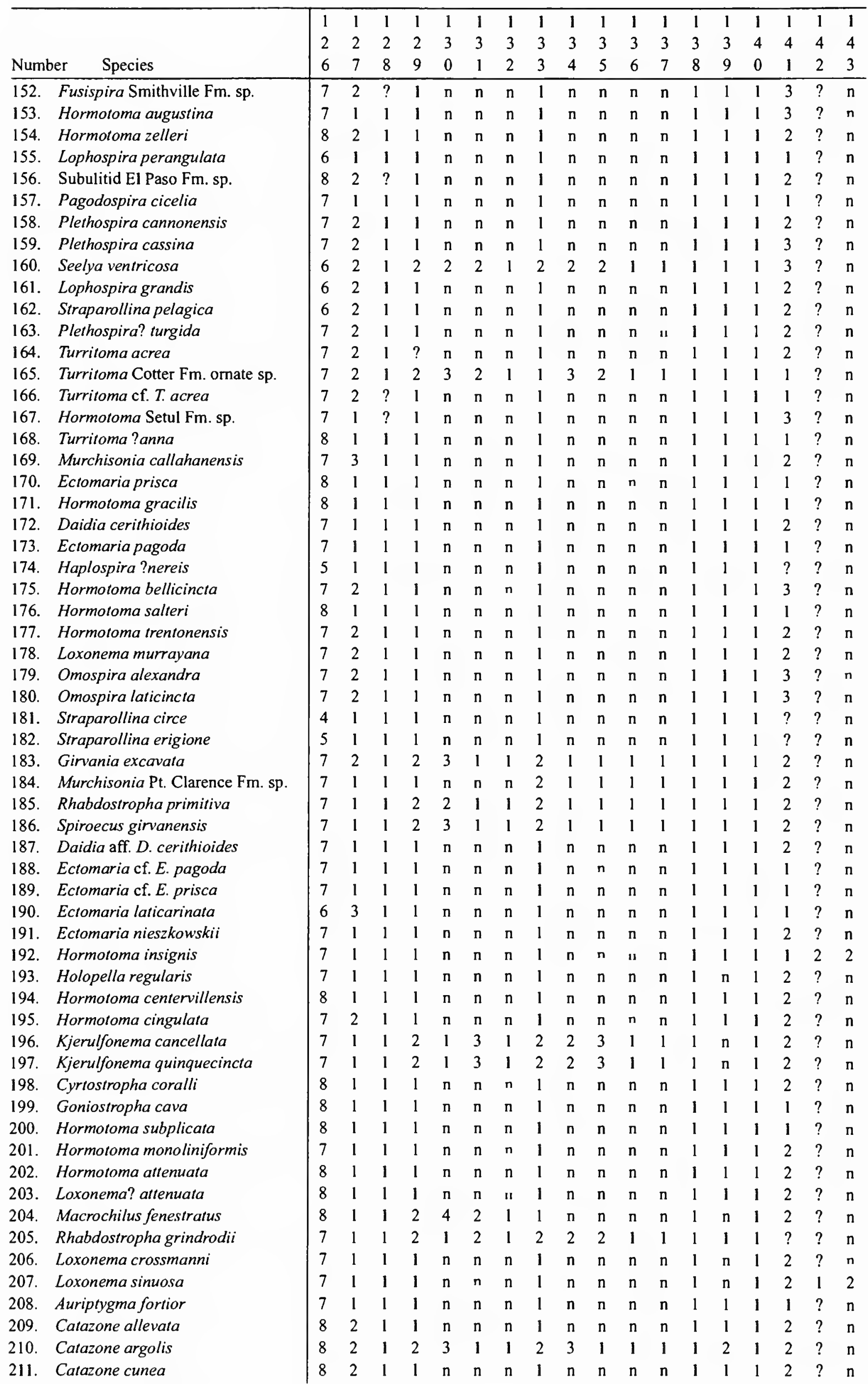


APPENDIX 2,-Continued.

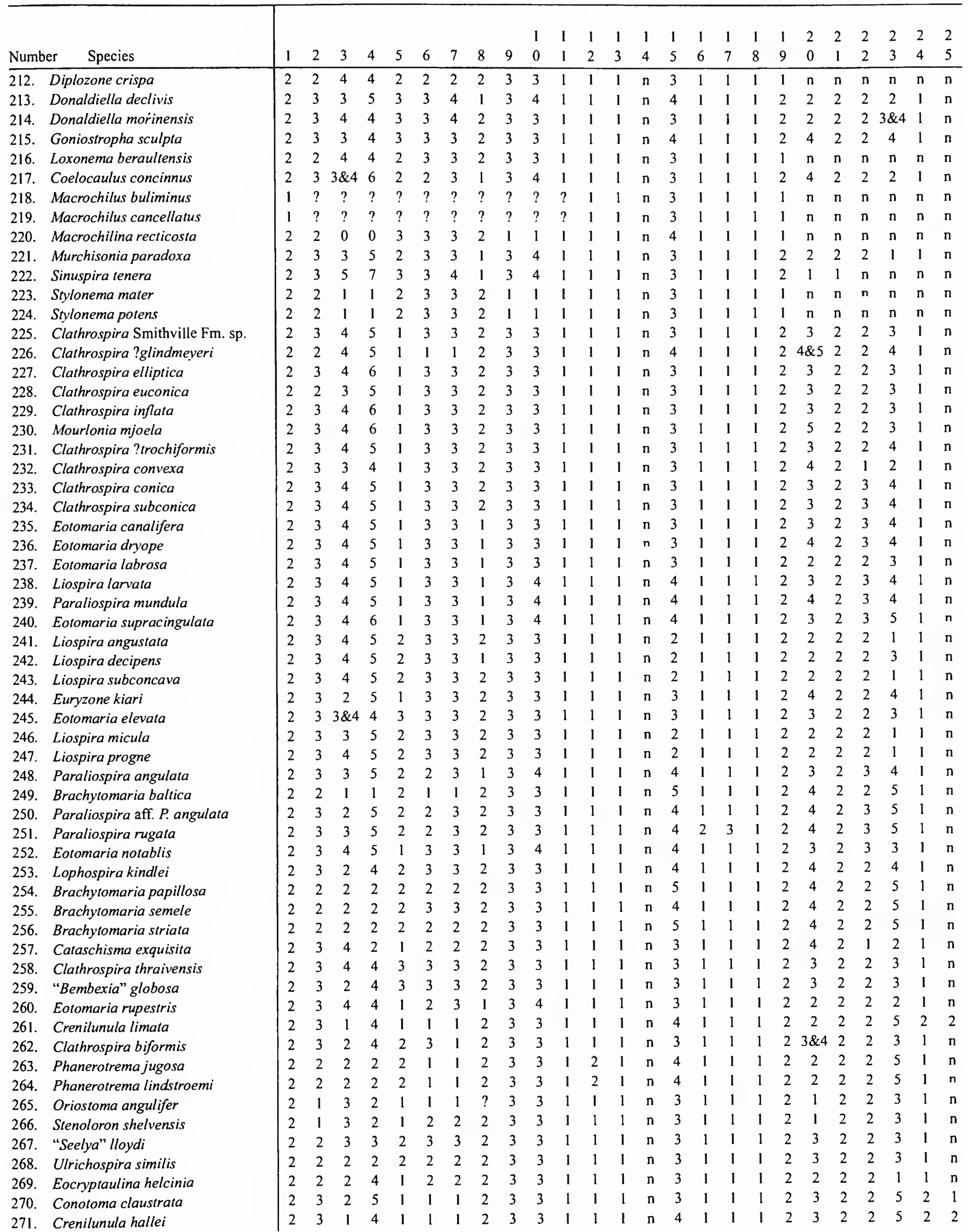


APPENDIX 2.-Continued.

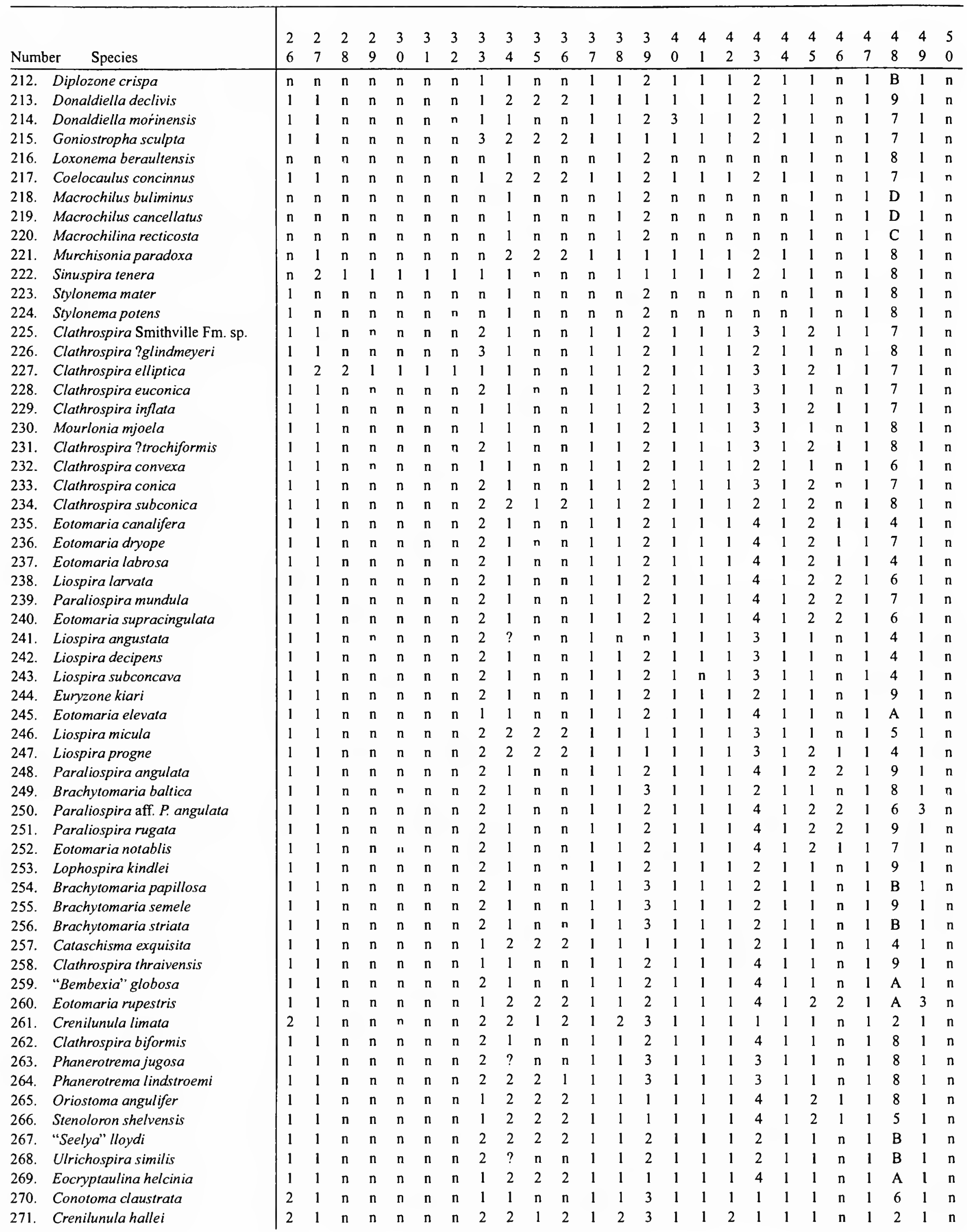


APPENDIX 2.-Continued.

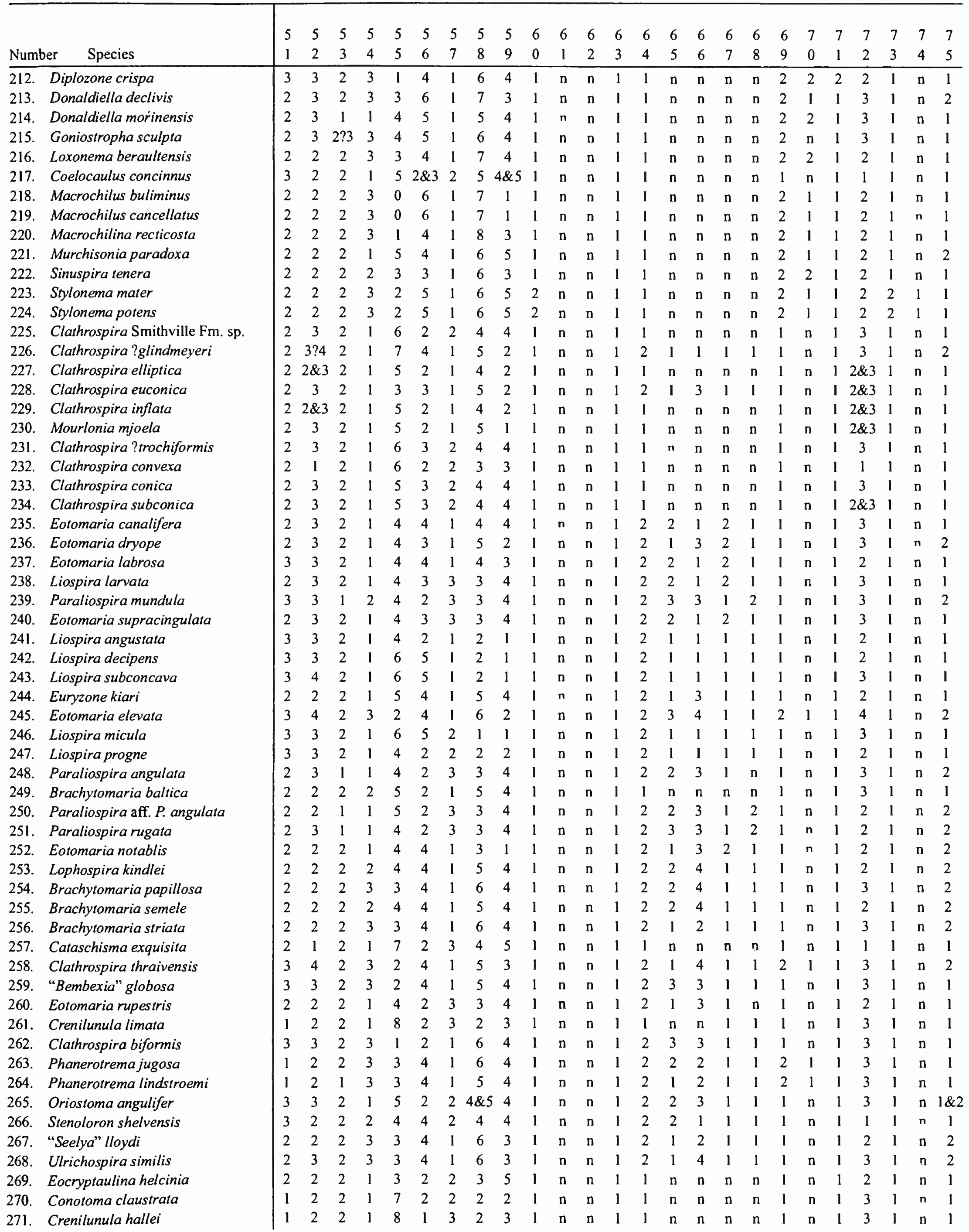


APPENDIX 2.-Continued.

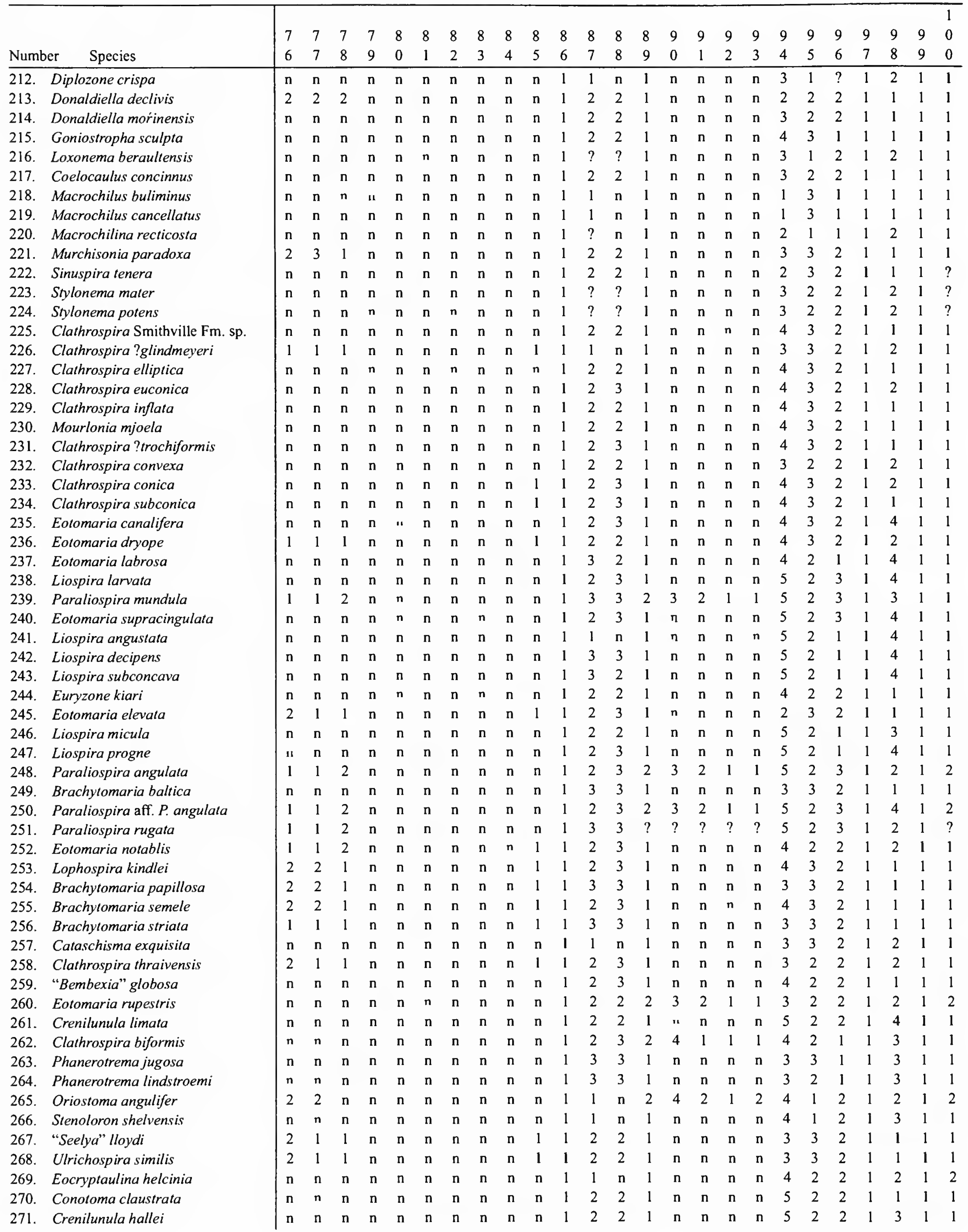


APPENDIX 2.--Continued.

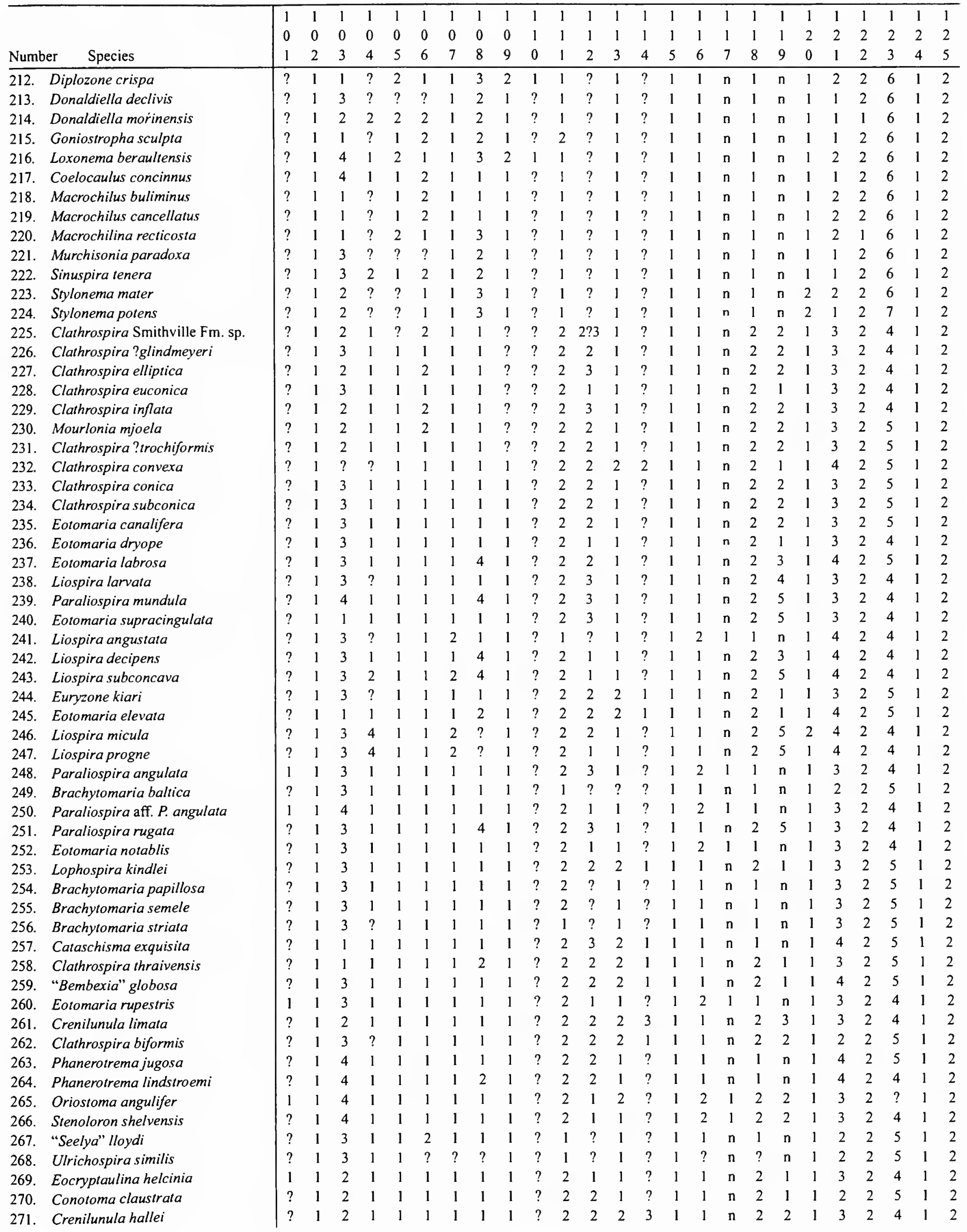


APPENDIX 2.-Continued.

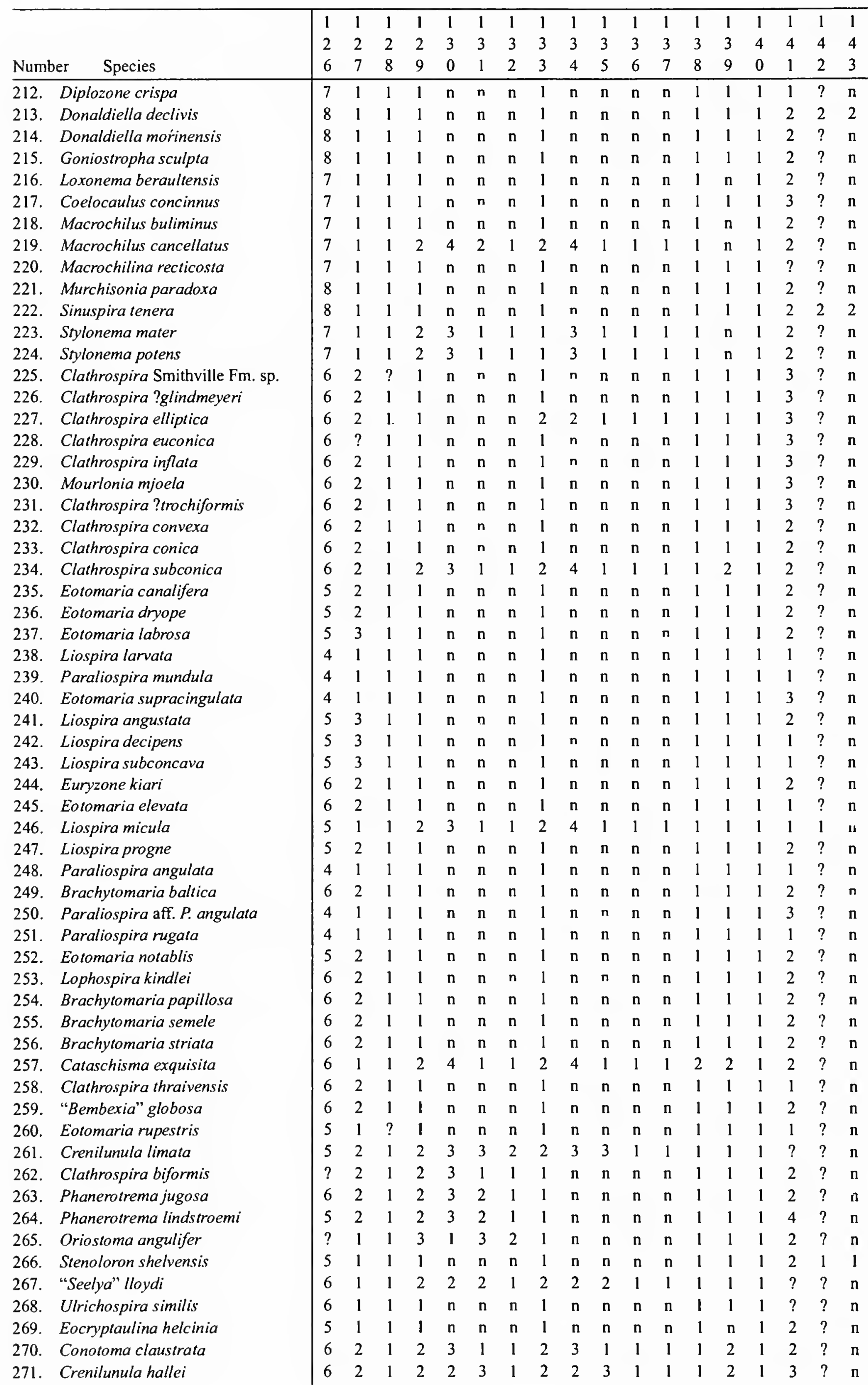


APPENDIX 2.-Continued.

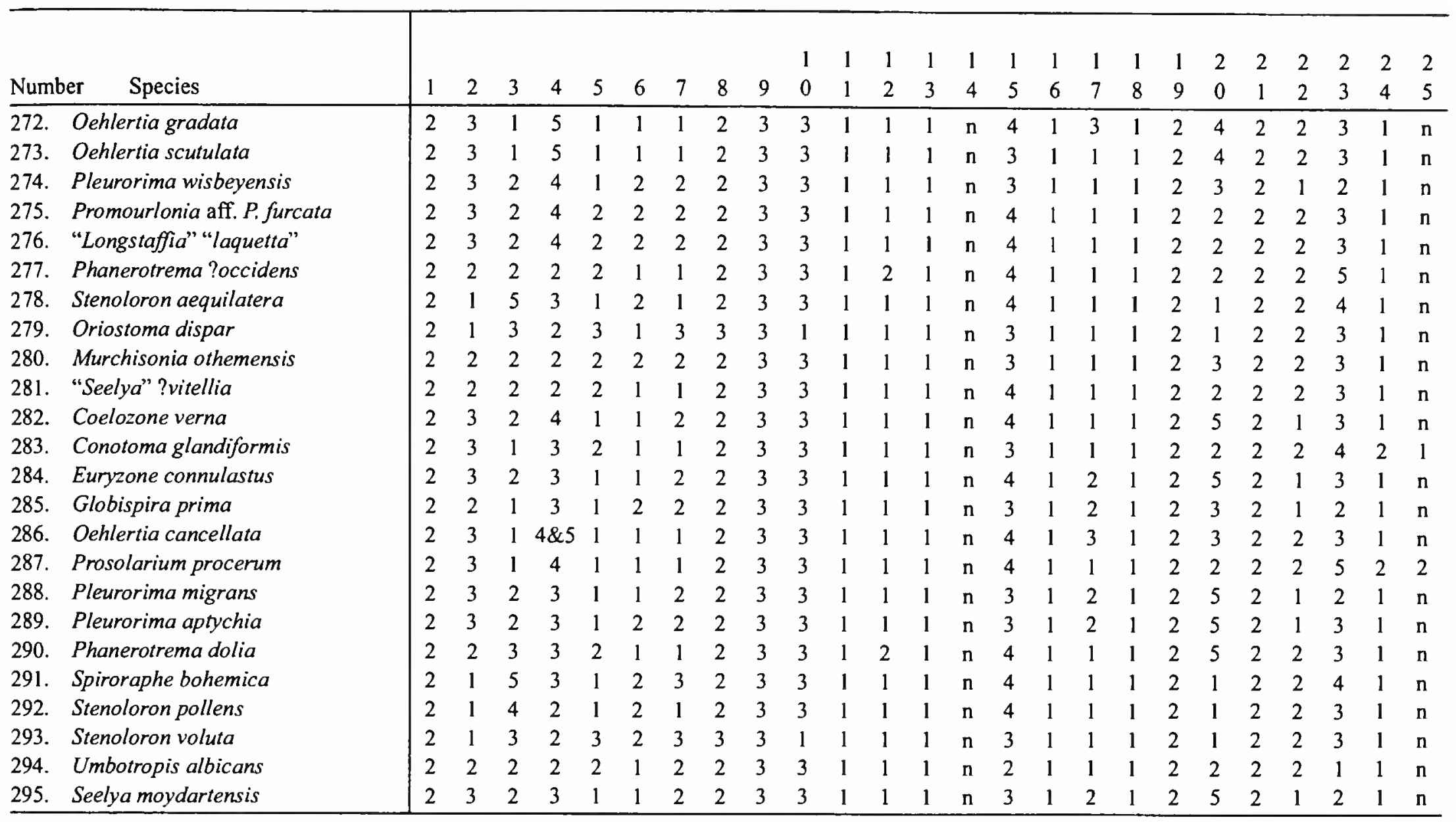

APPENDIX 2.-Continued.

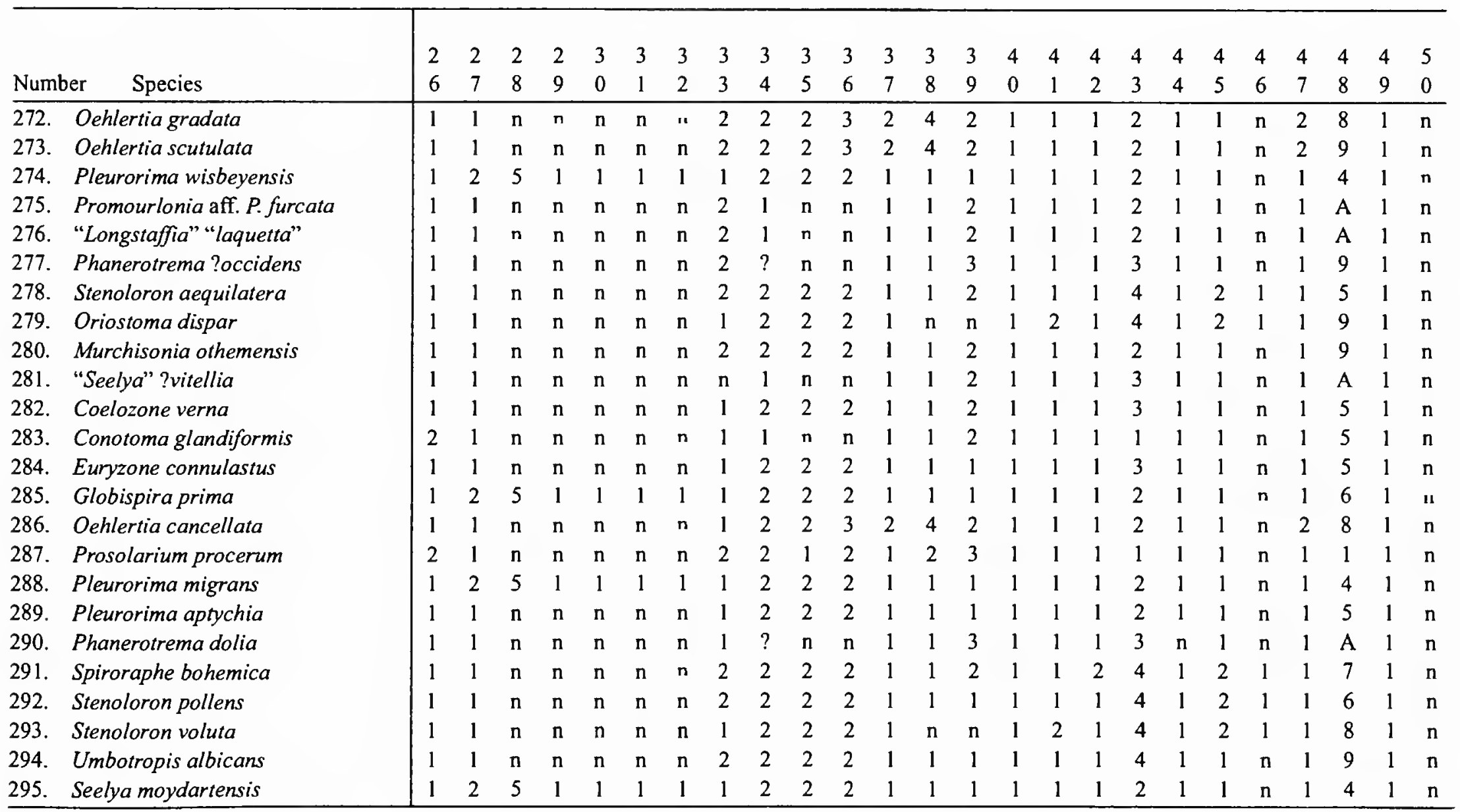


APPENDIX 2.-Continued.

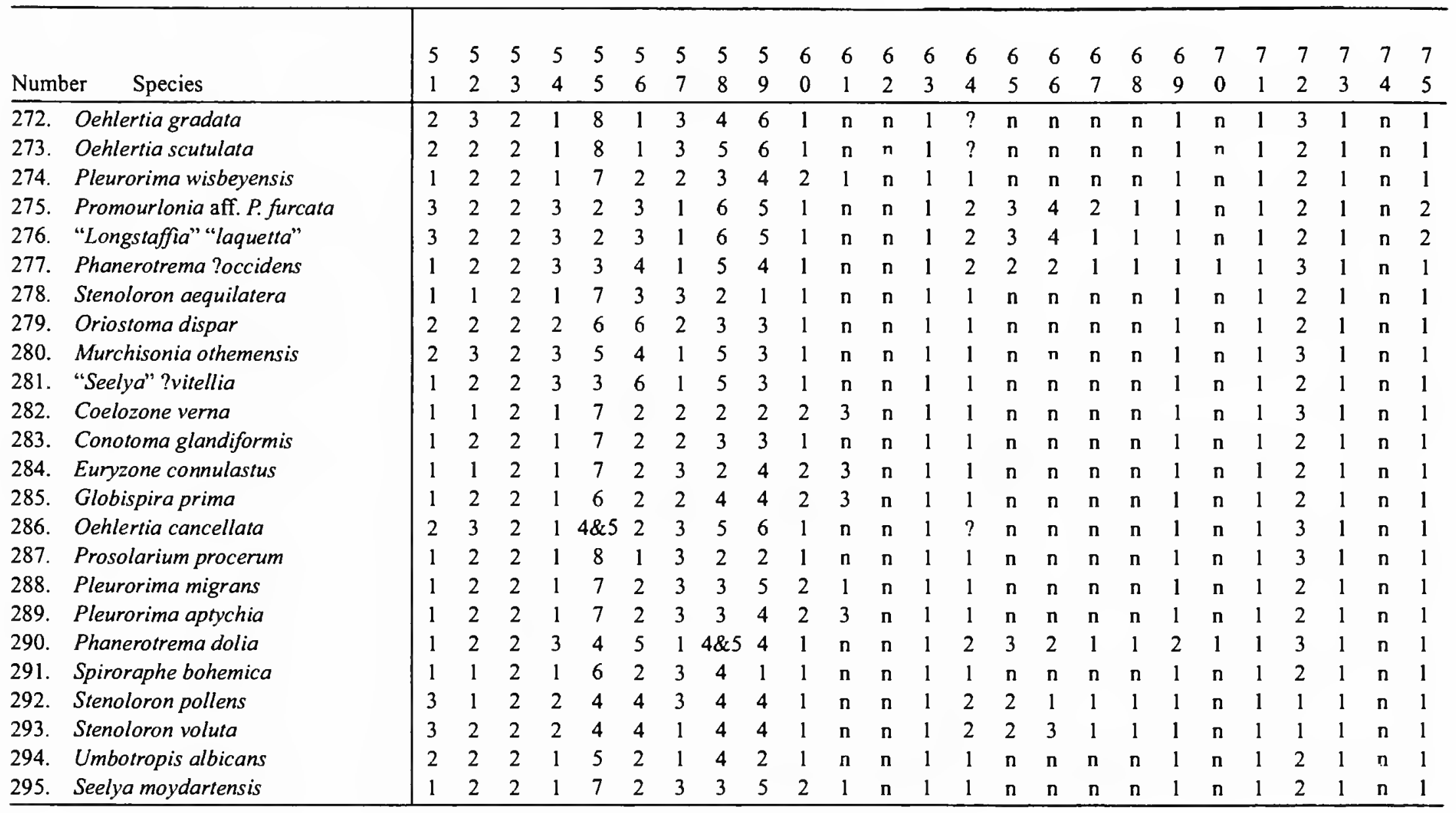

APPENDIX 2.-Continued.

\begin{tabular}{|c|c|c|c|c|c|c|c|c|c|c|c|c|c|c|c|c|c|c|c|c|c|c|c|c|c|c|}
\hline Number & Species & $\begin{array}{l}7 \\
6\end{array}$ & $\begin{array}{l}7 \\
7\end{array}$ & $\begin{array}{l}7 \\
8\end{array}$ & $\begin{array}{l}7 \\
9\end{array}$ & $\begin{array}{l}8 \\
0\end{array}$ & $\begin{array}{l}8 \\
1\end{array}$ & $\begin{array}{l}8 \\
2\end{array}$ & $\begin{array}{l}8 \\
3\end{array}$ & $\begin{array}{l}8 \\
4\end{array}$ & $\begin{array}{l}8 \\
5\end{array}$ & $\begin{array}{l}8 \\
6\end{array}$ & $\begin{array}{l}8 \\
7\end{array}$ & $\begin{array}{l}8 \\
8\end{array}$ & $\begin{array}{l}8 \\
9\end{array}$ & $\begin{array}{l}9 \\
0\end{array}$ & $\begin{array}{l}9 \\
1\end{array}$ & $\begin{array}{l}9 \\
2\end{array}$ & $\begin{array}{l}9 \\
3\end{array}$ & $\begin{array}{l}9 \\
4\end{array}$ & $\begin{array}{l}9 \\
5\end{array}$ & $\begin{array}{l}9 \\
6\end{array}$ & $\begin{array}{l}9 \\
7\end{array}$ & $\begin{array}{l}9 \\
8\end{array}$ & $\begin{array}{l}9 \\
9\end{array}$ & 0 \\
\hline 272. 0 & Oehlertia gradata & $n$ & $\mathrm{n}$ & $\mathbf{n}$ & $\mathrm{n}$ & $\mathbf{n}$ & $\mathbf{n}$ & $n$ & $\mathbf{n}$ & $\mathbf{n}$ & $\mathbf{n}$ & 1 & 2 & 3 & 2 & 2 & 1 & 1 & 1 & 3 & 2 & 1 & 1 & 1 & 1 & 1 \\
\hline 274. $P l$ & Pleurorima wisbeyensis & $\mathbf{n}$ & n & $\mathbf{n}$ & $\mathrm{n}$ & $\mathbf{n}$ & $\mathbf{n}$ & $\mathbf{n}$ & $\mathbf{n}$ & $\mathbf{n}$ & $\mathbf{n}$ & 1 & 1 & $\mathbf{n}$ & 1 & $\mathrm{n}$ & $\mathrm{n}$ & $\mathrm{n}$ & $\mathbf{n}$ & 3 & 2 & 2 & 1 & 2 & 1 & 1 \\
\hline 275. $P r$ & Promourlonia aff. $P$. furcata & 2 & 3 & $\mathbf{n}$ & $\mathrm{n}$ & $\mathbf{n}$ & $\mathrm{n}$ & $\mathrm{n}$ & $\mathrm{n}$ & $\mathbf{n}$ & 1 & 1 & 2 & 3 & 1 & $\mathrm{n}$ & $\mathrm{n}$ & $\mathrm{n}$ & $\mathbf{n}$ & 4 & 2 & 2 & 1 & 2 & 1 & 1 \\
\hline 276. " $L$ & "Longstaffia" "laquetta" & 2 & 3 & $\mathbf{n}$ & $\mathbf{n}$ & $\mathrm{n}$ & $\mathrm{n}$ & $\mathrm{n}$ & $\mathbf{n}$ & $\mathrm{n}$ & 1 & 1 & 2 & 3 & 1 & n & $\mathbf{n}$ & $\mathrm{n}$ & $\mathbf{n}$ & 3 & 3 & 2 & 1 & 1 & 1 & 1 \\
\hline 279. $O$ & Oriostoma dispar & $\mathbf{n}$ & $\mathrm{n}$ & $\mathbf{n}$ & $\mathrm{n}$ & $\mathbf{n}$ & $\mathbf{n}$ & n & $\mathbf{n}$ & $\mathbf{n}$ & $\mathbf{n}$ & 1 & $?$ & $?$ & 2 & $\mathrm{n}$ & $\mathrm{n}$ & $\mathrm{n}$ & $\mathbf{n}$ & 4 & 2 & 2 & 1 & 4 & 1 & 1 \\
\hline 280. $M$ & Murchisonia othemensis & $\mathbf{n}$ & $\mathbf{n}$ & n & $\mathrm{n}$ & $\mathbf{n}$ & $\mathbf{n}$ & $\mathbf{n}$ & $\mathbf{n}$ & $\mathrm{n}$ & $\mathrm{n}$ & $?$ & 2 & 2 & 1 & $\mathrm{n}$ & $\mathrm{n}$ & $\mathrm{n}$ & $\mathbf{n}$ & 3 & 3 & 2 & 1 & 1 & 1 & 1 \\
\hline 281. "S & "Seelya" ?vitellia & $\mathrm{n}$ & $\mathrm{n}$ & $\mathrm{n}$ & $\mathbf{n}$ & $\mathrm{n}$ & $\mathrm{n}$ & $\mathrm{n}$ & $\mathrm{n}$ & $\mathrm{n}$ & $\mathbf{n}$ & 1 & 2 & 3 & 1 & $\mathbf{n}$ & $\mathrm{n}$ & $\mathrm{n}$ & $\mathbf{n}$ & 3 & 2 & 2 & 1 & 1 & 1 & 1 \\
\hline 282. $C$ & Coelozone verna & $\mathbf{n}$ & $\mathrm{n}$ & $\mathbf{n}$ & $\mathrm{n}$ & $\mathbf{n}$ & $\mathrm{n}$ & $\mathbf{n}$ & $\mathbf{n}$ & $\mathrm{n}$ & $\mathbf{n}$ & 1 & 2 & 1 & 1 & $\mathbf{n}$ & $\mathrm{n}$ & $\mathbf{n}$ & $\mathbf{n}$ & 5 & 2 & 2 & 1 & 2 & 1 & 1 \\
\hline 283. $C$ & Conotoma glandiformis & $\mathbf{n}$ & $\mathrm{n}$ & $n$ & $n$ & $\mathbf{n}$ & $n$ & $\mathbf{n}$ & $\mathrm{n}$ & $n$ & $\mathbf{n}$ & 1 & 2 & 2 & 1 & $n$ & $\mathrm{n}$ & $\mathrm{n}$ & $\mathbf{n}$ & 3 & 3 & 2 & 1 & 1 & 1 & 1 \\
\hline 284. $\quad E_{2}$ & Euryzone connulastus & $\mathrm{n}$ & $\mathbf{n}$ & $\mathrm{n}$ & $\mathrm{n}$ & $\mathbf{n}$ & $\mathrm{n}$ & $\mathbf{n}$ & $\mathrm{n}$ & $\mathrm{n}$ & $\mathrm{n}$ & 1 & 2 & 1 & 1 & $\mathrm{n}$ & $\mathrm{n}$ & $\mathrm{n}$ & $\mathbf{n}$ & 5 & 2 & 2 & 1 & 2 & 1 & 1 \\
\hline 289. $\mathrm{Pl}$ & Pleurorima aptychia & $\mathrm{n}$ & $\mathbf{n}$ & $\mathrm{n}$ & $\mathrm{n}$ & $\mathrm{n}$ & $\mathbf{n}$ & $\mathbf{n}$ & $\mathbf{n}$ & $\mathbf{n}$ & $\mathbf{n}$ & 1 & 2 & 2 & 1 & $\mathrm{n}$ & $\mathrm{n}$ & $\mathrm{n}$ & $\mathbf{n}$ & 3 & 2 & 2 & 1 & 2 & 1 & 1 \\
\hline 290. $\mathrm{Pr}$ & Phanerotrema dolia & $\mathrm{n}$ & $\mathbf{n}$ & $\mathbf{n}$ & $\mathrm{n}$ & $\mathbf{n}$ & $\mathbf{n}$ & $\mathbf{n}$ & $\mathrm{n}$ & $\mathbf{n}$ & $\mathbf{n}$ & 1 & 1 & 2 & 1 & n & $\mathrm{n}$ & $\mathrm{n}$ & $\mathrm{n}$ & 3 & 3 & 2 & 1 & 2 & 1 & 1 \\
\hline 291. $S p$ & Spiroraphe bohemica & $\mathrm{n}$ & $\mathrm{n}$ & $\mathrm{n}$ & $\mathrm{n}$ & $\mathbf{n}$ & $\mathrm{n}$ & $\mathbf{n}$ & $\mathrm{n}$ & $\mathbf{n}$ & $\mathrm{n}$ & 1 & 1 & $\mathrm{n}$ & 1 & $\mathbf{n}$ & $\mathbf{n}$ & $\mathrm{n}$ & $\mathrm{n}$ & 5 & 2 & 2 & 1 & 3 & 1 & 1 \\
\hline 292. $S t$ & Stenoloron pollens & $\mathrm{n}$ & $\mathrm{n}$ & $\mathrm{n}$ & $\mathrm{n}$ & $\mathrm{n}$ & $\mathrm{n}$ & $\mathbf{n}$ & $\mathrm{n}$ & $\mathbf{n}$ & $\mathrm{n}$ & 1 & 1 & $\mathrm{n}$ & 1 & $\mathrm{n}$ & $\mathbf{n}$ & $\mathrm{n}$ & $\mathrm{n}$ & 5 & 1 & 2 & 1 & 3 & 1 & 1 \\
\hline 293. $S t$ & Stenoloron voluta & $\mathrm{n}$ & $\mathrm{n}$ & $\mathrm{n}$ & $\mathrm{n}$ & $\mathrm{n}$ & $\mathrm{n}$ & $\mathbf{n}$ & $\mathrm{n}$ & $\mathrm{n}$ & $\mathrm{n}$ & 1 & $?$ & $?$ & 1 & $\mathrm{n}$ & $\mathbf{n}$ & $\mathrm{n}$ & $\mathrm{n}$ & 4 & 2 & 2 & 1 & 3 & 1 & 1 \\
\hline 294. U & Umbotropis albicans & $\mathrm{n}$ & $\mathrm{n}$ & n & $\mathbf{n}$ & $n$ & $\mathrm{n}$ & $\mathbf{n}$ & $\mathrm{n}$ & $\mathrm{n}$ & $\mathbf{n}$ & 1 & 1 & $n$ & 1 & $\mathrm{n}$ & $\mathbf{n}$ & $\mathrm{n}$ & $n$ & 5 & 2 & 2 & 1 & 2 & 1 & 1 \\
\hline 295. $S e$ & Seelya moydartensis & $\mathrm{n}$ & $\mathrm{n}$ & $\mathrm{n}$ & $\mathbf{n}$ & $\mathrm{n}$ & $\mathrm{n}$ & $\mathbf{n}$ & $\mathbf{n}$ & $\mathrm{n}$ & $\mathrm{n}$ & 1 & 2 & 2 & 1 & $\mathrm{n}$ & $\mathbf{n}$ & $\mathrm{n}$ & $\mathbf{n}$ & 3 & 2 & 2 & 1 & 2 & 1 & 1 \\
\hline
\end{tabular}


APPENDIX 2.-Continued.

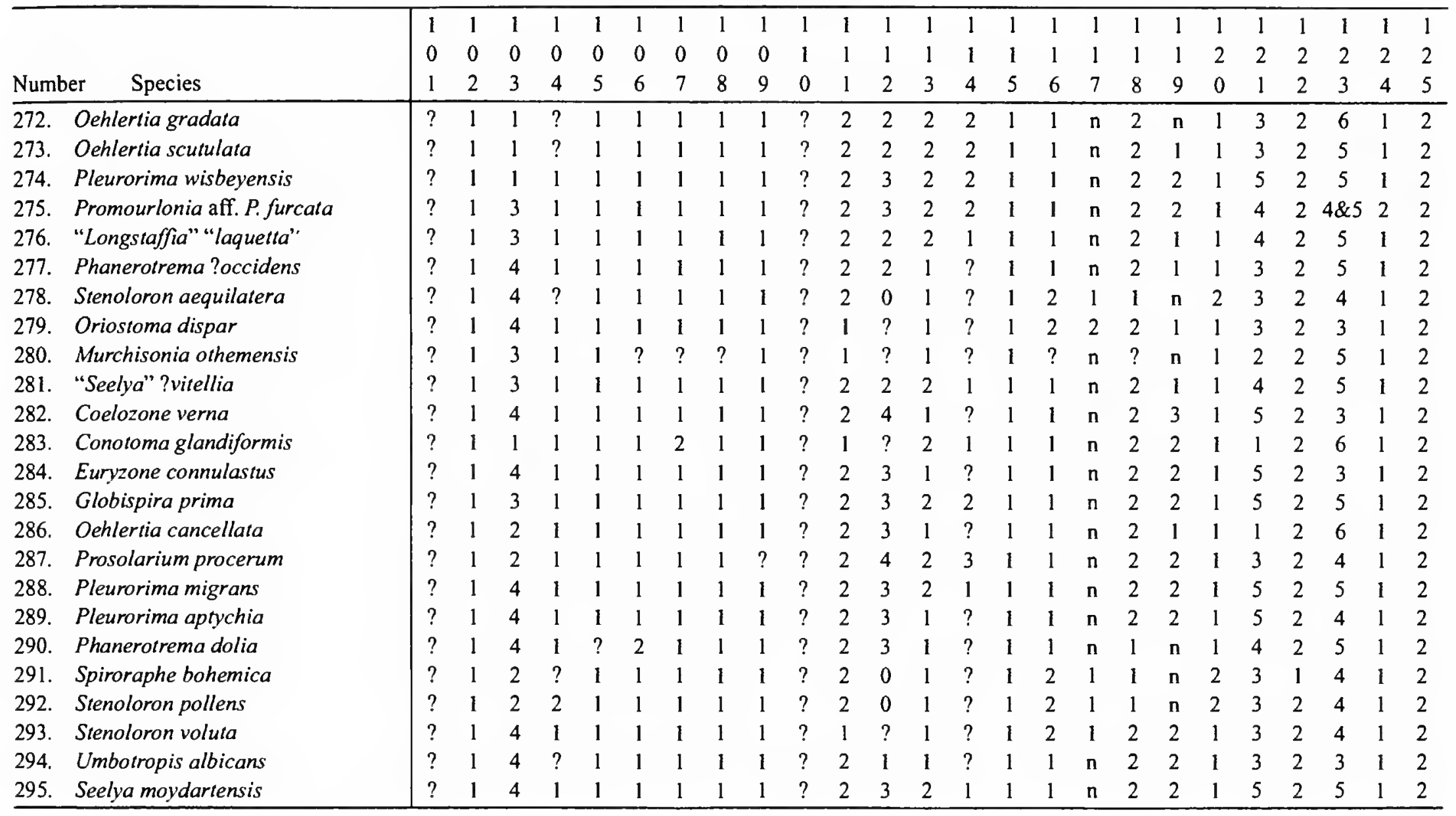

APPENDIX 2.-Continued.

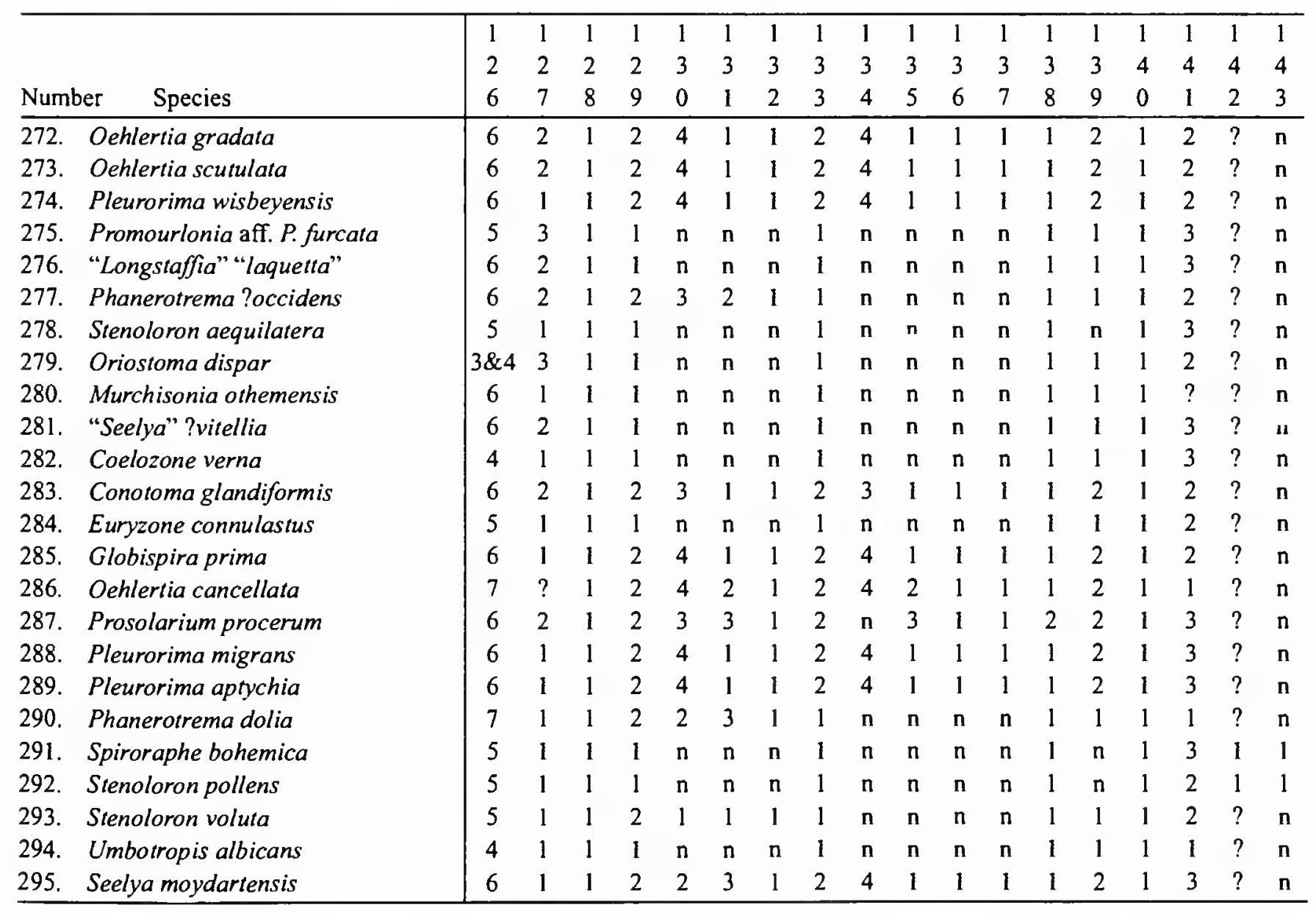




\section{Appendix 3. Stratigraphic Data}

Species are arranged within clades or paraclades of similar species (e.g., "Hormotomoids" include all high-spired "murchisoniinae"). Stratigraphic "time" scales for each clade or paraclade precede the data giving first appearance (FKA), last appearance (LKA), lower and upper $95 \%$ confidence intervals (LB and UB), and number of sampled horizons (H). Biogeographic time scales reflect the numbers of sampling opportunities within the four main Ordovician/Silurian provinces (see Wagner, 1995a, for details). Generic names reflect the names used prior to the revisions suggested by this study.

\section{Early "Archaeogastropods"}

"Time" Scales

\begin{tabular}{l|cccc}
\hline \multicolumn{1}{c|}{ Stage/Province } & Laurentia & $\begin{array}{c}\text { Toquima- } \\
\text { Table Head }\end{array}$ & Baltica & Gondwana \\
\hline Dolgellian & $1-10$ & - & - & - \\
Early Tremadoc & $11-48$ & - & - & - \\
Late Tremadoc & $49-64$ & - & - & - \\
Early Arenig & $65-111$ & - & - & - \\
Middle Arenig & - & - & - & - \\
\hline
\end{tabular}

Finds and Ranges

\begin{tabular}{l|crrrrr}
\hline \multicolumn{1}{c|}{ Species } & Province & H & FKA & \multicolumn{1}{c}{ LB } & LKA & \multicolumn{1}{c}{ UB } \\
\hline 1. Dirhachopea normalis & Laur & 10 & 1 & -4.0 & 10 & 15.0 \\
2. Dirhachopea subrotunda & Laur & 8 & 1 & -5.8 & 10 & 16.8 \\
3. Schizopea typica & Laur & 13 & 1 & -13.4 & 40 & 54.4 \\
4. Sinuopea sweeti & Laur & 5 & 11 & -33.1 & 40 & 84.1 \\
5. Taeniospira emminencis & Laur & 8 & 1 & -26.2 & 40 & 67.2 \\
6. Ceratopea canadensis & Laur & 9 & 41 & 12.0 & 90 & 119.0 \\
7. Gasconadia putilla & Laur & 21 & 11 & 1.0 & 60 & 70.0 \\
8. Jarlopsis conicus & Laur & 16 & 11 & -3.8 & 63 & 77.8 \\
9. Ophileta supraplana & Laur & 19 & 11 & 0.0 & 60 & 71.0 \\
10. Rhombella umbilicata & Laur & 5 & 11 & -66.9 & 63 & 140.9 \\
11. Prohelicotoma uniangulata & Laur & 7 & 11 & -30.5 & 60 & 101.5 \\
12. Sinuopea basiplanata & Laur & 8 & 11 & -9.4 & 40 & 60.4 \\
13. Taeniospira?st. clairi & Laur & 3 & 11 & -133.9 & 40 & 184.9 \\
14. Bridgeites?disjuncta & Laur & 4 & 49 & 14.5 & 63 & 97.5 \\
15. Bridgeites planodorsalis & Laur & 17 & 49 & 32.6 & 111 & 127.4 \\
16. Bridgeites supraconvexa & Laur & 8 & 49 & 20.4 & 90 & 118.6 \\
17. Euconia etna & Laur & 8 & 49 & 6.2 & 111 & 153.8 \\
18. Ceratopea ?laurentina & Laur & 4 & 65 & 44.3 & 73 & 93.7 \\
19. Ceratopea pygmaea & Laur & 22 & 65 & 56.1 & 111 & 120.2 \\
20. Orospira bigranosa & Laur & 10 & 65 & 52.0 & 90 & 103.0 \\
\hline
\end{tabular}




\section{I. "EuOMPhalinaES":}

I.1. "Ophiletoids" and I.2. "Macluritoids"

"Time" Scales

\begin{tabular}{l|cccc}
\hline \multicolumn{1}{c|}{ Stage/Province } & Laurentia & $\begin{array}{c}\text { Toquima- } \\
\text { Table Head }\end{array}$ & Baltica & Gondwana \\
\hline Dolgellian & - & - & - & - \\
Early Tremadoc & $1-21$ & - & - & - \\
Late Tremadoc & $22-36$ & - & - & - \\
Early Arenig & $37-53$ & - & - & - \\
Middle Arenig & - & - & - & - \\
Late Arenig & 54 & $54-79$ & $55-60$ & - \\
Llanvim & $55-69$ & $80-85$ & 61 & - \\
Llandeilo & $70-77$ & 96 & $62-63$ & - \\
Early Caradoc & $78-90$ & 100 & $64-65$ & - \\
Middle Caradoc & $91-114$ & - & - & - \\
Late Caradoc & $115-122$ & - & 66 & - \\
Ashgill & $123-125$ & - & $67-72$ & \\
\hline
\end{tabular}

Finds and Ranges

\begin{tabular}{|c|c|c|c|c|c|c|}
\hline Species & Province & $\mathrm{H}$ & FKA & LB & LKA & UB \\
\hline 9. Ophileta supraplana & Laur & 19 & 1 & .6 .0 & 32 & 39.0 \\
\hline 11. Prohelicotoma uniangulata & Laur & 7 & 1 & -25.6 & 32 & 58.6 \\
\hline 21. Macluritella stantoni & Laur & 2 & 22 & -295.1 & 32 & 349.1 \\
\hline 22. Teiichispira odenvillensis & Laur & 8 & 40 & 30.5 & 53 & 62.5 \\
\hline 23. Teiichispira ?oceana & Laur & 7 & 33 & 15.6 & 53 & 70.4 \\
\hline 24. Palliseria robusta & Laur & 4 & 46 & 51.7 & 54 & 56.3 \\
\hline 25. Mitrospira longwelli & ToqTab & 5 & 60 & 21.8 & 85 & 123.2 \\
\hline 26. Teiichispira kobayashi & ToqTab & 11 & 55 & 39.6 & 89 & 104.4 \\
\hline 27. Teiichispira sylpha & ToqTab & 10 & 46 & 26.0 & 85 & 105.0 \\
\hline 28. Monitorella auricula & ToqTab & 3 & 60 & -65.6 & 85 & 210.6 \\
\hline 29. Maclurites magna & Laur & 25 & 55 & 47.9 & 96 & 103.2 \\
\hline 30. "Eccyliopterus ornatus" & Laur & 6 & 82 & 72.5 & 90 & 99.5 \\
\hline 31. Maclurites bigsbyi & Laur & 6 & 82 & 72.5 & 90 & 99.5 \\
\hline 32. Maclurina logani & Laur & 24 & 78 & 71.7 & 114 & 120.3 \\
\hline 33. Maclurina manitobensis & Laur & 15 & 82 & 68.7 & 125 & 138.2 \\
\hline 34. Maclurites sedgewicki & ToqTab & 3 & 90 & 56.2 & 96 & 129.8 \\
\hline 35. Maclurites expansa & Laur & 1 & 123 & undef & 125 & undef \\
\hline Maclurites expansa & Balt & 1 & 67 & undef & 72 & undef \\
\hline 36. Ophileta complanata & Laur & 8 & 1 & -26.9 & 41 & 68.9 \\
\hline 37. Lecanospira compacta & Laur & 7 & 22 & 12.9 & 32 & 41.1 \\
\hline 38. Lecanospira nereine & Laur & 4 & 22 & -3.3 & 32 & 57.3 \\
\hline 39. Barnesella ?lecanospiroides & Laur & 2 & 42 & -73.3 & 45 & 160.3 \\
\hline Barnesella ?lecanospiroides & ToqTab & 2 & 55 & -89.1 & 59 & 203.2 \\
\hline 40. Malayaspira hintzei & ToqTab & 8 & 55 & 26.4 & 96 & 124.6 \\
\hline 41. Malayaspira rugosa & ToqTab & 10 & 54 & 36.5 & 88 & 105.5 \\
\hline 42. Barnesella measuresae & ToqTab & 7 & 60 & 38.4 & 85 & 106.6 \\
\hline 43. Lytospira angelini & Balt & 9 & 55 & 48.0 & 66 & 73.0 \\
\hline 44. Lytospira yochelsoni & ToqTab & 2 & $60^{\circ}$ & -1122.0 & 100 & 1282.0 \\
\hline 45. Maclurina ?annulata & ToqTab & 5 & 60 & 21.8 & 85 & 123.2 \\
\hline 46. Rossospira harrisae & ToqTab & 1 & 60 & undef & 85 & undef \\
\hline 47. Ecculiomphalus bucklandi & ToqTab & 3 & 90 & 36.9 & 100 & 153.1 \\
\hline Ecculiomphalus bucklandi & Laur & 4 & 55 & 2.1 & 77 & 129.9 \\
\hline 48. Lytospira gerrula & ToqTab & 1 & 90 & undef & 96 & undef \\
\hline 49. Lytospira ?norvegica & Balt & 3 & 62 & 37.9 & 66 & 90.2 \\
\hline 50. Ophiletina cf. O. sublaxa & ToqTab & 2 & 97 & -18.3 & 100 & 215.3 \\
\hline Ophiletina cf. O. sublaxa & Laur & 1 & 123 & undef & 125 & undef \\
\hline 51. Lytospira subrotunda & Laur & 2 & 102 & -589.9 & 125 & 816.9 \\
\hline
\end{tabular}




\section{I. "EUOMPHALINAES":}

\section{I.3.1 "Raphistomatids"}

"Time" Scales

\begin{tabular}{l|cccc}
\hline \multicolumn{1}{c|}{ Stage/Province } & Laurentia & $\begin{array}{c}\text { Toquima- } \\
\text { Table Head }\end{array}$ & Baltica & Gondwana \\
\hline Dolgellian & - & - & - & - \\
Early Tremadoc & - & - & - & - \\
Late Tremadoc & - & - & - & - \\
Early Arenig & 1 & - & 2 & 2 \\
Middle Arenig & - & -5 & $3-26$ & $3-21$ \\
Late Arenig & - & $22-34$ & $27-46$ & 22 \\
Llanvim & $2-19$ & $25-40$ & $47-48$ & $23-34$ \\
Llandeilo & $20-30$ & - & $49-66$ & $35-40$ \\
Early Caradoc & $31-84$ & $41-42$ & $67-73$ & - \\
Middle Caradoc & $85-103$ & $41-42$ & $74-94$ & - \\
Late Caradoc & $104-117$ & $41-42$ & $95-97$ & - \\
Ashgill & $118-121$ & - & - & - \\
Early Llandovery & $122-123$ & - & - & - \\
Late Llandovery & $124-125$ & - & - & - \\
Early Wenlock & $126-132$ & - & - & 136 \\
Late Wenlock & $133-135$ & - & - & 137 \\
Early Ludlow & - & - & - & - \\
Late Ludlow & - & - & & - \\
Pridoli & & &
\end{tabular}

Finds and Ranges

\begin{tabular}{|c|c|c|c|c|c|c|}
\hline Species & Province & $\mathrm{H}$ & FKA & LB & LKA & UB \\
\hline 52. Pararaphistoma lemoni & Laur & 1 & 1 & undef & 1 & undef \\
\hline Pararaphistoma lemoni & ToqTab & 8 & 2 & -20.4 & 34 & 56.4 \\
\hline 53. Climacoraphistoma vaginati & Gond & 4 & 3 & -6.2 & 6 & 15.2 \\
\hline Climacoraphistoma vaginati & Balt & 10 & 5 & -17.0 & 48 & 70.0 \\
\hline 54. Lesueurilla bipatellare & Balt & 8 & 2 & -30.0 & 48 & 80.0 \\
\hline 55. Lesueurilla marginalis & Balt & 36 & 2 & -8.5 & 96 & 106.5 \\
\hline Lesueurilla marginalis & ToqTab & 1 & 36 & undef & 40 & undef \\
\hline 56. Lesueurilla prima & Gond & 4 & 2 & -16.4 & 9 & 27.4 \\
\hline 57. Palaeomphalus giganteus & ToqTab & 11 & 6 & -6.8 & 34 & 46.8 \\
\hline 58. Climacoraphistoma damesi & Balt & 1 & 5 & undef & 16 & undef \\
\hline 59. Eccyliopterus alatus & Balt & 6 & 5 & -41.6 & 48 & 94.6 \\
\hline 60. Eccyliopterus ?princeps & Balt & 18 & 24 & 12.0 & 73 & 85.0 \\
\hline 61. Eccyliopterus regularis & Balt & 20 & 5 & -4.2 & 48 & 57.2 \\
\hline 62. Lesueurilla infundibula & Balt & 9 & 5 & -6.0 & 23 & 34.0 \\
\hline 63. Eccyliopterus louderbacki & ToqTab & 2 & 3 & -544.8 & 21 & 568.8 \\
\hline 64. Lesueurilla declivis & Balt & 5 & 5 & -12.6 & 16 & 33.6 \\
\hline Lesueurilla declivis & ToqTab & 2 & 3 & -544.8 & 21 & 568.8 \\
\hline 65. Pararaphistoma qualteriata & Balt & 15 & 5 & -22.0 & 94 & 121.0 \\
\hline Pararaphistoma qualteriata & ToqTab & 6 & 3 & -37.3 & 40 & 80.3 \\
\hline 66. Pararaphistoma schmidti & Balt & 8 & 5 & -24.9 & 48 & 77.9 \\
\hline Pararaphistoma schmidti & ToqTab & 1 & 36 & undef & 40 & undef \\
\hline 67. Helicotoma gubanovi & ToqTab & 1 & 6 & undef & 21 & undef \\
\hline 68. Scalites katoi & ToqTab & 14 & 6 & -3.1 & 40 & 49.1 \\
\hline 69. Helicotoma medfraensis & ToqTab & 1 & 22 & undef & 34 & undef \\
\hline 70. Lesueurilla scotica & ToqTab & 2 & 22 & -352.8 & 34 & 408.8 \\
\hline 71. Pachystrophia devexa & Balt & 22 & 27 & 13.5 & 97 & 111.1 \\
\hline 72. Raphistoma striata & Laur & 29 & 2 & -1.8 & 30 & 33.8 \\
\hline 73. Raphistomina lapicida & ToqTab & 2 & 6 & -455.3 & 21 & 482.3 \\
\hline Raphistomina lapicida & Laur & 7 & 11 & -57.1 & 92 & 160.1 \\
\hline 74. Scalites angulatus & Laur & 5 & 2 & -40.6 & 30 & 72.6 \\
\hline 75. Holopea insignis & Laur & 14 & 31 & 2.3 & 117 & 145.7 \\
\hline 76. Eccyliopterus beloitensis & Laur & 5 & 31 & -48.4 & 84 & 163.4 \\
\hline
\end{tabular}




\begin{tabular}{l|crrrrr}
\hline \multicolumn{1}{c|}{ Species } & Province & H & FKA & LB & LKA & \multicolumn{1}{c}{ UB } \\
\hline 77. Holopea rotunda & Laur & 4 & 65 & -22.4 & 102 & 189.4 \\
78. Pachystrophia contigua & Laur & 1 & 31 & undef & 32 & undef \\
79. Pachystrophia spiralis & ToqTab & 5 & 6 & -31.1 & 40 & 77.1 \\
80. Raphistomina aperta & Laur & 41 & 33 & 26.0 & 102 & 109.0 \\
81. Raphistomina fissurata & Laur & 1 & 65 & undef & 84 & undef \\
82. Eccyliopterus owenanus & Laur & 13 & 93 & 84.7 & 115 & 123.3 \\
83. Holopea ampla & Laur & 8 & 32 & -3.9 & 84 & 112.1 \\
84. Holopea pyrene & Laur & 4 & 85 & 43.6 & 102 & 143.4 \\
85. Holopea symmetrica & Laur & 5 & 67 & 29.4 & 94 & 127.6 \\
86. Raphistoma peracuta & Laur & 5 & 85 & 46.4 & 117 & 130.6 \\
87. Raphistomina rugata & Laur & 2 & 93 & -743.1 & 121 & 957.1 \\
88. Raphistoma tellerensis & Laur & 2 & 118 & 2.7 & 121 & 236.3 \\
89. Sinutropis ?esthetica & Laur & 3 & 118 & 98.7 & 121 & 140.3 \\
90. Pachystrophia gotlandica & Laur & 8 & 122 & 114.5 & 132 & 139.5 \\
91. Lytospira triquestra & Laur & 6 & 125 & 105.9 & 142 & 161.1 \\
92. Euomphalus tubus & Laur & 1 & 127 & undef & 132 & undef \\
93. Lytospira subuloides & Gond & 3 & 136 & 121.5 & 138 & 142.5 \\
\hline
\end{tabular}

I. "Euomphalinaes":

"Helicotomids"

"Time" Scales

\begin{tabular}{l|cccc}
\hline \multicolumn{1}{c|}{ Stage/Province } & Laurentia & $\begin{array}{c}\text { Toquima- } \\
\text { Table Head }\end{array}$ & Baltica & Gondwana \\
\hline Dolgellian & - & - & - & - \\
Early Tremadoc & - & - & - & - \\
Late Tremadoc & 1 & - & - & - \\
Early Arenig & $1-44$ & - & - & - \\
Middle Arenig & - & - & - & - \\
Late Arenig & - & $45-48$ & $-49-50$ & - \\
Llanvim & - & - & - & - \\
Llandeilo & - & $49-59$ & - & - \\
Early Caradoc & $45-69$ & $49-59$ & - & - \\
Middle Caradoc & $70-83$ & $49-59$ & $51-60$ & - \\
Late Caradoc & $84-86$ & - & - & 159 \\
Ashgill & $87-96$ & - & - & $160-171$ \\
Early Llandovery & $97-103$ & - & - & 172 \\
Late Llandovery & $104-110$ & - & - & - \\
Early Wenlock & $111-142$ & - & - & - \\
Late Wenlock & $143-158$ & -180 & - & -
\end{tabular}

Finds and Ranges

\begin{tabular}{l|crrrrr}
\hline \multicolumn{1}{c|}{ Species } & Province & H & FKA & LB & LKA & UB \\
\hline 19. Ceratopea pygmaea & Laur & 22 & 2 & -6.2 & 44 & 52.4 \\
94. Ceratopea unguis & Laur & 16 & 1 & -11.3 & 44 & 56.3 \\
95. Boucotspira aff. B. fimbriata & ToqTab & 8 & 45 & 34.8 & 59 & 69.2 \\
96. Lophonema peccatonica & Laur & 12 & 2 & -14.8 & 44 & 60.8 \\
97. Polehemia taneyensis & Laur & 15 & 2 & -10.9 & 44 & 56.9 \\
98. Walcottoma frydai & ToqTab & 2 & 45 & -70.3 & 48 & 163.3 \\
99. Helicotoma planulata & Laur & 26 & 45 & 36.7 & 96 & 104.4 \\
100. Helicotoma tennesseensis & Laur & 11 & 45 & 34.0 & 69 & 80.0 \\
101. Ophiletina sublaxa & Laur & 6 & 45 & 4.7 & 82 & 122.3 \\
102. Ophiletina angularis & Laur & 1 & 70 & undef & 79 & undef \\
103. Oriostoma bromidensis & Laur & 1 & 45 & undef & 46 & undef
\end{tabular}




\begin{tabular}{|c|c|c|c|c|c|c|}
\hline Species & Province & $\mathrm{H}$ & FKA & LB & LKA & UB \\
\hline 104. Euomphalopterus ?ordovicius & ToqTab & 1 & 49 & undef & 59 & undef \\
\hline Euomphalopterus ?ordovicius & Laur & 2 & 87 & -201.3 & 96 & 384.3 \\
\hline 105. Euomphalopterus aff. E. ordovicius & ToqTab & 1 & 49 & undef & 59 & undef \\
\hline 106. Euomphalopterus cariniferus & Balt & 5 & 49 & -145.0 & 180 & 374.0 \\
\hline 107. Palaeomphalus ?gradatus & Balt & 7 & 46 & 33.6 & 60 & 72.5 \\
\hline 108. Trochomphalus?dimidiatus & Balt & 3 & 46 & -26.5 & 60 & 132.5 \\
\hline 109. Helicotoma blodgetti & Laur & 2 & 87 & -201.3 & 96 & 384.3 \\
\hline 110. Helicotoma robinsoni & Laur & 1 & 87 & undef & 96 & undef \\
\hline 111. Helicotoma? Girvan sp. & Laur & 1 & 87 & undef & 96 & undef \\
\hline 112. Straparollina cf. S. circe & Laur & 3 & 87 & 38.7 & 96 & 144.3 \\
\hline 113. Euomphalopterus alatus & Laur & 35 & 101 & 91.4 & 187 & 196.6 \\
\hline Euomphalopterus alatus & Gond & 5 & 159 & 122.3 & 183 & 219.8 \\
\hline 114. Euomphalopterus frenatus & Laur & 1 & 101 & undef & 103 & undef \\
\hline 115. Euomphalopterus praetextus & Laur & 1 & 101 & undef & 103 & undef \\
\hline 116. Euomphalopterus subcarinatus & Laur & 11 & 97 & 57.0 & 187 & 227.0 \\
\hline 117. Euomphalopterus togatus & Laur & 3 & 101 & -285.4 & 180 & 566.4 \\
\hline 118. Euomphalopterus undulans & Laur & 2 & 101 & 14.5 & 103 & 189.5 \\
\hline 119. Grantlandispira christei & Laur & 1 & 97 & undef & 103 & undef \\
\hline 120. Poleumita discors & Laur & 34 & 101 & 91.2 & 189 & 198.8 \\
\hline 121. Pycnomphalus acutus & Laur & 9 & 101 & 54.6 & 180 & 226.4 \\
\hline 122. Pycnomphalus obesus & Laur & 6 & 101 & 16.2 & 180 & 264.8 \\
\hline Pycnomphalus obesus & Gond & 3 & 159 & 101.0 & 170 & 228.0 \\
\hline 123. Discordichilus dalli & Laur & 2 & 107 & -1392.2 & 158 & 1657.2 \\
\hline 124. Discordichilus mollis & Laur & 5 & 127 & 47.6 & 180 & 259.4 \\
\hline 125. Discordichilus kolmodini & Laur & 2 & 127 & -334.3 & 142 & 603.3 \\
\hline 126. Poleumita alata & Laur & 3 & 104 & -161.7 & 158 & 423.7 \\
\hline 127. Poleumita octavia & Laur & 7 & 128 & 81.5 & 183 & 229.5 \\
\hline 128. Poleumita rugosa & Laur & 24 & 107 & 94.4 & 180 & 192.9 \\
\hline 129. Pseudophorus profundus & Laur & 1 & 132 & undef & 142 & undef \\
\hline 130. Pseudophorus stuxbergi & Laur & 4 & 107 & -10.3 & 157 & 274.3 \\
\hline 131. Siluriphorus gotlandicus & Laur & 10 & 104 & 84.5 & 142 & 161.5 \\
\hline 132. Siluriphorus undulans & Laur & 4 & 132 & 72.2 & 157 & 216.8 \\
\hline 133. Streptotrochus incisus & Laur & 6 & 107 & 68.8 & 142 & 180.2 \\
\hline 134. Streptotrochus aff. S. incisus & Laur & 4 & 107 & 24.2 & 142 & 224.8 \\
\hline 135. Streptotrochus lamellosus & Laur & 2 & 112 & -781.7 & 142 & 1035.7 \\
\hline 136. Streptotrochus lundgreni & Laur & 3 & 112 & -37.7 & 142 & 291.7 \\
\hline 137. Streptotrochus? visbeyensis & Laur & 4 & 111 & 37.4 & 142 & 215.6 \\
\hline 138. Hystricoceras astraciformis & Laur & 2 & 143 & -289.5 & 157 & 589.5 \\
\hline 139. Poleumita granulosa & Laur & 5 & 143 & 126.8 & 153 & 169.2 \\
\hline 140. Euomphalus walmstedti & Laur & 3 & 143 & -40.5 & 180 & 363.5 \\
\hline 141. Centrifugus planorbis & Laur & 11 & 159 & 149.3 & 180 & 189.7 \\
\hline 142. Spinicharybdis wilsoni & Laur & 1 & 181 & undef & 189 & undef \\
\hline 143. Turbocheilus immaturum & Gond & 4 & 158 & 128.1 & 170 & 199.9 \\
\hline 144. Pseudotectus comes & Gond & 1 & 159 & -244.6 & 170 & 575.6 \\
\hline 145. Straparollus bohemicus & Gond & 3 & 159 & 101.0 & 170 & 228.0 \\
\hline
\end{tabular}


II. MURChISONIINAES":

II.3. "Hormotomoids"

"Time" Scales

\begin{tabular}{l|cccc}
\hline \multicolumn{1}{c|}{ Stage/Province } & Laurentia & $\begin{array}{c}\text { Toquima- } \\
\text { Table Head }\end{array}$ & Baltica & Gondwana \\
\hline Dolgellian & - & - & - & - \\
Early Tremadoc & $1-3$ & - & - & - \\
Late Tremadoc & $4-12$ & - & - & - \\
Early Arenig & $13-87$ & - & - & - \\
Middle Arenig & - & - & - & - \\
Late Arenig & $88-89$ & $111-122$ & - & - \\
Llanvirn & 90 & $123-126$ & - & - \\
Llandeilo & 91 & $127-128$ & - & - \\
Early Caradoc & $92-134$ & $127-128$ & - & - \\
Middle Caradoc & $135-216$ & $127-128$ & $288-290$ & - \\
Late Caradoc & $217-295$ & - & $291-300$ & - \\
Ashgill & $296-308$ & - & - & - \\
Llandovery & $309-324$ & - & - & 345 \\
Late Llandovery & $325-330$ & - & - & $346-357$ \\
Early Wenlock & $331-338$ & - & - & $358-359$ \\
Late Wenlock & $339-344$ & - & - & - \\
Early Ludlow & $345-360$ & - & - & - \\
Late Ludlow & $361-364$ & - & & \\
Pridolí & $365-367$ & &
\end{tabular}

Finds and Ranges

\begin{tabular}{|c|c|c|c|c|c|c|}
\hline Species & Province & $\mathrm{H}$ & FKA & LB & LKA & UB \\
\hline 13. Taeniospira ?st. clairi & Laur & 3 & 1 & -13.5 & 3 & 17.5 \\
\hline 146. Hormotoma artemesia & Laur & 15 & 4 & -21.2 & 87 & 112.2 \\
\hline 147. Hormotoma confusa & Laur & 8 & 4 & -53.1 & 87 & 144.1 \\
\hline 148. Hormotoma ?dubia & Laur & 3 & 4 & -121.6 & 29 & 154.6 \\
\hline 149. Hormotoma ?simulatrix & Laur & 37 & 4 & -5.2 & 87 & 96.2 \\
\hline 150. Ectomaria adelina & Laur & 6 & 13 & -107.8 & 126 & 246.8 \\
\hline 151. "Hormotoma" "cassina" & Laur & 8 & 36 & 0.6 & 87 & 122.4 \\
\hline 152. Fusispira Smithville Fm. sp. & Laur & 5 & 36 & -40.4 & 87 & 163.4 \\
\hline 153. Hormotoma augustina & Laur & 7 & 30 & -18.1 & 87 & 135.1 \\
\hline Hormotoma augustina & ToqTab & 20 & 91 & 84.3 & 122 & 128.7 \\
\hline 154. Hormotoma zelleri & Laur & 3 & 20 & -28.3 & 29 & 77.3 \\
\hline 155. Lophospira perangulata & Laur & 85 & 36 & 25.1 & 308 & 318.1 \\
\hline 156. Subulitid El Paso Fm. sp. & Laur & 2 & 36 & -1463.2 & 87 & 1586.2 \\
\hline 157. Pagodospira cicelia & Laur & 7 & 36 & -7.2 & 87 & 130.2 \\
\hline Pagodospira cicelia & ToqTab & 7 & 91 & 61.1 & 126 & 155.9 \\
\hline 158. Plethospira cannonensis & Laur & 6 & 16 & -60.3 & 87 & 163.3 \\
\hline 159. Plethospira cassina & Laur & 4 & 20 & -136.4 & 87 & 243.4 \\
\hline 160. Seelya ventricosa & Laur & 1 & 20 & undef & 29 & undef \\
\hline 161. Lophospira grandis & Laur & 23 & 16 & -37.5 & 312 & 368.8 \\
\hline 162. Straparollina pelagica & Laur & 7 & 13 & -51.7 & 90 & 154.7 \\
\hline 163. Plethospira? turgida & Laur & 5 & 20 & -80.0 & 87 & 187.0 \\
\hline 164. Turritoma acrea & Laur & 1 & 13 & undef & 15 & undef \\
\hline 165. Turritoma Cotter Fm. ornate sp. & Laur & 2 & 13 & -188.8 & 19 & 220.8 \\
\hline 166. Turritoma cf. T. acrea & Laur & 3 & 36 & -215.2 & 87 & 338.2 \\
\hline 167. Hormotoma Setul Fm. sp. & ToqTab & 6 & 91 & 57.1 & 122 & 155.9 \\
\hline 168. Turritoma ?anna & ToqTab & 7 & 91 & 64.4 & 122 & 148.6 \\
\hline 169. Murchisonia callahanensis & ToqTab & 4 & 88 & -6.3 & 128 & 222.3 \\
\hline 170. Ectomaria prisca & Laur & 11 & 92 & -3.5 & 308 & 403.5 \\
\hline 171. Hormotoma gracilis & Laur & 80 & 91 & 80.1 & 308 & 319.3 \\
\hline Hormotoma gracilis & Balt & 3 & 288 & -923.3 & 300 & 1314.3 \\
\hline 172. Daidia cerithioides & Laur & 4 & 93 & -102.5 & 177 & 372.5 \\
\hline 173. Ectomaria pagoda & Laur & 11 & 93 & -2.0 & 308 & 403.0 \\
\hline
\end{tabular}




\begin{tabular}{|c|c|c|c|c|c|c|}
\hline Species & Province & $\mathrm{H}$ & FKA & LB & LKA & UB \\
\hline 174. Haplospira?nereis & Laur & 8 & 93 & 35.2 & 177 & 234.8 \\
\hline 175. Hormotoma bellicincta & Laur & 57 & 93 & 75.7 & 308 & 325.3 \\
\hline 176. Hormotoma salteri & Laur & 36 & 93 & 69.2 & 308 & 331.8 \\
\hline 177. Hormotoma trentonensis & Laur & 93 & 93 & 85.2 & 287 & 295.0 \\
\hline 178. Loxonema murryana & Laur & 6 & 93 & 2.9 & 177 & 267.1 \\
\hline 179. Omospira alexandra & Laur & 9 & 93 & 43.7 & 177 & 226.3 \\
\hline 180. Oinospira laticincta & Laur & 1 & 93 & undef & 134 & undef \\
\hline 181. Straparollina circe & Laur & 3 & 93 & -317.6 & 177 & 587.6 \\
\hline 182. Straparollina erigione & Laur & 2 & 135 & 89.4 & 177 & 222.6 \\
\hline 183. Girvania excavata & Laur & 1 & 288 & undef & 295 & undef \\
\hline 184. Murchisonia Pt. Clarence Fm. sp. & Laur & 2 & 288 & -317.4 & 308 & 913.4 \\
\hline 185. Rhabdostropha primitiva & Laur & 4 & 288 & 239.7 & 308 & 356.3 \\
\hline 186. Spiroecus girvanensis & Laur & 2 & 288 & -317.4 & 308 & 913.4 \\
\hline 187. Daidia aff. $D$. cerithioides & Laur & 1 & 298 & undef & 308 & undef \\
\hline 188. Ectomaria cf. E. pagoda & Laur & 2 & 298 & 244.9 & 308 & 361.1 \\
\hline 189. Ectomaria cf. E. prisca & Laur & 3 & 298 & -19.1 & 308 & 625.1 \\
\hline 190. Ectomaria laticarinata & Laur & 1 & 298 & undef & 308 & undef \\
\hline 191. Ectomaria nieszkowskii & Balt & 3 & 291 & 242.7 & 300 & 348.3 \\
\hline 192. Hormotoma insignis & Balt & 8 & 288 & 281.2 & 297 & 303.8 \\
\hline 193. Holopella regularis & Laur & 4 & 300 & 159.7 & 360 & 500.3 \\
\hline 194. Hormotoma centervillensis & Laur & 2 & 309 & 251.3 & 310 & 367.7 \\
\hline 195. Hormotoma cingulata & Laur & 6 & 313 & 262.1 & 360 & 410.9 \\
\hline Hormotoma cingulata & Gond & l & 300 & undef & 312 & undef \\
\hline 196. Kjerulfonema cancellata & Laur & 8 & 313 & 294.4 & 323 & 362.6 \\
\hline 197. Kjerulfonema quinquecincta & Laur & 2 & 311 & -63.8 & 323 & 697.8 \\
\hline 198. Cyrtostropha coralli & Laur & 2 & 328 & -623.4 & 360 & 1311.4 \\
\hline 199. Goniostropha cava & Laur & 7 & 327 & 312.1 & 344 & 358.9 \\
\hline 200. Hormotoma subplicata & Laur & 2 & 325 & 36.7 & 334 & 622.3 \\
\hline 201. Hormotoma monoliniformis & Laur & 2 & 327 & -19.0 & 338 & 684.0 \\
\hline 202. Hormotoma attenuata & Laur & 10 & 325 & 307.0 & 360 & 378.0 \\
\hline 203. Loxonema? attenuata & Laur & 1 & 330 & undef & 338 & undef \\
\hline 204. Macrochilus fenestratus & Laur & 1 & 330 & undef & 338 & undef \\
\hline 205. Rhabdostropha grindrodii & Laur & 2 & 328 & -623.4 & 360 & 1311.4 \\
\hline 206. Loxonema crossmanni & Laur & 1 & 328 & undef & 332 & undef \\
\hline 207. Loxonema sinuosa & Laur & 4 & 339 & 272.3 & 367 & 433.7 \\
\hline 208. Auriptygma fortior & Gond & 4 & 346 & 270.1 & 357 & 341.9 \\
\hline 209. Catazone allevata & Gond & 4 & 346 & 270.1 & 357 & 341.9 \\
\hline 210. Catazone argolis & Gond & 2 & 346 & -74.8 & 357 & 686.8 \\
\hline 211. Catazone cunea & Gond & 2 & 346 & -74.8 & 357 & 686.8 \\
\hline 212. Diplozone crispa & Laur & 3 & 345 & 267.7 & 360 & 437.3 \\
\hline 213. Donaldiella declivis & Gond & 6 & 346 & 286.2 & 312 & 325.8 \\
\hline 214. Donaldiella morinensis & Laur & 2 & 345 & -116.3 & 357 & 821.3 \\
\hline 215. Goniostropha sculpta & Gond & 2 & 346 & -74.8 & 357 & 686.8 \\
\hline 216. Loxonema beraullensis & Gond & 3 & 346 & 237.2 & 357 & 374.8 \\
\hline 217. Coelocaulus concinnus & Gond & 1 & 346 & undef & 358 & undef \\
\hline 218. Macrochilus buliminus & Laur & 2 & 345 & -116.3 & 360 & 821.3 \\
\hline 219. Macrochilus cancellatus & Laur & 3 & 345 & 267.7 & 360 & 437.3 \\
\hline Macrochilus cancellatus & Gond & 1 & 346 & undef & 357 & undef \\
\hline 220. Macrochilina recticosıa & Gond & 3 & 346 & 232.4 & 359 & 380.6 \\
\hline 221. Murchisonia paradoxa & Laur & 1 & 345 & undef & 360 & undef \\
\hline 222. Sinuspira tenera & Gond & 4 & 346 & 270.1 & 357 & 341.9 \\
\hline 223. Stylonema mater & Gond & 1 & 346 & undef & 357 & undef \\
\hline 224. Stylonema potens & Gond & 3 & 346 & 237.2 & 359 & 374.8 \\
\hline
\end{tabular}




\section{II. "MuRChisoninaES":}

\section{II.4. "Eotomarioids"}

"Time" Scales

\begin{tabular}{|c|c|c|c|c|}
\hline Stage/Province & Laurentia & $\begin{array}{l}\text { Toquima- } \\
\text { Table Head }\end{array}$ & Baltica & Gondwana \\
\hline Dolgellian & - & - & - & - \\
\hline Early Tremadoc & - & - & - & - \\
\hline Late Tremadoc & - & - & & - \\
\hline Early Arenig & $1-2$ & - & & - \\
\hline Middle Arenig & $3-4$ & - & & - \\
\hline Late Arenig & 5 & $5-8$ & $8-17$ & - \\
\hline Llanvim & 6 & $9-14$ & $18-33$ & - \\
\hline Llandeilo & 7 & $15-21$ & 34 & - \\
\hline Early Caradoc & $8-61$ & $21-28$ & $35-59$ & - \\
\hline Middle Caradoc & $62-126$ & $21-28$ & $60-66$ & _- \\
\hline Late Caradoc & $127-174$ & $21-28$ & $67-71$ & - \\
\hline Ashgill & $175-192$ & - & $72-83$ & - \\
\hline Early Llandovery & $193-212$ & - & - & - \\
\hline Late Llandovery & $213-219$ & - & - & \\
\hline Early Wenlock & $220-241$ & - & - & \\
\hline Late Wenlock & $242-248$ & - & - & \\
\hline Early Ludlow & $249-263$ & - & - & $249-256$ \\
\hline Late Ludlow & $264-272$ & - & - & $257-273$ \\
\hline Prídolí & $273-275$ & - & - & 274 \\
\hline
\end{tabular}

Finds and Ranges

\begin{tabular}{|c|c|c|c|c|c|c|}
\hline Species & Province & $\mathrm{H}$ & FKA & LB & LKA & UB \\
\hline 225. Clathrospira Smithville Fm. sp. & Laur & 8 & 1 & -58.2 & 87 & 146.2 \\
\hline 226. Clathrospira?glindmeyeri & ToqTab & 3 & 5 & 0.0 & 15 & 0.0 \\
\hline 227. Clathrospira elliptica & Balt & 45 & 5 & -1.0 & 71 & 77.0 \\
\hline 228. Clathrospira euconica & Laur & 1 & 5 & undef & 6 & undef \\
\hline 229. Clathrospira inflata & Balt & 24 & 12 & 4.9 & 53 & 60.2 \\
\hline 230. Mourlonia mjoela & Balt & 9 & 11 & -24.4 & 71 & 106.4 \\
\hline 231. Clathrospira?trochiformis & Laur & 3 & 7 & -89.6 & 26 & 122.6 \\
\hline 232. Clathrospira convexa & Laur & 4 & 20 & -377.9 & 192 & 589.9 \\
\hline 233. Clathrospira conica & Laur & 17 & 8 & -40.1 & 192 & 240.1 \\
\hline 234. Clathrospira subconica & Laur & 30 & 8 & -3.1 & 92 & 103.1 \\
\hline 235. Eotomaria canalifera & Laur & 4 & 8 & -111.6 & 59 & 178.6 \\
\hline 236. Eotomaria dryope & Laur & 15 & 8 & -22.6 & 109 & 139.6 \\
\hline 237. Eotomaria labrosa & Laur & 1 & 8 & undef & 9 & undef \\
\hline 238. Liospira larvata & Laur & 11 & 10 & -34.0 & 109 & 153.0 \\
\hline 239. Paraliospira mundula & Laur & 7 & 8 & -83.3 & 117 & 208.3 \\
\hline 240. Eotomaria supracingulata & Laur & 11 & 20 & -19.6 & 109 & 148.6 \\
\hline 241. Liospira angustata & Laur & 4 & 20 & -187.0 & 109 & 316.0 \\
\hline 242. Liospira decipens & Laur & 12 & 8 & -31.8 & 109 & 148.8 \\
\hline 243. Liospira subconcava & Laur & 19 & 10 & -12.0 & 109 & 131.0 \\
\hline 244. Euryzone kiari & Balt & 7 & 60 & 41.7 & 81 & 99.3 \\
\hline 245. Eotomaria elevata & Laur & 1 & 62 & undef & 126 & undef \\
\hline 246. Liospira micula & Laur & 35 & 102 & 92.0 & 192 & 202.0 \\
\hline 247. Liospira progne & Laur & 76 & 25 & 16.0 & 174 & 183.4 \\
\hline 248. Paraliospira angulata & Laur & 6 & 25 & -153.1 & 192 & 370.1 \\
\hline 249. Brachytomaria baltica & Balt & 3 & 69 & 6.2 & 81 & 143.8 \\
\hline 250. Paraliospira aff. $P$. angulata & Laur & 2 & 177 & -284.3 & 192 & 653.3 \\
\hline 251. Paraliospira rugata & Laur & 3 & 175 & 146.0 & 180 & 209.0 \\
\hline 252. Eotomaria notablis & Balt & 16 & 35 & 15.9 & 81 & 101.1 \\
\hline 253. Lophospira kindlei & Laur & 1 & 177 & undef & 192 & undef \\
\hline Lophospira kindlei & Balt & 1 & 82 & undef & 83 & undef \\
\hline 254. Brachytomaria papillosa & Laur & 2 & 177 & -284.3 & 192 & 653.3 \\
\hline Brachytomaria papillosa & Balt & 1 & 72 & undef & 81 & undef \\
\hline 255. Brachytomaria semele & Balt & 4 & 72 & -169.5 & 176 & 417.5 \\
\hline
\end{tabular}




\begin{tabular}{|c|c|c|c|c|c|c|}
\hline Species & Province & $\mathrm{H}$ & FKA & LB & LKA & UB \\
\hline Brachytomaria semele & Laur & 2 & 177 & 61.7 & 180 & 295.3 \\
\hline 256. Brachytomaria striata & Laur & 1 & 177 & undef & 192 & undef \\
\hline 257. Cataschisma exquisita & Laur & 3 & 177 & -151.4 & 244 & 572.4 \\
\hline 258. Clathrospira thraivensis & Laur & 2 & 177 & -284.3 & 192 & 653.3 \\
\hline 259. "Bembexia" globosa & Laur & 1 & 177 & undef & 192 & undef \\
\hline 260. Eotomaria rupestris & Balt & 3 & 72 & 14.0 & 83 & 141.0 \\
\hline 261. Crenilunula limata & Laur & 19 & 210 & 198.1 & 263 & 274.9 \\
\hline 262. Clathrospira biformis & Laur & 3 & 210 & 41.0 & 244 & 413.1 \\
\hline 263. Phanerotrema jugosa & Laur & 5 & 193 & 168.0 & 209 & 234.0 \\
\hline 264. Phanerotrema lindstroemi & Laur & 6 & 210 & 176.1 & 263 & 274.9 \\
\hline 265. Oriostoma angulifer & Laur & 4 & 210 & 163.0 & 241 & 288.0 \\
\hline 266. Stenoloron shelvensis & Laur & 9 & 199 & 174.1 & 241 & 265.9 \\
\hline 267. "Seelya" lloydi & Gond & 17 & 210 & 193.1 & 274 & 290.9 \\
\hline 268. Ulrichospira similis & Laur & 2 & 199 & -118.1 & 209 & 526.1 \\
\hline 269. Eocryptaulina helcinia & Laur & 2 & 210 & -799.1 & 244 & 1253.1 \\
\hline 270. Conotoma claustrata & Laur & 5 & 213 & 170.4 & 241 & 283.6 \\
\hline 271. Crenilunula hallei & Laur & 11 & 213 & 190.6 & 263 & 285.4 \\
\hline Crenilunula hallei & Gond & 7 & 257 & 242.1 & 274 & 288.9 \\
\hline 272. Oehlertia gradata & Laur & 6 & 213 & 158.9 & 263 & 317.1 \\
\hline 273. Oehlertia scutulata & Laur & 4 & 216 & 156.2 & 241 & 300.8 \\
\hline 274. Pleurorima wisbeyensis & Laur & 1 & 229 & undef & 241 & undef \\
\hline 275. Promourlonia aff. $P$. furcata & Laur & 5 & 213 & 124.8 & 272 & 360.2 \\
\hline 276. "Longstaffia" "laquetta" & Laur & 1 & 213 & undef & 215 & undef \\
\hline 277. Phanerotrema ?occidens & Laur & 6 & 227 & 187.8 & 263 & 302.2 \\
\hline Phanerotrema ?occidens & Gond & 2 & 227 & -205.5 & 241 & 673.5 \\
\hline 278. Stenoloron aequilatera & Laur & 9 & 219 & 201.6 & 248 & 265.4 \\
\hline 279. Oriostoma dispar & Laur & 1 & 229 & undef & 241 & undef \\
\hline 280. Murchisonia othemensis & Laur & 1 & 227 & undef & 241 & undef \\
\hline 281. "Seelya"?vitellia & Laur & 2 & 242 & -392.3 & 263 & 897.3 \\
\hline 282. Coelozone verna & Gond & 3 & 257 & 170.1 & 274 & 360.9 \\
\hline 283. Conotoma glandiformis & Laur & 2 & 249 & -183.5 & 263 & 695.5 \\
\hline 284. Euryzone connulastus & Gond & 4 & 257 & 215.6 & 274 & 315.4 \\
\hline 285. Globispira prima & Gond & 3 & 250 & 129.3 & 274 & 394.8 \\
\hline 286. Oehlertia cancellata & Laur & 3 & 249 & 176.6 & 263 & 335.5 \\
\hline 287. Prosolarium procerum & Gond & 1 & 257 & undef & 274 & undef \\
\hline Prosolarium procerum & Laur & 1 & 273 & undef & 275 & undef \\
\hline 288. Pleurorima migrans & Gond & 16 & 250 & 243.0 & 274 & 281.0 \\
\hline 289. Pleurorima aptychia & Gond & 1 & 257 & undef & 274 & undef \\
\hline 290. Phanerotrema dolia & Laur & 1 & 264 & undef & 272 & undef \\
\hline 291. Spiroraphe bohemica & Gond & 3 & 257 & 170.1 & 274 & 360.9 \\
\hline 292. Stenoloron pollens & Gond & 2 & 257 & -261.9 & 274 & 792.9 \\
\hline 293. Stenoloron voluta & Laur & 1 & 249 & undef & 263 & undef \\
\hline 294. Umbotropsis albicans & Gond & 2 & 257 & -261.9 & 274 & 792.9 \\
\hline 295. Seelya moydartensis & Laur & 4 & 264 & 243.3 & 272 & 292.7 \\
\hline
\end{tabular}




\section{Literature Cited}

Adrain, J.M., and B.D.E. Chatterton

1990. Odontopleura (Trilobita, Silurian), and a Method of Constrained Congruency Analysis. Journal of Paleontology, 64:600-614.

Alroy, J.

1994a. Appearance Event Ordination: A New Biochronologic Method. $\mathrm{Pa}$ leobiology, 20:191-207.

1994b. Four Permutation Tests for the Presence of Phylogenetic Structure. Systematic Biology, 43:430-437.

1995. Continuous Track Analysis: A New Phylogenetic and Biogeographic Method. Systematic Biology, 44:153-172.

Anstey, R.L.

1986. Bryozoan Provinces and Patterns of Generic Evolution and Extinction in the Late Ordovician of North America. Lethaia, 19:33-51.

Archie, J.W.

1985. Methods for Coding Variable Morphological Features for Numerical Taxonomic Analysis. Systematic Zoology, 34:326-345.

1989. Homoplasy Excess Ratios: New Indices for Measuring Levels of Homoplasy in Phylogenetic Systematics and a Critique of the Consistency Index. Systematic Zoology, 38:253-269.

Atchley, W.R., and B.K. Hall

1991. A Model for Development and Evolution of Complex Morphological Structures. Biological Review, 66:101-157.

Ballard, J.W.O., G.J. Olsen, D.P. Faith, W.A. Odgers, D.M. Rowell, and P.W. Atkinson

1992. Evidence from 12S Ribosomal RNA Sequences that Onychophorans Are Modified Arthropods. Science, 258:1345-1348.

Bandel, K.

1988. Repäsentieren die Euomphaloidea eine natürliche Einhart der Gastropoden? Mitteilungen aus dem Geologisch-Paläontologischen Institut der Universität Hamburg, 67:1-33.

1991. Ontogenetic Changes Reflected in the Morphology of the Molluscan Shell. In N. Schmidt-Kittler and K. Vogel, editors, Constructional Morphology and Evolution, pages 211-230. Berlin: Springer-Verlag.

1992. Platyceratidae from the Triassic St. Cassian Formation and the Evolutionary History of the Neritomorpha (Gastropoda). Paläontologische Zeitschrift, 66:231-240.

1993. Evolutionary History of Sinistral Archaeogastropods with and without Slit (Cirroidea, Vetigastropods). Freiberger Forschungshefte, 450:4I-81.

1998. The Early Ontogenetic Shell as Tool to Understand Gastropod Evolution. [Abstract.] In R. Bieler and P.M. Mikkelsen, editors, World Congress of Malacology, Abstracts, page 24. Chicago, Illinois: UNITAS Malacologica.

Barnes, R.D.

1987. Invertebrate Zoology. Fifth edition, 893 pages. Fort Worth, Texas: Saunders College Publishing.

Batten, R.L.

1972. The Ultrastructure of Five Common Pennsylvanian Pleurotomarian Gastropod Species of Eastern United States. American Museum Novitates, 2501:1-34.

1984. The Calcitic Wall in the Paleozoic Families Euomphalidae and Platyceratidae (Archaeogastropoda). Journal of Paleontology, 58:1186-1192.

1989. Permian Gastropods of the Southwestern United States, 7: Pleurotomariacea: Eotomariidae, Lophospiridae, Gosseletinidae. American Museum Novitates, 2958:1-64.

Beresi, M.S., and J.K. Rigby

1993. The Lower Ordovician Sponges of San Juan, Argentina. Brigham Young University, Geology Studies, 39:1-63.
Berg-Madsen, V., and J.S. Peel

1994. A Tergomyan Mollusc from the Upper Cambrian of Wales. Palaeontology, 37:505-512.

Bieler, R.

1988. Phylogenetic Relationships in the Gastropod Family Architectonicidae, with Notes on the Family Mathilididae (Allogastropoda). In W.F. Ponder, editor, Prosobranch Phylogeny: Proceedings of the Ninth International Malacological Congress, pages 205-240. Edinburgh, Scotland: Malacological Review.

1992. Gastropod Phylogeny and Systematics. Annual Review of Ecology and Systematics, 23:211-238.

Billings, E.

1857. Report for the Year 1856. In W.E. Logan, editor, Geological Survey of Canada: Report of Progress for the Years 1853-54-55-56, pages 247-345. Toronto, Canada: John Lovell.

1865. Palaeozoic Fossils. Volume 1, 426 pages. Montreal: Dawson Brothers.

Blodgett, R.B.

1987. Wisconsinella, a New Rapistomatinid Gastropod Genus from the Middle Devonian of Wisconsin. Journal of Paleontology, 62:442444.

1992. Taxonomy and Paleobiogeographic Affinities of an Early Middle Devonian (Eifelian) Gastropod Faunule from the Livengood Quadrangle, East-Central Alaska. Palaeotographica, Abteilung $A$, $221: 125-168$.

1993. Dutrochus, a New Microdomatid (Gastropoda) Genus from the Middle Devonian (Eifelian) of West-Central Alaska. Journal of Paleontology, 67:194-197.

Blodgett, R.B., and J.G. Johnson

1992. Early Middle Devonian (Eifelian) Gastropods of Central Nevada. Palaeontographica, Abteilung A, 222:85-139.

Blodgett, R.B., D.M. Rohr, and A.J. Boucot

1988. Lower Devonian Gastropod Biogeography of the Western Hemisphere. In N.J. McMillan, A.F. Embry, and D.J. Glass, editors, Devonian of the World. Proceedings of the Second International Symposium on the Devonian System, Volume III, pages 281-294. Calgary, Alberta: Canadian Society of Petroleum Geologists.

1990. Early and Middle Devonian Gastropod Biogeography. In W.S. McKerrow and C.R. Scotese, editors, Palaeozoic Palaeogeography and Biogeography, pages 277-284. London: The Geological Society.

Blodgett, R.B., D.M. Rohr, A.G. Harris, and J.-Y. Rong

1988. A Major Unconformity between Upper Ordovician and Lower Devonian Strata in the Nanook Limestone, Shublik Mountains, Northeastern Brooks Range. United States Geological Survey Circular, 1016:18-23.

Bottjer, D.J., and D. Jablonski

1988. Paleoenvironmental Patterns in the Evolution of Post-Paleozoic Benthic Marine Invertebrates. Palaios, 3:540-560.

Boucot, A.J., J.G. Johnson, C. Harper, and V.G. Walmsley

1967. Silurian Brachiopods and Gastropods of Southern New Brunswick. Bulletin of the Geological Survey of Canada, 140:1-45.

Boucot, A.J., and E.L. Yochelson

1966. Paleozoic Gastropoda from the Moose River Synclinorium, Northern Maine. United States Geological Survey Professional Paper, 503-A: 20 pages.

Boulding, E.G., and T.K. Hay

1993. Quantitative Genetics of Shell Formation of an Intertidal Snail: Constraints on Short-Term Response to Selection. Evolution, 47:576-592. 
Branson, E.B

1909. The Fauna of the Residuary Auburn Chert of Lincoln County, Missouri. Transactions of the Academy of Science of St. Louis, 18:39-52.

Bridge, J., and P.E. Cloud

1947. New Gastropods and Trilobites Critical in the Correlation of Lower Ordovician Rocks. American Journal of Science, 245: 545-559.

Bronn, H.G.

1834. Lethaea Geognostica, oder Abbildungen und Beschreibungen der für die Gebirgs-Formationen bezeichnendsten Versteinerungen. Stuttgart: C.F. Winter.

Butts, C.

1926. The Paleozoic Rocks. Geological Survey of Alabama, 14:14-230.

Carson, G.A.

1991. Silicification of Fossils. In P.A. Allison and D.E.G. Briggs, editors, Taphonomy: Releasing the Data Locked in the Fossil Record, pages 455-499. New York: Plenum Press.

Chappill, J.A.

1989. Quantitative Characters in Phylogenetic Analysis. Cladistics, 5: 217-234

Clarke, J.M., and R. Ruedemann

1903. Guelph Fauna in the State of New York. Memoirs of the New York State Museum of Natural History; 5:1-100.

Cocks, L.R.M., and R.A. Fortey

1990. Biogeography of Ordovician and Silurian Faunas. In W.S. McKerrow and C.R. Scotese, editors, Palaeozoic Palaeogeography and Biogeography, pages 97-104. London: The Geological Society.

Cocks, L.R.M., and W.S. McKerrow

1993. A Reassessment of the Early Ordovician Brachiopod Province. Journal of the Geological Society, London, i 50:1039-1042.

Cocks, L.R.M., and J.-Y. Ruang

1988. A Review of the Late Ordovician Foliomena Brachiopod Fauna with New Data from China, Wales, and Poland. Palaeontology, 31: $53-67$.

Conrad, T.A.

1838. Report on the Palaeontological Department of the Survey. New York Geological Survey, Annual Report, 2:107-119.

Cossmann, M.

1903. Rectifications de nomenclature. Revue Critique de Paléozoologie, 7:67-68.

1908. Rectifications de nomenclature. Revue Critique de Paléozoologie. 12:96-98.

1918. Essais de paléoconchologie comparée. Volume 1, 292 pages. Paris. Cox, L.R.

1960. Gastropoda-General Characteristics of Gastropoda. In Raymond C. Moore, editor, Treatise on Invertebrate Paleontology, Part 1, Mollusca (1):84-169. Lawrence, Kansas: University of Kansas Press.

Cox, L.R., and J.B. Knight

1960. Thoughts on the Classification of the Gastropoda. Proceedings of the Malacological Society of London, 33:262-265.

Cranston, P.S., and C.J. Humphries

1988. Cladistics and Computers: A Chironomid Conundrum? Cladistics, 4:72-92.

Cullison, J.S.

1944. The Stratigraphy of Sorne Lower Ordovician Formations of the Ozark Uplift. University of Missouri, Bulletin of the School of Mines and Metallurgy, Technical Series, 15:1-112.

d'Archaic, E.J.A.

1841. Note sur le genre Murchisonia. Bulletin de la Société Géologique de France, 1st series, 12:154-169.

Dake, C.L., and J. Bridge

1932. Faunal Correlations of the Ellcnburger Limestone of Texas. Bulletin of the Geological Society of America, 43:725-741.
Davis, G.M., Y.-H. Kuo, K.E. Hoagland, P.-L. Chen, H.-M. Yang, and D.-J. Chen

1985. Erhaia, A New Genus and New Species of Pomatiopsidae from China (Gastropoda: Rissoacea). Proceedings of the Academy of Natural Sciences of Philadelphia, 137:48-78.

Davis, G.M., and M.C. Pons da Silva

1984. Potamolithus: Morphology, Convergence, and Relationships among Hydroboid Snails. Malacologia, 25:73-108.

Defrance, M.J.L

1824. Rectification des caractéres du genre Bellérophe, établi dans la Concyliologie de Denys de Montfort. Annales des Sciences Naturelles, $1: 264-265$

de Koninck, L.G.

1844. Description des animaux fossiles qui se trouvent dans le terrain carbonifère de Belgique. 650 pages. Liége.

1881. Faune du calcaire carbonifêre de la Belgique, $3^{\mathrm{e}}$ partie: Gastéropodes. Annales du Musée Royale d'Historie de Belgique, Série Paléontoloque, 6:1-170.

1883. Faune du calcaire carbonifère de la Belgique, $4^{\mathrm{e}}$ partie: Gastéropodes (suite en fin). Annales du Musée Royale d'Historie de Belgique. Série Paléontoloque, 8:1-240.

De la Beche, H.T.

1831. Geological Manual. 535 pages. London: Treuttel and Würtz.

1832. Handbuch der Geognosie. Berlin: Privately published.

de Montfort, P.D

1810. Conchylioge systématique, et classification méthodique des coquilles. Paris.

de Queiroz, K.

1992. Phylogenetic Definitions and Taxonomic Philosophy. Biology and Philosophy, 7:295-313.

de Queiroz, K., and M.J. Donoghue

1988. Phylogenetic Systematics and the Species Problem. Cladistics, 4:317-338.

de Queiroz, K., and J. Gauthier

1990. Phylogeny as a Central Principle in Taxonomy: Phylogenetic Definitions of Taxon Names. Systematic Zoology, 39:307-322.

1992. Phylogenetic Taxonomy. Annual Review of Ecology and Systematics, 23:449-480

1994. Toward a Phylogenetic System of Biological Nomenclature. Trends in Frology and Evolution, 9:27-31

Donald, J.G.

1902. On Some of the Proterozoic Gasteropoda which Have Been Referred to Murchisonia and Pleurotomaria, with Descriptions of New Subgenera and Species. Quarterly Journal of the Geological Society of London, 58:313-339.

1905. Observations on Some of the Loxonematidae, with Descriptions of Two Species. Quarterly Journal of the Geological Society of London, 61:564-566.

1906. Notes on the Genera Omospira, Lophospira, and Turritoma: with Descriptions of New Proterozoic Species. Quarterly Journal of the Geological Society of London, 62:552 -572.

Donoghue, M.J., J.A. Doyle, J. Gauthier, A.G. Kluge, and T. Rowe

1989. The Importance of Fossils in Phylogeny Reconstruction. Annual Review of Ecology and Systematics, 20:431-460.

Dzik, J

1978. Larval Development of Hyolithids. Lethaia, 11:293-299.

1981. Larval Development, Musculature, and Relationships of Sinuitopsis and Related Baltic Bellerophonts. Norsk Geologisk Tidsskrift. 61:111-121.

1982. Larval Development and Relationships of Mimospira: A Presumably Hyperstrophic Ordovician Gastropod. Geologiska Föreningens i Stockholm Förhandlingar, 104:231-239.

1994. Evolution of 'Small Shelly Fossils' Assemblages. Acta Palaeontologica Polonica, 39:247-313. 
Eichwald, C.E. von

1859. Lethaea Rossica, ou Paléontologie de la Russie, I: L'ancienne période. 1562 pages. Stuttgart: E. Schweizerband.

Eldredge, N., and J. Cracraft

1980. Phylogenetic Patterns and the Evolutionary Process-Methods and Theory in Comparative Biology. 349 pages. New York: Columbia University Press.

Emmons, E.

1842. Comprising the Survey of the Second Geological District. In Natural History of New York, IV: Geology of New York, 2: 437 pages. Albany, New York: W. \& A. White and J. Visscher.

Endo, R.

1932. The Canadian and Ordovician Formations and Fossils of South Manchuria. Bulletin of the United States National Museum. 164 152 pages.

Erwin, D.H.

1988. The Genus Glyptospira (Gastropoda: Trochacea) from the Permian of the Southwestern United States. Journal of Paleontology, 88:868-879

1990a. Carboniferous-Triassic Gastropod Diversity Pattems and the Permo-Triassic Mass Extinction. Paleobiology, 16:187-203.

1990b. A Phylogenetic Analysis of Major Paleozoic Gastropod Clades [Abstract.] Geological Society of America, Abstracts with Programs, 22:A265.

1992. Morphometric and Phylogenetic Analyses of the Paleozoic Subulitoidea (Gastropoda). [Abstract.] In S. Lidgard and P.R. Crane, editors, Fifth North American Paleontological Convention, Abstracts and Program, page 93. Knoxville, Tennessee: The Paleontological Society.

Estabrook, G.F.

1986. Evolutionary Classification Using Convex Phenetics. Systematic Zoology, 35:560-570.

Etheridge, R., Jr.

1891. Further Descriptions of the Upper Silurian Fossils from the Lilydale Limestone, Upper Yarra District, Victoria. Records of the Australian Museum, 1:125-130.

Faith, D.P

1991. Cladistic Permutation Tests for Monophyly and Nonmonophyly. Systematic Zoology; 40:366-375.

Faith, D.P., and P.S. Cranston

1991. Could a Cladogram This Short Have Arisen by Chance Alone? On Permutation Tests for Cladistic Structure. Cladistics, 7:1-28.

Farris, J.S.

1969. A Successive Approximations Approach to Character Weighting. Systematic Zoology, 18:413-444.

1989. The Retention Index and the Rescaled Consistency lndex. Cladistics, 5:417-419.

1990. Phenetics in Camouflage. Cladistics, 6:91-100.

Felsenstein, J

1978. Cases in which Parsimony or Compatibility Methods Will Be Positively Misleading. Systematic Zoology, 27:401-410.

1981. Evolutionary Trees from Gene Frequencies and Quantitative Characters: Finding Maximum Likelihood Estimates. Evolution, 35: 1229-1242.

1985. Phylogenies and the Comparative Method. American Naturalist, 125:1-15.

1988. Phylogenies and Quantitative Characters. Annual Review of Ecology and Systematics, 19:445-471.

Fischer, P.H.

1885. Manuel de conchyliologie et de paléontologie conchyliologique, ou histoire naturelle des molluscques vivants et fossiles. Part 8, 1369 pages. Paris.

Fisher, D.C.

1991. Phylogenetic Analysis and Its Implication in Evolutionary Paleobiology. In N.L. Gilinsky and P.W. Signor, editors, Analytical Paleobi- ology, pages 103-122. Knoxville, Tennessee: The Paleontological Society.

1994. Stratocladistics: Morphological and Temporal Pattems and Their Relation to Phylogenetic Process. In L. Grande and O. Rieppel, editors, Interpreting the Hierarchy of Nature-From Systematic Patterns to Evolutionary Theories, pages 133-171. Orlando, Florida: Academic Press.

Flower, R.H

1968a. Part 1: Some El Paso Guide Fossils. New Mexico Institute of Mining and Technology, Memoir, 22:1-21.

1968b. Part Il: Fossils from the Smith Basin Limestone of the Fort Ann Region New York. New Mexico Institute of Mining and Technology, Memoir, 22:22-27.

Foerste, A.F

1893. Fossils of the Clinton Group in Ohio and Indiana. Report of the Geological Survey of Ohio, 7:516-597.

1914. Notes on the Lorraien Faunas of New York and the Province of Quebec. Bulletin of the Scientific Laboratories of Denison University, 17:247-328

1923. Notes on the Medinan, Niagaran, and Chester Fossils. Bulletin of the Scientific Laboratories of Denison University, 23:37-120.

1936. Silurian Cephalopods of the Port Daniel Area on Gaspé Peninsula, in Eastem Canada. Bulletin of the Scientific Laboratories of Denison University, 31:21-92.

Foote, M

1996. On the Probability of Ancestors in the Fossil Record. Paleobiolog: 22:141-151.

Foote, M., and D.M. Raup

1996. Fossil Preservation and the Stratigraphic Ranges of Taxa. Paleobiology, 22:121-140.

Fretter, V., and A. Graham

1962. British Prosobranch Mollusks, Their Function, Anatomy and Ecology. 755 pages. London: Ray Society.

Fryda, J., and K. Bandel

1997. New Early Devonian Gastropods from the Plectonotus (Boucotonotus)-Palaeozygopleura Community in the Prague Basin (Bohemia) Mitteilungen aus dem Geologisch-Paläontologischen Institut der Universität Hamburg, 80:1-57.

Gauthier, J., A.G. Kluge, and T. Rowe

1988. Amniote Phylogeny and the Importance of Fossils. Cladistics, $4: 105-209$.

Gayon, J.

1990. Critics and Criticisms of the Modern Synthesis-the Viewpoint of a Philosopher. Evolutionary Biologv, 24:1-49.

Ghiselin, M.T.

1966. The Adaptive Significance of Gastropod Torsion. Evolution, 20:337-348.

Goldfuss, G.A

1844. Petrefacta Germanie et ea, quae in Museuo Universitatis Regiae, Borussicae Frederischiae Wilhelmiae Rhenanae Servantur et alia quacungue in Museis Hueninghausiano. Muensteriano aliisque exstant, iconibus et descriptionnibus illustrata, part 3.128 pages. Dusseldorf.

Goldman, N.

1988. Methods for Discrete Coding of Morphological Characters for $\mathrm{Nu}$ merical Analysis. Cladistics, 4:59-71.

Goloboff, P.

1993. Estimating Character Weights during Tree Search. Cladistics, 9:83-91

Gordon, M., Jr., and E.L. Yochelson

1983. A Gastropod Fauna from the Cravenoceras hesperium Ammonoid Zone (Upper Mississippian) in East-Central Nevada. Journal of Paleontologv. 57:971-991.

Grabau, A.W.

1922. Ordovician Fossils of North China. Palaeontologia Sinica, series 
B, 1:1-98.

Gubanov, A.P., J.S. Peel, and I.A. Pianovskaya

1995. Soft-Sediment Adaptations in a Silurian Gastropod from Central Asia. Palaeontology, 38:831-842.

Gunderson, G.O.

1993. New Genus of Late Cambrian Gastropod. Journal of Paleontology, 67:1083-1084

Hall, J.

1847. Containing Descriptions of the Organic Remains of the Lower Division of the New York System (Equivalent of the Lower Silurian Rocks of Europe). In Natural History of New York, VI: Paleontology of New York, 1: 338 pages. Albany, New York: C. Van Benthuysen.

1859. Containing Descriptions and Figures of the Organic Remains of the Lower Helderberg Group and the Oriskany Sandstone. In Natural History of New York, VI: Paleontology of New York, 3: 532 pages. Albany, New York: C. Van Benthuysen.

1861. Descriptions of New Species of Fossils from the Upper Helderberg Hamilton, and Chemung Groups: With Observations upon Previously Described Species. Annual Report of the Regents of the University [of the State of New York] of the Condition of the State Cabinet of Natural History and the Historical and Antiquarian Collection Annexed Thereto, 14:99-109.

1868. Account of Some New or Little Known Species of Fossils from Rocks of the Age of the Niagara Group. Annual Report of the Regents of the University [of the State of New York] of the Condition of the State Cabinet of Natural History and the Historical and Antiquarian Collection Annexed Thereto, 20:305-352. [Preprint 1867.]

1872. Descriptions of New Species of Fossils from the Hudson River Group, in the Vicinity of Cincinnati, Ohio. Annual Report on the New York State Museum of Natural History by the Regents of the University of the State of New York, 24:225-232.

1879. Containing Descriptions of the Gasteropoda, Pteropoda, and Cephalopoda of the Upper Helderberg, Hamilton, Portage, and Chemung Groups. In Natural History of New York, VI: Paleontology of New York, 5(2): 492 pages. Albany, New York: C. Van Benthuysen.

Hall, J., and R.P. Whitfield

1872. Descriptions of New Species of Fossils from the Devonian Rocks of Iowa, with a Preliminary Note on the Formations. 724 pages.

Hall, J., and J.D. Whitney

1862. Report of the Geological Survey of the State of Wisconsin. Volume 1, pages 428-444. Madison: The Geological Survey of the State of Wisconsin.

Harland, W.B., R.L. Armstrong, A.V. Cox, L.E. Craig, A.G. Smith, and D.G. Smith

1990. A Geologic Time Scale 1989. 263 pages. Cambridge: Cambridge University Press.

Harper, J.A., and H.B. Rollins

1982. Recognition of Monoplacophora and Gastropoda in the Fossli Record: A Functional Morphological Look at the Bellerphont Controversy. In Bernard L. Mamet and M.J. Copeland, editors, Proceedings of the Third North American Paleontological Convention, pages 227-232.

Haszprunar, G.

1987. The Fine Structure of the Ctenidial Sense Organs (Bursicles) of Vetigastropoda (Zeugobranchia, Trochoidea) and Their Functional and Phylogenetic Significance. Journal of Molluscan Studies, 53:46-51.

1988. On the Origin and Evolution of Major Gastropod Groups, with Special Reference to the Streptoneura. Journal of Molluscan Studies, 54:367-441.

1989. New Slit-Limpets (Scissurellacea and Fissurellacea) from Hydrothermal Vents, Part 2: Anatomy and Relationships. Contributions in Science, Natural History Museum of Los Angeles County, 408:1-17.

Hauser, D.L., and W. Presch

1991. The Effect of Ordered Characters on Phylogenetic Reconstruction. Cladistics, 7:243-265.
Heller, R.L.

1954. Stratigraphy and Paleontology of the Roubidoux Formation of Missouri. 60 pages. Rolla, Missouri: State of Missouri Department of Business and Administration, Division of Geological Survey and Water Resources.

Hennig, W.

1969. Die Stammesgeschichte der Insekten. 200 pages. Frankfort: Waldemar Kramer.

Hickman, C.S.

1988. Archaeogastropod Evolution, Phylogeny and Systematics: A Reevaluation. In W.F. Ponder, editor, Prosobranch Phylogeny, Proceedings of the Ninth International Malacological Congress, pages 17-34. Edinburgh, Scotland: Malacological Review.

1996. Phylogeny and Patterns of Evolutionary Radiation in Trochoidean Gastropods. In J. Taylor, editor, Origin and Evolutionary Radiation of the Mollusca, pages 177-198. Oxford: Oxford University Press.

Hickman, C.S., and J.H. McLean

1990. Systematic Revision and Suprageneric Classification of Trochacean Gastropods. Science Series, Natural History Museum of Los Angeles County, 35: 95 pages.

Hillis, D.M., and J.P. Huelsenbeck

1992. Signal, Noise, and Reliability in Molecular Phylogenetic Analysis. Journal of Heredity, 83:189-195.

Hisinger, W. von

1829. Anteckningar i Physik och Geognosi under resor uti Sverige och Norrige. Volume 4. Stockholm.

Hoelzer, G.A., and D.J. Melnick

1994. Patterns of Speciation and Limits to Phylogenetic Resolution. Trends in Ecology and Evolution, 9:104-107.

Homý, R.J.

1952. Two New Representantives of the Family Murchisonidae Koken (Gastropoda) from the Silurian of Central Bohemia. Sbornik, Ustredniho Ustavu Geologického oddil Paleontologický, 19: 209-228.

1953. New Gastropods from the Silurian of Central Bohemia. Sbornik, Ustredniho Ustavu Geologického oddil Paleontologický, 20: 189-211.

1955. Palaeozygopleuridae nov. fam. (Gastropoda) ze stredočeskeho Devonu. Sbornik Ústredniho Ustavu Geologického oddil Paleontologickj, 21:17-74.

1962. Lower Paleozoic Belleropontina (Gastropoda) of Bohemia. Sbornik Geologickýck Vëd, 2:57-164.

1965. Cyrtolites Conrad, 1838 and 1ts Position among the Monoplacophora (Mollusca). Acta Musei Nationalis Pragae, 21(B):57-70.

1991. Shell Morphology and Muscle Scars of Sinuitopsis neglecta Pemer (Mollusca, Monoplacophora). Ćasopis Národniho Musea, Rada Prírodovēná, 157:81-105.

1992a. Lytospira Koken and Murchisonia (Hormotomina) Grabau et Shimer in the Lower Devonian of Bohemia. Casopis Národniho Musea, Řada Prírodovẽná, 160:55-56.

1992b. Muscle Scars in Sinuites (Mollusca, Gastropoda) from the Lower Ordovician of Bohemia. Ćasopis Národniho Musea, Ŕada Prirodovèná, 158:79-100.

1995a. Secondary Shell Deposits and Presumed Mode of Life in Sinuites (Mollusca, Gastropoda). Acta Musei Nationalis Pragae, Series B (Historia Naturalis), 51:89-103.

1995b. Adapertural Location of the Retractor Muscle Attachment Area in Oriostoma (Mollusca, Gastropoda): A Consequence of Mode of Life. Časopis Národniho Musea, Řada Pr̈irodovéná, 164:39-44.

Houbrick, R.S

1979. Classification and Systematic Relationships of the Abyssochrysidae, a Relict Family of Bathyal Snails (Prosobranchia: Gastropoda). Smithsonian Contributions to Zoology, 290: 21 pages.

1984. Revision of Higher Taxa in Genus Cerithidea (Mesogastropoda: Potamididae) Based on Comparative Morphology and Biological 
Data. American Malacological Bulletin, 2:1-20.

1988. Cerithioidean Phylogeny. In W.F. Ponder, editor, Prosobranch Phylogeny, Proceedings of the Ninth International Malacological Congress, pages 88-128. Edinburgh, Scotland: Malacological Review.

Huelsenbeck, J.P.

1991a. When are Fossils Better than Extant Taxa in Phylogenetic Analysis? Systematic Zoology, 40:458-469.

1991b. Tree-Length Distribution Skewness: An Indicator of Phylogenetic Information. Systematic Zoology, 40:257-270.

1994. Comparing the Stratigraphic Record to Estimates of Phylogeny. $\mathrm{Pa}$ leobiology, 20:470-483.

Huelsenbeck, J.P., and D.M. Hillis

1993. Success of Phylogenetic Methods in the Four-Taxon Case. Systematic Biology, 42:247-264.

Hughes, N.C.

1991. Morphological Plasticity and Genetic Flexibility in a Cambrian Trilobite. Geology, 19:913-916.

Jahn, J.J.

1894. Neue Thierreste aus dem böhmischen Silur. Jahrbuch der Kaiserlich-Köninglichen Geologischen Reichsanstalt, 44:381-388.

Janis, C.

1992. The 1mportance of Paraphyletic Groups in Mammalian Paleobiology. [Abstract.] In S. Lidgard and P.R. Crane, editors, Fifth North American Paleontology Convention. Abstracts and Program, page 148. Knoxville, Tennessee: The Paleontological Society.

Janvier, $\mathrm{P}$.

1984. Cladistics: Theory, Purpose, and Evolutionary Implications. In J.W Pollard, editor, Evolutionary Theory: Paths into the Future, pages 39-75. New York: John Wiley and Sons, Ltd.

Jung, $\mathrm{Y}$.

1992. Phylogenetic Relationships of Some Planorbid Genera (Gastropoda: Lymophila). Malacological Review, 25:73-192.

Källersjö, M., J.S. Farris, A.G. Kluge, and C. Bult

1992. Skewness and Permutation. Cladistics, 8:275-287.

Kase, T.

1989. Autecology of Labrocuspis, a Middle Devonian Omphalotrochid Gastropod. Lethaia, 22:149-157.

Kemp, P., and M.K. Bertness

1984. Snail Shape and Growth Rates: Evidence for Plastic Shell Allometry in Littorina littorea. Proceedings of the National Academy of Sciences, 81:811-813.

Kirk, E.

1927. Macluritella, a New Gasteropod Genus from the Lower Ordovician of Colorodo. American Journal of Science, 14:288-292.

1928. Bathmopterus, a New Fossil Gasteropod Genus from the Silurian of Alaska. Proceedings of the United States National Museum, 74(18) $1-4$.

1929. Mitrospira, a New Ordovician Gasteropod Genus. Proceedings of the United States National Museum, 76(22):1-6.

Kluge, A.G., and J.S. Farris

1969. Quantitative Phyletics and the Evolution of Anurans. Systematic Zoology, 18:1-32.

Knight, J.B

1934. The Gastropods of the St. Louis, Missouri, Pennsylvanian Outlier, VIII: The Turritellidae. Journal of Paleontology, 8:433-447.

1941. Paleozoic Gastropod Genotypes. Geological Society of America, Special Paper, 32:1-510.

1945. Some New Genera of Paleozoic Gastropoda. Journal of Paleontology, 19:573-587.

1948. Further New Cambrian Bellerophont Gastropods. Smithsonian Miscellaneous Collections, 111(3):1-6.

1952. Primitive Fossil Gastropods and Their Bearing on Gastropod Classification. Smithsonian Miscellaneous Collections, 117(13):1-56.

1956. New Families of Gastropoda. Journal of the Washington Academy of Sciences, 46:41-42.
Knight, J.B., R.L. Batten, and E.L. Yochelson

1954. Mollusca: Gastropoda. Bulletin of the Museum of Comparative Zoology, 112:173-179.

Knight, J.B., L.R. Cox, A.M. Keen, R.L. Batten, E. Yochelson, and R. Robertson

1960. Systematic Descriptions. In Raymond C. Moore, editor, Treatise on Invertebrate Paleontology, Part I, Mollusca (1): pages 169-324. Lawrence, Kansas: University of Kansas Press.

Kobayashi, T.

1934. The Cambro-Ordovician Formations and Faunas of South Chosen; Paleontology, Part 1: Middle Ordovician Faunas. Journal of the Faculty of Science, Imperial University of Tokyo, section 2, 3: 335-519.

1959. On Some Ordovician Fossils from Northem Malaya and Her Adjacence. Tokyo University, Faculty Science Journal, section 2, 11: $387-407$.

Koken, E.F.R.K.

1889. Ueber die Entwickelung der Gastropoden vom Cambrium bis zur Trias. Neues Jahrbuch für Mineralogie, Geologie und Paläontologie, 6:305-484.

1896. Die Leitfossilien. 846 pages. Leipzig.

1897. Die Gastropoden des baltischen Untersilurs. Bulletin de l'Académie Impériale des Sciences de St. Pétersburg, 7:97-214.

1898. Ueber untersilurische Gastropoden. Neues Jahrbuch für Mineralogie, Geologic und Paleontology unter Nitweking einer Anzahl von Fachgenossen. 1:1-25.

1925. Die Gastropoden des baltischen Untersilurs. 326 pages. Leningrad. Kool, S.P.

1993a. Phylogenetic Analysis of the Rapaninae (Neogastropoda: Muricidae). Malacologia, 35:155-259.

1993b. The Systematic Position of the Genus Nucella (Prosobranchia: Muricidae: Ocenbrinae). Nautilus, 107:43-57.

Lanyon, S.M

1985. Detecting Internal Inconsistencies in Distance Data. Systematic Zoology, 34:397-403.

Lecointre, G., H. Philippe, H.L. Ván Lé, and H. Le Guyader

1993. Species Sampling Has a Major Impact on Phylogenetic Inference. Molecular Phylogenetics and Evolution, 2:205-224.

Le Sueur, C.A.

1818. Observations on a New Genus of Fossil Shells. Journal of the Academy of Natural Sciences of Philadelphia, 1:310-313.

Léveillé, $\mathrm{C}$

1835. Aperçu géologiique de quelques localités très riches en coquilles sur les forntiers de France et de Belgique. Mémoires de la Société Géologique de France, 2:29-40.

Lindberg, D.R.

1988. The Patellogastropoda. In W.F. Ponder, editor, Prosobranch Phylogeny, Proceedings of the Ninth International Malacological Congress, pages 35-63. Edinburgh, Scotland: Malacological Review.

Lindström, $\mathrm{G}$.

1884. The Silurian Gastropoda and Pteropoda of Gotland. Kongliga Svenska Vetenskaps-akademiens Handlingar, 19:1-250.

Linsley, R.M

1968. Gastropods of the Middle Devonian Anderdon Limestone. Bulletins of American Paleontology, 54:333-465.

1973. The Omphalocirridae: A New Family of Palaeozoic Gastropoda which Exhibit Sexual Dimorphism. Memoirs of the National Museum of Victoria, 39:33-54.

1978. Locomotion Rates and Shell Form in the Gastropoda. Malacologia, 17:193-206.

1979. Gastropods of the Devonian. In M.R. House, C.T. Scrutton, and M.G. Bassett, editors, The Devonian System, pages 249-254. London: The Palaeontological Association.

Linsley, R.M., and W.M. Kier

1984. The Paragastropoda: A Proposal for a New Class of Paleozoic Mollusca. Malacologia, 25:241-254. 
Linsley, R.M., and E.L. Yochelson

1973. Devonian Carrier Shells (Euomphalidae) from North America and Germany. United States Geological Survey Professional Paper, 824: 23 pages.

Linsley, R.M., E.L. Yochelson, and D.M. Rohr

1978. A Reinterpretation of the Mode of Life of Some Paleozoic Frilled Gastropods. Lethaia, 11:105-112.

Longstaff, J.G.

1924. Descriptions of Gasteropoda, Chiefly in Mrs. Robert Gray's Collection, from the Ordovician and Lower Silurian of Girvan. Quarterly Journal of the Geological Society of London, 80:408-446.

M'Coy, F.

1851. On Some New Silurian Mollusca. Annals and Magazine of Natural History, Including Zoology, Botany, and Geology, second series, 7: 45-63.

Maddison, D.R.

1991. The Discovery and 1mportance of Multiple Islands of Most-Parsimonious Trees. Systematic Zoology, 40:315-328.

Maddison, W.P.

1993. Missing Data Versus Missing Characters in Phylogenetic Analysis. Systematic Biology, 42:576-581.

Maley, C., H. Robeck, and M. Donoghue

1997. Simulations of the Impact of Classification Systems on Diversity Patterns. [Abstract.] Geological Society of America, Abstracts with Program, 29:31.

Marshall, C.R.

1990. Confidence Intervals on Stratigraphic Ranges. Paleobiology, 16: $1-10$.

1994. Confidence Intervals on Stratigraphic Ranges: Partial Relaxation of the Assumption of Randomly Distributed Fossil Horizons. Paleobiology, 20:459-469.

McGhee, G.R., Jr.

1989. The Frasnian-Famennian Extinction Event. In S.K. Donovan, editor, Mass Extinctions-Processes and Evidence, pages 133-151. New York: Columbia University Press.

McKerrow, W.S., and L.R.S. Cocks

1986. Oceans, lsland Arcs and Olistostromes: The Use of Fossils in Distinguishing Sutures, Terranes and Environments around the lapetus

McLean, J.H. Ocean. Journal of the Geological Society, London, 143: 185-191.

1981. The Galapagos Rift Limpet Neomphalus: Relevance to Understanding the Evolution of a Major Paleozoic-Mesozoic Radiation. Malacologia, 21:291-336.

1989. New Archaeogastropod Limpets from Hydrothermal Vents: New Family Peltospiridae, New Superfamily Peltospiracea. Zoologica Scripta, 18:49-66.

1990. A New Genus and Species of Neomphalid Limpet from the Mariana Vents with a Review of Current Understanding of Relationships among Neomphalacea and Peltospiracea. Nautilus, 104: 77-86.

McLearn, F.H.

1924. Palaeontology of the Silurian Rocks of Arisaig, Nova Scotia. Geological Survey of Canada, Memoir. 137:1-124.

McNair, C.G., W.M. Kier, P.D. LaCroix, and R.M. Linsley

1981. The Functional Significance of Aperture Form in Gastropods. Lethaia, 14:63-70.

Meek, F.B.

1872. Descriptions of New Species of Invertebrate Fossils from the Carboniferous and Devonian Rocks of Ohio. Proceedings of the Academy of Natural Sciences of Philadelphia, 1871:159-184.

1873. Descriptions of Invertebrate Fossils of the Silurian and Devonian Systems. In Report of the Geological Survey of Ohio, volume 1, part 2 (Paleontology): pages 1-243.

Meek, F.B., and A.H. Worthen

1866. Descriptions of Invertebrates from the Carboniferous System. In Geological Survey of Illinois, volume 2 (Paleontology): pages $143-411$.
Michaux, B

1989. Cladograms Can Reconstruct Phylogenies: An Example from the Fossil Record. Alcheringa, 13:21-36.

Miller, S.A.

1877. The American Palaeozoic Fossils: A Catalogue of the Genera and Species. Second edition, 293 pages. Cincinatti.

1889. North American Geology and Palaeontology for the Use of Amateurs, Students, and Scientists. 718 pages. Cincinnati.

Morris, N.J.

1990. Early Radiation of the Mollusca. In P.D. Taylor and G.P. Larwood, editors, Major Evolutionary Radiations, pages 73-90. Oxford: Clarendon Press.

Morris, N.J., and R.J. Cleevely

1981. Phanerotinus cristatus (Phillips) and the Nature of Euomphalacean Gastropods, Molluscans. Bulletin of the British Museum (Natural History), Geology, 35:195-212.

Morris, P.J.

1991. Functional Morphology and Phylogeny: An Assessment of Monophyly in the Kingdom Animalia and Paleozoic Nearly-Planispiral Snail-Like Mollusks. 406 pages. Doctoral dissertation, Harvard University, Cambridge, Massachusetts.

Munier-Chalmas, E.

1876. Mollusques nouveux des terrains paléozoiques des environs de Rennes. Journal de Conchyliologie, third series, 16:102-109.

Murchison, R.1.

1839. The Silurian System. 768 pages. London: Geological Society of London.

Naef, A.

1911. Studien zur generellen Morphologie der Mollusken, Teil 1: Über Torsion und asymmetrie der Gastropoden. Ergebnisse und Fortschritte der Zoologie. 3:73-164.

Neuman, R.B.

1964. Fossils in the Ordovician Tuffs Northeastern Maine. Bulletin of the United States Geological Survey, 1181-E:E1-E38.

Neuman, R.B., and D.L. Bruton

1989. Brachiopods and Trilobites from the Ordovician Lower Hovin Group (Arenig/Llanvirn), Hølanda Area, Trondheim Region, Norway: New and Revised Taxa and Paleogeographic Interpretation. Norges Geologiske Undersokelse, 414:49-89.

Neuman, R.B., and D.A.T. Harper

1992. Paleogeographic Significance of Arenig-Llanvirn Toquima-Table Head and Celtic Brachiopod Assemblages. $\ln$ B.D. Webby and J.R. Laurie, editors, Global Perspectives on Ordovician Geology, pages 241-254. Rotterdam: Balkema.

Nixon, K.C., and Q.D. Wheeler

1990. An Amplification of the Phylogenetic Species Concept. Cladistics, 6:211-223.

O'Grady, R.T., G.B. Deets, and G.W. Benz

1989. Additional Observations on Nonredundant Linear Coding of Multistate Characters. Systematic Zoology, 38:54-57.

Oehlert, D.P.

1877. Sur le fossils dévoniens de départment de la Mayenne. Bulletin de la Société Géologique de France, series 3, 5:578-603.

1888. Descriptions de quelques espèces dévoniennes de département de la Mayenne. Bulletin de la Société d'Etudes Scientifiques d'Angers, 1887:65-120.

Okulitch, V.J.

1935. Fauna of the Black River Group in the Vicinity of Montreal. Canadian Field Naturalist, 49:96-107.

Palmer, A.R.

1985. Quantum Changes in Gastropod Shell Morphology Need Not Reflect Speciation. Evolution, 39:699-705.

Patterson, $\mathrm{C}$.

1994. Bony Fishes. In D.R. Prothero and R.M. Schoch, editors, Major Features of Vertebrate Evolution, pages 57-84. Knoxville: Tennes- 
see: The Paleontological Society.

Patterson, C., and D.E. Rosen

1977. Review of lcthyodectiform and Other Mesozoic Teleost Fishes and the Theory and Practice of Classifying Fossils. Bulletin of the American Museum of Natural History. 158:81-172.

Peel, J.S.

1975a. Arjamannia, a New Upper Ordovician-Silurian Pleurotomariacean Gastropod from Britain and North America. Palaeontology, 18: 385-390.

1975b. A New Silurian Gastropod from Wisconsin and the Ecology of Uncoiling in Paleozoic Gastropods. Bulletin of the Geological Society of Denmark, 24:211-221.

1977. Systematics and Palaeontology of the Silurian Gastropods of the Arisaig Group. Kongelige Danske Videnskabernes Selskab. Biologiske Skrifter, 21:1-89.

1979. Revision of Ordovician-Silurian Gastropods from North Greenland Rapport Gronlands Geologische Underschrift, 91:61-70.

1984a. Autecology and Systematics of a New Silurian Anomphalid Gastropod from Western Greenland. Rapport Gronlands Geologiske Undersogelse, 121:77-87.

1984b. Pseudoscalites (Gastropoda; Pleurotomariacea) from the Silurian of Gotland. Geologiska Föreningens i Stockholm Förhandlingar. 105:371-374.

1991a. The Classes Tergomya and Helcionelloida, and Early Molluscan Evolution. Gronlands Geologiske Undersogelse Bulletin, 161: $11-65$.

1991b. Functional Morphology of the Class Helcionelloida nov., and the Early Evolution of the Mollusca. In A. Simonetta and S. Conway Morris, editors, The Early Evolution of the Metazoa and the Significance of Problematic Taxa, pages 157-177. Cambridge: Cambridge University Press.

1991c. Salpingostoma and Related Bellerophontacean Gastropods from Greenland and the Baltic Region. Gronlands Geologiske Undersogelse Bulletin, 161:67-116.

1993. Muscle Scars and Mode of Life of Carinaropsis (Bellerophontoidea, Gastropoda) from the Ordovician of Tennessee. Journal of Paleontology, 67:528-523.

Peel, J.S., and E.L. Yochelson

1976. Two New Gastropod Genera from the Lower Silurian of the Oslo Region, Norway. Norsk Geologisk Tidsskrift, 56:15-27.

Perner, J.

1903. Patellidae et Bellerophontidae. In J. Barrandé, Systême Silurien du Centre de la Bohême, volume 4 (Gastéropodes), 1: 164 pages. Prague.

1907. Pleurotomaridae et Murchisonidae. In J. Barrandé, Systême Silurien du Centre de la Bohême, volume 4 (Gastéropodes), 2: 380 pages. Prague.

Phillips, J.

1841. Figures and Descriptions of the Palaeozoic Fossils of Cornwall. Devon, and West Somerset; Observed in the Course of the Ordinance Geological Survey of that District. 231 pages. London: Geological Society of London.

Pimentel, R.A., and R. Riggins

1987. The Nature of Cladistic Data. Cladistics, 3:201-209.

Pitcher, B.L.

1939. The Upper Valentian Gastropod Fauna of Shropshire. Annals and Magazine of Natural History, series 11, 4:82-132.

Pojeta, J.J.

1980. Molluscan Phylogeny. Tulane Studies in Geology and Paleontology, 16:55-80.

Ponder, W.F.

1984. A Review of the Genera of the Iravadiidae (Gastropoda: Rissoacea) with an Assessment of the Relationships within the Family. Malacologia, 25:21-71.

1990a. The Anatomy and Relationships of a Marine Valvatoidean (Gas- tropoda: Heterobranchia). Journal of Molluscan Studies, 56: 533-555.

1990b. The Anatomy and Relationships of the Orbitestellidae (Gastropoda: Heterobranchia). Journal of Molluscan Studies, 56: 515-532.

Ponder, W.F., and D.R. Lindberg

1996. Gastropod Phylogeny-Challenges for the 90s. In J. Taylor, editor, Origin and Evolutionary Radiation of the Mollusca, pages 135-154. Oxford: Oxford University Press.

1997. Towards a Phylogeny of Gastropod Molluscs: An Analysis Using Morphological Characters. Zoological Journal of the Linnean Society, 83-265.

Portlock, J.E

1843. Report on the Geology of the County of Londonderry and of Parts of Tyrone and Fermanagh. 784 pages. Dublin.

Purdue, A.H

1916. Eureka Springs-Harrison Folio, Arkansas-Missouri. Washington, D.C.: United States Geological Survey, Geological Atlas of the United States.

Purvis, A., S. Nee, and P.H. Harvey

1995. Macroevolutionary Inferences from Primate Phylogeny. Proceedings of the Royal Society of London, series B, 260:329-333.

Raup, D.M.

1966. Geometric Analysis of Shell Coiling: General Problems. Journal of Paleontology, 40:1178-1190.

1975. Taxonomic Diversity Estimation Using Rarefaction. Paleobiology, 1:333-342.

Raup, D.M., and S.J. Gould

1974. Stochastic Simulation and Evolution of Morphology-Towards a Nomothetic Paleontology. Systematic Zoology, 23:305-322.

Raymond, P.E.

1908. The Gastropoda of the Chazy Formation. Annals of the Carnegie Museum, 4:168-225.

Reid, D.G.

1989. The Comparative Morphology, Phylogeny and Evolution of the Gastropod Family Littorinidae. Philosophical Transactions of the Royal Society of London. series B, 324:1-110.

Remelé, A

1888. Ueber einige Glossophoren aus Untersilur-Schieben des norddeuthschen Diluviums. Zeitschrift der Deutschen Geologischen Gesellschaft, 40:666-670.

Roemer, C.F. von

1876. Lethaea geognostica, oder Beschreibung und Abbildung der für die Gebirgs-Formationen bezeichnendsten Versteinerungen, 1: Lethaea Palaeozoica. 323 pages. Stuttgart.

Roemer, F.A.

1854. Beiträge zur geologischen Kenntniss des nordwestlichen Harzgebirges. Palaeontographica, 5:1-44.

Rohr, D.M.

1980. Ordovician-Devonian Gastropoda from the Klamath Mountains, California. Palaeontographica, Abteilung A, 171:141-199.

1988. Upper Ordovician Gastropods from the Seward Peninsula, Alaska. Journal of Paleontology, 62:551-566.

1993. Middle Ordovician Carrier Shell Lytospira (Mollusca, Gastropoda) from Alaska. Journal of Paleontology, 67:959-962.

1994. Ordovician (Whiterockian) Gastropods of Nevada: Bellerophontoidea, Macluritoidea, and Euomphaloidea. Journal of Paleontology, 68:473-486.

1996. Ordovician (Whiterockian) Gastropods of Nevada, Part 2. Journal of Paleontology, 70:56-63.

Rohr, D.M., and R.B. Blodgett

1985. Upper Ordovician Gastropoda from West-Central Alaska. Journal of Paleontology, 59:667-673.

1988. First Occurrence of Helicotoma Salter (Gastropoda) from the Ordovician of Alaska. Journal of Paleontology. 62:304-306. 
Rohr, D.M., R.B. Blodgett, and W.M. Furnish

1992. Maclurina manitobensis (Whiteaves) (Ordovician Gastropoda): The Largest Known Paleozoic Gastropod. Journal of Paleontology, 66: 880-884

Rohr, D.M., J.T. Dutro, Jr., and R.B. Blodgett

1992. Gastropods and Brachiopods from the Ordovician Telsitna Formation, Northern Kuskokwim Mountains, West-Central Alaska. In B.D. Webby and J.R. Laurie, editors, Global Perspectives on Ordovician Geology, pages 499-512. Rotterdam: Balkema.

Rohr, D.M., and R.W. Huddleston

1982. Yochelsoniella, nom. nov., a New Name for Ellisella, Rohr, 1980 (Gastropoda) non Gray, 1858 (Coelenterata). Proceedings of the Biological Society of Washington, 95:269.

Rohr, D.M., and R.A. Johns

1990. First Occurrence of Oriostoma (Gastropoda) from the Middle Ordovician. Journal of Paleontology, 64:732-735.

Rohr, D.M., B.S. Norford, and E.L. Yochelson

1995. Stratigraphically Significant Early and Middle Ordovician Gastropod Occurrences, Western and Northwestern Canada. Journal of Paleontology, 69:1047-1053.

Rohr, D.M., and J. Packard

1982. Spine-Bearing Gastropods from the Silurian of Canada. Journal of Paleontology, 56:324-334.

Rohr, D.M., and A.W. Potter

1987. Rousseauspira: New Gastropod Operculum from the Ordovician of Alaska and California. Journal of Paleontology, 61:284-289.

Rosenberg, G., G.S. Kuncio, G.M. Davis, and M.G. Harasewych

1994. Preliminary Ribosomal RNA Phylogeny of Gastropod and Unionoidean Bivalve Mollusks. Nautilus, Supplement. 2:111-121.

Rosov, S.N.

1975. A New Order of the Monoplacophora. Paleontological Journal, 1975:39-43.

Runnegar, B.

1981. Muscle Scars, Shell Form and Torsion in Cambrian and Ordovician Univalved Molluscs. Lethaia, 14:311-322.

1996. Early Evolution of the Mollusca: The Fossil Record. In J.D. Taylor, editor, Origin and Evolutionary Radiation of the Mollusca, pages 77-87. Oxford: Oxford University Press.

Runnegar, B., and J.J. Pojeta, Jr.

1974. Molluscan Phylogeny: The Paleontological Viewpoint. Science, 186:311-317.

1985. Origin and Diversification of the Mollusca. In E.R. Trueman and M.R. Clarke, editors, Mollusca 10-Evolution, pages 1-57. Orlando, Florida: Academic Press, Inc.

Salter, J.W.

1859. Figures and Descriptions of Canadian Organic Remains. 47 pages. Montreal: J. Lowell, Printer.

1866. On the Fossils of North Wales. In A.C. Ramsay, editor, The Geology of North Wales, pages 239-381. London: Geological Survey of Great Britain.

Salvini-Plawen, L.v., and G. Haszprunar

1987. The Vetigastropoda and the Systematics of Streptoneurous Gastropoda. Journal of Zoology, London, series A, 211:747-770

Sanderson, M.J., and G. Bharathan

1993. Does Cladistic Information Affect Inferences about Branching Rates? Systematic Biology, 42:1-17.

Sanderson, M.J., and M.J. Donoghue

1989. Patterns of Variation in Levels of Homoplasy. Evolution, 43: 1781-1795.

Sarderson, F.W

1896. The Fauna of the Magnesian Series. Bulletin of the Minnesota Academy of Science, 4:92-105.

Schaeffer, S.A., and G.V. Lauder

1986. Historical Transformation of Functional Design: Evolutionary Morphology of Feeding Mechanisms in Loricarioid Catfishes. Systematic Zoology, 35:489-508.
Schindel, D.E.

1990. Unoccupied Morphospace and the Coiled Geometry of Gastropods: Architectural Constraint or Geometric Covariation? In R.M. Ross and W.D. Allmon, editors, Causes of Evolution-A Paleontological Perspective, pages 270-304. Chicago: The University of Chicago Press.

Schlotheim, E.F. von

1820. Die Petrefactenkunde auf ihrem jetzigen Standpunkte durch die Beschreibung seiner Sammlung versteinerter und fossiler Überreste des Thier- und Pflanzernreichs der Vorwelt erläutert. 457 pages. Gotha.

Schlüter, C.A.J.

1894. Ueber einige neue Fossilien des rheinischen Devon. Verhandlungen des Naturhistorischen Vereins der Preussischen Rheinlande, und Westfalens, 51:63-69.

Scotese, C.R.

1989. Phanerozoic Reconstructions: A New Look at the Assembly of Asia. Phanerozoic Mapping Project Progress Report, 19:1-10.

Sedgwick, A., and F. M'Coy

1852. A Synopsis of the Classification of the British Paleozoic Rocks (Sedgwick) with a Systematic Description of the British Paleozoic Fossils in the Geological Museum of the University of Cambridge $\left(M^{\circ} \mathrm{Coy}\right) .500$ pages. London: Cambridge University.

Sepkoski, J.J., Jr

1987. Reply to C. Patterson and A.B. Smith "ls the Periodicity of Extinctions a Taxonomic Artefact?" Nature, 330:252.

Sepkoski, J.J., Jr., and D.C. Kendrick

1993. Numerical Experiments with Model Monophyletic and Paraphyletic Taxa. Paleobiology, 19:168-184.

Signor, P.W.

1982. Influence of Shell Shape on Burrowing Rates in Infaunal Turritelliform Snails. In B. Mamet and M.J. Copeland, editors, Proceedings of the Third North American Paleontological Convention, pages 483-487. Montreal: Geological Survey of Canada.

Simpson, G.G.

1961. Principles of Animal Taxonomy. 247 pages. New York: Columbia University Press.

Skelton, R.R., and H.M. McHenry

1992. Evolutionary Relationships among Early Hominids. Journal of Human Evolution, 23:309-329.

Smith, A.B.

1989. RNA Sequence Data in Phylogenetic Reconstruction: Testing the Limits of Its Resolution. Cladistics, 5:321-344.

1994. Systematics and the Fossil Record-Documenting Evolutionary Patterns. 223 pages. Oxford: Blackwell Scientific Publications.

Sober, E.

1988. Reconstructing the Past. 265 pages. Cambridge, Massachusetts: Massachusetts Institute of Technology Prcss.

Sokal, R.R., and F.J. Rohlf

1981. Biometry. Second edition, 859 pages. New York: W.H. Freeman and $\mathrm{Co}$.

Sowerby, J.d.C.

1814. The Mineral Conchology of Great Britain. Volumes 9, 10. London.

Spitz, A.

1907. Die Gastropoden des Karnischen Unterdevon: Beiträge zur Paläontologie und Geologie Österreich-Ungarns und des Orients. Mitteilungen aus dem Geologischen und Paläontologischen Institute der Universität Wein, 20:115-190.

Spriesterbach, J.

1919. Neue Versteinerungen aus dem Lenneschiefer. Jahrbuch der Königlich Preussischen Geologischen Landesanstalt zu Berlin für das Jahr 1917, 38:434-512.

Stauffer, C.R

1937. A Diminutive Fauna from the Shakopee Dolomite (Ordovician) at Cannon Falls, Minnesota. Journal of Paleontology, 11:55-60. 
Steele, H.M., and G.W. Sinclair

1971. A Middle Ordovician Fauna from Braeside, Ottawa Valley, Ontario Bulletin of the Geological Survey of Canada, 211:1-96.

Stoyanow, A.

1948. Molluscan Faunule from Devonian Island Mesa Beds, Arizona. Journal of Plaeontology. 22:783-791.

Strauss, D., and P.M. Sadler

1989. Classical Confidence Intervals and Bayesian Probability Estimates for Ends of Local Taxon Ranges. Mathematical Geology, 21 : $411-427$.

Suter, S.J.

1994. Cladistic Analysis of Cassiduloid Echinoids: Trying to See the Phylogeny for the Trees. Biological Journal of the Linnean Society, 53: 31-72.

Swofford, D.L.

1993. PAUP: Phylogenetic Analysis Using Parsimony, Version 3.1.1. Champaign, Illinois: Illinois Natural History Survey.

Swofford, D.L., and W.P. Maddison

1987. Reconstructing Ancestral Character States under Wagner Parsimony. Mathematical Biosciences, 87:119-229.

Swofford, D.L., and G.J. Olsen

1990. Phylogeny Reconstruction. In D.M. Hillis and G. Moritz, editors, Molecular Systematics, pages 411-501. Sunderland: Sinauer Associates.

Tassell, C.B.

1979. Gastropods from the Early Devonian Bell Point Limestone, Cape Liptrap Penninsula, Victoria. Memoirs of the Natural History Museum of Victoria, 30:19-32.

Teichert, C.

1988. Main Features of Cephalopod Evolution. In M.R. Clarke and E.R. Trueman, editors, The Mollusca II-The Paleontology and Neontology of Cephalopods, pages 11-75. Orlando: Academic Press.

Thiele, K., and P.Y. Ladiges

1988. A Cladistic Analysis of Angophora Cav. (Myrtaceae). Cladistics, 4: $2 i-42$.

Thorpe, R.S.

1984. Coding Morphometric Characters for Constructing Distance Wagner Networks. Evolution, 38:244-255.

Tillier, S., M. Masselot, H. Philippe, and A. Tillier

1992. Phylogénie moléculaire des Gastropoda (Mollusca) fondée sur le séquençage partiel de l'ARN ribosomique 28S. Compte Rendu de Académie des Sciences, 314:79-85.

Tracey, S., J.A. Todd, and D.H. Erwin

1993. Mollusca: Gastropoda. In M.J. Benton, editor, The Fossil Record 2, pages 131-167. London: Chapman and Hall.

Ulrich, E.O.

1911. Revision of the Paleozoic Systems. Bulletin of the Geological Society of America, 22:281-680.

Ulrich, E.O., A.F. Foerste, and J. Bridge

1930. Systematic Paleontology. In J. Bridge, editor, Geology of the Eminence and Cardareva Quadrangles, pages 186-225. Missouri Geological Survey and Water Resources.

Ulrich, E.O., and W.H. Scofield

1897. The Lower Silurian Gastropoda of Minnesota. In The Geology of Minnesota, volume 3, part 2 (Paleontology): pages 813-1081.

van den Beggelaar, J.A.M.

1993. Cleavage Pattem in Embryos of Haliotis tuberculata (Archaeogastropoda) and Gastropod Phylogeny. Journal of Morphology, 216: 121-139.

Vanuxem, $\mathrm{L}$.

1842. Comprising the Survey of the Third Geological District. In Natural Van Valen, $L$. History of New York, IV: Geology of New York, 3: 306 pages.

1978. Why Not To Be a Cladist. Evolutionary Theory, 3:285-299.
Vostokova, V.A.

1955. Gastropoder från Ordovicium i Leningrads-trakten och Baltikum. Voprosy Paleontologii, 2:82-124.

Wagner, P.J.

1990. Phylogenetic Analysis of the Lophospiridae (Gastropoda: Pleurotomariina) of the Ordovician and Silurian. 130 pages. Master's thesis, Michigan State University, Lansing, Michigan.

1995a. Stratigraphic Tests of Cladistic Hypotheses. Paleobiology, 21: 153-178.

1995b. Testing Evolutionary Constraint Hypotheses: Examples with Early Paleozoic Gastropods. Paleobiology, 21:248-272.

1995c. Diversification among Early Paleozoic Gastropods-Contrasting Taxonomic and Phylogenetic Data. Paleobiology, 21:410-439.

1995d. The Generation and Maintenance of Morphologic and Phylogenetic Diversity among Early Gastropods. 533 pages. Doctoral dissertation, University of Chicago, Chicago, Illinois.

1996. Morphologic Diversification of Early Paleozoic "Archaeogastropods." In J.D. Taylor, editor, Origin and Evolutionary Radiation of the Mollusca, pages 161-169. Oxford: Oxford University Press.

1998. A Likelihood Approach for Estimating Phylogenetic Relationships among Fossil Taxa. Paleobiology, 24:430-449.

1999. Phylogenetics of Ordovician-Silurian Lophospiridae (Gastropoda: Murchisoniina): The Importance of Stratigraphic Data. American Malacological Bulletin, 15:1-31.

2000. The Quality of the Fossil Record and the Accuracy of Phylogenetic Inferences about Sampling and Diversity. Systematic Biology, 49: $2 i-42$.

Wagner, P.J., and D.H. Erwin

1995. Phylogenetic Tests of Speciation Hypotheses. In D.H. Erwin and R.L. Anstey, editors, New Approaches to Studying Speciation in the Fossil Record, pages 87-122. New York: Columbia University Press.

Wahlenberg, G.

1821. Petrificata telluris svecanae examinata. Uppsala: Acta Societatis Regiae Scientarium

Wahlman, G.P.

1992. Middle and Upper Ordovician Symmetrical Univalved Molluscs (Monoplacophora and Bellerophontina) of the Cincinnati Arch Region. United States Geological Survey Professional Paper, 1066-O: 213 pages.

Wake, D.B., and G. Roth

1989. The Linkage between Ontogeny and Phylogeny in the Evolution of Complex Systems. In D.B. Wake and G. Roth, editors, Complex Organismal Functions: Integration and Evolution in Vertebrates. pages 361-377. New York: John Wiley and Sons, Ltd.

Walcott, C.D

1884. Paleontology of the Eureka District, Nevada. United States Geological Survey, Monograph, 8:1-298.

1924. Cambrian Geology and Paleontology, 11: No. 9, New York Potsdam-Hoyt Fauna. Smithsonian Miscellaneous Collections, 75 (2136): 1-51.

Wängberg-Eriksson, $\mathrm{K}$.

1964. Isospira reticulata n. sp. from the Upper Ordovician Boda Limestone, Sweden. Geologiska Föreningens i Stockholm Förhandlingar. 86:229-237.

1979. Macluritacean Gastropods from the Ordovician and Silurian of Sweden. Sveriges Geologiska Undersökning, series C, 758(72):1- 33.

Webers, G.F., J.J. Pojeta, Jr., and E.L. Yochelson

1992. Cambrian Mollusca from the Minaret Formation, Ellsworth Mountains, West Antarctica. Geological Society of America, Memoir, 170:181-248.

Webers, G.F., and E.L. Yochelson

1989. Late Cambrian Molluscan Faunas and the Origin of the Cephalopoda. In J.A. Crame, editor, Origins and Evolution of the Antarctic Biota, pages 29-42. Special Publications of the Geological Society of London. 
Weller, S., and S. St. Clair

1928. Geology of Ste. Genevieve County, Missouri. Missouri Bureau of Geology and Mines, 2nd series, 22:1-352.

Wenz, W.

1938. Gastropoda. 240 pages. Berlin: Bonntraeger

Whiteaves, J.F.

1890. Descriptions of Eight New Species of Fossils from the Cambro-Silurian Rocks of Manitoba. Transactions of the Royal Society of Canada, 7:75-83.

1895. Revision of the Fauna of the Guelph Formation of Ontario, with Descriptions of a Few New Species. Palaeozoic Fossils, 3:45-109.

Whitfield, R.P.

1882. Paleontology. In Geology of Wisconsin, 4(3):163-363. Wisconsin Geological Survey.

1886. Notice of Geological lnvestigations along the Eastern Shore of Lake Champlain, Conducted by Prof. H.J. Seely and Pres. Ezra Brainerd, of Middlebury College, with Descriptions of the New Fossils Dis covered. Bulletin of the American Museum of Natural History, 1: 24-35.

Wiley, E.O.

1979. An Annotated Linnaean Hierarchy, with Comments on Natural Taxa and Competing Systems. Systematic Zoology, 28:308-337.

Wilson, A.E.

1921. The Range of Certain Lower Ordovician Faunas of the Ottawa Valley with Descriptions of Some New Species. Geological Survey of Canada, Museum Bulletin, 33:19-57.

1924. A New Genus and a New Species of Gastropod from the Upper Ordovician of British Columbia. Canadian Natural History, 1: 81-114.

Wingstrand, K.G.

1985. On the Anatomy and Relationships of Recent Monoplacophora. Galathea Report, 16:1-94.

Yin, H.-F., and E.L. Yochelson

1983. Middle Triassic Gastropoda from Qingyan, Ghizhou Province, China, 3: Euomphalacea and Loxonematacea. Journal of Paleontol ogy, 57:1098-1127.

Yochelson, E.L.

1963. The Middle Ordovician of the Oslo Region, Norway. Norsk Geologisk Tidsskrift, 43:133-213.

1966a. An Operculum Associated with the Ordovician Gastropod Helicotoma. Journal of Paleontology, 40:3.

1966b. A Reinvestigation of the Middele Devonian Gastropoda Arctomphalus and Omphalocirrus. Arsbok, Norsk Polarinstitutt, 1965: $37-48$.

1967. Quo vadis, Bellerophon? In C. Teichert and E.L. Yochelson, editors, Essays in Paleontology and Stratigraphy, pages 141-161. Lawrence, Kansas: University of Kansas Press.

1968. Tremadocian Mollusks from the Nochixtlán Region, Oaxaca, Mexico. Journal of Paleontology, 42:801-803.

1971. A New Late Devonian Gastropod and lts Bearing on Problems of Open Coiling and Septation. In J.T. Dutro, Jr., editor, Paleozoic Perspectives: A Paleontological Tribute to G. Arthur Cooper.
Smithsonian Contributions to Paleobiology, 3:231-241.

1973. The Late Early Ordovician Gastropod Ceratopea in the Arbuckle Mountains, Oklahoma. Oklahoma Geology Notes, 33:67-78.

1975. Early Ordovician Gastropod Opercula and Epicontinental Seas. United States Geological Survey, Journal of Research, 3:447-450.

1982. Mollusques monoplacopheres et gastropodes. In C. Babin, R. Courtessole, M. Melour, J. Pillet, D. Vizcaino, and E.L. Yochelson, editors, Brachiopodes (Articules) et Mollusques (Bivalves, Rostroconches, Monoplacophores, Gastropodes) de l'Ordovicien Inferieur (Tremadocien-Arenigien) de la Montagne Noire (France Meridionale), pages 51-63. Carcasgonne: Mémoire de la Société des Etudes Scientifiques de l'Aude.

1984. Historic and Current Considerations for Revision of Paleozoic Gastropod Classification. Journal of Paleontology, 58:259-269.

1990. Billings' Second Operculum: A Late Early Ordovician Maclurites (Gastropoda) from Westem Newfoundland and the Canadian Arctic. Canadian Journal of Earth Sciences, 27:669-676.

Yochelson, E.L., and J. Bridge

1957. The Lower Ordovician Gastropod Ceratopea. United States Geological Survey Professional Paper, 294-H:281-304.

Yochelson, E.L., and M.J. Copeland

1974. Taphonomy and Taxonomy of the Early Ordovician Gastropod Ceratopea canadensis (Billings), 1865. Canadian Journal of Earth Sciences, 11:189-207.

Yochelson, E.L., R.H. Flower, and G.F. Webers

1973. The Bearing of the New Late Cambrian Monoplacophoran Genus Knightoconus on the Origin of the Cephalopoda. Lethaia, 6: 275-310.

Yochelson, E.L., and C.R. Jones

1968. Teiichispira, a New Early Ordovician Gastropod Genus. United States Geological Survey Professional Paper, 613: 15 pages.

Yochelson, E.L., and R.M. Linley

1972. Opercula of Two Gastropods from the Lilydale Limestone (Early Devonian) of Victoria, Australia. Memoirs of the National Museum of Victoria, 33:1-14.

Yochelson, E.L., and B.W. Saunders

1967. A Bibliographic Index of North American Late Paleozoic Hyolitha, Amphineura, Scaphopoda, and Gastropoda. Geological Survey Bulletin, 1210:1-271.

Yochelson, E.L., and B.L. Stinchcomb

1987. Recognition of Macluritella (Gastropoda) from the Upper Cambrian of Missouri and Nevada. Journal of Paleontology, 61:56-61.

Yochelson, E.L., and O.A. Wise, Jr.

1972. A Life Association of Shell and Operculum in the Early Ordovician Gastropod Ceratopea unguis. Journal of Paleontology, 46: 681-684.

Yü, W.

1961. Some Lower Ordovician Gastropods from Zhuozishan Districh, Inner Mongolia. Acta Paleonotologica Sinica, 1:30-37.

1993. Early Ordovician Gastropods from the Canning Basin, Western Australia. Records of the Western Australian Museum, 16:437-458. 




\section{REQUIREMENTS FOR SMITHSONIAN SERIES PUBLICATION}

Manuscripts intended for series publication receive substantive review (conducted by their originating Smithsonian museums or offices) and are submitted to the Smithsonian Institution Press with Form SI-36, which must show the approval of the appropriate authority designated by the sponsoring organizational unit. Requests for special treatment-use of color, foldouts, case-bound covers, etc.-require, on the same form, the added approval of the sponsoring authority.

Review of manuscripts and art by the Press for requirements of series format and style, completeness and clarity of copy, and arrangement of all material, as outlined below, will govern, within the judgment of the Press, acceptance or rejection of manuscripts and art.

Copy must be prepared on typewriter or word processor, double-spaced, on one side of standard white bond paper (not erasable), with $1 \frac{1 / 4^{\prime \prime}}{}$ margins, submitted as ribbon copy (not carbon or xerox), in loose sheets (not stapled or bound), and accompanied by original art. Minimum acceptable length is 30 pages.

Front matter (preceding the text) should include: title page with only title and author and no other information; abstract page with author, title, series, etc., following the established format; table of contents with indents reflecting the hierarchy of heads in the paper; also, foreword and/or preface, if appropriate.

First page of text should carry the title and author at the top of the page; second page should have only the author's name and professional mailing address, to be used as an unnumbered footnote on the first page of printed text.

Center heads of whatever level should be typed with initial caps of major words, with extra space above and below the head, but no other preparation (such as all caps or underline, except for the underline necessary for generic and specific epithets). Run-in paragraph heads should use period/dashes or colons as necessary.

Tabulations within text (lists of data, often in parallel columns) can be typed on the text page where they occur, but they should not contain rules or numbered table captions.

Formal tables (numbered, with captions, boxheads, stubs, rules) should be submitted as carefully typed, double-spaced copy separate from the text; they will be typeset unless otherwise requested. If camera-copy use is anticipated, do not draw rules on manuscript copy.

Taxonomic keys in natural history papers should use the aligned-couplet form for zoology and may use the multi-level indent form for botany. If cross referencing is required between key and text, do not include page references within the key, but number the keyed-out taxa, using the same numbers with their corresponding heads in the text.

Synonymy in zoology must use the short form (taxon, author, year:page), with full reference at the end of the paper under "Literature Cited." For botany, the long form (taxon, author, abbreviated journal or book title, volume, page, year, with no reference in "Literature Cited") is optional.

Text-reference system (author, year:page used within the text, with full citation in "Literature Cited" at the end of the text) must be used in place of bibliographic footnotes in all Contributions Series and is strongly recommended in the Studies Series: "(Jones, 1910:122)" or "...Jones (1910:122)." If bibliographic footnotes are required, use the short form (author, brief title, page) with the full citation in the bibliography.

Footnotes, when few in number, whether annotative or bibliographic, should be typed on separate sheets and inserted immediately after the text pages on which the references occur. Extensive notes must be gathered together and placed at the end of the text in a notes section.

Bibliography, depending upon use, is termed "Literature Cited," "References," or "Bibliography." Spell out titles of books, articles, journals, and monographic series. For book and article titles use sentence-style capitalization according to the rules of the language employed (exception: capitalize all major words in English). For journal and series titles, capitalize the initial word and all subsequent words except articles, conjunctions, and prepositions. Transliterate languages that use a non-Roman alphabet according to the Library of Congress system. Underline (for italics) titles of journals and series and titles of books that are not part of a series. Use the parentheses/colon system for volume (number):pagination: "10(2):5-9." For alignment and arrangement of elements, follow the format of recent publications in the series for which the manuscript is intended. Guidelines for preparing bibliography may be secured from Series Section, SI Press.

Legends for illustrations must be submitted at the end of the manuscript, with as many legends typed, double-spaced, to a page as convenient.

Illustrations must be submitted as original art (not copies) accompanying, but separate from, the manuscript. Guidelines for preparing art may be secured from the Series Section, SI Press. All types of illustrations (photographs, line drawings, maps, etc.) may be intermixed throughout the printed text. They should be termed Figures and should be numbered consecutively as they will appear in the monograph. If several illustrations are treated as components of a single composite figure, they should be designated by lowercase italic letters on the illustration; also, in the legend and in text references the italic letters (underlined in copy) should be used: "Figure 9b." Illustrations that are intended to follow the printed text may be termed Plates, and any components should be similarly lettered and referenced: "Plate 9 b..$"$ Keys to any symbols within an illustation should appear on the art rather than in the legend.

Some points of style: Do not use periods after such abbreviations as "mm, $f$, USNM, NNE." Spell out numbers "one" through "nine" in expository text, but use digits in all other cases if possible. Use of the metric system of measurement is preferable; where use of the English system is unavoidable, supply metric equivalents in parentheses. Use the decimal system for precise measurements and relationships, common fractions for approximations. Use day/month/ year sequence for dates: "9 April 1976." For months in tabular listings or data sections, use three-letter abbreviations with no periods: "Jan, Mar, Jun," etc. Omit space between initials of a personal name: "J.B. Jones."

Arrange and paginate sequentially every sheet of manuscript in the following order: (1) title page, (2) abstract, (3) contents, (4) foreword and/or preface, (5) text, (6) appendices, (7) notes section, (8) glossary, (9) bibliography, (10) legends, (11) tables. Index copy may be submitted at page proof stage, but plans for an index should be indicated when the manuscript is submitted. 


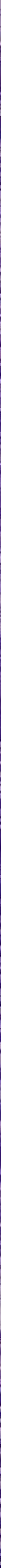

